Guilherme Araujo Lima da Silva

\title{
Transferência de Calor e Massa no ESCOAMENTO BIFÁSICO EM TORNO DE Aerofólios Equipados com Sistemas de Antigelo Aeronáuticos
}

Tese apresentada à Escola Politécnica da Universidade de São Paulo para obtenção do Título de Doutor em Engenharia Mecânica. 
Guilherme Araujo Lima da Silva

\section{Transferência de Calor e Massa no ESCOAMENTO BIFÁSICO EM TORNO DE AERofólios Equipados com Sistemas dE Antigelo Aeronáuticos}

Tese apresentada à Escola Politécnica da Universidade de São Paulo para obtenção do Título de Doutor em Engenharia Mecânica.

Área de concentração:

Engenharia Mecânica

Orientador:

Prof. Livre Docente Otávio de Mattos Silvares 
Este exemplar foi revisado e alterado em relação à versão original, sob responsabilidade única do autor e com a anuência de seu orientador.

São Paulo, 12 de Fevereiro de 2009

Assinatura do autor

Assinatura do orientador

\section{Ficha Catalográfica}

Silva, Guilherme Araujo Lima da

Transferência de Calor e Massa no Escoamento Bifásico em torno de Aerofólios Equipados com Sistemas de Antigelo Aeronáuticos/ G.A.L. da Silva - São Paulo, 2009.

$277 \mathrm{p}$.

Tese (Doutorado) — Escola Politécnica da Universidade de São Paulo. Departamento de Engenharia Mecânica.

1. Escoamento Bifásico. 2. Transferência de Calor. 3. Transferência de Massa. 4. Aerodinâmica de Aeronaves (Simulação) I. Universidade de São Paulo. Escola Politécnica. Departamento de Engenharia Mecânica. II. t. 
À Luciana e Anita. 


\section{AGRADECIMENTOS}

Ao amigo e orientador Prof. Otávio de Mattos Silvares pela orientação paciente e competente. Sou grato também a sua ajuda nos momentos de decisão pelos quais passei e pelo seu apoio incondicional durante o nosso trabalho nos últimos onze anos.

Ao amigo Prof. Euryale Jorge Godoy de Jesus Zerbini pela colaboração fundamental para a realização do trabalho de pesquisa e o desenvolvimento dos artigos. Agradeço suas sugestões, sempre feitas com criatividade e bom senso.

Ao Prof. Marcos de Mattos Pimenta e Prof. Tuncer Cebeci por todo o apoio para a realização do projeto colaborativo na California State University Long Beach, California, EUA, para aplicação do código de camada-limite diferencial à simulação térmica de antigelo.

Aos Profs. Hamid Hefazi, H. H. Chen e Kalle Kaups por me receberem na California State University Long Beach, pelo profissionalismo e pelo apoio dedicado durante o aprendizado e a adaptação do código diferencial de camada-limite às necessidades da presente tese.

À Fundação de Amparo à Pesquisa do Estado de São Paulo (FAPESP) pelo apoio na forma da bolsa de doutorado 2007/00419-0.

À Gerência de Sistemas Ambientais da Empresa Brasileira de Aeronáutica, Embraer S.A., pelo apoio durante os três anos iniciais deste projeto.

Ao meu pai, Valdir da Silva, e minha mãe, Norma Pereira de Araujo Lima e Silva, pela leitura crítica e ajuda inestimável de revisão.

Finalmente, a John Coltrane, Miles Davis e Dave Brubeck pela trilha sonora. 


\section{Resumo}

Há a necessidade de prevenir formação de gelo nas asas e nos estabilizadores de aeronaves, pois as formas de gelo podem causar a degradação do desempenho aerodinâmico, o aumento de peso, bem como dificuldades de controle e manobra que, em casos críticos, leva a uma diminuição da margem de segurança operacional. Quando as aeronaves atravessam nuvens com gotículas de água sub-resfriadas, ou seja, em equilíbrio metaestável, o crescimento de gelo ocorre nas superfícies não protegidas. Usualmente, os sistemas antigelo térmicos de aerofólios são projetados, desenvolvidos e certificados com o auxílio de programas de simulação numérica. $O$ presente trabalho visa desenvolver e implementar um modelo matemático para prever a transferência de calor e massa no escoamento bidimensional bifásico em torno de aerofólios de uso aeronáuticos, equipados com sistema de antigelo térmico operando em regime permanente. Em condições de formação de gelo, é necessário aquecer o bordo de ataque e controlar a temperatura da região protegida para que não ocorra formação de gelo. O sistema de aquecimento compensa os efeitos do resfriamento imposto principalmente pelos mecanismos acoplados de evaporação e transferência de calor por convecção, que são causados pelo escoamento do ar carregado de gotículas sub-resfriadas e pelo escoamento da água líquida residual. $\bigcirc$ modelo deverá estimar a distribuição de temperaturas de superfície e o coeficiente de transferência de calor com precisão ao uso em aplicações aeronáuticas. O presente trabalho implementou novos submodelos para: 1) estimar a molhabilidade da superfície do aerofólio por meio de um modelo matemático para caracterizar o escoamento da água líquida residual na padrão de filme e de filetes; 2) avaliar o comportamento dinâmico e térmico da camada-limite laminar e turbulenta por meio de análises integral e diferencial, que considera efeitos do gradiente de pressão, da transição laminar-turbulenta, da transpiração e da não uniformidade de temperatura da superfície e 3) estimar o início e o término da região de transição laminar-turbulenta. $O$ presente trabalho seguiu um processo de desenvolvimento de código numérico que: verificou os resultados de cada submodelo separadamente para depois implementados no modelo do antigelo; validou os resultados da simulação de desempenho do sistema antigelo com os novos submodelos implementados. Os resultados obtidos foram considerados satisfatórios para o modelo do antigelo que utilizou os submodelos de ruptura de filme e formação de filetes pelo critério da Energia Mecânica Total Mínima, de camada-limite diferencial compressível e de previsão da transição laminar-turbulenta por correlações algébricas, que consideraram efeitos do gradiente de pressão e do nível de turbulência ao longe. 


\section{Abstract}

It is required to prevent ice accretion on wings and horizontal stabilizers because it may cause aerodynamic performance degradation, weight increase, flight control difficulties and, in critical cases, may lead to operational safety margins reduction. When aircraft flies through clouds containnig supercooled water droplets, which are in metastable equilibrium, ice will form in all non-protected surfaces. Usually, anti-ice protection systems are designed, developed and certified with a support from a numerical tool. The present describes the development and implementation of a mathematical model for prediction of heat and mass transfer in two-phase flow around airfoils, which are equipped with thermal anti-ice system and operating in steady state regime. Under icing conditions, it is necessary to heat and control the temperature of the airfoil surface at leading edge region to prevent ice formation. The heating system balances the evaporative cooling effects, which are caused by the coupled heat and mass convection transfer, imposed by the air flow loaded with supercooled water droplets and the runback water flow around the airfoil. The present work implemented submodels to: 1) estimate airfoil surface wetness factor by adopting a liquid water film flow model as well as a rivulet formation and flow model; 2) evaluate laminar and turbulent boundary layers with pressure gradient and laminar-turbulent transition over nonisothermal and permeable airfoil surface by implementing differential boundary layer analysis and 3) predict the onset position and length of laminar-turbulent transition region. The present paper followed a validation and verification process during the numerical code development. All sub-models results were verified separately against experimental data before their inclusion in anti-ice model.The results of anti-ice model with selected submodels were validated against reference cases. The results were considered suficiently accurate when solving the film breakdown and rivulets formation by total mechanical energy method, compressible boundary layer by differential analysis and laminar-turbulent transition prediction by algebraic correlations, which considered pressure gradient and freestream turbulence level. 


\section{SUMÁRIO}

\section{Lista de Figuras}

\section{Lista de Tabelas}

\section{Lista de Abreviaturas}

\section{Nomenclatura}

1 Introdução 1

1.1 Objetivo ............................ 6

1.2 Relevância da Tese . . . . . . . . . . . . . . . . . 6

1.3 Organização da Tese . . . . . . . . . . . . . . . . . 9

2 Modelagem do Escoamento Bifásico em torno de Aerofólios com Sistema Térmico de Antigelo 12

2.1 Revisão Bibliográfica . . . . . . . . . . . . . . . . . . . . . . . . . 12

2.2 Níveis de Modelagem . . . . . . . . . . . . . . . . . . . 17

2.3 Estrutura da Simulação Térmica do Aerofólio com Sistema de Antigelo 20

2.4 Casos-Padrão de Aerofólio com Sistema Térmico de Antigelo . . . . . 20

2.5 Modelagem Térmica do Aerofólio com Sistema de Antigelo . . . . . . 23

2.5.1 Primeira Lei da Termodinâmica Aplicada à Superfície Sólida do Aerofólio . . . . . . . . . . . . . . . . . . 25

2.5.2 Primeira Lei da Termodinâmica Aplicada ao Escoamento de Água Líquida . . . . . . . . . . . . . . . . . . . . . 27

2.5.3 Conservação da Massa Aplicada ao Escoamento de Água Líquida . . . . . . . . . . . . . . . . 27 
2.5.4 Conservação da Quantidade de Movimento Aplicada ao Escoamento de Água Líquida . . . . . . . . . . . . . . . . . 30

2.6 Implementação Numérica do Modelo Matemático . . . . . . . . . . 30

2.6.1 Solução do Escoamento e das Trajetórias das Gotículas . . . . 31

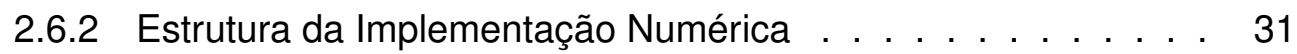

\section{Modelagem da Molhabilidade de Aerofólios com Sistema Térmico de An-} tigelo

3.1 Modelagem do Escoamento Água Líquida Residual . . . . . . . . . 36

3.1.1 Padrão de Escoamento de Filme Contínuo . . . . . . . . . . . 36

3.1 .2 Padrão de Escoamento de Filetes . . . . . . . . . . . . . . . 37

3.1.3 Critérios para a Ruptura do Padrão Filme de Líquido Contínuo 40

3.1.4 Outros Modelos para a Ruptura do Filme Contínuo . . . . . . . 42

3.2 Critério de energia total mínima . . . . . . . . . . . . . . 43

3.2.1 Modelo Matemático de Mikielewicz e Moszynski (1975) . . . . 44

3.2.2 Fundamento Termodinâmico do Critério da Energia Total Mínima $(\mathrm{ETM}) \ldots \ldots \ldots$. . . . . . . . . . . . . . . . . . 44

3.2.3 Determinação do Ângulo de Contato . . . . . . . . . . . . . . 46

3.3 Inclusão do Efeito da Formação de Filetes de Água Líquida sobre o Aerofólio . . . . . . . . . . . . . . . . . . . . . 47

3.3.1 Escoamento do Filme de Água Líquida . . . . . . . . . . . . . 47

3.3.2 Ruptura do Filme e Formação dos Filetes . . . . . . . . . . . . 47

3.3.3 Escoamento de Filetes de Água Líquida . . . . . . . . . . . . 49

3.4 Verificação dos Resultados Numéricos . . . . . . . . . . . . . . . . 50

3.4.1 Caso de Teste . . . . . . . . . . . . . . . . . 50

3.4.2 Modelos Matemáticos e Códigos Externos Utilizados . . . . . . 51

3.4.3 Estimativa do Ângulo de Contato . . . . . . . . . . . . . 51

3.4 .4 Resultados numéricos . . . . . . . . . . . . . . . . . 52

3.5 Comentários . . . . . . . . . . . . . . . . . . 53 
4 Modelagem da Camada-Limite em Aerofólios com Sistema Térmico de Antigelo

4.1 Modelagem da Camada-Limite aplicada a Aerofólios com Sistemas de Antigelo . . . . . . . . . . . . . . . 62

4.2 Análise Integral da Camada-Limite - Trabalho Anterior . . . . . . . . . 65

4.2.1 Transferência de Quantidade de Movimento . . . . . . . . . . 66

4.2.2 Transferência de Calor . . . . . . . . . . . . . . . . 67

4.3 Análise Integral da Camadas-Limite - Presente Trabalho . . . . . . . . 68

4.3.1 Escoamento laminar sobre superfície isotérmica . . . . . . . 69

4.3.2 Escoamento laminar sobre superfície não-isotérmica . . . . . . 70

4.3.3 Escoamento turbulento sobre superfície isotérmica . . . . . . . 72

4.3.4 Escoamento turbulento sobre superfície não-isotérmica $\ldots$. . . 75

4.4 Análise Diferencial das Camadas-Limite Dinâmica e Térmica - Presente Trabalho . . . . . . . . . . . . . . . . . . . 76

4.4.1 Modelo de Cebeci e Cousteix (2005) . . . . . . . . . . . . 77

4.4.2 Modelo de Kays, Crawford e Weigand (2004) . . . . . . . . . . 78

4.5 Verificação dos Resultados Numéricos . . . . . . . . . . . . . . . . 79

4.5.1 Casos-Teste para Verificação dos Resultados Numéricos . . . 80

4.5.2 Modelos Matemáticos e Programas Utilizados . . . . . . . . . 83

4.5 .3 Resultados Numéricos . . . . . . . . . . . . . . . . . . . . . . 84

4.6 Comentários . . . . . . . . . . . . . . . . . . . . . . . . 95

5 Modelagem da Transição em Aerofólios com Sistema Térmico de Antigelo

5.1 Modelagem do Processo de Transição do Escoamento Laminar para o Turbulento . . . . . . . . . . . . . . . . . . . 100

5.1.1 Mapeamento das Rotas de Transição Laminar-turbulenta . . . 102

5.1 .2 Transição Natural . . . . . . . . . . . . . . . . . . . . . 106

5.1.3 Transição de Contorno (Bypass) . . . . . . . . . . . . . . . 106

5.1 .4 Intermitência Laminar-turbulenta . . . . . . . . . . . . 107 
5.2 Modelos de Previsão de Transição Laminar-turbulenta . . . . . . . . . 110

5.2.1 Modelo de Michel (1951) . . . . . . . . . . . . . . . . . 110

5.2.2 Modelo de Abu-Ghannam e Shaw (1980) . . . . . . . . . . . 111

5.2.3 Modelo de Wazzan, Gazley e Smith (1981) . . . . . . . . . . . 112

5.2.4 Modelo de Mayle (1991) . . . . . . . . . . . . . . . . . . . 113

5.3 Modelos para Intermitência Laminar-turbulenta . . . . . . . . . . . . . 114

5.3.1 Modelo de Narasimha (1957) . . . . . . . . . . . . . . . . 114

5.3.2 Modelo de Reynolds, Kays e Kline (1958b) . . . . . . . . . . 116

5.3.3 Modelo de Chen e Thyson (1971) . . . . . . . . . . . . 117

5.3.4 Modelo de Abu-Ghannam e Shaw (1980) . . . . . . . . . . . 118

5.3.5 Modelo de Sharma (1987) . . . . . . . . . . . . . . 119

5.3.6 Modelo de Mayle (1991) . . . . . . . . . . . . . . . . 120

5.3.7 Modelo de Johnson e Fashifar (1994) . . . . . . . . . . . . . 121

5.3.8 Comparação de Modelos de Intermitência . . . . . . . . . . . 122

5.4 Outros Modelos . . . . . . . . . . . . . . . . . . . . . . 123

5.5 Seleção do Modelo de Transição Laminar-Turbulenta . . . . . . . . . 125

5.6 Verificação dos Resultados Numéricos . . . . . . . . . . . . . . . . 125

5.6.1 Casos-Teste . . . . . . . . . . . . . . . . 126

5.6.2 Modelos e Códigos Numéricos Utilizados na Verificação de Resultados . . . . . . . . . . . . . . . . 130

5.6.3 Resultados Numéricos . . . . . . . . . . . . . . . . . . . . 132

5.7 Comentários . . . . . . . . . . . . . . . . . . . . . . 145

6 Resultados da Simulação do Escoamento em Aerofólios com Sistema $\begin{array}{ll}\text { Térmico de Antigelo } & 146\end{array}$

6.1 Casos-Teste . . . . . . . . . . . . . . . . . . . . 147

6.1.1 Casos de Al-Khalil et al. (2001) . . . . . . . . . . . . . . 149

6.1.2 Casos de Gelder e Lewis (1951) . . . . . . . . . . . . . . 150

6.2 Resultados Numéricos - Análise Integral da Camada-Limite . . . . . . 151 
6.2.1 Submodelo de Transição Laminar-turbulenta Abrupta e Submodelo de Filme Contínuo . . . . . . . . . . . . . . . . . . . . 151

6.2.2 Submodelo Clássico de Camada-Limite e Submodelo de Filme e Filetes . . . . . . . . . . . . . . . . . . . . 157

6.2.3 Método de Sobreposição aplicado à Camada-Limite Térmica 169

6.3 Resultados Numéricos - Análise Diferencial da Camada-Limite . . . . 180

6.3.1 Modelos Utilizados e Parâmetros da Simulação . . . . . . . . 181

6.3.2 Resultados Numéricos e Comparação . . . . . . . . . . . . . 182

6.3.3 Análise de Demanda Térmica e da Área Protegida . . . . . . . 191

6.4 Comentários . . . . . . . . . . . . . . . . . . . . . . 192

7 Conclusões e Próximos Trabalhos $\quad 194$

7.1 Conclusões . . . . . . . . . . . . . . . . . . . . . . . . . . . . . 194

7.2 Sugestões para Próximos Trabalhos . . . . . . . . . . . . . . . . 200

$\begin{array}{ll}\text { Anexo A - Conceitos Gerais } & 202\end{array}$

A.1 Conteúdo de água Líquida (Liquid Water Content (LWC) - Liquid Water Content) . . . . . . . . . . . . . . . . . . . . . . . . . . 202

A.2 Diâmetro Mediano Volumétrico (Median Volumetric Diameter (MVD) Median Volumetric Diameter . . . . . . . . . . . . . . . . . . . . 202

A.3 Eficiência de Coleta Local $(\beta)$. . . . . . . . . . . . . . . . . 203

A.4 Fração de Congelamento $\left(n_{f}\right) \ldots$. . . . . . . . . . . . . . . 204

A.5 Formação de Gelo . . . . . . . . . . . . . . . . . . . . . . . . . . 205

A.6 Formação de Nuvens de Gotículas Sub-Resfriadas . . . . . . . . . 206

A.7 Tipos de Formação de Gelo . . . . . . . . . . . . . . . . . . . . . 208

A.8 Crescimento de Gelo _ . . . . . . . . . . . . . . . . . . . . . . . 209

A.9 Água Residual (Runback) . . . . . . . . . . . . . . . . . . . . 210

A.10 Aspectos Operacionais da Aeronaves . . . . . . . . . . . . . . . . . . 210

A.11 Prevenção contra a Formação de Gelo . . . . . . . . . . . . . . . . . 211

A.11.1 Sistemas Antigelo de Ar Quente . . . . . . . . . . . . . . . . 214 
B.1 Reynolds Averaged Navier-Stokes (RANS) Compressível . . . . . . . 215

B.1.1 RANS Compressível da camada-limite . . . . . . . . . . 215

B.1.2 Modelo de Turbulência de Cebeci e Smith (1974) . . . . . . . 216

B.2 Descrição Breve do Código BLP2C . . . . . . . . . . . . . . . . . 216

B.2.1 Transformação de Falkner-Skan . . . . . . . . . . . . . . . 216

B.2.2 Método numérico . . . . . . . . . . . . . . . . . . 218

B.2.3 Mudança de variáveis . . . . . . . . . . . . . . . . 219

B.2.4 Método da Caixa de Keller (1970) . . . . . . . . . . . . . 219

B.2.5 Método de Newton . . . . . . . . . . . . . . . . . 221

B.2.6 Eliminação de blocos . . . . . . . . . . . . . . . . . . . 222

B.2.7 Entradas/Saídas . . . . . . . . . . . . . . . . . . . 222

B.2.8 Fluxograma do Código Numérico . . . . . . . . . . . . . 222

B.2.9 Algoritmo - Programa Principal - MAIN . . . . . . . . . . 225

B.2.10 Subrotinas . . . . . . . . . . . . . . . . . 226

B.3 Descrição Breve do Código TEXSTAN . . . . . . . . . . . . . . . . 228

B.3.1 Equações para a camada-limite . . . . . . . . . . . . . 228

B.3.2 Modelo de turbulência de Kays e Crawford (1993) . . . . . . . 228

B.3.3 Equações de Transporte . . . . . . . . . . . . . . . . . . . 229

B.3.4 Condições de Contorno . . . . . . . . . . . . . . . . 230

B.3.5 Condições Iniciais . . . . . . . . . . . . . . . . . . 231

B.3.6 Propriedades Termodinâmicas . . . . . . . . . . . . . . . . 231

B.3.7 Modelos de Turbulência . . . . . . . . . . . . . . . . . . . 232

B.3.8 Modelos de Transição . . . . . . . . . . . . . . . . . . 233

B.3.9 Método numérico . . . . . . . . . . . . . . . 233

C.1 Introdução . . . . . . . . . . . . . . . . . . . 235 
C.2 Modelo Matemático para Estabilidade Linear . . . . . . . . . . . . . . 236

C.3 Estabilidade Linear por meio do Método $e^{9} \ldots$. . . . . . . . . . . . . 239

C.4 Previsão do início da transição laminar-turbulenta . . . . . . . . . . . 240

C.5 Descrição do Procedimento de cálculo . . . . . . . . . . . . . . . . . 242

C.6 Descrição Breve do Código STPD2 . . . . . . . . . . . . . . . . . . . 245

C.6.1 Sub-Rotinas do STPD2 . . . . . . . . . . . . . . . . 245

\section{Apêndice A - Efeito da Transfêrencia de Massa na Camada-Limite Térmica 248}

A.1 Modelo de Evaporação da Água . . . . . . . . . . . . . . . . . . . . . 248

A.1.1 Regime Turbulento . . . . . . . . . . . . . . . . . . . . 249

A.1.2 Resultados . . . . . . . . . . . . . . . . . . 249

A.1.3 Conclusão . . . . . . . . . . . . . . . . . 250

A.2 Validade da Correção para Regime Laminar . . . . . . . . . . . . . 250

A.2.1 Conclusão . . . . . . . . . . . . . . . . . . . . . . . . . 251

A.3 Validade da Correção para Regime Turbulento . . . . . . . . . . . . . 252

A.3.1 Condições do Teste . . . . . . . . . . . . . . . . . 252

A.3.2 Resultados . . . . . . . . . . . . . . . . . . . . 252

A.3.3 Conclusões . . . . . . . . . . . . . . . . . . . . . . . . 254

Apêndice B - Verificação dos Resultados Numéricos para os Casos Euro-

pean Research Community of Flow, Turbulence and Combustion (ER-

$\begin{array}{ll}\text { COFTAC) } & 255\end{array}$

B.1 Definição dos Casos . . . . . . . . . . . . . . . . . . . . . 255

B.2 Fatores Críticos de Amplificação . . . . . . . . . . . . . . . . . 255

B.3 Caso T3А . . . . . . . . . . . . . . . . 256

B.4 Caso T3АM . . . . . . . . . . . . . . . . . . . 258

B.5 Caso T3С2 . . . . . . . . . . . . . . . . . . . . . . . 261

B.6 Caso ТзС5 . . . . . . . . . . . . . . . . . . . . . . 264

$\begin{array}{ll}\text { Referências Bibliográficas } & 266\end{array}$ 


\section{LISTA DE FIGURAS}

1.1 Regiões e equipamentos de uma aeronave sujeitos a formação de gelo (HEINRICH et al., 1991) . . . . . . . . . . . . . . . . 2

1.2 Coeficiente de sustentação, $C_{L}$, em função do ângulo de ataque, $\alpha$, de um perfil NACA 63A415 sem formação de gelo (limpo) e com vários tipos de formação de gelo ${ }^{1} \ldots \ldots \ldots . \ldots 2$

1.3 Organização da Presente Tese de Doutorado . . . . . . . . . . . . . 11

2.1 Níveis de modelagem abordados na presente tese . . . . . . . . . . . 17

2.2 Aerofólio NACA 0012 com aquecedores elétricos de Al-Khalil et al. (2001) 21

2.3 Modelagem de um aerofólio aquecido operando sob condições de formação de gelo $($ SILVA, 2002) . . . . . . . . . . . . . . . . . . 23

2.4 Modelagem da transferência de massa (SPALDING, 1963) . . . . . . 28

2.5 Estrutura da implementação numérica $\ldots . . \ldots 32$

3.1 Escoamento de um filme de água líquida movido por cisalhamento, depois de Rothmayer e Tsao (2000) . . . . . . . . . . . . . . . . 34

3.2 Escoamento de filme contínuo e de filetes, depois de Mikielewicz e Moszynski (1975) . . . . . . . . . . . . . . . . . . . . 35

3.3 Geometria do filete (corte A-A da Fig. 3.2) . . . . . . . . . . . . 38

3.4 Velocidades no filete. Comparação solução bidimensional numérica e interpolada com aproximação de filme (AL-KHALIL, 1991) . . . . . . . 39

3.5 Resultados de simulação de sistema antigelo com modelo de filetes (AL-KHALIL, 1991) . . . . . . . . . . . . . . . . . . . 42

3.6 Modelo de filme contínuo - Temperaturas e Transferência de Calor Caso 67A . . . . . . . . . . . . . . . . . . . . . . 54

3.7 Modelo de filme contínuo - Espessura e Vazão de Água Residual Caso 67A . . . . . . . . . . . . . . . . . . . . 55

3.8 Modelo de filme contínuo - Cisalhamento e Molhabilidade - Caso 67A 56 
3.9 Modelo de filetes - Temperaturas e Transferência de Calor-Caso 67A 57

3.10 Modelo de filetes - Espessura e Vazão de Água Residual - Caso 67A . 58

3.11 Modelo de filetes - Cisalhamento e Molhabilidade - Caso 67A . . . . . 59

4.1 Dados Experimentais Utilizados como Entrada para as Análises Integral e Diferencial da Camada-Limite Térmica (MORETTI, 1964) . . . . 80

4.2 Geometria do Aerofólio NACA0012 . . . . . . . . . . . . . . . . . . . 81

4.3 Geometria do Aerofólio NACA 65(2)016 . . . . . . . . . . . . . 82

4.4 St estimado pelas Análises Integral e Diferencial . . . . . . . . . . . . 85

4.5 Estimativas de $C_{p}$ - Casos 1 e 2 - Perfil NACA $0012 \ldots 86$

4.6 Estimativas de $C_{f}$ - Casos 1 e 2 - Perfil NACA $0012 \ldots 87$

4.7 Estimativas de St - Casos 1 e 2 - Perfil NACA $0012 \ldots 8$

4.8 Coeficiente de Pressão - $C_{p}$ - Caso NACA 65(2)016- $\alpha=0^{\circ}$ - Transição Livre e Fixada . . . . . . . . . . . . . . . . . . . . . . . . . . . . . . 89

4.9 Temperatura de superfície - $T_{s}$ - Caso NACA 65(2)016 . . . . . 990

4.10 Coeficiente de Transferência de Calor - $h_{a r}$ - Caso NACA 65(2)016 Transição Livre . . . . . . . . . . . . . . . . . . . . . . . . . . . . . . . 91

4.11 Coeficiente de Transferência de Calor - $h_{a r}$ - Caso NACA 65(2)016 Transição Fixada . . . . . . . . . . . . . . . . . . . . . . . . . . . . . 92

5.1 Esquema da transição laminar-turbulenta numa camada-limite sobre uma placa plana sem gradiente de pressão e ângulo de incidência nulo (SCHLICHTING; GERSTEN, 2000). . . . . . . . . . . . . . . . . 103

5.2 Rotas de transição para a turbulência (RESHOTKO, 2001) . . . . . 105

5.3 Estágios da desestabilização da camada-limite laminar sujeita a perturbações de baixa amplitude. (NARASIMHA, 1990) . . . . . . . . . 109

5.4 Comparação de Modelos de Intermitência . . . . . . . . . . . . . . 122

5.5 Aparato Experimental dos Casos do ERCOFTAC ${ }^{1} \ldots \ldots$

5.6 Geometria do Perfil MBB-V2 (MATEER; MONSON; MENTER, 1996) . 129

5.7 Coeficiente de Atrito - $C_{f}$ - Caso T3A - Tu $=3,0 \%$ - gradiente de pressão nulo ao longo da placa - correlação algébrica . . . . . . . . . . . 133 
5.8 Caso T3A - Tu = 2, 9\% - gradiente de pressão nulo - estabilidade linear diferencial

5.9 Coeficiente de Atrito $-C_{f}$ - Caso T3AM - Tu $=1,0 \%$ (integral e BLP2C)

- TU $=0,5 \%$ (TEXSTAN) - gradiente de pressão nulo ao longo da placa - correlação algébrica . . . . . . . . . . . . . . . . . . . 136

5.10 Caso T3AM - Tu = 0,34\% - gradiente de pressão nulo - estabilidade linear diferencial . . . . . . . . . . . . . . . . . . . . 136

5.11 Velocidade na borda da camada-limite - dados experimentais Savill (1992)

5.12 Coeficiente de atrito $-C_{f}$ - Caso T3C2 - Tu $=2,0 \%$ - gradiente de pressão variável - correlação algébrica . . . . . . . . . . . . . . . . . 138

5.13 Caso T3C2 - Tu = 3,0\% - gradiente de pressão variável - estabilidade linear diferencial . . . . . . . . . . . . . . . . . . . 138

5.14 Coeficiente de atrito - $C_{f}$ - Caso T3C5 - Tu $=2,45 \%$ - gradiente de pressão variável - correlação algébrica . . . . . . . . . . . . . . . . 139

5.15 Caso T3C5 - Tu = 3,0\% - gradiente de pressão variável - estabilidade linear diferencial . . . . . . . . . . . . . . . . . . . . . . . 139

5.16 Coeficiente de pressão $-C_{p}$ - perfil MBB-V2 $\ldots . . .140$

5.17 Coeficiente de Atrito $-C_{f}$ - Caso M1 - MBBV2 - $\alpha=-0,5^{\circ} \ldots 141$

5.18 Coeficiente de Atrito $-C_{f}$ - Caso M2 - MBBV2 - $\alpha=3,5^{\circ} \ldots 142$

5.19 Coeficiente de Atrito $-C_{f}$ - Caso M3 - MBBV2 - $\alpha=-0,5^{\circ} \ldots \ldots$

5.20 Coeficiente de Atrito $-C_{f}$ - Caso M4 - MBBV2 - $\alpha=-0,5^{\circ} \ldots 144$

6.1 Processo Global de Validação e Verificação dos Resultados . . . . . . 147

6.2 Processo de Verificação dos Resultados dos Submodelos de Formação de Filetes, Transferência de Calor e Transição Laminar-turbulenta 148

6.3 Temperatura de superfície - $T_{s}$ - Caso 22A - Comparação entre modelos 153

6.4 Coeficientes de transferência de calor global $U$ e convectivo $h_{a r}$ - Caso 22A - Comparação entre modelos . . . . . . . . . . . . . . . . . . 154

6.5 Temperatura de superfície - $T_{s}$ - Caso 67A - Comparação entre modelos 155

6.6 Coeficientes de transferência de calor global $U$ e convectivo $h_{a r}$ - Caso 67A - Comparação entre modelos . . . . . . . . . . . . . . . 156 
6.7 Case $22 \mathrm{~A}$ - Comparações entre Modelos $-T_{s}$ e $U \ldots \ldots$

6.8 Case 22A - Comparações entre Modelos - $h_{a r}$, potência elétrica e $\dot{m}_{r} \quad 161$

6.9 Caso 67A - Comparações entre Modelos $-T_{s}$ e $U \ldots \ldots$

6.10 Caso 67A - Comparações entre Modelos - $h_{a r}$, potência elétrica e $\dot{m}_{r} 164$

6.11 Previsões do presente código para fator global de molhabilidade - F . 165

6.12 Condição de gelo 8 - Previsões do código atual comparadas com dados experimentais clássicos . . . . . . . . . . . . . . . . . . 166

6.13 Caso 8GL - Comparação entre modelos . . . . . . . . . . . . . . . . 167

6.14 Caso 8GL ar seco - Comparação entre modelos . . . . . . . . . . . . 168

6.15 Caso 22A - Comparação entre modelo de sobreposição, nãoisotérmico e isotérmico

6.16 Caso 22A - Comparação entre modelo de sobreposição, nãoisotérmico e isotérmico

6.17 Caso 67A - Comparação entre modelo de sobreposição, nãoisotérmico e isotérmico

6.18 Fator de molhabilidade $-F \ldots \ldots$. . . . . . . . . . . . . 174

6.19 Caso 67A - Comparação entre modelo de sobreposição, nãoisotérmico e isotérmico

6.20 Caso 8GL - Condição de gelo - Comparação entre modelo de sobreposição, não-isotérmico e isotérmico . . . . . . . . . . . . . . . 17

6.21 Caso 8GL - Condição de gelo - Comparação entre modelo de sobreposição, não-isotérmico e isotérmico

6.22 Caso 8GL - Condição de ar seco - Comparação entre modelo de sobreposição, não-isotérmico e isotérmico

6.23 Caso 8GL - Comparação entre modelo de sobreposição, nãoisotérmico e isotérmico

6.24 Resultados de Temperatura e Transferência de Calor - Caso 22A . . . 185

6.25 Resultados do Escoamento da Água Residual - Caso 22A . . . . . . . 186

6.26 Resultados de Temperatura e Transferência de Calor - Caso 67A . . . 187

6.27 Resultados do Escoamento da Água Residual - Caso 67A . . . . . . . 188 
6.28 Resultados de Temperatura e Transferência de Calor - Caso 67B . . . 189

6.29 Resultados do Escoamento da Água Residual - Caso 67B . . . . . . . 190

A.1 Trajetórias das gotículas, definição da eficiência de coleta local, $\beta, e$ dos limites de impingimento superior $S_{U}$ e inferior $S_{L} \ldots \ldots 203$

A.2 Eficiência de coleta local, $\beta$. . . . . . . . . . . . . . . 204

A.3 Formação de gelo num aerofólio (sítio da rede internet, ONERA 2002) ${ }^{1} 206$

A.4 Formação de gelo sobre um aerofólio enflechado ${ }^{2}$. . . . . . . . . . . 207

A.5 Forma de gelo real do tipo rime em aerofólio NACA 0012 com enflechamento de $45^{\circ}$ (VARGAS; TSAO, 2007) . . . . . . . . . . . . 209

A.6 Forma de gelo do tipo glaze sobre aerofólio de uso em asas rotativas ${ }^{2} 209$

A.7 Processos naturais primários de formação de nuvens ${ }^{3}$. . . . . . . . . 211

A.8 Mecanismo de um Sistema de Degelo Pneumático - "Boot System" (HEINRICH et al., 1991) . . . . . . . . . . . . . . . . . . . 212

A.9 Aerofólio com sistema de antigelo de ar quente (DOMINGOS et al., 2007) . . . . . . . . . . . . . . . . . . 213

A.10 Jatos incidentes de ar quente descarregados pelo tubo piccolo do Sistema de Antigelo de um aerofólio (BUCHLIN et al., 1994) . . . . . . . 214

B.1 Malha de diferenças finitas para o método da caixa de Keller (1970) . 220

B.2 Entradas e Saídas do BLP2C . . . . . . . . . . . . . . . . . . 222

B.3 Fluxograma para o programa $B L P 2 C$ - Parte $1 \ldots 223$

B.4 Fluxograma para o programa BLP2C - Parte $2 \ldots . . . . . . . . .224$

B.5 Condições de contorno para o código TEXSTAN . . . . . . . . . . . 231

C.1 Curva de estabilidade neutra para (a) Rayleigh e (b) Orr-Sommerfeld. $O$ perfil de velocidade (a) tem ponto de inflexão $\mathrm{PI}$ e o (b) não tem ponto de inflexão (SCHLICHTING; GERSTEN, 2000) . . . . . . . . . 238

C.2 Comparações das medições de Schubauer e Skramstad (1948) com as previsões de Tollmien em 1927 (SCHLICHTING; GERSTEN, 2000) 239

C.3 Curvas de estabilidade neutra para vários gradientes de pressão, representado pelo fator de gradiente de pressão $\Lambda=\left(\delta_{1}^{2} / \nu\right)\left(d U_{e} / d x\right)$ (SCHLICHTING; GERSTEN, 2000) . . . . . . . . . . . . . . 240 
C.4 $\operatorname{Re}_{\delta 1}$ no ponto de indiferença em função do fator de gradiente de pressão $\Lambda=\left(\delta_{1}^{2} / \nu\right)\left(d U_{e} / d x\right)($ SCHLICHTING; GERSTEN, 2000) . . . . . . 241

C.5 Curvas de estabilidade neutra para várias temperaturas de parede $T_{w}$ $/ T_{\infty}($ WHITE, 2000) . . . . . . . . . . . . . . . . . . 242

C.6 Estratégia para cálculo da transição por meio do método e ${ }^{n}$ (CEBECI, 2000) .

C.7 Variação do fator de amplificação integrada com a distância e frequência para escoamento com gradiente de pressão nulo (CEBECI, 2000) . 244

C.8 O princípio do método $e^{n}($ ARNAL, 1994) . . . . . . . . . . . . . . . . 245

A.1 Parâmetros de Insuflamento . . . . . . . . . . . . . . . . . 250

A.2 Comparação do caso laminar com o modelo proposto . . . . . . . . . 252

A.3 Relação entre Stanton e Reynolds e Correção do Stanton . . . . . . . 253

A.4 Diversos casos experimentais . . . . . . . . . . . . . . . 253

A.5 Correção do Número de Stanton para vários valores de $F$. . . . . . . 254

B.1 Caso T3A - coeficiente de Atrito - $C_{f}-T u=3,0 \%$ - gradiente de pressão nulo ao longo da placa - correlação algébrica . . . . . . . . . . 256

B.2 Caso T3A - Tu = 3, 0\% - gradiente de pressão nulo - correlação algébrica256

B.3 Caso T3A - Tu = 3,0\% - gradiente de pressão nulo - estabilidade linear diferencial

B.4 Caso T3A - Tu = 2, 9\% - gradiente de pressão nulo - estabilidade linear diferencial

B.5 Caso T3AM - Coeficiente de Atrito $-C_{f}-T u=0,87 \%$ - gradiente de pressão nulo ao longo da placa - correlação algébrica . . . . . . . . . 258

B.6 Caso T3AM - Tu $=0,87 \%$ - gradiente de pressão nulo - correlação algébrica . . . . . . . . . . . . . . . . . 258

B.7 Caso T3AM - Tu $=0,5 \%$ - gradiente de pressão nulo - correlação algébrica . . . . . . . . . . . . . . . . . 259

B.8 Caso T3AM - Coeficiente de Atrito - $C_{f}-T u=0,5 \%$ - gradiente de pressão nulo ao longo da placa - correlação algébrica . . . . . . . . . 259

B.9 Caso T3AM - Tu $=0,87 \%$ - gradiente de pressão nulo - estabilidade linear diferencial . . . . . . . . . . . . . . . . . . . . . . . 259 
B.10 Caso T3AM - Tu =0,34\% - gradiente de pressão nulo - estabilidade linear diferencial . . . . . . . . . . . . . . . . . . 260

B.11 Dados experimentais da velocidade na borda da camada-limite e resultados das interpolações - gradiente de pressão variável . . . . . . 261

B.12 Caso T3C2 - Coeficiente de Atrito - $C_{f}-T u=2,4 \%$ - gradiente de pressão variável - correlação algébrica . . . . . . . . . . . . . . . 261

B.13 Caso T3C2 - Tu = 2, 4\% - gradiente de pressão variável - correlação algébrica . . . . . . . . . . . . . . . . . . . . 262

B.14 Caso T3C2 - coeficiente de atrito $-C_{f}-T u=2,0 \%$ - gradiente de pressão variável - correlação algébrica . . . . . . . . . . . . . . . 262

B.15 Caso T3C2 - Tu = 2, 0\% - gradiente de pressão variável . . . . . . . . 262

B.16 Caso T3C2 - Tu = 2, 4\% - gradiente de pressão variável - estabilidade linear diferencial . . . . . . . . . . . . . . . . 263

B.17 Caso T3C2 - Tu $=3.0 \%$ - gradiente de pressão variável - estabilidade linear diferencial . . . . . . . . . . . . . . . . 263

B.18 Coeficiente de atrito $-C_{f}$ - Caso T3C5 - Tu $=2,45 \%$ - gradiente de pressão variável - correlação algébrica . . . . . . . . . . . . . . 264

B.19 Caso T3C5 - Tu = 2, 45\% - gradiente de pressão variável - correlação algébrica . . . . . . . . . . . . . . . . . . . . . . 264

B.20 Caso T3C5 - Tu = 3,0\% - gradiente de pressão variável - estabilidade linear diferencial . . . . . . . . . . . . . . . . . 265 


\section{LISTA DE TABELAS}

1.1 Contribuições de Trabalhos Anteriores . . . . . . . . . . . . . . 8

2.1 Comprimentos dos Aquecedores (AL-KHALIL et al., 2001) . . . . . . . 22

3.1 Resumo dos critérios de ruptura de filmes de líquido . . . . . . . . . . 41

3.2 Distribuição de Densidade de Potência dos Aquecedores Elétricos para Caso 67A(AL-KHALIL et al., 2001) . . . . . . . . . . . . . . . 50

3.3 Parâmetros da Região de Transição Laminar-Turbulenta para Caso 67A 52

4.1 Condições de contorno para a avaliação da convecção de calor e de massa em torno de aerofólios . . . . . . . . . . . . . . . . . . . 61

4.2 Procedimentos de análise integral de camada-limite implementados . 63

4.3 Modelos de Evolução da Intermitência na Região de Transição Laminar-Turbulenta . . . . . . . . . . . . . . . . . . 64

4.4 Caso 1 - NACA0012 - Ma=0,4 (AMICK, 1950) . . . . . . . . . . . 81

4.5 Casos NACA 65(2)016 (FRICK; MCCULLOUGH, 1942) . . . . . . . . 82

4.6 Fluxo de calor estimado e seu desvio relativo ao dados experimentais (FRICK; MCCULLOUGH, 1942) de potência fornecida ao segundo compartimento $(0,146<x / c<0,263)$ do aerofólio NACA 65(2)016 . 90

5.1 Modelos empíricos para previsão de início e término da região de transição laminar-turbulenta . . . . . . . . . . . . . . . . . . . 100

5.2 Condições do Escoamento para Escoamento em torno de Aerofólios com Sistema Térmico de Antigelo . . . . . . . . . . . . . . . . . . . 126

5.3 Casos Selecionados ERCOFTAC . . . . . . . . . . . . . . . . 128

5.4 Casos MBB-V2 (MATEER; MONSON; MENTER, 1996) . . . . . . . . 129

6.1 Casos de Teste para Validação do Modelo do Antigelo . . . . . . . . 150

6.2 Comprimentos e Densidades de Potência Elétrica dos Aquecedores Casos-teste de Al-Khalil et al. (2001) . . . . . . . . . . . . . . . 150 
6.3 Comprimentos e Densidades de Potência Elétrica dos Aquecedores Caso-teste da Gelder e Lewis (1951) . . . . . . . . . . . . . . . . . . 151

6.4 Modelos de Camada-Limite Térmica e Transição Laminar-Turbulenta . 158

6.5 Parâmetros para a região de transição do presente modelo . . . . . . 158

6.6 Término do escoamento de água residual, incidência e limites de área protegida contra gelo . . . . . . . . . . . . . . . . . . . 162

6.7 Modelos de Camada Limite . . . . . . . . . . . . . . . . . . . . . . . 169

6.8 Parâmetros da Região de Transição para Modelos Não-isotérmico, Isotérmico e de Sobreposição . . . . . . . . . . . . . . . . . . . 169

6.9 Término do escoamento de água residual, incidência e limites de área protegida contra gelo . . . . . . . . . . . . . . . 180

6.10 Modelos e Parâmetros das Simulações - Caso 22A . . . . . . . . . . 182

6.11 Modelos e Parâmatros das Simulações - Caso 67A . . . . . . . . . . 182

6.12 Modelos e Parâmetros das Simulações - Caso 67B . . . . . . . . . . 183

6.13 Conservação da Massa - Escoamento de Água Residual - Caso 22A . 184

6.14 Conservação da Massa - Escoamento de Água Residual - Caso 67A . 184

6.15 Conservação da Massa - Escoamento de Água Residual - Caso 67B . 184

6.16 Análise do Fluxo de Calor Requerido e Fornecido . . . . . . . . . . . 191

6.17 Análise do Escoamento da Água Residual . . . . . . . . . . . . . . . 192

B.1 Coeficientes para a equação de transporte . . . . . . . . . . . . . . 230

B.2 constantes do modelo de turbulência . . . . . . . . . . . . . . 233

A.1 Efeito da variação da Temperatura da Água . . . . . . . . . . . . . 250

A.2 Combinações de $M, T_{\text {ar }}$,alt tunel e $F \ldots \ldots$. . . . . . . . . 251

A.3 Valores de $C_{1}, C_{2}$ e $C_{3}$ para $\operatorname{Pr}=0.7 \ldots \ldots . \ldots . \ldots 251$

B.1 Casos Selecionados ERCOFTAC . . . . . . . . . . . . . . 255

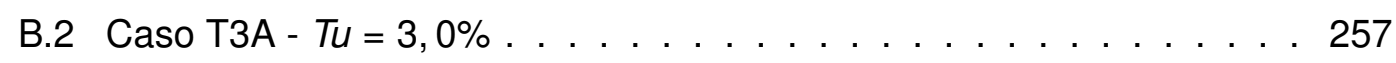

B.3 Caso T3A $-\mathrm{Tu}=2,9 \% \ldots \ldots \ldots . \ldots \ldots$. . . . . . . . . . . . . . . . . . .

B.4 Fatores Críticos de Amplificação - Caso T3AM - Tu =0,87\% . . . . . 260

B.5 Fatores Críticos de Amplificação - Caso T3AM - Tu=0,34\% . . . . . 260 
B.6 Fatores Críticos de Amplificação - Caso T3C2 - Tu=2,4\% . . . . . . 263

B.7 Fatores Críticos de Amplificação - Caso T3C2 - Tu=3,0\% . . . . . . 263

B.8 Fatores Críticos de Amplificação - Caso T3C5 - Tu=3,0\% . . . . . . 265 


\title{
Lista de ABREVIATURAS
}

\author{
CFD Computational Fluid Dynamics \\ EMBRAER Empresa Brasileira de Aeronáutica \\ ETM Energia Total Mínima \\ IRT Icing Research Tunnel \\ NACA National Advisory Committee for Aeronautics \\ NASA National Aeronautics and Space Administration \\ RANS Reynolds Averaged Navier-Stokes \\ DNS Direct Numerical Simulation \\ MVD Median Volumetric Diameter \\ LWC Liquid Water Content \\ SLD Supercooled Large Droplets \\ FAR Federal Aviation Regulation \\ MED Median Effective Diameter \\ ANAC Agência Nacional de Aviação Civil \\ FAA Federal Aviation Administration \\ RBHA Regulamento Brasileiro de Homologação Aeronáutica \\ ERCOFTAC European Research Community of Flow, Turbulence and Combustion \\ LES Large Eddy Simulation \\ RAE Royal Aircraft Establishment
}

ONERA Office National D'etudes et de Recherches Aérospatiales 


\section{NOMENCLATURA}

$\mathcal{A}_{i} \quad$ área da interface $i, \mathrm{~m}^{2}$

$\mathcal{A}_{r} \quad$ área da base do filete, $\mathrm{m}^{2}$

$\mathrm{B}_{h} \quad$ força motriz para a transferência de calor

$\mathrm{B}_{m} \quad$ força motriz para a transferência de massa

c corda do aerofólio, $\mathrm{m}$

$C_{f} \quad$ coeficiente de atrito local, $\tau /\left(1 / 2 \cdot \rho_{e} \cdot u_{e}^{2}\right)$

$C_{p} \quad$ coeficiente de pressão, $\left(p-p_{\infty}\right) /\left(1 / 2 \cdot \rho_{e} \cdot V_{\infty}^{2}\right)$

$c_{p} \quad$ calor específico, $\mathrm{J} /(\mathrm{kg} \cdot \mathrm{K})$

$D \quad$ difusividade mássica, $\mathrm{m}^{2} / \mathrm{s}$

E energia mecânica total, J

e energia mecânica total por área de filme, $\mathrm{J} / \mathrm{m}^{2}$

$F \quad$ fator de molhabilidade, $A_{\text {molhada }} / A_{\text {total }}$

$\mathcal{F} \quad$ função de Helmholtz, J

$F_{r} \quad$ fator de molhabilidade gerado pela presença dos filetes

$F_{s} \quad$ fator de molhabilidade na direção do escoamento gerado pelo desaparecimento da água líquida

G fluxo mássico $\rho \cdot u_{e}, \mathrm{~kg} /\left(\mathrm{s} \cdot \mathrm{m}^{2}\right)$

$g_{m} \quad$ condutância de transferência de massa, $\mathrm{kg} /\left(\mathrm{s} \cdot \mathrm{m}^{2}\right)$

$g(\alpha)$ função auxiliar, $-1 / 4 \cos ^{3} \alpha-13 / 8 \cos \alpha+15 \alpha / 8 \sin \alpha-3 / 2 \alpha \sin \alpha$

$H \quad$ fator de forma, $H=\delta_{1} / \delta_{2}$

$h_{0} \quad$ altura crítica de filme na posição de ruptura, $\mathrm{m}$

h coeficiente de transferência de calor por convecção, $\mathrm{W} /\left(\mathrm{m}^{2} \cdot \mathrm{K}\right)$ 
$h^{+} \quad$ altura crítica adimensional na posição de ruptura do filme contínuo de líquido, $\left(\rho \tau^{2} h_{0}^{3}\right) /\left(6 \mu^{2} \sigma_{f g}\right)$

$h_{r} \quad$ altura do filete na posição de ruptura, m

$h(w)$ altura do filete, $R(\cos \theta-\cos \alpha), \mathrm{m}$

i entalpia específica, $\mathrm{J} / \mathrm{kg}$

i entalpia específica, $\mathrm{J} /(\mathrm{kg} \cdot \mathrm{K})$

$k \quad$ condutividade térmica, $\mathrm{W} /(\mathrm{m} \cdot \mathrm{K})$

$k_{s} \quad$ altura da rugosidade tipo grão de areia, m

Le $\quad$ número de Lewis, $c_{p} \cdot D_{\text {agua,ar }} \cdot \rho / k$

$l_{j} \quad$ localização do ponto de quebra para aproximação de degraus

$I(\lambda) \quad$ função do gradiente de pressão na Eq. (4.5)

LWC conteúdo de água líquida, $\mathrm{g} / \mathrm{m}^{3}$

m vazão mássica, $\mathrm{kg} / \mathrm{s}$

$m$ gradiente de pressão no escoamento laminar similar sobre cunha

Ma número de Mach

$m f_{H 2 O}$ fração mássica de vapor d'água na mistura

$b_{j} \quad$ inclinação da rampa no ponto de quebra $n$

$m_{n} \quad$ degrau no ponto de quebra $j$

MVD diâmetro volumétrico mediano, $\mu \mathrm{m}$

$a_{n} \quad$ localização do ponto de quebra para aproximação de rampas

$n_{\text {crit }} \quad$ fator de amplificação máxima das instabilidades lineares

$\mathrm{Nu} \quad$ número de Nusselt local do escoamento bifásico, $\left(h_{a r} \cdot s\right) / k_{a r}=\mathrm{St}_{a r} \cdot \operatorname{Re}_{s} \cdot \operatorname{Pr}_{a r}$

p pressão, $\mathrm{Pa}$

$p^{+} \quad$ pressão na camada-limite, $(\mu d \bar{P} / d x) /\left(\rho^{1 / 2} \tau_{w}^{3 / 2}\right)$

$p_{\text {mist }}$ pressão total da mistura ar-vapor d'água, $\mathrm{Pa}$

Pr número de Prandtl, $\mu \cdot c_{p} / k$ 
Pr número de Prandtl, $\nu \cdot \rho \cdot c_{p} / k$

$p_{\text {vap }}$ pressão parcial de vapor saturado, $\mathrm{Pa}$

$\dot{q}^{\prime \prime} \quad$ fluxo de calor, $\mathrm{W} / \mathrm{m}^{2}$

$\dot{q}_{\text {perd }}$ taxa de transferência de calor perdido para o escoamento gasoso, W

$\dot{\bar{q}}_{t u r b}^{\prime \prime} \quad$ fluxo de calor médio turbulento, $\mathrm{W} / \mathrm{m}^{2}$

$R \quad$ raio do filete, $\mathrm{m}$

$r \quad$ fator de recuperação

$\mathrm{Re}_{\text {crit }}$ valor crítico de $\mathrm{Re}$ para início da transição laminar-turbulenta

$\operatorname{Re}_{\Delta_{2}}$ número de Reynolds baseado na espessura de entalpia $u_{e} \cdot \Delta_{2} / \nu_{a r}$

$\mathrm{Re}_{\delta_{2}}$ número de Reynolds baseado na espessura de quantidade de movimento, $u_{e} \cdot \delta_{2} / \nu$

$\operatorname{Re}_{\infty}$ número de Reynolds baseado na corda e velocidade do escoamento livre, $V_{\infty} \cdot c / \nu_{a r}$

$\operatorname{Re}_{k} \quad$ Reynolds baseado na altura da rugosidade $u_{e} k_{s} / \nu_{a r}$

$\operatorname{Re}_{\sigma} \operatorname{Re}$ com base no desvio padrão da região de transição $u_{e} \cdot \sigma / \nu_{\text {air }}$

$\operatorname{Re}_{s_{m}} \operatorname{Re}$ com base na posição média da região de transição $u_{e} \cdot s_{m} / \nu_{\text {air }}$

$\operatorname{Re}_{s} \quad \operatorname{Re}$ com base na distância na superfície do aerofólio, $u_{e} \cdot s / \nu_{\text {air }}$

$R_{m} \quad$ raio médio do filete no volume finito, $1 / 2 \cdot\left(R_{\text {out }}+R_{\text {in }}\right)$, m

$R_{t} \quad$ resistência térmica, $\mathrm{K} / \mathrm{W}$

s distância na direção do escoamento a partir da estagnação, m

$s_{m} \quad$ posição média da região de transição laminar-turbulenta, $m$

St número de Stanton local, $h /\left(\rho \cdot u_{e} \cdot c_{p}\right)$

$T$ temperatura, ${ }^{\circ} \mathrm{C}$ ou $\mathrm{K}$

$t^{+} \quad$ temperatura na camada-limite, $\left[\left(T_{w}-\bar{T}\right)\left(\tau_{w} / \rho\right)^{1 / 2}\right] /\left[\left(\dot{q}_{w}^{\prime \prime} /\left(\rho c_{p}\right)\right]\right.$

$T_{\text {tot }} \quad$ temperatura total, ${ }^{\circ} \mathrm{C}$ ou $\mathrm{K}$

$U \quad$ coeficiente de transferência de calor global, $\mathrm{W} /\left(\mathrm{m}^{2} \cdot \mathrm{K}\right)$ 
$u \quad$ velocidade dentro da camada-limite, paralela a superfície do aerofólio, $\mathrm{m} / \mathrm{s}$

$u_{e} \quad$ velocidade do escoamento na borda superior da camada-limite, $\mathrm{m} / \mathrm{s}$

$u^{+} \quad$ velocidade dentro da camada-limite, $\bar{u} / u_{T}$

$\bar{u} \quad$ velocidade média do escoamento, $\mathrm{m} / \mathrm{s}$

$u_{T} \quad$ velocidade de cisalhamento, $\left(\tau_{w} / \rho\right)^{1 / 2}$

$V \quad$ velocidade, $\mathrm{m} / \mathrm{s}$

$v \quad$ velocidade dentro da camada-limite, normal à superfície do aerofólio, $\mathrm{m} / \mathrm{s}$

$v_{f} \quad$ velocidade do filme de água líquida, $\mathrm{m} / \mathrm{s}$

$\bar{v}_{f} \quad$ velocidade média do filme de água líquida, $\mathrm{m} / \mathrm{s}$

$v_{w}^{+} \quad$ velocidade de transpiração na camada-limite, $v_{w} / u_{T}$

$w \quad$ distância na interface sólido-líquido do filete, $0 \leq w \leq R \sin \alpha, \mathrm{m}$

$w_{s l} \quad$ trabalho mínimo de adesão sólido-líquido por unidade de área, $\mathrm{J} / \mathrm{m}^{2}$

y distância normal a superfície do aerofólio, m

$y^{+} \quad$ coordenada y dentro da camada-limite, $y u_{T} / \nu$

$\sigma \quad$ desvio padrão da região de transição, $\mathrm{m}$

\section{Subscritos}

$0 \quad y=0$

ar escoamento gasoso da mistura ar e vapor d'água

anti aquecimento do antigelo

cin cinética

d gotícula de água sub-resfriada

e borda externa da camada-limite

entra entrada do volume finito

G posição no escoamento gasoso da mistura ar-vapor d'água na borda superior da camada-limite 
imp incidência de gotículas de água líquida sub-resfriadas

$\infty \quad$ escoamento ao longe não perturbado pelo aerofólio

int líquido-vapor, se molhado, ou sólido-vapor, se seco

iso escoamento sobre superfície isotérmica

lam referente ao escoamento laminar

sl sólido-líquido

IV líquido-vapor

$m$ posição média da região de transição

rec referente a recuperação

ref referência $\mathrm{T}=273,15 \mathrm{~K}$

sai saída do volume finito

S posição logo acima da superfície da água líquida

s $\quad$ superfície sólida do aerofólio

stag ponto de estagnação do aerofólio

sup superficial

$t$ término da região de transição laminar-turbulenta

$T \quad$ total

tr início da transição (onset)

turb referente ao escoamento plenamente turbulento

agua água líquida ou vapor

\section{Símbolos Gregos}

$\rho \quad$ massa específica, $\mathrm{kg} / \mathrm{m}^{3}$

$\alpha \quad$ ângulo de contato

$\alpha \quad$ ângulo de ataque

$\gamma \quad$ intermitência, fração de tempo na qual o escoamento é turbulento numa posição $s$ 
$\beta \quad$ eficiência de coleta local

$\beta \quad$ ângulo da cunha sobre a qual há escoamento laminar

$\beta_{r} \quad$ função Beta Incompleta, $\beta_{r}(a, b)=\int_{0}^{r} z^{a-1}(1-z)^{b-1} d z$

$\delta_{f} \quad$ altura do filme de água líquida, $\mathrm{m}$

$\delta \quad$ espessura da camada-limite de velocidades, $\bar{u}(\delta)=0,99 * u_{e}, \mathrm{~m} / \mathrm{s}$

$\delta_{1} \quad$ espessura de deslocamento, $\int_{0}^{\infty} 1-\rho u /\left(\rho_{e} u_{e}\right) d y, \mathrm{~m}$

$\Delta_{2} \quad$ espessura de entalpia, $\int_{0}^{\infty} \rho u /\left(\rho_{e} u_{e}\right)\left(i-i_{e}\right) /\left(i_{0}-i_{e}\right) d y, \mathrm{~m}$

$\delta_{2} \quad$ espessura de quantidade de movimento, $\int_{0}^{\infty} \rho u /\left(\rho_{e} u_{e}\right)\left(1-u / u_{e}\right) d y, \mathrm{~m}$

$\Delta_{4} \quad$ espessura de condução, $k_{a r} / h_{a r}, \mathrm{~m}$

$\Delta s \quad$ comprimento do volume finito, $\mathrm{m}$

$\Delta T$ diferença de temperatura entre a temperatura de recuperação e a da interface líquido-vapor ou vapor-sólido, $\mathrm{K}$

$\Gamma \quad$ função Gama, $\Gamma(z)=\int_{0}^{\infty} t^{z-1} e^{-t} d t$

$\lambda \quad$ parâmetro de gradiente de pressão

$\lambda_{f} \quad$ distância entre centros dos filetes, $\mathrm{m}$

$\lambda_{f, 0} \quad$ distância entre centros de filetes na posição de ruptura do filme, $\mathrm{m}$

$\mu \quad$ viscosidade dinâmica, $\mathrm{Pa} \cdot \mathrm{s}$

$\nu \quad$ viscosidade cinemática, $\mathrm{m}^{2} / \mathrm{s}$

$\phi(\alpha) \quad$ função auxiliar, $\sin \alpha-\frac{1}{3} \sin ^{3} \alpha-\alpha \cos \alpha$

$\varphi \quad$ ângulo entre a trajetória das gotículas e a normal da superfície no ponto de impacto

$\xi \quad$ correção de área para a interface líquido-gás do filete, $\alpha / \sin \alpha$

$\rho \quad$ massa específica, $\mathrm{kg} / \mathrm{m}^{3}$

$\sigma \quad$ tensão superficial, $\mathrm{N} / \mathrm{m}$

$\sigma_{t r}$ desvio-padrão da região de transição laminar-turbulenta, $\mathrm{m}$ 
$\tau \quad$ tensão de cisalhamento, $\mathrm{Pa}$

$\theta \quad$ coordenada angular do filete, $0 \leq \theta \leq \alpha$

\section{Sobrescritos}

* $\quad$ indica o efeito da transpiração no número Stanton local entre a superfície da água líquida e o escoamento gasoso 


\section{INTRODUÇÃO}

Uma das causas de acidentes aeronáuticos, durante voo sob condições atmosféricas adversas, é a formação gelo em regiões e equipamentos das aeronaves. A presença do gelo na superfície de uma asa, por exemplo, pode gerar uma degradação significativa do seu desempenho aerodinâmico. No Anexo A são apresentados os conceitos gerais envolvidos na formação de gelo e na sua prevenção.

Outros equipamentos e sistemas também, como mostrados na Fig. 1.1, estão sujeitos à formação de gelo, pois ficam expostos às condições ambientais externas. Alguns deles são: partes de motores, entradas de ar, antenas, sondas, sensores, asas, aerofólios e parabrisas.

Para prevenir a degradação operacional da aeronave causada pela formação de gelo, são instalados sistemas térmicos ou mecânicos para manter as superfícies limpas. Existem dois tipos de sistemas térmicos:

1) sistema de degelo: é acionado ciclicamente para remover as camadas de gelo formadas sobre a superfície durante um período de exposição;

2) sistema de antigelo: é acionado continuamente para prevenir a formação de gelo sobre as superfícies de interesse.

A maioria dos aviões comerciais possuem sistemas térmicos de antigelo para proteger a superfície das asas e dos estabilizadores horizontais. Se as superfícies dos aerofólios apresentarem gelo acumulado, haverá uma alteração do desempenho aerodinâmico que pode diminuir as margens de segurança operacionais.

Na Fig. 1.2 são apresentados os efeitos de vários tipos de formação de gelo na sustentação aerodinâmica de um aerofólio. A presença do gelo pode diminuir a sustentação, aumentar o peso, o arrasto e a mínima velocidade de estol. Além disso, pode afetar a manobrabilidade e controlabilidade da aeronave.

Os sistemas térmicos de antigelo mantêm uma temperatura de superfície do aerofólio acima da temperatura total de $0^{\circ} \mathrm{C}$ para prevenir a formação de gelo. Usualmente, sistemas antigelo eletrotérmicos são compostos por conjuntos de painéis de 


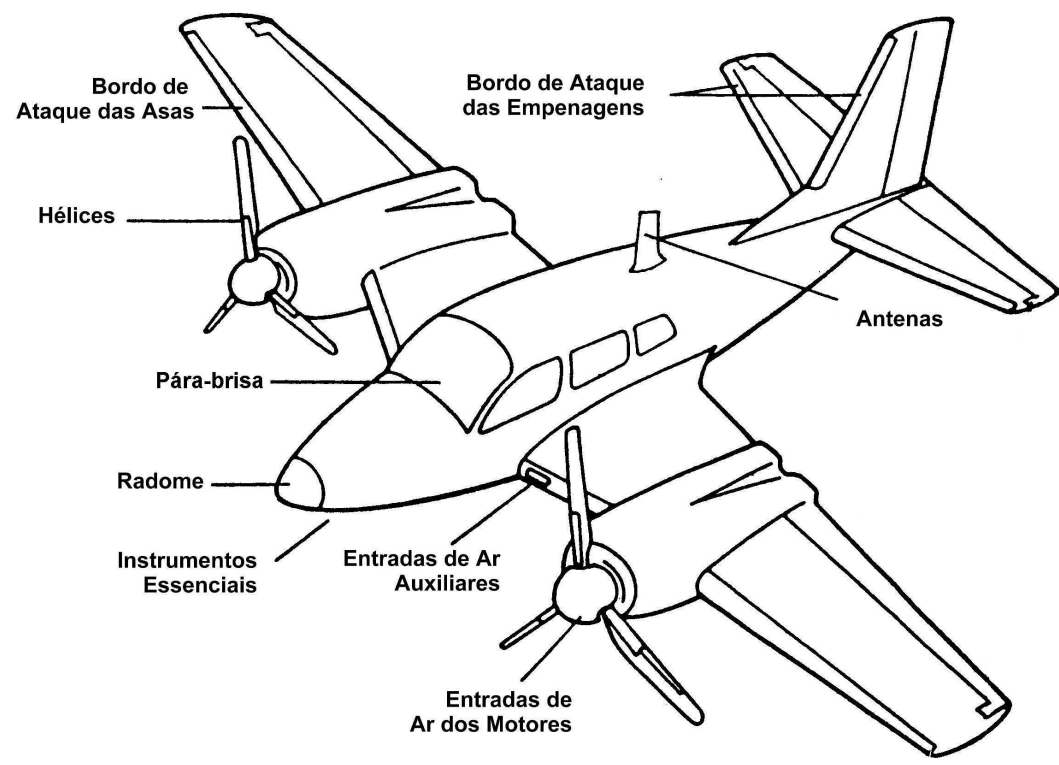

Figura 1.1: Regiões e equipamentos de uma aeronave sujeitos a formação de gelo (HEINRICH et al., 1991)

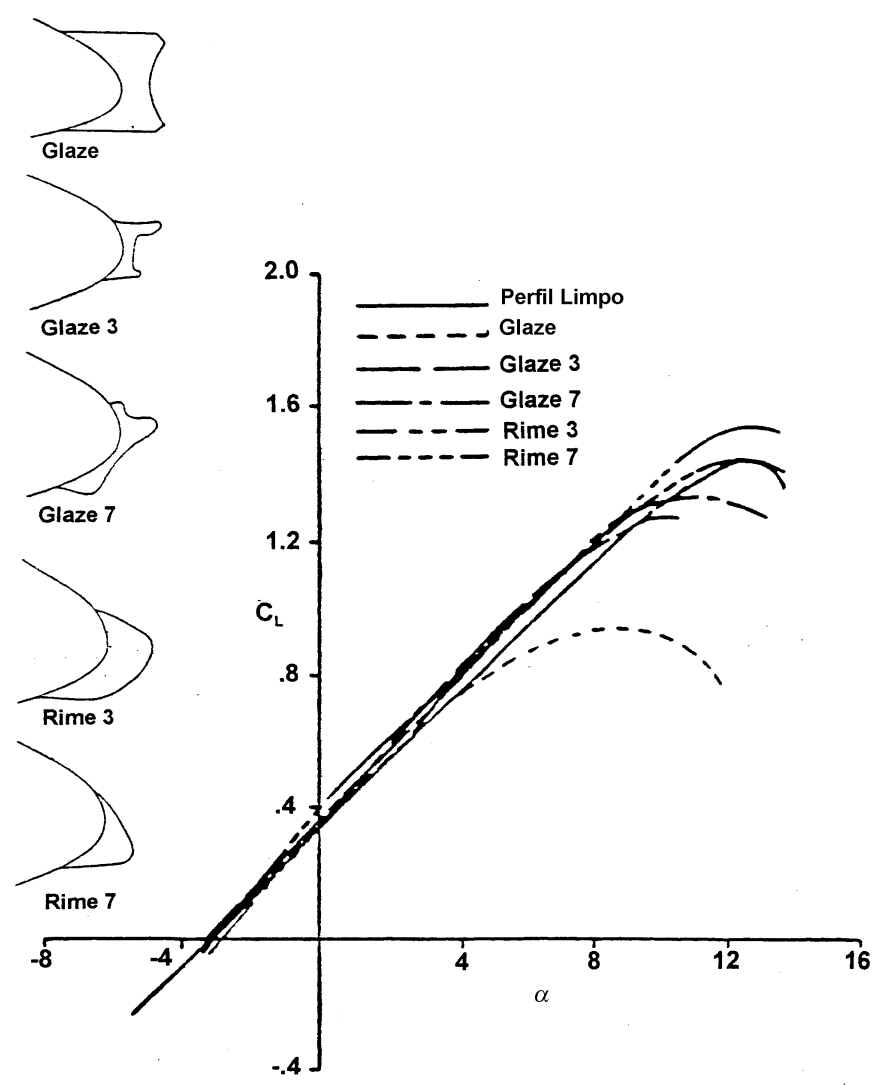

Figura 1.2: Coeficiente de sustentação, $C_{L}$, em função do ângulo de ataque, $\alpha$, de um perfil NACA 63A415 sem formação de gelo (limpo) e com vários tipos de formação de gelo ${ }^{1}$ 
aquecimento distribuídos na direção da envergadura, instalados lado a lado. Cada painel possui vários elementos aquecedores, de comprimentos e potência diferentes, instalados ao longo das superfícies do intradorso e extradorso na direção do escoamento, principalmente nas regiões sujeitas à maior incidência de gotículas subresfriadas.

Dependendo da potência térmica fornecida pelo sistema antigelo ao aerofólio, três regimes de operação podem ser identificados:

1) totalmente evaporativo (fully evaporative): a potência de aquecimento fornecida supera a demanda de resfriamento imposta pelas condições ambientais; a água é vaporizada dentro dos limites de captação de gotículas; logo não há escoamento de água residual nas regiões a jusante do limite de incidência;

2) evaporativo (evaporative): a potência de aquecimento fornecida supera a demanda de resfriamento imposta pelas condições ambientais, no entanto, a água líquida evapora numa posição a jusante do limite de captaa̧ão e a montante do final da região aquecida;

3) molhado (running wet): a potência de aquecimento fornecida é igual ou inferior a demanda de resfriamento imposta pelas condições ambientais; a água líquida escoa para regiões a jusante da região protegida e forma gelo residual (runback ice).

Um programa confiável de simulação térmica de aerofólios com sistemas de antigelo pode ser utilizado nas fases de concepção, definição da arquitetura, projeto, desenvolvimento e integração de sistemas. Pode ser também uma ferramenta útil na fase de certificação, pois ajuda a definir a matriz de casos críticos e o planejamento da campanha de testes. Se os resultados numéricos forem validados com dados experimentais confiáveis, o custo e a duração dos testes em túnel de gelo e de voo sob condições de gelo podem ser minimizados.

No trabalho anterior (SILVA, 2002), foi desenvolvido e implementado um modelo matemático para simular a operação, em regime permanente, um sistema de antigelo considerando que a água residual escoa na forma de filme contínuo, e utilizando uma análise integral de camada-limite com região de transição laminar-turbulenta ajustada pelo usuário. Os resultados numéricos obtidos foram satisfatórios para um conjunto restrito de condições operacionais e configurações do sistema antigelo. A faixa de

\footnotetext{
${ }^{1}$ KOHLMAN, D. L.; SAND, W. (The Univeristy of Kansas, Overland Park, Kansas, EUA) Aircraft icing: meteorology, protective systems, instrumentation and certification. Material do curso de especialização.
} 
aplicação do simulador numérico foi limitada devido ao conjunto de hipóteses adotado para a modelagem matemática do escoamento de camada-limite, da transição laminar-turbulenta e do escoamento de água residual. Os maiores desvios entre os resultados numéricos e dados experimentais foram observados principalmente naqueles casos que apresentaram regime evaporativo ou regime molhado de operação. Nesses regimes, o escoamento de água residual cobre a maior parte ou toda a área protegida termicamente. Mesmo nos casos que as previsões foram satisfatórias, houve a necessidade de impor o início e término da região de transição laminarturbulenta no escoamento da camada-limite de ar em torno do aerofólio. A definição dos parâmetros de transição foi feita com base nas observações experimentais e na minimização dos desvios entre resultados numéricos e dados experimentais para o coeficiente de transferência de calor global ao longo do aerofólio.

A falta de um modelo de formação e escoamento de filetes de água residual na dissertação de mestrado (SILVA, 2002), forçou a escolha do início e término da região de transição para cada caso simulado de forma a fornecer resultados numéricos de coeficiente de transferência de calor mais próximos dos dados experimentais. Como a análise integral de camada-limite não permitiu representar os efeitos da história do escoamento causada pela variação de temperatura de superfície e de gradiente de pressão, o ajuste da região de transição laminar-turbulenta também foi utilizada para diminuir os desvios entre as previsões numéricas e as medições. Em resumo, o ajuste dos parâmetros de transição laminar-turbulenta encobriu algumas incertezas e limitações da modelagem física e matemática. A região de transição ajustada, em alguns casos, tinha características pouco comuns: o seu início (onset) ocorria muito próximo do ponto de estagnação do aerofólio, onde há um escoamento laminar estável, indiferente às perturbações do ambiente ou da superfície; e o seu término ocorria bem a jusante da área protegida $(s / c>0.2)$, ou seja, tinha comprimento mais longo do que o esperado para escoamento em torno de aerofólios de uso aeronáutico. Consequentemente, a previsão de transição laminar-turbulenta por correlações algébricas, tentativamente implementada no mestrado, não forneceu resultados próximos aos dados experimentais de temperatura nem de coeficiente de transferência de calor.

Logo, foi necessário continuar o desenvolvimento do programa de simulação numérica do desempenho térmico de sistemas de antigelo, iniciado na dissertação de mestrado de Silva (2002), para:

- reduzir os desvios entre os resultados numéricos e os dados experimentais publicados na literatura, parcialmente provocados pelo modelo de molhabilidade 
da superfície do aerofólio a jusante dos limites de captação de gotículas de água, como verificado por Silva, Silvares e Zerbini (2006);

- tornar mais precisa a estimativa de coeficiente de transferência de calor e fluxo mássico de evaporação por meio da modelagem da camada-limite térmica em torno do aerofólio considerando os efeitos:

- da variação de temperatura de superfície do aerofólio,

- do insuflamento causado pela evaporação da água líquida,

- da variação de gradiente de pressão no escoamento externo e

- da ocorrência da transição laminar-turbulenta;

- aumentar a aplicação do programa de simulação para várias geometrias e maiores faixas de condições atmosféricas e de voo. 


\subsection{Objetivo}

O objetivo deste trabalho é prever a transferência de calor e de massa no escoamento bidimensional bifásico em torno de aerofólios de uso aeronáutico equipados com sistema de antigelo térmico, que operem em regime permanente e sob condições de formação de gelo. Em resumo, a proposta de trabalho:

1) estima a molhabilidade da superfície do aerofólio usando um modelo matemático para o escoamento da água liquida, que preveja a ruptura do filme contínuo e a formação de filetes;

2) avalia as camadas-limite dinâmica e térmica, nos regimes laminar, transicional e turbulento, em torno do aerofólio com superfície lisa não isotérmica e com transpiração por meio de modelos integrais e diferenciais;

3) estima a posição de início ("onset") e término da região de transição laminarturbulenta das camadas-limite dinâmica e térmica por meio de correlações e modelos algébricos;

4) valida os resultados numéricos com dados experimentais de temperaturas de superfície e de coeficiente de transferência de calor obtidos na operação de sistemas eletrotérmicos de antigelo em túneis de vento sob condições de formação de gelo.

\subsection{Relevância da Tese}

Os trabalhos de simulação térmica de antigelo revistos por Gent, Dart e Cansdale (2000) e publicados pelos institutos de pesquisa National Aeronautics and Space Administration (NASA), Office National D'etudes et de Recherches Aérospatiales (ONERA) e Royal Aircraft Establishment (RAE):

- avaliaram a camada-limite dinâmica laminar e turbulenta por meio da análise integral, que pode apresentar desvios significativos nos casos de gradiente pressão adverso e variação de gradiente de pressão (aceleração do escoamento);

- consideraram que a superfície do aerofólio é rugosa, mas como a superfície dos aerofólios com antigelo é aproximadamente lisa, a análise integral camadalimite dinâmica turbulenta superestimou o coeficiente de transferência de calor; 
- utilizaram analogia entre transferência de quantidade de movimento e transferência de calor para estimar o coeficiente de transferência de calor por convecção a partir do coeficiente de atrito, que perde a validade quando a superfície não é isotérmica e há efeitos da evaporação;

- admitiram a ocorrência da transição laminar-turbulenta de forma abrupta, na qual a passagem do regime laminar para o turbulento ocorre instantâneamente, ou seja, que a região de transiç tem comprimento nulo;

- previram o início da região de transição por correlações empíricas, com a de Makkonen (1985), que utilizam a altura da rugosidade;

- não implementaram modelos de padrões escoamento de água líquida residual para estimar a molhabilidade variável da superfície.

Henry (1992) desenvolveu uma versão do programa de simulação ONERA2D, dedicada a simulação térmica de aerofólios com sistemas degelo e antigelo, que:

- avaliou as propriedades da camada-limite dinâmica e térmica por meio de diferenças finitas;

- não possuía modelos de padrões escoamento de água líquida residual para estimar a molhabilidade variável da superfície.

Ainda no trabalho de Henry (1992), não há informações sobre o regime do escoamento, se laminar ou turbulento, nem como modelou a previsão do início e término da transição laminar-turbulenta e da sua intermitência.

Morency, Tezok e Paraschivoiu (1999a) implementaram o programa de simulação CANICE FD que:

- avaliou as propriedades da camada-limite dinâmica e térmica por meio de diferenças finitas nos regimes laminar, transicional e turbulento.

- estimou inicio da transição laminar-turbulenta por meio da correlação empírica de Michel (1951), que é apropriada somente para transição natural e não tem efeitos do nível de turbulência do escoamento livre;

- não implementou modelos de padrões escoamento de água líquida residual para estimar a molhabilidade variável da superfície e, portanto, nem simulou casos que tinham escoamento de água líquida a jusante dos limites de captação; 
Al-Khalil et al. (2001) desenvolveram o programa ANTICE que:

- não previu a distribuição do coeficientes de transferência de calor em torno do aerofólio nos regimes laminar, turbulento e transicional;

- utilizou medições experimentais de coeficiente de transferência de calor;

- não previu nem o início nem o término da região de transição laminarturbulenta;

- estimou a molhabilidade parcial da superfície por meio de modelos de padrões escoamento da água líquida residual.

Tabela 1.1: Contribuições de Trabalhos Anteriores

\begin{tabular}{|c|c|c|c|c|c|}
\hline \multirow[b]{2}{*}{ Código } & \multirow[b]{2}{*}{ Autor(es) } & \multicolumn{4}{|c|}{ Características } \\
\hline & & $\begin{array}{l}\text { Camadas- } \\
\text { Limite }\end{array}$ & $\begin{array}{l}\text { Molhabili- } \\
\text { dade }\end{array}$ & $\begin{array}{l}\text { Região de } \\
\text { Transição }\end{array}$ & $\begin{array}{l}\text { Início e } \\
\text { Término da } \\
\text { Transição }\end{array}$ \\
\hline ANTICE & $\begin{array}{l}\text { Al-Khalil et al. } \\
\text { (2001) }\end{array}$ & - & $\begin{array}{l}\text { padrão de } \\
\text { escoamento } \\
\text { de filetes }\end{array}$ & - & - \\
\hline ONERA & Henry (1992) & diferencial & - & - & - \\
\hline CANICE FD & $\begin{array}{l}\text { Morency, } \\
\text { Tezok e } \\
\text { Paraschivoiu } \\
\text { (1999a) }\end{array}$ & diferencial & - & intermitência & $\begin{array}{l}\text { Efeitos de } \\
\text { Reynolds }\end{array}$ \\
\hline Mestrado & Silva (2002) & $\begin{array}{l}\text { integral não- } \\
\text { isotérmico }\end{array}$ & - & probabilística & ajustado \\
\hline $\begin{array}{l}\text { Proposta de } \\
\text { Trabalho }\end{array}$ & presente tese & diferencial & $\begin{array}{l}\text { padrão de } \\
\text { escoamento } \\
\text { de filetes }\end{array}$ & intermitência & $\begin{array}{l}\text { Efeitos de } \\
\text { Re, gradiente } \\
\text { pressão e } \\
\text { nível de } \\
\text { turbulência }\end{array}$ \\
\hline
\end{tabular}

A relevância do presente trabalho é preencher as lacunas deixadas por trabalhos anteriores, como destacado na Tabela 1.1, a saber:

- avaliar diferencialmente as camadas-limite térmica e dinâmica no escoamento em torno de aerofólios com superfície lisa, não-isotérmica e permeável nos regimes laminar e turbulento; 
- estimar a molhabilidade parcial da superfície por meio da modelagem dos padrões de escoamento da água líquida residual sobre a superfície do aerofólio;

- estimar as propriedades das camadas-limite térmica e dinâmica dentro da região de transição por meio de modelos de intermitência e de previsão de início e término da região de transição, que considere os efeitos do gradiente de pressão e do nível de turbulência do escoamento livre.

\subsection{Organização da Tese}

A organização dos capítulos reflete o processo de desenvolvimento da tese, com etapas incrementais de modelagem do desempenho térmico do aerofólio com antigelo no Capítulo 2, do escoamento de água líquida no Capítulo 3, das camadaslimite no Capítulo 4 e da transição laminar-turbulenta no Capítulo 5. A validação dos resultados da simulação são comparados com dados experimentais de desempenho térmico de aerofólios com antigelo no Capítulo 6. A organização da presente tese está resumida graficamente na Fig. 1.3, localizada no final deste capítulo.

Esta organização permite ao leitor, nos Capítulos 3, 4 e 5: a) o acesso à bibliografia pesquisada, que apresenta a contribuição de cada autor sobre a etapa da modelagem abordada em cada capítulo; b) a identificação da contribuição da presente tese por meio da formulação matemática e verificação dos resultados dos modelos incorporados ao modelo-base do Capítulo 2. Além disso, com este formato gradual, o leitor pode acompanhar a verificação, conhecer os métodos utilizados e, consequentemente, adquirir confiança nos resultados obtidos.

No Capítulo 2, apresenta-se o modelo do escoamento em torno de aerofólios equipados com sistemas térmicos de antigelo, desenvolvido na dissertação de mestrado (SILVA, 2002). Apresenta-se também uma revisão bibliográfica dedicada à simulação do desempenho térmico do sistema antigelo. Maiores detalhes sobre a implementação numérica podem ser encontrados em Silva (2002).

Os Capítulos 3, 4 e 5 desenvolvem a proposta de trabalho desta tese. Os Capítulos 6 e 7 representam os resultados e as conclusões desta proposta.

O modelo para ruptura do filme e formação de filetes no escoamento de água residual em torno do aerofólio está descrito no Capítulo 3. Neste capítulo ainda, apresentam-se as modificações no modelo-base do Capítulo 2, que serão inclusas para considerar os efeitos da molhabilidade parcial da superfície. Os resultados numéricos, obtidos com o modelo de filetes, são comparados com dados experimentais 
descritos na literatura e com a simulação do escoamento de água líquida na forma de filme contínuo, sem a formação de filetes.

No Capítulo 4, descrevem-se as análises integral e diferencial das camadaslimite no escoamento em torno de aerofólios. Estas análises serão utilizadas no Capítulo 6 pelo novo modelo térmico do desempenho térmico do antigelo, que foi desenvolvido no Capítulo 2 e modificado no Capítulo 3 . É apresentada também, no Capítulo 4, a verificação dos procedimentos implementados para a análise de camada-limite laminar e turbulenta. Os códigos numéricos de análise diferencial de camada-limite (TEXSTAN e BLP2C) utilizados no processo de verificação dos submodelos são descritos no Anexo B.

O Capítulo 5 apresenta os modelos matemáticos e as verificações realizadas para escoamentos para a previsão das propriedades das camadas-limite dinâmica e térmica dentro da região transição entre o regime laminar e o plenamente turbulento. Os modelos de intermitência e de previsão de início e término da região de transição são incluídos no modelo-base do escoamento em torno do aerofólio com antigelo do Capítulo 2 e seus efeitos no desempenho térmico são analisados no Capítulo 6 . 0 modelo matemático e o código numérico diferencial para a análise linear de estabilidade do escoamento laminar são descritos no Anexo C.

Os resultados da transferência de calor e de massa no escoamento bifásico em torno de aerofólios com antigelo térmico são apresentados no Capítulo 6. Para isso, é utilizado o modelo térmico apresentado no Capítulo 2 e modificado no Capítulo 3 para prever a molhabilidade parcial da superfície. São incluídos também no modelo térmico as análises integral (isotérmico, não-isotérmico e por sobreposição) e diferencial $(B L P 2 C)$ das camadas-limite apresentadas no Capítulo 4. Por fim, são incluídos os modelos de transição laminar-turbulenta desenvolvidos e verificados no Capítulo 5. Para validação do modelo de simulação térmica de aerofólios com antigelo, são selecionados casos de bancos dados experimentais de fontes confiáveis e representativos da operação de sistemas de antigelo elétricos.

As conclusões do presente trabalho e sugestões para próximos trabalhos constituem o Capítulo 7. 


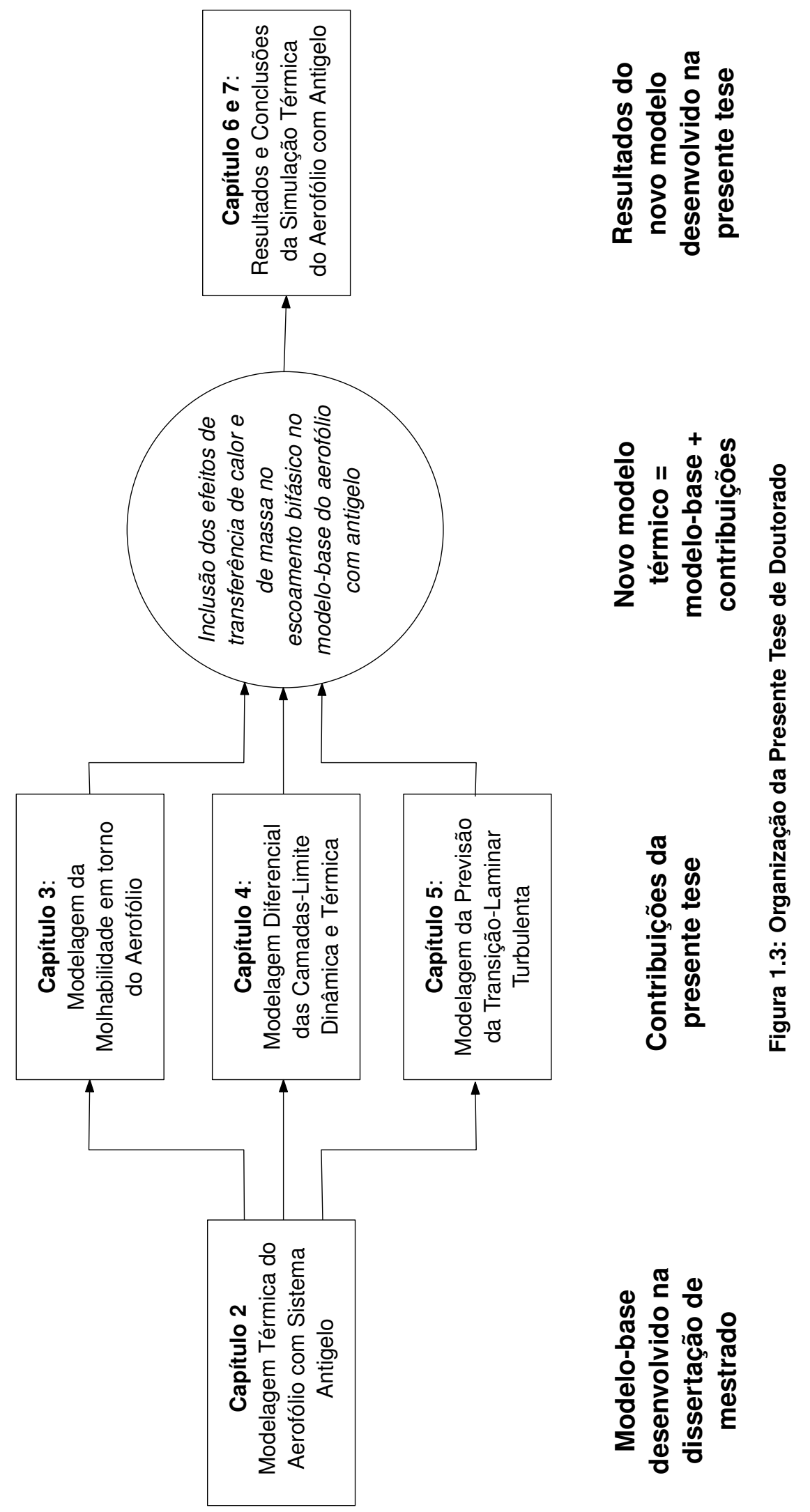




\section{Modelagem do Escoamento BIFÁSICO EM TORNO DE Aerofólios COM Sistema TÉRMICO DE ANTIGELO}

\subsection{Revisão Bibliográfica}

Os códigos clássicos LEWICE(MACARTHUR; KELLER; LUERS, 1982; RUFF; BERKOWITZ, 1990), TRAJICE2 (CANSDALE; GENT, 1983; GENT, 1990) e ONERA2D(GUFFOND; BRUNET, 1988) estimam formas de gelo sobre superfícies de aerofólios sem proteção térmica.

Wright, Gent e Guffond (1997) publicaram uma revisão dos modelos implementados nos simuladores numéricos de crescimento de gelo, LEWICE, TRAJICE2 e ONERA2D, e uma comparação entre eles quanto à capacidade de previsão numérica. Os módulos principais destes códigos clássicos para previsão de formação de gelo são: 1) Módulo de Escoamento, que resolve o escoamento em torno do aerofólio; 2) Módulo de Trajetória, que calcula a trajetória das gotículas e estima a eficiência de coleta local sobre o aerofólio; 3) Módulo Térmico, que estima o crescimento do gelo.

De acordo com a literatura pesquisada, a maioria dos códigos numéricos para simulação de sistemas antigelo utiliza o primeiro e o segundo módulos, sem mudanças nos modelos matemáticos de solução do escoamento e das trajetórias das gotículas. O terceiro módulo não é utilizado, já que avalia a formação de gelo e não sua prevenção. No seu lugar, os códigos da literatura introduzem um novo módulo térmico, que considera a distribuição de fluxo de calor fornecido pelo sistema antigelo para calcular a temperatura da superfície sólida e a fluxo de massa de água líquida residual em torno do aerofólio.

No Royal Aircraft Establishment, Inglaterra, Cansdale e Gent (1983) desenvolveram um modelo matemático de balanço térmico em torno de aerofólios sem aqueci- 
mento. Os autores modificaram o modelo de Messinger (1953) para a aplicação em escoamentos compressíveis e consideraram a concentração de vapor d'água local para o cálculo da taxa de evaporação. Posteriormente, Gent (1990) desenvolveu o programa de simulação TRAJICE2 para prever formas bidimensionais de gelo. Para calcular o coeficiente de transferência de calor por convecção $h_{a r}$, o autor admitiu que o escoamento sobre o bordo de ataque do aerofólio com gelo é aproximadamente àquele sobre a parte frontal de um cilindro com a superfície rugosa. Como alternativa às expressões empíricas, Gent (1990) implementou em seu programa uma análise integral da camada-limite para avaliar a transferência de calor nos regimes laminar e turbulento sobre uma superfície quase isotérmica sem efeitos de transferência de massa. A transição laminar-turbulenta é iniciada quando o número de Reynolds, baseado na rugosidade equivalente de grão de areia $k_{s}$, for maior que um valor crítico, considerado como $R e_{k}=u_{e} k_{s} / \nu>600$. Gent et al. (2003) publicaram um programa de simulação numérica para rotores de helicópteros que estima $h_{a r}$ com o mesmo procedimento adotado no TRAJICE2, todavia, os autores concluíram que a avaliação de $h_{a r}$ não foi satisfatória e que ainda precisa ser desenvolvida em trabalhos futuros.

Makkonen (1985) propôs um procedimento de cálculo para a transferência de calor por convecção nos regime laminar e turbulento entre o escoamento de ar carregado com as gotículas e a superfície rugosa de um cilindro em condições de formação de gelo. O autor utilizou este procedimento para estimar a formação de gelo em fios de transmissão de potência elétrica. Basicamente, $h_{a r}$ é avaliado por meio na análise integral da camada-limite baseada nos trabalhos de Kays e Crawford (1993). Para avaliar $h_{a r}$, no regime laminar é calculada a espessura de condução $\Delta_{4}$ (SMITH; SPALDING, 1958) e no regime turbulento $h_{a r}$ é estimado por meio de um número de Stanton, $\mathrm{St}_{t u r b}$, que requer o coeficiente de atrito sobre superfícies rugosas, $C_{f, \text { turb }}$, e o número de Prandtl turbulento, $\operatorname{Pr}_{\text {turb }}$ (PIMENTA, 1975). O procedimento de cálculo de $h_{a r}$ para os regimes laminar e turbulento utiliza analogia entre transferência de quantidade de movimento e de calor que, por definição, admitem o escoamento sobre uma superfície isotérmica, sem transferência de massa e com gradiente de pressão moderado. Makkonen (1985) admite uma transição abrupta do escoamento laminar para o turbulento e que a espessura de quantidade de movimento é contínua no ponto de transição $\delta_{2, l a m}=\delta_{2, \text { turb }}$. O autor propôs um critério de transição, diferente dos trabalhos anteriores, que contabiliza o efeito do gradiente de pressão e da altura da rugosidade.

Wade (1986), Downs e James (1988) implementaram um código numérico para simular o sistema de antigelo com ar quente do bordo de ataque da nacelle de um 
motor aeronáutico. Os autores estimaram $h_{a r}$ entre o escoamento gasoso, carregado com gotículas sub-resfriadas, e a superfície exposta da entrada de ar do motor por meio de expressões semi-empíricas. O modelo desenvolvido foi uma combinação do escoamento em torno da parte frontal de um cilindro seguido pelo escoamento ao longo de duas placas planas paralelas. As correlações de $h_{a r}$ para cilindro e placa plana são combinadas de forma a diminuir o desvio entre as suas previsões e os dados experimentais.

Henry (1989) desenvolveu um programa de simulação para prever parâmetros operacionais de funcionamento de sistemas térmicos de degelo de aerofólios aeronáuticos. Este tipo de sistema térmico opera em ciclos de aquecimento, no qual o gelo derrete e desprende, e de resfriamento, no qual há o acúmulo de gelo. O código numérico prevê o aumento e a diminuição das temperaturas de superfície no tempo, durante a duração de cada ciclo. Logo, a operação de um sistema pode ser simulada considerando os resultados em regime permanente de um ciclo de aquecimento de duração longa. Num trabalho posterior, Henry (1992) aplicou um código de camada-limite diferencial, para avaliar $h_{a r}$ laminar e turbulento sobre a superfície não-isotérmica, acoplado com o cálculo bidimensional da evolução dinâmica da frente de congelamento (RAW; SCHNEIDER, 1985).

Al-Khalil (1991) criou um modelo matemático para sistemas antigelo que considera os efeitos da formação de filetes na aplicação da Primeira Lei da Termodinâmica no escoamento da água líquida. Depois, Al-Khalil et al. (2001) implementaram o código ANTICE para prever parâmetros da operação de sistemas antigelo térmicos de aerofólios e validaram os seus resultados numéricos com dados experimentais. Este programa utiliza as rotinas do código LEWICE para a avaliação das propriedades do escoamento em torno do aerofólio e para o cálculo da distribuição de eficiência de coleta das gotículas ao longo do bordo de ataque (WRIGHT, 1995; WRIGHT, 1999).

O código numérico original do LEWICE adota a formulação de Messinger (1953) para prever o congelamento sobre a superfície adiabática do aerofólio. Então, AlKhalil et al. (2001) desenvolveram um novo balanço térmico com a adição dos seguintes efeitos: 1) fluxo de calor na superfície do aerofólio fornecida pelo sistema antigelo elétrico ou de ar quente; 2) superfície sólida do aerofólio parcialmente coberta pelo escoamento de água nas regiões a jusante da quebra de filme e da formação de filetes de água. A análise integral da camada-limite do LEWICE é indicada para o caso de transferência de calor sobre superfícies plenamente rugosas, não permeáveis e isotérmicas, ou seja, para superfícies sujeitas à formação de gelo. Para avaliação de $h_{a r}$, o código LEWICE estima a espessura de condução $\Delta_{4}$ no regime laminar, admite que a transição laminar-turbulenta é abrupta e é iniciada quando um valor-limite 
de $\operatorname{Re}_{k}=u_{\tau} k_{s} / \nu$ é atingido. No regime turbulento, o procedimento de cálculo de $h_{a r}$ é similar ao descrito por Kays e Crawford (1993) para o escoamento sobre superfícies isotérmicas rugosas. Apesar do ANTICE permitir o uso da distribuição de coeficiente de transferência de calor $h_{a r}$ estimada pela rotina numérica do LEWICE, Al-Khalil et al. (2001) utilizaram dados experimentais de fluxo de calor, medido na superfície sólida do aerofólio, para validar os resultados numéricos de temperatura e vazão de água líquida residual obtidos pelo ANTICE. Ou seja, o cálculo de $h_{a r}$ do LEWICE não foi validado para uso em simulação de sistemas antigelo.

Morency, Tezok e Paraschivoiu (1999b) implementaram um código para simulação numérica de sistemas antigelo térmicos e validaram seus resultados com os dados experimentais de Al-Khalil et al. (2001). Os autores publicaram duas versões do seu código: 1) CANICE A, que usou a distribuição de coeficiente de transferência de calor global experimental medida por Al-Khalil et al. (2001); 2) CANICE B, que usou $h_{a r}$ de Smith e Spalding (1958) no regime laminar, Ambrok (1957) no turbulento, e considera uma posição da transição laminar-turbulenta abrupta fornecida pelo usuário ou estimada pela correlação clássica de Michel(1951), apud Cebeci e Bradshaw (1984). O código CANICE B considera os efeitos do gradiente de temperatura da superfície $d T_{s} / d s$ na espessura de entalpia turbulenta $\Delta_{2}$. Os autores não publicaram como foi feita a ligação da transição do escoamento laminar para turbulento, nem como foi estimada a origem virtual da camada-limite turbulenta. Já Morency, Tezok e Paraschivoiu (1999a) publicaram os resultados do código CANICE FD que aplica um esquema de diferenças finitas para avaliar a transferência de quantidade de movimento, calor e massa do escoamento em torno do aerofólio. O procedimento adotado pelos autores leva em conta a camada-limite dinâmica e térmica laminar, turbulenta e também uma região de transição laminar-turbulenta. O modelo de camada-limite inclui uma função de intermitência como descrita por Cebeci e Bradshaw (1984).

Silveira (2001) implementou o código Aeroicing para prever a forma de gelo em bordos de ataque de aerofólios aeronáuticos bidimensionais. O autor adotou o modelo matemático do código LEWICE na versão 1.6 de Wright (1995). Este código foi expandido no âmbito de um projeto conjunto FAPESP-Embraer ${ }^{1}$, para incluir também a capacidade de simulação de sistemas antigelo. No entanto, este código estima a transferência de calor por meio dos modelos de Kays e Crawford (1993), Wright (1995), ou seja, admite hipóteses semelhantes àquelas dos códigos clássicos de formação de gelo. Os autores não consideraram que as condições de contorno de um aerofólio sujeito à formação de gelo são diferentes daquelas para um aerofólio equi-

\footnotetext{
${ }^{1}$ Maliska, C. R. et al. Projeto FAPESP-Embraer. Inovação Tecnológica de Aplicações Avançadas de Mecânica dos Fluidos Computacional para Aeronaves de Alto Desempenho. Pacote A13, 2003
} 
pado com sistema de antigelo. Não foram encontradas publicações com validações dos resultados do Aeroicing para sistemas antigelo de aerofólios.

Silva e Silvares (2002) descreveram detalhadamente o desenvolvimento de um modelo matemático para simulação de um sistema antigelo térmico e resumiram a revisão bibliográfica, resultados, contribuições e conclusões de Silva (2002). Nos artigos, Silva, Silvares e Zerbini (2003), Silva, Silvares e Zerbini (2005) foram apresentados brevemente o modelo matemático, a sua implementação e compararam as suas previsões, para os regimes evaporativo e molhado (running wet), com dados experimentais e resultados numéricos de outros códigos. Com base nos trabalhos anteriores, Silva, Silvares e Zerbini (2007a), Silva, Silvares e Zerbini (2007b) apresentaram uma descrição completa do modelo, detalhes da implementação numérica e resultados mais recentes gerados pelo código numérico. Devido, principalmente, à importância dos efeitos da transição laminar-turbulenta e do gradiente de temperatura na superfície sólida sobre a convecção de calor e massa em torno do aerofólio, os autores deram mais destaque, à modelagem do escoamento de camada-limite e apresentaram uma revisão crítica da bibliografia e uma discussão dos resultados obtidos.

O modelo matemático de Silva (2002) aplica a Primeira Lei da Termodinâmica ao escoamento de água líquida e à superfície sólida do aerofólio, e também os princípios de conservação da massa e de quantidade de movimento ao escoamento de água. Nos primeiros estágios da implementação do modelo matemático, Silva (2002) tentou utilizar os procedimentos de avaliação de camada-limite de Makkonen (1985), que são também adotados pelo código ONERA2D, porém o coeficiente de transferência de calor $h_{a r}$ foi superestimado. A análise integral de camada-limite implementada nos códigos clássicos de formação de gelo, como o ONERA2D, pode ser adequada para previsões de formas de gelo, porém possui algumas limitações para aplicação em simulação de sistemas de antigelo térmicos como: 1) o cálculo de $h_{a r}$ considera que a superfície do aerofólio ou do gelo é plenamente rugosa; 2) a hipótese que a transição laminar-turbulenta ocorre de forma abrupta e é disparada pela altura da rugosidade do gelo formado; 3) o efeito do gradiente de temperatura da superfície na direção do escoamento $d T_{s} / d s$ é desprezado pois a superfície com crescimento de gelo é aproximadamente isotérmica; 4) o efeito da evaporação na camada-limite térmica é desprezado nos cálculos de forma de gelo. A primeira hipótese é adequada para superfícies com gelo acumulado, mas não para superfícies aproximadamente lisas como aquelas dos aerofólios com sistema antigelo. A segunda, não é aplicável ao escoamento em torno de um aerofólio com sistema antigelo, já que o comprimento da transição laminar-turbulenta pode ser maior em escoa- 
mentos em torno de aerofólios limpos do que contaminados com formações de gelo, que atuam como disparadores (trips). No mais, outras perturbações do escoamento livre ou da superfície podem causar o início da região de transição no escoamento sobre o aerofólio com antigelo térmico além da altura da rugosidade. Já a terceira hipótese também não é adequada, pois a superfície aquecida pode ter gradientes de temperatura significativos. Ao contrário da quarta hipótese de Makkonen (1985), o efeito da evaporação no comportamento da camada-limite térmica é importante em superfícies protegidas contra formação de gelo, pois a temperatura é bem mais alta que $0^{\circ} \mathrm{C}$, normalmente entre $30^{\circ} \mathrm{C}<T_{s}<80^{\circ} \mathrm{C}$. Desse modo, Silva (2002) concluiu que era necessário implementar um código numérico que solucionasse as equações integrais de camada-limite de quantidade de movimento e térmica considerando um escoamento laminar, turbulento e de transição em torno de um aerofólio com superfície lisa, não-isotérmica e permeável.

\subsection{Níveis de Modelagem}

Quatro níveis hierárquicos funcionais de modelagem, abordados na presente tese, são representados na Fig. 2.1 e descritos a seguir:

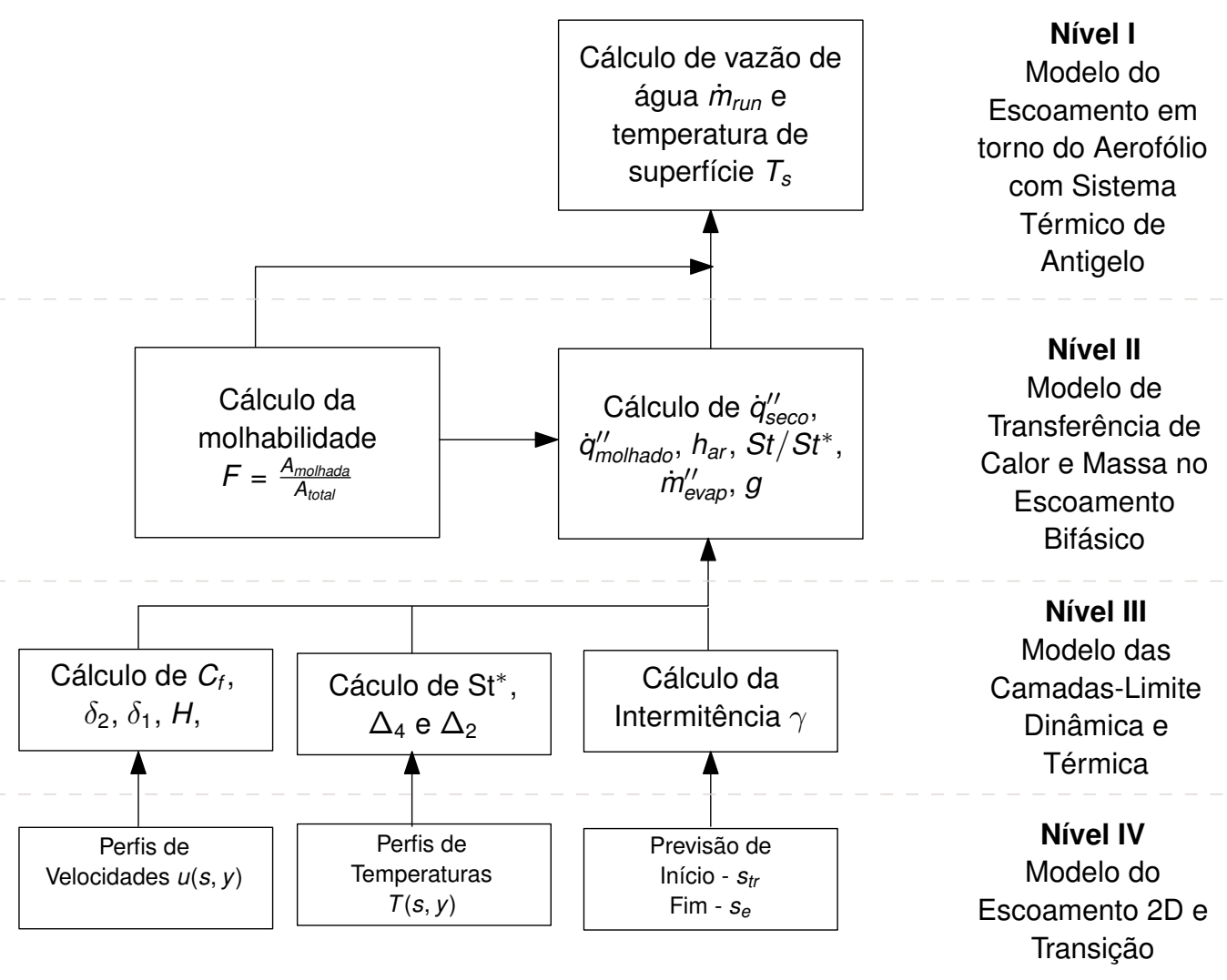

Figura 2.1: Níveis de modelagem abordados na presente tese 
Nível I) Modelo do escoamento em torno do aerofólio com sistema térmico de antigelo:

- Primeira Lei da Termodinâmica: distribuição de temperatura de superfície $T_{s}$, posição onde a água congela, caso não evopare totalmente;

- Conservação da massa: distribuição de vazão de água residual $\dot{m}_{r}$, posição onde a água evapora totalmente;

- Conservação da Quantidade de Movimento: distribuição de altura do filme de água $\delta_{f}$ e dos filetes $h_{r}$;

Nível II) Modelos de transferência de calor e de massa no escoamento bifásico em torno do aerofólio:

- Escoamento bifásico: distribuição de tensão de cisalhamento $\tau$ na interface líquido-gás, fluxo de calor sobre a superfície da interface sólido-gás $(1-F) \cdot \dot{q}^{\prime \prime}$ e sobre a líquido-gás $F \cdot \dot{q}^{\prime \prime}$;

- Escoamento de Filme e Filetes de Água: distribuição de fator de molhabilidade da superfície $F$;

- Convecção de calor e de massa: distribuições de coeficiente de transferência de calor $h_{a r}$, de temperatura de recuperação $T_{\text {rec }}$; de fluxo de evaporação $\dot{m}_{\text {evap }}^{\prime \prime}$, de coeficiente de transferência de massa $g_{a r}$ e da correção St/St*, que é devida aos efeitos da transferência de massa na camada-limite de entalpia;

Nível III) Modelos das camadas-limite dinâmica e térmica:

- Camada-limite térmica e de entalpia: distribuição de espessura de entalpia $\Delta_{2}$ para a estimativa do número de Stanton local St;

- Camada-limite de deslocamento e de quantidade de movimento: distribuição de espessura de deslocamento $\delta_{1}$ e de quantidade de movimento $\delta_{2}$ para o cálculo de fator de forma $H$, coeficiente de atrito local $C_{f}$;

- Modelo de Transição: distribuição de intermitência $\gamma$ ao longo da região de transição, que depende da posição de seu início $s_{t r}$ e, algumas vezes, também do seu término $s_{e}$;

Nível IV) Modelo do escoamento bidimensional e da previsão de transição: 
- Conservação da Quantidade de Movimento: distribuição do perfil de velocidades $v(s, y)$ ao longo do escoamento por solução da equação RANS, no caso da análise diferencial, ou por hipótese de lei de potência ou similaridade, no caso da análise integral;

- Primeira Lei da Termodinâmica: distribuição do perfil de temperaturas $T(s, y)$ ao longo do escoamento, no caso da análise diferencial; ou por hipótese de lei de potência, analogia ou similaridade, no caso da análise integral;

- Modelo de Turbulência: previsão de viscosidade turbilhonar (eddy viscosity) por meio dos modelos de comprimento de mistura de Cebeci e Smith (1974);

- Correlações Algébricas: estimativa de início e término da região de transição com base do gradiente de pressão e no nível de turbulência ao longe Tu;

- Estabilidade: análise diferencial da estabilidade linear para cálculo do fator de amplificação $n$;

- Método $e^{n}$ : correlações algébricas empíricas para estimar $n_{\text {crit }}$ em função da turbulência ao longe $T u$;

O primeiro nível (I) é relacionado diretamente com a aplicação de engenharia, ou seja, é aquele da simulação do escoamento em torno do aerofólio com sistema térmico de antigelo, que fornece os resultados das distribuições de temperatura da superfície do aerofólio e fluxo de água líquida residual; o quarto (IV) e último nível é aquele mais fundamental, ou seja, é o nível da modelagem do escoamento bidimensional e do processo de transição laminar-turbulenta. Logo, fica claro que sem uma estimativa adequada dos modelos dos níveis II, III e IV, a precisão e confiabilidade dos resultados do nível I não podem ser melhoradas.

Com o aumento da complexidade do programa de simulação e da multiplicidade de modelos utilizados (níveis II, III e IV), também aumenta a dificuldade de validação dos resultados do sistema antigelo (apenas nível I). Para possibilitar a análise dos resultados do nível I, é necessário que haja a verificação dos resultados para cada efeito físico incorporado no modelo matemático. Com este processo, garante-se que o modelo incorporado realize os cálculos conforme o esperado. A validação e verificação por partes possui a vantagem de ajudar a escolha do submodelo, dentre os encontrados na literatura, para cada fenômeno físico considerado.

Ao modelo-base do escoamento em torno do aerofólio com antigelo (nível I), apresentado no presente capítulo e desenvolvido originalmente no trabalho ante- 
rior(SILVA, 2002), serão adicionados os modelos de molhabilidade (nível II), camadalimite diferencial (níveis III e IV) e de transição laminar-turbulenta (níveis III e IV), que estão localizados nos Capítulos 3, 4 e 5.

\subsection{Estrutura da Simulação do Escoamento em Torno do Aerofólio com Sistema Térmico de Antigelo}

Para solucionar o modelo matemático são requeridos:

1) a solução dos campos de velocidade e pressão em torno do aerofólio;

2) o cálculo das trajetórias das gotículas em direção ao bordo de ataque do aerofólio;

3) a previsão da distribuição da eficiência de coleta local;

4) a aplicação da Primeira Lei da Termodinâmica ao escoamento de água líquida residual e à superfície do aerofólio considerando a condução de calor ao longo do aerofólio;

5) a aplicação dos princípios de conservação de massa e quantidade de movimento ao escoamento de água líquida residual;

6) a avaliação da transferência de calor e de massa da superfície do aerofólio para o escoamento externo.

Os dados de escoamento (item 1) e de eficiência de coleta local (item 2) podem ser obtidos de um código numérico externo, tal como o ONERA2D(GUFFOND; BRUNET, 1988), utilizado por Silva (2002) e Silva, Silvares e Zerbini (2007b), ou os códigos XFOIL(DRELA; GILES, 1987) e CFD $++^{2}$, utilizados no presente trabalho. A partir desses resultados, o código numérico do modelo de antigelo é executado (itens 3 e 4) e estima as distribuições de temperatura de superfície sólida, de vazão de água líquida e de coeficiente de transferência de calor por convecção.

\subsection{Casos-Padrão de Aerofólio com Sistema Térmico de Antigelo}

A definição dos casos-padrão é necessária para limitar o escopo do modelo matemático, definir um conjunto de hipóteses, simplificar as equações e auxiliar a validação dos resultados. Al-Khalil et al. (2001) realizaram uma série de experimentos no

\footnotetext{
${ }^{2}$ CFD++. Metacomp Technologies Inc. www.metacomptech.com
} 

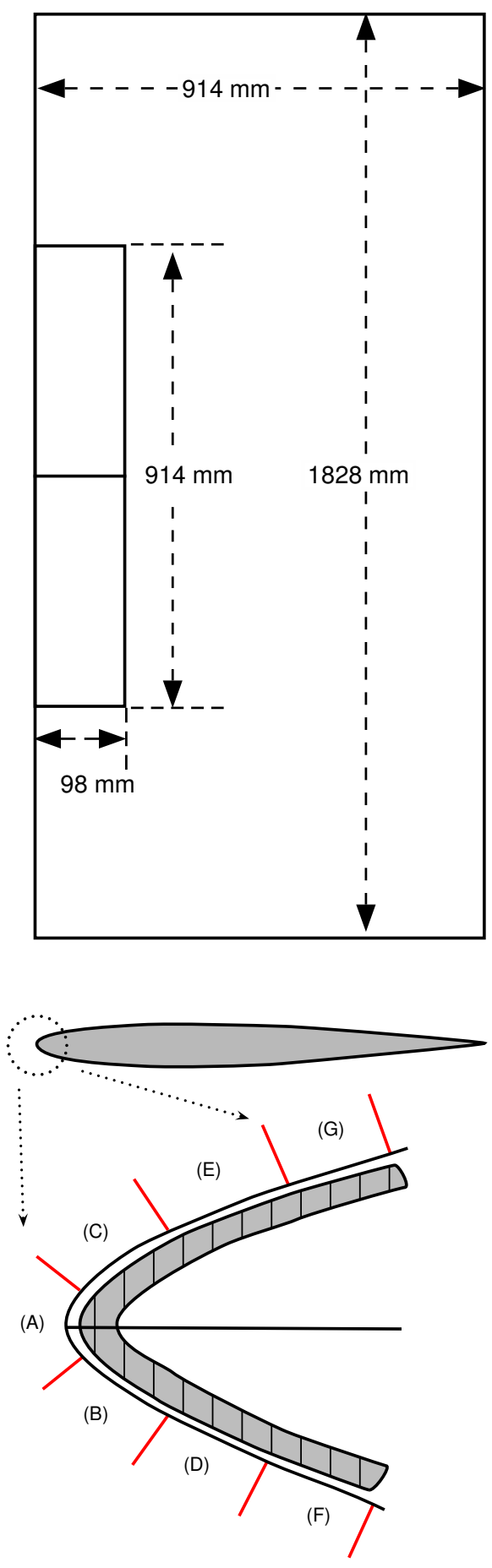

Figura 2.2: Aerofólio NACA 0012 com aquecedores elétricos de Al-Khalil et al. (2001)

Túnel para Pesquisas em Formação de Gelo - Icing Research Tunnel (IRT), do Centro de Pesquisas Glenn, NASA, Clevenland, Ohio, EUA. Os autores mediram temperatura e fluxo de calor em diversas posições ao longo da superfície do aerofólio, no sentido do escoamento. Os valores medidos de fluxo de calor foram usados como dados de entrada do código ANTICE, que estimou as temperaturas de superfície. Essas, por sua vez, foram comparadas com os dados experimentais. Como apresentado na Fig. 2.2, o aerofólio tinha um perfil NACA 0012 e 1,828 m de envergadura por 0, 914 $\mathrm{m}$ de corda com aquecedores elétricos controlados eletronicamente. 
Cada aquecedor tinha embutido um termopar, um termoresistor e um medidor de fluxo de calor. Havia dois painéis de aquecedores colocados lado a lado na direção da envergadura e cada painel tinha sete aquecedores na direção do escoamento, que são indicados de $A$ a $G$ na Fig. 2.2. A área total protegida era de $0,914 \mathrm{~m}$ na direção da envergadura (cada painel tinha 0,457 m) por 0,197 m na direção da corda, considerando a soma da extensão protegida do extradorso e do intradorso na região do bordo de ataque do aerofólio.

O sistema de aquecimento do bordo de ataque utilizado no teste de Al-Khalil et al. (2001) era composto por seis camadas da superfície externa para o interior do aerofólio: aço inoxidável $(0,20 \mathrm{~mm})$, elastômero $(0,28 \mathrm{~mm})$, elemento aquecedor $(0,01$ $\mathrm{mm})$, elastômero $(0,28 \mathrm{~mm})$, composto de fibra de vidro e epóxi $(0,89 \mathrm{~mm})$, isolamento de espuma de silicone $(3,43 \mathrm{~mm})$. Considera-se que camadas do aquecedor estão na mesma temperatura e que condutividade térmica equivalente no sentido do escoamento é $k=16,27 \mathrm{~W} /\left(\mathrm{m}^{2} \cdot \mathrm{K}\right)$.

Tabela 2.1: Comprimentos dos Aquecedores (AL-KHALIL et al., 2001)

\begin{tabular}{ccc}
\hline \multirow{2}{*}{$\begin{array}{c}\text { Elemento } \\
\text { Aquecedor }\end{array}$} & \multicolumn{2}{c}{$s / c$, distância pela corda } \\
\cline { 2 - 3 } & início & final \\
\hline F & $-0,1024$ & $-0,0607$ \\
D & $-0,0607$ & $-0,0329$ \\
B & $-0,0329$ & $-0,0051$ \\
A & $-0,0051$ & 0,0157 \\
C & 0,0157 & 0,0435 \\
E & 0,0435 & 0,0713 \\
G & 0,0713 & 0,1129 \\
\hline
\end{tabular}

A Tabela 2.1 apresenta a posição de cada um dos elementos aquecedores no aerofólio de perfil NACA0012 mostrado na Fig. 2.2.

A partir do conjunto de condições de teste de Al-Khalil et al. (2001), foram escoIhidos casos-padrão que representassem os regimes molhado, parcialmente e plenamente evaporativo.

As rodadas experimentais escolhidas como casos-padrão tiveram:

- potência total fornecida aos aquecedores elétricos de 0,96 kW a 2, 2 kW;

- velocidades do escoamento livre variaram de $V_{\infty}=44,4$ a $88,8 \mathrm{~m} / \mathrm{s}$;

- ângulo de ataque constante, $\alpha=0^{\circ}$.

E as condições de gelo associadas aos casos foram: 
- temperatura total, $T_{\text {tot }}=-21,6^{\circ} \mathrm{C}$;

- conteúdo de água líquida, Liquid Water Content (LWC) de 0,55 a 0,78 g/m³;

- diâmetro volumétrico mediano, Median Volumetric Diameter (MVD) de $20 \mu \mathrm{m}$.

\subsection{Modelagem do Escoamento Bifásico em torno Ae- rofólio com Sistema Térmico de Antigelo}

O sistema de coordenadas e os cinco domínios, com suas respectivas hipóteses, utilizados na modelagem do escoamento bifásico em torno de aerofólios com sistemas térmicos de antigelo, em regime permanente, são apresentados na Fig, 2.3 e descritos abaixo:

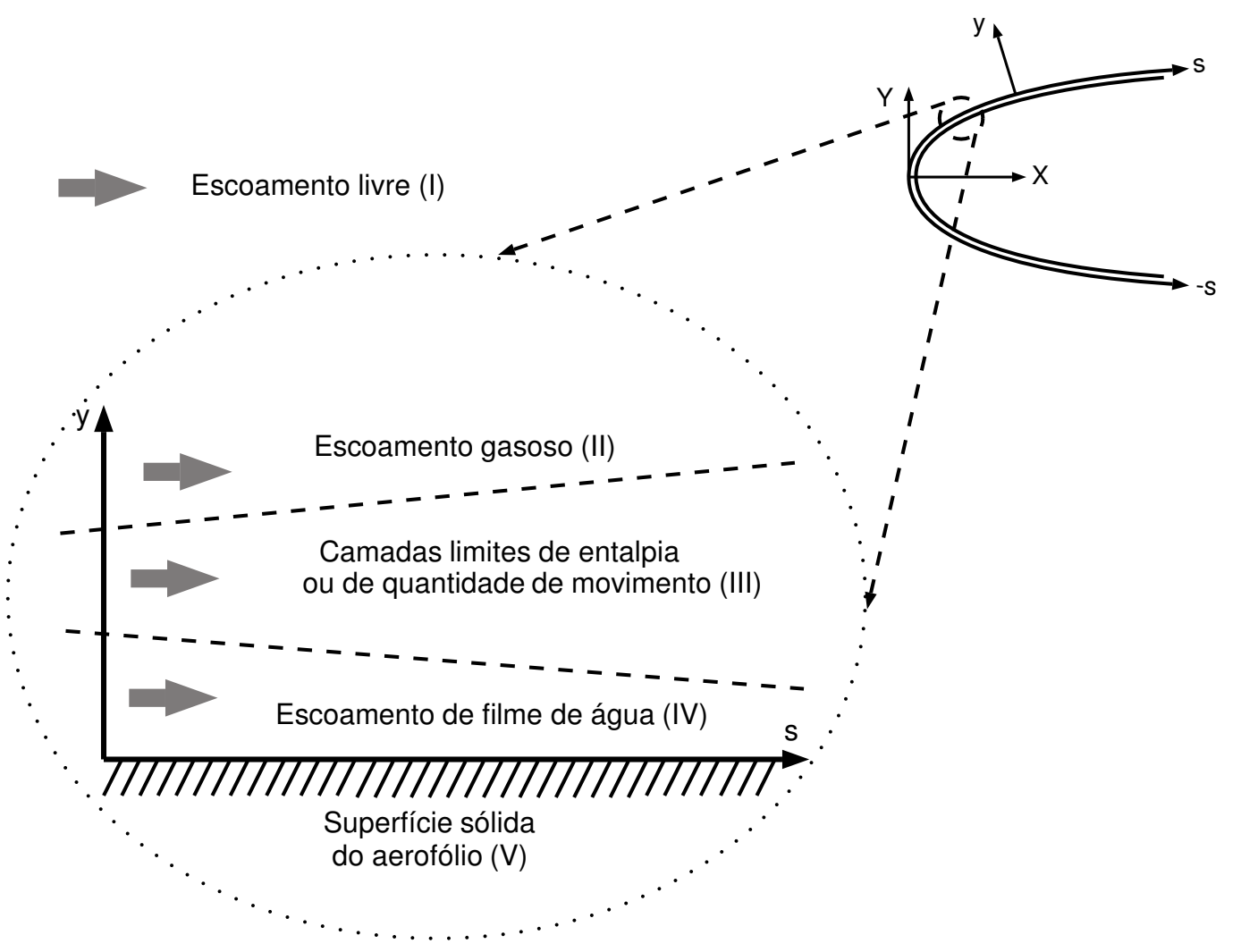

Figura 2.3: Modelagem de um aerofólio aquecido operando sob condições de formação de gelo (SILVA, 2002)

Domínio I - escoamento livre, não perturbado pela presença do aerofólio;

- velocidade constante;

- temperatura total constante;

- nível de turbulência;

Domínio II - escoamento gasoso (água e vapor d’água) em torno do aerofólio: 
- escoamento compressível;

- processo isentrópico desde o escoamento ao longe;

- velocidade variável, na borda da camada-limite, dada pelo coeficiente de pressão, $C_{p}$, em torno do aerofólio;

- nenhum efeito da camada-limite;

Domínio III - escoamento nas camadas-limite dinâmica e térmica sobre a superfície do escoamento de água residual ou seca do aerofólio:

- superfície lisa;

- gradiente de pressão e sua variação no escoamento gasoso em torno do aerofólio;

- superfície com variações de temperatura;

- efeito da taxa de evaporação na transferência de calor;

- efeito da temperatura de recuperação na transferência de calor;

- propriedades termodinâmicas variáveis;

- ocorrência de região de transição laminar-turbulenta;

- nível de turbulência só afeta a previsão da transição laminarturbulenta;

- nenhum efeito do raio de curvatura da superfície;

- nenhum efeito da altura do escoamento de água residual;

Domínio IV - escoamento de água líquida residual sobre a superfície sólida do aerofólio:

- superfície lisa;

- gradiente de pressão;

- cisalhamento aplicado pelo escoamento da camada-limite;

- variações de temperatura de superfície;

- propriedades termodinâmicas variáveis;

- padrões de escoamento da água líquida residual que molhem a superfície do aerofólio totalmente ou parcialmente;

Domínio V - superfície sólida do aerofólio:

- fluxo de calor dos aquecedores; 
- fração da superfície molhada pelo escoamento de água líquida residual;

- fração da superfície seca exposta ao escoamento de camadalimite;

- condução térmica unidimensional no sentido do escoamento;

- temperatura constante ao longo da direção normal através dos diferentes materiais construtivos;

Com essa estratégia de divisão de domínios e suas hipóteses associadas, o modelo pode ser organizado e simplificado para os objetivos do presente trabalho. Adicionalmente às hipóteses comuns à todos os modelos, que são citadas acima, outras, específicas para cada domínio, serão apresentadas nas próximas seções e capítulos. Uma explicação detalhada sobre os efeitos físicos e os volumes de controle considerados na modelagem de cada domínio ser encontrada na dissertação de mestrado (SILVA, 2002).

O domínio (I) serve como condição de contorno para os outros cálculos. O domínio (II) é resolvido por um programa externo, que soluciona o escoamento em torno do aerofólio. Já a modelagens dos domínios (III), (IV) e (V) são desenvolvidas, verificadas e validadas na presente tese.

O aerofólio é dividido em volumes de controle, representados no destaque da Fig. 2.3, a partir da estagnação até o bordo de fuga em cada um dos cinco domínios. A discretização segue a mesma estratégia e aplica um esquema de volumes finitos as equações do modelo matemático. Ou seja, cada domínio possui sua malha computacional. Logo, cada malha tem o início num elemento próximo à estagnação e o término em outro elemento próximo ao bordo de fuga ao longo da superfície do extradorso e do intradorso do aerofólio.

\subsubsection{Primeira Lei da Termodinâmica Aplicada à Superfície Só- lida do Aerofólio}

A aplicação da Primeira Lei da Termodinâmica à superfície sólida do aerofólio (domínio V) resulta em:

$$
\begin{aligned}
\frac{d}{d s}\left(k_{s} \cdot \frac{d T_{s}}{d s}\right)-F \cdot h_{\text {agua }} \cdot\left(T_{s}-T_{\text {agua }}\right) & +\dot{q}_{a n t i}^{\prime \prime} \\
& +(1-F) \cdot\left[-h_{a r} \cdot\left(T_{s}-T_{\text {rec }}\right)\right]=0
\end{aligned}
$$


Equação (2.1) considera a transferência de calor na direção $s$ mas não considera na direção y. O fator de molhabilidade é dado pela relação entre área molhada e área total no volume finito. A distribuição do termo de fluxo de calor $\dot{q}_{a n t i}^{\prime \prime}$ na Eq. (2.1) é determinada pela densidade de potência dos aquecedores.

A temperatura de recuperação, $T_{\text {rec}}$, utilizada na avaliação da transferência de calor por convecção em escoamentos compressíveis, é estimada por:

$$
T_{\text {rec }}=(1-r) \cdot T_{e}+r \cdot T_{\text {total }}
$$

Onde a temperatura da borda da camada-limite, $T_{e}$, é avaliada no escoamento isentrópico desde o escoamento ao longe até uma posição ao redor do aerofólio por:

$$
T_{e}=T_{\text {total }} /\left(1+0,2 \cdot \mathrm{Ma}_{e}^{2}\right)
$$

Admite-se que o fator de recuperação é $\operatorname{Pr}^{1 / 2}$ no regime laminar e $\operatorname{Pr}^{1 / 3}$ no regime turbulento. Um fator de molhabilidade $F$ representa a razão entre a área molhada e seca:

$$
F=\frac{A_{\text {molhada }}}{A_{\text {total }}} \Rightarrow \begin{cases}F=1 & \text { totalmente molhada } \\ 0<F<1 & \text { parcialmente molhada } \\ F=0 & \text { totalmente seca }\end{cases}
$$

O último ponto nas vizinhanças do bordo de fuga do aerofólio é considerado adiabático e impermeável, logo não há transferência de calor nem de massa na fronteira entre o extradorso e o intradorso. As propriedades termodinâmicas do ar em escoamento de alta velocidade são avaliadas na temperatura (ECKERT, 1955):

$$
\bar{T}_{a r}=T_{e}+0,5 \cdot\left(T_{\text {int }}-T_{e}\right)+0,22 \cdot\left(T_{\text {rec }}-T_{e}\right)
$$

na qual $T_{\text {int }}$ pode assumir o valor de $T_{s}$ ou $T_{\text {agua }}$, dependendo se a superfície está seca ou molhada, respectivamente, 


\subsubsection{Primeira Lei da Termodinâmica Aplicada ao Escoamento de Água Líquida}

A aplicação da Primeira Lei da Termodinâmica ao escoamento de água líquida resulta em:

$$
\begin{gathered}
F \cdot A \cdot h_{a r}^{*} \cdot\left(T_{\text {rec }}-T_{\text {agua }}\right)+F \cdot A \cdot h_{\text {agua }} \cdot\left(T_{s}-T_{\text {agua }}\right)+\dot{m}_{\text {entra }} \cdot c_{p, \text { agua }} \cdot\left(T_{\text {entra }}-T_{\text {ref }}\right) \\
-\dot{m}_{\text {sai }} \cdot c_{p, \text { agua }} \cdot\left(T_{\text {sai }}-T_{\text {ref }}\right)+ \\
+A \cdot \dot{m}_{\text {imp }} \cdot\left[c_{p, \text { agua }} \cdot\left(T_{d}-T_{\text {ref }}\right)+\frac{V_{d}^{2}}{2}\right] \\
+\dot{m}_{\text {evap }} \cdot\left[i_{l v}-c_{p, \text { agua }} \cdot\left(T_{\text {sai }}-T_{\text {ref }}\right)\right]=0
\end{gathered}
$$

na qual,

$$
T_{\text {agua }}=\left(T_{\text {entra }}-T_{\text {sai }}\right) / 2
$$

O coeficiente $h_{\text {agua }}$ entre o escoamento de água líquida (IV) e a superfície sólida (V), pode ser calculado por meio da:

1) analogia de Colburn entre transferência de quantidade de movimento e calor no escoamento da água líquida:

$$
h_{\text {agua }}=\rho_{\text {agua }} \cdot v_{f}\left(s, \delta_{f}\right) \cdot c_{p, \text { agua }} \cdot 0,5 \cdot C_{f} \cdot \operatorname{Pr}_{\text {agua }}^{-2 / 3}
$$

2) hipótese de perfil linear de velocidades no escoamento da água líquida:

$$
\mathrm{Nu}_{\delta}=\frac{h_{\text {agua }} \cdot \delta_{f}}{k_{\text {agua }}} \approx 2
$$

As propriedades termodinâmicas da água são avaliadas na temperatura (ECKERT, 1955):

$$
\bar{T}_{\text {agua }}=T_{s}+0,5 \cdot\left(T_{\text {agua }}-T_{s}\right)
$$

\subsubsection{Conservação da Massa Aplicada ao Escoamento de Água Líquida}

Por meio da aplicação do princípio da Conservação da Massa ao escoamento de água líquida (IV), as seguintes equações são obtidas:

$$
\dot{m}_{\text {entra }}+\dot{m}_{i m p}=\dot{m}_{s a i}+\dot{m}_{\text {evap }}
$$

A transferência de massa por convecção é definida por Spalding (1963) como:

$$
\dot{m}_{\text {evap }}^{\prime \prime}=g_{m} \cdot \mathrm{B}_{m}
$$




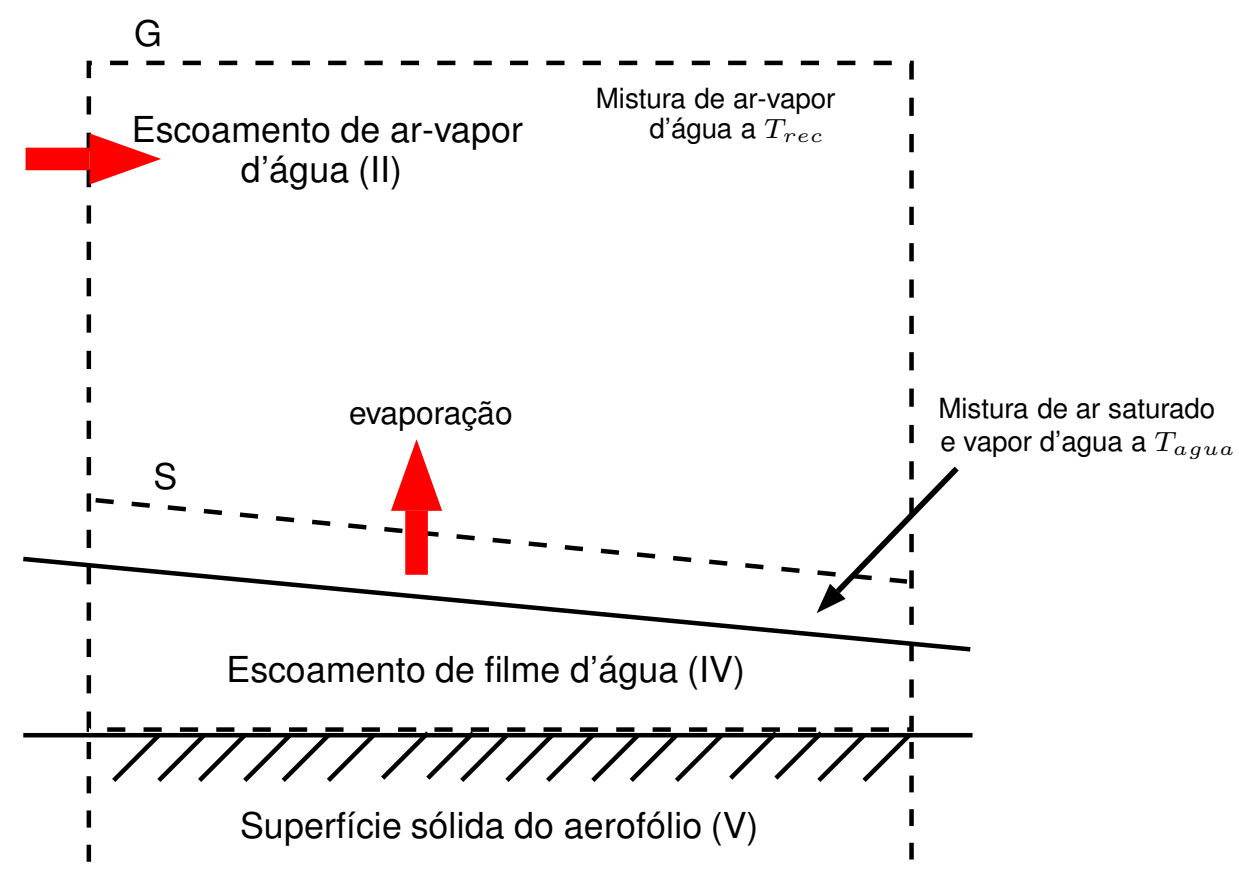

Figura 2.4: Modelagem da transferência de massa (SPALDING, 1963)

$$
\begin{gathered}
g_{m}=\mathrm{St} \cdot G \cdot \mathrm{Le}^{2 / 3} \cdot \frac{\ln \left(1+\mathrm{B}_{m}\right)}{\mathrm{B}_{m}} \\
\mathrm{~B}_{m}=\frac{m f_{H 2 O, G}-m f_{H 2 O, S}}{m f_{H 2 O, S}-1}
\end{gathered}
$$

Com as hipóteses de gás ideal e da lei de Dalton, as frações mássicas bem perto da superfície do líquido (subscrito $S$ ) e no escoamento gasoso da mistura ar-vapor d'água (subscrito $G$ ) são avaliadas por meio de:

$$
\begin{aligned}
m f_{H 2 O, G} & =\frac{p_{\text {vap }, G}}{1,61 \cdot p_{\text {mist }, G}-0,61 \cdot p_{\text {vap }, G}} \\
m f_{H 2 O, S} & =\frac{p_{\text {vap }, S}}{1,61 \cdot p_{\text {mist }, S}-0,61 \cdot p_{\text {vap }, S}}
\end{aligned}
$$

A Fig. 2.4 apresenta um esquema do modelo de transferência de massa adotado no presente trabalho e as posições onde as pressões de vapor saturado são avaliadas. A força motriz de transferência de calor é definida como (SPALDING, 1963; PIMENTA, 1975; KAYS; CRAWFORD, 1993):

$$
\mathrm{B}_{h}=\frac{\dot{m}_{\text {evap }}^{\prime \prime}}{\mathrm{St}^{*} \cdot \mathrm{G}}
$$

Considerando a magnitude do fluxo de transferência de massa e de gradiente de pressão dos casos-padrão, o efeito da transpiração, causada pelo fluxo de evaporação, na convecção de calor é:

$$
\frac{S t^{*}}{S t}=\frac{\ln \left(1+B_{h}\right)}{B_{h}}
$$


No processo acoplado de transferência de calor e massa, St* depende de $\mathrm{B}_{h}$, Eq. (2.18), que depende tanto de $\dot{m}_{\text {evap }}^{\prime \prime}$ quanto de St*, Eq. (2.17). O cálculo iterativo só termina quando a Primeira Lei da Termodinâmica,Eq. (2.6), é satisfeita em cada volume finito,

A vazão de água líquida captada pelo aerofólio é dada por:

$$
\dot{m}_{i m p}=V_{\infty} \cdot \beta \cdot L W C \cdot d s \cdot 1
$$

na qual o conteúdo de água líquida na nuvem é dado pelo LWC, a velocidade do escoamento ao longe é representada por $V_{\text {infty }}$, e a eficiência de coleta local, $\beta$, é a proporção entre a distância infinitesimal entre duas gotículas de água no escoamento livre, $d y$, e a distância entre seus pontos de captação na superfície do aerofólio, $d s$. As definições de LWC e $\beta$ e podem ser verificadas no Anexo A. A eficiência de coleta é dada por:

$$
\beta=\frac{d y}{d s}
$$

No ponto de estagnação do escoamento em torno do aerofólio, é admitido que só há entrada de água devida à incidência de gotículas. Assim, a Eq. (2.11) é resolvida a partir do ponto de estagnação até o final da superfície do intradorso e extradorso.

No volume finito onde $T_{\text {agua }}$ atinge a temperatura de solidificação, é admitido que não há vazão mássica de água líquida de saída, $\dot{m}_{s a i}=0$, o que marca o começo do congelamento. Como no modelo básico de Al-Khalil (1991), a Eq. (2.6) não considera os efeitos da entalpia de solidificação e a Eq. (2.11) despreza a existência de um volume finito contendo água parcialmente congelada. Estas hipóteses parecem muito simples, porém são satisfatoriamente conservadoras para verificar se o sistema não está adequadamente projetado pois: 1) o sistema antigelo é projetado para operar em temperaturas de superfície sólida médias acima de $0^{\circ} \mathrm{C}$; 2 ) se o efeito do aquecimento devido a liberação da entalpia de solidificação fosse considerado, o modelo iria indicar uma posição inicial de congelamento mais a jusante do que o presente modelo.

Para possibilitar a comparação dos resultados numéricos com dados experimentais de Al-Khalil et al. (2001), define-se um coeficiente de transferência de calor global $U$ para contabilizar os efeitos da convecção de calor através das superfícies das interfaces sólido-líquido e líquido-gás (i,e, $h_{\text {agua }}$ e $h_{a r}$ ), a entalpia associada a vazão de água líquida que entra e sai do volume finito, a entalpia das gotículas de água incidentes e a entalpia de evaporação:

$$
U=\frac{\dot{q}_{\text {perd }}}{1 \cdot \Delta s \cdot \Delta T}
$$




$$
\begin{aligned}
\dot{q}_{\text {perd }}=R_{t}^{-1} \cdot 1 \cdot \Delta s \cdot \Delta T-\dot{m}_{\text {evap }} \cdot\left(i_{v}+i_{\text {agua }}\right)+ & \dot{m}_{\text {imp }} \cdot i_{d} \\
& +\dot{m}_{\text {entra }} \cdot i_{\text {entra }}-\dot{m}_{\text {sai }} \cdot i_{\text {sai }}
\end{aligned}
$$

\subsubsection{Conservação da Quantidade de Movimento Aplicada ao Es- coamento de Água Líquida}

Admitindo-se que a água escoa em torno do aerofólio na forma de um filme contínuo, que não há formação de gotas ou de filetes, o princípio da Conservação da Quantidade de Movimento aplicado ao escoamento da água líquida resulta em:

$$
\frac{1}{\rho_{\text {agua }}} \cdot \frac{\partial p_{e}}{\partial s}=\nu_{\text {agua }} \cdot \frac{\partial^{2} v_{f}(s, y)}{\partial y^{2}}
$$

A Equação (2.23) é resolvida com as seguintes condições de contorno:

$$
\begin{aligned}
& y=\delta_{f} \Rightarrow \mu_{\text {agua }} \cdot\left[\frac{\partial v_{f}(s, y)}{\partial y}\right]_{\delta_{f}}=\tau+\dot{m}_{i m p}^{\prime \prime} \cdot v_{d} \cdot \sin \varphi \\
& y=0 \Rightarrow v(s, y)=0
\end{aligned}
$$

A solução de Eq. (2.23) fornece um perfil de velocidade no filme de água dado por:

$$
v_{f}(s, y)=\frac{\partial p_{e}}{\partial s} \cdot \frac{y^{2}}{2 \cdot \mu_{\text {agua }}}+\left[\tau+\dot{m}_{i m p}^{\prime \prime} \cdot v_{d} \cdot \sin \varphi-\delta_{f}(s) \cdot \frac{\partial p_{e}}{\partial s}\right] \cdot \frac{y}{\mu_{\text {agua }}}
$$

A altura do filme de água líquida é estimada por:

$$
\delta_{f}=\frac{\dot{m}_{\text {entra }}+\dot{m}_{\text {sai }}}{2 \cdot \rho_{\text {agua }} \cdot \bar{v}_{f}}
$$

\subsection{Implementação Numérica do Modelo Matemático}

A simulação térmica de aerofólios com sistemas antigelo compreende:

1) código externo para solucionar o escoamento em torno do aerofólio e calcular as trajetórias das gotículas de água sub-resfriadas;

2) programa para simular o desempenho térmico do sistema antigelo do aerofólio aeronáutico (programa principal), iniciado no mestrado e continuado na presente tese;

3) sub-rotina, chamada pelo programa principal, para cálculo da molhabiliadade da superfície do aerofólio de acordo com o padrão de escoamento da água líquida 
residual, desenvolvidas na presente tese;

4) sub-rotina, chamada pelo programa principal, para resolver a camada-limite de quantidade de movimento e térmica com gradiente de pressão variável e transição laminar-turbulenta sobre superfícies não-isotérmicas, lisas e com transpiração, implementadas na presente tese;

5) sub-rotina, chamada pela sub-rotina de camada-limite, para prever o início e o término da região de transição da camada-limite em torno do aerofólio, também implementadas na presente tese;

\subsubsection{Solução do Escoamento e das Trajetórias das Gotículas}

O código externo requer dados da geometria do perfil do aerofólio, do ambiente (LWC, MVD, $\left.T_{\infty}, p_{\infty}\right)$ e da condição de voo $\left(V_{\infty}, \alpha\right)$ para fornecer as distribuições de coeficiente de pressão $C_{p}$ e eficiência de coleta local $\beta$. No presente trabalho, somente dois tipos de soluções são requeridas do código externo para gerar as entradas para a simulação do sistema antigelo:

- solução do escoamento em torno do aerofólio;

- solução das trajetória das gotículas de água carregadas pelo escoamento;

- estimativa da distribuição de $\beta$ na superfície do aerofólio,

\subsubsection{Estrutura da Implementação Numérica}

Para representar adequadamente os fenômenos de transferência de calor e massa, foi implementado um novo programa de simulação térmica (SILVA, 2002; SILVA; SILVARES; ZERBINI, 2007a). A Fig. 2.5 apresenta um resumo da implementação numérica. O programa principal de simulação começa o cálculo depois da coleta dos dados do usuário e do código externo. Uma rotina de avaliação de camada-limite fornece distribuições de $h_{a r}$ e $C_{f}$ em torno do aerofólio. As equações de conservação de massa e quantidade de movimento aplicadas ao escoamento de água líquida são resolvidas para, depois, possibilitar a aplicação da Primeira Lei da Termodinâmica ao escoamento de água e à superfície sólida. A solução do sistema de equações em cada volume finito é considerada satisfatória quando os fluxos de transferência de calor e massa por convecção convergem. Assim, as equações são resolvidas em todos os volumes finitos ao longo do intradorso, a partir do ponto de estagnação até o último elemento no bordo de fuga. De forma análoga, as equações 


\section{Código Externo}

Campo de escoamento

e dados de incidência
Usuário

Condições de vôo e gelo

Configuração dos aquecedores e

densidade de potência

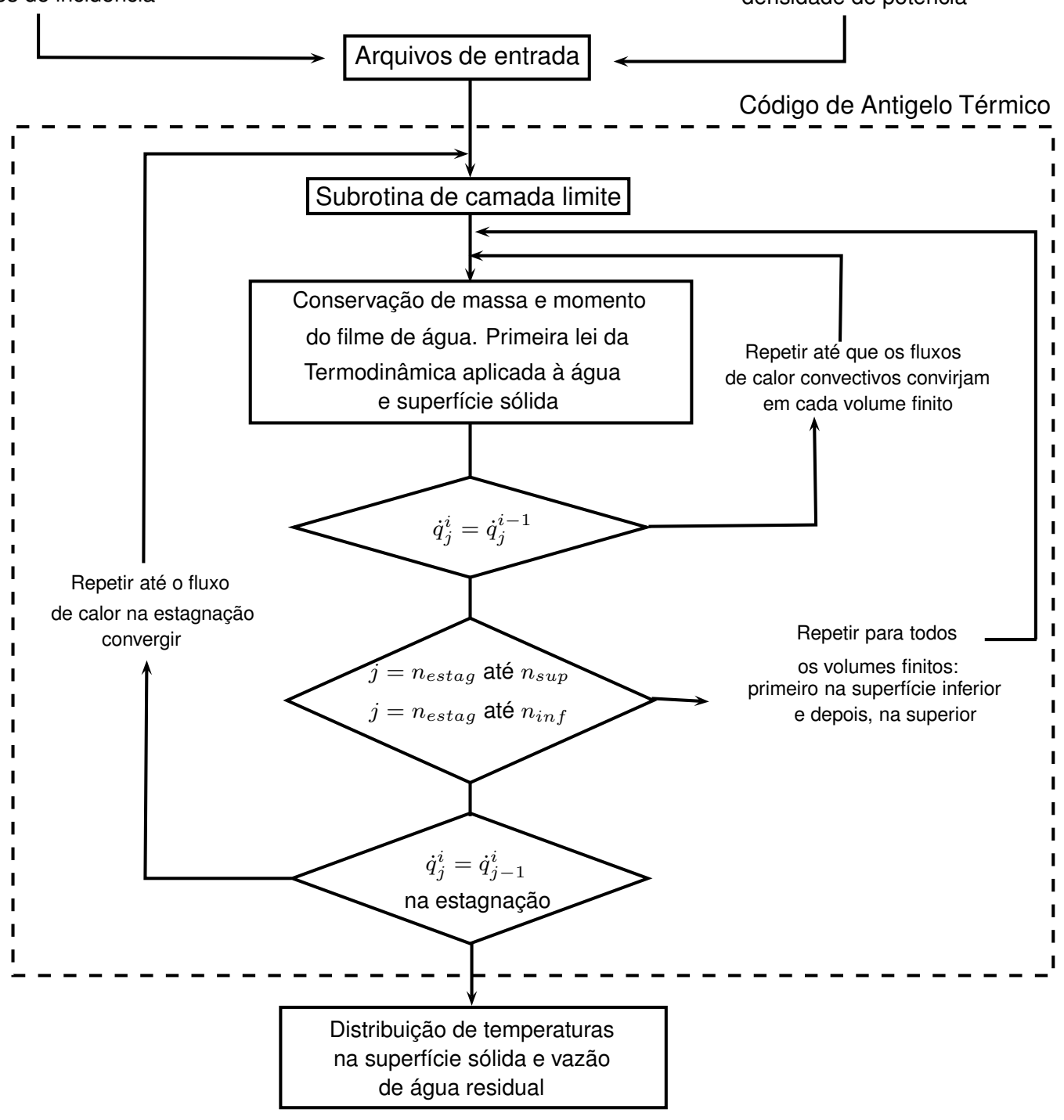

Figura 2.5: Estrutura da implementação numérica

são resolvidas ao longo do extradorso. Este procedimento de solução é, então, repetido até que a continuidade do fluxo de calor no ponto de estagnação seja verificada. No final do processo de cálculo, o programa é capaz de estimar os parâmetros operacionais do sistema antigelo, como as temperaturas de superfície, $T_{s}$, e vazões de água líquida residual, $\dot{m}_{\text {run }}$. 


\section{Modelagem da Molhabilidade DA SUPERFÍCIE dE AEROFÓlIOS COM SISTEMA TÉRMICO DE ANTIGELO}

O escoamento de líquidos sobre superfícies sólidas sob ação das forças de cisalhamento ou da gravidade é um fenômeno importante para muitas aplicações de engenharia. Em muitos equipamentos e processos, o líquido pode sofrer evaporação ou congelamento enquanto escoa sobre uma superfície sólida.

Há o escoamento de líquido por cisalhamento nas seguintes aplicações:

1) nas turbinas a vapor, quando há a formação de um filme de água líquida nas superfície das pás dos últimos estágios devido à presença de gotículas de condensado, que incidem e escoam sobre as pás dos rotores e estatores (TRELA; MIKIELEWICZ, 1992);

2) no resfriamento industrial de alimentos, com escoamento bifásico ar-água, as gotículas de água líquida captadas escorrem sobre os alimentos e causam um aumento significativo do coeficiente de transferência de calor por convecção, devido ao efeito térmico da evaporação (ALLAIS; ALVAREZ; FLICK, 1997; AIHARA, 1990);

3) na superfície sólida da asa de aeronave equipada com sistema antigelo térmico. Neste último caso, a evaporação da água líquida precisa ser maximizada e o congelamento residual a jusante da área protegida minimizado. O desempenho do sistema de antigelo térmico será dependente do padrão do escoamento da água líquida e da fração de área molhada da superfície (AL-KHALIL, 1991; ALKHALIL; KEITH; DE, 1994; SILVA; SILVARES; ZERBINI, 2006).

$\mathrm{Na}$ operação de sistemas antigelo, há o escoamento de água por cisalhamento e gradiente de pressão aplicado pelo escoamento concorrente de um gás em alta 
velocidade. Há também a contribuição da quantidade de movimento das gotículas captadas para a movimentação da água líquida.

Quando uma aeronave atravessa uma nuvem, muitas gotículas sub-resfriadas de água líquida são captadas por bordos de ataque aerofólios, entradas de ar de motores, hélices, sensores e antenas. As gotículas podem congelar no local de impacto ou escoar e congelar numa posição mais a jusante da região de incidência.

Por outro lado, quando um aerofólio equipado com sistema antigelo entra numa nuvem, as gotículas de água líquida sub-resfriada incidem no bordo de ataque e formam pequenas gotas (beads) na posição de incidência. Essas gotículas podem ficar estáticas, sem escoar, devido a resistência da tensão superficial. Com maior tempo de exposição ao escoamento bifásico ar-água dentro da nuvem, o número de gotas na superfície aumenta até o começo da coalescência, que aumenta a dimensão das gotas e diminui seu número. Com o aumento de dimensões das gotas, as forças de cisalhamento se sobrepõem as tensões de superfície e a água líquida escoa sob a forma de um filme ou de filetes (ROTHMAYER; TSAO, 2001).

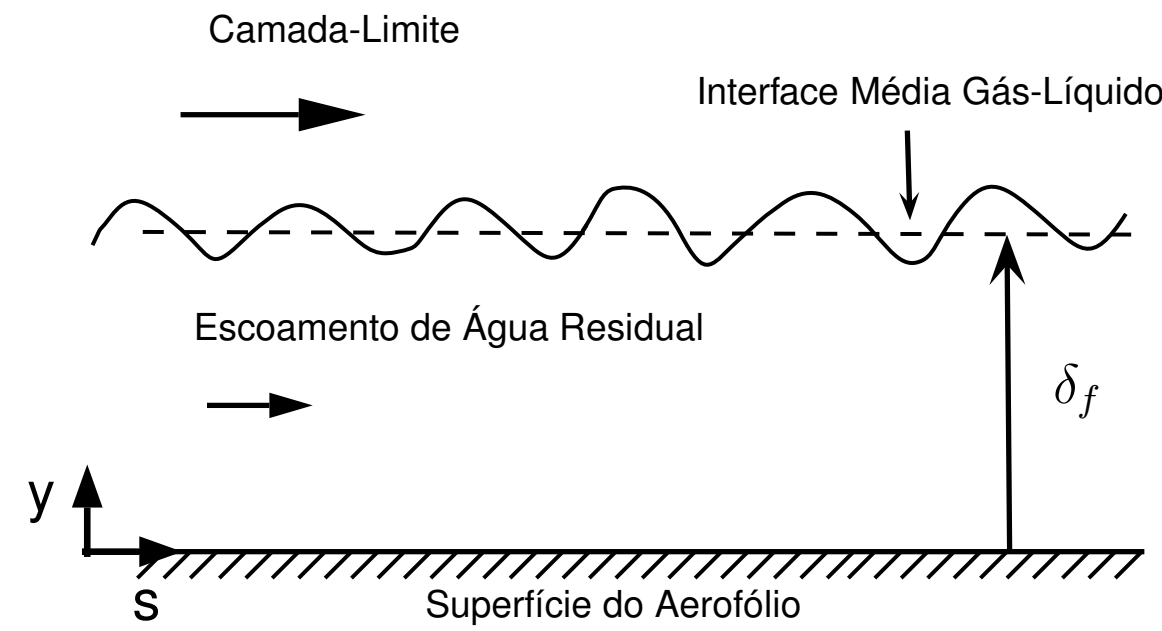

Figura 3.1: Escoamento de um filme de água líquida movido por cisalhamento, depois de Rothmayer e Tsao (2000)

Se houver a formação do filme, a água escoa para regiões a jusante pela ação das forças de cisalhamento aplicadas pelo escoamento de ar em torno do aerofólio, como mostrado na Fig. 3.1. Devido ao efeito da captação de gotículas, da evaporação, do cisalhamento ou do aquecimento, a espessura do líquido pode variar (diminuir ou aumentar) ao longo do escoamento.

Caso uma determinada altura mínima de filme de água for atingida, o cisalhamento aplicado pelo escoamento externo sobre o escoamento de água líquida supera a tensão superficial da água líquida. Nesse momento, ocorre a ruptura do filme contínuo e formam-se filetes (rivulets) de água líquida, que continuam a escoar para regiões a jusante. 
Na passagem do padrão de escoamento de filme para o de filetes, há uma diminuição de área molhada, pois existem regiões secas entre os filetes, onde a superfície sólida fica exposta diretamente ao escoamento do ar. Devido a conservação da massa de água líquida, a espessura dos filetes é maior do que a do filme, pois há a mesma quantidade de água numa área transversal menor.

O escoamento dos filetes diminui a efetividade da transferência de calor do sistema antigelo para a água, já que as áreas de contato líquido-sólido e líquido vapor são menores nos filetes do que no filme de água líquida. Consequentemente, a água pode não ser evaporada totalmente e, então, escorrer a jusante da região protegida e formar, naquele local, o gelo residual (runback ice).

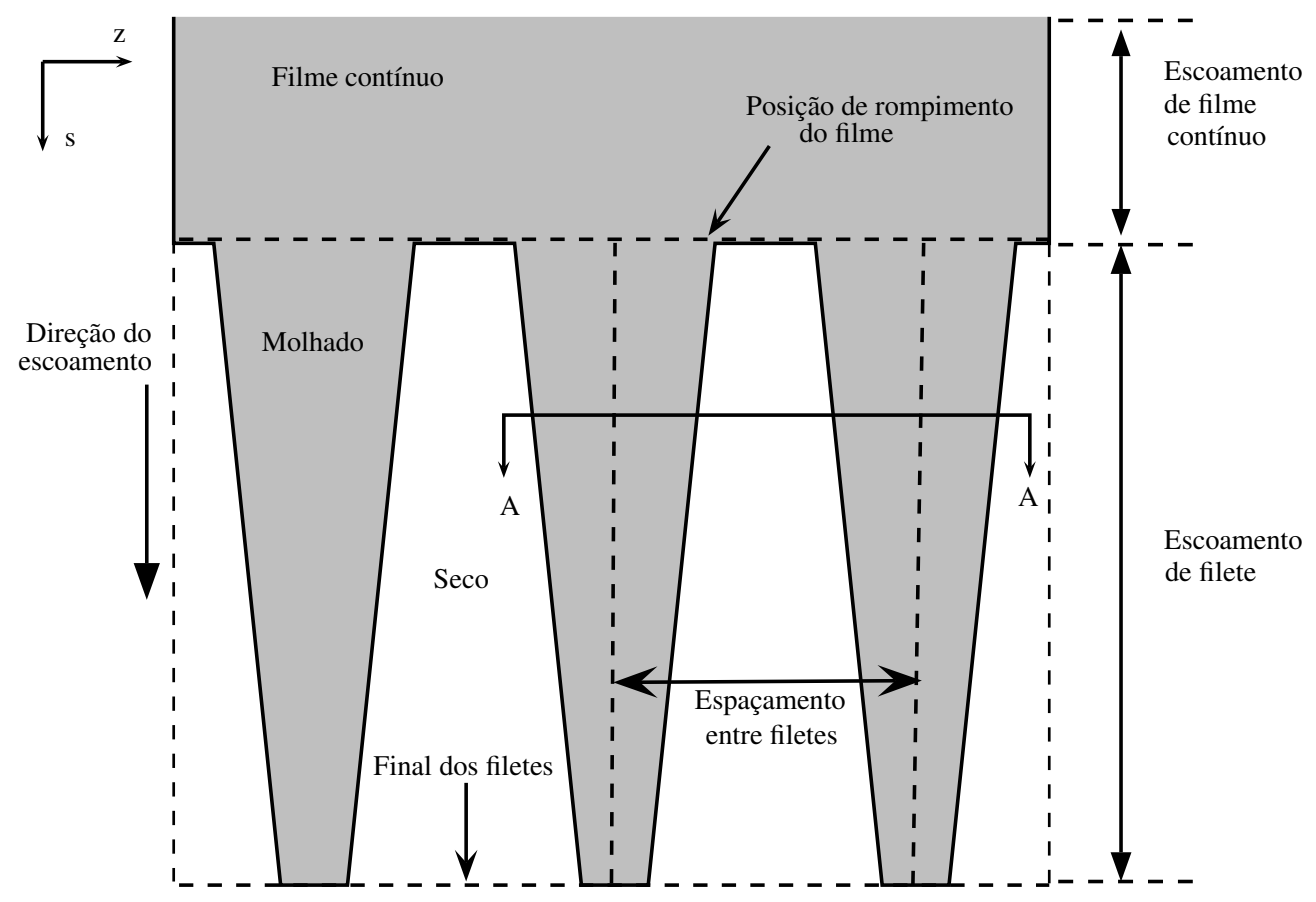

Figura 3.2: Escoamento de filme contínuo e de filetes, depois de Mikielewicz e Moszynski (1975)

Os fluxos de calor entre a superfície da água líquida e o escoamento do ar $\dot{q}_{\text {molhado }}^{\prime \prime}$, e entre a superfície sólida e o escoamento do ar $\dot{q}_{s e c o}^{\prime \prime}$ podem ser expressos como:

$$
\begin{gathered}
\dot{q}_{\text {molhado }}^{\prime \prime}=U_{\infty} \cdot F \cdot \Delta T \\
\dot{q}_{\text {seco }}^{\prime \prime}=h_{a r} \cdot(1-F) \cdot \Delta T \\
\dot{q}_{\text {total }}^{\prime \prime}=\dot{q}_{\text {seco }}^{\prime \prime}+\dot{q}_{\text {molhado }}^{\prime \prime} \\
F=\frac{A_{\text {molhada }}}{A}
\end{gathered}
$$

$\mathrm{Na}$ qual, $U_{\infty}$ é o coeficiente global de transferência de calor, que combina efeitos térmicos acoplados de convecção, evaporação, escoamento do líquido e captação 
de gotículas; $h_{a r}$ é o coeficiente de transferência de calor somente por convecção; e $\dot{q}_{\text {total }}^{\prime \prime}$ é o fluxo de calor na superfície sólida do aerofólio, ou seja, a carga térmica por unidade de área.

A Fig. 3.2 apresenta uma vista de topo de um escoamento de filetes sobre uma superfície sólida e as regiões secas entre os filetes, segundo o modelo de Mikielewicz e Moszynski (1975).

No presente trabalho, considera-se as seguintes hipóteses simplificadoras para a modelagem matemática da ruptura do filme e formação dos filetes no escoamento de água líquida residual:

1) que o sistema antigelo opera no regime permanente;

2) que há um escoamento de um filme contínuo de água $(F=1)$ na região de captação, ou seja, não há escoamento de filetes ou gotas estáticas (paradas);

3) que os filetes escoam de forma retilínea;

4) que o espaçamento entre filetes é constante a jusante da posição de ruptura do filme de água;

5) que a ruptura do filme de água ocorre de forma concentrada, numa mesma linha na direção transversal ao escoamento;

6) que a ruptura do filme de água é abrupta, i.e., a molhabilidade da superfície decresce instantaneamente de $F=1$, da superfície totalmente molhada pelo filme contínuo, para um valor de $0<F<1$, da superfície parcialmente molhada pelo escoamento de filetes;

7) que o ângulo de contato da água sobre a superfície do aerofólio, $\alpha$, é constante, ou seja, não varia durante o escoamento dos filetes nem é afetado por variações de temperatura da água.

\subsection{Modelagem do Escoamento Água Líquida Resi- dual}

\subsubsection{Padrão de Escoamento de Filme Contínuo}

O campo de velocidades unidimensional $v=v(y)$ do filme de água líquida movido por cisalhamento e gradiente de pressão é descrito pelo escoamento de Poiseuille:

$$
v=\frac{1}{\mu} \frac{d p}{d z} y^{2}+\left(\frac{\tau}{\mu}-\frac{2}{\mu} \frac{d p}{d z} \delta_{f}\right) y
$$


Se os efeitos do gradiente de pressão sobre o filme forem desprezíveis, o filme de água líquida é movido somente por cisalhamento e o campo de velocidades é descrito pelo escoamento de Couette:

$$
v=\frac{\tau}{\mu} y
$$

A hipótese de escoamento promovido apenas por cisalhamento foi adotada na modelagem matemática de filmes líquidos em turbinas a vapor e em aerofólios aeronáuticos equipados com sistema antigelo. Considera-se que o escoamento de Couette foi uma hipótese adotada somente para simplificar o modelo (ou ad hoc), já que os autores não apresentaram análises para confirmá-la (MIKIELEWICZ; MOSZYNSKI, 1975; AL-KHALIL, 1991)..

Rothmayer e Tsao (2000) estudaram o escoamento de um filme da água líquida ( $\left.5 \leq \delta_{f} \leq 50 \mu \mathrm{m}\right)$ com ondas sobre um aerofólio movido pelo escoamento de uma camada-limite de ar. Os autores concluíram que existe uma espessura crítica na qual as ondas da superfície da água líquida deixam de ser movidas principalmente por cisalhamento e começam ser movidas por gradiente de pressão. O crossover entre a força motriz de cisalhamento e a pressão ocorre quando a espessura do filme é uma fração da espessura da camada-limite, que pode ser de 5 a $40 \%$ dependendo das condições do escoamento. Segundo o desenvolvimento desses autores, se a espessura do filme for muito menor do que o limite crítico de crossover, a hipótese de escoamento de Couette é válida.

\subsubsection{Padrão de Escoamento de Filetes}

Depois da ruptura do filme, a água líquida escoa na forma de filetes sobre a superfície sólida do aerofólio. A Fig. 3.3 apresenta um corte transversal do filete e os seus principais parâmetros, onde as coordenadas são $(r, \theta, z) ; R$ é o raio da superfície do filete; $\alpha$ é o ângulo de contato entre o líquido e a região bifásica; $z$ é a posição na direção normal do plano de corte. Já a coordenada cartesiana $w$, associada à largura do filme contínuo, tem origem no centro do filete na direção da interface sólido-líquido na base do filete; a coordenada cartesiana $y$, associada à altura do filme contínuo, é normal a superfície sólida.

Se considerarmos a distância entre as linhas de centro de dois filetes consecutivos $\lambda_{f}$ e um filete com geometria de segmento de cilindro de raio $R$ com ângulo de contato $\alpha$, a área molhada pelo filete é definida por $2 R \sin \theta$. Logo, a fração de área 


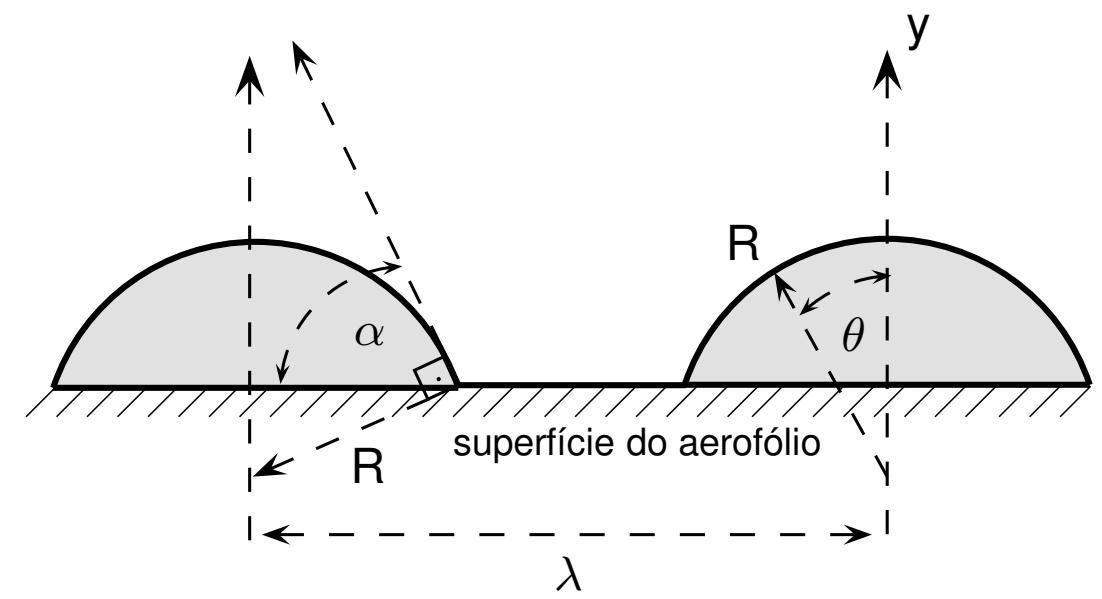

Figura 3.3: Geometria do filete (corte A-A da Fig. 3.2)

molhada da superfície é:

$$
F_{r}=\frac{2 R \sin \alpha}{\lambda_{f}}
$$

As velocidades dentro do filete de líquido podem ser representadas como um campo unidimensional $v=v(y)$, de forma similar a um escoamento em um filme, como na Eq. (3.3). Porém, para isso é necessária a definição da distância da superfície do filete de líquido até a superfície sólida em função $\theta$ como (MIKIELEWICZ; MOSZYNSKI, 1975):

$$
h(w)=R \cdot(\cos \theta-\cos \alpha)
$$

Quando $\theta=0$, a posição $w_{0}$ está na linha de centro e a distância entre a superfície do filete e a superfície sólida $h\left(w_{0}\right)$ é máxima. Assim a altura do filete é dada por:

$$
\theta=0 \quad \Rightarrow \quad h_{r}=R \cdot(1-\cos \alpha)
$$

Por outro lado, quando $\theta=\alpha=90^{\circ}$ a distância entre a superfície do filete é nula $h\left(w_{1}\right)=0$, ou seja, as superfície das interfaces líquido-gás e líquido-sólido do filete se encontram na posição $w_{1}$.

Substitui-se a Eq. (3.5) na (3.3) ou, se o gradiente de pressão for importante, na Eq. (3.2), para avaliar o campo de velocidades unidimensional nos filetes.

Para melhorar as previsões de altura crítica de filme, na qual a ruptura ocorre e causa a formação de filetes, do seu modelo unidimensional, Mikielewicz e Moszynski (1978) desenvolveram um procedimento para estimar o campo de velocidades bidimensional $v(x, y)$ por meio de uma transformação conforme de coordenadas.

Segundo Mikielewicz e Moszynski (1978), para escoamento movido por cisaIhamento simples, a hipótese de perfil unidimensional de velocidades gera desvios menores que $20 \%$ na energia mecânica total, para $\alpha<60^{\circ}$, se comparada com 
resultados do modelo bidimensional de velocidades.

Towell e Rothfeld (1966) e Bentwich et al. (1976) desenvolveram outros procedimentos para calcular $v(x, y)$ no filete de líquido retilíneo por meio de soluções analíticas ou com interpolação. Allen e Biggin (1974) resolveram o escoamento de um filete de líquido sobre um plano inclinado com o método de elementos finitos para estimar $v(x, y)$.

Recentemente, Al-Khalil (1991) também usou elementos finitos para estimar a distribuição de velocidades no filete e comparar com a aproximação de escoamento de Couette. Para possibilitar a implementação em programas de simulação de sistemas antigelo, o autor definiu funções trigonométricas interpoladoras, chamadas de regression model nas Figs. 3.4(a), 3.4(b) e 3.4(c), a partir dos resultados numéricos do campo $v(x, y)$ obtidos por meio da análise de elementos finitos, chamadas de numerical Figs. 3.4(a), 3.4(b) e 3.4(c).

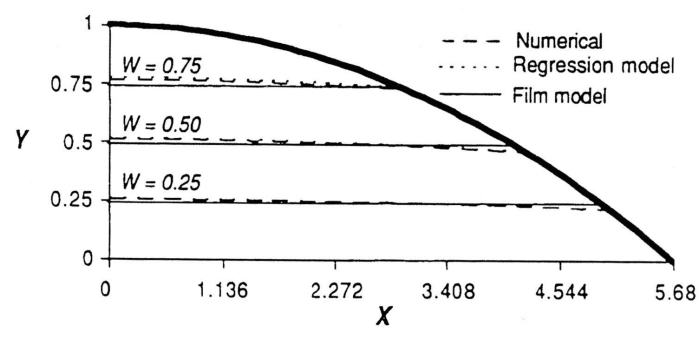

(a) $\alpha=20^{\circ}$

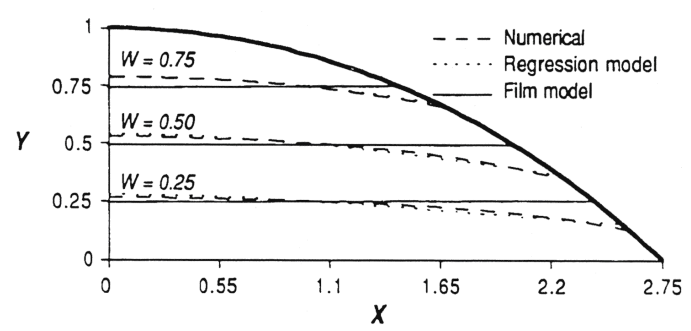

(b) $\alpha=40^{\circ}$

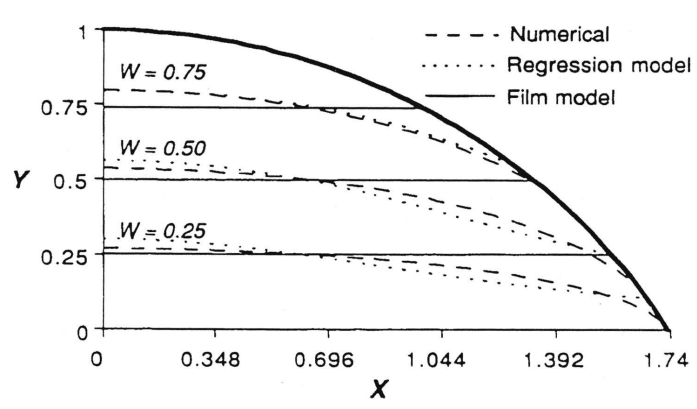

(c) $\alpha=60^{\circ}$

Figura 3.4: Velocidades no filete. Comparação solução bidimensional numérica e interpolada com aproximação de filme (AL-KHALIL, 1991)

A Fig. 3.4 apresenta os resultados de estudo paramétrico para demonstrar o des- 
vio das soluções do campo do escoamento com a variação do ângulo de contato $\alpha$ (AL-KHALIL, 1991; AL-KHALIL; KEITH; DE, 1994). Para $\alpha \leq 20^{\circ}$, os resultados do modelo de filme unidimensional (film na legenda da Fig. 3.4) são próximos da solução numérica de elementos finitos (numerical na Fig. 3.4) e da interpolação trigonométrica (regression model na Fig. 3.4). Para $\alpha \leq 40^{\circ}$, o modelo de filme unidimensional (film) produziu resultados mais afastados da solução numérica de elementos finitos e da interpolação trigonométrica, principalmente na região mais periférica do filete. Para $\alpha \geq 60^{\circ}$, o modelo de filme unidimensional produziu resultados que se distanciam da solução numérica de elementos finitos e da interpolação trigonométrica conforme a Fig. 3.4(c). As previsões da interpolação trigonométrica (regression) e a solução numérica de elementos finitos (numerical) para o campo bidimensional de velocidades no interior do filete não apresentaram desvios para $\alpha \leq 60^{\circ}$, conforme as Figs. 3.4(a), 3.4(b) e 3.4(c).

Se a hipótese do filete com forma de segmento de cilindro não for adotada, a geometria bidimensional da interface líquido-gás precisa ser estimada. El-Genk e Saber (2001) estimaram o raio de curvatura da superfície do filete por meio da equação de Laplace, que aplica o equilíbrio da tensão na superfície líquido-vapor com as pressões interna e externa ao filete.

\subsubsection{Critérios para a Ruptura do Padrão Filme de Líquido Contí- nuo}

Diversos critérios foram desenvolvidos para determinar a espessura crítica de filme de líquido e início da formação de filetes. Os modelos tem como base os conceitos de energia total mínima, equilíbrio de forças e análises de estabilidade.

Os principais critérios, que foram encontrados na literatura, são apresentados e comentados na Tabela 3.1.

Neste trabalho, foi adotado o critério da Energia Total Mínima (ETM) devido a:

1) simplicidade de implementação no programa de simulação térmica de aerofólios com sistema antigelo;

2) menores desvios entre as suas previsões e dados experimentais em relação aos outros procedimentos encontrados na literatura;

3) aplicação do critério à simulação térmica de desempenho de aerofólios com sistemas antigelo por outros pesquisadores (AL-KHALIL, 1991). 
Tabela 3.1: Resumo dos critérios de ruptura de filmes de líquido

\begin{tabular}{|c|c|c|}
\hline Critério & Autores & Comentários \\
\hline Energia total mínima & $\begin{array}{l}\text { Hobler (1965), Bankoff } \\
\text { (1971a), Mikielewicz e } \\
\text { Moszynski (1975), Al-Khalil } \\
\text { (1991), Saber e El-Genk } \\
\text { (2004) }\end{array}$ & $\begin{array}{l}\text { - considera efeito do } \\
\text { ângulo de contato; } \\
\text { - estima altura crítica de } \\
\text { ruptura do filme } h_{0} \text {, } \\
\text { fração de área } \\
\text { molhada } F \text {, raio do } \\
\text { filete } R \text {; } \\
\text { - apresenta os menores } \\
\text { desvios entre } \\
\text { resultados numéricos e } \\
\text { dados experimentais } \\
\text { dentre os critérios } \\
\text { desta tabela; } \\
\text { - é fundamentada em } \\
\text { conceitos } \\
\text { termodinâmicos }\end{array}$ \\
\hline Equilíbrio de forças & Hartley e Murgatroyd (1964) & $\begin{array}{l}\text { - só considera o } \\
\text { equilíbrio de forças no } \\
\text { ponto de estagnação } \\
\text { da região seca; } \\
\text { - previsões só tem } \\
\text { desvio pequeno em } \\
\text { relação aos } \\
\text { experimentos se forem } \\
\text { adotados ângulos de } \\
\text { contato não-realistas }\end{array}$ \\
\hline Potência transmitida mínima & Hartley e Murgatroyd (1964) & $\begin{array}{l}\text { - mínima taxa de } \\
\text { variação de energia } \\
\text { total numa seção } \\
\text { transversal; } \\
\text { - não considera ângulo } \\
\text { de contato no } \\
\text { equacionamento; } \\
\text { - baseia-se em hipótese } \\
\text { ad-hoc sem } \\
\text { fundamento físico; }\end{array}$ \\
\hline Estabilidade linear & Bankoff (1971b) & $\begin{array}{l}\text { - perde sentido se a } \\
\text { amplitude da } \\
\text { perturbação para } \\
\text { quebrar o filme não for } \\
\text { infinitesimal; } \\
\text { - não considera ângulo } \\
\text { de contato no } \\
\text { equacionamento }\end{array}$ \\
\hline
\end{tabular}




\subsubsection{Outros Modelos para a Ruptura do Filme Contínuo}

Mikielewicz e Moszynski (1978) resolveram o sistema de equações do critério Energia Total Mínima (ETM) com hipóteses de cisalhamento simples, mas com um perfil bidimensional de velocidades.

Comparando os resultados dos modelos que consideram campo de velocidades unidimensional e bidimensional no filete sob ação de escoamento cisalhante de um gás, a diferenças máximas entre as previsões de $e_{\text {cin }}$ e $\dot{m}_{f}^{\prime}$ são: 1) para $\theta=40^{\circ}$ os desvios são desprezíveis; 2 ) para $\theta=60^{\circ}$ os desvios são $\approx+31 \%$ (unidimensional) $\mathrm{e} \approx+8 \%$ (bidimensional) e 3 ) para $\theta=90^{\circ}$ os desvio são $\approx+57 \%$ (unidimensional) $\mathrm{e} \approx+25 \%$ (bidimensional).

Para desenvolver um modelo de simulação de sistema antigelo térmico, que considera o efeito térmico do escoamento de filme e filetes sobre a superfície sólida de um aerofólio, Al-Khalil (1991): 1) implementou critério de energia total mínima para ruptura do filme e formação de filetes; 2) adotou perfil de velocidades bidimensional; 3) calculou campo de velocidades e de temperatura no filete por meio de método numérico (elementos finitos) e por interpolação, para acelerar o cálculo dos filetes durante a simulação; 4) admitiu cisalhamento simples no filme e nos filetes; 5) adotou uma forma de segmento de cilindro para o filete; 6 ) modelou o filete como retangular no modelo antigelo, mas definiu um fator de correção de área para contabilizar a diferença entre a forma cilíndrica e retangular; 7) implementou o modelo de filete com evaporação e congelamento sobre a superfície da asa.

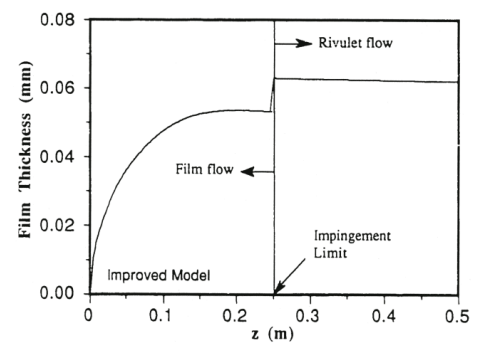

(a) Espessura de filme

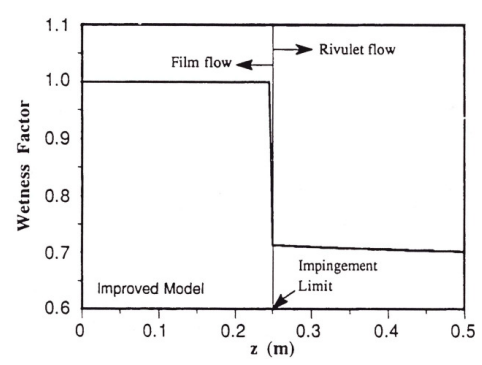

(b) Fração de área molhada

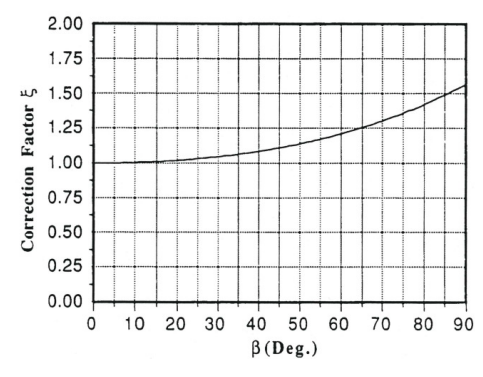

(c) Correção para filete

Figura 3.5: Resultados de simulação de sistema antigelo com modelo de filetes (AL-KHALIL, 1991)

Na Fig. 3.5, são apresentados os resultados numéricos de Al-Khalil (1991) para $h, F$ e para um fator de correção $\xi$, que corrige erros na área líquido-vapor, gerados pela adoção da hipótese de filete retangular. O autor optou por manter o escoamento de filme na região de captação de gotículas, mesmo quando a espessura do filme é menor do que a crítica. Assim que o filme sai da área de captação, a formação dos filetes ocorre imediatamente, como apresentado na Fig. 3.5(a), e a fração de área 
molhada passa de $F=1$ para um valor de $F \approx 0.75$, na Fig. 3.5(b). Com base em experiência, o autor admitiu $\alpha=40^{\circ}$ para os filetes para o caso simulado mostrado na Fig. 3.5(c).

Trela e Mikielewicz (1992) identificaram instabilidades tridimensionais em filmes de líquidos movidos por cisalhamento sobre a superfície de um cilindro aquecido imerso num escoamento bifásico de ar e gotículas de água líquida, em alta e baixa velocidade. Depois de captada pelo cilindro, a água líquida escoa e forma instabilidades na direção transversal ao escoamento. A partir de experimentos e desenvolvimento teórico, os autores concluíram que o número de onda das instabilidades tridimensionais podem ser relacionadas ao número de filetes formados após a ruptura do filme.

El-Genk e Saber (2001), El-Genk e Saber (2002), Saber e El-Genk (2004) desenvolveram trabalhos sobre previsão da espessura crítica para ruptura de filme de líquido em filetes que consideram: 1) critério de energia total mínima ETM; 2) escoamento de Couette; 3) campo bidimensional de velocidades $v(x, y)$; 4) perfil do filete calculado $\phi(x, y)$. Com isso, o desvio das previsões numéricas em relação a vários conjuntos de dados experimentais foram obtidos: 1) para $h_{0}$ o desvio é de 10 a $15 \%$ e 2) para $F_{r}$ o desvio é de $20 \%$.

\subsection{Critério de energia total mínima}

O critério da energia total mínima propõe um sistema de três equações para encontrar a espessura mínima de filme $h_{0}$, fração de área molhada $F$ e raio do filete $R$, ou seja, três incógnitas, na posição da ruptura do filme. O sistema de equações do modelo matemático é composto por princípios termodinâmicos de conservação, que são:

1) conservação da massa na transição de escoamento de filme para o de filetes no sentido do escoamento;

2) conservação da energia total $\left(E_{\text {total }}=E_{\text {cin }}+E_{\text {sup }}\right)$ na transição do escoamento do filme para os filetes no sentido do escoamento;

3) minimização da energia mecânica total no filete, pois a sua configuração geométrica é estável quando sua energia mecânica total é mínima; 


\subsubsection{Modelo Matemático de Mikielewicz e Moszynski (1975)}

As vazões mássicas no filme $\dot{m}_{f}^{\prime}$ e no filete $\dot{m}_{r}^{\prime}$ por unidade de largura são determinadas por:

$$
\begin{gathered}
\dot{m}_{f}^{\prime}=\int_{0}^{h_{0}} \rho_{\text {agua }} v(y) d y \\
\dot{m}_{r}^{\prime}=\frac{1}{\lambda_{f}} \int_{0}^{R \sin \theta} \int_{0}^{h(w)} \rho_{\text {agua }} v(w, y) d y d w
\end{gathered}
$$

Onde $v=v(y)$ é o perfil de velocidades do filme de um escoamento de Couette. As energias mecânicas totais do filme $e_{f}$ e no filete $e_{r}$ por área da base do filme são:

$$
\begin{gathered}
\frac{E_{f}}{1 \cdot \lambda_{f}}=e_{f}=\int_{0}^{h_{0}} \frac{\rho_{\text {agua }}}{2} v^{2}(y) d y+\sigma_{l s}+\sigma_{l v} \\
\frac{E_{r}}{1 \cdot \lambda_{r}}=e_{r}=\frac{1}{\lambda_{f}} \int_{0}^{R \sin \theta} \int_{0}^{h(w)} \rho_{\text {agua }} v^{2}(w, y) d y d w \\
+\left(\frac{2 R \theta}{\lambda_{f}}+\cos \theta-\frac{R \sin 2 \theta}{\lambda_{f}}\right) \sigma_{l v}+\sigma_{l s}
\end{gathered}
$$

A configuração mais estável do escoamento de filetes é obtida por meio da minimização da energia mecânica total dos filetes por área de filme em relação a fração de área molhada $F_{r}$ :

$$
\frac{\partial e_{r}}{\partial F_{r}}=0 \quad \text { e } \quad \frac{\partial^{2} e_{r}}{\partial F_{r}^{2}}>0
$$

\subsubsection{Fundamento Termodinâmico do Critério da ETM}

O critério da Energia Total Mínima (ETM) e seu conjunto de hipóteses podem ser deduzidos a partir da função de Helmholtz:

$$
\mathcal{F}=E_{\text {total }}-T \cdot S=E_{\text {cin }}+E_{\text {pot }}+U-T \cdot S
$$

Onde $E_{\text {total }}$ é a soma da energia cinética $E_{c i n}$, da potencial $E_{p o t}$ e da energia interna $U$; $S$ é a entropia; $T$ é a temperatura.O diferencial da função de Helmholtz Eq. (3.12) é dado por:

$$
d \mathcal{F}=d E_{\text {cin }}+d E_{\text {pot }}+d U-T \cdot d S-S \cdot d T
$$

Se for admitido que o processo é reversível, a combinação da Primeira com a Segunda Lei da Termodinâmica, Eqs. (3.14a) e (3.14b), resulta na Eq. (3.14c) apre- 
sentada abaixo:

$$
\begin{gathered}
d U=\delta Q+\delta W \\
d S=\left.\frac{\delta Q}{T}\right|_{r e v} \\
\delta W=d U-T \cdot d S
\end{gathered}
$$

Onde $\delta Q$ é o calor recebido do meio pelo sistema através um processo reversível e $\delta W$ é o trabalho realizado pelo meio no sistema, desse modo, ambos $\delta W>0$ e $\delta Q>0$ aumentam a energia interna $d U>0$. Considerando que o único trabalho é aquele realizado pelas forças superficiais,

$$
\delta W=\sum \sigma_{i} \cdot d \mathcal{A}_{i}
$$

a Eq. (3.13) resulta em:

$$
d \mathcal{F}=d E_{\text {cin }}+d E_{\text {pot }}-S \cdot d T+\sum \sigma_{i} \cdot d \mathcal{A}_{i}
$$

Onde $\mathcal{A}_{i}$ é a área da interface $i$ líquido-vapor, líquido-sólido ou sólido-vapor; $\sigma_{i}$ é a tensão superficial entre as fases na interface $i$. Se os efeitos das variações da temperatura e da energia potencial são desconsiderados e a Eq. (3.16) é simplificada para:

$$
d \mathcal{F}=d E_{\text {cin }}+\sum \sigma_{i} \cdot d \mathcal{A}_{i}
$$

O princípio de equilíbrio termodinâmico é aplicado ao escoamento dos filetes para estimar a largura de filete mais estável por meio da minimização da função de Helmholtz. Se o diferencial da Eq. (3.17) for dividido pelo diferencial da área da base do filete temos:

$$
\frac{d \mathcal{F}}{d \mathcal{A}_{r}}=\frac{d E_{c i n}}{d \mathcal{A}_{r}}+\sum \sigma_{i} \cdot \frac{d \mathcal{A}_{i}}{d \mathcal{A}_{r}}
$$

Considerando que a distância entre filetes $\lambda_{f}$ é constante e que os filetes tem comprimento unitário:

$$
\mathcal{A}_{r}=F_{r} \cdot \lambda_{f} \cdot 1 \quad \text { e } \quad d \mathcal{A}_{r}=\lambda_{f} \cdot d F_{r}
$$

Onde $\mathcal{A}_{r}$ é a área da base do filete. A Eq. (3.18) é desenvolvida com auxílio da Eq. (3.19) e igualada a zero $\left(d \mathcal{F} / d \mathcal{A}_{r}=0\right)$. Assim o critério da Energia Total Mínima (ETM) da Eq. (3.11) é obtido por meio da minimização da função de Helmholtz $\mathcal{F}$ em função da área da base do filete $\mathcal{A}_{r}$. 


\subsubsection{Determinação do Ângulo de Contato}

Aplicação do equilíbrio de tensões superficiais a um filete sobre um sólido numa atmosfera gasosa resulta na equação de Young:

$$
\sigma_{l v} \cos \alpha=\sigma_{s v}-\sigma_{s l}
$$

O trabalho de adesão $w_{s l}$ é o trabalho mínimo (processo reversível) por unidade de área necessário para desprender o líquido de uma superfície sólida, ou seja, considerando uma mesma área, as novas interfaces líquido-vapor e sólido-vapor aparecem e a interface sólido-líquido desaparece. A aplicação da função de Helmholtz ao processo reversível e isotérmico de desprendimento de uma área unitária do líquido do sólido resulta em:

$$
w_{s l}=\sigma_{l v}+\sigma_{s v}-\sigma_{s l}
$$

O trabalho de adesão por unidade de área é definido por Fowkes (CAREY, 1992) como:

$$
w_{s l} \approx 2\left(\sigma_{l v} \sigma_{s V}\right)^{1 / 2}
$$

Com as Eqs. (3.20) e (3.21), o ângulo de contato pode ser avaliado por meio do modelo semi-empírico simplificado de Girifalco-Good (CAREY, 1992; ADAMSON, 1990):

$$
\cos \alpha= \begin{cases}2\left(\frac{\sigma_{s v}}{\sigma_{V}}\right)^{1 / 2}-1 & \text { se } \sigma_{s V}>\sigma_{l V} \\ 1 & \text { se } \sigma_{s V} \leq \sigma_{l V}\end{cases}
$$

Mikielewicz e Moszynski (1982) utilizam uma relação semi-empírica para água molhando superfícies metálicas $\cos \alpha=\sigma_{c} / \sigma_{V}$, onde $\sigma_{c}$ é o valor da tensão crítica no qual o líquido molha completamente o sólido (IHNATOWICZ; GUMKOWSKI; MIKIELEWICZ, 1979).

As equações acima são apenas exemplos de como $\alpha$ poderia ser calculado, pois há vários modelos matemáticos para a determinação do ângulo de contato. As referências encontradas não divulgaram a margem de erro nem a faixa de validade das expressões semi-empíricas. As superfícies de alumínio polido limpo, como os bordos de ataque de asas de aeronaves com sistemas antigelo de ar quente, tem comportamento hidrofóbico. Além disso, as gotas de água apresentam valores de $\alpha$ diferentes em temperaturas moderadas e em altas. Por meio de um ajuste linear de dados experimentais, Bernardin et al. (1997) concluiu que $\alpha \approx 90^{\circ}$ se a temperatura da superfície de alumínio menor do que $120^{\circ} \mathrm{C}$. 


\subsection{Inclusão do Efeito da Formação de Filetes de Água Líquida sobre o Aerofólio}

O modelo-base do escoamento bifásico em torno de aerofólios com sistema térmico de antigelo, descrito no Capítulo 2, é modificado para incluir o efeito da molhabilidade variável da superfície do aerofólio, gerada pela ruptura do filme contínuo e a formação dos filetes de água. Nas próximas seções, são descritas as equações adicionadas àquele modelo matemático por Silva, Silvares e Zerbini (2006).

\subsubsection{Escoamento do Filme de Água Líquida}

O escoamento de água na forma de filme contínuo é descrito pela aplicação do princípio da quantidade de movimento ao escoamento de Poseuille, ou seja, a solução da equação da quantidade de movimento Eq. (2.23) com as condições de contorno da Eq. (2.25).

O perfil de velocidades no filme de água líquida movido por cisalhamento e gradiente de pressão é dado pela Eq. (2.26), que é repetida aqui para referência:

$$
v_{f}(s, y)=\frac{\partial p_{e}}{\partial s} \cdot \frac{y^{2}}{2 \cdot \mu_{\text {agua }}}+\left[\tau+\dot{m}_{\text {imp }}^{\prime \prime} \cdot v_{d} \cdot \sin \varphi-\delta_{f}(s) \cdot \frac{\partial p_{e}}{\partial s}\right] \cdot \frac{y}{\mu_{\text {agua }}}
$$

A espessura do filme de água $\left(\delta_{f}\right)$ é estimada com a velocidade média $\bar{v}_{f}$, obtida pela média das $v_{f}$ calculada pela Eq. (2.26) em y na posição $s$ :

$$
\delta_{f}=\frac{\dot{m}_{\text {entra }}+\dot{m}_{\text {sai }}}{2 \cdot \rho_{\text {agua }} \cdot \bar{v}_{f}}
$$

\subsubsection{Ruptura do Filme e Formação dos Filetes}

Mikielewicz e Moszynski (1975) propõem o critério da Energia Total Mínima (ETM) que possui quatro equações para achar a altura crítica do filme contínuo $h_{0}$, a molhabilidade gerada pela presença dos filetes $F_{r}$, o raio do filete $R$ e a distância entre filetes $\lambda_{f}$.

Na Primeira Lei da Termodinâmica aplicada à superfície do aerofólio e ao escoamento de água líquida, Eqs. (2.1) e (2.6), o efeito da formação dos filetes é considerado por meio da inclusão fator de molhabilidade global $F$, que é composto por:

$$
F=F_{r} \cdot F_{s}
$$

Onde $F_{r}$ é a razão entre a largura da base do filete e a distância entre dois 
centros de filetes; $F_{S}$ é a razão da comprimento molhado na direção do escoamento e comprimento total do volume finito (SILVA; SILVARES; ZERBINI, 2006)

Com a hipótese de geometria de segmento de cilindro apresentado na Fig. 3.3, que é um corte transversal na seção AA do escoamento apresentado na Fig. 3.2, o fator de molhabilidade $F_{r}$ é dado pela Eq. (3.4).

Considerando um escoamento de Couette e as Eqs. (3.7) e (3.8) (MIKIELEWICZ; MOSZYNSKI, 1975), a vazão mássica do filme $\dot{m}_{f}^{\prime}$ e do filete $\dot{m}_{r}^{\prime}$ são estimadas por:

$$
\begin{gathered}
\frac{\dot{m}_{f}}{\lambda_{f}}=\dot{m}_{f}^{\prime}=\frac{\rho \tau}{2 \mu} h_{0}^{2} \\
\frac{\dot{m}_{r}}{\lambda_{f}}=\dot{m}_{r}^{\prime}=\frac{\rho \tau}{\mu} \frac{\phi(\alpha)}{\lambda_{f}} R^{3}
\end{gathered}
$$

Segundo Mikielewicz e Moszynski (1975), a energia mecânica total do filme e dos filetes por área de interface sólido-líquido do filme, Eqs.(3.9) e (3.10), resultam em:

$$
\begin{aligned}
e_{f}= & \frac{\rho \tau^{2}}{6 \mu^{2}} h_{0}^{3}+\sigma_{l v}+\sigma_{l s} \\
e_{r}=\frac{\rho \tau^{2}}{6 \mu^{2}} \cdot g(\alpha) \cdot h_{0}^{3} \cdot\left(\frac{\sin \alpha}{\phi(\alpha)}\right)^{3 / 2} & \cdot F_{r}^{-1 / 2} \\
& +\left(F_{r} \frac{\alpha}{\sin \alpha}+\cos \alpha-F_{r} \cos \alpha\right) \cdot \sigma_{l v}+\sigma_{l s}
\end{aligned}
$$

A aplicação dos princípios da conservação de massa $\left(\dot{m}_{f}=\dot{m}_{r}\right)$ e de energia mecânica total $\left(e_{f}=e_{r}\right)$ na transição do padrão de escoamento de filme para o de filetes, ou seja, a Eq. (3.25) é igual à Eq. (3.26) e a Eq. (3.27) é igual à Eq. (3.28) na posição da ruptura do filme de água, resulta em:

$$
\begin{gathered}
R=h_{0}\left(\frac{\sin \alpha}{\phi(\alpha) F_{r}}\right)^{1 / 2} \\
h^{+}=g(\alpha)\left(\frac{\sin \alpha}{\phi(\alpha)}\right)^{3 / 2} \cdot F_{r}^{-1 / 2}+\left(\frac{\alpha}{\sin \alpha}-\cos \alpha\right) \cdot F_{r} \\
-(1-\cos \alpha)-h^{+}=0
\end{gathered}
$$

Onde a altura crítica adimensional do filme é definida como:

$$
h^{+}=\frac{\rho \tau^{2} h_{0}^{3}}{6 \mu^{2} \sigma_{f g}}
$$

A configuração mais estável para o escoamento dos filetes de água é encontrada por 
meio da aplicação do critério da ETM, ou seja, a minimização de $e_{r}$, Eq. (3.28), em relação a $F_{r}$ conforme a Eq. (3.11), ou seja:

$$
\frac{\partial e_{r}}{\partial F_{r}}=0 \quad \text { e } \frac{\partial^{2} e_{r}}{\partial F_{r}^{2}}>0
$$

Com as Eqs. (3.29),(3.30) e (3.11), a espessura crítica adimensional $h^{+}$resulta em:

$$
h^{+}=(3.2)^{-3 / 2} \cdot\left(\frac{\alpha}{\sin \alpha}-\cos \alpha\right) \cdot\left[h^{+} \cdot g(\alpha)\right]^{2 / 3} \cdot \frac{\sin \alpha}{\phi(\alpha)}-(1-\cos \alpha)
$$

Adotou-se a hipótese que devido à captação múltipla e a deformação das gotículas no momento do impacto, a superfície do aerofólio permanece totalmente molhada a montante dos limites de captação no extradorso e intradorso.

Logo, as Eqs. (3.24), (3.29), (3.31), (3.32) são resolvidas para estimar $F_{r}, R, \lambda_{t}$ e $h_{0}$ nas posições de limite de incidência de gotículas do extradorso e intradorso do aerofólio.

Quando a altura do filme é menor que a altura crítica nos limites da região de incidência, $\delta_{f}<h_{0}$, considera-se que $h_{0}=\delta_{f}$ e, consequentemente, não se aplica o critério da ETM. Nesse caso, $h_{0}$ é conhecido e somente $F_{r}, R$ e $\lambda_{f}$ são estimados por meio das Eqs. (3.24), (3.29) e (3.31).

\subsubsection{Escoamento de Filetes de Água Líquida}

Nas posições a jusante da posição de ruptura do filme de água líquida, os parâmetros do escoamento de filetes $\left(R, F_{r}, \lambda_{f}\right)$ são calculados por meio da definição de molhabilidade, da hipótese de distância entre filetes $\lambda_{f}$ constante e da conservação da massa do escoamento de água líquida para o de filetes.

Na região sem incidência de gotículas, mas com a presença dos filetes, a vazão de água líquida é dada por:

$$
\dot{m}_{r, \text { in }}^{\prime}=\dot{m}_{r, \text { out }}^{\prime}+\dot{m}_{r, \text { evap }}^{\prime}
$$

Considerando que $\mu, \rho, \tau, \alpha$ e $F_{r}$ são constantes dentro de cada volume finito, temos que:

$$
\begin{gathered}
R_{\text {out }}^{2}=R_{\text {in }}^{2}+\frac{2 \mu \alpha}{\rho \tau \phi(\alpha)} \cdot\left(-\dot{m}_{r, \text { evap }}^{\prime \prime} \cdot \Delta s\right) \\
F_{r}=\frac{2 R_{m} \sin \alpha}{\lambda_{f}} \\
\lambda_{f}=\lambda_{f, 0}
\end{gathered}
$$




$$
\text { onde } \quad \frac{\dot{m}_{r, \text { evap }}}{\lambda_{f}}=\dot{m}_{r, \text { evap }}^{\prime}=\dot{m}_{r, \text { evap }}^{\prime \prime} \cdot \Delta s \cdot F_{r} \cdot F_{s} \cdot \xi
$$

O fator $\xi$ é a correção para compensar a curvatura da superfície superior do filete, dada pela razão entre a área exposta de um filete, com forma de segmento cilíndrico, e a área da largura na sua base. Conforme mostrado na Fig. 3.3, esse fator é estimado por:

$$
\xi=\frac{2 R \alpha}{2 R \sin \alpha}=\frac{\alpha}{\sin \alpha}
$$

Como na Eq. (3.5), o raio do filete $R$ se correlaciona a sua altura $h_{r}$ (distância do centro até o topo do segmento de cilindro) por meio da Eq. (3.6):

$$
h_{r}=R \cdot(1-\cos \alpha)
$$

A espessura do escoamento da água líquida na forma de filme e filetes é dado por valores de: a) $\delta_{f}$ nas regiões de incidência de gotículas, em posições a montante da ruptura do filme; b) $h_{0}$ nas posições de ruptura do filme; c) $h_{r}$ nas regiões a jusante da ruptura do filme;

\subsection{Verificação dos Resultados Numéricos}

\subsubsection{Caso de Teste}

Dentre o conjunto de dados experimentais de Al-Khalil et al. (2001), escolhido como caso-padrão e apresentado na seção 2.4 do Tabela 3.2: Distribuição de Densidade de Potência dos Aquecedores Elétricos para Caso 67A(AL-KHALIL et al., 2001) presente texto, selecionou-se o caso 67A para a verificação da implementação modelo de ruptura do filme e formação de filetes, pois representa uma condição de teste que possui uma vazão de água residual líquida significativa e tem uma temperatura média da superfície sólida próxima das encontradas na operação de um sistema real. Os painéis de aquecedores elétricos são instalados no aerofólio NACA0012 como apresentado

\begin{tabular}{cc}
\hline Elemento & \multicolumn{2}{c}{ Caso 67A } \\
\cline { 2 - 2 } Aquecedor & $\dot{q}_{\text {antigelo }}^{\prime \prime}\left[\mathrm{kW} \cdot \mathrm{m}^{-2}\right]$ \\
\hline F & 20,15 \\
D & 21,70 \\
B & 32,55 \\
A & 43,40 \\
C & 26,35 \\
E & 18,60 \\
G & 18,60 \\
\hline
\end{tabular}

na Fig. 2.2. A densidade de potência, em cada elemento aquecedor definido na Tabela 2.1, utilizada no caso 67A é mostrada na Tabela 3.2. Considera-se que camadas do aquecedor estão na mesma tempera- 
tura e que condutividade térmica equivalente no sentido do escoamento é $k=16,27$ $\mathrm{W} /\left(\mathrm{m}^{2} \cdot \mathrm{K}\right)$.

O caso 67A foi testado no túnel de gelo por Al-Khalil et al. (2001) com as condições: $V_{\infty}=89,4 \mathrm{~m} / \mathrm{s} ; T_{\text {total }}=-21,6^{\circ} \mathrm{C} ; L W C=0,55 \mathrm{~g} / \mathrm{m}^{3} ; M V D=20 \mu \mathrm{m}$ e $\alpha=0^{\circ}$.

\subsubsection{Modelos Matemáticos e Códigos Externos Utilizados}

O código externo ONERA (GUFFOND; BRUNET, 1988) foi utilizado por Silva, Silvares e Zerbini (2006) para resolver o campo do escoamento em torno do aerofólio NACA0012e estimar a trajetórias das gotículas de água sub-resfriadas nas condições do caso 67A. O ONERA forneceu, naquela oportunidade, as distribuições de coeficiente de pressão $C_{p}$ e eficiência de coleta local $\beta$.

Há dois modelos de escoamento de água residual implementados no programa de simulação do presente capítulo: 1) o modelo de filme, que considera que a água escoa na forma de filme contínuo sobre a superfície sólida do aerofólio (SILVA, 2002); 2) o modelo de filete, que incorpora o padrão de escoamento de filme contínuo, a ruptura do filme e o padrão de escoamento de filetes (SILVA; SILVARES; ZERBINI, 2006).

\subsubsection{Estimativa do Ângulo de Contato}

Schmuki e Laso (1990) mediram $\alpha$ para filetes de água, a $22^{\circ} \mathrm{C}$, escoando sobre uma superfície inclinada. Os autores obtiveram um ângulo de contato dinâmico de $68^{\circ} \pm 8^{\circ}$, ângulo de avanço de $62^{\circ} \pm 3^{\circ}$, ângulo de recesso de $49^{\circ} \pm 3^{\circ}$. Segundo os autores, os ângulos dinâmicos podem variar ao longo do filete, provavelmente devido a imperfeições da superfície. Apesar da precisão da medida de ângulo dinâmico ser a mais baixa, Schmuki e Laso (1990) recomendam a utilização do ângulo dinâmico, pois, é a medida que representa mais adequadamente a condição de escoamento de filete. Logo, a simulação do presente trabalho considerou $\alpha=68^{\circ}$.

Verificou-se, por meio de uma análise de sensibilidade, que as distribuições de $T_{s}$ e $\dot{m}_{\text {agua }}$ não apresentaram uma variação significativa quando o ângulo de contato foi variado na faixa, $15^{\circ}<\alpha<70^{\circ}$. Esta conclusão confirma as observações de Schmuki e Laso (1990) sobre a sensibilidade do escoamento de filetes à variação de $\alpha$. 
Tabela 3.3: Parâmetros da Região de Transição Laminar-Turbulenta para Caso 67A

\begin{tabular}{|c|c|c|c|c|c|}
\hline \multirow[b]{3}{*}{ modelo de escoamento } & \multicolumn{4}{|c|}{ Presente trabalho } & \multirow{3}{*}{$\begin{array}{c}\text { Al-Khalil et al. (2001) } \\
\text { Ambos } \\
s_{t r} / c\end{array}$} \\
\hline & \multicolumn{2}{|c|}{ Extradorso } & \multicolumn{2}{|c|}{ Intradorso } & \\
\hline & $s_{m} / c$ & $\sigma_{t r} / c$ & $s_{m} / c$ & $\sigma_{t r} / c$ & \\
\hline filme contínuo & 0,094 & 0,005 & $-0,086$ & 0,005 & $\pm 0,056$ \\
\hline filete & 0,070 & 0,007 & $-0,067$ & 0,007 & $\pm 0,056$ \\
\hline
\end{tabular}

\subsubsection{Resultados numéricos}

Na Tabela 3.3, os parâmetros da região de transição laminar-turbulenta, a posição média $s_{m} / c$ e seu desvio padrão $\sigma_{t r} / c$, adotados nos modelos de filme e filetes são comparados com aqueles publicados por Al-Khalil et al. (2001). Os parâmetros $s_{m} / c$ and $\sigma_{t r} / c$ foram ajustados para minimizar o desvio entre as previsões numéricas e os resultados experimentais de coeficiente global de transferência de calor $U_{\infty}$ e de temperatura de superfície $T_{s}$.

A Fig. 3.6(a) apresenta a distribuição de $T_{s}$ prevista pelo presente modelo considerando o escoamento da água na forma de filme contínuo. O modelo de filme previu temperaturas de superfície próximas dos resultados do ANTICE, mas obteve desvios significativos em relação aos dados experimentais. Já a utilização do mesmo código com o modelo de filete produziu $T_{s}$ mais próximas aos dados experimentais do que aquelas obtidas com o modelo de filme. Como mostrado na Fig. 3.9(a), o modelo de filetes previu uma diminuição nas temperaturas de superfície, a jusante do final do filme no intradorso, que não foi obtido pelo ANTICE. No mais, para comparar a margem de erro de resultados dos programas de simulação, de modo rigoroso, é necessário haver menor espaçamento entre sensores em torno do aerofólio, principalmente onde os gradientes de temperatura $d T / d s$ são significativos.

Os efeitos do escoamento dos filetes de água líquida ficam evidentes quando as distribuições de $U_{\infty}$ e $h_{a r}$, das Figs. 3.6(b) e 3.9(b), são comparadas. Devido às diferenças no processo de transferência de calor e massa, as posições de desaparecimento da água líquida previstas pelo modelo de filetes são localizadas mais a montante do que aquelas geradas pelo modelo de filme, como observado nas Figs. 3.7(a) e 3.10(a). Não foi possível determinar qual modelo previu a distribuição de $\dot{m}_{\text {agua }}$ mais próxima da realidade, já que não há medições.

Outros parâmetros como espessura da água líquida residual $h_{r}$, tensão de cisalhamento $\tau$ aplicada pelo escoamento externo e o fator de molhabilidade $F$ são mostrados nas Figs. 3.10(b), 3.11(a) e 3.11(b). Para comparação, os mesmos parâmetros para o modelo de filme contínuo são apresentados nas Figs. Fig. 3.7(b), 
Fig. 3.8(a) e Fig. 3.8(b). Nas posições de ruptura do filme de água líquida, o modelo de filete estimou um aumento abrupto na altura da água líquida (Fig. 3.10(b)), pois toda a vazão de água do filme foi concentrada em alguns filetes. Foram observados valores decrescentes do fator de molhabilidade $F$ na Fig. 3.11(b) nas posições a montante da ruptura do filme. Como esperado para o modelo de filme, $h_{r}$ não sofreu variações abruptas e $F$ permaneceu constante na região molhada do aerofólio, Figs. 3.7(b) e 3.8(b).

\subsection{Comentários}

No presente capítulo, foi adotado o critério da Energia Total Mínima (ETM) na modelagem da ruptura do filme e formação dos filetes para estimar:

- altura crítica na qual o filme contínuo se rompe e gera os filetes;

- molhabilidade da superfície no padrão de escoamento de filetes;

- raio dos filetes;

- distância entre filetes.

O modelo para o cálculo da molhabilidade de superfície, desenvolvido e verificado no presente capítulo, foi incluído no modelo-base do escoamento em torno do aerofólio com sistema térmico de antigelo, apresentado no Capítulo 2. Os resultados finais, considerando a molhabilidade parcial da superfície, os modelos de camadalimite e transição laminar-turbulenta, são apresentados e discutidos no Capítulo 6 As conclusões finais da presente tese podem ser encontradas no Capítulo 7. 


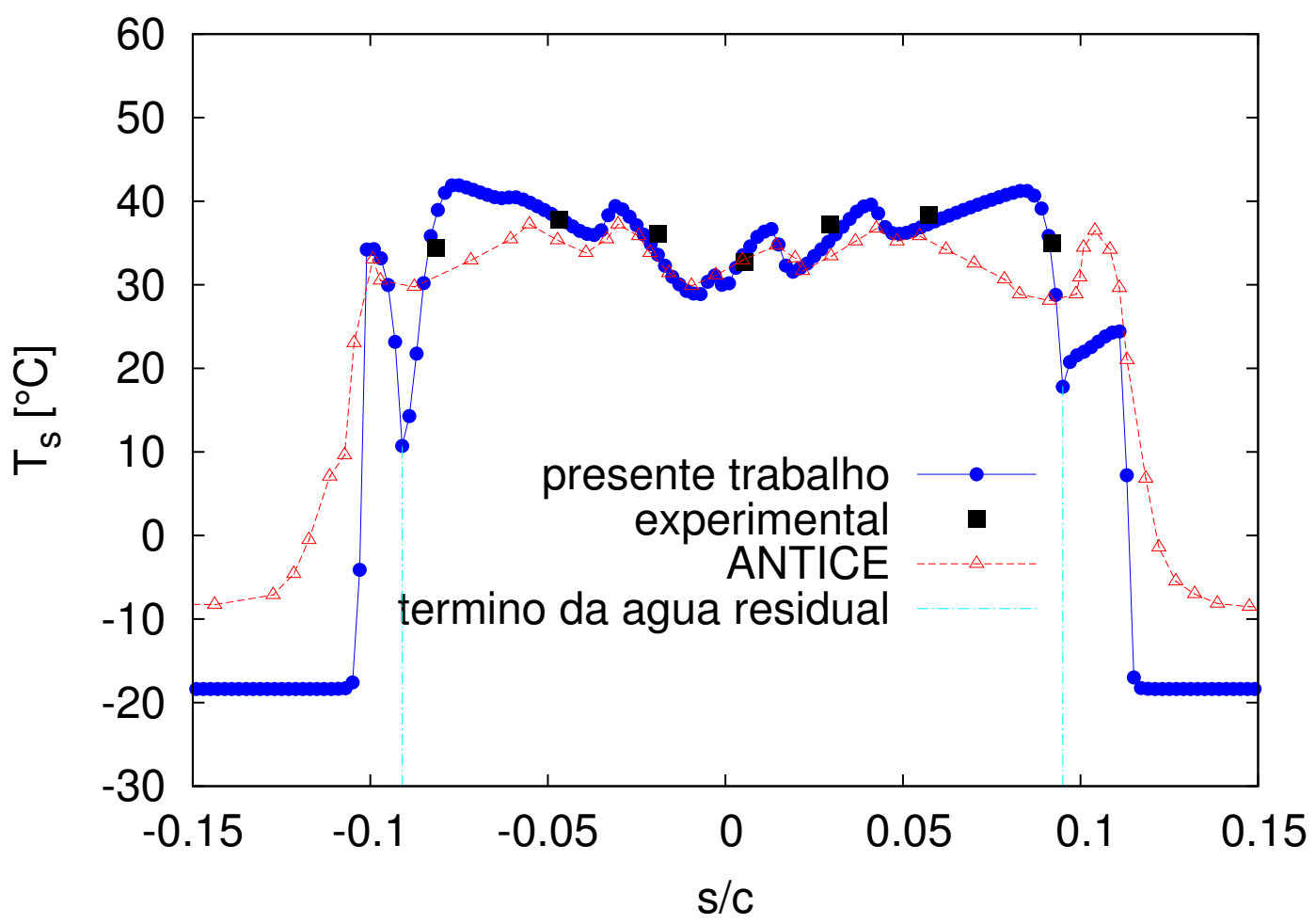

(a) Temperatura da superfície sólida - comparação com ANTICE

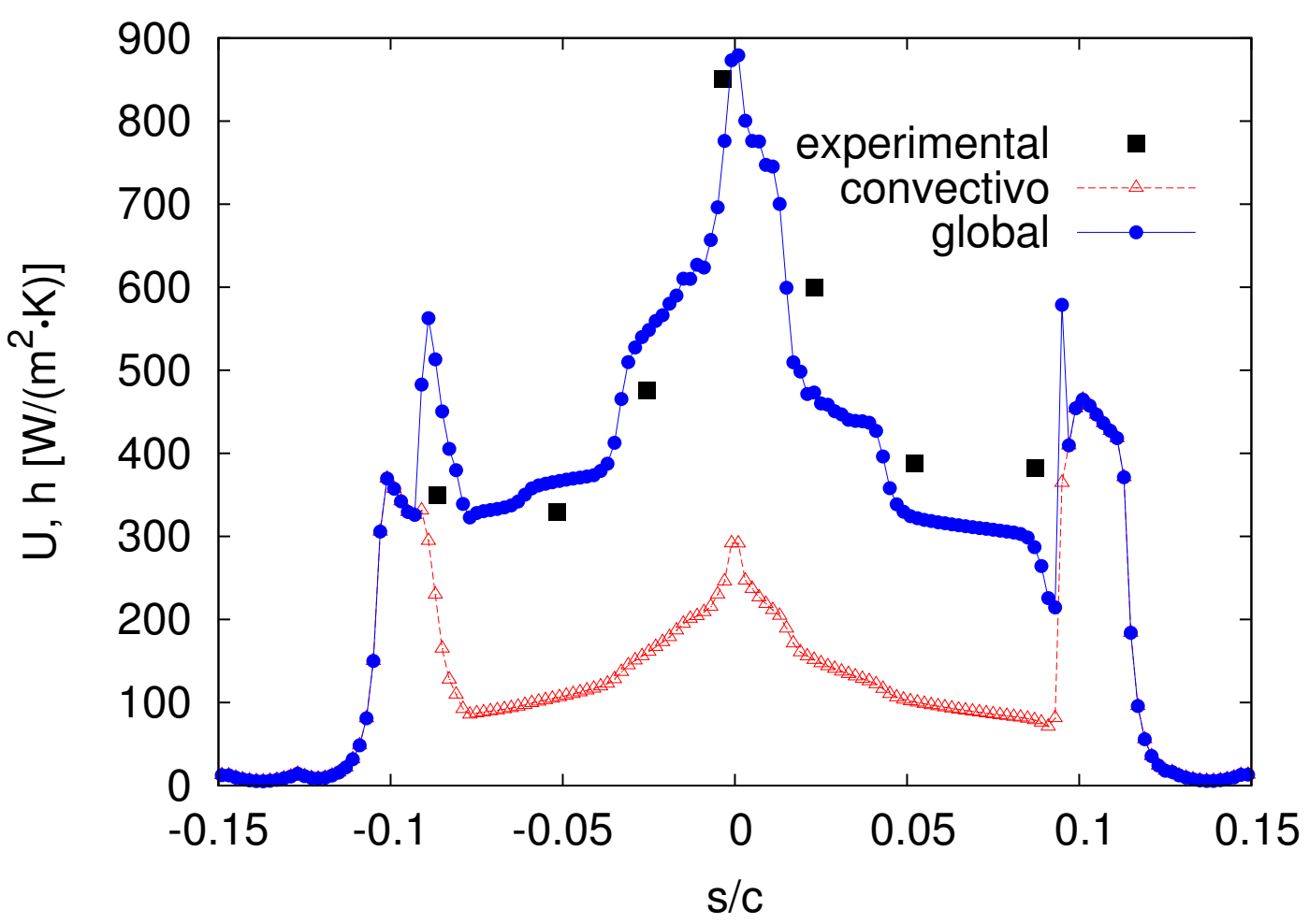

(b) Coeficiente de transferência de calor global e convectivo

Figura 3.6: Modelo de filme contínuo - Temperaturas e Transferência de Calor Caso 67A 


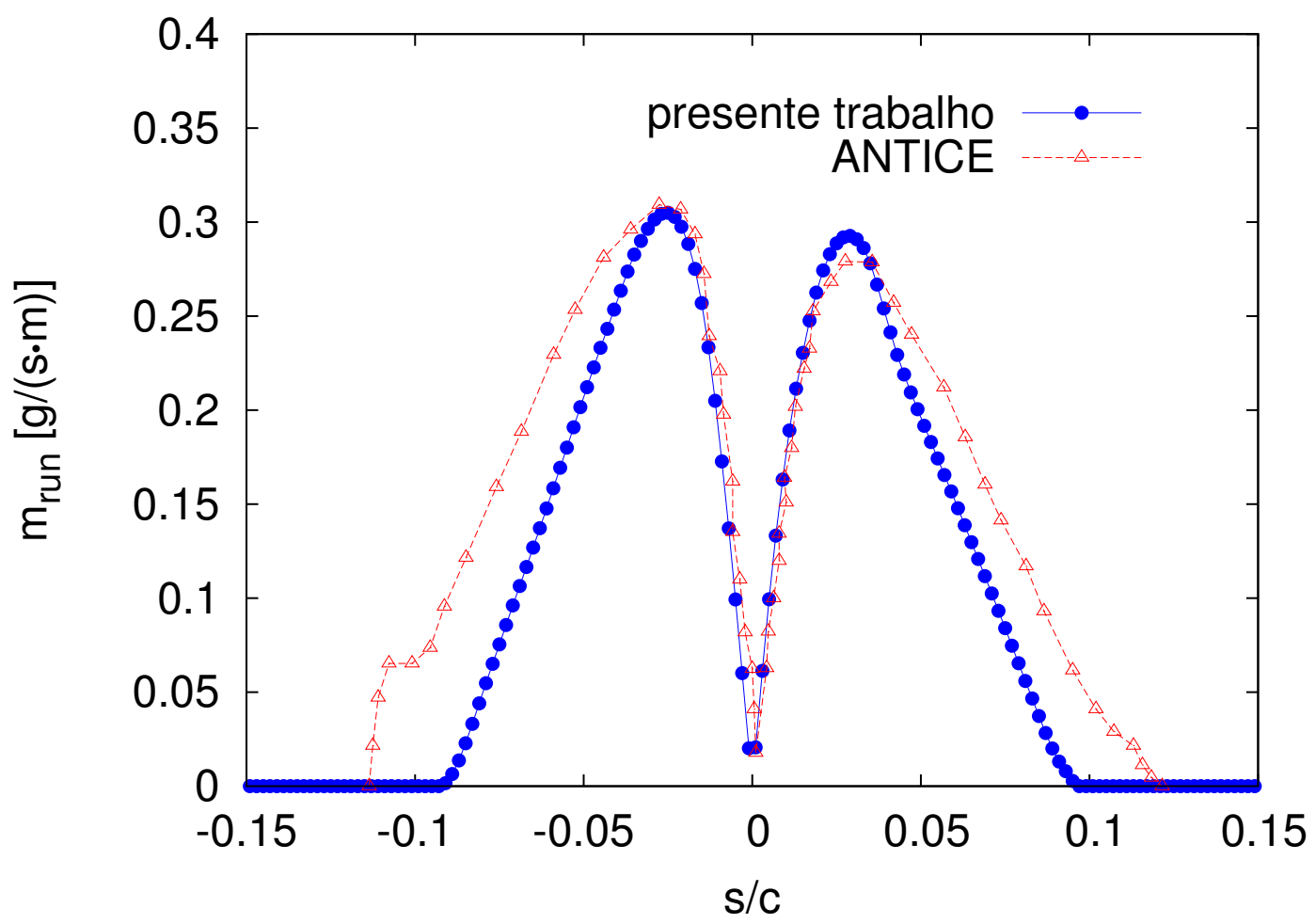

(a) Fluxo de água residual

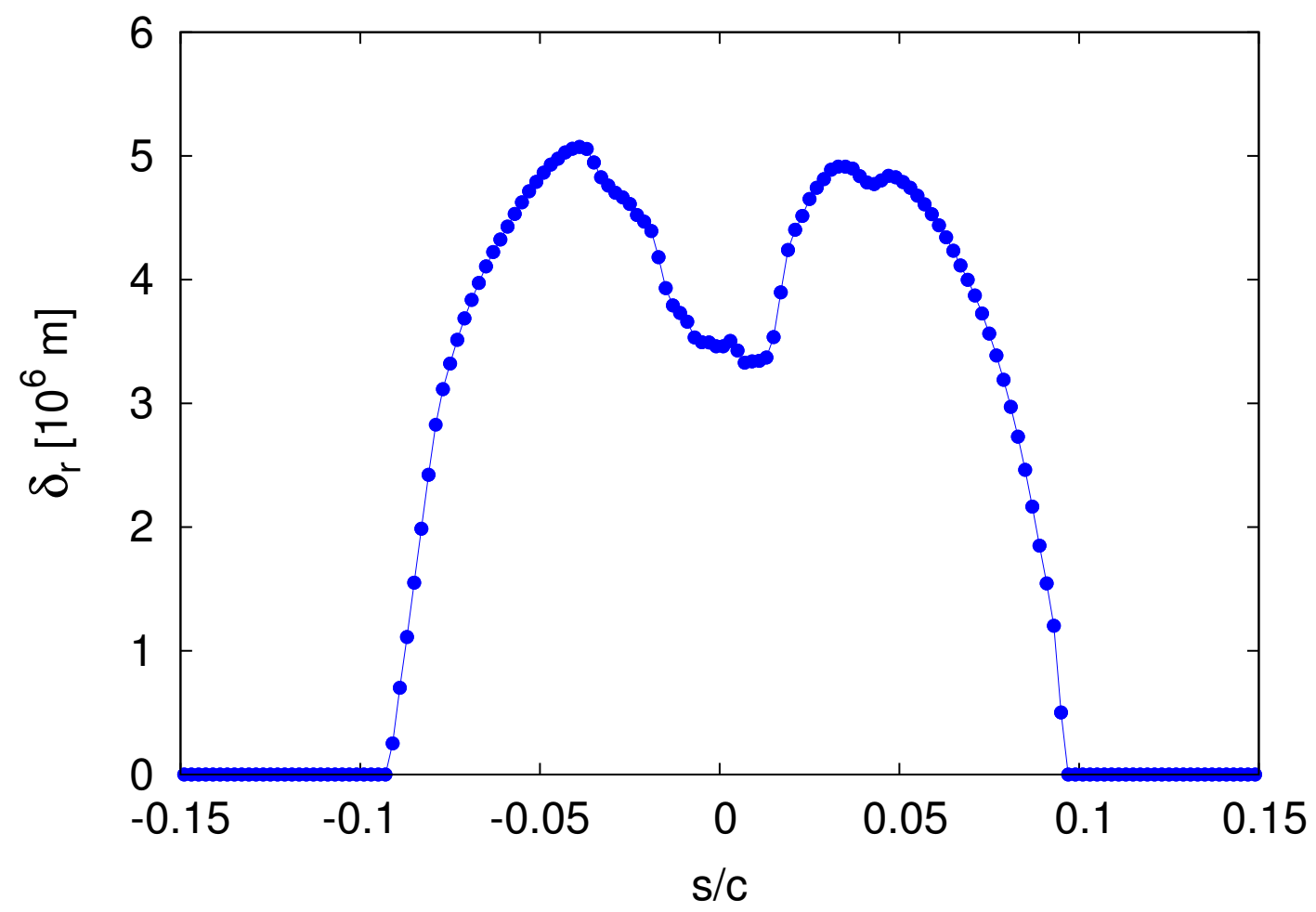

(b) Espessura do filme

Figura 3.7: Modelo de filme contínuo - Espessura e Vazão de Água Residual - Caso 67A 


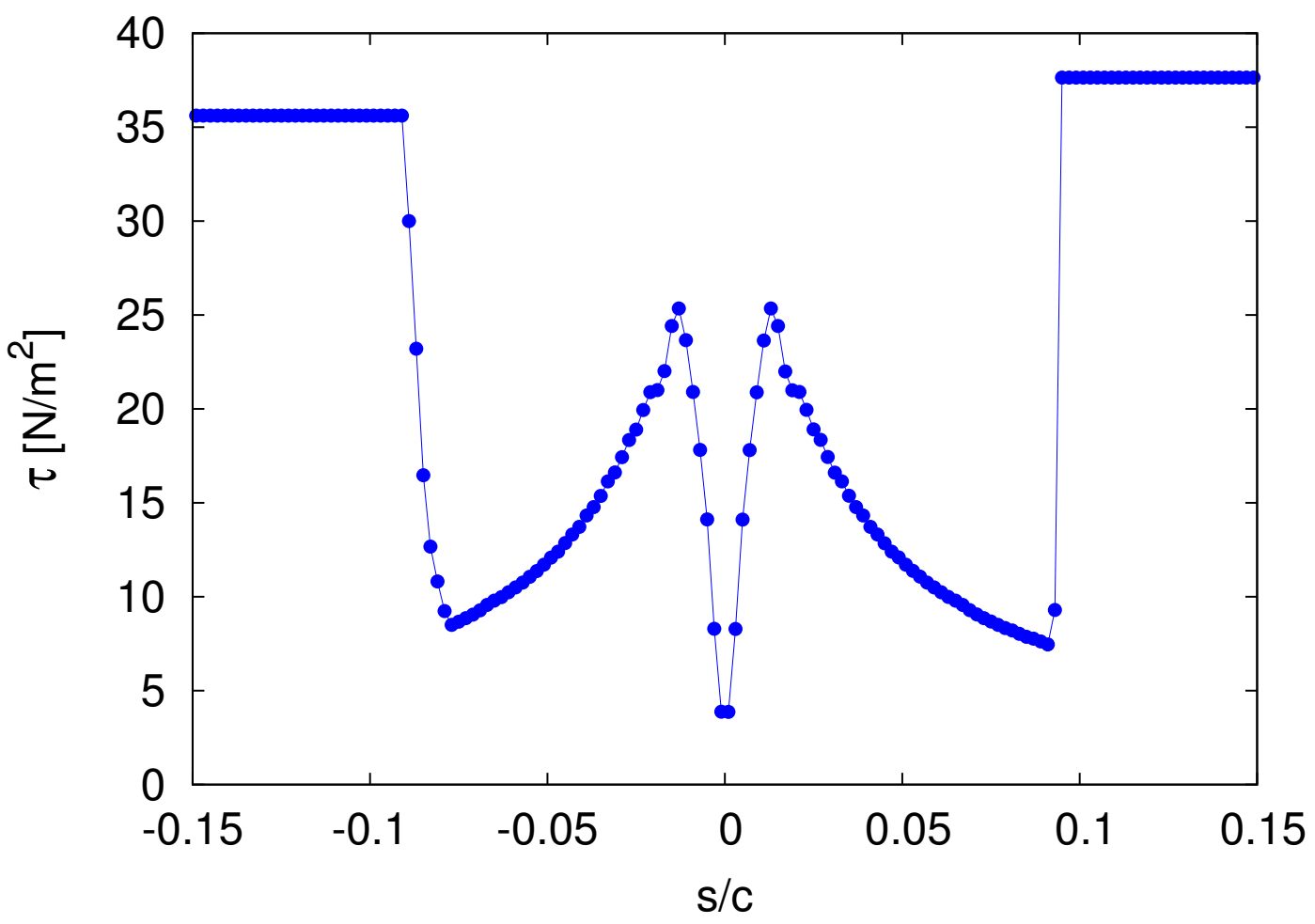

(a) Tensão de cisalhamento

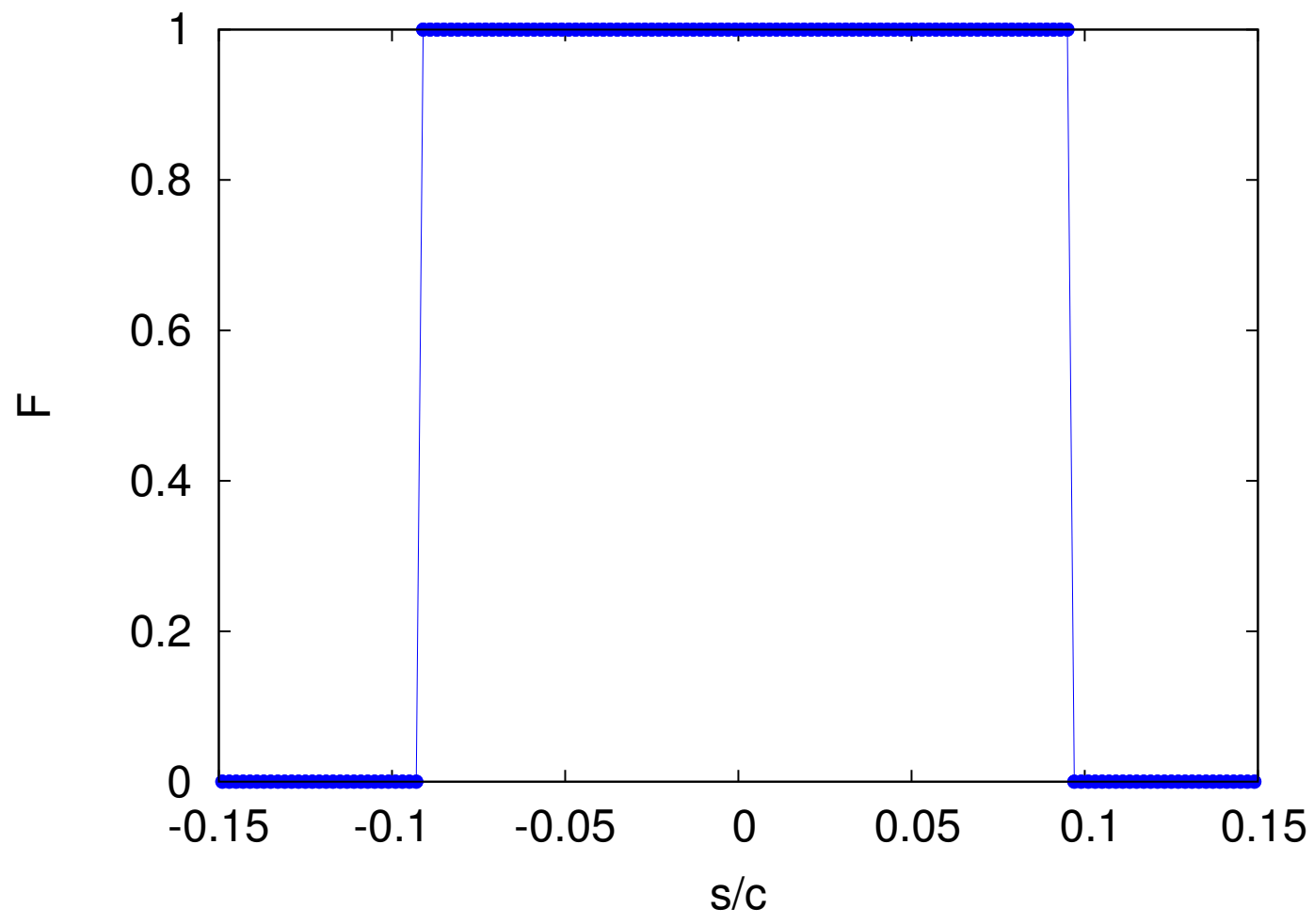

(b) Fator de molhabilidade

Figura 3.8: Modelo de filme contínuo - Cisalhamento e Molhabilidade - Caso 67A 


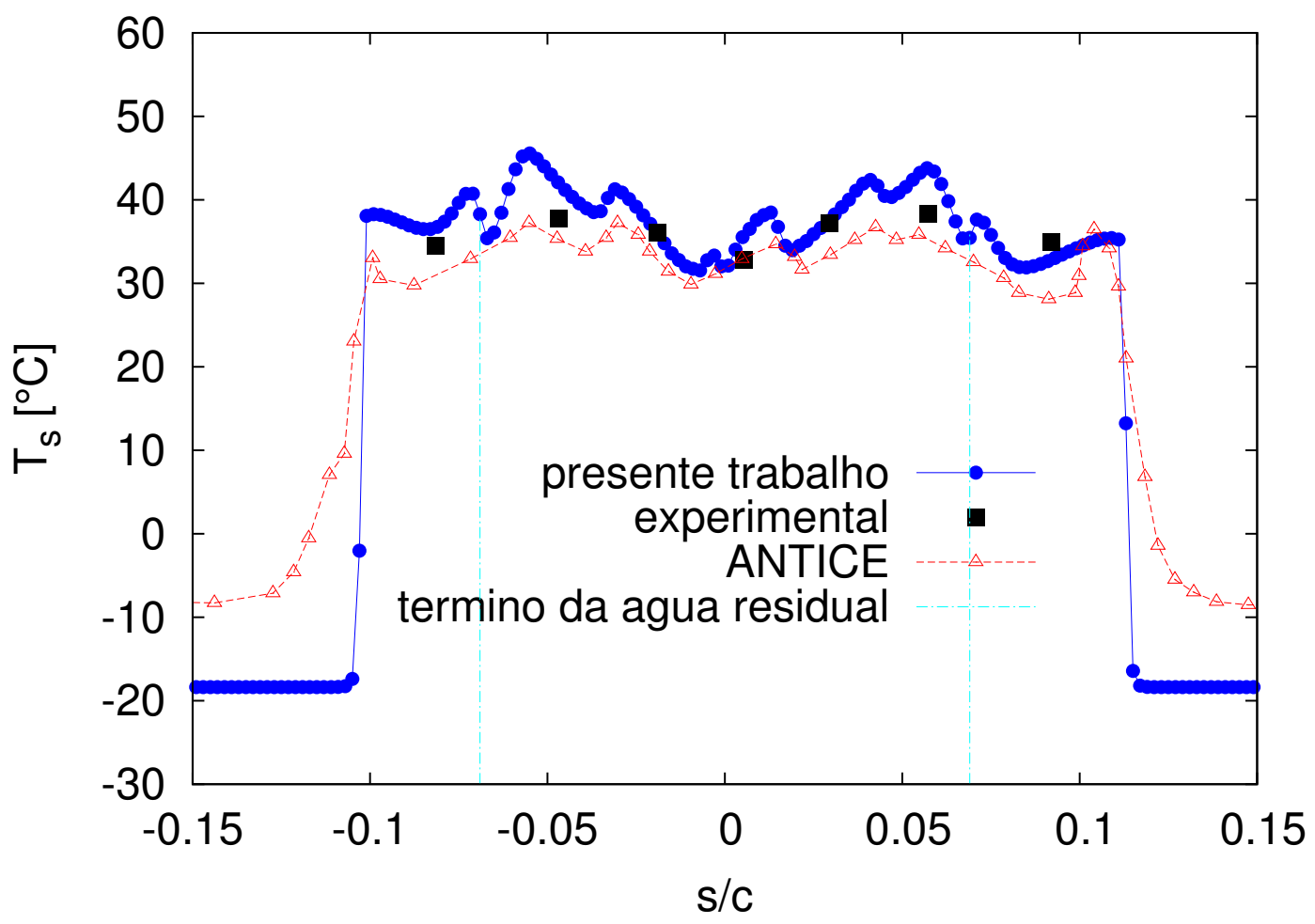

(a) Temperatura da superfície sólida - comparação com ANTICE

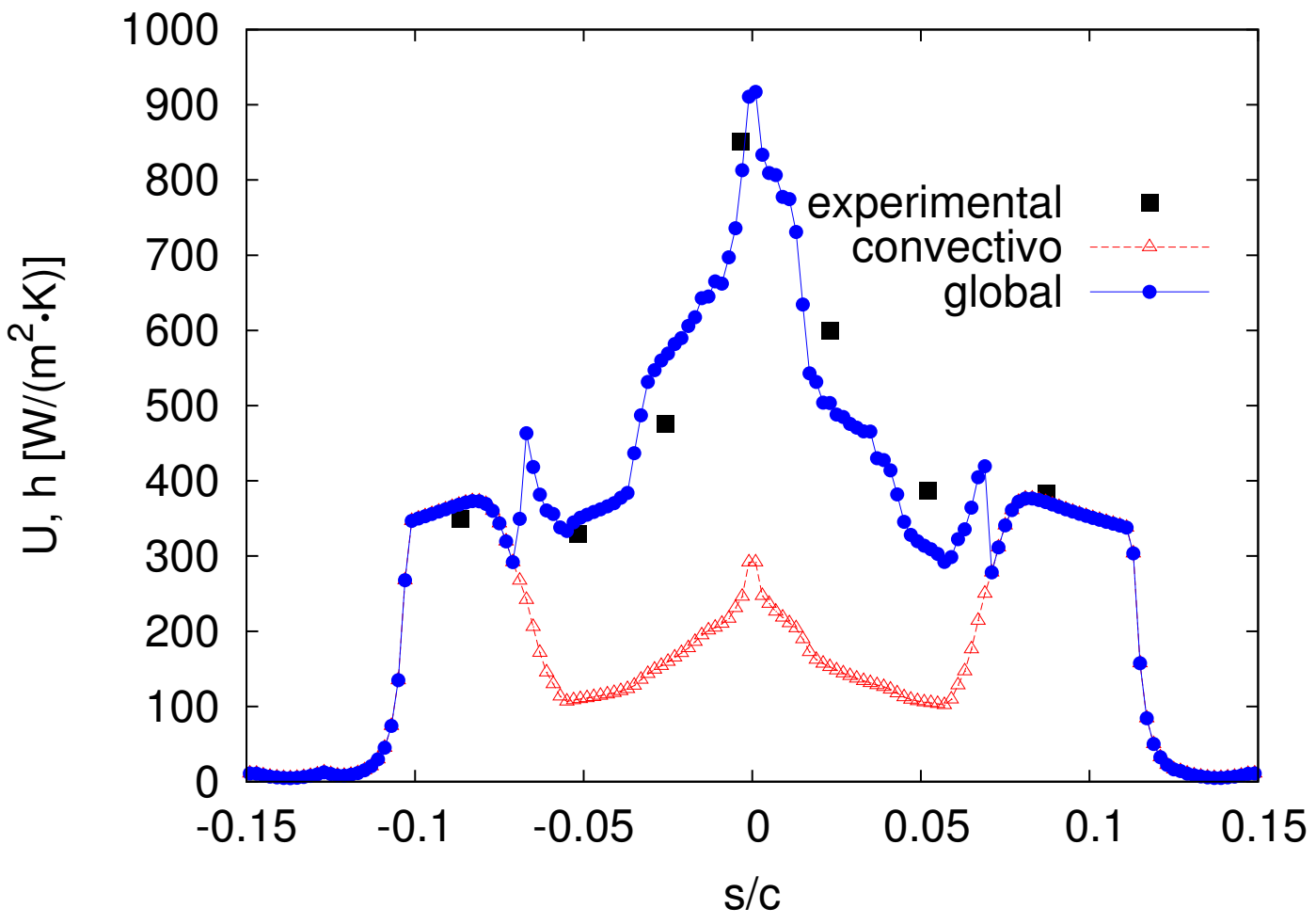

(b) Coeficiente de transferência de calor global e convectivo

Figura 3.9: Modelo de filetes - Temperaturas e Transferência de Calor - Caso 67A 


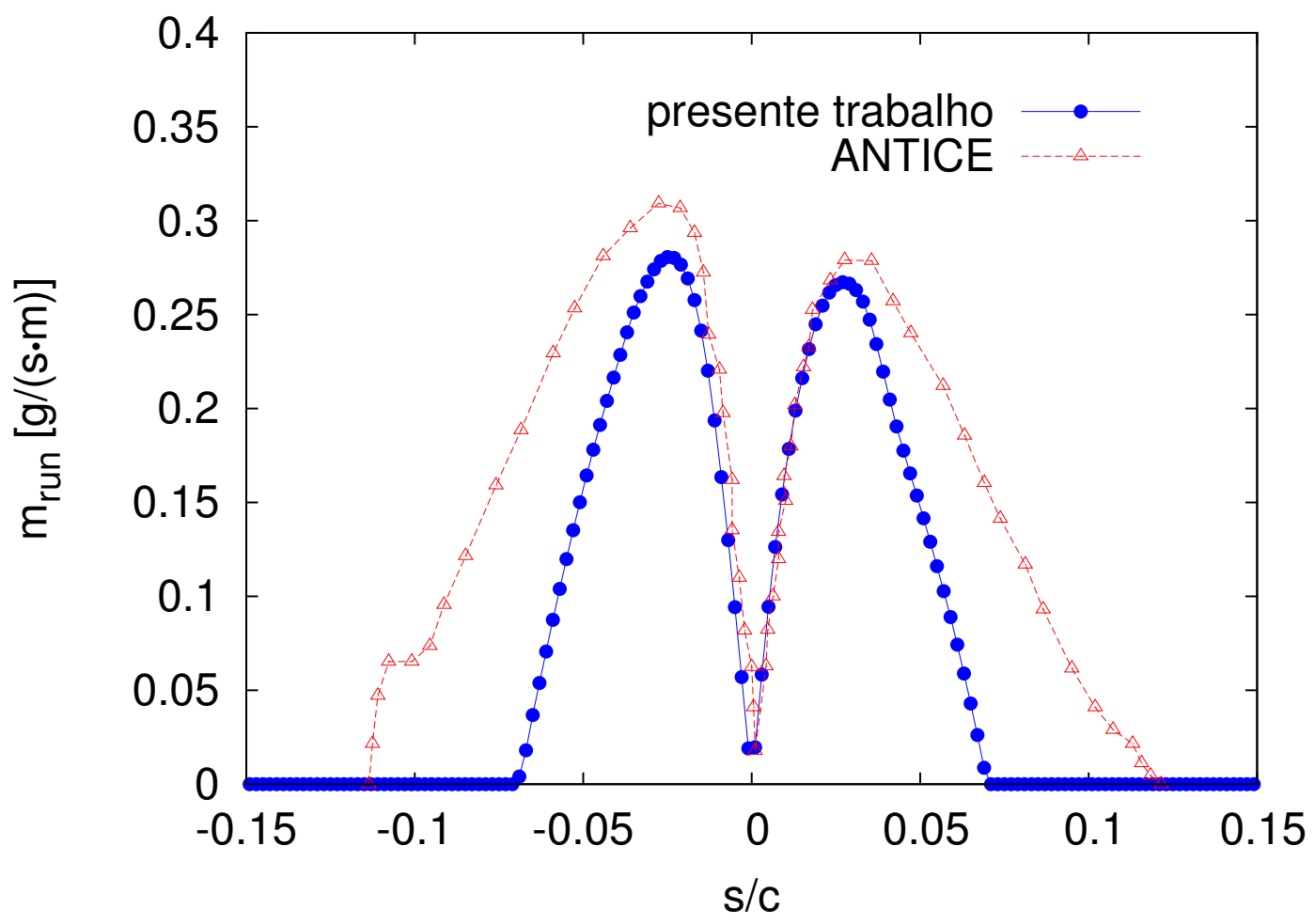

(a) Fluxo de água residual

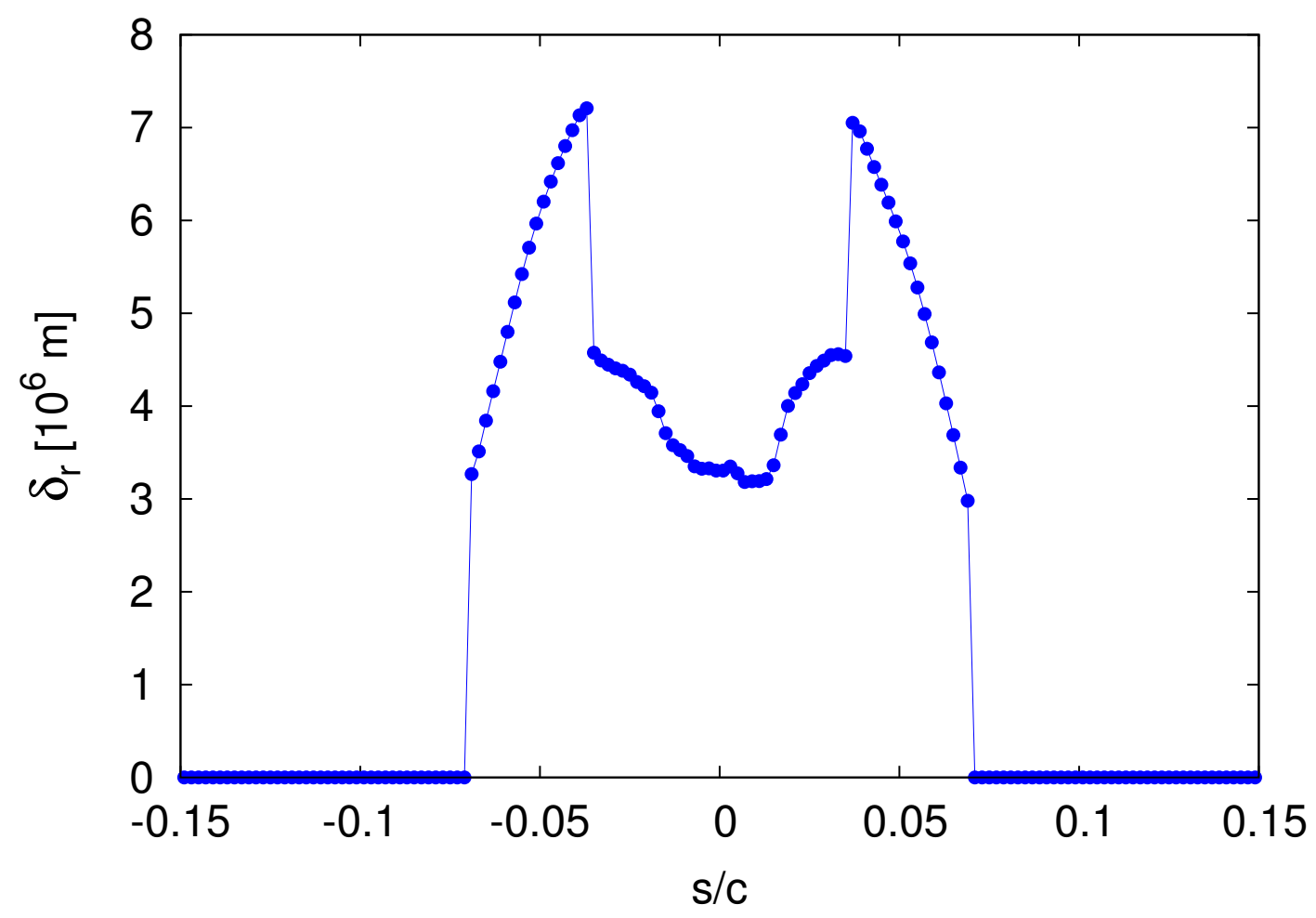

(b) Espessura do filme e dos filetes

Figura 3.10: Modelo de filetes - Espessura e Vazão de Água Residual - Caso 67A 


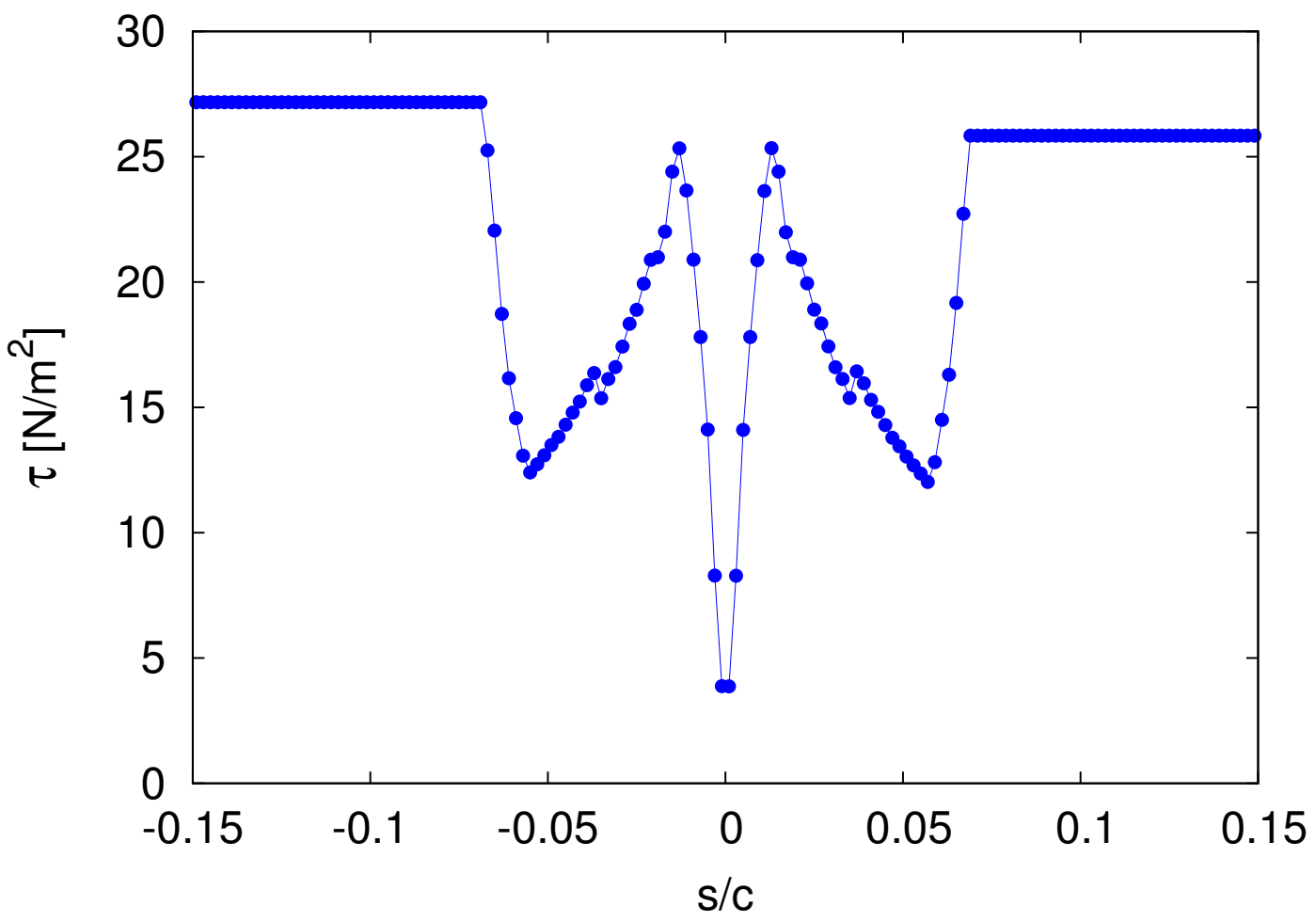

(a) Tensão de cisalhamento

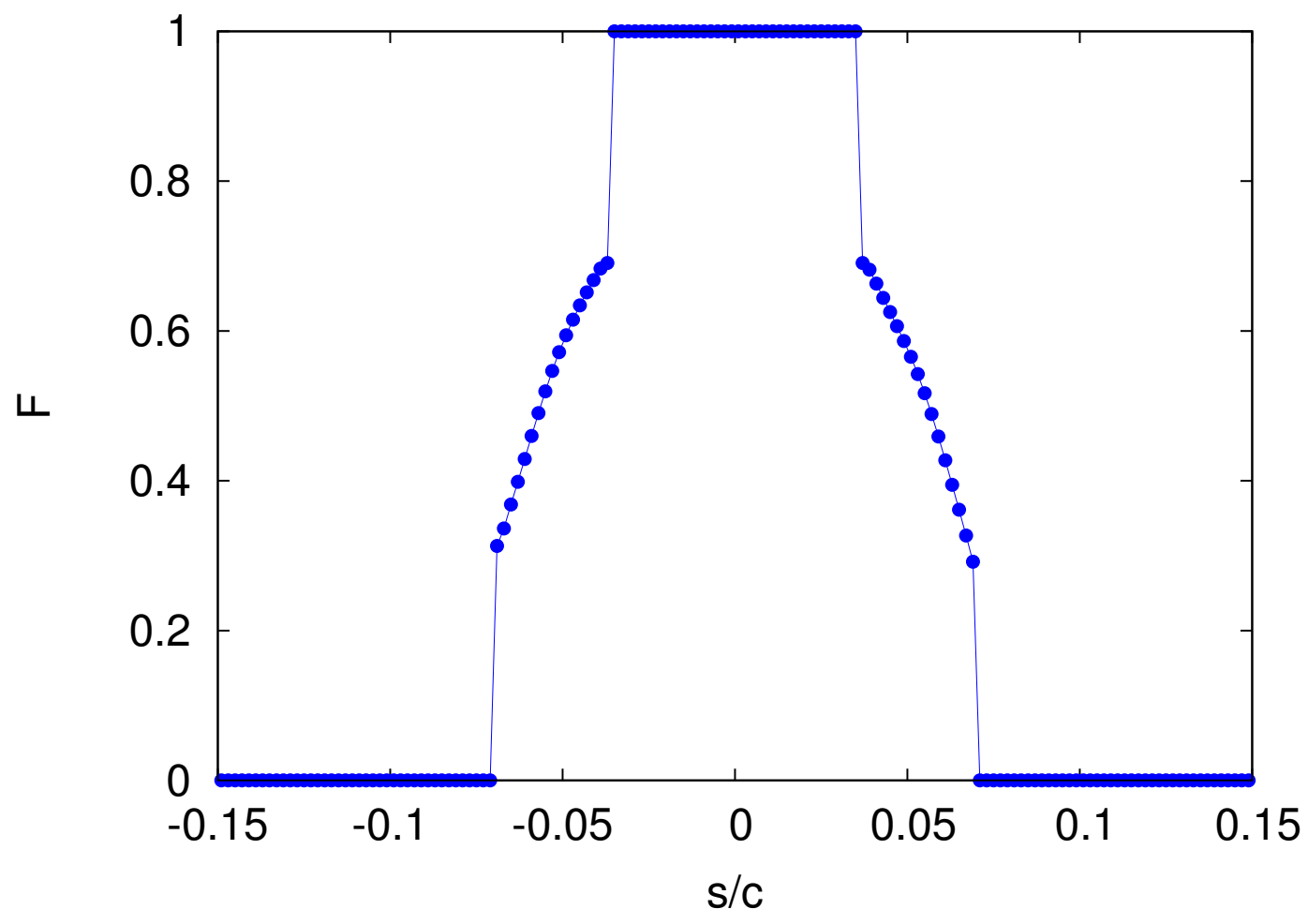

(b) Fator de molhabilidade

Figura 3.11: Modelo de filetes - Cisalhamento e Molhabilidade - Caso 67A 


\section{MODELAGEM DAS \\ CAMADAS-LIMITE DINÂMICA E TÉRMICA DO ESCOAMENTO EM TORNO DE AEROFÓlIOS COM Sistema Térmico de ANTIGelo}

$\mathrm{Na}$ simulação de escoamento em torno de aerofólios com sistemas térmicos de antigelo, a transferência de calor e massa do da superfície do aerofólio para o escoamento externno determina a demanda térmica necessária para prevenir o congelamento das gotículas de água captadas pela a superfície do aerofólio. Diferentemente da simulação de formação de gelo, a superfície aquecida possui uma temperatura de superfície acima daquela do escoamento ao longe $T_{s}>T_{\infty}$, o que influencia diretamente o fluxo de calor por convecção $\dot{q}_{c o n v}^{\prime \prime}=h_{a r} \cdot \Delta T_{\text {int }}$. Nas áreas molhadas pelo escoamento de água líquida, a evaporação intensifica a transferência de calor e causa temperaturas mais baixas do que nas regiões secas. Como definido na Eq. (2.12), o fluxo mássico de evaporação $\dot{m}_{\text {evap }}$ depende do coeficiente de transferência de calor $h_{a r}$ e da diferença de temperatura $\Delta T_{\text {int }}$. Assim, a magnitude da diferença de temperatura $\Delta T_{\text {int }}$, a extensão da região molhada, bem como o acoplamento entre a transferência de calor e a de massa, tornam os resultados de $T_{s}$ e $\dot{m}_{\text {agua }}$ sensíveis à estimativa da distribuição de $h_{a r}$.

Silva (2002) aplicou a análise integral de camadas-limite térmica à simulação de sistemas de antigelo. O presente autor considerou o escoamento, nos regimes laminar e turbulento, com gradiente de pressão sobre superfície permeável, nãoisotérmica e lisa bem como uma região de transição laminar-turbulenta.

Na simulação numérica de formas de gelo em aerofólios, a convecção de calor é importante para a determinação da forma do gelo tipo glaze, que é definido no Anexo $\mathrm{A}$, que se forma em temperaturas mais próximas de $0^{\circ} \mathrm{C}$ e em nuvem com valores altos de $L W C$, já que a convecção de calor é o principal mecanismo para transferir a entalpia de solidificação da água para o escoamento. A transferência 
Tabela 4.1: Condições de contorno para a avaliação da convecção de calor e de massa em torno de aerofólios

\begin{tabular}{lll}
\hline Condição de Contorno & Sistema Antigelo & Formação de Gelo \\
\hline Rugosidade da superfície & aproximadamente lisa & $\begin{array}{l}\text { protuberâncias e grãos } \\
\text { de gelo }\end{array}$ \\
$\begin{array}{l}\text { Diferença de temperatura } \\
\Delta T_{\text {int }}\end{array}$ & $\begin{array}{l}\text { significativa, superfície } \\
\text { aquecida }\end{array}$ & $\begin{array}{l}\text { equilíbrio, superfície } \\
\text { adiabática }\end{array}$ \\
$\begin{array}{l}\text { Gradiente de Pressão } \\
d P / d s\end{array}$ & $\begin{array}{l}\text { depende do aerofólio e } \\
\text { do ângulo de ataque }\end{array}$ & $\begin{array}{l}\text { depende do aerofólio, do } \\
\text { ângulo de ataque e da } \\
\text { forma do gelo }\end{array}$ \\
$\begin{array}{l}\text { Gradiente de } \\
\text { Temperatura } d T_{s} / d s\end{array}$ & superfície não-isotérmica & $\begin{array}{l}\text { superfície } \\
\text { aproximadamente } \\
\text { isotérmica }\end{array}$ \\
Transpiração $\dot{m}_{\text {evap }}$ & significativa, $T_{s}>40^{\circ} \mathrm{C}$ & desprezível, $T_{s} \leq 0^{\circ} \mathrm{C}$ \\
\hline
\end{tabular}

de calor por convecção não é tão importante na formação de gelo do tipo rime, que também é descrito no Anexo $A$, que cresce em temperaturas bem mais baixas que $0^{\circ}$ $\mathrm{C}$ e com valores baixos de $L W C$. Nesse último caso, o congelamento ocorre quase que instantaneamente no momento do impacto.

Para previsão de formação de gelo, os códigos LEWICE, ONERA2D e TRAJICE2 (WRIGHT; GENT; GUFFOND, 1997) estimam o coeficiente de transferência de calor por convecção $h_{a r}$ por meio de procedimento integral para o escoamento laminar e turbulento em torno do aerofólio. Uma abordagem similar é utilizada também para simular a formação de gelo em torno de cabos elétricos em regiões frias (MAKKONEN, 1985). Em comum, esses autores resolveram as equações integrais de camada-limite para o escoamento com gradiente de pressão sobre superfície impermeável, isotérmica e plenamente rugosa nos regimes laminar e turbulento, considerando uma transição laminar-turbulenta abrupta e disparada por rugosidade. Foi encontrado apenas dois grupos de pesquisadores que aplicaram o método de diferenças finitas de Cebeci (1971) para calcular $h_{a r}$ e $C_{f}$ sobre formas de gelo em aerofólios (CEBECI, 1989a; HAVUGIMANA et al., 2002).

A Tabela 4.1 apresenta as condições de contorno para o cálculo da camadalimite térmica em torno de um aerofólio sujeito à formação de gelo ou equipado com sistema de antigelo. Como as perturbações na camada-limite são diferentes nos dois casos, é necessário ter equações integrais distintas. No entanto, essa não é a prática da indústria aeronáutica e de alguns pesquisadores (WRIGHT, 1999; AL-KHALIL et al., 2001; GENT et al., 2003). Na falta de dados experimentais, esses autores aplicaram os modelos próprios para a avaliação da convecção sobre formas de gelo à 
estimativa da transferência de calor e de massa em torno de aerofólios protegidos. Para tentar melhorar as previsões da distribuição de $h_{a r}$, uns adotaram, sem sucesso, as expressões de Ambrok (1957) para o escoamento turbulento (MORENCY; TEZOK; PARASCHIVOIU, 1999b), e outros partiram para o uso de métodos de diferenças finitas (MORENCY; TEZOK; PARASCHIVOIU, 1999a; HENRY, 1992). Uma discussão sobre a literatura de sistema antigelo podem ser encontrados na revisão bibliográfica do Capítulo 2.

Apesar da estimativa do coeficiente de transferência de calor $h_{a r}$ ser importante para a avaliação da transferência de calor em aerofólios com sistema antigelo e com formação de gelo, observa-se que:

1) os procedimentos encontrados na literatura tem dificuldades de avaliar $h_{a r}$ com a precisão requerida pela aplicação de engenharia devido à limitações da modelagem matemática ou das hipóteses adotadas;

2) a aplicação da solução das equações de Navier-Stokes por média de Reynolds à solução da transferência de calor e massa em torno de aerofólios com sistema antigelo, conhecidas pela sigla RANS, foi tentada por alguns pesquisadores como aqueles que:

- aplicam as equações RANS simplificadas, na forma de diferenças finitas, para camadas-limite térmica e de quantidade de movimento (CEBECI; SMITH, 1974; MORENCY; TEZOK; PARASCHIVOIU, 1999a; HENRY, 1992);

- desenvolveram ferramentas numéricas RANS e tridimensionais utilizando a abordagem de elementos finitos com modelos de turbulência com duas ou mais equações (CROCE; BEAUGENDRE; HABASHI, 2002).

\subsection{Modelagem da Camada-Limite aplicada a Aerofó- lios com Sistemas de Antigelo}

As características principais dos procedimentos integrais, para a avaliação das camadas-limite térmicas e de quantidade de movimento, são a simplicidade de cálculo e a precisão satisfatória das previsões para a maioria das aplicações de engenharia. Em contrapartida, os procedimentos integrais não consideram efeitos da história do escoamento, já que o cálculo depende somente das propriedades locais do escoamento em torno do aerofólio. 
Enquanto alguns procedimentos integrais adotam a forma do perfil de velocidade dentro da camada-limite, outros desconsideram totalmente os efeitos do perfil de velocidades na taxa de crescimento da camada-limite. É, também, comum que o sistema de equações integrais seja fechado por uma correlação obtida por meio de análise dimensional, de evidências empíricas, de uma família de soluções analíticas ou de algum tipo de analogia.

A Tabela 4.2 apresenta os modelos matemáticos integrais implementados no presente trabalho. Alguns dos procedimentos integrais também são utilizados nos códigos clássicos como LEWICE, ONERA2D, TRAJICE2 e CANICE B. Todos os modelos implementados por Silva (2002) são utilizados no presente trabalho.

Tabela 4.2: Procedimentos de análise integral de camada-limite implementados

\begin{tabular}{|c|c|c|c|}
\hline $\begin{array}{l}\text { Camada } \\
\text { Limite }\end{array}$ & $\begin{array}{l}\text { Parâmetro } \\
\text { Estimado }\end{array}$ & $\begin{array}{l}\text { Modelo } \\
\text { (Autor) }\end{array}$ & Aplicado por \\
\hline$\delta_{2, l a m}$ & $C_{f, l a m}$ & (THWAITES, 1949) & $\begin{array}{l}\text { ONERA2D, } \\
\text { CANICE B e Silva } \\
(2002)\end{array}$ \\
\hline$\delta_{2, \text { turb }}$ & $C_{f, \text { turb }}$ & $\begin{array}{l}\text { (KAYS; CRAWFORD, } \\
\text { 1993) }\end{array}$ & $\begin{array}{l}\text { LEWICE, TRAJICE2, } \\
\text { ONERA2D, } \\
\text { CANICE B e Silva } \\
(2002)\end{array}$ \\
\hline \multirow[t]{2}{*}{$\Delta_{4, l a m}$} & $\mathrm{St}_{\mathrm{lam}}$ & $\begin{array}{l}\text { isotérmico (SMITH; } \\
\text { SPALDING, 1958) }\end{array}$ & $\begin{array}{l}\text { LEWICE, TRAJICE2, } \\
\text { ONERA2D, } \\
\text { CANICE B e Silva } \\
(2002)\end{array}$ \\
\hline & & $\begin{array}{l}\text { sobreposição } \\
\text { (LIGHTHILL, 1950; } \\
\text { SPALDING, 1958) }\end{array}$ & presente trabalho \\
\hline$\Delta_{2, \text { lam }}$ & $\mathrm{St}_{\text {lam }}$ & $\begin{array}{l}\text { não-isotérmico } \\
\text { (AMBROK, 1957) }\end{array}$ & Silva (2002) \\
\hline \multirow[t]{3}{*}{$\Delta_{2, \text { turb }}$} & $\mathrm{St}_{\text {turb }}$ & $\begin{array}{l}\text { não-isotérmico } \\
\text { (AMBROK, 1957) }\end{array}$ & $\begin{array}{l}\text { CANICE B e Silva } \\
(2002)\end{array}$ \\
\hline & & $\begin{array}{l}\text { sobreposição } \\
\text { (REYNOLDS; KAYS; } \\
\text { KLINE, 1958a) }\end{array}$ & presente trabalho \\
\hline & & $\begin{array}{l}\text { isotérmico } \\
\text { (MORETTI; KAYS, } \\
\text { 1965) }\end{array}$ & presente trabalho \\
\hline \multirow[t]{2}{*}{$\delta_{2, \text { turb }}$} & $C_{t, \text { turb }}$ e St turb & Analogia de Colburn & Silva (2002) \\
\hline & & $\begin{array}{l}\text { Analogias de Kármán, } \\
\text { Prandtl e Kays }\end{array}$ & presente trabalho \\
\hline
\end{tabular}

A estimativa das propriedades da camada-limite dinâmica e térmica ao longo da região de transição laminar-turbulenta é feita por combinação linear, de St e $C_{f}$ nos regimes laminar e turbulento, a partir do início (onset) da região de transição, onde 
há a formação dos primeiros núcleos (spots) turbulentos, até o término da região de transição, onde o escoamento é plenamente turbulento. Os tipos de função-peso utilizadas para combinar linearmente $\mathrm{St}_{\text {lam }}$ com St $t_{\text {turb }}$ e, também, $C_{f, \text { lam }} \operatorname{com} C_{f, \text { turb }}$ são mostradas na Tabela 4.3.

Tabela 4.3: Modelos de Evolução da Intermitência na Região de Transição Laminar-Turbulenta

\begin{tabular}{lll}
\hline $\begin{array}{l}\text { Função-peso da } \\
\text { combinação linear }\end{array}$ & Autor & Aplicado por \\
\hline $\begin{array}{l}\text { Probabilística } \\
\text { (distribuição normal) }\end{array}$ & $\begin{array}{l}\text { Reynolds, Kays e Kline } \\
(1958 \mathrm{~b})\end{array}$ & $\begin{array}{l}\text { Silva (2002) e presente } \\
\text { trabalho }\end{array}$ \\
Intermitência $(\gamma)$ & Chen e Thyson (1971) & $\begin{array}{l}\text { CANICE FD, } \\
\text { Fortified-LEWICE e presente } \\
\text { trabalho }\end{array}$ \\
& & $\begin{array}{l}\text { Abu-Ghannam e Shaw (1980) } \\
\text { presente trabalho }\end{array}$ \\
Intermitência $(\gamma)$ & Makkonen (1985), Wright & $\begin{array}{l}\text { LEWICE, ONERA, TRAJICE2, } \\
\text { CANICE B e presente trabalho }\end{array}$ \\
\hline
\end{tabular}

Geralmente os códigos de simulação de formação de gelo e antigelo utilizam uma função-peso tipo degrau para representar uma transição abrupta entre o escoamento laminar e o turbulento:

$$
\text { transição abrupta: }\left\{\begin{array}{lll}
\gamma(s)=0 & \text { se } & s<s_{t r} \\
\gamma(s)=1 & \text { se } & s \geq s_{t r}
\end{array}\right.
$$

As únicas exceções encontradas na literatura são os códigos CANICE FD (MORENCY; TEZOK; PARASCHIVOIU, 1999a) e Fortified-LEWICE (CEBECI, 1989a; CEBECI; CHEN; ALEMDAROGLU, 1991). Estes códigos usam análises diferenciais de camada-limite, que adotam o modelo de turbulência de Cebeci e Smith (1974) e aumentam a viscosidade aparente turbulenta por meio da função de intermitência de Chen e Thyson (1971). O código de Henry (1992) também usa o método de diferenças finitas, mas não há informações sobre quais foram os modelos de turbulência e de transição adotados.

No programa de simulação de antigelo de Silva (2002) foi implementado um modelo probabilístico da região de transição laminar-turbulenta, que representa a probabilidade de aparecimento de núcleos turbulentos como uma distribuição normal acumulada em função da posição $s$. No presente trabalho foram implementadas todas as funções-peso apresentadas na Tabela 4.3.

A avaliação diferencial na camada-limite do escoamento de Cebeci (1971) foi aplicada, com sucesso, à simulação de sistema antigelo por Morency, Tezok e Pa- 
raschivoiu (1999a) no programa CANICE FD. No entanto, estes autores utilizaram expressões empíricas e algébricas para estimar o início e o término da região de transição.

Henry (1992) avaliou, por meio de diferenças finitas, o comportamento térmico da camada-limite em torno de um aerofólio com sistema de proteção contra a formação de gelo operando no regime transitório (degelo). Porém, o autor não informou qual código de solução do escoamento foi utilizado nem como foram estimados o início e o término da região de transição laminar-turbulenta.

O código Fortified-LEWICE, na versão implementada por Cebeci (1989a), também usou o modelo de diferenças finitas de Cebeci e Smith (1974) para estimar o arrasto e a transferência de calor sobre a superfície rugosa e de geometria irregular (chifre) do gelo formado no aerofólio.

\subsection{Análise Integral das Camada-Limites Dinâmica e Térmica - Trabalho Anterior}

Em Silva (2002), as equações de camada-limite dinâmica e térmica foram simplificadas considerando:

- o escoamento unidimensional;

- regime permanente;

- perfis de velocidade:

- similaridade no regime laminar

- perfil de potência (1/7) no regime turbulento

- gradiente de pressão moderado $(d P / d s)$ e

- superfície lisa, não-isotérmica e impermeável.

Essas hipóteses resultam nas Eqs. (4.2) e (4.8). Observe que o fluxo mássico de evaporação é desconsiderado nessas equações, todavia, o efeito do insuflamento de vapor d'água é estimado por meio das Eqs. (2.17) e (2.18), que, por sua vez, influenciam o cálculo da temperatura da água líquida e da superfície sólida do aerofólio. $A$ solução da camada-limite térmica fornece o valor de St sem o efeito do insuflamento para estimar $\dot{m}_{\text {evap }}^{\prime \prime}$ e $\mathrm{B}_{h}$, que são utilizados para calcular St* considerando o efeito do insuflamento. 
Para estimar as distribuições de $C_{f}$ e $h_{a r}$ em torno do aerofólio equipado com um sistema antigelo eletrotérmico, Silva (2002) propôs a implementação de um conjunto de equações para avaliação de espessura de quantidade de movimento $\delta_{2}$ e espessura de entalpia $\Delta_{2}$, nos regimes laminar e turbulento. Os resultados da implementação do cálculo de camada-limite, proposta por Silva (2002), foram comparados com dados experimentais para vários regimes de operação do sistema antigelo (SILVA; SILVARES; ZERBINI, 2007b).

\subsubsection{Transferência de Quantidade de Movimento}

No modelo de Silva (2002), a camada-limite de quantidade de movimento é convenientemente expressa numa equação de espessura de quantidade de movimento, na forma adimensional (KAYS; CRAWFORD, 1993):

$$
\frac{C_{f}}{2}=\frac{d \delta_{2}}{d s}+\delta_{2} \cdot\left[\left(2+\frac{\delta_{1}}{\delta_{2}}\right) \cdot \frac{1}{u_{e}} \cdot \frac{d u_{e}}{d s}\right]
$$

Com base na aproximação de Thwaites (1960), Kays e Crawford (1993) integraram a Eq. (4.2) para obter a espessura de quantidade de movimento no regime laminar:

$$
\delta_{2, \text { lam }}=\frac{0,664 \cdot \nu_{a r}^{1 / 2}}{u_{e}^{2,84}} \cdot\left(\int_{s_{s t a g}}^{s_{t r}} u_{e}^{4,68} d s\right)^{1 / 2}
$$

O coeficiente de atrito laminar $C_{f, l a m}$ é avaliado em função do parâmetro de gradiente de pressão $\lambda$ por meio da interpolação, também inspirada em Thwaites (1960), desenvolvida por Cebeci e Bradshaw (1984):

$$
C_{f, l a m}=\frac{2 \cdot I(\lambda)}{\operatorname{Re}_{\delta_{2}}}
$$

onde

$$
I(\lambda) \begin{cases}=0,225+1,61 \cdot \lambda-3,75 \cdot \lambda^{2}+5,24 \cdot \lambda^{3} & \Rightarrow 0<\lambda<0,1 \\ =0,225+1,472 \cdot \lambda-(0,0147 \cdot \lambda) /(\lambda+0,107) & \Rightarrow 0>\lambda>-0,1\end{cases}
$$

A equação integral da espessura da quantidade de movimento no regime turbulento, Eq. (4.2), adotada foi aquela desenvolvida por Kays e Crawford (1993):

$$
\delta_{2, t u r b}=\left[\frac{0,0156 \cdot \nu_{a r}^{1 / 4}}{u_{e}^{4,11}} \cdot \int_{s_{t r}}^{s} u_{e}^{3,86} d s+\left(\delta_{2, t r}\right)^{5 / 4} \cdot\left(\frac{u_{e, t r}}{u_{e}}\right)^{4,11}\right]^{4 / 5}
$$


A Eq. (4.6) é avaliada com a hipótese de continuidade de $\delta_{2}$ através da transição laminar turbulenta, ou seja, $\delta_{2, t r}=\delta_{2, l a m}=\delta_{2, t u r b}$. Assim a Eq. (4.3) fornece a condição inicial para a integral na Eq. (4.6) na posição, $s_{t r}$, de início da região de transição laminar-turbulenta.

O coeficiente de atrito $C_{f}$, em função de $\mathrm{Re}_{\delta_{2, t u r b}}$, é obtido pela seguinte expressão:

$$
\frac{C_{f, t u r b}}{2}=0,0125 \cdot R e_{\delta_{2, t u r b}^{-0,25}}
$$

\subsubsection{Transferência de Calor}

Para avaliar a distribuição de $h_{a r}$ à jusante do ponto de estagnação ao longo das superfícies do intradorso e extradorso, é conveniente representar a camada-limite térmica incompressível na forma adimensional em função da espessura de entalpia $\Delta_{2}$ (KAYS; CRAWFORD, 1993):

$$
\mathrm{St}=\frac{d \Delta_{2}}{d s}+\Delta_{2} \cdot\left(\frac{1}{u_{e}} \cdot \frac{d u_{e}}{d s}+\frac{1}{i_{0}} \cdot \frac{d i_{0}}{d s}\right)
$$

Para velocidade da borda da camada-limite, $u_{e}$, propriedades termodinâmicas e temperatura de superfície constantes, a transferência de calor no regime laminar pode ser aproximada por analogia com a transferência de quantidade de movimento:

$$
\mathrm{Nu}=\mathrm{St} \cdot \mathrm{Re} \cdot \operatorname{Pr}=0,332 \cdot \operatorname{Pr}^{0,5} \cdot \operatorname{Re}^{0,5}
$$

A partir das Eqs. 4.8 e 4.9, da hipótese de propriedades termodinâmicas constantes e gás perfeito,$\Delta i_{0}=c_{p} \cdot \Delta T$, Ambrok (1957) desenvolveu uma expressão para avaliar $h_{a r}$ no regime laminar causado pelo escoamento de ar sobre superfícies não-isotérmicas com gradiente de pressão moderado:

$$
\mathrm{Nu}_{\text {lam }}=0,3 \cdot \operatorname{Re}_{s} \cdot \Delta T \cdot\left(\int_{s_{\text {stag }}}^{s_{s t r}} \frac{u_{e} \cdot \Delta T^{2}}{\nu_{a r}} d s\right)^{-1 / 2}
$$

na qual $\Delta T$ é a diferença de temperatura entre a temperatura de superfície da interface sólido-gás ou líquido-gás $T_{\text {int }}$ e a de recuperação, $T_{\text {rec }}$. O cálculo de $\Delta_{2, t u r b}$ por meio de Eq. (4.14) requer o conhecimento de $\Delta_{2, l a m}$, na posição de início da região de transição, como condição inicial. Assim, a simplificação de Eq. (4.8) resulta em (AMBROK, 1957):

$$
\operatorname{Re}_{\Delta_{2, \text { lam }}}=\frac{0,83}{\Delta T} \cdot\left(\int_{s_{\text {stag }}}^{s_{\text {tr }}} \frac{u_{e} \cdot \Delta T^{2}}{\nu_{a r}} d s\right)^{1 / 2}
$$


No ponto de estagnação do aerofólio, com aproximação de escoamento similar $u_{e}=s$ e a Eq. (4.15), Smith e Spalding (1958) aproximou o coeficiente de transferência de calor por convecção por:

$$
\mathrm{Nu}_{s t a g}=\left[0,\left.246 \cdot \operatorname{Re}_{\infty} \cdot \frac{d\left(u_{e} / V_{\infty}\right)}{d(s / c)}\right|_{s=s_{\text {stag }}}\right]^{1 / 2}
$$

No regime turbulento, $h_{a r}$ é avaliado por meio da expressão de Ambrok (1957), Kays e Crawford (1993):

$$
\mathrm{St}_{\text {turb }}=0,0125 \cdot \operatorname{Re}_{\Delta_{2, \text { turb }}}^{-0,25} \cdot \operatorname{Pr}^{-1 / 2}
$$

Como na análise da camada-limite de quantidade de movimento, é admitido que $\Delta_{2}$ é uma função contínua através da região de transição. Logo, com a Eq. (4.11) e a hipótese de $\Delta_{2, t r}=\Delta_{2, \text { lam }}=\Delta_{2, \text { turb }}$, a espessura de entalpia no regime turbulento é avaliada por:

$$
\begin{aligned}
\operatorname{Re}_{\Delta_{2}, \text { turb }} \cdot \Delta T= & \\
& {\left[0,0156 \cdot \operatorname{Pr}^{-1 / 2} \cdot \mu_{a r}^{-1} \cdot \int_{s_{t r}}^{s} G \cdot \Delta T^{1,25} d s+\left(\operatorname{Re}_{\Delta_{2, t r}} \cdot \Delta T_{t r}\right)^{1,25}\right]^{0,8} }
\end{aligned}
$$

\subsection{Análise Integral das Camadas-Limite Dinâmica e Térmica - Presente Trabalho}

Na presente tese, foram implementados outros procedimentos de avaliação da camada-limite térmica para estimar a distribuição de $h_{a r}$ no escoamento bifásico em torno do aerofólio. O objetivo é que o presente código possua a capacidade de estimar a transferência de calor em uma faixa de condições operacionais do sistema antigelo, como definido na Tabela 4.2. Assim, a implementação de alguns modelos selecionados, que tem hipóteses e limitações de aplicabilidade diferentes, pode resultar em maior flexibilidade na utilização da ferramenta numérica e, em alguns casos, maior precisão dos resultados.

A comparação entre resultados de modelos diferentes, para os mesmos casos de teste, possibilita uma análise dos efeitos das hipóteses, adotadas em cada modelo, no resultado final. Desse modo, pode haver entendimento dos fenômenos físicos mais importantes para a estimativa da transferência de calor. 


\subsubsection{Escoamento laminar sobre superfície isotérmica}

De forma análoga ao trabalho de Thwaites (1949) para a avaliação da espessura de quantidade de movimento $\delta_{2}$ e estimativa de coeficiente de atrito $C_{f}$, Smith e Spalding (1958) desenvolveram um procedimento de avaliação da camada-limite térmica do escoamento laminar sobre superfície isotérmica, que:

1) admite o número de Prandtl, Pr, constante;

2) não considera os efeitos da forma ou da espessura da camada-limite de velocidade;

3) admite que a taxa de crescimento da espessura da camada-limite térmica só depende das condições locais do escoamento;

A última consideração, é a hipótese crucial do modelo (SMITH; SPALDING, 1958), na qual os autores admitem que as soluções analíticas para os escoamentos sobre cunha (wedge flows ou Falkner-Skan) são aplicáveis também a escoamentos com gradiente de pressão variável, ou seja, quando $u_{e}$ é uma função de $s$.

A partir dessas hipóteses e de análise dimensional, Smith e Spalding (1958) concluíram que a espessura de condução $\Delta_{4}$ pode ser representada por:

$$
\frac{u_{e}}{\nu} \frac{d \Delta_{4}}{d s}=f\left(\frac{\Delta_{4}^{2}}{\nu} \frac{d u_{e}}{d s}\right)
$$

na qual a função $f$ do lado esquerdo da Eq. (4.15) foi determinada a partir das soluções analíticas dos escoamentos sobre cunha, que é a família de soluções similares para vários gradientes de pressão $m$ dada por:

$$
\begin{gathered}
u_{e}=C \cdot s^{m} \\
m=\frac{s}{u_{e}} \frac{d u_{e}}{d s}=\frac{\beta / \pi}{2-\beta / \pi}
\end{gathered}
$$

Uma família de escoamentos com gradiente de pressão variável foi resolvida analiticamente por Eckert (1942) apud Smith e Spalding (1958). A partir dessas soluções, Smith e Spalding (1958) pode avaliar o desvio entre equação da espessura de condução proposta que eles propuseram e as soluções analíticas:

$$
\left[\frac{u_{e}^{2,87}}{\nu} \Delta_{4}^{2}\right]_{0}^{s}=11,68 \int_{0}^{s} u_{e}^{1,87} d s+\int_{0}^{s} u_{e}^{1,87} E_{4}\left(\frac{\Delta_{4}^{2}}{\nu} \frac{d u_{e}}{d s}\right) d s
$$


Onde a função $E_{4}$, do lado direito da Eq. (4.18), é uma correção ao desvio da solução analítica tabelada pelos autores. Devido ao pequeno valor de $E_{4}$ e para evitar a solução iterativa, este termo foi desconsiderado no presente trabalho.

No ponto de estagnação do aerofólio $(s \rightarrow 0)$, considera-se que o escoamento é similar e plano no ponto de estagnação, ou seja, $C=1$ e $m=1$ substituídos na Eq. (4.16). Com essa hipótese, a Eq. (4.18) é simplificada em:

$$
\begin{aligned}
& \Delta_{4}=\frac{2,017 \cdot s}{\sqrt{R e_{s}}} \\
& \frac{\mathrm{Nu}_{s}}{\sqrt{\mathrm{Re}_{s}}}=0,4957
\end{aligned}
$$

A solução analítica do escoamento do ponto de estagnação fornece 0,5017 para o lado direito da Eq. (4.19b), o que demonstra uma aproximação satisfatória para regiões na vizinhança da estagnação (KAYS; CRAWFORD, 1993).

Para avaliar $\Delta_{2, \text { lam }}$ sobre superfícies isotérmicas de aerofólios, Spalding (1958) elaborou um procedimento que considera: 1) Pr constante; 2) o efeito da espessura de cisalhamento $\left.\delta_{4} ; 3\right)$ e que a taxa de crescimento da espessura da camada-limite térmica só depende das condições locais. Com base em resultados analíticos, o autor concluiu que a espessura de entalpia é estimada pelo sistema de equações:

$$
\begin{gathered}
{\left[\left(u_{e} \Delta_{2, l a m}\right)^{3 / 2}\right]_{0}^{s}=0,7 \cdot \frac{k_{a r}}{\rho c p_{a r}} \int_{0}^{s}\left(\frac{u_{e}}{\delta_{4}}\right)^{1 / 2} d x} \\
\delta_{4}=\frac{u_{e}}{\left(\frac{d u_{e}}{d y}\right)_{0}}=\frac{2 \cdot \mu_{a r}}{\rho_{a r} u_{e} C_{f}}
\end{gathered}
$$

No presente trabalho, as Eqs. (4.20a) e (4.20b) são utilizadas para estimar $\Delta_{2, \text { lam }}$ quando o cálculo de $\Delta_{4}$ é feito pela Eq. (4.18). O valor de $\Delta_{2, \text { lam }}$ é necessário para fornecer a condição de continuidade na posição de início da transição laminar-turbulenta $\Delta_{2, \text { lam }}=\Delta_{2, \text { tr }}=\Delta_{2, \text { turb }}$

\subsubsection{Escoamento laminar sobre superfície não-isotérmica}

O procedimento de Ambrok (1957), para estimar a transferência de calor no escoamento laminar com gradiente de pressão sobre superfícies não-isotérmicas, apresenta desvios, em relação a solução diferencial, nas regiões onde há gradientes de pressão e temperatura significativos ou abruptos. O autor adota uma aproximação da Eq. (4.8), que admite que o termo do lado esquerdo só depende de $\operatorname{Re}_{s}$ e $\operatorname{Pr}$, ou seja, pode ser representado com $\mathrm{St}_{\text {lam }}$ do escoamento laminar sem gradiente de 
pressão e não sofre efeito dos termos $d u_{e} / d s$ e $d T_{s} / d s$.

Se a temperatura de superfície $T_{s}$ varia de forma conhecida no aerofólio, uma maneira alternativa de estimar a distribuição de $S_{\text {lam }}$ é adotar sobreposições de várias distribuições de $\mathrm{St}_{/ a m \text {,iso }}$ sobre superfícies com temperaturas uniformes e diferentes. Alguns autores (BAXTER; REYNOLDS, 1958; SPALDING, 1958; KAYS; CRAWFORD, 1993; WHITE, 2000; CEBECI; BRADSHAW, 1984) afirmam que a análise integral com sobreposição fornece resultados próximos daqueles da análise diferencial para o caso de temperaturas de superfície variáveis. O procedimento foi inicialmente proposto por Lighthill (1950) e modificado por vários autores conforme os requisitos de cada aplicação de interesse.

A distribuição de diferenças de temperatura $\Delta T_{\text {int }}$, entre a superfície de interface sólido-gás e o escoamento bifásico em torno do aerofólio, pode ser aproximada por uma série de rampas e degraus (REYNOLDS; KAYS; KLINE, 1958a), representada por:

$$
\begin{gathered}
\Delta T_{\text {int }}(s)=\sum_{n=1}^{N} m_{n}\left(s-a_{n}\right)+\sum_{j=1}^{J} b_{j} \\
\frac{d\left(\Delta T_{\text {int }}\right)}{d s}(s)=\sum_{n=1}^{N} m_{n}
\end{gathered}
$$

na qual $m_{n}$ é a inclinação da rampa no ponto de quebra $n$, localizado na posição $a_{n}$; $N$ é número total de quebras para aproximação de rampas; $b_{j}$ é o degrau no ponto de quebra $j$, localizado na posição $l_{j}$; $J$ é o número total de quebras para aproximação de degraus.

Então, a transferência de calor pode ser calculada por vários $\mathrm{St}_{/ a m}$ devido às componentes de rampa e degrau da Eq. (4.21a) por meio de:

$$
\mathrm{St}_{\text {lam }}=\mathrm{St}_{\text {lam }, \text { iso }}\left[1+\frac{s}{\Delta T_{\text {int }}} \sum_{n=1}^{N} m_{n} F_{A}\left(\frac{a_{n}}{x}\right)+\frac{1}{\Delta T_{\text {int }}} \sum_{j=1}^{J} b_{j} F_{S}\left(\frac{l_{j}}{x}\right)\right]
$$

E considerando as seguintes funções auxiliares:

$$
\begin{gathered}
F_{A}\left(\frac{a_{n}}{x}\right)=(4 / 3) \cdot \beta_{r}(2 / 3,4 / 3)-\left(1-\frac{a_{n}}{s}\right) \\
F_{S}\left(\frac{l_{j}}{x}\right)=\left[1-\left(\frac{l_{j}}{s}\right)^{3 / 4}\right]^{-1 / 3}-1 \\
r_{n}=1-\left(\frac{a_{n}}{s}\right)^{3 / 4} \\
\beta_{r}(2 / 3,4 / 3)=\frac{\Gamma\left(\frac{4}{3} r_{n}\right) \Gamma\left(\frac{2}{3}\right)}{\Gamma\left(\frac{4}{3} r_{n}+\frac{2}{3}\right)}
\end{gathered}
$$


Onde $\Gamma(p)$ é a função Gama e $\beta_{r}$ é a função Beta Incompleta, que é resultado da integral de sobreposição de Stietjes aplicada por Lighthill (1950) à transferência de calor no escoamento laminar sobre superfícies de temperatura não-uniforme.

Baxter e Reynolds (1958) estimam a distribuição $\mathrm{St}_{\text {/am,iso }}$ por meio da solução do escoamento laminar sem gradiente de pressão sobre superfície isotérmica, ou seja, a solução do escoamento de Blasius dada por:

$$
\mathrm{St}_{\text {lam,iso }}=0,332 \mathrm{Pr}^{-2 / 3} \operatorname{Re}_{s}^{-1 / 2}
$$

Neste trabalho, o gradiente de pressão precisa ser considerado pois o escoamento de interesse é em torno de um aerofólio. Assim, para estimar $\mathrm{St}_{\text {/am,iso }}$ e avaliar $\mathrm{St}_{\text {/am }}$ com o procedimento de sobreposição, adotou-se as soluções desenvolvidas por Smith e Spalding (1958), que consideram o efeito do gradiente de pressão na Eq. (4.18).

\subsubsection{Escoamento turbulento sobre superfície isotérmica}

Para avaliar a transferência de calor no escoamento turbulento sobre uma superfície isotérmica, pode-se adotar algum tipo de analogia entre transferência de calor e quantidade de movimento (KAYS; CRAWFORD, 1993; WHITE, 2000; SCHLICHTING; GERSTEN, 2000).

Desconsiderando o efeito do gradiente de pressão ( $u_{e}=$ constante), a equação da camada-limite de quantidade de movimento, a Eq. (4.2) é simplificada para:

$$
\frac{C_{f}}{2}=\frac{d \delta_{2}}{d s}
$$

Se os gradientes de pressão e de temperatura de superfície ao longo do escoamento forem nulos, a Eq. (4.8) resulta em:

$$
\mathrm{St}=\frac{d \Delta_{2}}{d s}
$$

Admitindo-se que a espessura de entalpia $\Delta_{2}$ é aproximadamente igual à espessura de quantidade de movimento $\delta_{2}$ ao longo da direção do escoamento, as taxas de crescimento $\delta_{2} / d s$ e $\Delta_{2} / d s$ também são aproximadamente as mesmas. Isso ocorre pois a superfície considerada é isotérmica, o que garante que as duas camadaslimite tenham a mesma origem (posição inicial onde a espessura é zero). Desse modo, as Eqs. (4.25) e (4.26) podem ser igualadas e define-se a chamada analogia 
de Reynolds:

$$
\mathrm{St}_{\text {turb }}=\frac{C_{f, t u r b}}{2}
$$

A relação da difusividade molecular de quantidade de movimento com a difusividade de transferência de calor é dada pelo número de Prandtl:

$$
\operatorname{Pr}=\frac{\nu \rho c_{p}}{k}
$$

No regime turbulento, a relação da difusividade turbulenta de quantidade de movimento com a de transferência de calor é dada pelo conceito do número de Prandtl turbulento:

$$
\operatorname{Pr}_{t}=\frac{\nu_{t} \rho c_{p}}{k_{t}}
$$

Uma forma mais geral de definir a Analogia de Reynolds é admitir que: 1) os números de Prandtl são unitários $\left.\operatorname{Pr}_{t}=\operatorname{Pr}=1 ; 2\right)$ a velocidade da borda é constante $u_{e}=$ constante e 3$)$ a superfície é isotérmica $\left(T_{w}-T_{e}\right)=$ constante. Esse conjunto de hipóteses resulta em perfis similares de velocidades $u^{+}$e de temperaturas $t^{+}$na camada-limite na direção normal ao escoamento. Assim, as taxas de crescimento das espessuras $\delta_{2}$ e $\Delta_{2}$ também são similares e podem ser correlacionadas por um fator de analogia.

Evidências experimentais (KAYS; CRAWFORD, 1993) indicam que a hipótese de $\operatorname{Pr}_{t} \approx 1$ representa escoamentos no regime turbulento de fluidos com número de Prandtl molecular de 0,7<Pr $<5$, 9. O valores de $\operatorname{Pr}_{t}$ para escoamentos turbulentos de ar varia de 0,7 a 0,9, com uma tendência de valores próximos a 0, 85 .

Já no regime laminar, devido às características do transporte de quantidade de movimento e de calor, ambas espessuras das camadas-limite possuem uma dependência significativa do Pr do fluido. Para efeito de comparação, o escoamento laminar e sem gradiente de pressão de um fluido com $0,5<\operatorname{Pr}<50$, em que a relação $\delta_{2} / \Delta_{2}$ é função do Re, a correlação entre transferência de calor e de quantidade de movimento resulta na Analogia de Colburn, que é dada por:

$$
\mathrm{St}_{l a m} \mathrm{Pr}^{2 / 3}=\frac{C_{f, l a m}}{2}
$$

Segundo Kays e Crawford (1993), os perfis de velocidades e temperatura dentro da camada-limite, nas regiões da subcamada-laminar e na região logarítmica plenamente turbulenta, para o escoamento de ar em regime turbulento são representados 
pelas chamadas leis de parede:

$$
\begin{aligned}
u^{+} & =\frac{1}{\kappa} \ln \frac{y^{+}}{10,8}+10,8 & u^{+} & =\frac{1}{\sqrt{C_{f, \text { turb }} / 2}} \\
t^{+} & =\frac{\operatorname{Pr}_{t}}{\kappa} \ln \frac{y^{+}}{13,2}+13,2 \operatorname{Pr} & t^{+} & =\frac{\sqrt{C_{f, \text { turb }} / 2}}{\mathrm{St}_{\text {turb }}}
\end{aligned}
$$

Substituindo os valores de valores de $\kappa=0,41$ e $\operatorname{Pr}_{t}=0,85$ nas das Eqs. (4.31a) e (4.31b), Kays e Crawford (1993) desenvolveram uma solução simplificada para transferência de calor com a adoção das seguintes hipóteses: 1) a velocidade do escoamento livre é constante, $u_{e}=$ constante; 2$)$ a superfície é isotérmica, ( $T_{w}-$ $\left.T_{e}\right)=$ constante; 3) as espessuras são aproximadamente iguais, $\delta_{2} \approx \Delta_{2}$ e 4) a esteira (na região externa superior) da camadas-limite térmica e de quantidade de movimento é aproximadamente representada com a adição da constante 2, 3 nas Eqs. (4.31a) e (4.31b).

Eliminando In $y^{+}$e igualando as Eqs. (4.31a) e (4.31b), o número de Stanton, St, pode ser representado como uma função de $C_{f}$, e analogia entre transferência de calor e quantidade de movimento, é dada por:

$$
\mathrm{St}_{\text {turb }}=\frac{C_{f, \text { turb }} / 2}{\sqrt{C_{f, \text { turb }} / 2}(13,2 \operatorname{Pr}-9,25)+0,85}
$$

Para o caso de velocidade na borda da camada-limite $u_{e}$ constante e a aproximação do perfil de velocidades dentro da camada-limite por $u^{+}=8,75\left(y^{+}\right)^{1 / 7}$, a Eq. (4.6) é simplificada para:

$$
C_{f, t u r b} / 2=0,0287 \mathrm{Re}_{s}^{-0,2}
$$

A substituição da Eq. (4.33) na Eq. (4.32) resulta em:

$$
S t_{\text {turb }}=\frac{0,0287 \mathrm{Re}_{s}^{-0,2}}{0,169 \mathrm{Re}_{s}^{-0,1}(13,2 \mathrm{Pr}-8,66)+0,85}
$$

O denominador da Eq. (4.34) pode ser aproximado por $\mathrm{Pr}^{0,4}$, para as faixas de $0,5<\operatorname{Pr}<1,0$ e $5 \times 10^{5}<\operatorname{Re}_{s}<5 \times 10^{6}$, o que resulta em:

$$
\mathrm{St}_{\text {turb }}=0,0287 \operatorname{Re}_{s}^{-0,2} \operatorname{Pr}^{-0,4}
$$

A substituição da Eq. (4.35) na Eq. (4.26) e a posterior integração, resulta em uma expressão que correlaciona St diretamente com $\Delta_{2}$, que é dada por:

$$
\mathrm{St}_{\text {turb }}=0,0125 \mathrm{Re}_{\Delta_{2}}^{-0,25} \operatorname{Pr}^{-0,5}
$$


No presente trabalho, o efeito do gradiente de pressão é considerado na avaliação do coeficiente de atrito viscoso $C_{f, t u r b}$ por meio da Eq. (4.7), que influencia a estimativa de $\mathrm{St}_{t u r b_{i} s o}$. Logo, a hipótese adicional é que o efeito da variação da velocidade do escoamento em torno do aerofólio na espessura de quantidade de movimento $\delta_{2}$ é o mesmo daquele na espessura de entalpia $\Delta_{2}$. O que pode ser uma aproximação adequada se o gradiente de pressão for moderado e sem variações abruptas.

Para considerar diretamente o efeito da variação da velocidade do escoamento bifásico em torno do aerofólio, sem depender do cálculo de $C_{f}$, Moretti (1964) utilizaram a solução de Ambrok (1957), Eqs. (4.13) e (4.14), e admitiram que a temperatura da superfície é constante. Assim, a distribuição de $\mathrm{St}_{\text {turb,iso }}$ resulta em:

$$
\begin{aligned}
\mathrm{St}_{\text {turb,iso }}= & 0,0125 \cdot \operatorname{Re}_{\Delta_{2, \text { turb }}}^{-0, \operatorname{Pr}^{-0,5}} \\
= & 0,0125 \operatorname{Pr}^{-0,5}\left[0,0156 \cdot \operatorname{Pr}^{-0,5} \cdot \mu_{a r}^{-1} \cdot \int_{s_{t r}}^{s} G \cdot d s\right. \\
& \left.+\left(\operatorname{Re}_{\Delta_{2, t r}}\right)^{1,25}\right]^{-0,2}
\end{aligned}
$$

Se o termo $\operatorname{Re}_{\Delta_{2, t r}}$ for nulo, ou seja, se a camada-limite térmica turbulenta começar na estagnação $\left(u_{e}=0\right)$ ou se a espessura de entalpia for nula no início da transição $\left(\Delta_{2, t r}\right)$, onde os núcleos turbulentos começam a aparecer, a Eq. (4.37) resulta em:

$$
\begin{aligned}
S_{t} \text { turb,iso } & =0,0125 \operatorname{Pr}^{-0,5}\left(0,0156 \cdot \operatorname{Pr}^{-0,5} \cdot \mu_{a r}^{-1} \cdot \int_{s_{t r}}^{s} G \cdot d s\right)^{-0,2} \\
& =0,0287 \operatorname{Pr}^{-0,4}\left(\mu_{a r}^{-1} \cdot \int_{s_{t r}}^{s} G \cdot d s\right)^{-0,2}
\end{aligned}
$$

Para $u_{e}$ constante, o termo entre parênteses da Eq. (4.38) é reduzido ao número de Reynolds $\operatorname{Re}_{s}$ e, consequentemente, a definição de número de St fica igual à analogia desenvolvida por Kays e Crawford (1993), dada pela Eq. (4.35).

\subsubsection{Escoamento turbulento sobre superfície não-isotérmica}

Reynolds, Kays e Kline (1958a) aplicaram o procedimentos integrais de sobreposição à camada-limite térmica turbulenta, originalmente desenvolvidos para o regime laminar (LIGHTHILL, 1950), e resolveram a transferência de calor por convecção no escoamento turbulento sobre uma superfície de temperatura variável.

De forma análoga ao escoamento de regime laminar, os autores aproximaram a distribuição de $\Delta_{i n t}$, diferença entre a temperatura de superfície de interface líquidogás ou sólido-gás, por uma sequência de rampas e degraus como na Eq. (4.21a). 
Então, a sobreposição de vários $\mathrm{St}_{t u r b, i s o}$ devido às componentes de rampa e degrau da Eq. (4.21a) resulta em:

$$
\mathrm{St}_{\text {turb }}=\mathrm{St}_{\text {turb,iso }}\left[1+\frac{s}{\Delta T_{\text {int }}} \sum_{n=1}^{N} m_{n} F_{A}\left(\frac{a_{n}}{x}\right)+\frac{1}{\Delta T_{\text {int }}} \sum_{j=1}^{J} b_{j} F_{S}\left(\frac{I_{j}}{x}\right)\right]
$$

E considerando as seguintes funções auxiliares:

$$
\begin{gathered}
F_{A}\left(\frac{a_{n}}{x}\right)=(10 / 9) \cdot \beta_{r}(8 / 9,10 / 9)-\left(1-\frac{a_{n}}{s}\right) \\
F_{S}\left(\frac{I_{j}}{x}\right)=\left[1-\left(\frac{I_{j}}{s}\right)^{9 / 10}\right]^{-1 / 9}-1 \\
r_{n}=1-\left(\frac{a_{n}}{s}\right)^{9 / 10} \\
\beta_{r}(8 / 9,10 / 9)=\frac{\Gamma\left(\frac{10}{9} r_{n}\right) \Gamma\left(\frac{8}{9}\right)}{\Gamma\left(\frac{10}{9} r_{n}+\frac{8}{9}\right)}
\end{gathered}
$$

A distribuição $\mathrm{St}_{\text {turb,iso, }}$, do escoamento turbulento sem gradiente de pressão sobre superfície isotérmica (Blasius), pode ser estimada por (BAXTER; REYNOLDS, 1958; REYNOLDS; KAYS; KLINE, 1958a):

$$
\mathrm{St}_{\text {turb,iso }}=0,0296 \operatorname{Pr}^{-0,4} \mathrm{Re}_{s}^{-0,2}
$$

Uma alternativa é avaliar $\mathrm{St}_{\text {turb,iso }}$ por meio de alguma analogia entre transferência de calor e quantidade de movimento, Eqs. (4.27), (4.32). Desse modo, o efeito do gradiente de pressão seria contabilizado indiretamente, por meio da variação do $C_{f}$ da Eq. (4.7).

Outra opção é utilizar a Eq. (4.37), que considera o efeito do gradiente de pressão na avaliação de $\mathrm{St}_{\text {turb,iso }}$ diretamente.

\subsection{Análise Diferencial das Camadas-Limite Dinâmica e Térmica - Presente Trabalho}

Para aplicação no presente trabalho, foram escolhidas duas implementações de resolução bidimensional do escoamento nos regimes laminar, de transição e turbulento, a saber:

- Modelo de Cebeci e Cousteix (2005) do código BLP2C;

- Modelo de Kays, Crawford e Weigand (2004) do código TEXSTAN; 
As duas aplicam o método das diferenças finitas para resolver as equações de média de Reynolds de Navier-Stokes simplificadas para camada-limite. A razão da adoção dessa abordagem no presente trabalho é que ela permite a contabilização dos efeitos de história do escoamento que são desconsiderados na abordagem integral. Uma vez que, no caso da simulação do sistema antigelo, é preciso estimar a resposta da camada-limite às variações de gradiente de pressão (aceleração do escoamento) e variações das condições de contorno na superfície, como a temperatura e a taxa de evaporação da água líquida.

\subsubsection{Modelo de Cebeci e Cousteix (2005)}

O programa BLP2C (CEBECI; COUSTEIX, 2005) resolve simultâneamente as equações de conservação de quantidade de movimento e de energia para escoamentos de camada-limite bidimensional compressível com transferência de calor, nos regimes laminar, transicional e turbulento. As equações utilizadas na construção do modelo são:

- conservação da massa:

$$
\frac{\partial}{\partial x}(\rho u)+\frac{\partial}{\partial y}(\overline{\rho v})=0
$$

- conservação da quantidade de movimento na camada-limite compressível (Navier-Stokes) :

$$
\rho u \frac{\partial u}{\partial x}+\overline{\rho v} \frac{\partial u}{\partial y}=-\frac{d p}{d x}+\frac{\partial}{\partial y}\left(\mu \frac{\partial u}{\partial y}-\rho \overline{u^{\prime} v^{\prime}}\right)
$$

- conservação da energia (Primeira Lei da Termodinâmica):

$$
\rho u \frac{\partial H}{\partial x}+\overline{\rho v} \frac{\partial H}{\partial y}=\frac{\partial}{\partial y}\left[k \frac{\partial T}{\partial y}-c_{p} \rho \overline{T^{\prime} v^{\prime}}+u\left(\mu \frac{\partial u}{\partial y}-\rho \overline{u^{\prime} v^{\prime}}\right)\right]
$$

- pressão na borda superior da camada-limite, na região de escoamento incompressível e isentrópico:

$$
-\frac{d p}{d x}=\rho_{e} u_{e}\left(\frac{d u_{e}}{d x}\right)
$$

- viscosidade aparente turbulenta ("eddy viscosity")

$$
-\overline{u^{\prime} v^{\prime}}=\epsilon_{m} \frac{\partial u}{\partial y} \quad \text { e } \quad-\overline{T^{\prime} v^{\prime}}=\frac{\epsilon_{m}}{\operatorname{Pr}_{t}} \frac{\partial u}{\partial y}
$$


- modelo algébrico de turbulência de Cebeci e Smith (1974)

$$
\begin{gathered}
\left(\epsilon_{m}\right)_{i}=I^{2}\left|\frac{\partial u}{\partial y}\right|^{2} \gamma_{t r} \gamma, \quad 0 \leq y \leq y_{c} \\
\left(\epsilon_{m}\right)_{o}=0,0168\left|\int_{0}^{\infty}\left(u_{e}-u\right) d y\right| \gamma_{t r} \gamma, \quad y_{c} \leq y \leq \delta \\
\left(\epsilon_{m}\right)_{o}=\left(\epsilon_{m}\right)_{i}, \quad y=y c \\
I=\kappa y\left[1-\exp \left(-\frac{y}{A}\right)\right], \quad N=\left[1-11,8 \frac{\mu_{w}}{\mu_{e}}\left(\frac{\rho_{e}}{\rho_{w}}\right)^{2} p^{+}\right]^{1 / 2} \\
A=26 \frac{\nu}{N} u_{T}^{-1}\left(\frac{\rho}{\rho_{w}}\right)^{1 / 2},
\end{gathered}
$$

- intermitência laminar-turbulenta de Chen e Thyson (1971)

$$
\begin{gathered}
\gamma_{t r}=1-\exp \left[-G\left(x-x_{t r}\right) \int_{x_{t r}}^{x} u_{e}^{-1} d x\right] \\
G=8,33 \cdot 10^{-4} \frac{u_{e}^{3}}{\nu^{2}} \operatorname{Re}_{x}^{-1,34}
\end{gathered}
$$

- intermitência da camada-limite para o escoamento externo

$$
\gamma=\left[1+5,5\left(\frac{y}{y_{0}}\right)^{6}\right]^{-1}, \quad y_{0} \text { é onde } \frac{u}{u_{e}}=0,995
$$

\subsubsection{Modelo de Kays, Crawford e Weigand (2004)}

O programa TEXSTAN2004 (KAYS; CRAWFORD; WEIGAND, 2004) resolve as equações de conservação de quantidade de movimento e de energia para escoamentos de camada-limite bidimensional incompressível com transferência de calor, nos regimes laminar, transicional e turbulento:

- conservação da massa:

$$
\frac{\partial}{\partial x} \bar{u}+\frac{\partial}{\partial y} \bar{v}=0
$$

- conservação da quantidade de movimento na camada-limite incompressível (Navier-Stokes):

$$
\bar{u} \frac{\partial u}{\partial x}+\bar{v} \frac{\partial u}{\partial y}=-\frac{1}{\rho} \frac{d p}{d x}+\frac{\partial}{\partial y}\left(\nu \frac{\partial \bar{u}}{\partial y}-\overline{u^{\prime} v^{\prime}}\right)
$$

- conservação da energia (Primeira Lei da Termodinâmica):

$$
\bar{u} \frac{\partial \bar{T}}{\partial x}+\bar{v} \frac{\partial \bar{T}}{\partial y}=\frac{\partial}{\partial y}\left(\frac{k}{\rho c_{p}} \frac{\partial \bar{T}}{\partial y}-\overline{T^{\prime} v^{\prime}}\right)
$$


- pressão na borda superior da camada-limite, na região de escoamento incompressível e isentrópico:

$$
-\frac{d p}{d x}=\rho_{e} u_{e}\left(\frac{d u_{e}}{d x}\right)
$$

- viscosidade aparente turbulenta ("eddy viscosity")

$$
-\overline{u^{\prime} v^{\prime}}=\epsilon_{m} \frac{\partial u}{\partial y} \quad e \quad-\overline{T^{\prime} v^{\prime}}=\frac{\epsilon_{m}}{\operatorname{Pr}_{t}} \frac{\partial u}{\partial y}
$$

- modelo algébrico de turbulência de Kays e Moffat (1975)

$$
\begin{gathered}
\left(\epsilon_{m}\right)_{i}=I^{2}\left|\frac{\partial u}{\partial y}\right|^{2} \\
I=\min \left\{\kappa y\left[1-\exp \left(-\frac{y^{+}}{A^{+}}\right)\right], \lambda \cdot \delta\right\} \\
A^{+}=\frac{25}{a\left\{v_{w}^{+} b\left[p^{+} /\left(1+c v_{w}^{+}\right)\right]\right\}+1} \\
\lambda=\min \left[0,085, \frac{0,24944}{\left(\operatorname{Re}_{\delta_{2}}\right)^{0,0125}}\left(1-67,5 \frac{v_{s}}{U_{\infty}}\right)\right]
\end{gathered}
$$

\subsection{Verificação dos Resultados Numéricos}

Na presente seção é realizada uma verificação dos resultados numéricos da análise integral e diferencial das camadas-limite térmica e dinâmica. O objetivo é comparar as previsões com resultados analíticos ou experimentais para os efeitos mais importantes que ocorrem no escoamento na camada-limite estudado, como mostrado na Tabela 4.2. Desse modo é possível verificar se a implementação numérica está correta e quantificar, para cada efeito separadamente, os desvios dos resultados numéricos em relação às soluções analíticas ou aos dados experimentais.

Os procedimento de cálculo para contabilizar os efeitos da evaporação na transferência de calor são analisados no Apêndice A.

Na presente seção, dois tipos de efeitos são estudados:

1) efeito da compressibilidade e do acoplamento entre a pressão e a velocidade;

2) efeito da variação de temperatura na superfície de uma placa plana e de um aerofólio. 


\subsubsection{Casos-Teste para Verificação dos Resultados Numéricos}

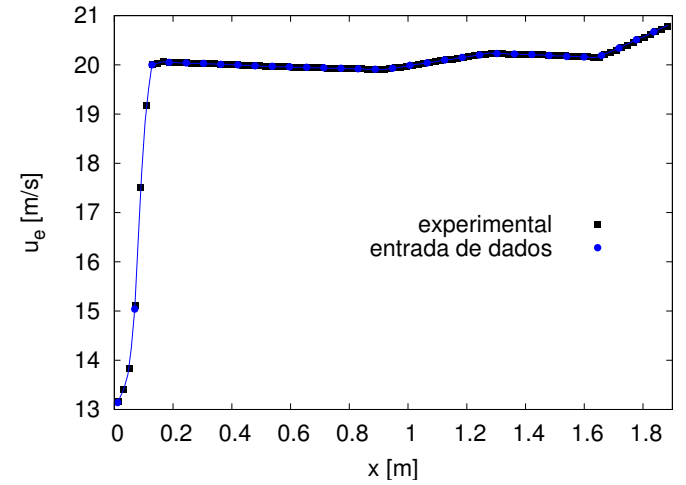

(a) Velocidade $-u_{e}$ - caso 1

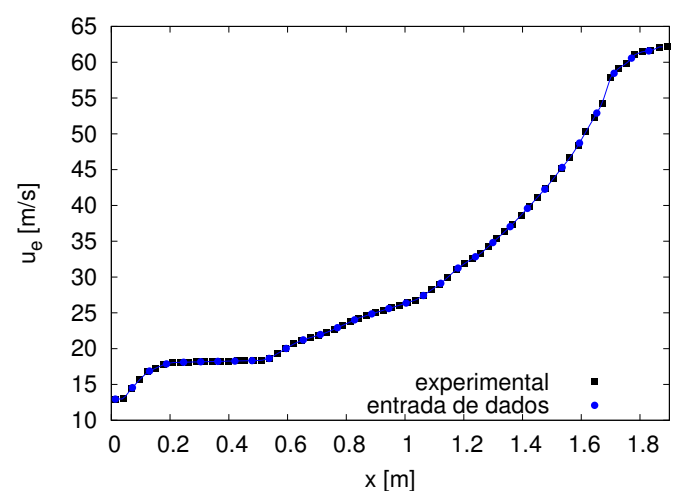

(c) Velocidade - $u_{e}$ - caso 24

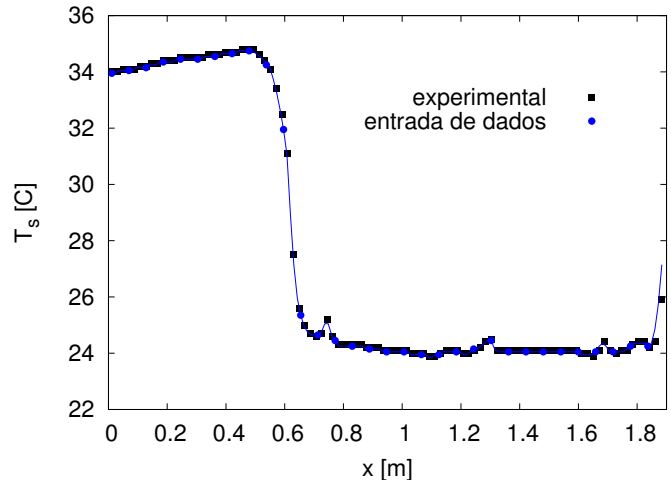

(b) Temperatura - $T_{s}$ - caso 1

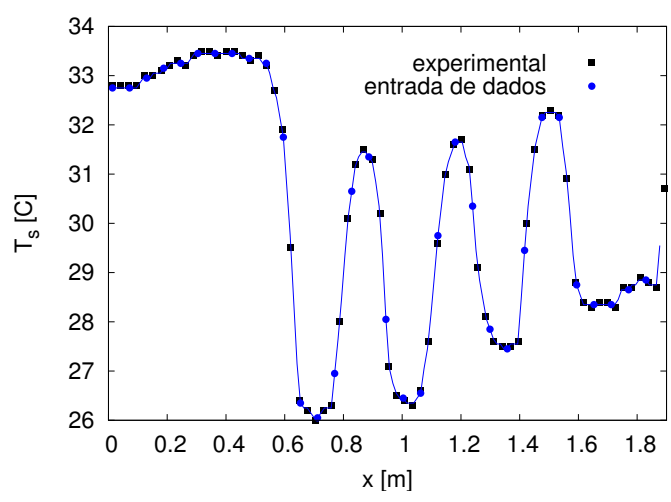

(d) Temperatura - $T_{s}$ - caso 24

Figura 4.1: Dados Experimentais Utilizados como Entrada para as Análises Integral e Diferencial da Camada-Limite Térmica (MORETTI, 1964)

Placa Plana: Moretti (1964) mediu St $_{t u r b}$ do escoamento na camada-limite turbulenta sobre placas planas com degraus, ou variações abruptas, de temperatura de superfície na presença de gradientes de pressão variáveis. O presente trabalho utiliza as rodadas experimentais \# 1 e \# 24 realizadas por Moretti (1964) na Universidade de Stanford, Califórnia, EUA:

- o caso \#1 possui uma variação abrupta na temperatura de superfície; $V_{\infty} \approx 20$ $\mathrm{m} / \mathrm{s}, T_{\text {tot }}=36^{\circ} \mathrm{C}, P_{\infty}=102438 \mathrm{~Pa}, \mathrm{Re}=1,5 \cdot 10^{5}$ e gradiente de pressão nulo.

- o caso \#24 possui variações de temperatura de superfície; $V_{\infty} \approx 13 \mathrm{~m} / \mathrm{s}$, $T_{\text {tot }}=35,5^{\circ} \mathrm{C}, P_{\infty}=104707 \mathrm{~Pa}, \mathrm{Re}=1 \cdot 10^{5}$. O gradiente de pressão foi constante, com $13<u_{e}<60 \mathrm{~m} / \mathrm{s}$.

A Fig. 4.1 exibe as distribuições experimentais da velocidade no bordo da camada-limite e distribuições experimentais de temperatura de parede para as rodadas experimentais \# 1 e \# 24. 
NACA0012: Foram rodados dois casos com aerofólio NACA0012, apresentado na Fig. 4.2, para verificar o efeito de compressibilidade. O caso 1 foi baseado nas condições experimentais de Amick (1950) para Ma= 0, 4 e são mostradas na Fig. 4.4. A corda do aerofólio utilizado nos experimentos era de $0,2 \mathrm{~m}$. O caso 2 possui a mesma geometria e mesmos $\operatorname{Re}$ e $\alpha$, mas Ma mais baixo do que caso 1 , ou seja, $\mathrm{Ma}=0,2$. Para os dois casos foi admitido um nível de turbulência de $1 \%$, que é mais alto do que os valores típicos de túneis de vento aerodinâmicos e de condições naturais de voo $(0,05<T u<0,5 \%)$, mas menor do que os valores encontrados na operação de túneis de formação de gelo $(1,5<T u<6 \%)$. Os parâmetros de transição e a intermitência foram estimados por meio do modelo de Abu-Ghannam e Shaw (1980). Foi admitida uma temperatura de superfície, $T_{s}$, constante de $5 \mathrm{~K}$ acima da temperatura de recuperação, $T_{\text {rec }}$.

Tabela 4.4: Caso 1 - NACA0012 - Ma=0,4 (AMICK, 1950)

\begin{tabular}{cc}
\hline parâmetro & valor \\
\hline$T_{\infty}$ & $300,0 \mathrm{~K}$ \\
$\mathrm{Ma}$ & 0,40 \\
$\mathrm{Re}$ & $0,176 \cdot 10^{7}$ \\
$\alpha$ & $0,0^{\circ}$ \\
geometria & $\mathrm{NACA} 0012$ \\
\hline
\end{tabular}

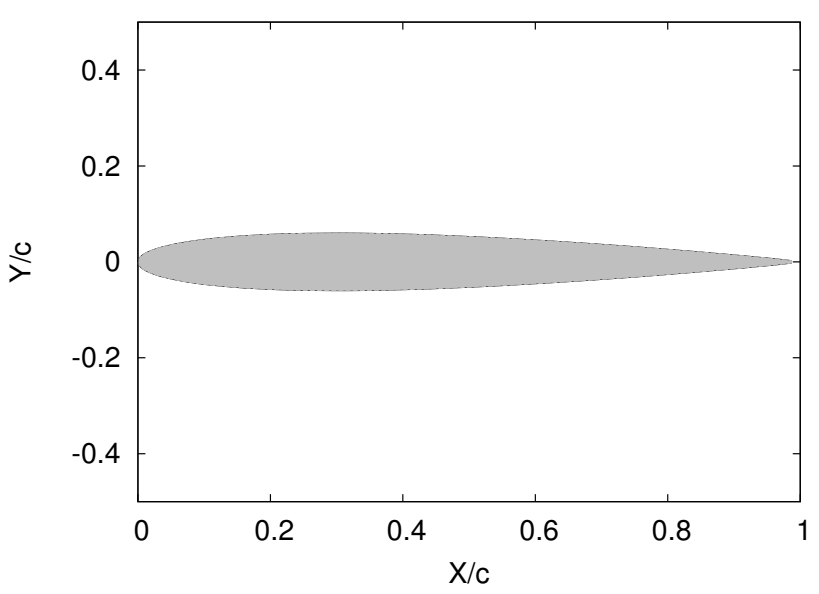

Figura 4.2: Geometria do Aerofólio NACA0012

NACA 65(2)016: Foram rodados dois casos com aerofólio NACA 65(2)016, apresentado na Fig. 4.3, para verificar a relevância do efeito de compressibilidade para os escoamentos em torno de aerofólios nas condições de operação de sistemas antigelo. Ambos são casos experimentais de Frick e McCullough (1942). Os casos no regime laminar e turbulento são apresentados na Tabela 4.5. No caso experimental turbulento, os autores fixaram a transição em $5 \%$ da corda $(x / c)$. Não há informações 
sobre o comprimento da região de transição nem sobre o método utilizado pelos autores para disparar o processo transicional. Logo, o presente trabalho admitiu que a transição se iniciou em 2, 1\% e terminou em 5, 45\%. Frick e McCullough (1942) mediram a distribuição de temperatura num aerofólio NACA 65(2)016 aquecido de 2, 134 $\mathrm{m}$ de corda por 2,134 $\mathrm{m}$ de envergadura. A potência de aquecimento foi fornecida por lâmpadas de bulbo na parte interna do aerofólio de alumínio. Foram instaladas 9 lâmpadas enfileiradas no sentido da envergadura em cada um dos três compartimentos no sentido do escoamento. Cada compartimento possuia uma área exposta a radiação térmica das lâmpadas no intradorso e outra no extradorso. Por meio da medição de tensão e corrente elétricas, os autores mediram a potência fornecida para cada compartimento durante o experimento. Os autores estimaram o fluxo de calor por convecção por meio da distribuição de temperaturas medida e do coeficiente de transferência de calor, $h_{a r}$. calculado pela análise integral sobre superfície isotérmica. A taxa de transferência de calor estimada por Frick e McCullough (1942) foi comparada com a potência de aquecimento fornecida para o segundo compartimento, compreendido entre 0,143<x/c<0,263.

Tabela 4.5: Casos NACA 65(2)016 (FRICK; MCCULLOUGH, 1942)

Transição Livre

\begin{tabular}{cc}
\hline parâmetro & valor \\
\hline$T_{\infty}$ & $300,0 \mathrm{~K}$ \\
$\mathrm{Ma}$ & 0,18 \\
$\mathrm{Re}$ & $0,697 \cdot 10^{7}$ \\
$\alpha$ & $0,0^{\circ}$ \\
geometria & $\mathrm{NACA} 65_{2} 016$ \\
\hline
\end{tabular}

Transição Fixada

\begin{tabular}{cc}
\hline parâmetro & valor \\
\hline$T_{\infty}$ & $300,0 \mathrm{~K}$ \\
$\mathrm{Ma}$ & 0,18 \\
$\mathrm{Re}$ & $0,717 \cdot 10^{7}$ \\
$\alpha$ & $0,0^{\circ}$ \\
geometria & $\mathrm{NACA}^{\circ} 5_{2} 016$ \\
\hline
\end{tabular}

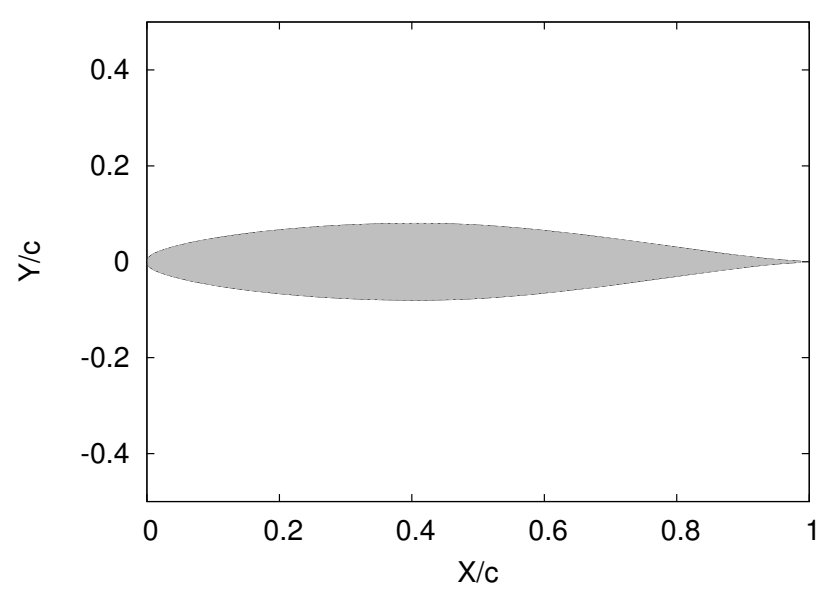

Figura 4.3: Geometria do Aerofólio NACA 65(2)016 


\subsubsection{Modelos Matemáticos e Programas Utilizados}

O código externo ONERA (GUFFOND; BRUNET, 1988) foi utilizado por Silva (2002) para resolver o campo do escoamento em torno do aerofólios NACA0012, NACA 65(2)016 para ângulo da ataque, $\alpha$, de 0 grau. O código ONERA2D (SILVA, 2002) forneceu as distribuições de coeficiente de pressão $C_{p}$ obtidas por meio da solução do escoamento potencial completo (compressível isentrópico e irrotacional). Mais detalhes sobre o ONERA podem ser encontrados em Bredif (1983), Bredif (1985) e no trabalho anterior do presente autor (SILVA, 2002). Recentemente, foram utilizados outros códigos externos, como o XFOIL (DRELA; GILES, 1987) e o HSPM (CEBECI; COUSTEIX, 2005), para estimar a distribuição de $C_{p}$ no escoamento potencial (incompressível e irrotacional) em torno do aerofólio NACA 65(2)016. Para corrigir com cálculos e considerar efeitos de compressibilidade, os dois códigos adotam a correção de Karman-Tsien (apud CEBECl et al.,1995) em regiões subsônicas do escoamento. Como os casos de antigelo avaliados no presente trabalho não possuem regiões sônicas, as aproximações adotadas são aceitáveis.

A análise integral de camada-limite sobre superfície não-isotérmica, nos regimes laminar, transicional e turbulento, por meio do método da sobreposição foi implementada no presente trabalho. Silva, Silvares e Zerbini (2008a) compararam os resultados dos procedimentos de sobreposição (Eqs. 4.22 e 4.39) com dados experimentais (MORETTI; KAYS, 1965) e aqueles resultados obtidos com o método integral nãoisotérmico de Ambrok (1957) e também de Smith e Spalding (1958) e da Analogia de Colburn (Eq. 4.30. No presente trabalho, seus resultados de St são comparados também com a soluções diferenciais obtidas com os códigos TEXSTAN e BLP2C.

Os resultados da avaliação integral da camada-limite são comparados com as previsões de dois códigos de análise por diferenças finitas: TEXSTAN2004 de Crawford (2004) e BLP2C de Cebeci e Cousteix (2005), que são adequados para servirem como referência de comparação pois: 1) foram verificados por partes com experimentos confiáveis e controlados para cada uma das várias configurações de escoamento e com diferentes condições de contorno; 2) foram verificados com resultados experimentais de aplicações de engenharia. O TEXSTAN2004 resolve a equação incompressível de Navier-Stokes na forma de média de Reynolds mais as equações de conservação da massa e da energia para a camada-limite. Já o código $B L P 2 C$ resolve as mesmas equações, mas para o escoamento compressível. Uma breve descrição de cada código pode ser encontrada no Anexo B.

O presente autor implementou o modelo de intermitência de Abu-Ghannam e Shaw (1980) no código BLP2C, que, originalmente, utilizava o modelo de Chen e 
Thyson (1971).

\subsubsection{Resultados Numéricos}

Foi estimada a distribuição de Stanton, St, sobre placa plana para dois casos medidos por Moretti e Kays (1965) com os programas de análise integral e diferencial. O objetivos foram: 1) verificar as limitações de cada código; 2) assegurar que as estimativas de St estavam sendo feitas corretamente, ou seja, um tipo de tese de sanidade, por meio da comparação dos resultados numéricos das análise integrais e diferenciais com os dados experimentais.

A Figura 4.4 apresenta a comparação entre previsões de St obtidas com a análise integral e diferencial por meios das soluções de: Ambrok não-isotérmico (Eq. 4.8) , Ambrok isotérmico modificado (Eq. 4.37), aplicação do princípio da sobreposição (Eq. 4.39), BLP2C, TEXSTAN e dados experimentais. A análise da Fig. 4.4(a) mostra que as previsões integrais de camada-limite térmica sobre superfície nãoisotérmica tiveram aderência aos dados experimentais. De forma esperada, a análise integral isotérmica não representa a distribuição de St quando há variação de temperatura de superfície. Como apresentado na Fig. 4.4(b), somente as previsões numéricas dos modelos integral de sobreposição e dos modelos diferenciais tiveram desvios aceitáveis em relação aos dados experimentais da rodada experimental 24. Esta possui uma série de degraus abruptos na temperatura da superfície e aceleração do escoamento (variação do gradiente de pressão).

A Fig. 4.5 apresenta os resultados das estimativas de coeficiente de pressão, $C_{p}$, a Fig. 4.6 coeficiente de atrito $C_{f}$ e a Fig. 4.7 número de Stanton, St, em torno de um aerofólio NACA0012 com 0,2 $\mathrm{m}$ de corda. As previsões numéricas para a distribuição de $C_{p}$ do Caso 1 (Tabela 4.4) são comparadas com dados experimentais de Amick (1950) na Fig. 4.5(a). Os resultados do ONERA2D foram obtidos por Silva (2002) e os do XFOIL (DRELA; GILES, 1987) foram obtidos no presente trabalho. A comparação mostra que os resultados numéricos de ambos os códigos são próximos dos resultados de Amick (1950). No Caso 2, Ma=0,2, os cálculos de $C_{p}$ são comparados com a extrapolação analítica que Amick (1950) realizou a partir dos dados experimentais de $\mathrm{Ma}=0,4$.

A distribuição de $C_{f}$ foi estimada por meio da análise integral (Eqs. 4.3 e 4.6) e das análises diferenciais (BLP2C e TEXSTAN) nos regimes laminar, transicional e turbulento. O presente trabalho implementou o modelo de intermitência e de previsão de transição de Abu-Ghannam e Shaw (1980) na análise integral e no BLP2C. O programa TEXSTAN já possui o modelo de Abu-Ghannam e Shaw (1980) implementado. 


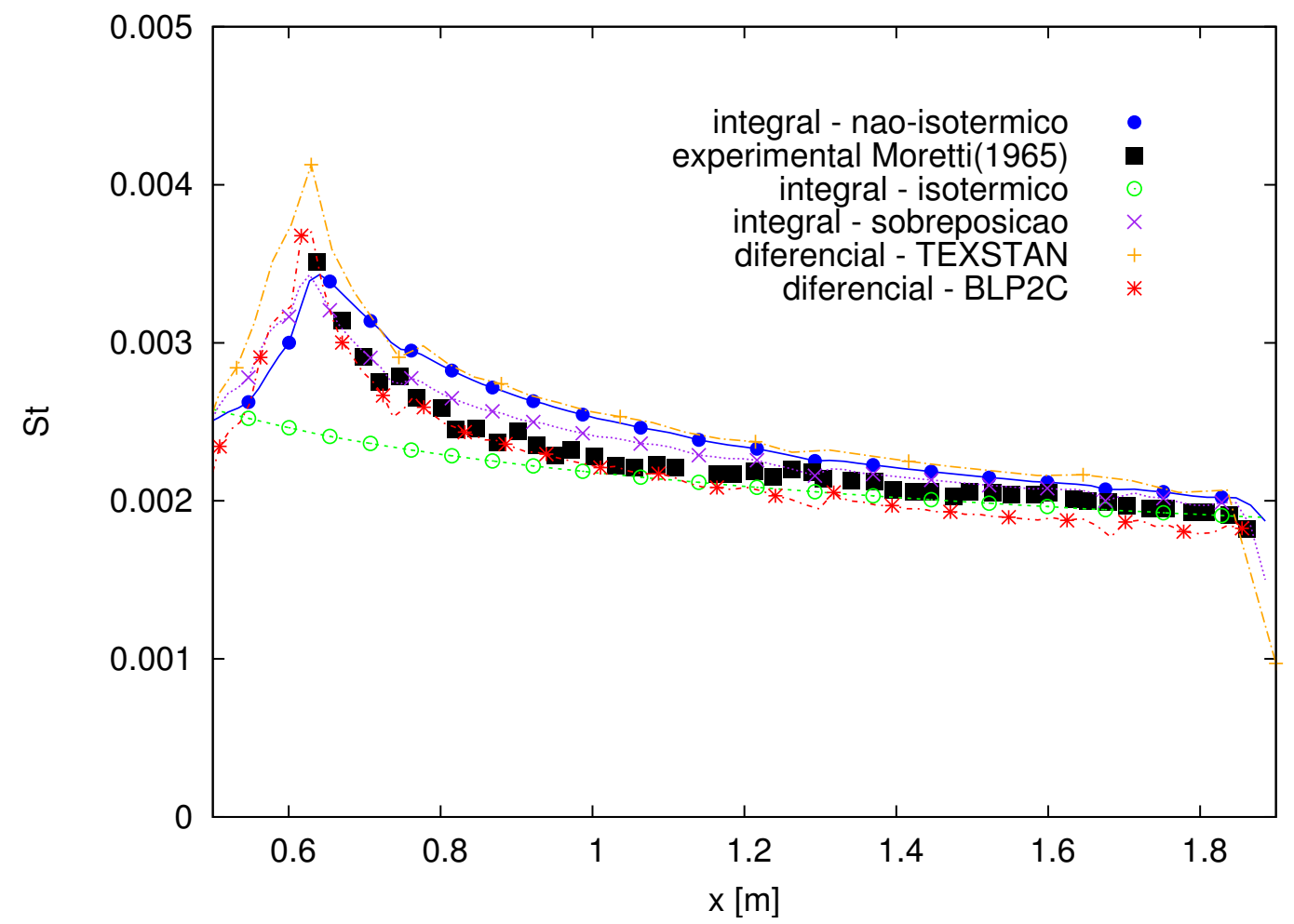

(a) Um degrau de temperatura $T_{s}$ e gradiente de pressão nulo - Caso 1

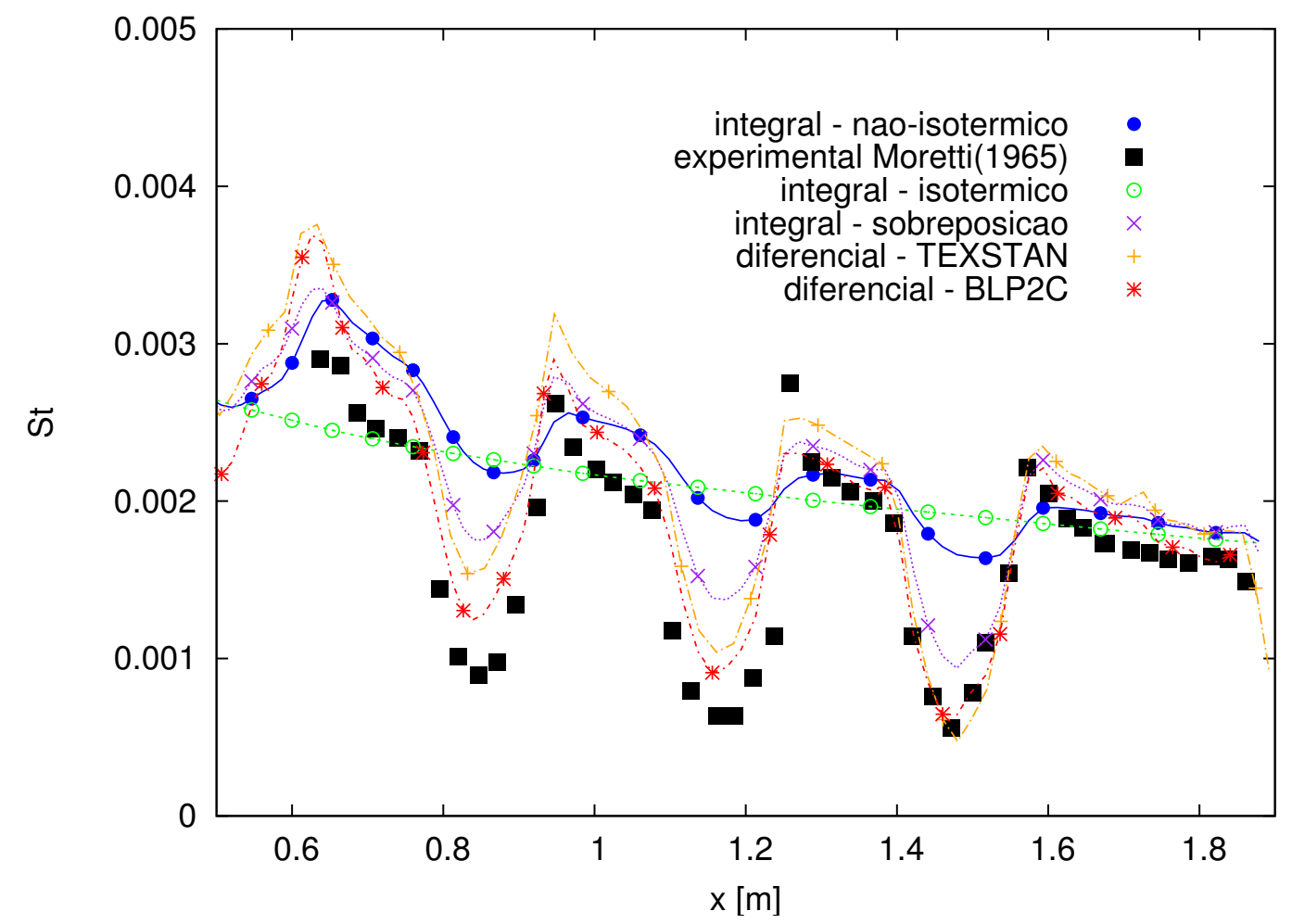

(b) Vários degraus de temperatura $T_{s}$ e gradiente de pressão variável - Caso 24

Figura 4.4: St estimado pelas Análises Integral e Diferencial 


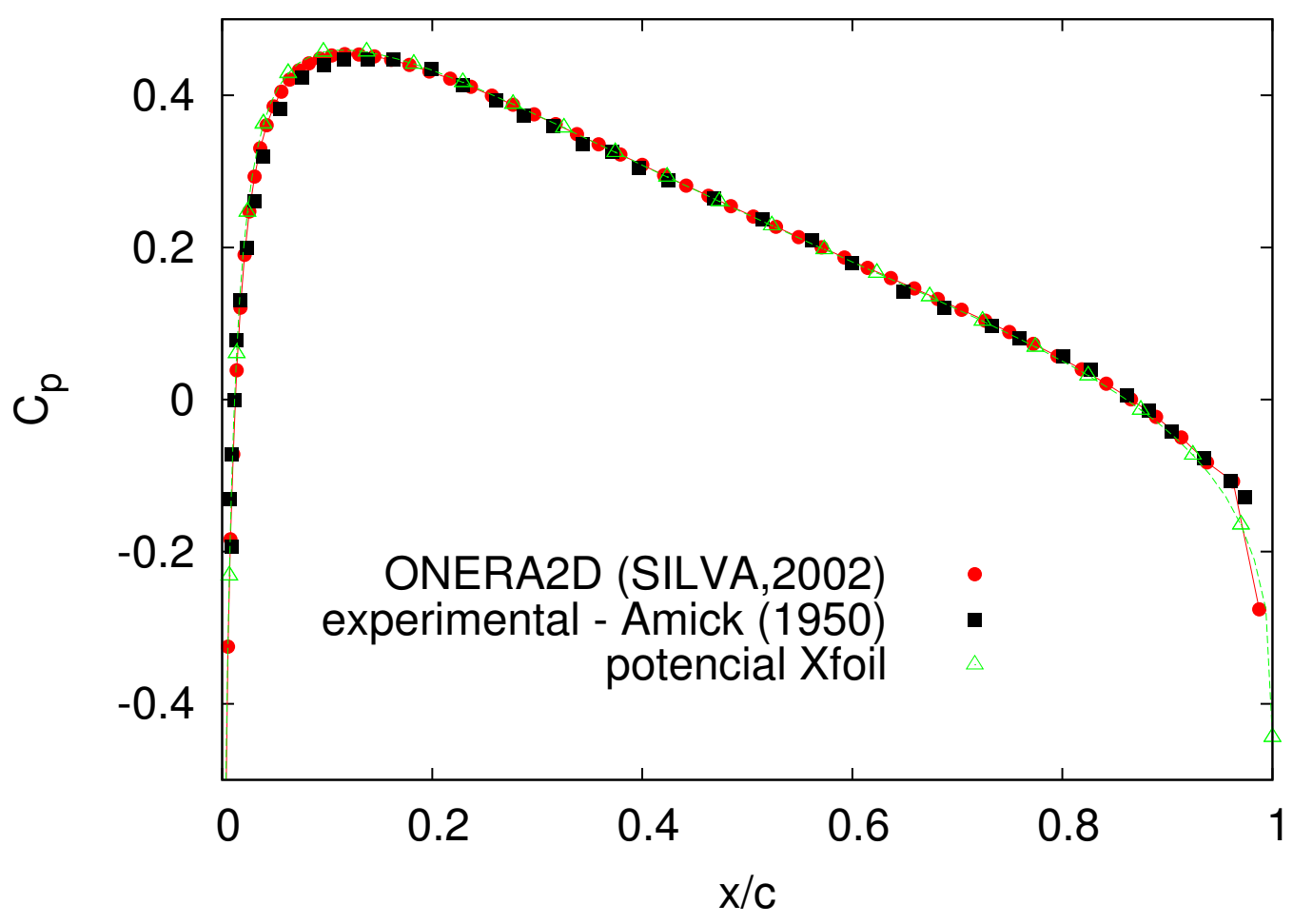

(a) Coeficiente de Pressão - $C_{p}$ - Caso $1-\mathrm{Ma}=0,4$

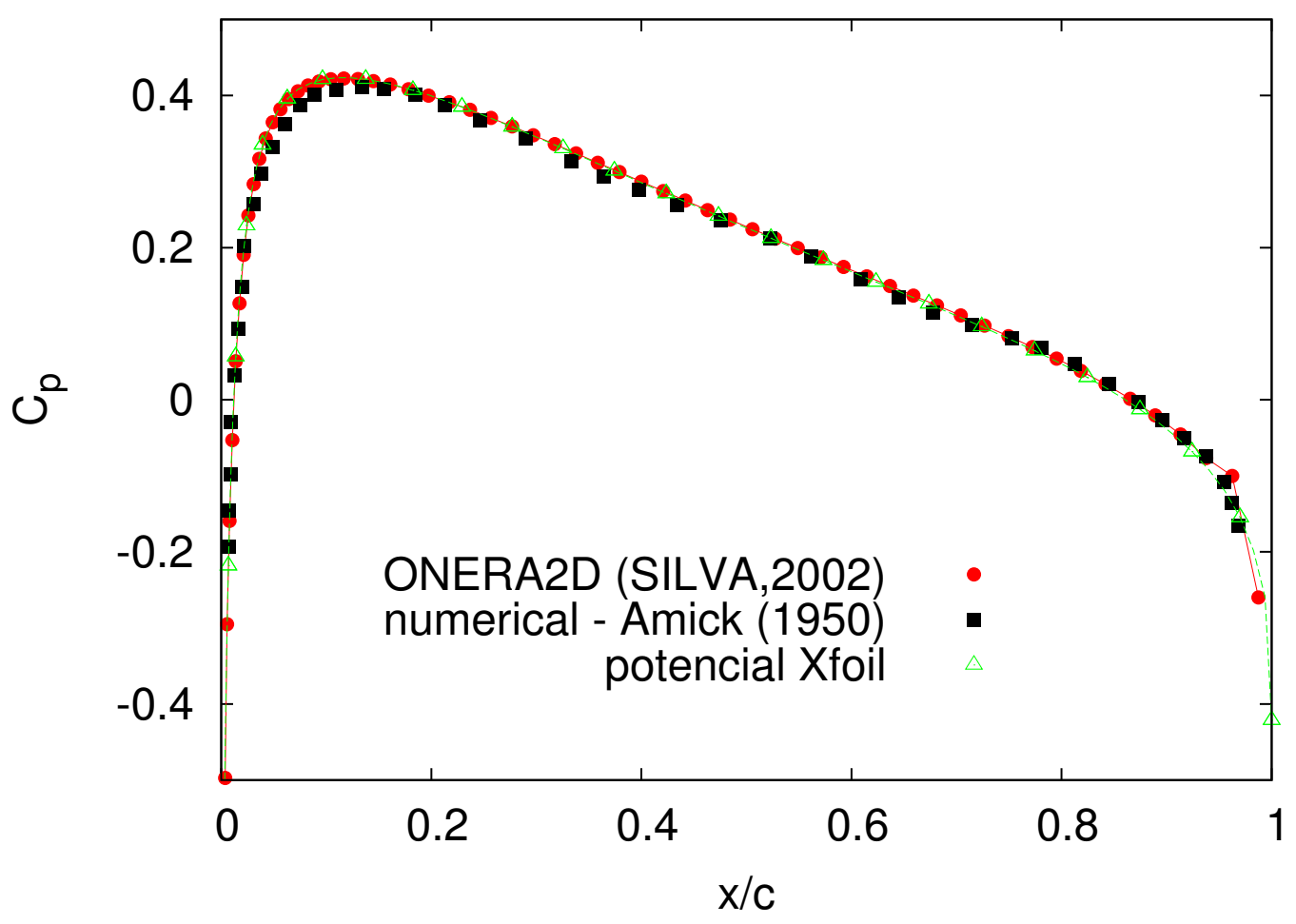

(b) Coeficiente de Pressão - $C_{p}$ - Caso 2 - Ma=0,2

Figura 4.5: Estimativas de $C_{p}$ - Casos 1 e 2 - Perfil NACA 0012 


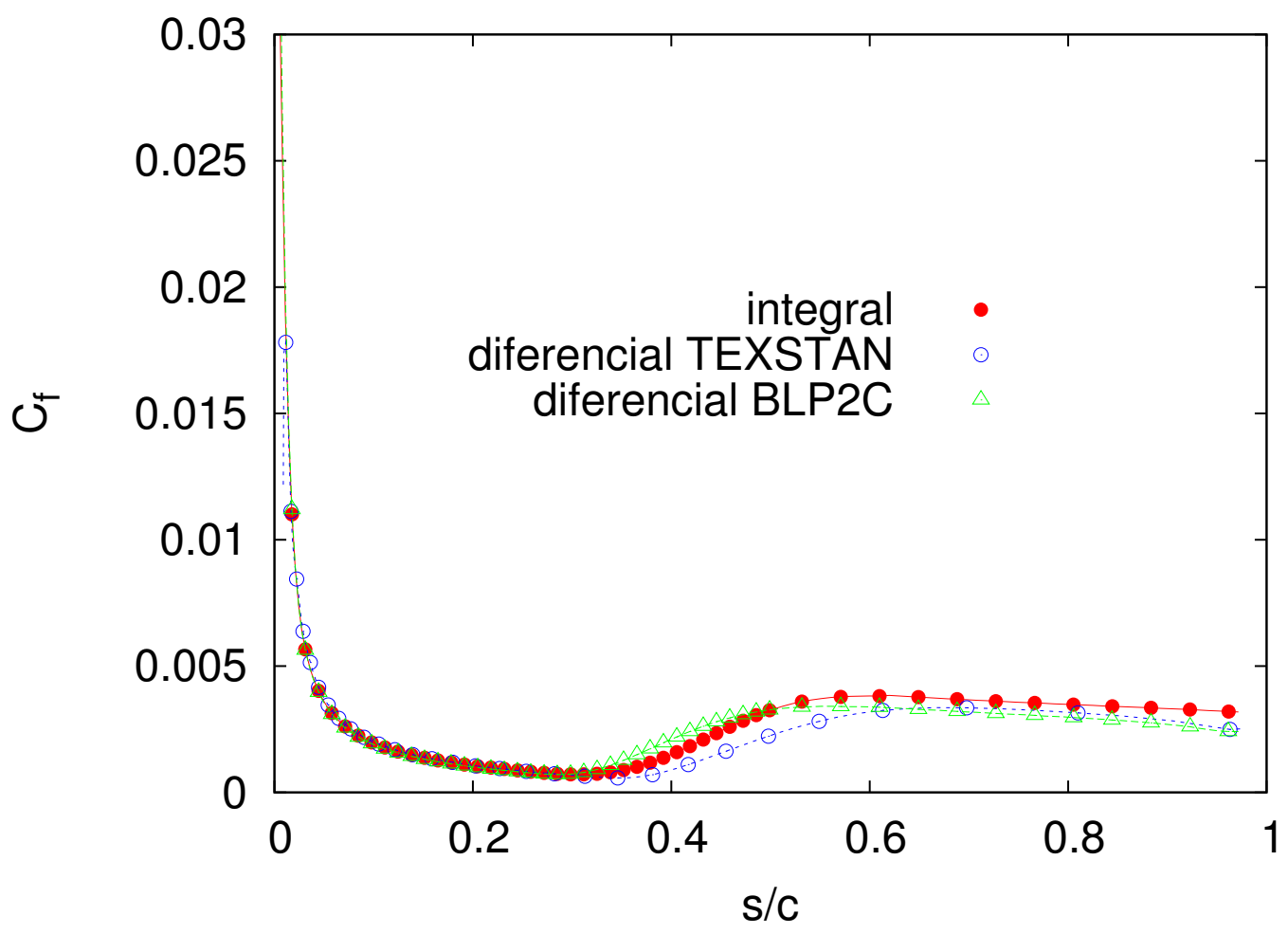

(a) Coeficiente de Atrito $-C_{f}$ - Caso $1-\mathrm{Ma}=0,4$

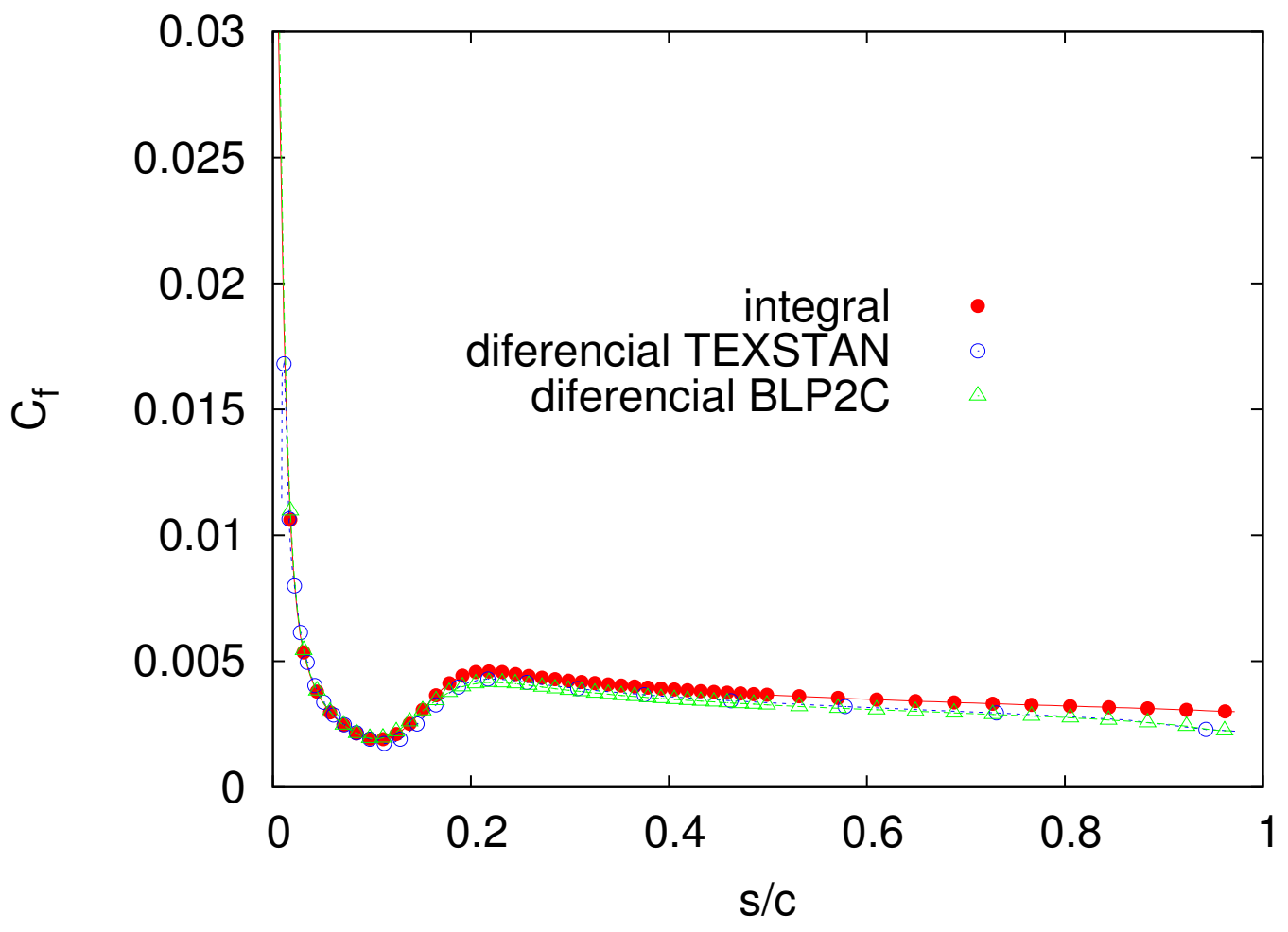

(b) Coeficiente de Atrito - $C_{f}$ - Caso 2 - Ma=0,2

Figura 4.6: Estimativas de $C_{f}$ - Casos 1 e 2 - Perfil NACA 0012 


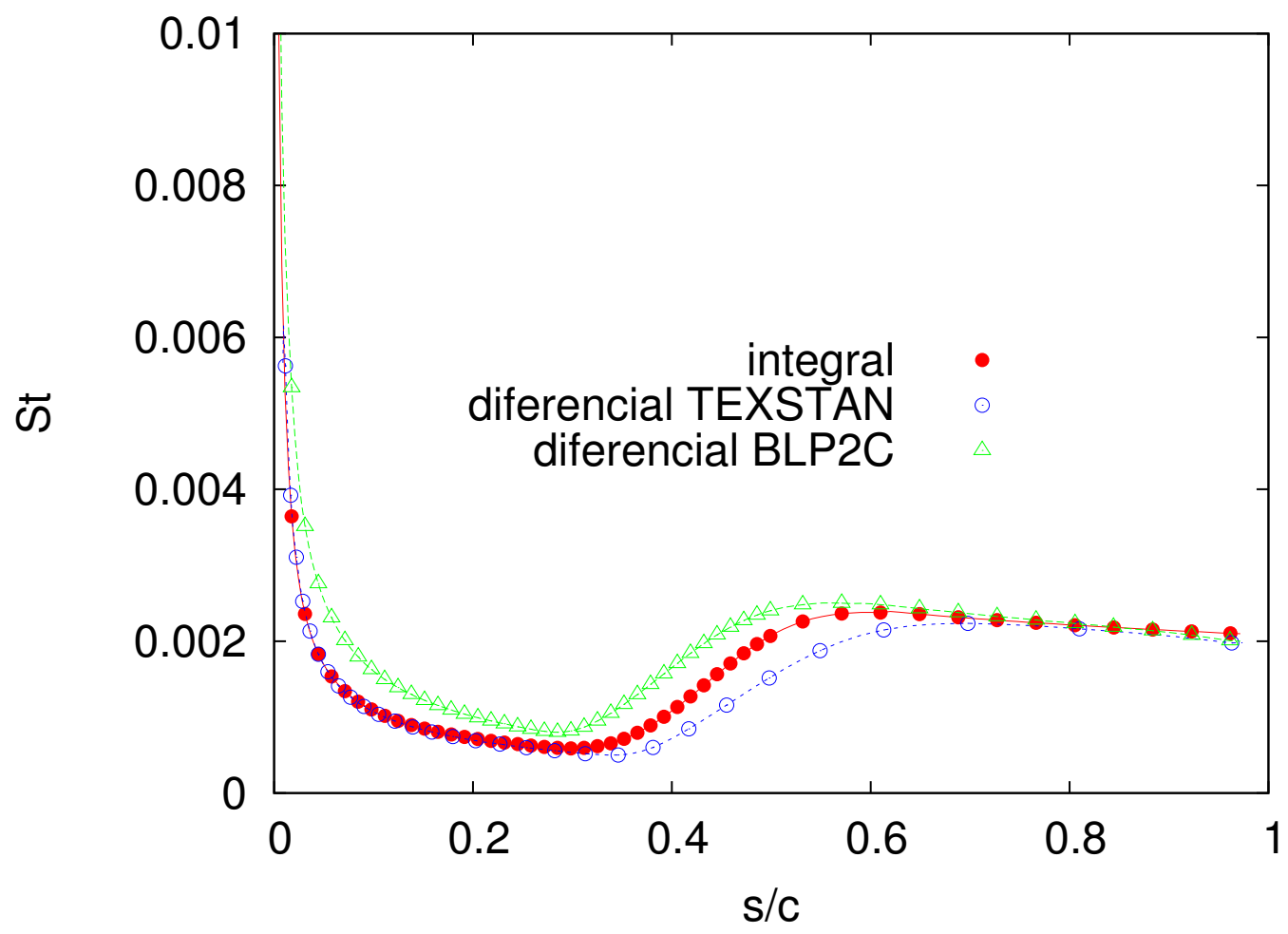

(a) Número de Stanton - St - Caso 1 - Ma=0,4

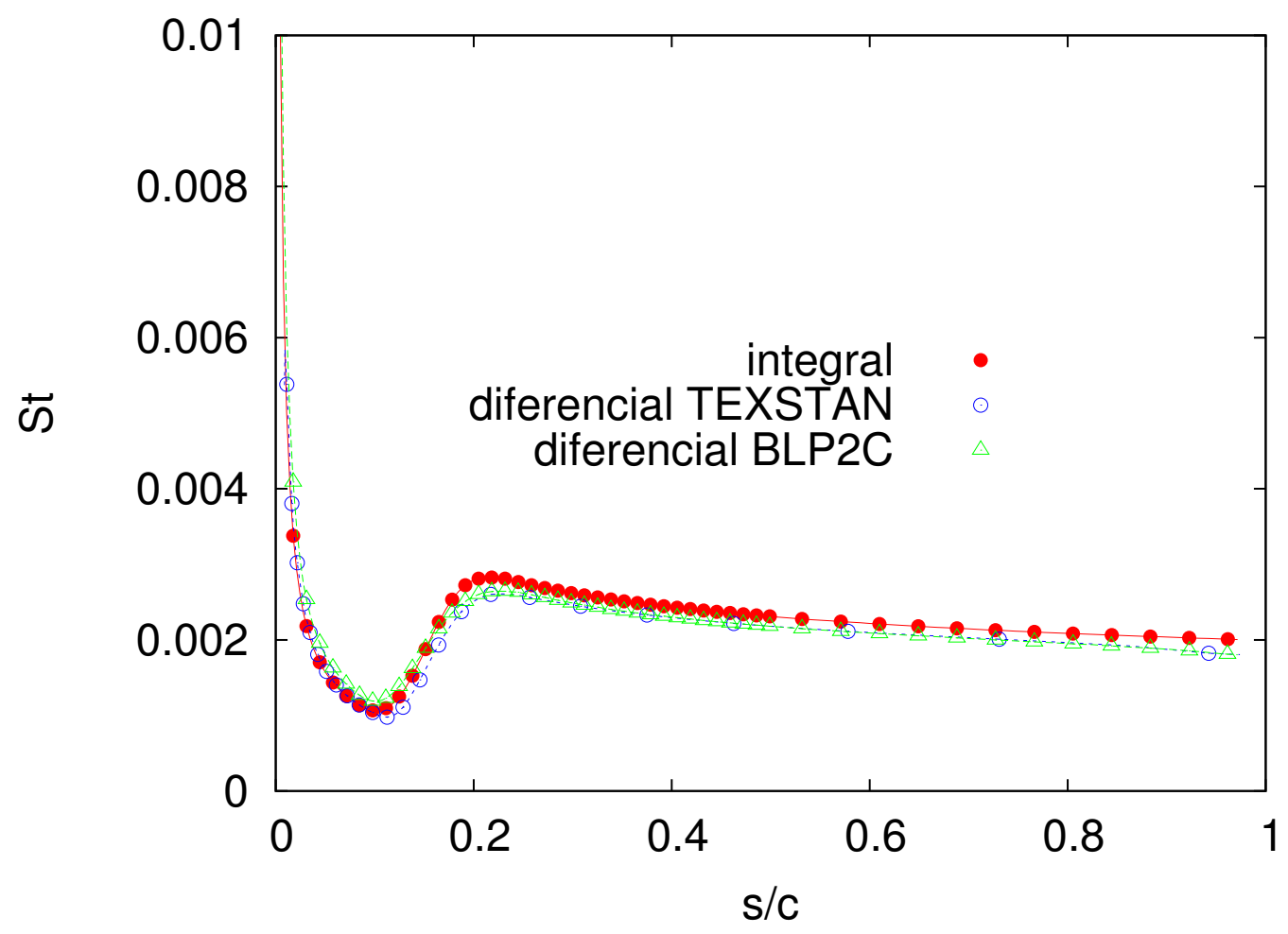

(b) Número de Stanton - St - Caso 2 - Ma=0,2

Figura 4.7: Estimativas de St - Casos 1 e 2 - Perfil NACA 0012 
Os resultados numéricos da análise integral e das diferenciais para a distribuição de $C_{f}$ apresentaram diferenças na região de transição e na região turbulenta perto do bordo de fuga do aerofólio. Como apresentado na Fig. 4.6(b), no caso 2 não houve diferença significativa entre os resultados numéricos até $s / c \approx 0,5$. A partir dessa posição, onde $\delta_{2}$ é significativo, os resultados da análise integral ficaram acima das previsões dos códigos diferenciais.

Na Fig. 4.7(a), dentro da região laminar do Caso 1, s/c<0,3, as distribuições de St local estimadas pelo procedimento integral e pelo TEXSTAN coincidiram, mas ficaram abaixo da previsão do código $B L P 2 C$, que leva em conta os efeitos de compressibilidade. Os resultados dos três programas voltam a ficar próximos entre si na região de escoamento plenamente turbulento, onde a intermitência $\gamma>0,99$, $s / c>0,7$, onde a velocidade local volta a ficar baixa e Ma $<0,3$. O mesmo fato é observado no caso 2, apresentado na Fig. 4.7(b). Devido a velocidade mais baixa, os três códigos apresentaram resultados muito próximos, inclusive ao longo da região de transição laminar-turbulenta.

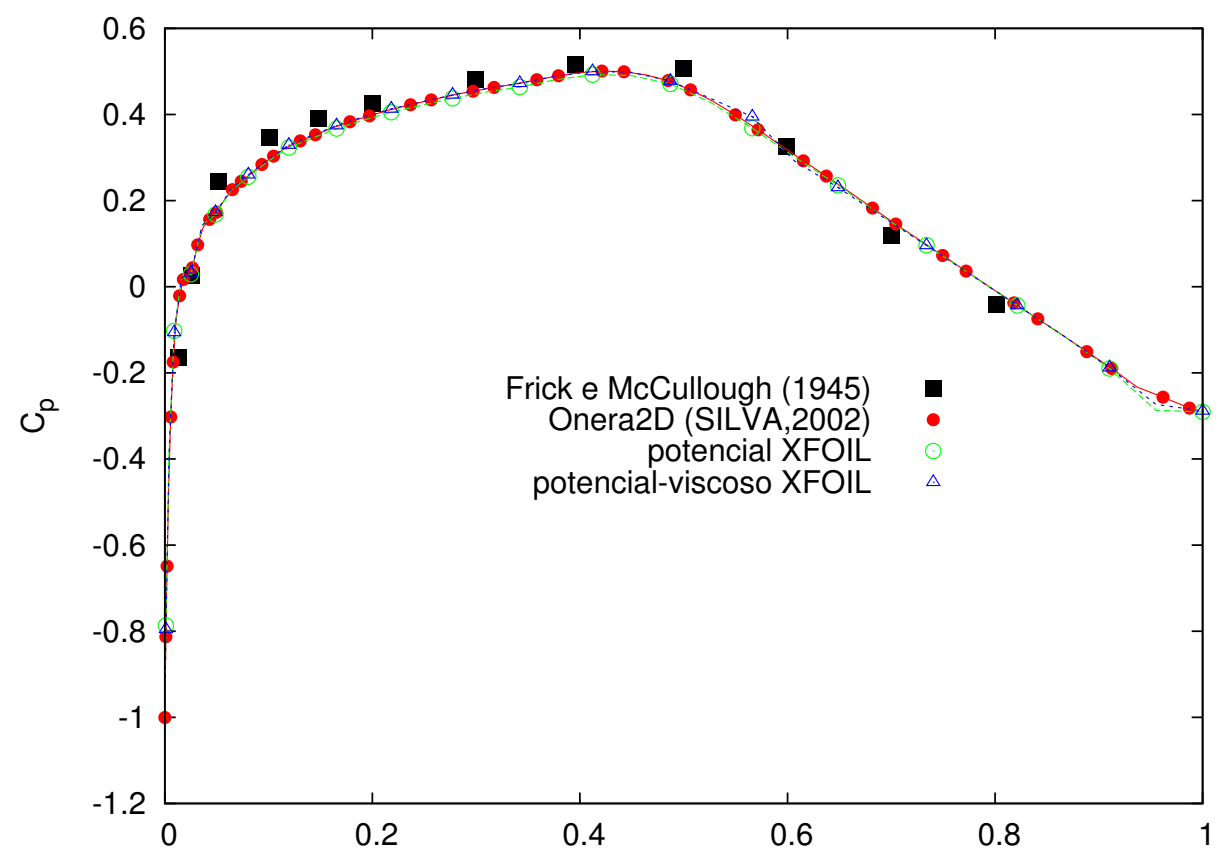

Figura 4.8: Coeficiente de Pressão - $C_{p}$ - Caso NACA 65(2)016- $\alpha=0^{\circ}$ - Transição Livre e Fixada

O número de Reynolds baseado na corda e dividido pela corda do experimento realizado por Frick e McCullough (1942) com o NACA 65(2)016 foi $\frac{\mathrm{Re}}{c}=V_{\infty} / \nu_{\infty}=$ $11 \cdot 10^{6}$. Os efeitos de compressibilidade não foram considerados pelo autor, pois o túnel de vento do Centro de Pesquisas Ames da NASA, EUA, de seção de 2,1 m por 3,05 m, foi operado em condições subsônicas. Na presente tese, admitiu-se que o escoamento ao longe possuía sempre $\mathrm{Ma}<0,3$, o que é coerente com as observações do trabalho de Frick e McCullough (1942). As medições experimentais do 


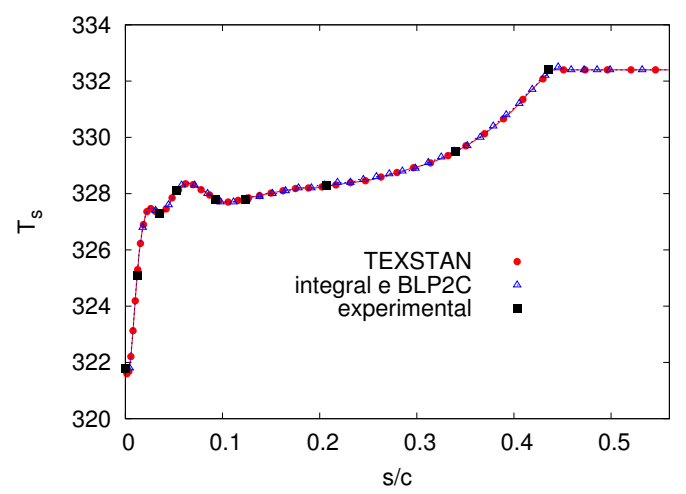

(a) Transição Livre - Superfície Não-Isotérmica

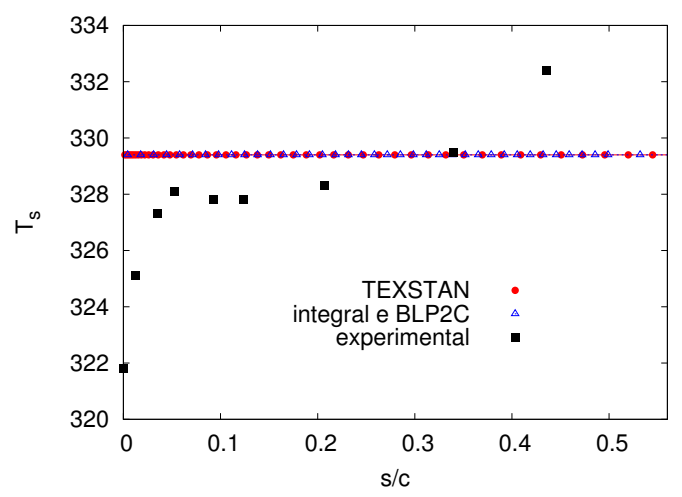

(c) Transição Livre - Superfície Isotérmica

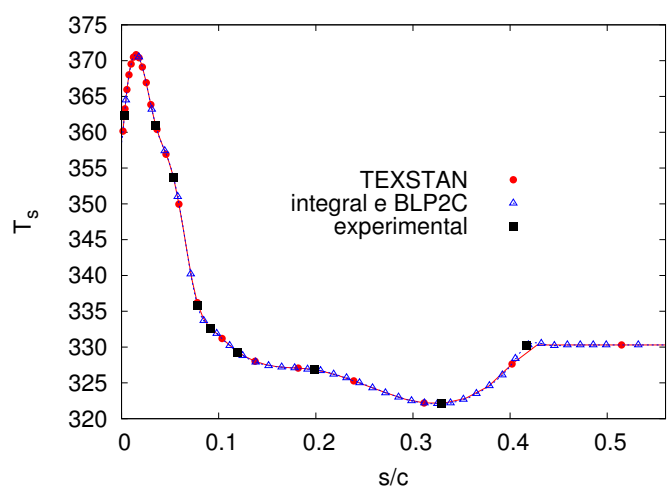

(b) Transição Fixada - Superfície Não-Isotérmica

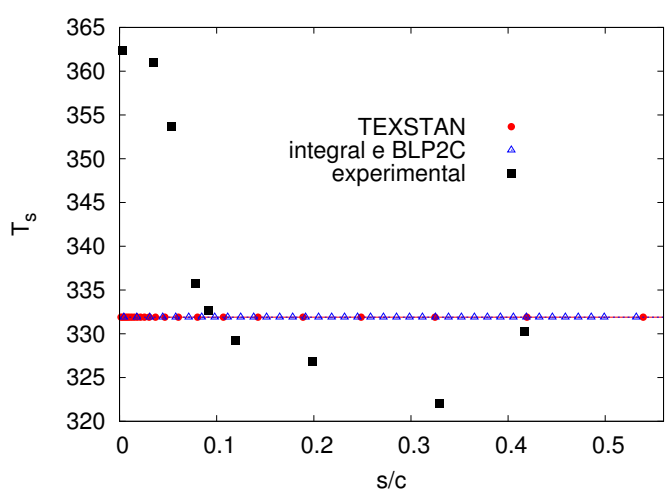

(d) Transição Fixada - Superfície Isotérmica

Figura 4.9: Temperatura de superfície - $T_{s}$ - Caso NACA 65(2)016

Tabela 4.6: Fluxo de calor estimado e seu desvio relativo ao dados experimentais (FRICK; MCCULLOUGH, 1942) de potência fornecida ao segundo compartimento $(0,146<x / c<0,263)$ do aerofólio NACA 65(2)016

\begin{tabular}{|c|c|c|c|c|c|}
\hline \multirow[b]{2}{*}{ integral } & \multirow[b]{2}{*}{ TEXSTAN } & \multirow[b]{2}{*}{$B L P 2 C$} & \multicolumn{3}{|c|}{ Frick e McCullough (1942) } \\
\hline & & & $\begin{array}{c}\text { cálculo } \\
\text { pres. trab. }\end{array}$ & $\begin{array}{l}\text { cálculo } \\
\text { original }\end{array}$ & $\begin{array}{l}\text { dados } \\
\text { teste }\end{array}$ \\
\hline \multicolumn{6}{|c|}{ Transição Livre - Superfície Não-Isotérmica- $\dot{q}$ [W] e desvio [\%] } \\
\hline 750,3 & 789,6 & 879,8 & 861,5 & 875,0 & 861,0 \\
\hline$-12,9$ & $-8,3$ & 2,2 & 0,1 & 1,6 & 0,0 \\
\hline \multicolumn{6}{|c|}{ Transição Livre - Superfície Isotérmica - $\dot{q}$ [W] e desvio [\%] } \\
\hline 780,8 & 797,1 & 891,4 & 895,9 & 875,0 & 861,0 \\
\hline$-9,3$ & $-7,4$ & 3,5 & 4,1 & 1,6 & 0,0 \\
\hline \multicolumn{6}{|c|}{ Transição Fixada - Superfície Não-Isotérmica - $\dot{q}$ [W] e desvio [\%] } \\
\hline 3846,4 & 3597,9 & 3765,0 & 3681,0 & 3750,0 & 3760,0 \\
\hline 2,3 & $-4,3$ & 0,1 & $-2,1$ & $-0,3$ & 0,0 \\
\hline \multicolumn{6}{|c|}{ Transição Fixada - Superfície Isotérmica- $\dot{q}$ [W] e desvio [\%] } \\
\hline 4965,5 & 4918, 3 & 5207,1 & 4435,7 & 3750,0 & 3760,0 \\
\hline 32,1 & 30,8 & 38,5 & 18,0 & $-0,3$ & 0,0 \\
\hline
\end{tabular}




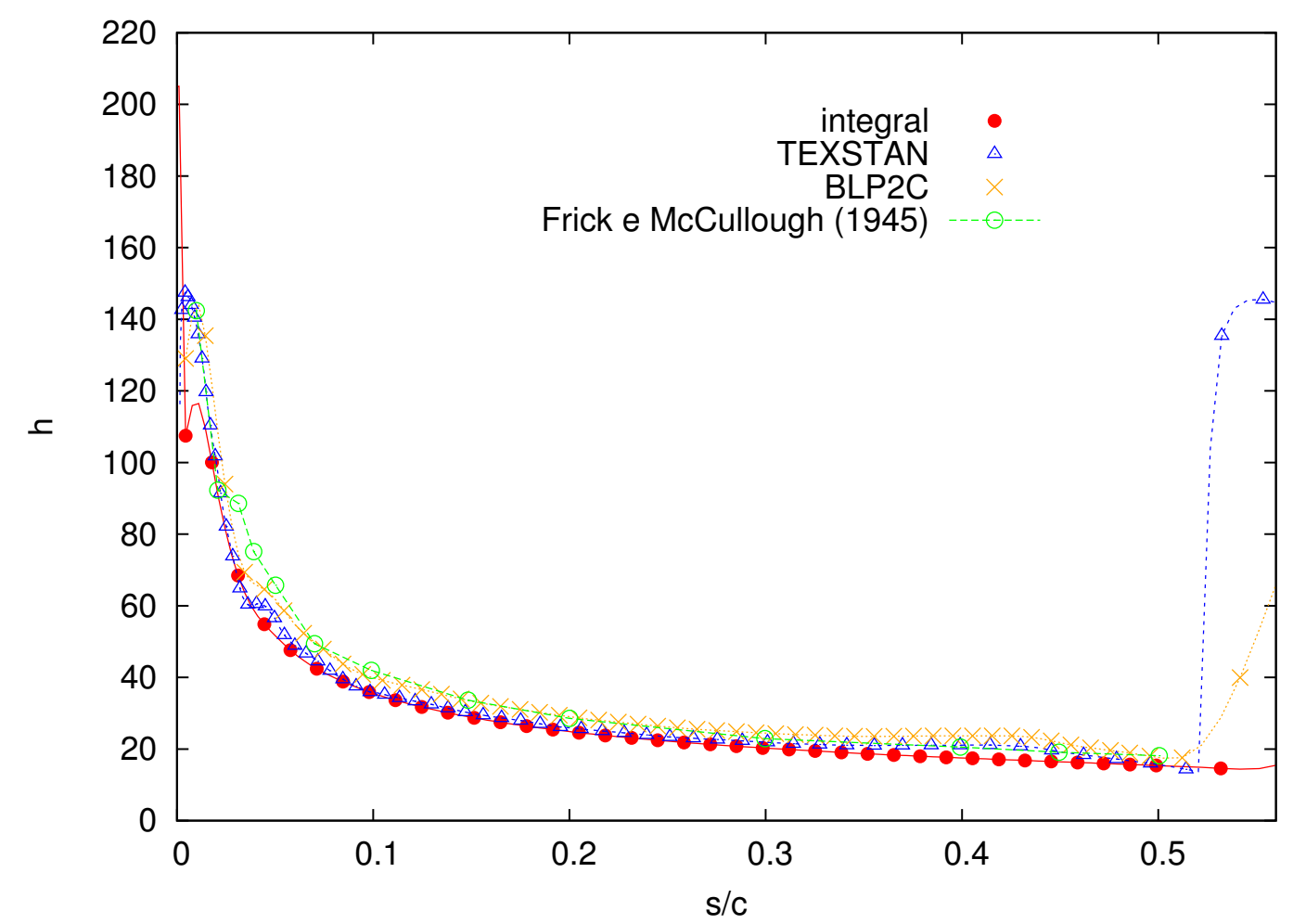

(a) Superfície Não-Isotérmica

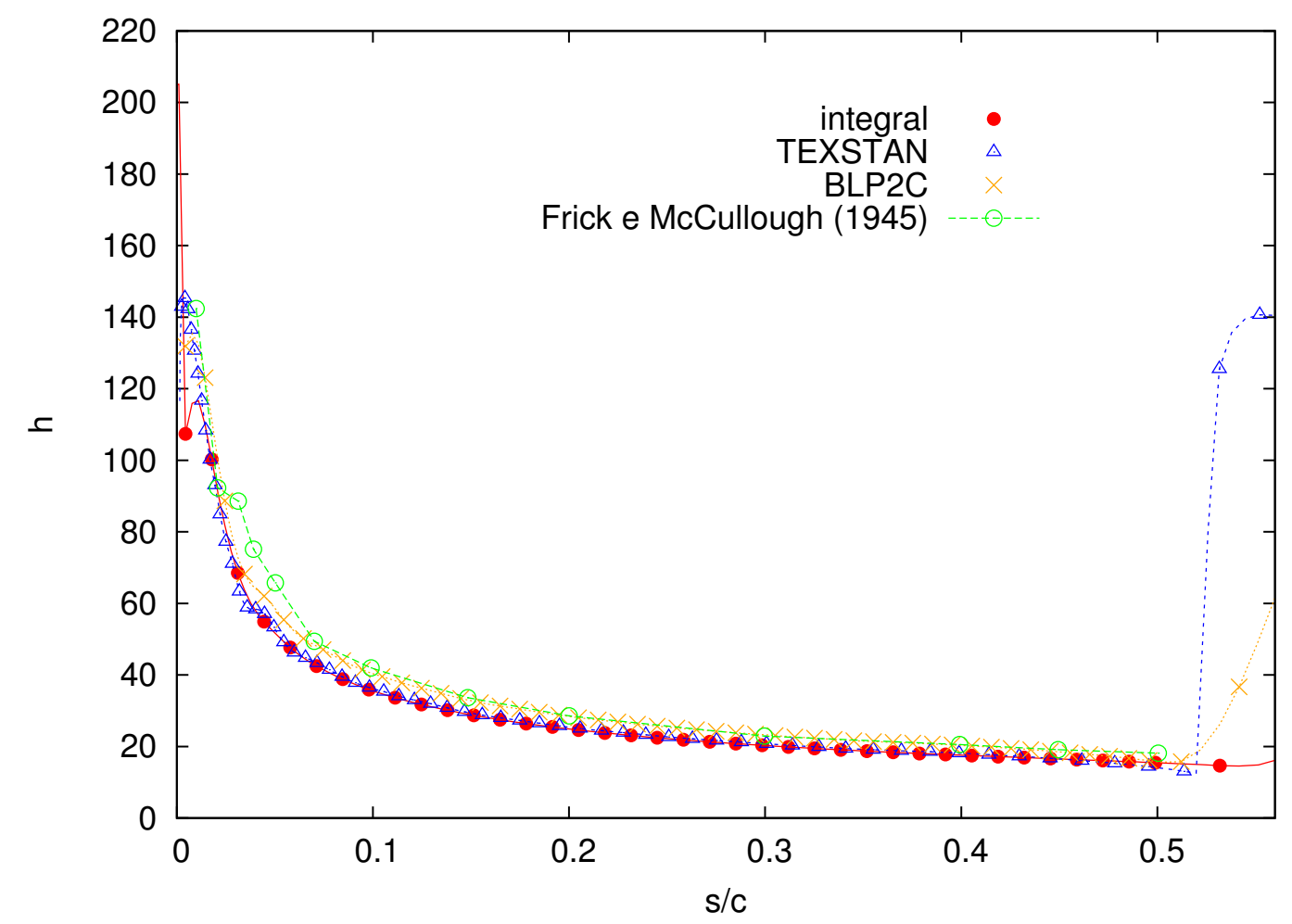

(b) Superfície Isotérmica

Figura 4.10: Coeficiente de Transferência de Calor - $h_{a r}$ - Caso NACA 65(2)016 Transição Livre 


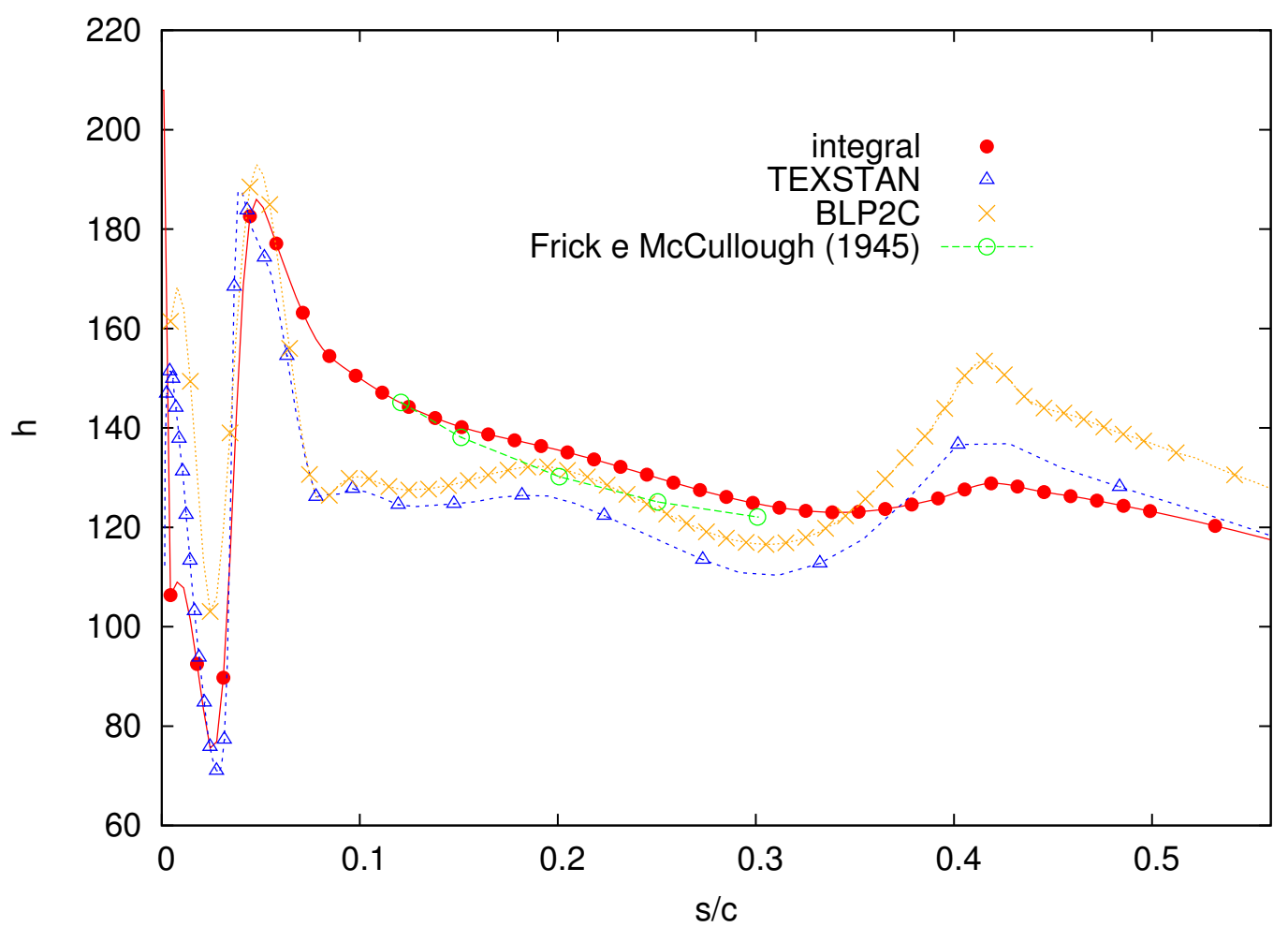

(a) Superfície Não-Isotérmica

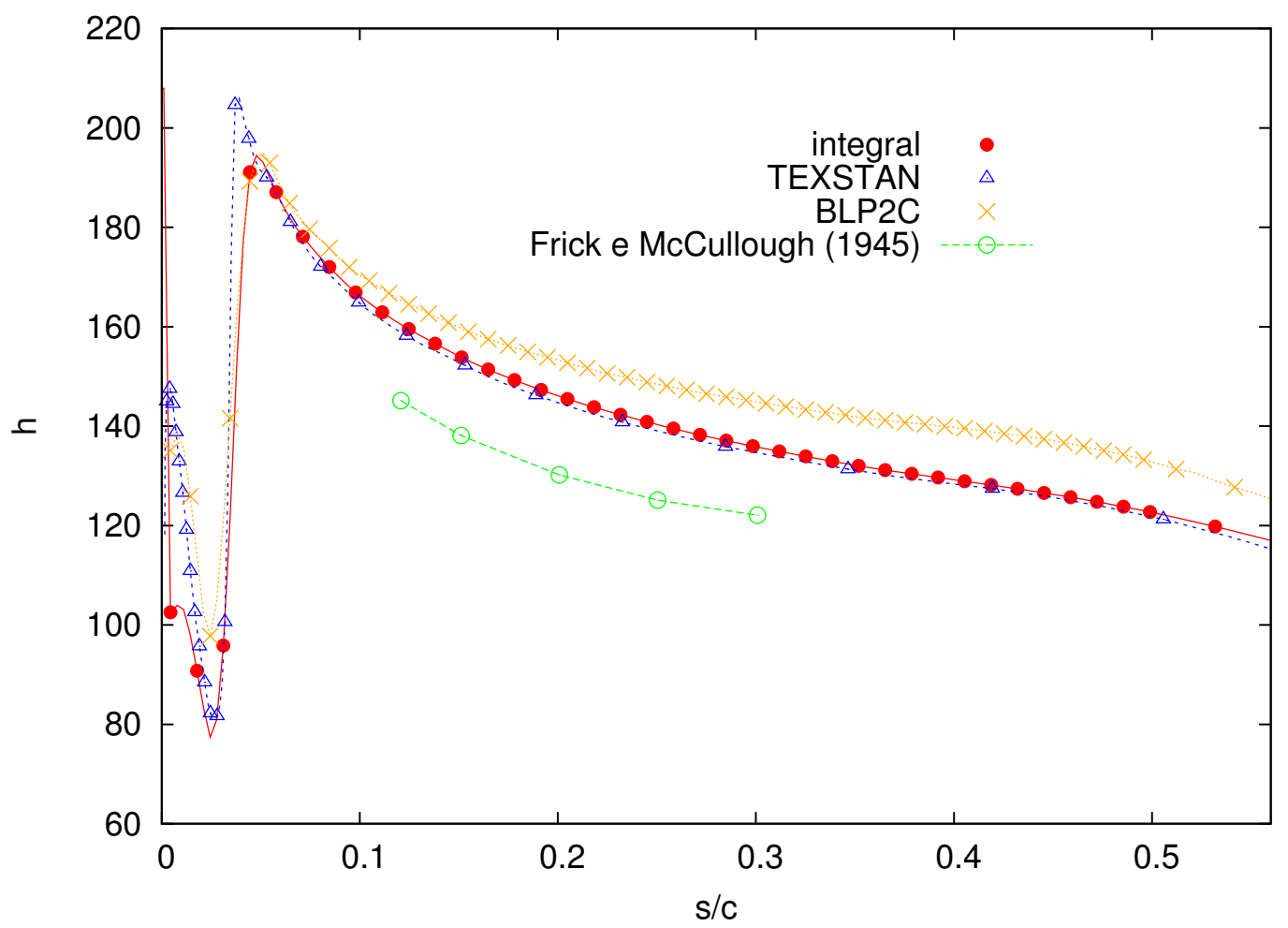

(b) Superfície Isotérmica

Figura 4.11: Coeficiente de Transferência de Calor - $h_{a r}$ - Caso NACA 65(2)016 Transição Fixada 
coeficiente de pressão, $C_{p}$, em torno do aerofólio NACA 65(2)016 são apresentadas na Fig. 4.8. Os desvios entre os dados experimentais e os resultados numéricos do ONERA2D, obtidos por Silva (2002), e os do XFOIL, obtidos no presente trabalho, são precisos suficientemente para serem usados na avaliação da camada-limite, pois representam o gradiente de pressão em torno do aerofólio.

Como mostrado na Fig. 4.8, a solução potencial do escoamento coincidiu com as soluções potencial completa, que é compressível isentrópica, e a potencial-viscosa, que considera o efeito da espessura de deslocamento, $\delta_{1}$ da camada-limite na distribuição de pressão em torno do aerofólio e, iterativamente, o efeito do gradiente de pressão na estimativa de $\delta_{1}$ (DRELA; GILES, 1987). Logo, o efeito da camada-limite e da compressibilidade na distribuição de $C_{p}$ não são significativos para o ângulo de ataque verificado, $0^{\circ}$.

A distribuição de temperaturas de superfície é apresentada na Fig. 4.9 para os casos no regime laminar, Fig. 4.9(a), e no turbulento, Fig. 4.9(b). Foi admitida que as rodadas no túnel de vento foram feitas a uma temperatura de $300 \mathrm{~K}$ e que a similaridade de Re foi valida no experimento. Apesar de ser um dos objetivos do experimento, Frick e McCullough (1942) não conseguiram manter a temperatura constante (superfície isotérmica) ao longo do segundo compartimento do perfil aquecido NACA 65(2)016. Para efeito de comparação, o presente autor propôs mais um caso laminar e um outro turbulento, nas mesmas condições originais (Tabela 4.5), mas admitindo que a superfície é isotérmica e sua temperatura é a média dos dados experimentais, como mostrado nas Figs. 4.9(c) e 4.9(d).

Para os casos de teste com o aerofólio NACA 65(2)016, foi adotado a análise integral de Ambrok (1957), descrita pelas Eqs. (4.11) e (4.14). Para o caso turbulento, a análise integral e o BLP2C utilizaram o modelo de intermitência de Abu-Ghannam e Shaw (1980). Nos casos no regime laminar, a posição de início da transição foi fixada logo a montante da posição de separação laminar, $s / c=0,56$, onde o coeficiente de atrito, $C_{f}$, se aproximou de zero. Para fixar a posição de início transição laminarturbulenta no código TEXSTAN , é necessário fornecer $\mathrm{Re}_{\delta 2, \text { crit }}$ e utilizar o modelo de intermitência de Kays e Moffat (1975). Nos casos turbulentos, a posição inicial e final foram fixadas manualmente em $s / c \approx 5 \%$, como reportado pelos autores.

Os resultados das estimativas de fluxo de calor obtidas no presente trabalho mais aqueles calculados e as potências elétricas medidas por Frick e McCullough (1942) são apresentados na Tabela 4.6. A região de interesse dos autores era o segundo compartimento aquecido, que tinha dois trechos de superfície sujeitos à convecção de calor para o escoamento externo: um no extradorso, entre 0,146< 
$x / c<0,263$, e outro no intradorso, entre $-0,146<x / c<-0,263$. Nas colunas da Tabela 4.6 são apresentados os resultados de cada procedimento de cálculo. Nas linhas são apresentados os quatro casos estudados: 1) escoamento laminar sobre superfície não-isotérmica; 2) escoamento laminar sobre superfície isotérmica; 3) escoamento turbulento sobre superfície não-isotérmica; 4) escoamento turbulento sobre superfície isotérmica. Embaixo de cada caso, há duas linhas de resultados: a primeira é o resultado do do fluxo de calor, $\dot{q}$, e a segunda é o desvio percentual do resultado de cada modelo em relação aos dados experimentais, $\left(\dot{q}-\dot{q}_{\text {exp }}\right) / \dot{q}_{\text {exp }}$. 100 , que são apresentados na última coluna. O fluxo de calor foi estimado com a área exposta, a distribuição de temperaturas de cada caso e os resultados de $h_{a r}$ obtidos pelos códigos integral, BLP2C e TEXSTAN. Esse procedimento foi aplicado por Frick e McCullough (1942) para estimar o fluxo de calor, que é apresentado na quarta coluna da Tabela 4.6. O fluxo de calor calculados, pelo presente autor, com os resultados de $h_{a r}$ de Frick e McCullough (1942) e as medições de temperatura são apresentados na quinta coluna. Já a sexta coluna da Tabela 4.6 mostra as medições da potência fornecida para cada caso.

No caso de tese de transição livre, com maior parte da superfície do aerofólio coberta pelo escoamento em regime laminar, tanto para o caso com a superfície isotérmica quanto o de superfície não-isotérmica, os resultados dos modelos estudados no presente trabalho ficaram próximos entre si e também em relação aos cálculos de Frick e McCullough (1942), que estão apresentados na Fig. 4.10. No entanto, quando são comparadas as estimativas de fluxo de calor transferidos do segundo compartimento para o escoamento, o código BLP2C teve maior sucesso entre os modelos utilizados no presente trabalho e obteve $\dot{q}=879,8 \mathrm{~W}$, ou seja, desvio de $2,2 \%$ em relação ao dado experimental $\dot{q}_{\text {exp }}=861 \mathrm{~W}$. No caso isotérmico, a Tabela 4.6 mostra que o BLP2C também foi o código que calculou mais precisamente o fluxo de calor de $891,4 \mathrm{~W}$ com desvio de 3,5\%. O desvio percentual do fluxo de calor calculado pelo presente autor com o $h_{a r}$ estimado por Frick e McCullough (1942) foi de 0,1\%, bem menor do que os 1,6\% calculado pelos próprios Frick e McCullough (1942). Isso indica que houve diferenças no procedimento de integração $\int h_{a r} \Delta T d s$ adotado pelos autores do experimento e aquele implementado pelo presente autor.

Antes de analisar a Fig. 4.11, é preciso lembrar que Frick e McCullough (1942) não mediram o coeficiente de transferência de calor e que apenas o estimaram numericamente. Os autores desenvolveram um análise integral da camada-limite no regime laminar e turbulento, com transição abupta e que admite que a superfície do aerofólio é isotérmica.

Como observado na na Fig. 4.11(a), o $h_{a r}$ estimado pelos códigos utilizados no 
presente trabalho apresentou oscilações. Esse é um efeito esperado já que a temperatura variável de superfície causa variações mais acentuadas no $h_{a r}$ do $B L P 2 C$ e TEXSTAN, menos acentuadas no $h_{a r}$ da análise integral e nenhuma variação no $h_{a r}$ de Frick e McCullough (1942). Consequentemente, a Fig. 4.11(b) apresenta as previsões numéricas dos presentes códigos sem oscilações, pois a temperatura de superfície é constante. No entanto, observa-se que a distribuição de $h_{a r}$ da Fig. 4.11(b) está num nível médio maior do que as Fig. 4.11(a).

Em termos de fluxo de calor total estimado no segundo compartimento considerando a superfície não-isotérmica, a Tabela 4.6 mostra que o código $B L P 2 C$ obteve estimativas de $\dot{q}=3765 \mathrm{~W}$ e um desvio de $0,1 \%$ em relação a potência elétrica fornecida. Entretanto, com a consideração de superfície isotérmica, todas as estimativas feitas pelo presente autor ficaram com desvios significativos, inclusive aquela que utiliza o $h_{a r}$ calculado pelos autores do experimento. Esse fato demonstra que a variações de temperatura de superfície e seus efeitos no coeficiente de transferência de calor são importantes para a estimativa do fluxo de calor na superfície.

\subsection{Comentários}

O presente capítulo apresentou e verificou a implementação das análises integral e diferencial de camada-limite que podem ser aplicadas ao modelo-base do escoamento em torno de aerofólios com sistema térmico de antigelo, apresentado no Capítulo 2 . Com exceção do modelo de Ambrok (1957), que foi implementado na dissertação de mestrado, todos os outros modelos foram selecionados, no caso dos códigos diferenciais, e implementados, no caso das análises integrais, na presente tese.

Logo, foram incluídos no programa de simulação térmica do aerofólio com sistema antigelo diversas opções de modelos de camada-limite, a saber:

- análise integral de camada-limite sobre superfície isotérmica no regime laminar e turbulento;

- análise integral de camada-limite, no regime laminar e turbulento, por meio da sobreposição de soluções isotérmicas;

- análise diferencial de camada-limite por meio da incorporação do código $B L P 2 C$;

Os resultados finais, considerando a molhabilidade parcial da superfície, os mo- 
delos de camada-limite e transição laminar-turbulenta, são apresentados e discutidos no Capítulo 6. As conclusões finais da presente tese podem ser encontradas no Capítulo 7. 


\section{Modelagem da TRANSIÇÃo LAMINAR-TURBULENTA EM TORNO DE AEROFÓLIOS COM Sistema TÉrmico de ANTIGElo}

A instabilidade do escoamento laminar e a transição do escoamento laminar para o turbulento são problemas de mecânica dos fluidos sem resposta definitiva desde os experimentos em dutos de Osborn Reynolds em 1883. Mesmo depois de mais de 125 anos o fenômeno da transição laminar-turbulenta não pode ser explicado completamente ou previsto com a precisão desejada (DRAZIN; REID, 2004).

As questões mais importantes no estudo da transição são:

1) Quais são os mecanismos que levam à turbulência?

2) Depois que as estruturas turbulentas são formadas, como ocorre a evolução do escoamento até o início do escoamento plenamente turbulento?

Para nenhuma das duas perguntas há respostas definitivas, ou seja, não há teoria física ou propriedade matemática que descrevam genericamente o início e o desenvolvimento da transição laminar-turbulenta (ARNAL, 1994; REED; SARIC, 2006).

A presença da transição laminar-turbulenta é importante para o desempenho térmico ou mecânico de componentes e equipamentos. Alguns problemas de engenharia típicos, encontrados na literatura, que dependem do conhecimento do processo transicional são:

- projeto de proteção térmica para veículos de reentrada na atmosfera;

- redução de arrasto de atrito de asas de aviões comerciais de transporte;

- resfriamento de palhetas (aerofólios) de turbinas a gás;

- redução de arrasto de navios e submarinos; 
- determinação de coeficiente de sustentação máximo de asas de aeronaves;

- geometria do gelo formado em bordos de ataque de asas de aeronaves civis;

- transferência de calor em aerofólios com sistema térmico de proteção contra formação de gelo.

Segundo Spalart (1996), na previsão do desempenho aerodinâmico de aeronaves comerciais convencionais em voos de alta velocidade, dependendo do tipo de aerofólio, a região coberta pelo escoamento laminar pode ser considerada pequena em relação àquela coberta pelo escoamento turbulento em torno da aeronave. $O$ autor considera aceitável a aproximação de escoamento plenamente turbulento em torno de toda a aeronave, já que a diferença entre as soluções, totalmente turbulenta e outra com trechos de escoamento laminar, seria pequena se comparadas ao arrasto total da aeronave.

Em termos de efeito médio da transferência de calor e de massa, tanto a posição inicial, $s_{t r}$, quanto o comprimento, $\Delta s_{t r}=s_{e}-s_{t r}$, da transição laminar-turbulenta são importantes na previsão da operação de sistema de antigelo de aerofólios. O trecho laminar não pode ser desprezado, já que, a área coberta pelo escoamento laminar pode ser significativa quando comparada à área total protegida contra formação de gelo. Um desvio na estimativa na posição ou comprimento da transição pode causar um desvio significativos na estimativa da transferência de calor e de massa, pois a transição laminar-turbulenta pode ocorrer dentro da região aquecida pelo sistema antigelo e sobre o escoamento de água líquida, o que afeta tanto a convecção de calor quanto a de massa. Isso também é observado no cálculo da força arrasto e da sustentação de asas, que são avaliações médias, portanto são integrais de valores locais de coeficientes de atrito, $C_{f}$, e de pressão, $C_{p}$, sobre toda a área exposta ao escoamento.

Nos seus estudos, Sogin (1954) observou que a estimativa do coeficiente de transferência de calor em torno das asas de aeronaves requer o conhecimento sobre o processo de transição do escoamento laminar para o turbulento. O mesmo autor notou a existência de uma região de transição laminar-turbulenta de comprimento finito, que pode ser mais longa nos túneis de gelo do que em voo sob condições naturais de formação de gelo.

O desempenho térmico de sistemas antigelo de aerofólios aeronáuticos é definido pela posição onde a água evapora totalmente ou pela posição e taxa inicial de congelamento de água, ou seja, é definido pela distribuição de valores locais de temperatura $T_{s}$ e vazão de água $\dot{m}_{\text {agua }}$ em torno do aerofólio, que dependem dos valores 
locais de coeficiente de transferência de calor e de massa. Como o cálculo é parabolico, esses coeficientes locais são influenciados pelos seus valores a montante. Assim, há uma influência da história do escoamento no desempenho do sistema antigelo.

A temperatura de superfície sólida $T_{s}$ e a vazão de água líquida $\dot{m}_{a g u a}$ são valores locais distribuídos ao longo da superfície do aerofólio. Como a ocorrência da transição laminar-turbulenta influencia diretamente mais os valores locais do que os médios, a previsão dos parâmetros operacionais do sistema antigelo depende fortemente da estimativa do início e do término da região de transição laminar-turbulenta.

O conhecimento do processo de transição laminar-turbulenta é necessário para estimar grandezas médias relacionadas com o desempenho térmico do sistema antigelo, como demanda térmica imposta pelo voo em condições de gelo. No entanto, o processo transicional é fundamental para prever valores locais de temperatura de superfície e, consequentemente, de distribuição de vazão de água líquida, que determina o ponto de congelamento ou evaporação da água líquida.

Similarmente, devido a relevância da distribuição de temperaturas para fins de projeto estrutural e de seleção de materiais para uma vida operacional mais longa, o conhecimento do comportamento dinâmico e térmico da camada-limite na transição laminar-turbulenta é também importante para a estimativa da distribuição de temperatura na superfície das pás das turbinas a gás (MAYLE, 1991).

A importância do efeito da transição laminar-turbulenta na operação de sistemas de proteção contra formação de gelo em aerofólios é confirmada pelas observações pioneiras de Sogin (1954) e pelos trabalhos mais recentes de Potapczuk (1999), AlKhalil et al. (2001) e Silva (2002). Evidências experimentais (KERHO; BRAGG, 1997) e alguns resultados de simulações numéricas (STEFANINI et al., 2007; STEFANINI et al., 2008) indicam que a posição inicial e o comprimento da região de transição laminar-turbulenta também podem ser importantes para determinação da geometria do gelo formado em aerofólios não aquecidos.

Geralmente, os códigos clássicos de formação de gelo admitem a ocorrência de uma processo transicional abrupto numa posição $s_{t r}$. Com base em evidências experimentais, o presente trabalho propõe a representação de uma região de transição, onde o escoamento passa do regime laminar ao turbulento. Usualmente, os parâmetros da região de transição, que definem o seu início e término, são determinados a partir de dados experimentais, correlações algébricas ou com base na experiência de engenharia. 
A Tabela 5.1 apresenta alguns modelos empíricos para previsão do início e término da região de transição do escoamento laminar para o turbulento.

Tabela 5.1: Modelos empíricos para previsão de início e término da região de transição laminar-turbulenta

\begin{tabular}{|c|c|c|c|}
\hline Previsão & Autor & Variáveis & Aplicado por \\
\hline início & Makkonen (1985) & $\begin{array}{l}\text { rugosidade } k_{s} \text { e } \\
\text { parâmetro } \\
\delta_{2}^{2} / \mu \cdot d u_{e} / d s\end{array}$ & ONERA \\
\hline início & $\begin{array}{l}\text { von Doenhoff e } \\
\text { Horton (1956) }\end{array}$ & rugosidade $k_{s}$ & $\begin{array}{l}\text { LEWICE, } \\
\text { TRAJICE2 }\end{array}$ \\
\hline início & Michel (1951) & $\operatorname{Re}_{s}$ e $\operatorname{Re}_{\delta_{2}}$ & $\begin{array}{l}\text { CANICE FD e } \\
B L P 2 C\end{array}$ \\
\hline término & $\begin{array}{l}\text { Chen e Thyson } \\
\text { (1971) }\end{array}$ & $\begin{array}{l}\text { gradiente de } \\
\text { pressão } d p / d s\end{array}$ & $\begin{array}{l}\text { CANICE FD, } \\
\text { Fortified-LEWICE } \\
\text { e } B L P 2 C\end{array}$ \\
\hline início e término & $\begin{array}{l}\text { Abu-Ghannam e } \\
\text { Shaw (1980) }\end{array}$ & $\begin{array}{l}\text { parâmetro } \\
\delta_{2}^{2} / \mu \cdot d u_{e} / d s \text { e } \\
\text { nível de } \\
\text { turbulência } T u\end{array}$ & $\begin{array}{l}\text { presente trabalho } \\
\text { (integral e } \\
\text { diferencial), } \\
\text { TEXSTAN }\end{array}$ \\
\hline
\end{tabular}

\subsection{Modelagem do Processo de Transição do Escoa- mento Laminar para o Turbulento}

A transição do escoamento laminar para o turbulento está diretamente relacionada ao conceito de estabilidade. Um estado físico é considerado estável quando suporta uma perturbação finita e retorna ao seu estado inicial. Por outro lado, se não há retorno ao estado original, o estado é considerado instável. O estado final pode ser completamente diferente do estado inicial, não sendo apenas um desvio do estado inicial. Um estado que é estável para pequenas perturbações, mas instável para perturbações maiores, é denominado metaestável. O objetivo do estudo da estabilidade de um sistema físico é testar os efeitos de uma perturbação particular. Para pequenas perturbações, as equações linearizadas de estabilidade podem ser aplicadas ao sistema com sucesso. Antes de abordar as análises de estabilidade de escoamentos laminares, é importante entender os estágios que levam à formação das erupções (spots) e núcleos (puffs) turbulentos. Segundo Arnal (1984), os estágios podem ser definidos como: 1) receptividade, no qual as perturbações são internalizadas pelo escoamento da camada-limite laminar; 2) instabilidade linear, no qual as instabilidades predominantes podem ser descritas pela análise linear de es- 
tabilidade do escoamento laminar na camada-limite; 3) instabilidade não-linear, no qual há o domínio de instabilidades não-lineares.

As posições onde ocorre o início da instabilização do escoamento laminar e, mais a jusante, o início do escoamento plenamente turbulento, podem ser representadas em termos de número de Reynolds baseados nos parâmetros da camada-limite $\left(\delta_{1}\right.$, $\delta_{2}$ ). Para um escoamento no regime laminar, com baixo nível de turbulência ao longe e sem gradiente de pressão sobre uma placa plana em ângulo de ataque nulo com superfície lisa, adiabática e sem transpiração, Schlichting e Gersten (2000) utilizaram resultados das equações de estabilidade linear e dados experimentais para estimar o limite de indiferença, abaixo do qual o escoamento laminar é plenamente estável independente da perturbação:

$$
R e_{\delta_{1, \text { ind }}} \geq 520
$$

Schlichting e Gersten (2000), a partir das mesmas hipóteses, definem o local onde a transição laminar-turbulenta se completa, denominado ponto crítico, e o escoamento plenamente turbulento ocorre:

$$
R e_{\delta_{1, \text { crit }}} \geq 950
$$

Alternativamente ao uso de $R e_{\delta_{1, \text { crit }}}$, alguns autores, encontrados na pesquisa bibliográfica, definem os limites da região de transição em termos de $\mathrm{Re}_{s}$.

A Fig. 5.1 apresenta os estágios de desenvolvimento da transição sobre uma placa plana como definidos por Schlichting e Gersten (2000):

Estágio 1 - é a região onde o escoamento laminar é estável e indiferente às perturbações das condições iniciais ou de contorno geradas pelo ambiente ou pela superfície;

Estágio 2 - é a região onde o escoamento laminar responde linearmente às perturbações, que podem ser amplificadas ou atenuadas, e desenvolve as denominadas ondas Tollmien-Schlichting (T-S);

Estágio 3 - é a região onde o escoamento laminar responde de forma não-linear às perturbações e desenvolve estruturas tridimensionais que interagem entre si como ondas e vórtices;

Estágio 4 - é a região onde ocorre há o decaimento dos vórtices, ou seja, ocorre a ruptura e diminuição das dimensões das estruturas tridimensionais; 
Estágio 5 - é a região onde há o aparecimento de erupções turbulentas perto da superfície da placa plana e a geração de núcleos turbulentos coesos (os chamados puffs'), que são arrastados pelo escoamento;

Estágio 6 - é a região onde o escoamento é plenamente turbulento, estável e em regime permanente.

No estágio (1) da Fig. 5.1, o escoamento dessa região é em regime laminar e estável. Já entre o início do estágio (2) e o término do estágio (5), o escoamento ainda é considerado laminar por alguns autores. No entanto, os mecanismos de transporte de quantidade de movimento, calor e de massa nessa região apresentam desvios em relação às características esperadas de um escoamento laminar pleno, pois contém perturbações e instabilidades. Outros autores, como Hassan (2006), consideram o regime do escoamento como sendo laminar perturbado entre os estágios (2) e (5). Essa região é onde as perturbações geradas pelo ambiente, pela superfície ou pelos mecanismos intrínsecos do escoamento agem sobre a camada-limite laminar. $A$ resposta dinâmica da camada-limite às perturbações determina o crescimento das instabilidades que levam ao aparecimento das erupções turbulentas. As pesquisas sobre receptividade e de estabilidade da camada-limite são concentradas nesse trecho do escoamento.

O estágio (5) da Fig. 5.1 é onde os modelos clássicos são aplicados para descrever a variação dos parâmetros da camada-limite $\left(\delta_{2}, \Delta_{2}\right.$. $C_{f}$ e St) ao longo da transição laminar-turbulenta. Dentro estágio (5) é que a intermitência do escoamento, $\gamma$, é definida como a fração de tempo na qual o escoamento é turbulento numa posição. Do início ao término do estágio (5), há um aumento do número de erupções turbulentas e de núcleos turbulentos (puffs). Com aglutinação dos núcleos turbulentos vizinhos, há também um aumento nas suas dimensões. Assim, a intermitência $\gamma$ indica a frequência de passagem e o tempo de passagem (comprimento) desses núcleos turbulentos por um sensor posicionado ao longo do estágio (5).

\subsubsection{Mapeamento das Rotas de Transição Laminar-turbulenta}

A rota para a turbulência depende da receptividade da camada-limite às perturbações forçadas geradas no ambiente, que podem ser flutuações de natureza transitórias ou permanente (SARIC; REED, 2006). A receptividade fornece as condições iniciais de perturbação de amplitude, frequência e fase para o início da instabilidades do escoamento no regime laminar. A camada-limite responde dinâmicamente às perturbações forçadas na forma de oscilações de velocidade, que podem ser atenuadas 


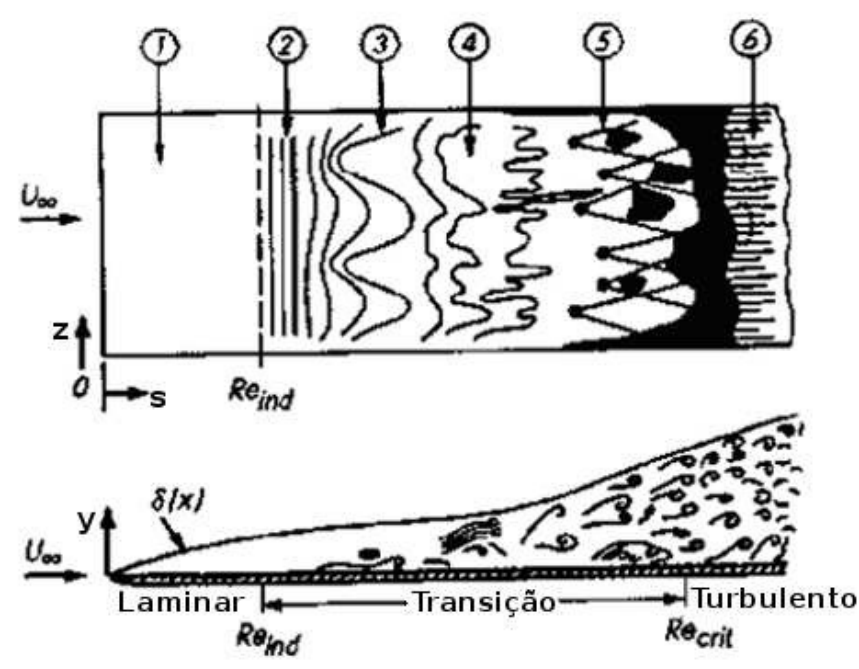
(1) regime laminar estável;
(2) ondas T-S instáveis;
(3) ondas tridimensionais e for- mação de vórtices;

(4) decaimento de vórtices;
(5) erupções turbulentas e nú- cleos $(0 \leq \lambda<1)$;

(6) regime turbulento pleno $(\lambda=1)$.

Figura 5.1: Esquema da transição laminar-turbulenta numa camada-limite sobre uma placa plana sem gradiente de pressão e ângulo de incidência nulo (SCHLICHTING; GERSTEN, 2000).

ou amplificadas na direção do escoamento dependendo das características da perturbação. A evolução dinâmica das instabilidades no escoamento da camada-limite laminar pode ser linear ou não-linear. Esses dois tipos de processos de transição podem ser distinguidos:

1) Se a amplitudes das perturbações forçadas forem infinitesimais, pode-se observar o aparecimento de oscilações mais ou menos regulares, que são denominadas ondas de Tollmien-Schlichting (T-S). São oscilações na velocidade instantânea, $u^{\prime}$, ao longo da largura da placa plana. Suas amplitudes podem ser amplificadas ou atenuadas ao longo do escoamento. Como as perturbações são infinitesimais, a equação da camada-limite de quantidade de movimento é linearizada e seu comportamento dinâmico é aproximadamente representado por uma equação diferencial homogênea de quarta ordem. As frequências d as oscilações são denominadas naturais ou autovalores. As amplitudes das oscilações, associadas a cada frequência de resposta, podem ser amplificadas até um nível crítico e causar a transição laminar-turbulenta. Esse processo é chamado de transição natural.

2) Se a amplitude das perturbações forçadas não for fraca (por exemplo, devido a presença de nível alto de turbulência do escoamento livre e elementos rugosos), os fenômenos não-lineares podem ocorrer e causar a transição a uma distância curta do bordo de ataque do corpo. Este mecanismo foi chamado de contorno (bypass) por Morkovin (1989), já que alguns processos da transição natural não ocorrem, ou seja, são contornados. 
Uma convenção sobre a classificação dos níveis de turbulência é dada por Reed e Saric (2006) como: 1) baixo quando a amplitude média da flutuações turbulentas é da ordem de $\overline{u^{\prime}} \leq 10^{-3} \mathrm{~m} / \mathrm{s}$; 2) moderado quando $\overline{u^{\prime}}<10^{-3}<10^{-2} \mathrm{~m} / \mathrm{s}$; 3) alto quando $\overline{u^{\prime}}<10^{-2}<10^{-1} \mathrm{~m} / \mathrm{s}$; 4) muito alto quando $\overline{u^{\prime}} \geq 10^{-1} \mathrm{~m} / \mathrm{s}$.

O nível de turbulência num escoamento também pode ser definido em termos da fração da velocidade ao longe:

$$
T u=\frac{\sqrt{\frac{1}{3}\left(\overline{u^{\prime 2}}+\overline{v^{\prime 2}}+\overline{w^{\prime 2}}\right)}}{V_{\infty}}
$$

Onde $u^{\prime}$ é flutuação turbulenta na direção do escoamento, $v^{\prime}$ é a flutuação turbulenta na direção normal a superfície e $w^{\prime}$ é a flutuação turbulenta da largura. Se for admitido que a turbulência ao longe foi gerada de forma isotrópica $\left(u^{\prime}=v^{\prime}=w^{\prime}\right)$, a Eq. (5.3) resulta em:

$$
T u=\frac{\sqrt{\overline{u^{\prime 2}}}}{V_{\infty}}
$$

Logo, considerando a convenção de nível de turbulência, a Eq. (5.4) e um escoamento com velocidade ao longe de $V_{\infty}=100 \mathrm{~m} / \mathrm{s}$, o nível de turbulência é considerado baixo quando $T u \leq 0,001 \%$, moderado quanto $0,001 \%<T u<0,01 \%$, alto quando $0,01 \%<T u<0,1 \%$, e muito alto quando $T u \geq 0,1 \%$.

A transição do escoamento laminar para o turbulento pode seguir várias rotas dependendo das perturbações geradas pelo ambiente. Como representado na Fig. 5.2, rota para o início da transição laminar-turbulenta depende das características das perturbações. Se elas forem de baixa amplitude, ocorre a transição natural, com predomínio de mecanismos lineares, e o processo segue pela rota A da Fig. 5.2. Por outro lado, na presença de perturbações de grande amplitude, o processo de transição pode seguir a rota $E$, ou seja, vai diretamente ao colapso turbulento. Esse último processo é fortemente não-linear e rápido (curto). É um contorno (bypass) das instabilidades lineares e do processo de transição natural.

Finalmente, as rotas B, C e D da Fig. 5.2 são rotas intermediárias iniciadas pelo crescimento transitório de perturbações (transient growth) de natureza linear. Essas instabilidades são geradas pela combinação linear entre as oscilações de frequências naturais ou fundamentais (REED; SARIC, 2006). Se as amplitudes máximas das perturbações transitórias forem suficiente intensas, a rota do processo de transição laminar-turbulenta é iniciada e continua até o colapso do escoamento laminar. Caso contrário, elas são atenuadas. 
Na transferência de calor sobre um aerofólio aquecido operando sob condições de formação de gelo, o processo de transição pode seguir: a rota $A$ se 0 voo for sob condições de formação gelo na atmosfera e a superfície do aerofólio estiver lisa; a rota $E$, num ensaio em túnel de gelo com alta intensidade de turbulência no escoamento livre.

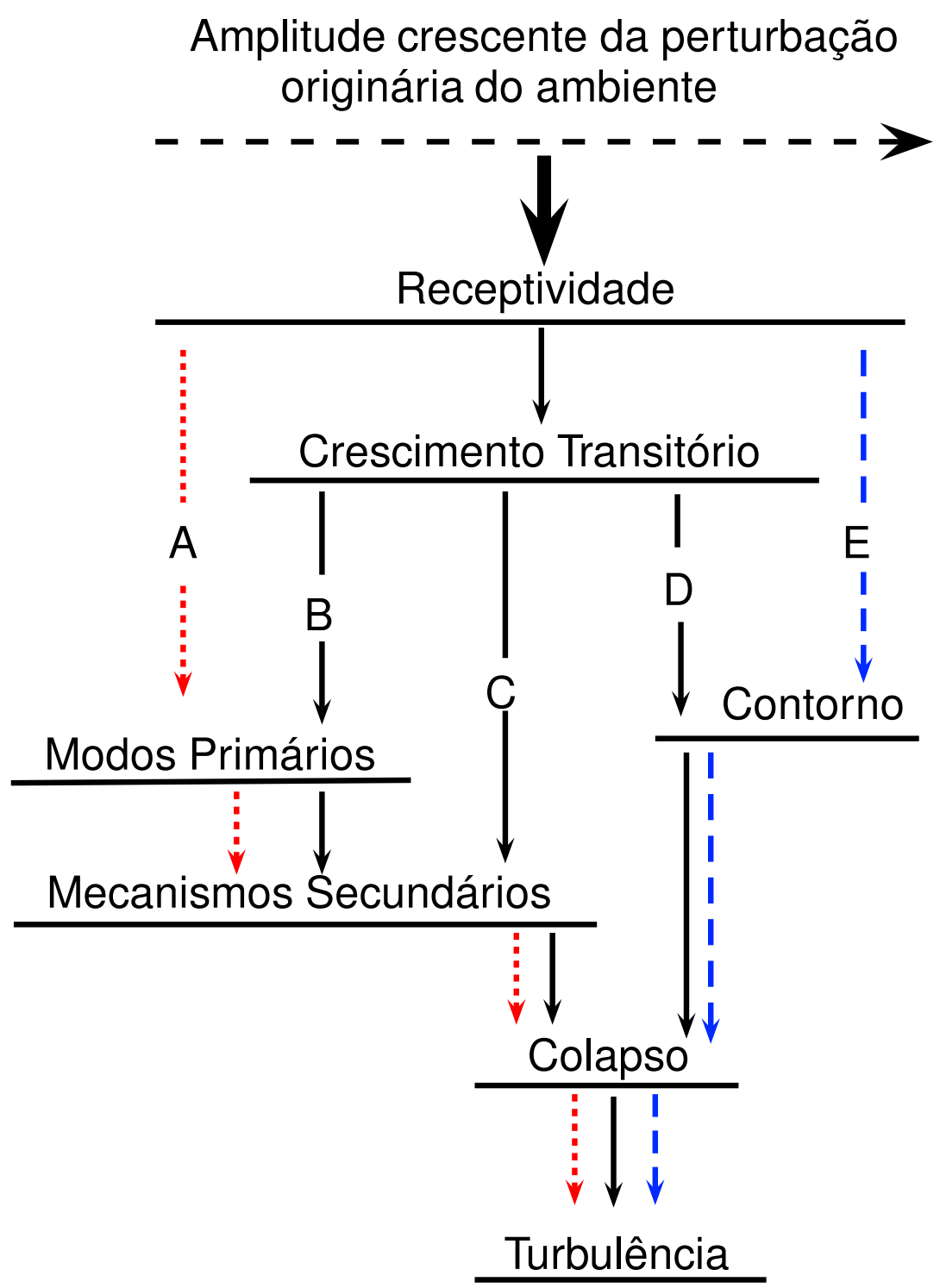

Figura 5.2: Rotas de transição para a turbulência (RESHOTKO, 2001)

De forma elegante, White (2000) resume o processo de transição natural como:

"(...) Após o colapso inicial do escoamento laminar devido a amplificações de perturbações infinitesimais, o escoamento passa por uma complicada sequência de mudanças espaciais, que tem como resultados um fenômeno, não-estacionário e desordenado, mas estranhamente racional e maravilhosamente estável, conhecido como turbulência.(...)". 


\subsubsection{Transição Natural}

A previsão teórica do surgimento das ondas T-S em escoamentos no regime laminar, sem gradiente de pressão, sem transferência de calor e de massa sobre placas planas, denominado escoamento de Blasius, foi feita por Tollmien em 1927, com base em desenvolvimentos anteriores de Rayleigh (1887) e Prandtl (1921) (apud VAN INGEN, 2008). Os estudos teóricos sobre estabilidade linear foram continuados por Schlichting em 1933, No entanto, a evidência experimental que provou a existência das ondas T-S somente foi encontrada após os experimentos de Schubauer e Skramstad (1948) no National Bureau of Standards, Washington, EUA. Os autores tiveram sucesso porque a experiência foi realizada num túnel de vento de baixo nível de turbulência do escoamento ao longe. Os valores baixos de $T u=0,02 \%$ do escoamento ao longe do túnel de vento, permitiram Schubauer e Skramstad (1948) detectar pela, primeira vez, as ondas T-S, que tinham sido previstas pela teoria de estabilidade linear da camada-limite laminar por Tollmien em 1927.

Arnal (1992) observa que o efeito do nível de turbulência do escoamento livre sobre a camada-limite é desprezível se $T u<0,1 \%$, e que as ondas T-S não ocorrem se $\mathrm{Tu}>3 \%$, ou seja, acima desse limite a transição é disparada por outros mecanismos de comportamento não-linear.

A transição natural também pode ocorrer por meio de outro tipo de instabilidade linear: os vórtices de Görtler (RESHOTKO, 2001), que são estruturas vorticais longitudinais disparadas por perturbações de amplitudes infinitesimais em escoamentos sobre superfícies côncavas. Se a espessura da camada-limite de quantidade de movimento é da ordem do raio de curvatura da superfície, há o aparecimento de um gradiente de pressão na direção normal $(d P / d y)$. Isso leva à instabilidade centrífuga do escoamento laminar e causa o aparecimento dos vórtices de Görtler. O início da formação das instabilidades ocorre quando

$$
G=\operatorname{Re}_{\delta_{2}} \sqrt{\frac{\delta_{2}}{R}}>0,3
$$

na qual $R$ é o raio de curvatura da superfície e $G$ é denominado número de Görtler.

\subsubsection{Transição de Contorno (Bypass)}

A transição de contorno (rota E da Fig. 5.2) pode ser definida com aquela que tem o crescimento das perturbações e cenários de transição não disparados pelas 
instabilidades lineares ou por suas combinações lineares. Nesse caso, a ocorrência das ondas T-S (rota A da Fig. 5.2) ou de outros mecanismos lineares (rotas B,C,D da Fig. 5.2) são contornados (bypassed). Um caso de alto nível de turbulência do escoamento livre pode causar uma transição rápida e contornar os mecanismos de transição natural, discutidos nas seções anteriores.

Este tipo de processo transicional é, geralmente, encontrado no escoamento sobre pás de turbinas à gás. Logo, é um mecanismo importante na previsão da transferência de calor em pás de turbinas e no projeto do seu resfriamento, para que a vida útil das pás e os limites de operação sejam aumentados. Em túneis de gelo, os níveis de turbulência podem atingir valores entre 0,5\% a 6\% (HENZE; BRAGG; KIM, 1998), dependendo das suas características construtivas e, principalmente, da configuração do sistema de nebulização de gotículas. Na formação de gelo, o escoamento é perturbado pela superfície rugosa e irregular da superfície do gelo. Essas perturbações também podem causar o disparo da transição por mecanismos de contorno.

Schmid e Henningson (2001) definem a rota E para a turbulência como a transição laminar-turbulenta iniciada por mecanismos de crescimento não-modais, ou seja, instabilidades não relacionadas com as frequências naturais. As perturbações causadas por crescimento não-modal são alongadas longitudinalmente. O processo de transição, disparado por um nível de Tu de moderado a alto, é dominado por oscilações de velocidade com amplitude maior na direção do escoamento(são as denominadas veias). Para os autores, o aparecimento das veias caracteriza a transição de contorno. Como as equações de estabilidade linear não podem ser aplicadas, previsão da rota para a turbulência pela transição de contorno é realizada por correlações algébricas ou por simulação direta das equações de Navier-Stokes [Direct Numerical Simulation (DNS)].

\subsubsection{Intermitência Laminar-turbulenta}

As erupções turbulentas são formadas aleatoriamente numa faixa longitudinal $\Delta s$, que é pequena quando comparada à extensão total da região de transição (DHAWAN; NARASIMHA, 1958). As erupções seguem com o escoamento. Logo, inevitavelmente, a coalescência das erupções ocorre numa região a jusante, onde erupções aparecem continuamente e prosperam. O volume ocupado pelas erupções aumenta exponencialmente, toma toda a camada-limite e o escoamento torna-se plenamente turbulento.

A intermitência laminar-turbulenta, $\gamma$, é a razão entre a somatória do tempo de passagem das erupções turbulentas por uma posição $s$ sobre o tempo total da me- 
dição. A cada passagem de uma erupção, o anemômetro registra flutuações de velocidade, que são típicas do regime turbulento. Antes e depois da passagem das erupções, o escoamento é calmo e não apresenta flutuações de velocidade, o que caracteriza o escoamento em regime laminar. Movendo o sensor para posições mais a jusante, a frequência e comprimento das erupções aumenta, o que aumenta a fração de tempo que o escoamento apresenta características de regime turbulento, i.e., a intermitência $\gamma$ cresce e tende ao valor unitário.

As primeiras medições das erupções turbulentas foram feitas por Emmons (1951) com anemômetro de fio quente. A evolução de $\gamma$ na direção do escoamento para várias condições de escoamento sobre placa plana foi feita por Schubauer e Klebanoff (1955).

O conceito de intermitência foi definido por Emmons (1951) como um modelo de geração e coalescência de erupções turbulentas. Este modelo admite que a geração $g(P)$ ocorre num ponto $P$ e que a fração do tempo que o escoamento permanece turbulento num ponto, intermitência $\gamma(P)$, é dada por:

$$
\gamma(P)=1-e^{-\int g(P) d V}
$$

Onde $g(P)$ é a taxa de geração de erupções turbulentas num volume infinitesimal $d V$, ou seja, elas nascem em vários pontos dentro da região de transição. A Eq. (5.6) está no regime permante, mas o modelo original é mais geral e abrange também efeitos transitórios na avaliação de $\gamma$. O crescimento e propagação das erupções é estimado com a avaliação da integral da taxa no volume. Com base na hipótese de que o escoamento é uma fração do tempo laminar e noutra turbulento na proporção $(\gamma-1) / \gamma$, Emmons (1951) propôs que o escoamento médio no tempo numa posição qualquer a jusante pode ser considerado como uma sobreposição das propriedades laminares e turbulentas:

$$
f=(1-\gamma) \cdot f_{L}+\gamma \cdot f_{T}
$$

Onde $f$ é uma propriedade da camada-limite, $f_{L}$ é seu valor no regime laminar e $f_{T}$ é seu valor plenamente turbulento. Nos trabalhos clássicos de transição, a variável $f$ pode ser substituída por $C_{f}, \bar{u}, H=\delta_{1} / \delta_{2}$ ou St, por exemplo. A evolução de $\gamma$ pode variar de acordo com o tipo de propriedade $f$, como as funções $\gamma$ propostas para estimativa de $H$ por Abu-Ghannam e Shaw (1980) ou para estimativa de St por Sharma (1987). A avaliação de $\gamma$ por meio de sobreposição é amplamente aplicado às análises diferenciais e integrais na literatura pesquisada.

Segundo Dey (2000), a combinação linear dos valores laminares e turbulentos 
na região de transição resulta num desequilíbrio local transitório de quantidade de movimento durante a passagem de uma erupção turbulenta. Para um escoamento sem gradiente de pressão sobre superfície adiabática e sem transpiração, o desvio estimado no cálculo de $C_{f}$ é da ordem de:

$$
2 \frac{d \delta_{2}}{d s}-C_{f} \approx 2\left[\frac{d \gamma}{d s}\left(\delta_{2, \text { turb }}-\delta_{2, \text { lam }}\right)+\gamma(1-\gamma) \int_{0}^{\delta}\left(\bar{u}_{I}-\bar{u}_{T}\right) d y\right]
$$

Onde o termo do lado esquerdo é o diferença entre o $C_{f}$, avaliado por meio da combinação linear, e o seu valor exato $d \delta_{2} / d s$ para este tipo de escoamento (Eq. 4.26). Durante a passagem de uma erupção turbulenta, o primeiro e o segundo termos do lado direito da Eq. (5.8) adquirem sinais opostos e quase se cancelam mutuamente. Com a aplicação da Eq. (5.8) aos dados experimentais de Schubauer e Klebanoff (1955), os autores estimaram em 2,5\% o erro médio no cálculo do $C_{f}$ por meio do modelo de sobreposição. Logo, em termos práticos, o modelo de combinação linear oferece uma precisão satisfatória cconjugadacom simplicidade de implementação e interpretação.

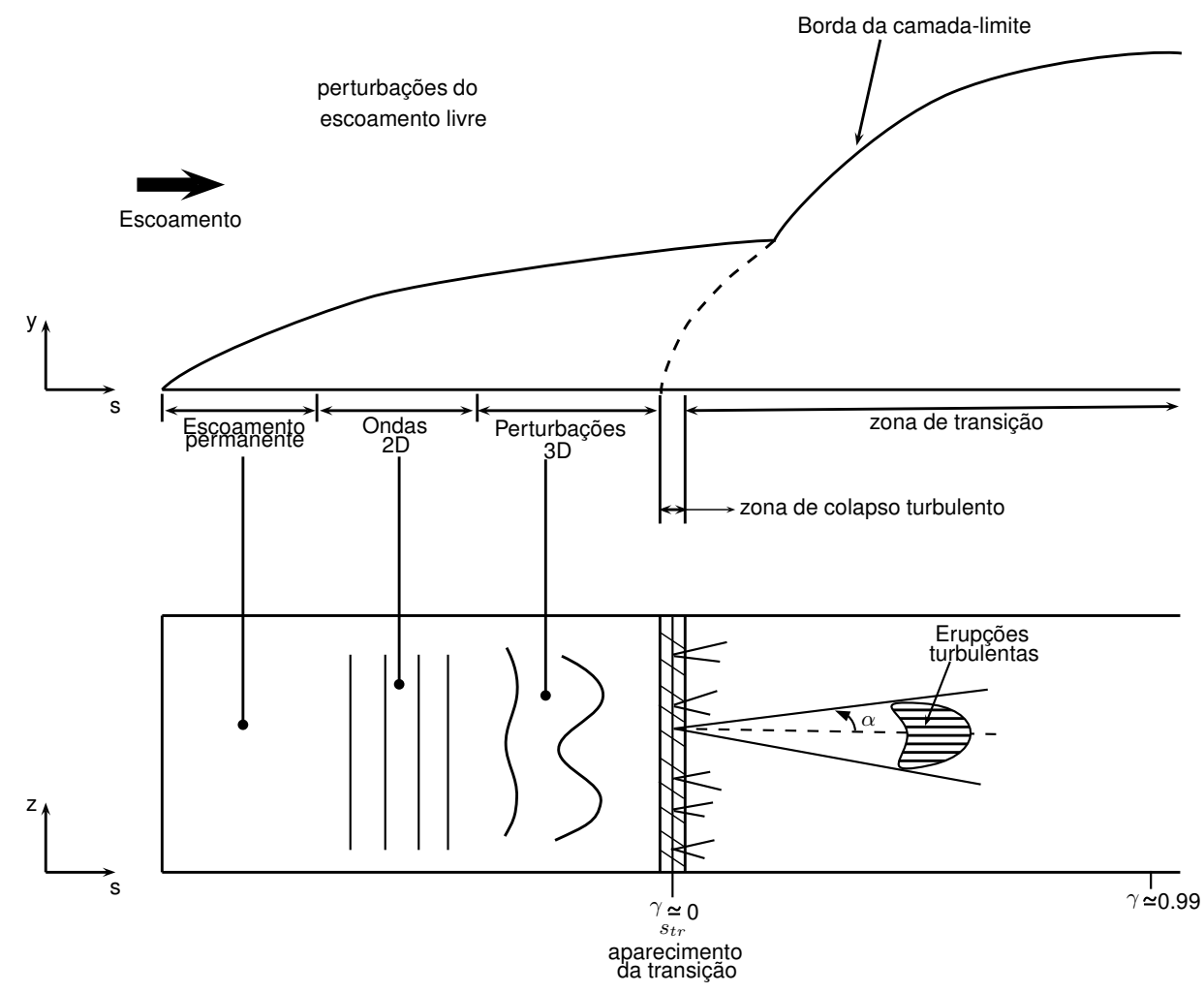

Figura 5.3: Estágios da desestabilização da camada-limite laminar sujeita a perturbações de baixa amplitude. (NARASIMHA, 1990)

A Fig. 5.3, idealizada por Narasimha (1990), a transição do escoamento laminar para o turbulento quando a amplitude das perturbações ambientais é baixa, ou seja, quando ocorre a transição natural. Há um trecho de escoamento laminar em regime 
permanente e não-perturbado, seguido por um longo período inicial de instabilidades lineares, gerada por ondas bidimensionais Tollmien-Schlichting (T-S). Depois há uma região curta de geração e colapso de estruturas tridimensionais fortemente instáveis. Após este estágio, Narasimha (1990) admite a ocorrência de uma ruptura (breakdown) concentrada (colapso do escoamento laminar) e o início da formação das erupções (spots) turbulentas, que marcam o início (onset) da região de transição laminar-turbulenta. Como mostrado na Fig. 5.3, a intermitência varia de $\gamma \approx 0$, na posição de ruptura concentrada e início das erupções turbulentas, a $\gamma=1$, no final da região de transição e início do escoamento plenamente turbulento.

Uma conclusão importante que pode ser tirada a partir da análise da Fig. 5.3 é que o escoamento a jusante do ponto de ruptura concentrada possui perturbações bidimensionais e tridimensionais. No entanto, os modelos de transição só preveem efeitos no coeficiente de atrito $C_{f}, H$ e St na região das erupções turbulentas, a partir da posição que a intermitência laminar-turbulenta começa ser diferente de zero.

\subsection{Modelos de Previsão de Transição Laminar- turbulenta}

Nos modelos integrais e diferenciais de camada-limite encontrados na literatura pesquisada, os dois parâmetros são usados para definir a região de transição laminar-turbulenta são: 1) $s_{t r}$, que é início (onset) da transição, onde ocorre o colapso para a turbulência e as erupções começam a aparecer; 2) $\Delta s_{t r}$, que é comprimento da região de transição, ou seja, a distância entre o aparecimento das erupções e o escoamento plenamente turbulento.

Análises integrais e diferenciais de camada-limite não preveem qualquer efeito das perturbações que ocorrem entre a posição de indiferença, definida por $\operatorname{Re}_{\delta_{2}, \text { ind }}$, e o início do colapso do escoamento laminar, $R_{t r}$. Essas análises consideram que o escoamento é plenamente laminar em qualquer posição a jusante do ponto de aparecimento das erupções.

\subsubsection{Modelo de Michel (1951)}

Para estimar o início da transição, Cebeci e Cousteix (2005) desenvolveram um procedimento de estimativa com base nas correlações algébricas de Michel (1951), determinada com base em experimentos, e de Smith e Gamberoni (1956), determinada com base em uma curva de soluções da análise de estabilidade linear. A curva 
proposta pelos autores é:

$$
\operatorname{Re}_{\delta_{2, t r}}=1,174 \cdot\left(1+\frac{22400}{\operatorname{Re}_{s, t r}}\right) \operatorname{Re}_{s, t r}^{0,46}
$$

Há a possibilidade de ocorrência de separação da camada-limite laminar $(\tau=0)$ a montante da posição de disparo da transição pela Eq. (5.9). Nesses casos, os autores sugerem a hipótese de que o início da transição acontece na posição da separação laminar.

Esse modelo é apropriado para transição natural em escoamentos de baixo nível de turbulência em torno de aerofólios com superfície adiabática, lisa e sem transpiração.

\subsubsection{Modelo de Abu-Ghannam e Shaw (1980)}

Para estimar o início e o comprimento da região de transição laminar-turbulenta, Abu-Ghannam e Shaw (1980) desenvolveram correlações algébricas com base numa coleção ampla de dados experimentais de escoamentos sobre placa plana com vários gradientes de pressão e níveis de turbulência ao longe. O início da transição, segundo os autores, pode ser estimado por:

$$
R e_{\delta_{2, t r}}=163+\exp \left(F(\lambda)-\frac{F(\lambda)}{6,91} \cdot T u\right)
$$

onde a função $F(\lambda)$ é dada por Eq. (5.11a) para $\lambda<0$ e por Eq. (5.11b) para $\lambda>0$ :

$$
\begin{aligned}
& F(\lambda)=6,91+12,75 \cdot \lambda+63,64 \cdot \lambda^{2} \\
& F(\lambda)=6,91+2,48 \cdot \lambda-12,27 \cdot \lambda^{2}
\end{aligned}
$$

O término da região de transição e início do escoamento plenamente turbulento é dado pela seguinte correlação:

$$
\begin{gathered}
R e_{\delta_{2}, t}=540+183,5 \cdot\left(R e_{L} \cdot 10^{-5}-1,5\right)(1-1,4 \lambda) \\
R e_{L}=16,8 \cdot\left(R e_{s, t r}\right)^{0,8}
\end{gathered}
$$

O modelo de Abu-Ghannam e Shaw (1980) é muito utilizado para prever os parâmetros da região de transição laminar-turbulenta do tipo natural e também para o tipo de contorno.

Para resolver escoamentos em pás de turbinas, Drela (1998) modificou essas correlações e substituiu o parâmetro de gradiente de pressão, $\lambda=\delta_{2}^{2} / \nu \cdot d u / d s$, pelo 
fator de forma, $H=\delta_{1} / \delta_{2}$. As razões apontadas pelo autor foram: 1) que a iteração da soluções da camada-limite e do escoamento externo pode divergir porque a transição laminar-turbulenta afeta $\lambda$ que, por sua vez, é usada para estimar o início da transição; 2) que o $H$ é menos afetado pela iteração com o escoamento externo e pela variação do gradiente de pressão; 3) que o disparo da transição laminar-turbulenta com o $H$ tem sentido físico, já que a estabilidade linear do escoamento laminar é dependente diretamente da forma do perfil de velocidade média na camada-limite; 4) que o conceito do $\lambda$ não pode ser usado na separação laminar, que pode ocorrer em ângulos de ataques e velocidades altas em certo aerofólios, porque atinge um valor mínimo de $\lambda=-0,09$ no ponto de separação e de $\lambda=0$ após a separação da camada-limite; 5) que o $H$ é uma função contínua através da bolha de separação da camada-limite laminar, e que esse fato, segundo o autor, garante maior robustez a solução numérica e tem comportamento mais físico. A correlação desenvolvida pelo autor para prever o início da transição é:

$$
\operatorname{Re}_{\delta_{2} t r}=155+89\left[0,25 \tanh \left(\frac{10}{H-1}-5,5\right)+1\right]\left(n_{\text {crit }}\right)^{1,25}
$$

$\mathrm{Na}$ qual, o fator de amplificação máxima das instabilidades lineares, $n_{\text {crit }}$, desenvolvido por Mack (1977) para escoamentos de baixo Tu com base em resultados da análise linear, é dado por:

$$
n_{\text {crit }}=-8,43-2,4 \cdot \ln \left(T u^{\prime}\right)
$$

Para obter resultados para níveis de turbulência mais altos, $T u>2,98 \%$, Drela (1998) modificou a 5.14 com a definição de:

$$
T u^{\prime}=2,7 \tanh \left(\frac{T u}{2,7}\right)
$$

A faixa de aplicação das correlações de Abu-Ghannam e Shaw (1980) vai de valores de $T u \approx 0$ até $T u \approx 10 \%$. Com isso, abrange vários tipos de rotas de transição laminar-turbulenta e considera o efeito do gradiente de pressão.

\subsubsection{Modelo de Wazzan, Gazley e Smith (1981)}

A partir de resultados numéricos de análise linear de estabilidade de escoamentos de água, no regime laminar, sobre cunhas (wedge flows) com presença de transferência de calor na superfície, Wazzan, Gazley e Smith (1981) propuseram seguinte 
a correlação:

$$
\begin{aligned}
& \log \left(\operatorname{Re}_{s, t r}\right)=-40,4557+ 64,8066 H-26,7538 H^{2}+3,3819 H^{3} \\
& \Leftrightarrow 2,1<H<2,8
\end{aligned}
$$

$\mathrm{Na}$ Eq. (5.16a), $\mathrm{Re}_{s, t r}$ é a posição de transição prevista com o método de análise linear. Não foram considerados resultados experimentais porque na época não havia dados em quantidade suficiente e com a precisão necessária. Apesar de ter considerado vários ângulos de cunha, ou seja, vários valores de gradiente de pressão, o fator de forma $H$ forneceu uma curva única relacionada com $\operatorname{Re}_{s, t r}$ da posição de transição, o que é apropriado para um critério deste tipo, As superfícies consideradas no estudo foram adiabáticas, aquecidas e resfriadas. Os autores recomendam o uso da correlação da Eq. (5.16a) até diferenças de temperatura, entre a superfície e o escoamento, de $23^{\circ} \mathrm{C}$, e que acima desse gradiente de temperatura há necessidade de uma análise de estabilidade. No entanto, diferenças da ordem de até $50^{\circ} \mathrm{C}$ foram utilizadas no desenvolvimento da correlação (WAZZAN; GAZLEY; SMITH, 1979) e apresentaram desvios satisfatórios até o valor mínimo de $H=2,1$. Outra limitação, deste tipo de correlação, é que a rota de transição é natural. Isso exclui casos, por exemplo, de níveis de turbulência de moderados a mais altos, $T u>1,5 \%$ como encontrados em túneis de formação de gelo, como o IRT.

\subsubsection{Modelo de Mayle (1991)}

Com base em um conjunto amplo de dados experimentais, variando entre $0<T u<10 \%$, Mayle (1991) propôs a seguinte correlação para início da região de transição:

$$
\operatorname{Re}_{\delta_{2}, t r}=400 T u^{-5 / 8}
$$

Apesar da Eq. (5.17) ter sido correlacionada para dados experimentais sobre placas planas sem gradiente de pressão, ela tem desvios aceitáveis para previsão da transição laminar-turbulenta para escoamentos com gradiente de pressão com $T u>3 \%$, como é o caso das condições operacionais das palhetas de turbinas à gás.

Segundo o mesmo autor, o comprimento da região de transição pode ser estimado com os parâmetros da camada-limite no início da transição, no local da ruptura do escoamento laminar:

$$
\operatorname{Re}_{\Delta s}=75 \operatorname{Re}_{\delta_{2}, t r}^{-5 / 4}
$$

Se houver a presença de bolhas de separação laminar, Mayle (1991) indica que 
a transição pode ser correlacionada por:

$$
\operatorname{Re}_{s, t r}-\operatorname{Re}_{s, s e p}=700 \cdot \operatorname{Re}_{\delta_{2}, \text { sep }}^{0,7}
$$

A constante 700 do lado direito da Eq. (5.19) pode ser substituída por 1000 para o caso de bolhas compridas ou de 300 para o caso das mais curtas. No caso de ocorrência da separação, o comprimento da região de transição laminar-turbulenta é estimado por:

$$
\operatorname{Re}_{\Delta s}=400 \operatorname{Re}_{\delta_{2}, t r}^{0,7}
$$

Onde $\Delta s$ é a distância entre o início e término da região de transição e $\operatorname{Re}_{\Delta} s$ é o número de Reynolds baseado em $\Delta s$.

\subsection{Modelos para Intermitência Laminar-turbulenta}

Após a estimativa do início e término da transição laminar-turbulenta, as mudanças de características do escoamento na região de transição precisam ser previstas até o início do escoamento plenamente turbulento.

Os modelos de intermitência da transição laminar-turbulenta podem ser do tipo:

- combinação linear, que admite a coexistência e a sobreposição de estados plenamente laminares e turbulentos na transição;

- algébricos, que multiplicam a intermitência pela viscosidade aparente turbulenta ("eddy viscosity");

- diferenciais, que modificam as equações diferenciais de transporte existentes ou introduzem novas para representar o transporte de $\gamma$ e algum tipo mecanismo de disparo da transição.

Revisões bibliográficas sobre modelagem de transição nas equações de transporte foram feitas por Singer (1993) e, mais recentemente, por Tobaldini Neto (2006).

\subsubsection{Modelo de Narasimha (1957)}

Com base nos trabalhos teóricos (EMMONS, 1951) e experimentais (SCHUBAUER; KLEBANOFF, 1955) anteriores, Dhawan e Narasimha (1958) admitiram que: 1) o crescimento e coalescência das erupções pode ser descrita apenas no plano $s z$, que é definido pelas direções de comprimento e de largura do plano sobre o qual 
há escoamento; 2) a ruptura concentrada, ou seja, toda a geração das erupções ocorreria com a mesma probabilidade ao longo de uma linha da direção da largura localizada numa posição $s$ ao longo do escoamento; 3) os efeitos transitórios não são significativos. A taxa de geração de erupções, $g$ da Eq. (5.6), foi idealizada pelos autores com auxílio da função delta de Dirac, que tem valor unitário na posição $s_{t r}$ e valor nulo em qualquer outra posição:

$$
g(s)=n \delta\left(s-s_{t r}\right) \quad \text {, na qual } \quad s \begin{cases}=s_{t r} & \Rightarrow \delta\left(s-s_{t r}\right)=1 \\ \neq s_{t r} & \Rightarrow \delta\left(s-s_{t r}\right)=0\end{cases}
$$

$\mathrm{Na}$ Eq. (5.21), $n$ é a taxa de produção de erupções na posição de ruptura concentrada. Se a função $g(s)$ da Eq. (5.21) for substituída na Eq. (5.6), a integral resulta aproximadamente em:

$$
\gamma=1-\exp \left[-\frac{n \sigma}{u_{e}}\left(s-s_{t r}\right)^{2}\right]
$$

$\mathrm{Na}$ Eq. (5.22), $\sigma$ é a taxa de espalhamento das erupções (crescimento da área), $n$ é a taxa de geração, $u_{e}$ é a velocidade do escoamento na borda da camada-limite. A intermitência laminar-turbulenta é utilizada para combinar linearmente os valores laminares e plenamente turbulentos na região de transição.

Com base em dados experimentais próprios, os autores propuseram a chamada distribuição "universal" para intermitência $\gamma$ considerando $n \sigma / u_{e}=0,412 / \lambda^{2}$, que se substituída na Eq. (5.22) resulta em:

$$
\begin{gathered}
\gamma=1-\exp \left[\frac{-0,412 \cdot\left(s-s_{t r}\right)^{2}}{\lambda_{n}^{2}}\right] \\
\lambda_{n}=s(\gamma=0,75)-s(\gamma=0,25)
\end{gathered}
$$

O modelo de intermitência de Dhawan e Narasimha (1958) considera o crescimento e a coalescência das erupções a partir de um ponto de geração inicial até a coalescência completa no ponto de termino da região de transição. Com base em observações experimentais disponíveis na época, os autores propuseram a hipótese de ruptura concentrada, ou seja, que, as erupções aparecem numa faixa bem estreita na direção da largura da placa plana (aproximadamente uma linha em $s_{t r}$ na direção de z) como apresentado na Fig. 5.3. Essa hipótese é satisfatória porque, além de concentradas em perto de $s_{t r}$, as erupções geradas nessa posição dominam a evolução da intermitência da distância $s$. Por esse modelo, são desconsideradas as erupções que apareçam a jusante de $s_{t r}$. Como elas são em menor número e tem dimensões pequenas, não influenciam o processo de coalescência (VINOD; GOVINDARAJAN, 2007). 
Volino e Simon (1995) simplificaram algébricamente a Eq. (5.23a) para que não houvesse uma dependência circular, pois o $\lambda_{n}$ depende do cálculo de $\gamma$, que por sua vez, depende do próprio $\lambda_{n}$. A nova equação encontrada pelos autores foi:

$$
\begin{gathered}
\gamma=1-\exp \left[\frac{-4,6 \cdot\left(s-s_{t r}\right)^{2}}{\lambda_{v}{ }^{2}}\right] \\
\lambda_{v}=s(\gamma=0)-s(\gamma=0,99)
\end{gathered}
$$

\subsubsection{Modelo de Reynolds, Kays e Kline (1958b)}

Reynolds, Kays e Kline (1958b) definiram a região de transição laminarturbulenta de forma estatística por meio de uma posição média, $s_{m}$ e um desvio padrão, $\sigma$. A intermitência é modelada como uma curva de distribuição normal acumulada, que tem o valor zero antes do início da transição e o valor unitário no início do regime plenamente turbulento. Diferentemente da função de intermitência idealizada por Emmons (1951) e a proposta por Narasimha (1957), a função $\gamma$ de Reynolds, Kays e Kline (1958b) é a probabilidade do escoamento se tornar turbulento numa posição $s$ a jusante do ponto de início dos primeiras erupções turbulentas.

Outra diferença fundamental em relação a outros modelos de intermitência é que os autores admitem que a geração das erupções ocorre em posições diferentes de $s$ ao longo da largura (direção $z$ ). O modelo de Reynolds, Kays e Kline (1958b), assim como o de Emmons (1951), não considera a hipótese de ruptura concentrada, mas sim o nascimento distribuído de erupções. É importante lembrar que a função de Dirac, $\delta\left(s-s_{t r}\right)$, usada na Eq. (5.21), pode ser entendida como o limite da distribuição normal quando o desvio padrão tende a zero. Portanto, o caso mais geral seria uma distribuição normal (gaussiana) da geração das erupções, e o caso particular seria a formação concentrada.

A intermitência laminar-turbulenta, segundo a interpretação de Reynolds, Kays e Kline (1958b), para avaliação da transferência de calor em escoamentos com gradiente de pressão sobre placas planas com superfície não isotérmica é estimada por:

$$
\gamma\left(\operatorname{Re}_{s}\right)=\int_{-\infty}^{\mathrm{Re}_{s}}\left(\frac{1}{\mathrm{Re}_{s} \cdot \sqrt{2 \cdot \pi}}\right) \cdot \exp \left[\frac{-\left(\mathrm{Re}_{s}-\mathrm{Re}_{s_{m}}\right)^{2}}{\left(2 \cdot \mathrm{Re}_{\sigma}^{2}\right)}\right] d\left(\mathrm{Re}_{s}\right)
$$

Os valores de St e $C_{f}$ durante a transição são calculados por combinação linear dos valores laminares $C_{f, l a m}$ e $\mathrm{St}_{\text {lam }}$ com os turbulentos $C_{f, t u r b}$ e $\mathrm{St}_{\text {turb. }}$. Esse modelo foi desenvolvido com base nos trabalhos e dados experimentais de Schubauer e 
Klebanoff (1955), que primeiro admitiram a ideia de representar a intermitência por uma curva de distribuição normal acumulada.

A transferência de calor da superfície de interface para o escoamento gasoso (sólido-gás ou líquido-gás) é aproximadamente estimada por:

$$
\dot{q}^{\prime \prime}(s)=[1-\gamma(s)] \cdot \dot{q}_{\text {lam }}^{\prime \prime}(s)+\gamma(s) \cdot \dot{\bar{q}}_{\text {turb }}^{\prime \prime}(s)
$$

na qual $\gamma(s)$ é a probabilidade do escoamento plenamente turbulento ocorrer na posição $s, \dot{q}_{l a m}^{\prime \prime}$ é fluxo de calor do regime laminar e $\dot{\bar{q}}_{t u r b}^{\prime \prime}$ é o fluxo de calor médio no regime turbulento. A Eq. (5.26) é utilizada na forma adimensional:

$$
s \begin{cases}s<s_{m}-2 \cdot \sigma & \Rightarrow \mathrm{St}(s)=\mathrm{St}_{/ a m}(s) \\ s \geq s_{m}-2 \cdot \sigma & \Rightarrow \mathrm{St}(s)=[1-\gamma(s)] \cdot \mathrm{St}_{/ a m}(s)+\gamma(s) \cdot \mathrm{St}_{t u r b}(s)\end{cases}
$$

Na Eq. (5.27), $s_{m}$ é a posição média onde $\gamma=50 \%$ e $\sigma$ é o desvio padrão da região do comprimento da transição. Os autores admitem que o início da transição ocorre aproximadamente em $s_{m}-2 \cdot \sigma$, onde $\gamma<3 \%$. De modo análogo, a sobreposição é também aplicado à avaliação do coeficiente de atrito $C_{f}$, ou seja, St(s) é substituído por $C_{f}$ na Eq. (5.27).

\subsubsection{Modelo de Chen e Thyson (1971)}

Com base nos conceitos desenvolvidos por Emmons (1951), mas admitindo que há a ruptura concentrada, que a velocidade da propagação das erupções é proporcional a velocidade externa $\left(u_{e}\right)$ e que o crescimento da erupção ocorre com ângulo constante entre a borda da erupção ("puff") e a linha de corrente, Chen e Thyson (1971) definem a intermitência como:

$$
\begin{gathered}
\gamma_{t r}=1-\exp \left[-G\left(s-s_{t r}\right) \int_{s_{t r}}^{s} \frac{d s}{u_{e}}\right] \\
G=\frac{3}{C^{2}} \frac{u_{e}^{3}}{\nu^{2}} R e_{s, s t r}-1,34
\end{gathered}
$$

Na qual, $C$ é uma constante de valor 60 . O comprimento da região de transição é também depende do nível de turbulência do escoamento livre, separação do escoamento, rugosidade, e pode diminuir quando esses fatores aumentam de intensidade. Pode-se corrigir a constante $C$ para situações de transição em bolhas de separação:

$$
C^{2}=213 \cdot\left(\log R e_{s, t r}-4,7323\right)
$$


Os efeitos da transição laminar-turbulenta são incluídos em modelos de turbulência, como o de Cebeci e Smith (1974), por meio da viscosidade aparente turbulenta. São os chamados modelos algébricos de transição. Assim, a viscosidade aparente turbulenta resulta em:

$$
\nu_{t, e f}=\nu_{t} \cdot \gamma
$$

A viscosidade turbulenta é $\nu_{t}$, a intermitência é $\gamma$ e a viscosidade turbulenta efetiva é $\nu_{t, e f}$.

\subsubsection{Modelo de Abu-Ghannam e Shaw (1980)}

Com base num conjunto de dados experimentais amplo, Abu-Ghannam e Shaw (1980) desenvolveram uma correlação para a intermitência dada por:

$$
\begin{aligned}
\gamma(s) & =1-\exp \left(-5 \eta^{3}\right) \\
\eta & =\frac{\mathrm{Re}_{s}-\mathrm{Re}_{s, t r}}{\mathrm{Re}_{s, t}-\mathrm{Re}_{s, t r}}
\end{aligned}
$$

$\mathrm{Na}$ qual, $s_{t r}$ é a posição de início e $s_{t}$ é a posição de término da transição. Logo, a diferença $s_{t}-s_{t r}$ é o comprimento da região transição. A posição $s_{t r}$ é prevista com a Eq. (5.10) e a $s_{t}$ com a Eq. (5.12a). Para escoamentos sem gradiente de pressão, o parâmetro $\eta$ é simplificado para:

$$
\eta=\frac{s-s_{t r}}{s_{E}-s_{t r}}
$$

A 5.31a é tem alguma semelhança com a equação desenvolvida por Emmons (1951) para a intermitência, pois tem um termo cúbico da distância da região de transição, $\eta^{3}$, dentro do exponencial.

O número de St e $C_{f}$ na região de transição são avaliados pelo procedimento de combinação linear dos valores do regimes laminar e turbulento.

Para avaliar $H=\delta_{1} / \delta_{2}$ na transição, os autores recomendam o emprego da uma curva ajustada aos dados experimentais. É a chamada de fração de fator de forma, mas faz o papel da intermitência na combinação linear de $H$. Por esse modelo, a estimativa de $H$ é feita por:

$$
\begin{gathered}
H^{\prime}=\sin \left(\frac{\pi}{2} \eta\right) \\
H=H_{t r}\left(1-H^{\prime}\right)+H_{t} \cdot H^{\prime}
\end{gathered}
$$

No caso da avaliação de $\delta_{2}$, outra curva ajustada é recomendada. O fator $\delta_{2}^{\prime}$ é 
usado com combinação linear de $\delta_{2, t r}$ e $\delta_{2, t}$ e é avaliado por:

$$
\begin{gathered}
\delta^{\prime}=\eta^{1,35} \\
\delta=\delta_{t r}\left(1-\delta^{\prime}\right)+\delta_{E} \cdot \delta^{\prime}
\end{gathered}
$$

As correlações propostas, Eqs. (5.33a) e (5.34a), são curvas ajustadas e não são baseadas hipóteses físicas ou estatísticas, como é o caso das correlações de intermitência. $O$ ajuste foi realizado considerado dados de escoamentos com vários níveis de turbulência e gradientes pressão nulos, adversos e favoráveis provenientes de experimentos.

Outra observação importante é que o ponto inicial $s_{\text {tr }}$ previsto pela Eq. (5.10) não é o de ruptura concentrada de Narasimha (1957) nem o de transição abrupta de Michel (1951). O modelo de intermitência de Abu-Ghannam e Shaw (1980) admite que a geração das erupções ocorre de forma distribuída numa faixa em torno de $s_{t r}$.

\subsubsection{Modelo de Sharma (1987)}

Sharma (1987) obteve a seguinte equação para a intermitência, $\gamma$, da camadalimite de quantidade de movimento:

$$
\gamma_{m}=1-\exp \left[-0,0167 \frac{\left(\operatorname{Re}_{s}-\operatorname{Re}_{s, t r}\right)^{2}}{\left(1+0,078 M_{e}^{1,92}\right)^{2}} \operatorname{Re}_{s, t r}^{2,68}\right]
$$

Considerando a equação de integral de Von Kármán dada pela Eq. (4.2), a validade da Eq. (5.35), uma correlação semi-empírica de $C_{f}$, mais as hipóteses de que o gradiente de pressão é nulo e que o início do avaliação de $\delta_{2,0}$ (origem virtual) coincide com o nascimento das erupções $\delta_{2, t r}$, o autor propôs a seguinte função para avaliação de $\gamma$ :

$$
\gamma_{m}=1-\exp \left(-\frac{\operatorname{Re}_{\delta_{2}}^{2,5}}{\operatorname{Re}_{s, t r}^{2,68}}\right)
$$

Mesmo com as hipótese acima, o autor considerou aceitáveis os desvios entre as previsões de $\gamma_{m}$ e os dados experimentais de escoamentos com gradiente de pressão. No entanto, as previsões para a intermitência na camada-limite térmica não apresentaram desvios satisfatórios. Foi observado que comprimento da região de transição térmica é maior do que a de quantidade de movimento para escoamentos com gradiente de pressão favorável. E menor para escoamentos com gradiente de 
pressão adverso. Logo, o autor modificou a Eq. (5.36) para:

$$
\begin{gathered}
\gamma_{h}=1-\exp \left(-\frac{\operatorname{Re}_{\delta_{2}}^{2,5}}{\operatorname{Re}_{T H}^{2,68}}\right) \\
\operatorname{Re}_{T H}=\operatorname{Re}_{s, t r}(1+C \lambda)
\end{gathered}
$$

Na Eq. (5.37b), $C=21$ quando o gradiente de pressão é favorável e $C=7,25$ quando o gradiente de pressão é adverso. Como o modelo não prevê o início da transição, Sharma (1987) recomendou o uso da Eq. (5.10).

\subsubsection{Modelo de Mayle (1991)}

Com objetivo de determinar as temperaturas e o desempenho aerodinâmico de palhetas de turbinas, Mayle (1991) desenvolveu um modelo para avaliação da intermitência:

$$
\begin{gathered}
\gamma=1-\exp \left[\hat{n} \sigma\left(\mathrm{Re}_{s}-\mathrm{Re}_{s, t r}\right)^{2}\right] \\
\hat{n} \sigma=1,5(10)^{11} \mathrm{Tu}^{7 / 4}
\end{gathered}
$$

Nesse modelo, o autor admite que a produção das erupções turbulentas depende somente dos parâmetros na posição inicial da transição e que elas simplemesmente são carregadas por convecção como no modelo de Chen e Thyson (1971). Dessa forma não há necessidade de cálculo de propriedades locais da camada-limite. 0 início da região de transição $s_{t r}$ é estimado por meio da Eq. (5.17) ou da (5.19). O autor seguiu a abordagem de Sharma (1987) e adaptou a Eq. (5.38a) para a previsão de transferência de calor como:

$$
\begin{gathered}
\gamma_{h}=1-\exp \left[(\hat{n} \sigma)_{h}\left(\operatorname{Re}_{s}-\operatorname{Re}_{s, t r}\right)^{2}\right] \\
(\hat{n} \sigma)_{h}=\hat{n} \sigma(C \lambda)
\end{gathered}
$$

Como em Sharma (1987), na Eq. (5.39b), a constante $C$ é igual a 21 ou 7,25, dependendo se há gradiente de pressão favorável ou adverso no escoamento; a taxa de geração n̂ $\sigma$ é dada pela Eq. (5.38b).

Para transição laminar-turbulenta disparada por separação da camada-limite laminar, o autor desenvolveu a seguinte expressão para estimar a taxa de nascimento das erupções:

$$
\hat{n} \sigma=2,28(10)^{5} \operatorname{Re}_{\delta_{2, t r}^{1,4}}^{1,4}
$$




\subsubsection{Modelo de Johnson e Fashifar (1994)}

Para um escoamento bidimensional a intermitência é fração de área infinitesimal no sentido transversal que é ocupada pelo escoamento turbulento. Com essa definição, os autores estabeleceram a seguinte relação:

$$
\frac{d \gamma}{d s}=N \sigma
$$

$\mathrm{Na}$ qual, $N$ é o número de erupções presentes por unidade de comprimento na linha transversal e $\sigma$ é a sua taxa adimensional de propagação, ou seja, a taxa de crescimento da área ocupada por uma erupção. As erupções nascem no início da transição a uma taxa $n$ por unidade de largura por unidade de tempo. Johnson e Fashifar (1994) definiram que a taxa de variação do números de erupções longitudinal pode ser calculada por:

$$
\frac{d N}{d s}=\frac{(1-\gamma) n}{U_{e}}-\frac{N^{2} \sigma}{(1-\gamma)}
$$

$\mathrm{Na}$ qual, $U_{e}$ é a velocidade média da erupção. O primeiro termo do lado direito da Eq. (5.42) representa a taxa na qual as erupções geradas a montante chegam nas regiões laminares de uma linha transversal. O segundo termo representa a taxa na qual as erupções coalescem lateralmente com suas vizinhas na linha transversal. Logo a contribuição do segundo termo é negativa, já que diminui o número de erupções. As Eqs. (5.41 e (5.42) resultam em:

$$
(1-\gamma) \frac{d^{2} \gamma}{d s^{2}}+\left(\frac{d \gamma}{d s}\right)^{2}-\frac{\sigma n}{U_{e}}(1-\gamma)^{2}=0
$$

Se a hipótese de $\sigma n / U_{e}$ constante for admitida, a equação Eq. (5.43) resulta na Eq. (5.22) de Narasimha (1957). E a taxa de observação de erupções, com base na Eq. (5.23a), é dada por:

$$
\frac{N}{N_{\max }}=1,5(1-\gamma) \lambda_{n}
$$

Johnson e Fashifar (1994) utilizaram dados experimentais para desenvolver um critério para iniciação das erupções turbulentas e uma correlação para o crescimento das flutuações de velocidade $u^{\prime}$ perto da superfície. Os autores concluiram que $\sigma n / U_{e}$ tem crescimento aproximadamente linear e a Eq. (5.43) é simplificada para:

$$
\begin{gathered}
\gamma=1-\exp \left[\frac{-0,0941 \cdot\left(s-s_{t r}\right)^{3}}{\lambda_{n}{ }^{3}}\right] \\
\frac{N}{N_{\max }}=0,528(1-\gamma) \lambda_{n}^{2}
\end{gathered}
$$

Dados que o comprimento total da região de transição é $\Delta s_{t r}=s(\gamma=0,99)-$ 
$s(\gamma=0)$ e que $\lambda_{n} \approx \Delta s_{t r} / 4,08$, a 5.45 a resulta em:

$$
\gamma \approx 1-\exp \left[\frac{-6,4 \cdot\left(s-s_{t r}\right)^{3}}{\Delta s_{t r}^{3}}\right]=1-\exp \left(-6,4 \cdot \eta^{3}\right)
$$

A Eq. (5.46) é diferente da intermitência de Abu-Ghannam e Shaw (1980), Eq. (5.31a), somente pelas constantes, 5 e 6, 4. Isso evidencia que a Eq. (5.31a) tem base teórica e que não pode ser considerada apenas um ajuste experimental. A diferença de $30 \%$ nas constantes é compreensível, porque o desenvolvimento do modelo de Johnson e Fashifar (1994) utilizou somente dados experimentais de escoamentos com gradiente de pressão nulo e Tu alto, ou seja, condições experimentais mais restritas do que aquelas consideradas no trabalho de Abu-Ghannam e Shaw (1980).

\subsubsection{Comparação de Modelos de Intermitência}

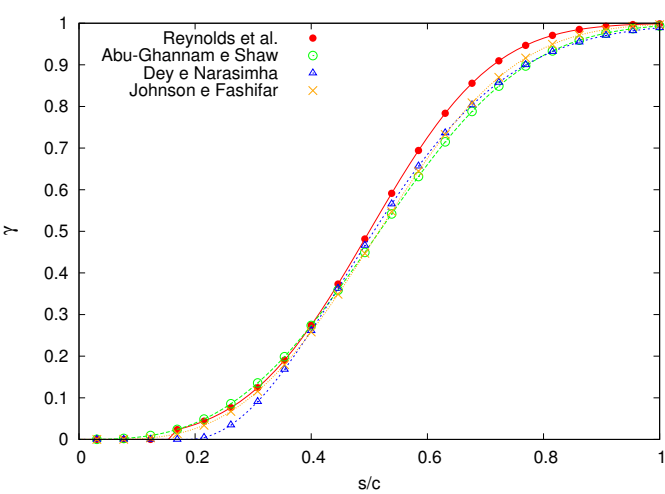

(a) Funções de Intermitência

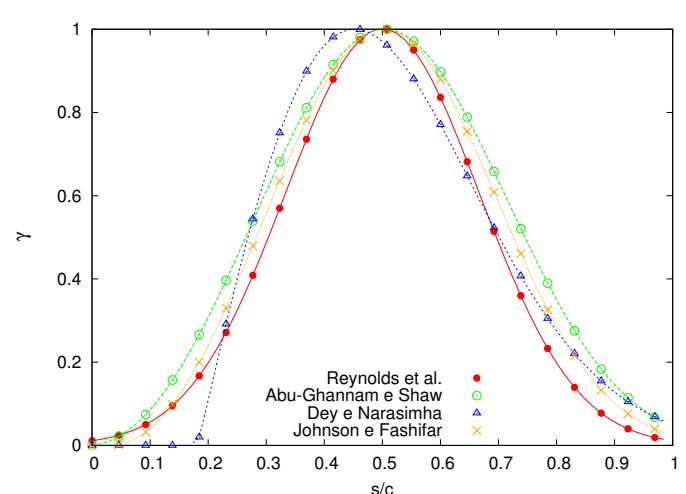

(b) Número de Erupções Locais em Relação ao Número Máximo de Erupções

Figura 5.4: Comparação de Modelos de Intermitência

A 5.4(a) apresenta as funções de intermitência de Reynolds, Kays e Kline (1958b), Abu-Ghannam e Shaw (1980), Narasimha (1957) e Johnson e Fashifar (1994). Oberva-se que o início da região de transição é diferente entre as funções. A Eq. (5.23a), que admite a ruptura concentrada, tem o início a jusante daquelas que admitem o nascimento das erupções distribuídas como a Eq. (5.25), Eq. (5.31a) e Eq. (5.46). Um fato é que a Eq. (5.31a) começa próxima da distribuição normal acumulada, Eq. (5.25), e termina próxima da equação universal de intermitência, Eq. (5.23a).

A taxa de observação do número de erupções é apresentada na Fig. 5.4(b). O aumento da taxa se dá por causa do nascimento e crescimento das erupções. Já o declínio representa a coalescência das erupções e a diminuição do seu número. O modelo de Narasimha (1957) apresenta um aumento significativo na taxa de ob- 
servação de erupções logo após o ponto de ruptura concentrada, $s_{t r}$. A evolução da taxa de observações do modelo de Abu-Ghannam e Shaw (1980) e de Johnson e Fashifar (1994) se assemelham com a distribuição normal adotada por Reynolds, Kays e Kline (1958b).

É importante conhecer as diferenças entre os modelos pois a avaliação das propriedades do escoamento de transição depende da posição de início, de término e da forma da função de intermitência.

\subsection{Outros Modelos}

Para prever o início da transição laminar-turbulenta, em escoamentos com $T u$ baixo, pode-se utilizar a solução das equações de estabilidade linear, também chamadas de Orr-Sommerfeld. A transição nesse caso é natural, a rota A da Fig. 5.2, que é disparada por perturbações infinitesimais. Esse conjunto de equações podem ser resolvidas juntamente com a avaliação diferencial da camada-limite. Nesse caso, para prever o término da região de transição laminar-turbulenta precisam ser implementadas correlações algébricas ou algum modelo de intermitência que preveja a formação, crescimento e propagação das erupções turbulentas.

A adoção da análise integral da camada-limite não impossibilita a estimativa da transição por meio da estabilidade linear. No entanto, para resolver as equações de Orr-Sommerfeld, é preciso considerar os perfis de velocidade da família de escoamentos sobre cunha, os chamados perfis de Falkner-Skan. Os procedimentos integrais de avaliação de propriedades da camada-limite não calculam perfis de velocidades, já que eles foram adotados para permitir o desenvolvimento das próprias equações. Segundo o procedimento de Drela (1998), as taxas de amplificação das flutuações lineares são calculadas e tabeladas em função de uma faixa de parâmetros de forma e de frequências instáveis. A solução conjunta da análise integral com a análise de estabilidade é utilizada por programas simples para cálculo rápido de desempenho aerodinâmico, como é o caso do XFOIL de Drela e Giles (1987).

A análise diferencial da camada-limite laminar possibilita a resolução das equações de Orr-Sommerfeld com mais precisão do que a análise integral, já que os perfis de velocidade na camada-limite são calculados para as condições do escoamento estudado. Assim, a história de escoamentos não-similares pode ser considerada incluindo as variações de gradiente de pressão, que são importantes em escoamentos em torno de aerofólios. Alguns programas de análise de estabilidade também consideram efeitos de raio curvatura e das variações de temperatura e de taxa de 
transpiração na superfície.O Anexo C apresenta as equações, o procedimento e os critérios utilizados na avaliação da análise linear de estabilidade. No presente trabaIho são utilizados os programas STP2D e STP2W desenvolvidos por Cebeci (2004) para avaliação da estabilidade do escoamento laminar sujeito à perturbações infinitesimais.

Para melhorar as previsões de transição laminar-turbulenta, nos casos com intensidade alta de turbulência no escoamento livre, rota E da Fig. 5.2, outros modelos podem ser implementados para previsão do início e do desenvolvimento da transição até o escoamento turbulento. Algumas das estratégias de modelagem encontradas em literatura mais recente são:

1) transporte de intermitência, que resolvem as equações de transporte de quantidade de movimento, energia, turbulência e mais as de intermitência. Esse tipo de modelo oferece flexibilidade para implementação da previsão de transição naqueles programas que utilizam formulações de equações de transporte em volumes finitos, como é o caso dos códigos comerciais de Computational Fluid Dynamics (CFD). Os modelos foram desenvolvidos principalmente para o cálculo de transferência de calor em torno de pás de turbinas, que, apesar da semeIhança, tem algumas diferenças com o assunto do presente trabalho. Os aerofólios de turbinas tem raio de curvatura mais significativo e o escoamento possui variação de gradiente de pressão mais intensa, nível de turbulência maior (transição de contorno) e, frequentemente, número de Reynolds $\left(\operatorname{Re}_{c}\right)$ menor do que os aerofólios de uso aerodináutico. Outra diferença é que as pás de turbinas sofrem influência da esteira dos estágios a montante, da carcaça (casing) e da alta rotação. Os trabalhos mais relevantes encontrados foram Abid (1993), Steelant e Dick (1996), Suzen e Huang (1999) e os mais recentes Savill (2002), Menter et al. (2004). O uso dessa estratégia em sistemas antigelo começou a ser estudada por Tobaldini Neto (2006).

2) regime laminar com flutuações: modelos que representem a região laminar perturbada (não-turbulenta), que utilizam resultados da estabilidade linear e análise dimensional (HASSAN, 2006).

Em comum, as estratégias de modelagem, ambas citadas acima, precisam ser implementas em códigos de solução diferencial de escoamento, como, por exemplo, os códigos de solução numérica por média de Reynolds para camadas-limite (BLP2C ou Texstan) ou Navier-Stokes (programas de CFD comerciais). 


\subsection{Seleção do Modelo de Transição Laminar- Turbulenta}

As correlações algébricas de Abu-Ghannam e Shaw (1980), Eq. (5.10) e Eq. (5.12a) e Eq. (5.31a), foram selecionadas para serem utilizadas no presente trabalho pois:

1) consideram efeitos do nível de turbulência Tu e do gradiente de pressão;

2) possuem compatibilidade entre o modelo de previsão da região de transição e o modelo de intermitência;

3) foram desenvolvidas a partir de um amplo banco de dados de medições experimentais;

4) abrangem uma faixa ampla de rotas de transição, de $T u<10 \%$;

5) foram implementadas em programas de avaliação de transiferência de calor em torno de aerofólios de turbinas, como TEXSTAN(KAYS; CRAWFORD; WEIGAND, 2004) e MISES(DRELA, 1998).

\subsection{Verificação dos Resultados Numéricos}

Nesta seção são verificados os resultados numéricos das análises integral e diferenciais da camada-limite com a presença de transição laminar-turbulenta em escoamentos com níveis médios a altos de turbulência ao longe, $0,5 \%<T u<3 \%$. Dois tipos de casos-teste foram selecionados para verificação dos resultados numéricos obtidos: 1) escoamento sobre placa plana com gradiente de pressão e níveis de turbulência ao longe variáveis com diferentes Re; 2) escoamento em torno de aerofólio com transição laminar-turbulenta com diferentes $\alpha$ e Re.

Foram feitas verificações de um número grande de casos, dos quais foram escoIhidos os preferencialmente tivessem $\operatorname{Re}>1 \cdot 10^{6}$ e $T u \leq 3,0 \%$.

A Tabela 5.2 apresenta as condições de escoamento, definidas por Ma e Re, para o casos adotados no capítulo 6 para validação dos resultados da simulação do antigelo. $\mathrm{O} \mathrm{Re}_{c}$ é o Reynolds baseado na corda, $\mathrm{Re}_{\text {prot }}$ é baseado no comprimento da área protegida dado por $(s / c)_{\text {prot }}$. Os casos experimentais $22 \mathrm{~A}$ e 67A são de Al-Khalil et al. (2001) e o 8GL é de Gelder e Lewis (1951). O número de Reynolds de interesse para o presente trabalho não é aquele baseado na corda, $\mathrm{Re}_{c}$, mas sim aquele com base no comprimento da área protegida do aerofólio, $\operatorname{Re}_{c, \text { prot }}$. $\mathrm{Na}$ 
Tabela 5.2 são listados ambos Re, Ma e o maior comprimento aquecido, $(s / c)_{\text {prot }}$, localizado nos extradorsos do NACA0012 e NACA 65(2)016.

Tabela 5.2: Condições do Escoamento para Escoamento em torno de Aerofólios com Sistema Térmico de Antigelo

\begin{tabular}{lccc}
\hline Parâmetro & 22A & 67A & 8GL \\
\hline $\mathrm{Re}_{c}$ & $6,72 \cdot 10^{6}$ & $1,38 \cdot 10^{7}$ & $1,11 \cdot 10^{7}$ \\
$(s / c)_{\text {prot }}$ & $\approx 10 \%$ & $\approx 10 \%$ & $\approx 57 \%$ \\
$\mathrm{Re}_{\text {prot }}$ & $6,72 \cdot 10^{5}$ & $1,38 \cdot 10^{6}$ & $6,42 \cdot 10^{6}$ \\
$\mathrm{Ma}$ & 0,1369 & 0,2813 & 0,2252 \\
\hline
\end{tabular}

\subsubsection{Casos-Teste}

Como as superfícies dos corpos de prova são adiabáticas para todos os casos dos bancos de dados selecionados, o número de St não foi estimado. No entanto, a previsão de St pelos modelos, adotados no presente tralho, foi verificada no 4 . Além disso, a distribuição dos valores locais de $C_{f}$ indica com precisão o início, o término e a evolução da transição laminar-turbulenta.

Os efeitos da transpiração, gerada pela evaporação da água líquida residual, no processo de transição foram desconsiderados no presente trabalho. Como a velocidade de insuflamento não é significativa, $v_{0} \approx 0$, a taxa de transpiração não influencia a camada-limite de quantidade de movimento.

A influência de rugosidades na interface ar-líquido (altura, forma e distribuição das ondas no filme e dos filetes de água residual) sobre a transição não foram considerados nas análises térmicas do sistema antigelo. Logo, os casos de tese selecionados para verificação dos resultados também não considerou esse efeito. Para asas enflechadas, que não é o presente caso de estudo, Saric e Reed (2006) provaram que rugosidades da ordem de até décimos de micra $\left(1 \cdot 10^{-6} \mathrm{~m}\right)$ podem interferir ou disparar o processo de transição. Como base de comparação, as dimensões das rugosidades encontradas em formas de gelo e em turbinas podem ser da ordem ou maiores que milímetros (BRAGG; CUMMINGS; HENZE, 1996; MAYLE, 1991).

Adicionalmente, admite-se que a temperatura da superfície afeta as propriedades (como exemplo, $\rho_{a r}$ e $\mu_{a r}$ ) do escoamento médio, que, por sua vez, afetam indiretamente as previsões dos parâmetros da região de transição por meio das correlações algébricas de Abu-Ghannam e Shaw (1980). Os casos de verificação selecionados não avaliaram essa influência indireta. 
ERCOFTAC Os institutos de pesquisa europeus fundaram em 1988 o European Research Community of Flow, Turbulence and Combustion (ERCOFTAC), sediado na Bélgica, para estudar problemas, investigar fundamentos científicos, promover o uso industrial das pesquisas, implementar bancos de dados de soluções de engenharia e trocar informações sobre experimentos e análises numéricas de escoamento, turbulência e combustão. Dentro esforço do ERCOFTAC foi organizado um grupo de trabalho para estudar transição laminar-turbulenta em escoamentos sobre placa plana com e sem gradiente de pressão, organização de pesquisa europeia dedicada a pesquisa em escoamentos, turbulência e combustão, sediada em Lausanne, Suiça (SAVILL, 1992). As medições foram realizadas na empresa inglesa, fabricante de turbinas e propulsores aeronáuticos, Rolls-Royce por ROACH e BRIERLEY (1992) ${ }^{1}$. Por serem bem completos, com medições de $C_{f}, H$ e perfis de velocidade média, $u$, e instantânea, $u^{\prime}$, esses dados experimentais foram utilizados para validação de códigos númericos clássicos integrais e RANS assim como outros mais recentes com base em Large Eddy Simulation (LES) e simulação numérica direta, DNS.

O aparato experimental utilizado para realizar os testes é apresentado na Fig. 5.5. A placa plana tinha comprimento total de $1,7 \mathrm{~m}$, espessura de $2 \mathrm{~mm}$ e bordo da ataque de 1,5 mm de diâmetro. Foi usada uma grelha para gerar turbulência isotrópica a 0,61 $\mathrm{m}$ a montante do bordo de ataque da placa plana.

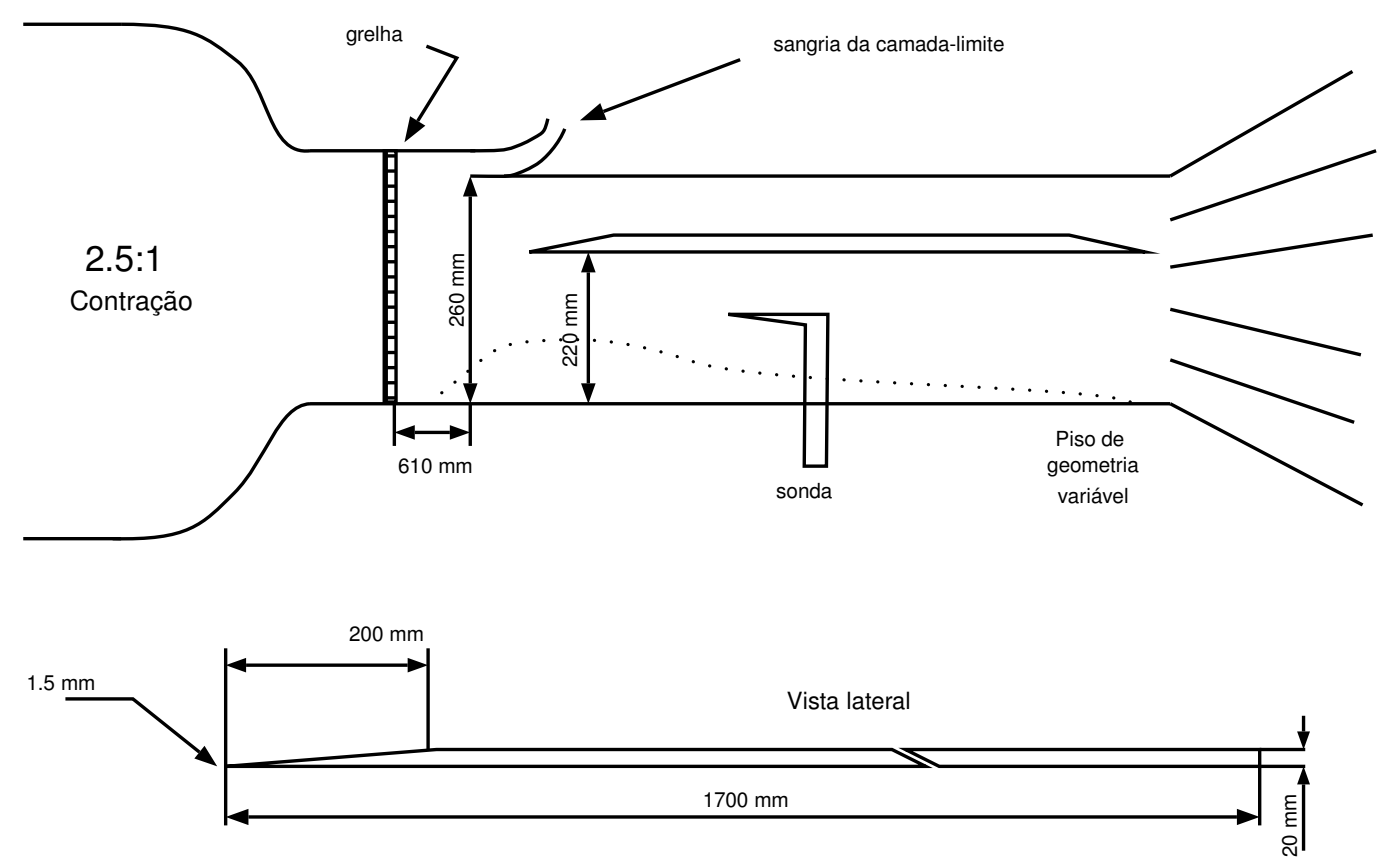

Figura 5.5: Aparato Experimental dos Casos do ERCOFTAC ${ }^{1}$

Dentre os casos do ERCOFTAC, os selecionados no presente trabalho foram aqueles escoamentos estão apresentados na Tabela 5.3 pois possuem: 1) $R e>$

\footnotetext{
${ }^{1}$ Banco de dados de resultados experimentais do ERCOFTAC, Sítio da rede mundial de computadores Internet. Flat Plate Transitional Boundary Layers Experiments. Disponível em: http://cfd.mace.manchester.ac.uk/ercoftac/index.html. Acesso em: 26 Agosto 2008,
} 
Tabela 5.3: Casos Selecionados ERCOFTAC

\begin{tabular}{lcccc}
\hline casos & T3A & T3AM & T3C2 & T3C5 \\
\hline $\operatorname{Re}_{L}\left(10^{6}\right)$ & 0,53 & 2,02 & 0,6 & 1,13 \\
$T u[\%]$ & 3,0 & 0,87 & 2,4 & 2,45 \\
$V_{\infty}[\mathrm{m} / \mathrm{s}]$ & 5,2 & 19,53 & 5,67 & 9,65 \\
$\rho_{\infty}\left[\mathrm{kg} / \mathrm{m}^{3}\right]$ & 1,21 & 1,19 & 1,18 & 1,21 \\
\hline
\end{tabular}

$0,5 \cdot 10^{6}$, pois os sistemas de antigelo de aerofólios de uso aeronáutico operam em condições de Re mais altos, como pode ser observado na Tabela 5.2; 2) nível de turbulência no escoamento $T u \leq 3,0 \%$; 3) ausência de separação laminar, que causa o início da transição laminar-turbulenta, pois a rota do processo de transição é diferente daquela prevista pelas correlações de Abu-Ghannam e Shaw (1980); além disso, os casos de antigelo estudados, Tabela 5.2, não apresentam regiões de separação da camada-limite laminar.

MBB-V2 Mateer, Monson e Menter (1996) mediram diretamente o atrito viscoso num filme de óleo por interferometria na superfície de um aerofólio MMB-V2 de corda de $200 \mathrm{~mm}$. O filme de óleo teve uma altura média de $0,9 \mathrm{~mm}$. Nese experimento, os autores também mediram a pressão estática na superfície. A geometria do perfil é mostrada na Fig. 5.6 e foi originalmente projetada pela empresa MesserschmitBolkow-Blohm Transport-und Verkehrsflugzeuge, Alemanha. Os testes foram realizados no Canal de Alto Reynolds do Centro de Pesquisa Ames da NASA, Moffett Field, California, EUA. A condição de alto Re é atingida no túnel de vento por meio do esvaziamento rápido de um reservatório pressurizado até 709,3 kPa (7 atm). A seção de teste (largura $401 \mathrm{~mm}$, altura $610 \mathrm{~mm}$, comprimento $2790 \mathrm{~mm}$ ) ficava num vaso pressurizado e mantém quase a mesma pressão estática do escoamento ao longe. Nos casos testados, as condições do escoamento foram: $\mathrm{Ma}=0,2 \mathrm{e}$ $0,6 \cdot 10^{6} \leq \operatorname{Re}_{c} / c \leq 6 \cdot 10^{6}$. O túnel possuía uma série de grelhas para condicionar o escoamento e diminuir o nível de turbulência. O nível das flutuações era de $\sqrt{u^{\prime 2}}=0,005 \cdot v_{\infty}$ e $\sqrt{p^{\prime 2}}=0,02 \cdot p_{\infty}$.

O critério de seleção dos casos experimentais do aerofólio MBB-V2 foi o mesmo utilizado para escolher os casos do ERCOFTAC. Adicionalmente, foi dada a preferência para casos de teste que tivessem ângulos de ataque mais próximos de zero, já que o programa de antigelo será verificado $\operatorname{com} \alpha=0^{\circ}$. A exceção foi que algumas rodadas apresentaram descolamento da camada-limite laminar. Como as bolhas de separação laminar estavam presentes na maioria dois casos testados por Mateer, Monson e Menter (1996), evitou-se aqueles casos de separação massiva, nos quais a região descolada é de grandes dimensões. 


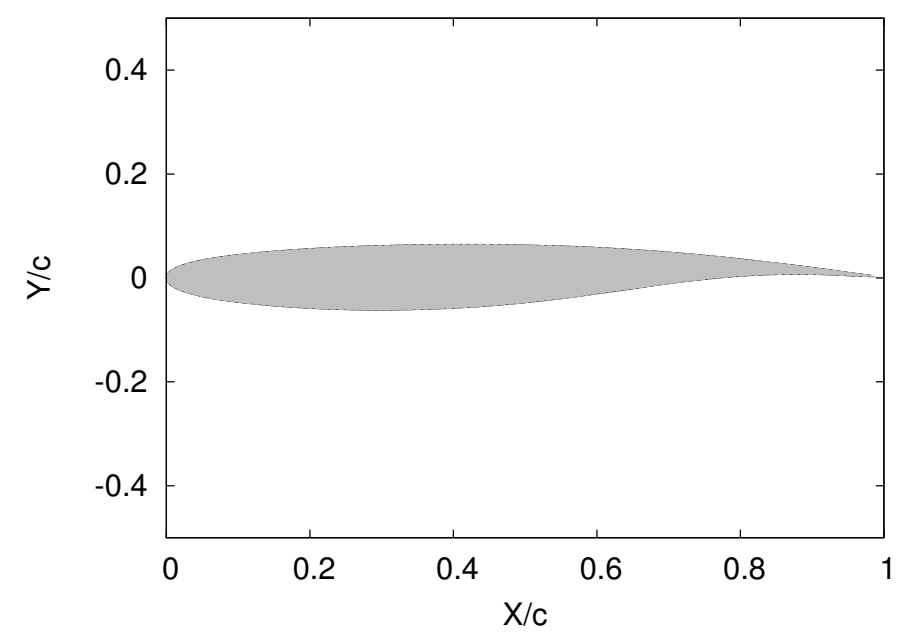

Figura 5.6: Geometria do Perfil MBB-V2 (MATEER; MONSON; MENTER, 1996)

Tabela 5.4: Casos MBB-V2 (MATEER; MONSON; MENTER, 1996)

\begin{tabular}{cc}
\multicolumn{2}{c}{ M3 - menor Re } \\
\hline parâmetro & valor \\
\hline$T_{\infty}$ & $300,0 \mathrm{~K}$ \\
$\mathrm{Ma}$ & 0,20 \\
$\mathrm{Re}$ & $0,192 E+06$ \\
$\alpha$ & $-0,5^{\circ}$ \\
geometria & $\mathrm{MBB}-\mathrm{V} 2$ \\
\hline
\end{tabular}

M1

\begin{tabular}{cc}
\hline parâmetro & valor \\
\hline$T_{\infty}$ & $300,0 \mathrm{~K}$ \\
$\mathrm{Ma}$ & 0,20 \\
$\mathrm{Re}$ & $0,639 E+06$ \\
$\alpha$ & $-0,5^{\circ}$ \\
geometria & $\mathrm{MBB}-\mathrm{V} 2$ \\
\hline
\end{tabular}

M2 - maior $\alpha$

\begin{tabular}{cc}
\hline parâmetro & valor \\
\hline$T_{\infty}$ & $300,0 \mathrm{~K}$ \\
$\mathrm{Ma}$ & 0,20 \\
$\mathrm{Re}$ & $0,639 E+06$ \\
$\alpha$ & $3,5^{\circ}$ \\
geometria & $\mathrm{MBB}-\mathrm{V} 2$ \\
\hline
\end{tabular}

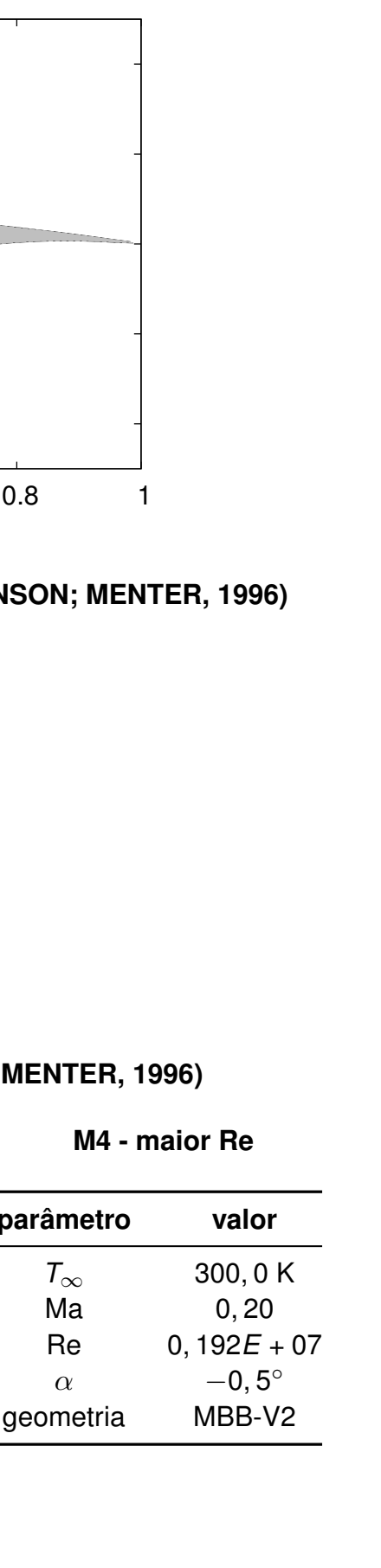

\begin{tabular}{cc}
\hline parâmetro & valor \\
\hline$T_{\infty}$ & $300,0 \mathrm{~K}$ \\
$\mathrm{Ma}$ & 0,20 \\
$\mathrm{Re}$ & $0,192 \mathrm{E}+07$ \\
$\alpha$ & $-0,5^{\circ}$ \\
geometria & $\mathrm{MBB}-\mathrm{V} 2$ \\
\hline
\end{tabular}


A Tabela 5.4 apresenta os casos do perfil MBB-V2 selecionados para o processo de verificação dos resultados dos modelos de transição laminar-turbulenta em aerofólios.

\subsubsection{Modelos e Códigos Numéricos Utilizados na Verificação de Resultados}

Foram utilizados os seguintes modelos e códigos para realizar a verificação de resultados das análise de camada-limite implementadas na presente tese:

1) análise integral da camada-limite de quantidade de movimento, Eqs. (4.3) e (4.6), implementada por Silva (2002); na presente tese, foi incluído o modelo de AbuGhannam e Shaw (1980) para intermitência, Eq. (5.31a), e previsão de transição (5.10) e (5.12a); os resultados numéricos obtidos foram publicados antes da edição da presente tese por Silva, Silvares e Zerbini (2008b) como parte da pesquisa do doutorado;

2) análise diferencial da camada-limite nos regimes laminar e turbulento por meio do código compressível BLP2C de Cebeci e Cousteix (2005);na presente tese, este autor modificou o código BLP2C e substituiu o modelos de intermitência e de previsão de transição adotados pelo $B L P 2 C$ por aqueles de Abu-Ghannam e Shaw (1980);

3) análise diferencial da camada-limite nos regimes laminar e turbulento por meio do código incompressível TEXSTAN de Kays, Crawford e Weigand (2004), que adota o modelo de intermitência e de previsão de transição de Abu-Ghannam e Shaw (1980), e não foi modificado pelo presente autor;

4) análise diferencial de estabilidade linear do escoamento laminar pelo código STP2D desenvolvido por Cebeci (2004) e que também não foi modificado na presente tese;

5) utilização dos critérios de amplificação máxima $\left(n_{c r i t}\right)$, desenvolvida por Mack (1977) e modificada por Drela (1998), definidos nas Eqs. (5.14) e (5.15).

Originalmente, o programa de simulação $B L P 2 C$ previa o desenvolvimento do escoamento na região de transição por meio do modelo de intermitência de Chen e Thyson (1971). A posição inicial da transição laminar-turbulenta era estimada por meio da correlação de Michel (1951) ou de resultado da análise linear de estabilidade. Ambos modelos foram substituídos pelas correlações de Abu-Ghannam e 
Shaw (1980). No caso do programa TEXSTAN, que tinha o modelo de transição implementado, o presente autor não o modificou pois não teve acesso ao seu códigofonte. Mais informações sobre esses códigos são encontradas no Anexo B.

As equações da análise de estabilidade linear e o programa STP2D são descritos no Anexo C. Esse código foi rodado externamente, de forma não iterativa com a solução da camada-limite apresentada na presente seção.

Para resolução do escoamento em torno do aerofólio MBB-V2 foi utilizado o código XFOIL de Drela e Giles (1987), que resolveu o escoamento potencial de forma iterativa com a resolução integral da camada-limite. Nas Figs. 5.16(a) e 5.16(b) os resultados do XFOIL estão identificados como solução potencial-viscosa.

Quando há a separação da camada-limite laminar, que ocorre devido à ação do gradiente de pressão adverso, na presente tese admite-se que há início do processo de transição laminar-turbulenta. No código de análise integral, foi implementado o disparo da transição quando a separação laminar é detectada. Foi admitido que a posição inicial de descolamento é onde o coeficiente de atrito abaixo de um valor pequeno, $C_{f}<10^{-5}$, ou quando o parâmetro de gradiente de pressão de Thwaites (1949) é $\lambda<-0,1$. Nesse caso o comprimento da região de transição é considerado curto e a intermitência de Abu-Ghannam e Shaw (1980) é utilizada. Foram ignorados os efeitos das dimensões da bolha de separação na camada-limite de deslocamento ou no comprimento da transição.

No presente trabalho, a definição do início e do comprimento da região de transição laminar-turbulenta em condições de separação laminar foi implementada no código BLP2C. Tal qual o código BLP2C original, o TEXSTAN não possui a previsão de transição em situações de separação laminar. Assim, quando o programa detecta que o cisalhamento na parede é nulo, $\tau \approx 0$, os cálculos são interrompidos e o programa termina sua execução. Não foi possível implementar qualquer tipo de critério de transição por separação no TEXSTAN pois o presente autor não teve acesso ao código-fonte.

Para avaliar as condições de estabilidade do escoamento laminar, foi utilizado o programa STP2D (CEBECI, 2004), que resolve a dinâmica linear do escoamento laminar sujeito a perturbações infinitesimais. A partir dos perfis de velocidades, $u(y)$, estimados pelo programa diferencial de camada-limite INBLP (CEBECI, 2004), que calcula o escoamento incompressível em torno do aerofólio. A equação linear de estabilidade, a chamada equação de Orr-Sommerfeld, bem como a estrutura do código BLP2C são descritas com mais detalhes nos Anexos B e C. Diferentemente do $B L P 2 C$, o código INBLP resolve as equações RANS do escoamento incompressível 
da camada-limite de quantidade de movimento e considera os efeitos das regiões do escoamento com separação laminar nos perfis de velocidade na direção $y$.

\subsubsection{Resultados Numéricos}

Todos os escoamentos na camada-limite sobre placa plana com transição do banco de dados experimentais do ERCOFTAC foram analisados pelo presente autor. Os apresentados na Tabela 5.3, foram selecionados para apresentação neste texto. Em cada caso estudado, foram estimados:

1) o coeficiente de atrito, $C_{f}$;

2) a posição de início, $s_{t r}$ e de término, $s_{t}$, da região de transição laminar-turbulenta;

3) a espessura de quantidade de movimento, $\delta_{2}$;

4) o fator de forma, $H=\delta_{1} / \delta_{2}$;

5) o fator de amplificação em cada frequência fundamental das instabilidades lineares do escoamento laminar, $n$;

6) o fator crítico de amplificação, a partir do qual a transição ocorre, e sua frequência crítica associada, $n_{\text {crit }}$.

Apenas os resultados de coeficiente de atrito, $C_{f}$, e de fator de amplificação para um nível de turbulência, Tu, são apresentados nesta seção. Devido à limitações de escopo e de espaço, os outros parâmetros da camada-limite e da transição laminarturbulenta em todos os Tu considerados são apresentados no Apêndice B.

A Fig. 5.7 apresenta o coeficiente de atrito, $C_{f}$, em função do número de Reynolds, $\operatorname{Re}_{s}$ ao longo do comprimento da placa placa. Todas as análises apresentadas utilizaram as correlações algébricas de início e comprimento e mais a função intermitência de Abu-Ghannam e Shaw (1980), respectivamente Eqs. (5.10), (5.12a) e (5.31a). Apesar de adotarem o mesmo modelo e calcularem valores próximos de $\delta_{2, \text { lam }}$ o código TEXSTAN apresentou um início da transição mais a montante do que a previsão dos outros códigos. Não foi possível identificar a causa do desvio devido a indisponibilidade do código-fonte ou de maiores detalhes da implementação númerica. Já os outros dois códigos, que tiveram as equações do modelo de transição implementadas na presente tese, apresentaram resultados próximos. A estimativa de $C_{f, \text { turb }}$ do BLP2C ficou um pouco abaixo do TEXSTAN e do método integral, mas ainda apresentou desvios aceitáveis em relação aos dados experimentais. Por outro 
lado, procedimento integral de cálculo para $C_{f, \text { lam }}$, dado pela Eq. (4.4), apresentou um desvio em relação aos dados experimentais na região inicial do escoamento, perto do bordo de ataque da placa plana.

A análise linear da estabilidade, por meio do código diferencial STP2D, foi aplicada ao caso T3A e seus resultados são apresentados na Fig. 5.8(b). As linhas contínuas representam o fator de amplificação, $n$, das instabilidades ao longo do comprimento da placa plana para cada frequência. A linhas horizontal tracejada no nível mais baixo representa o critério de transição da Eq. (5.14), o $n_{\text {crit }}$ de Mack (1977). Para referência, foi colocado no gráfico também o critério da Eq. (5.15), o $n_{\text {crit }}$ modificado de Drela e Giles (1987). Esse último, indicado na Fig. 5.8(b) pela linha horizontal mais alta, é utilizado no código XFOIL. Com base em dados experimentais, esses autores fizeram uma extensão do método de establidade linear para considerar os efeitos das perturbações geradas por níveis médios a altos de turbulência ao longe. Esses critérios são chamados de $e^{n}$, pois a transição ocorre quando a proporção da amplitude inicial e final das oscilações atingem um valor crítico, dado por $A / A_{0}=e^{n}$, na qual o valor de $n$ é correlacionado com o nível de $T u$.

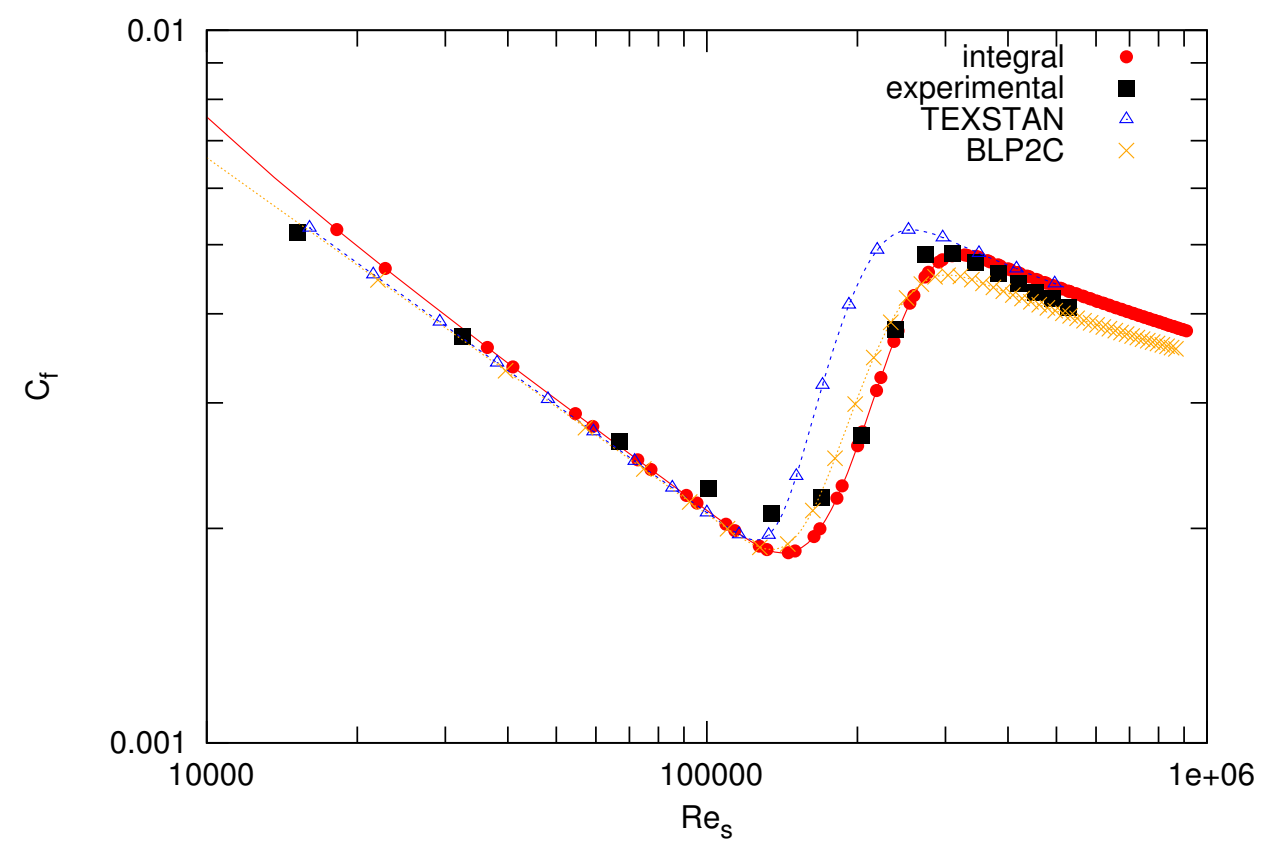

Figura 5.7: Coeficiente de Atrito - $C_{f}$ - Caso T3A - Tu = 3, $0 \%$ - gradiente de pressão nulo ao longo da placa - correlação algébrica

Se o Tu é suficientemente baixo, a transição segue pela rota A da Fig. 5.2 e é chamada de natural. Nesse caso, o valor crítico das amplificações $n_{\text {crit }}=9$ foi proposto por Smith e Gamberoni (1956) e paralelamente por van Ingen (1956) com base em bancos de dados experimentais. O método de analise de estabilidade linear e seu critério, que é chamado de $e^{9}$, é apresentado no Anexo $\mathrm{C}$. 


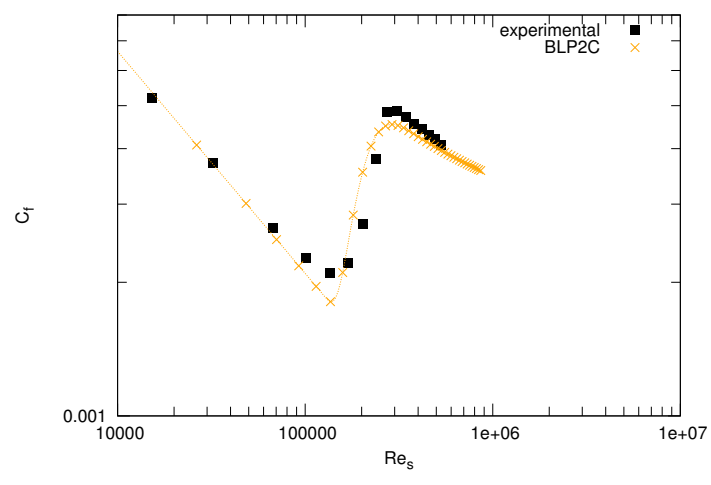

(a) Coeficiente de Atrito - $C_{f}$

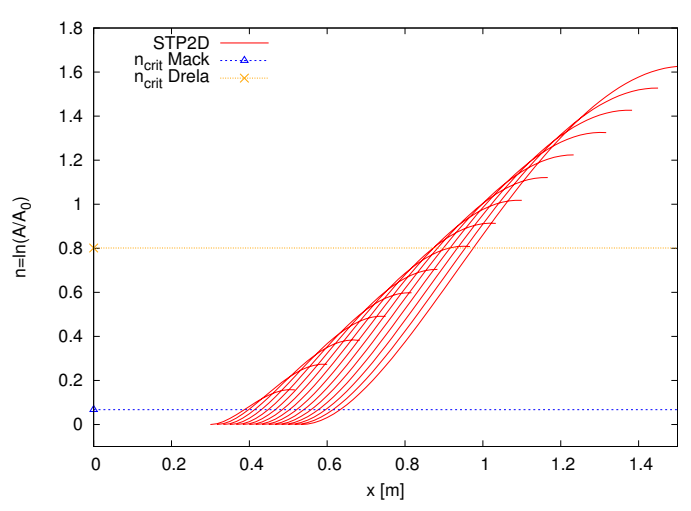

(b) Amplificação, $n$, e Critérios, $n_{\text {crit }}$

Figura 5.8: Caso T3A - Tu = 2,9\% - gradiente de pressão nulo - estabilidade linear diferencial

O presente trabalho adotou o critério de Mack (1977), que demonstrou previsões mais próximas dos dados experimentais para os casos selecionados, que tem $T u \leq 3,0 \%$, que é o limite aceito para a validade da análise de estabilidade linear. $A$ distribuição de $C_{f}$ prevista pelo $B L P 2 C$, com a posição inicial da transição estimada pela análise linear mais a posição final e intermitência prevista pelo modelo de Chen e Thyson (1971), é apresentada na Fig. 5.8(a). Houve a necessidade de diminuir a turbulência ao longe, no início da placa plana, do valor nominal, $T u=3,0 \%$, para $T u=2.9 \%$ para que o $C_{f}$ na região de transição ficasse mais perto dos dados experimentais. Os resultados da mesma previsão para o valor nominal do experimento, $T u=3,0 \%$, são apresentados no Apêndice B.

Os resultados de $C_{f}, H$ e de perfil de velocidades ao longo do escoamento, fornecidos pelos códigos BLP2C, TEXSTAN e integral do presente trabalho, foram comparados com os resultados de um modelo de média de Reynolds (RANS) com o modelo de transição por transporte de intermitência (TOBALDINI NETO; PIMENTA; SILVA, 2008). As principais conclusões daquele trabalho foram que os métodos diferenciais e integrais de camada-limite não consideram os efeitos das características do ambiente (por exemplo, intensidade e espectro de frequências da turbulência do escoamento ao longe) nas solução do escoamento nos regimes laminar e plenamente turbulento. O processo de transição é feito externamente por meio de correlações algébricas e não afetam as propriedades do escoamento médio laminar. Por outro lado, um modelo diferencial de transporte intermitência pode considerar as influências da turbulência do escoamento externo na camada-limite laminar, na região a jusante do colapso turbulento.

De forma geral para todos os casos, aqui simulados, os desvios encontrados são considerados aceitáveis pois há fatores diferentes entre os dados experimentais do ERCOFTAC e aqueles testes que geraram as correlações de previsão de transição: 
1) a faixa de escalas da turbulência gerada;

2) a geometria do bordo de ataque;

3) a posição de instalação do corpo de prova em relação a seção de teste e ao dispositivo gerador de turbulência;

4) a posição onde o Tu é medido nos experimentos ou definido nas correlações algébricas;

5) a condição da superfície do corpo de prova, se tem a presença de rugosidades ou ondulações não previstas;

6) as ruídos acústicos presentes na seção de teste do túnel.

O último fator é mais importante quando o teste é realizado em escoamentos com Tu baixos ou muito baixos. Essas diferenças de condições de teste e instalações experimentais, bem como os meios de identificá-las e contabilizá-las no cálculo da transição, são discutidas na literatura (VAN INGEN, 2008; SARIC; REED, 2006; NARASIMHA, 1985). Um dos meios de considerar outras perturbações no disparo e desenvolvimento da transição, que foi adotado no presente trabalho, é considerar o valor de Tu como um valor efetivo ou equivalente.

A Fig. 5.9 apresenta os resultados da distribuição de $C_{f}$ em função do $\operatorname{Re}_{s}$ para o caso T3AM. O código TEXSTAN não previu adequadamente o $C_{f}$ na transição porque tem uma limitação de implementação: não aceita valores de $T u<1,0 \%$. $O$ nível de turbulência foi modificado do seu valor nominal de $T u=0,87 \%$ para $0,5 \%$. Como no caso T3A, o valor de Tu para cálculo da transição por meio do crítério do $n_{\text {crit }}$ precisou ser menor do que o valor adotado para as correlações algébricas de Abu-Ghannam e Shaw (1980).

Na Fig. 5.10(b) fica evidente a região das instabilidades, de onde saem as linhas de fator de amplificação para cada frequência. A montante da primeira linha não há instabilidades e o regime laminar é estável. A última linha a montante é definida pela amplificação máxima atingida, pela ocorrência de separação laminar ou pelo final do corpo de teste. O programa STP2D não cálcula as linhas completamente nem aquelas que não passam a amplificação máxima, pois seu objetivo é estimar a curva crítica, que é formada pela envoltória dos valores máximos de amplificação ao longo do escoamento.

A distribuição de velocidades para os casos T3C2 e T3C5 são mostradas nas Figs. 5.11(a) e B.11(b). Esses casos, além de possuirem uma velocidade variável no sentido do escoamento sobre placa, têm as derivadas da velocidade da borda 


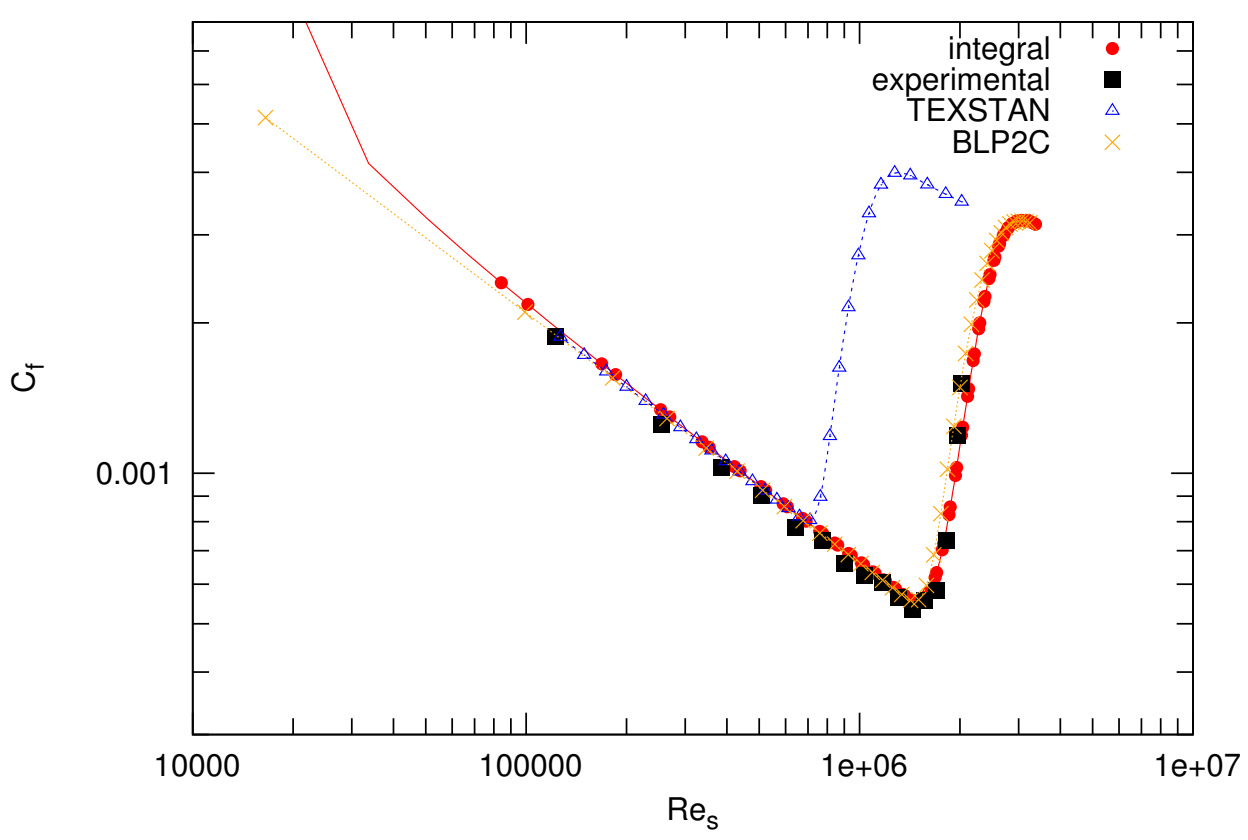

Figura 5.9: Coeficiente de Atrito - $C_{f}$ - Caso T3AM - Tu $=1,0 \%$ (integral e BLP2C) $T u=0,5 \%$ (TEXSTAN) - gradiente de pressão nulo ao longo da placa - correlação algébrica

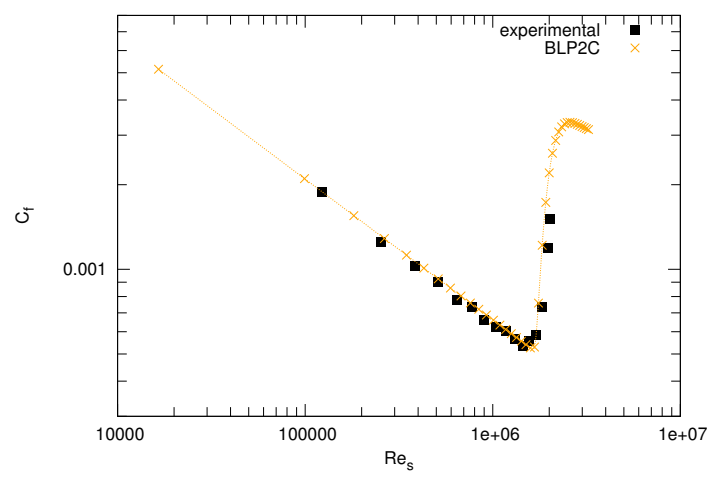

(a) Coeficiente de Atrito - $C_{f}$

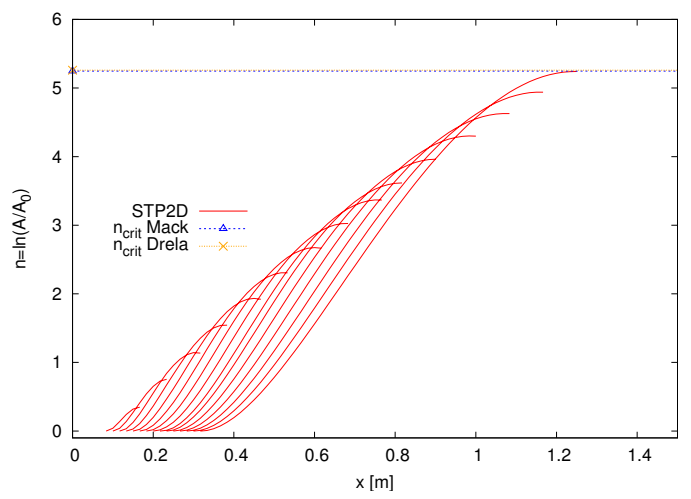

(b) Amplificação, $n$, e Critérios, $n_{\text {crit }}$

Figura 5.10: Caso T3AM - $T u=0,34 \%$ - gradiente de pressão nulo - estabilidade linear diferencial 
da camada-limite, $d u_{e} / d s$ também variáveis. Há uma região de aceleração e uma região de desaceleração do escoamento sobre a placa plana. A diferença entre os dos casos basicamente é a magnitude das velocidades, como pode ser observado na Tabela 5.3.

Devido a aceleração do escoamento e a inflexão do gradiente de pressão, a análise integral apresentou resultados com maiores desvios em relação aos dados experimentais do que os códigos diferenciais, como apresentado na Fig. 5.12. A separação laminar foi prevista mais a montante pelos procedimentos integrais do que pelo TEXSTAN, onde $C_{f} \approx 0$. Como implementado neste trabalho, a transição foi disparada pelo código integral no local da separação. Foi admitida uma transição rápida e não foram considerados os efeitos das dimensões da bolha do escoamento na camada-limite. O código TEXSTAN não conseguiu prever a transição devido a ocorrência da separação, pois não há nenhum mecanismo implementado para lidar com regiões descoladas do escoamento. Com $T u=2,0 \%$, o código $B L P 2 C$ previu a tendência da distribuição de $C_{f}$ ao longo da placa, o que pode ser verificados pelos outros parâmetros apresentados no Apêndice B. O valor nominal do nível de turbulência do caso T3C2 foi $T u=2,4 \%$.

A Fig. 5.13(b) apresenta o fator de amplificação para o caso T3C2 com Tu = $3,0 \%$. Como a expressão de $n_{\text {crit }}$ apresentou valores negativos, o seu valor mínimo foi mantido em zero. Assim se considerarmos, por mero exercício, que a ocorrência da transição foi causada pela primeira frequência e com $n_{\text {crit }} \approx 0$ (ou $A \approx A_{0}$, a amplitude da instabilidade é a inicial), a posição de início prevista seria na posição $s=0,95 \mathrm{~m}$. O resultado dessa hipótese na previsão de $C_{f}$ pode ser observado na Fig. 5.13(a). Nesse caso, o processo de transição poderia ter contornado os mecanismos lineares (indicado pelas rotas da Fig. 5.2) e o método $e^{n}$ não ter mais aplicabilidade.

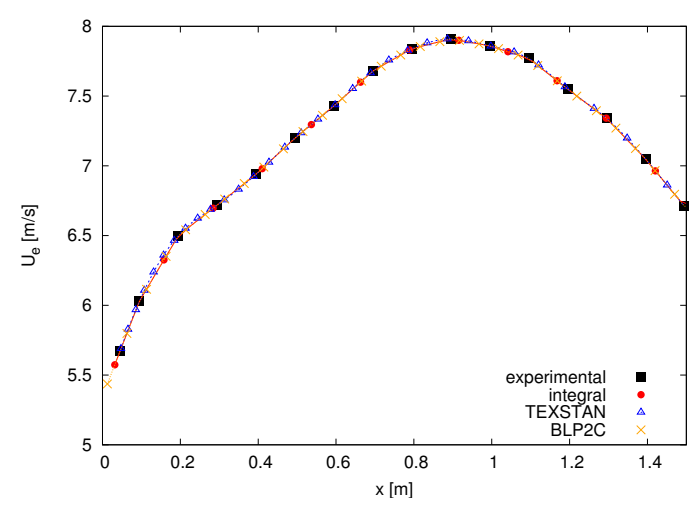

(a) Caso T3C2

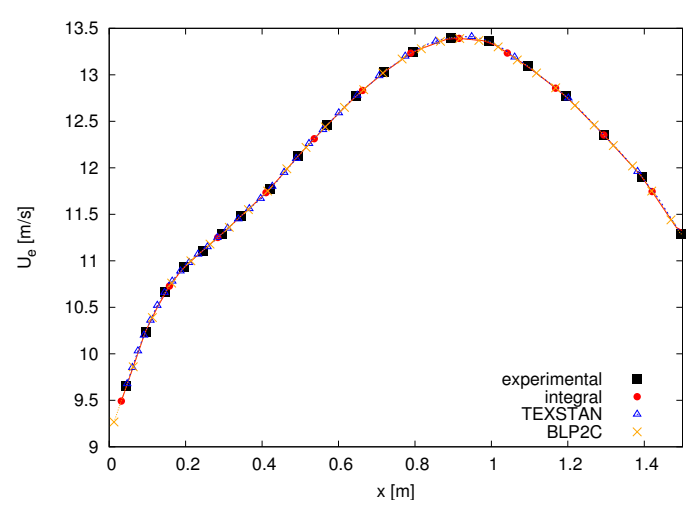

(b) Caso T3C5

Figura 5.11: Velocidade na borda da camada-limite - dados experimentais Savill 


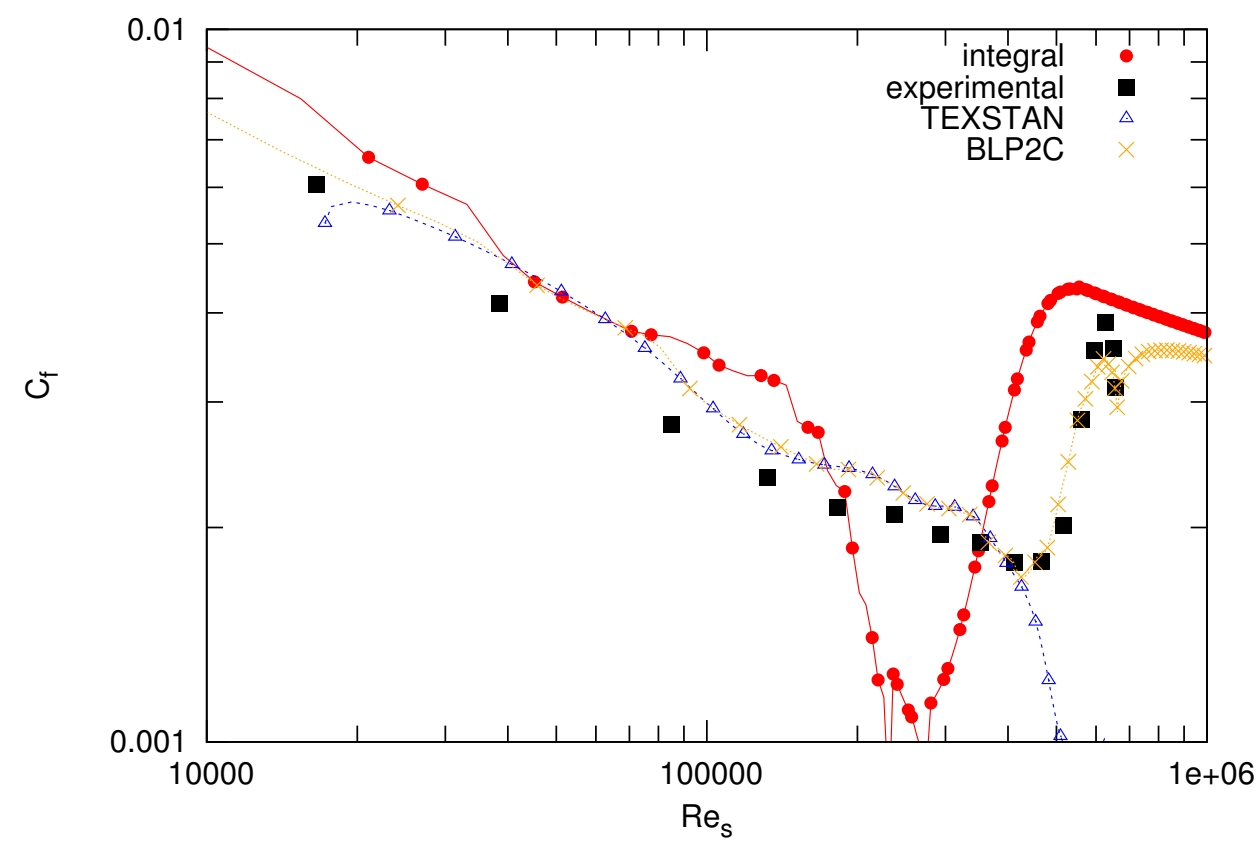

Figura 5.12: Coeficiente de atrito - $C_{f}$ - Caso T3C2 - Tu $=2,0 \%$ - gradiente de pressão variável - correlação algébrica

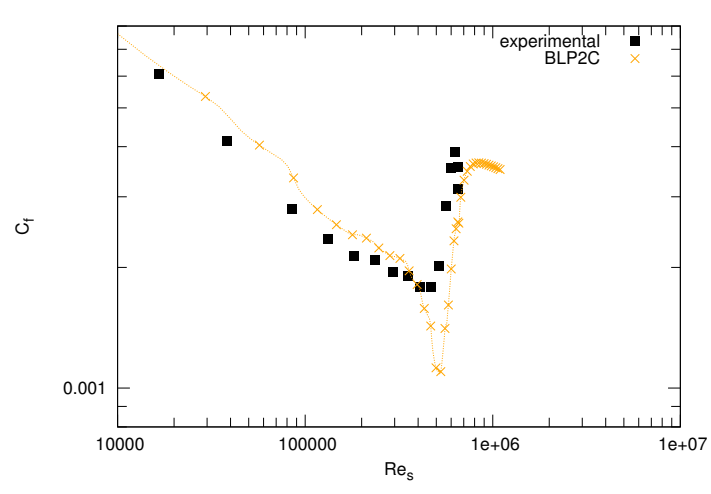

(a) Coeficiente de Atrito - $C_{f}$

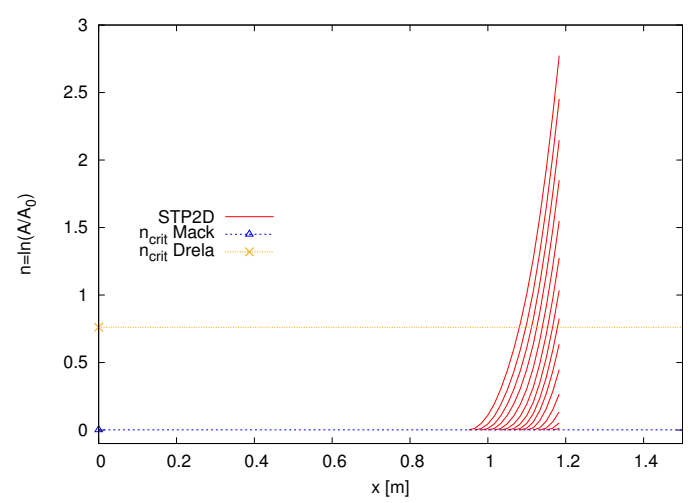

(b) Amplificação, $n$, e Critérios, $n_{\text {crit }}$

Figura 5.13: Caso T3C2 - $T u=3,0 \%$ - gradiente de pressão variável - estabilidade linear diferencial 


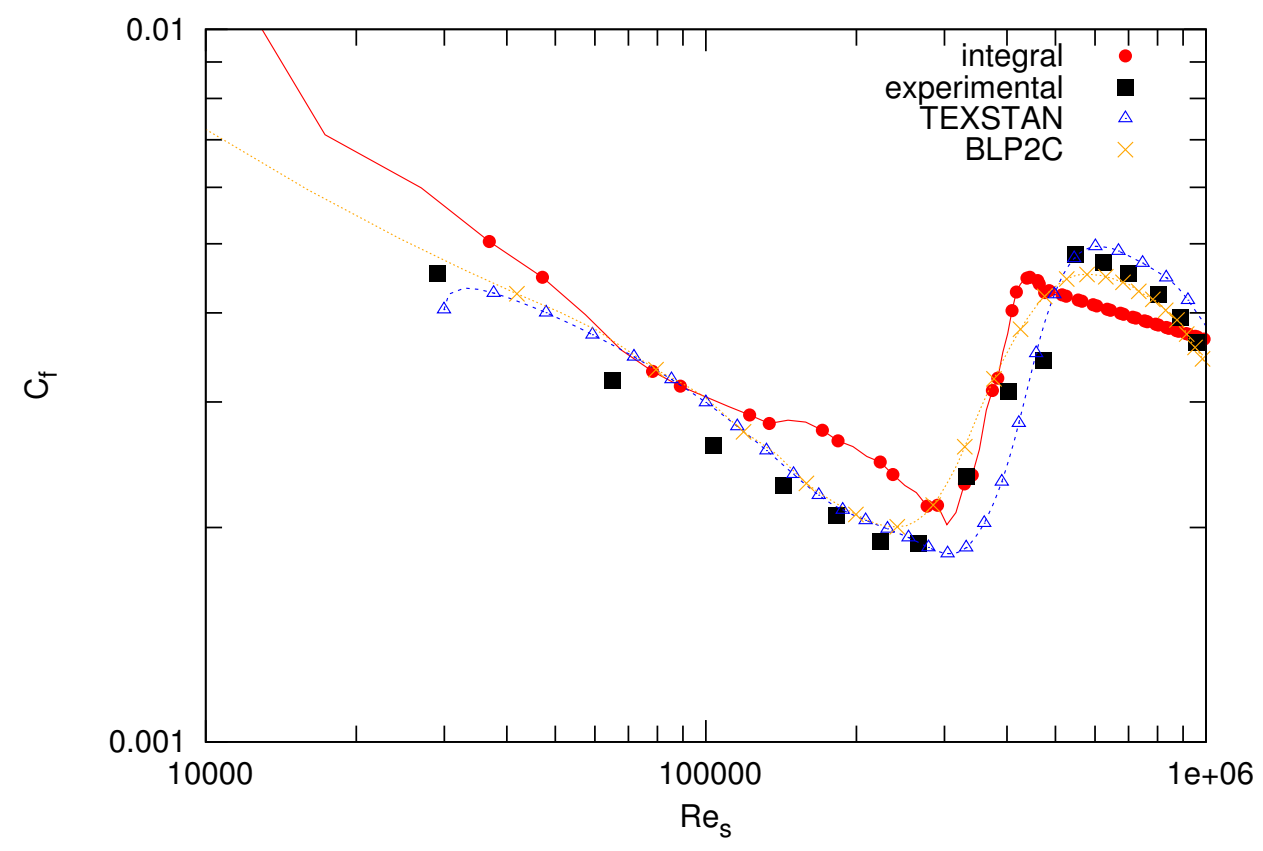

Figura 5.14: Coeficiente de atrito - $C_{f}$ - Caso T3C5 - Tu $=2,45 \%$ - gradiente de pressão variável - correlação algébrica

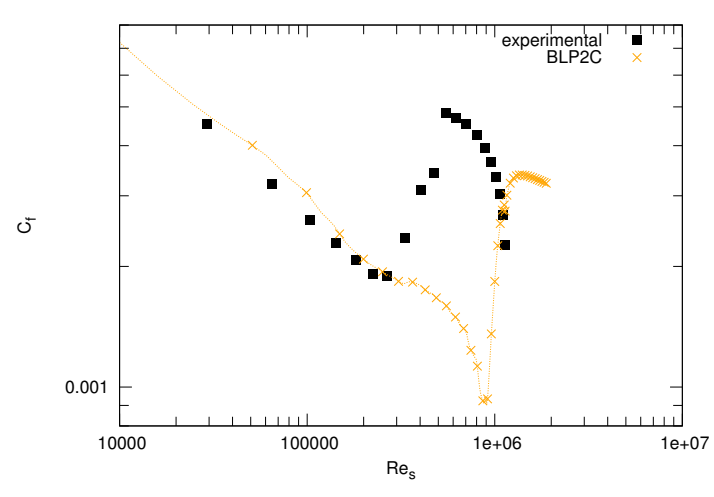

(a) Coeficiente de atrito - $C_{f}$

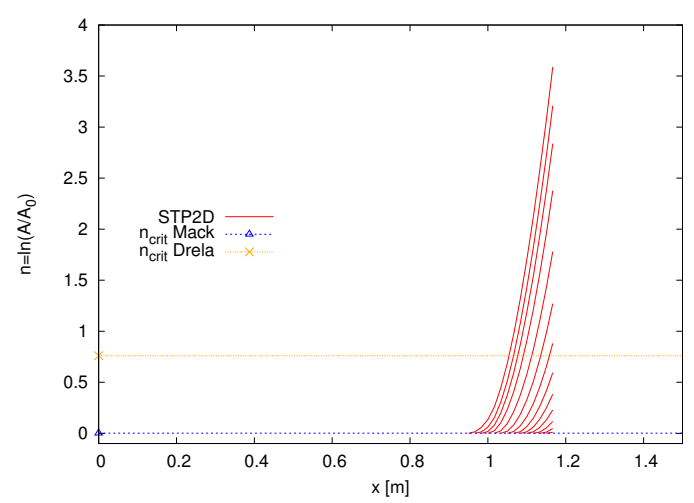

(b) Amplificação, $n$, e critérios, $n_{\text {crit }}$

Figura 5.15: Caso T3C5 - $T u=3,0 \%$ - gradiente de pressão variável - estabilidade linear diferencial 
Com Tu e variação de $u_{e}$ similares ao caso T3C3, mas com $R e_{L}$ mais de duas vezes maior, o caso T3C5 apresentou menores desvios entre os resultados numéricos e os dados experimentais, como mostra a Fig. 5.14. A intensidade da turbulência adotada foi a nominal do experimento, $T u=2,45 \%$.

O critério $e^{n}$ foi aplicado ao caso T3C5 como apresentado na Fig. 5.15. Similarmente ao caso T3C2, a establidade linear não apresentou resultados satisfatórios. Provavelmente, porque os efeitos dos mecanismos não-lineares foram dominantes no processo de transição. Essa limitação de previsão não é encontrada nas correlações algébricas de Abu-Ghannam e Shaw (1980), como apresentado na Fig. 5.14, que foram desenvolvidas com um banco de dados de experimentos que apresentaram vários tipos de rotas de transição do escoamento laminar para o turbulento.

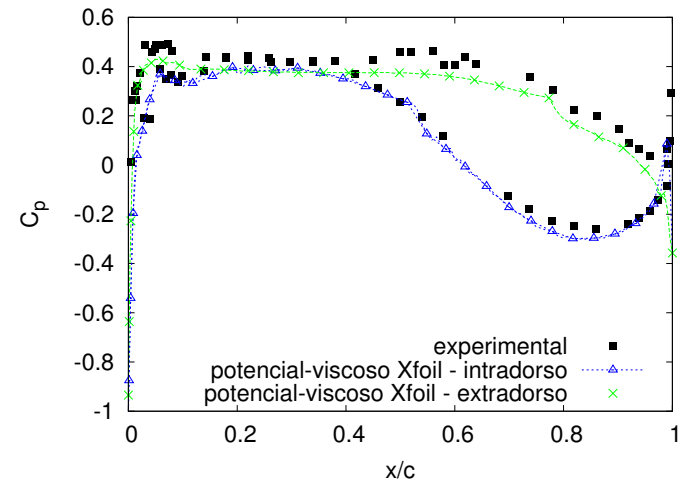

(a) Caso M1,M2,M4 - $\alpha=-0,5^{\circ}$

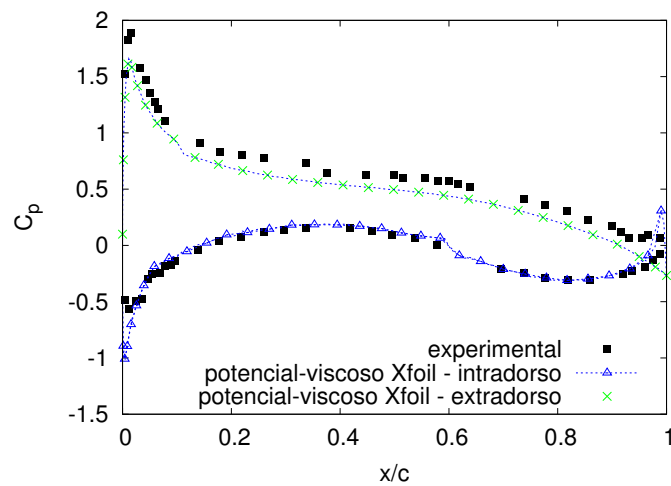

(b) Caso $\mathrm{M} 2-\alpha=3,5^{\circ}$

Figura 5.16: Coeficiente de pressão $-C_{p}$ - perfil MBB-V2

Os resultados obtidos com o XFOIL para o $C_{p}$ em torno do aerofólio MBB-V2 são comparados com os dados experimentais (MATEER; MONSON; MENTER, 1996) na Fig. 5.16 para dois ângulos de ataque: $-0,5^{\circ}$ e $3,5^{\circ}$. Houve desvios mais significativos, principalmente, no extradorso do aerofólio. No entanto, os desvios observados são menos importantes pois o gradiente de pressão foi bem representado. Provavelmente os desvios foram causados por diferenças entre a digitalização do perfil publicado pelos autores, na forma gráfica, e o perfil real testado.

A Fig. 5.17 mostra as previsões de $C_{f}$ fornecidas pelos códigos $B L P 2 C$, TEXSTAN e integral e as compara com os dados experimentais. A condição nominal de intensidade de turbulência é de $0,5 \%$, mas os autores não informam qual foi a geometria do gerador de turbulência, a distância do corpo de prova, o ponto de medição de Tu e nem a uniformidade das medições. Adotou-se o mesmo procedimento usado nos casos do ERCOFTAC e variou-se o valor de $T u$. Com $T u=0,5 \%$, a Fig. 5.17(b) mostra que a posição da transição ocorre devido a separação laminar, pois sua posição fica bem mais a jusante que os dados experimentais. No extra- 


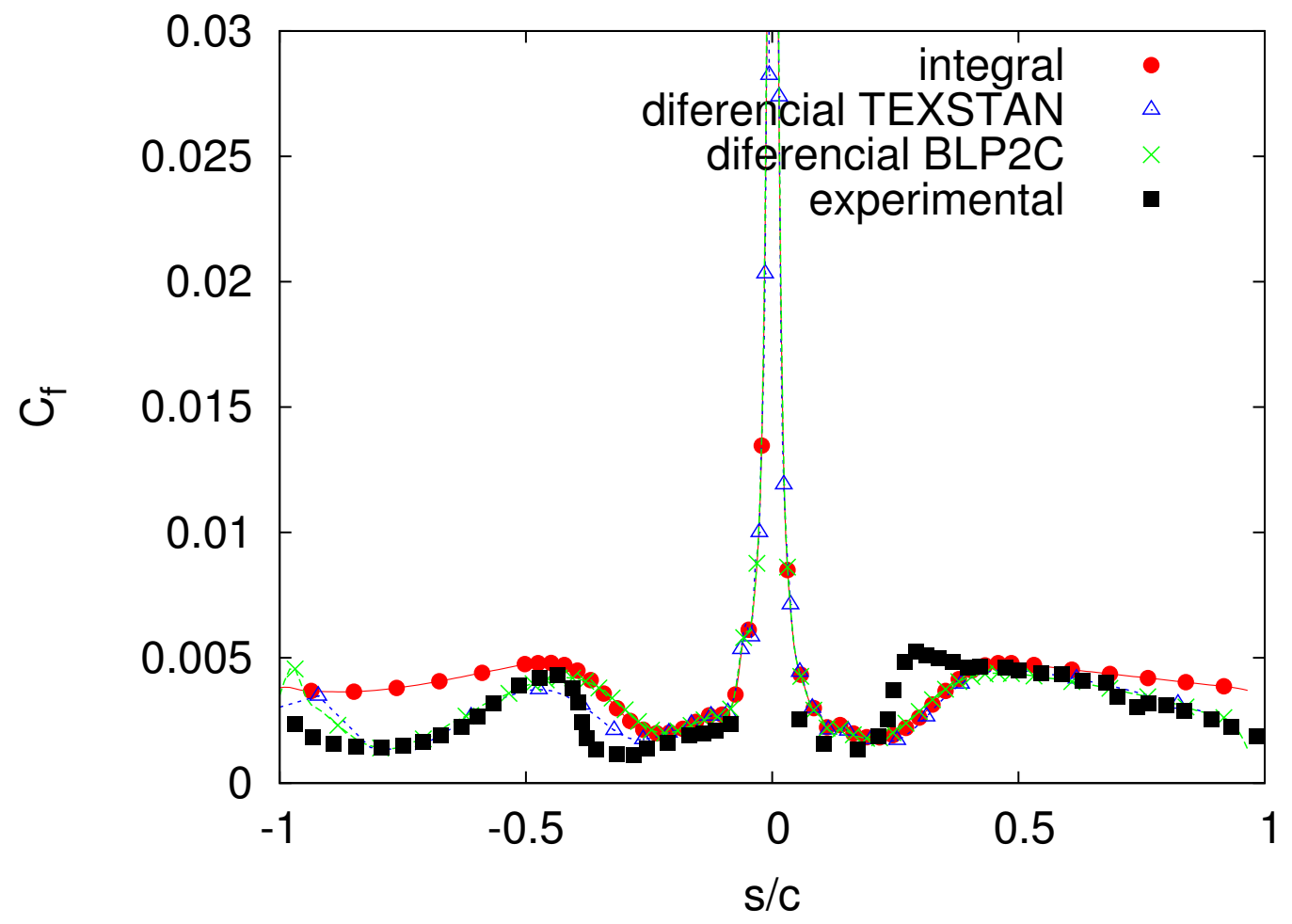

(a) $T u=3,0 \%$

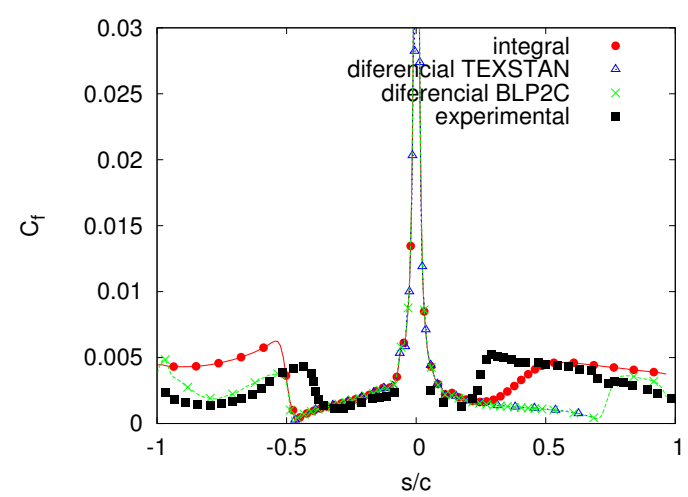

(b) $T u=0,5 \%$, exceto TEXSTAN Tu $=1,0 \%$

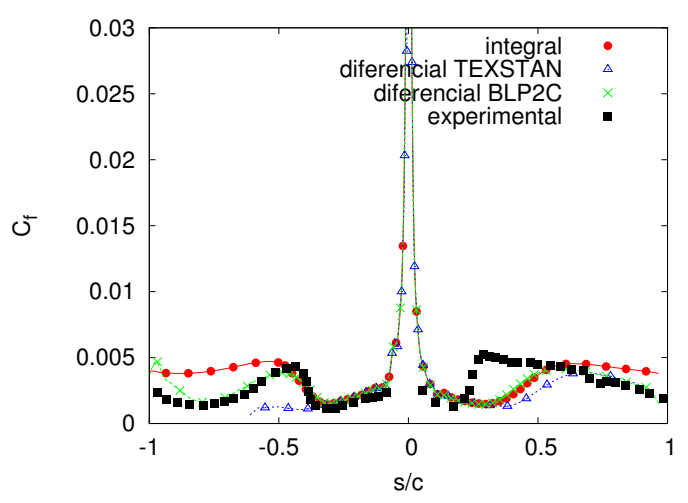

(c) $T u=2,2 \%$

Figura 5.17: Coeficiente de Atrito $-C_{f}-$ Caso M1 - MBBV2 $-\alpha=-0,5^{\circ}$ 
dorso, o código integral previu uma posição inicial da transição antes da separação.É sempre bom lembrar que o código TEXSTAN não aceita valores de $T u<1,0 \%$, logo os seus resultados são para esse valor mínimo. Com $T u=2,2 \%$, o $C_{f}$ previsto pelos códigos $B L P 2 C$ e integral ficam bem próximos aos dados experimentais no intradorso, mas com maiores desvios na região de transição do extradorso. Os resultados do código TEXSTAN separação laminar da camada-limite no intradorso, como mostrado na Fig. 5.17(c). Para Tu = 3, 0\%, conforme a Fig. 5.17(a), a posição prevista de início da transição está mais próxima, mas tem o comprimento maior do que os dados experimentais extradorso. De forma geral, o código integral não conseguiu prever o $C_{f}$ nas regiões de gradiente de pressão adverso no regime turbulento, a jusante de $s / c=0,5$. Já o desempenho dos códigos diferenciais foi bem mais satisfatório e os resultados de $C_{f, \text { lam }}$ e $C_{f, \text { turb }}$ foram considerados satisfatórios.

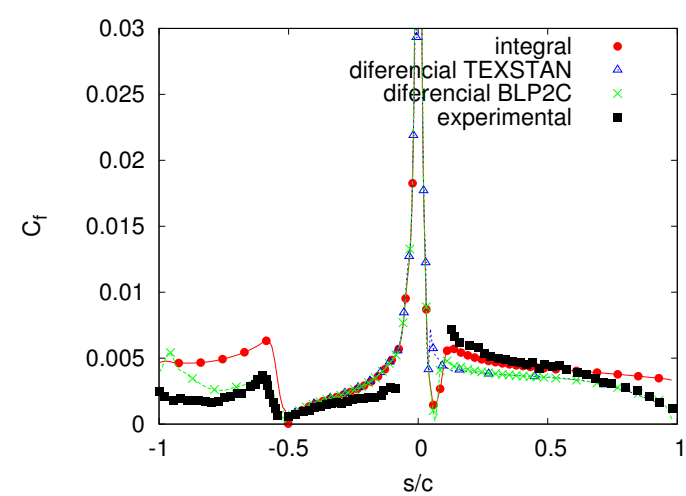

(a) $T u=0,5 \%$, exceto TEXSTAN Tu $=1,0 \%$

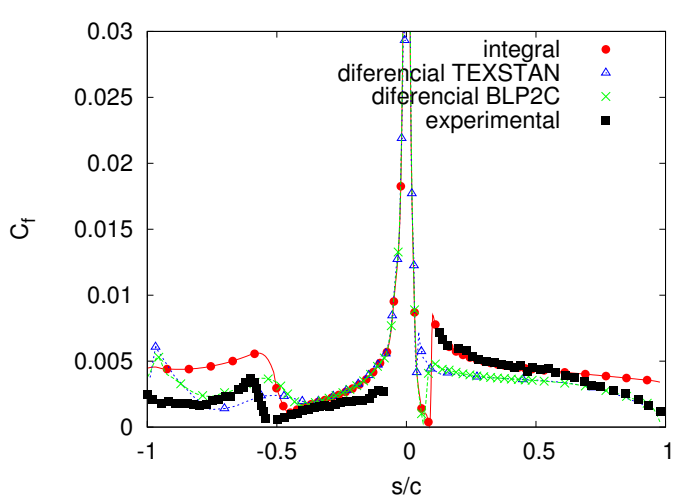

(b) $T u=2,2 \%$

Figura 5.18: Coeficiente de Atrito - $C_{f}$ - Caso M2 - MBBV2 - $\alpha=3,5^{\circ}$

Para um ângulo de ataque maior, $\alpha=3,5^{\circ}$, e a condição nominal de $T u=0,5 \%$ a transição no extradorso foi disparada por uma bolha de separação laminar, localizada perto do bordo de ataque e causada pela presença de forte gradiente de pressão adverso, como mostrado nas Figs. 5.16(b) e 5.18(a). Os códigos BLP2C e integral previram a transição causada pelo descolamento como esperado, mas o integral gerou resultados com menores desvios em relação aos dados experimentais. O código TEXSTAN previu a transição a jusante da separação pois não aceita valores menores de turbulência ao longe de 1,0\%. No extradorso, Fig. 5.18(a), o TEXSTAN parou o cálculo na separação e os outros dois códigos dispararam a transição. A transição no intradorso para $T u=2,2 \%$ ocorreu a jusante da separação segundo a previsão de todos os códigos, como observado na Fig. 5.18(b).

Os resultados para o caso $\mathrm{M} 4$, em $\operatorname{Re}_{c}$ mais baixo e mesmo $\alpha=-0,5^{\circ}$ do caso M1,são apresentados na Fig. 5.6.3. Na condição nominal do tunel, $T u=0,5 \%$, os códigos BLP2C e integral previram o início da transição laminar-turbulenta na posição de separação. Previsões desses dois códigos apresentaram desvios em relação 


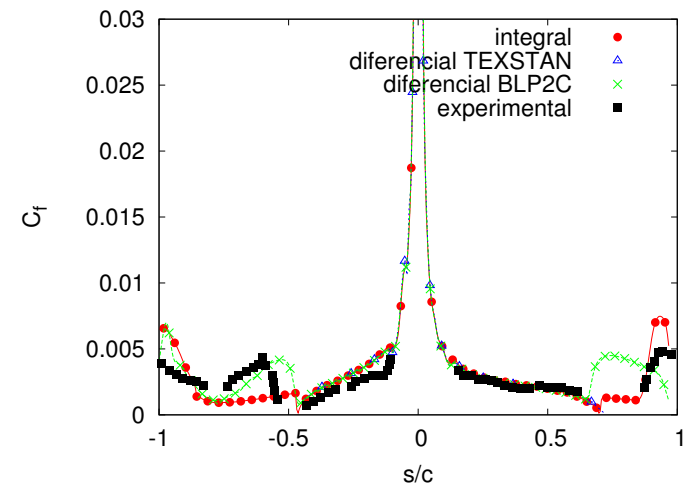

(a) $T u=0,5 \%$, exceto TEXSTAN Tu $=1,0 \%$

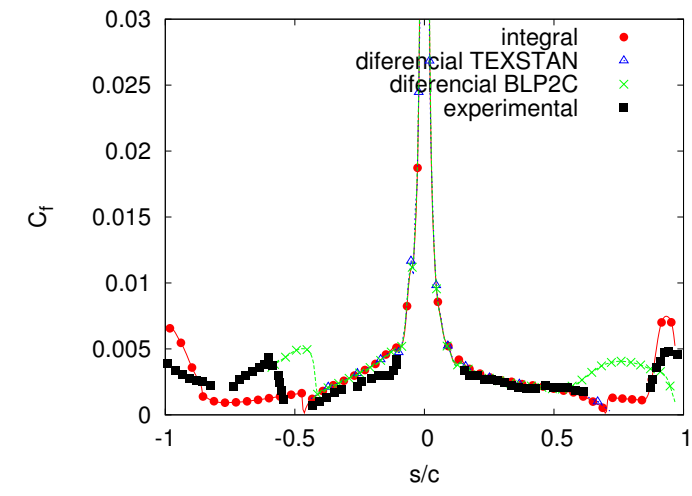

(b) $T u=3,0 \%$

Figura 5.19: Coeficiente de Atrito - $C_{f}$ - Caso M3 - MBBV2 - $\alpha=-0,5^{\circ}$

aos dados experimentais aceitáveis. Os principais desvios foram encontrados no extradorso, a jusante da posição de separação e a montante da região separada, ou seja, ao longo da bolha de separação. Todavia, o modelo de transição rápida implementado nos códigos integral e $B L P 2 C$ não preveem a presença dessas bolhas para o cálculo do comprimento nem das propriedades do escoamento ao longo dessa região separada. Essa hipótese é confirmada quando as previsões de $C_{f}$ no intradorso são analisadas. Devido ao tamanho reduzido da bolha de separação no intradorso, os desvios foram menores. O desempenho do código TEXSTAN ao longo da transição não pode ser analisado, já que esse código não realiza previsões a jusante da posição de separação. No entanto, os casos de escoamento em torno de aerofólios com sistema térmico de antigelo simulados na presente tese não apresentam regiões de separação laminar, portanto não fazem parte do escopo da tese. O caso de $T u=3,0 \%$, apresentado na Fig. 5.19(b), a transição prevista pelo BLP2C foi a montante da posição de separação, mas a solução divergiu no intradorso.

Para o caso M4, de Re maior e mesmo $\alpha$ do caso M1, as previsões do código BLP2C apresentaram menores desvios em relação ao dados experimentais do que outros dois códigos (integral e TEXSTAN), como pode ser observado nas Figs. 5.20 (c) e 5.20(a). A menos da região a jusante de $s / c=0,5$, as soluções dos procedimentos integrais e do TEXSTAN foram muito próximas. O nível de turbulência ao longe de 3,0\% foi o que resultou na melhor previsão de início e comprimento da região de transição laminar-turbulenta. Como $\mathrm{Ma}=0,2$ e $\alpha=-0,5^{\circ}$ para os casos M1 e M4, mas os desvios foram menores para o caso M4, conclui-se que o código $B L P 2 C$ tenha melhor precisão para número de Reynolds maiores. 


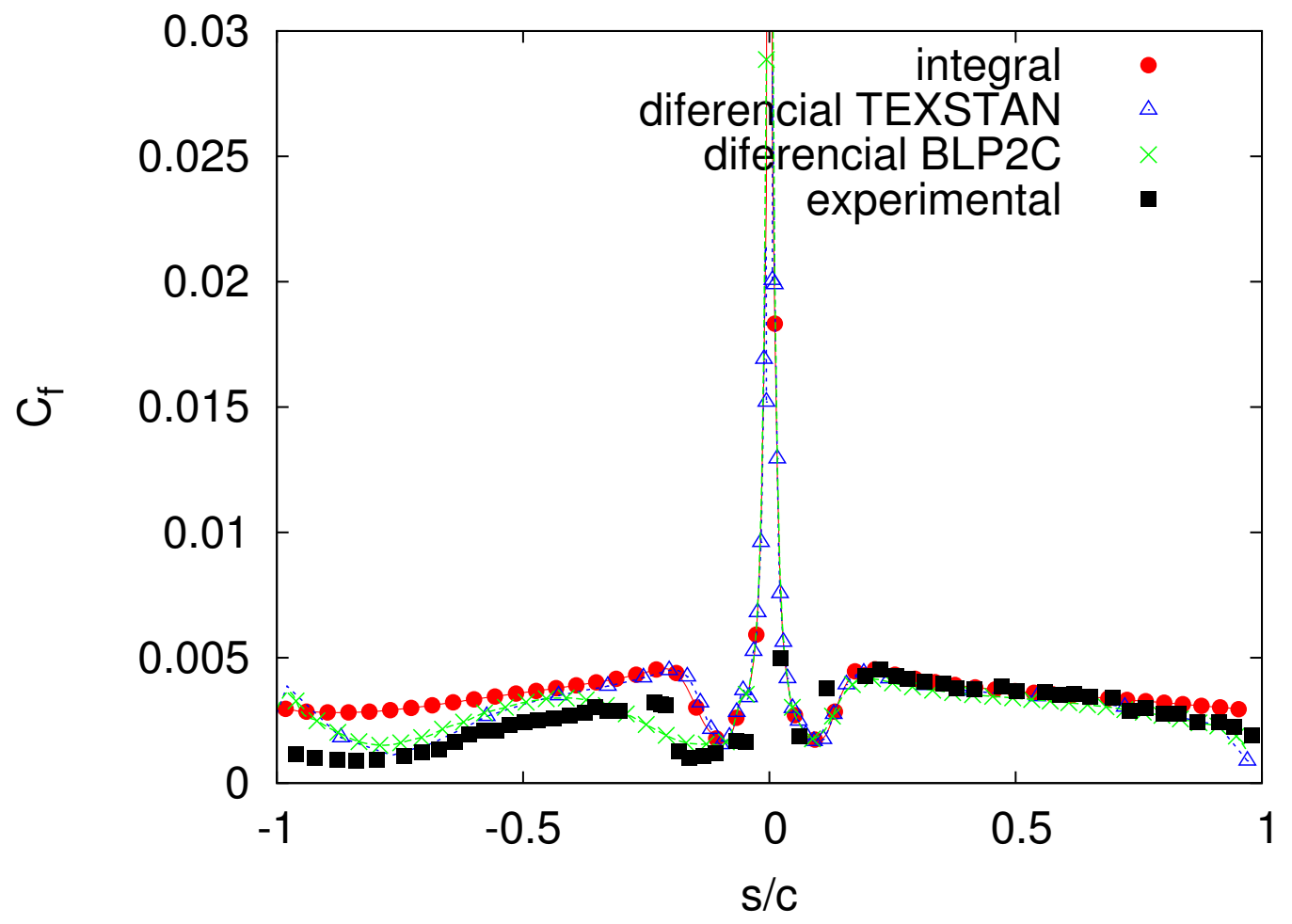

(a) $T u=3,0 \%$

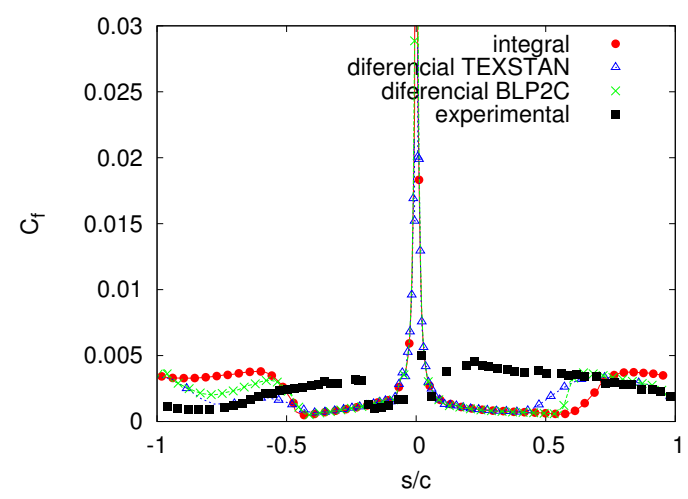

(b) $T u=0,5 \%$, exceto TEXSTAN Tu $=1,0 \%$

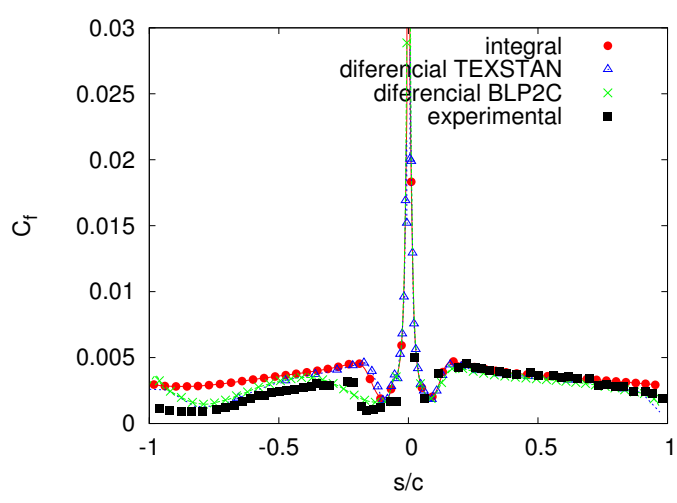

(c) $T u=2,2 \%$

Figura 5.20: Coeficiente de Atrito $-C_{f}-$ Caso M4 - MBBV2 $-\alpha=-0,5^{\circ}$ 


\subsection{Comentários}

O presente capítulo apresentou, implementou e verificou os resultados de modelos de previsão e intermitência da transição laminar-turbulenta. Em relação aos modelos de intermitência, o de Reynolds, Kays e Kline (1958b) foi implementado na dissertação de mestrado, e o de Abu-Ghannam e Shaw (1980) na presente tese. Já em relação a previsão de início e o término da região de transição laminar-turbulenta, foi somente no presente trabalho que o autor pesquisou, implementou e testou modelos. No seu trabalho anterior (SILVA, 2002) a região de transição não era prevista, era somente um modo de ajuste dos resultados numéricos aos dados experimentais de temperatura de superfície e coeficiente de transferência de calor.

Nenhum trabalho na literatura de simulação térmica de aerofólios com sistema antigelo, revisada no Capítulo 2, tinha modelos de previsão da transição laminarturbulenta que considerasse ambos os efeitos do gradiente de pressão e do nível de turbulência, Tu. Esta característica é importante para simular escoamentos em túneis de gelo, que possuem $1,5 \%>T u>6 \%$, e em condições de vôo natural, $T u<1 \%$. Além disso, por meio de um Tu equivalente pode-se representar outras perturbações do ambiente e da superfície, que também alteram a posição de início e o comprimento da região de transição laminar-turbulenta.

Os resultados finais, considerando a molhabilidade parcial da superfície, a análise de camada-limite e os modelos de transição laminar-turbulenta, são apresentados e discutidos no Capítulo 6. As conclusões finais da presente tese podem ser encontradas no Capítulo 7. 


\section{Resultados da Simulação NUMÉRICA dO ESCOAMENTO BIFÁSICO EM TORNO DE AERofólios COM Sistema TÉRMICO DE ANTIGELO}

Neste capítulo é apresentada a validação dos resultados da simulação do escoamento bifásico em torno de aerofólios equipados com sistema eletrotérmico antigelo de aplicação aeronáutica. São obtidas as distribuições de temperatura de superfície e de vazão de água líquida residual em torno do aerofólio.

Os submodelos de molhabilidade de superfície, camada-limite e de transição laminar-turbulenta, desenvolvidas e verificadas respectivamente nos Capítulos 3, 4, 5, são incluídos no modelo-base, desenvolvido no Capítulo 2, para a simulação de escoamento em torno de aerofólios com antigelo.

A Fig. 6.1 apresenta uma visão geral do processo global de verificação e validação. Todos os modelos foram implementados e os casos simulados durante 0 presente trabalho.

O processo de verificação dos resultados dos submodelos, apresentado na Fig. 6.2, é aplicado aos três submodelos desenvolvidos na presente tese de doutorado:

- molhabilidade: quebra de filme e formação de filetes no escoamento de água líquida residual;

- transferência de calor por convecção: escoamento na camadas-limite de quantidade de movimento e de entalpia;

- transição laminar-turbulenta: evolução da intermitência do escoamento ao longo da transição; previsão de início e término da região de transição.

Os códigos externos TEXSTAN e STP2D foram utilizados apenas como apoio 


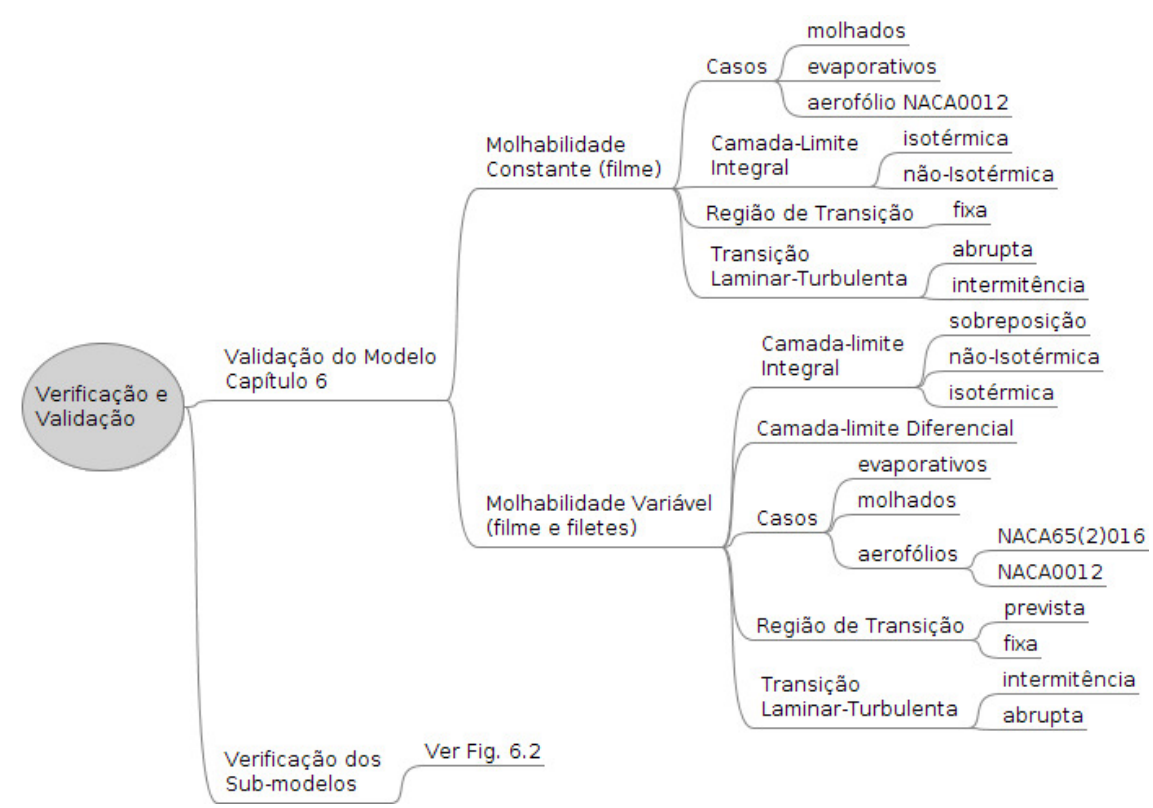

Figura 6.1: Processo Global de Validação e Verificação dos Resultados

e referência durante o processo de verificação nos Capítulos 4 e 5.

Já o código externo $B L P 2 C$, descrito no Anexo $B$ e que não desenvolvido na presente tese, foi incluído no simulador térmico do escoamento em torno do aerofólio com antigelo e é utilizado na validação dos resultados apresentada no presente capítulo.

O desenvolvimento, aqui descrito, abrangeu pelo menos quatro níveis de modelagem matemática, como mostrado resumidamente na Fig. 2.1 e descritos na Seção 2.2 .

Uma das contribuições principais deste trabalho é integrar os quatro níveis. A integração dos sub-modelos dos níveis II, III e IV ao modelo do nível I é um dos objetivos do processo de validação e verificação, Figs. 6.1 e 6.2.

\subsection{Casos-Teste}

Para a validação são utilizados dados experimentais de casos representativos de operação de antigelo elétrico em túneis de gelo sob condições de gelo selecionados dos experimentos clássicos de Gelder e Lewis (1951) e dos mais recentes de AlKhalil et al. (2001). Coincidentemente, os experimentos foram realizados no mesmo centro de pesquisa, mas com aerofólios, condições, equipamentos de medições e instalações experimentais totalmente distintas.

Nota-se que há uma diferença de 50 anos entre as publicações. A da década de 50 pode ter sido motivada pela necessidade, cada vez mais frequente naquela época, 


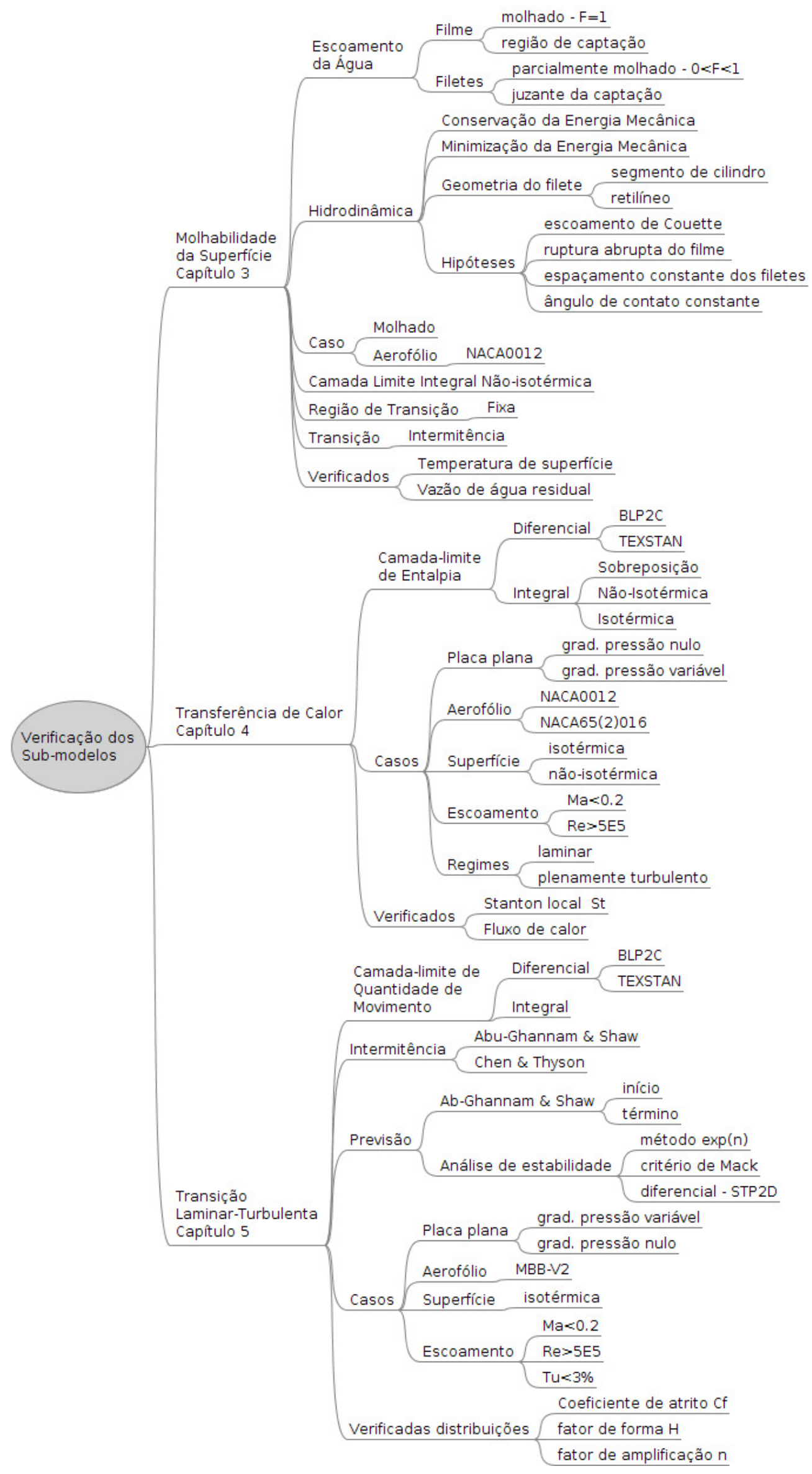

Figura 6.2: Processo de Verificação dos Resultados dos Submodelos de Formação de Filetes, Transferência de Calor e Transição Laminar-turbulenta 
de voos transoceânicos ou transcontinentais comerciais sob qualquer condição de tempo. Essa foi restrição crítica ao crescimento das linhas aéreas no período pósguerra. Por outro lado, a campanha de ensaios realizada a partir do meio da década de 90 na NASA, foi motivada pelos acidentes aéreos ocorridos no início dos anos 90 com aviões turboélice. Essas aeronaves utilizavam sistemas de degelo pneumáticos e voaram sob condições de gelo muito severas. A resposta do governo estadunidense foi o investimento em pesquisa em formação de gelo, simulação numérica e em projeto de sistemas térmicos de antigelo.

Dentre os dados experimentais de Gelder e Lewis (1951) e Al-Khalil et al. (2001), foram selecionados casos de teste que:

1) possuissem dados experimentais completos, ou seja, de temperatura, densidade de potência fornecida pelo sistema antigelo e de transferência de calor;

2) tivessem ângulo de ataque, $\alpha$, nulo para evitar a presença de separação do escoamento laminar;

3) abrangessem os regimes evaporativo e molhado de operação do antigelo.

\subsubsection{Casos de Al-Khalil et al. (2001)}

Al-Khalil et al. (2001) realizaram experimentos de antigelo no Túnel de Pesquisa de Formação de Gelo (IRT) do Glenn Research Center de Al-Khalil et al. (2001) (excentro de pesquisas Lewis), em Cleveland, Ohio, EUA. O objetivo dos autores foi medir as distribuições de temperatura de superfície e de coeficiente de transferência de calor global para validar resultados do código numérico ANTICE, desenvolvidos pelos próprios. Esse programa é a versão do $L E W I C E$ dedicada à simulação térmica de antigelo. O aerofólio testado foi um perfil NACA 0012, apresentado na Fig. 4.2, de 1,828 $\mathrm{m}$ de envergadura por 0,914 $\mathrm{m}$ de corda com aquecedores controlados eletronicamente. A condutividade térmica no sentido do escoamento é $k=16,27$ $\mathrm{W} /\left(\mathrm{m}^{2} \cdot \mathrm{K}\right)$.

Cada elemento do aquecedor, posicionados na direção do escoamento, tinha um termopar, um sensor termoresistor e um medidor de fluxo de calor. Três casos dos dados experimentais de Al-Khalil et al. (2001) são utilizados: o caso 22A, que é uma condição evaporativa com água residual que determina os limites de água incidente à montante; e também os casos 67A e 67B, que têm mais água percorrendo o bordo de ataque do que o 22A. A Tabela 6.1 apresenta as condições experimentais, a Tabela 6.2 a geometria dos aquecedores e também as densidades de potência fornecidas pelo sistema antigelo. 
Tabela 6.1: Casos de Teste para Validação do Modelo do Antigelo

\begin{tabular}{|c|c|c|c|c|}
\hline \multirow[b]{2}{*}{ Parâmetro } & \multicolumn{2}{|c|}{ Gelder e Lewis (1951) } & \multicolumn{2}{|c|}{ Al-Khalil et al. (2001) } \\
\hline & $8 G L$ & $8 G L$ seco 8 & $22 \mathrm{~A}$ & $67 A$ e $67 B$ \\
\hline$V_{\infty}[\mathrm{m} / \mathrm{s}]$ & 73,8 & 73,8 & 44,7 & 89,4 \\
\hline$T_{\text {tot }}\left[{ }^{\circ} \mathrm{C}\right]$ & $-6,1$ & $-6,1$ & $-7,6$ & $-21,6$ \\
\hline$\alpha$ & $0^{\circ}$ & $0^{\circ}$ & $0^{\circ}$ & $0^{\circ}$ \\
\hline$L W C\left[\mathrm{~g} / \mathrm{m}^{-3}\right]$ & 0,5 & - & 0,78 & 0,55 \\
\hline$M V D[\mu \mathrm{m}]$ & 11 & - & 20 & 20 \\
\hline aerofólio & NACA $65_{2}-0016$ & NACA $65_{2}-0016$ & NACA 0012 & NACA 0012 \\
\hline corda $[\mathrm{m}]$ & 2,438 & 2,438 & 0,914 & 0,914 \\
\hline
\end{tabular}

Tabela 6.2: Comprimentos e Densidades de Potência Elétrica dos Aquecedores Casos-teste de Al-Khalil et al. (2001)

\begin{tabular}{ccccccr}
\hline \multirow{2}{*}{ Elemento } & \multicolumn{3}{c}{$s / c$} & & \multicolumn{3}{c}{$\dot{q}_{\text {antigelo }}^{\prime \prime}\left[\mathrm{kW} / \mathrm{m}^{2}\right]$} \\
\cline { 2 - 3 } \cline { 5 - 6 } Aquecedor & \multicolumn{1}{c}{ início } & final & & $22 \mathrm{~A}$ & $67 \mathrm{~A}$ & $67 \mathrm{~B}$ \\
\hline$F$ & $-0,1024$ & $-0,0607$ & & 9,92 & 20,15 & 8,37 \\
$D$ & $-0,0607$ & $-0,0329$ & 10,23 & 21,70 & 11,93 \\
$B$ & $-0,0329$ & $-0,0051$ & 32,55 & 32,55 & 10,85 \\
$A$ & $-0,0051$ & 0,0157 & 46,5 & 43,40 & 15,19 \\
$C$ & 0,0157 & 0,0435 & 18,6 & 26,35 & 9,92 \\
$E$ & 0,0435 & 0,0713 & 6,97 & 18,60 & 12,86 \\
$G$ & 0,0713 & 0,1129 & 10,23 & 18,60 & 8,68 \\
\hline
\end{tabular}

\subsubsection{Casos de Gelder e Lewis (1951)}

Gelder e Lewis (1951) conduziram uma das primeiras investigações da transferência de calor de um aerofólio em condições de gelo e ar seco em um túnel de gelo de circuito fechado do antigo centro de pesquisa Lewis da NACA. Os testes utilizaram um aerofólio NACA 652-0016, apresentado na Fig. 4.3, com 1,839 m de envergadura por 2,438 m de corda, que foi previamente adotado por Neel e Bergrun (1947) em ensaios de voo de proteção antigelo sob condições de formação de gelo e distribuições de potência de aquecimento elétrico similares. A superfície do aerofólio é coberta por uma chapa de $0,15 \mathrm{~mm}$ de espessura e que condutividade térmica equivalente no sentido do escoamento é $k=170 \mathrm{~W} /\left(\mathrm{m}^{2} \cdot \mathrm{K}\right)$.

Os autores observaram um adiantamento do ponto de início da transição laminarturbulenta, induzido pela captação de água e pelo nível de turbulência do escoamento ao longe, que era maior no túnel do que em condição de voo. Outra importante evidência experimental foi que as distribuições de aquecimento e temperatura afetam o coeficiente de transferência de calor de modo significativo. O presente trabalho utiliza 
Tabela 6.3: Comprimentos e Densidades de Potência Elétrica dos Aquecedores Caso-teste da Gelder e Lewis (1951)

\begin{tabular}{cccc}
\hline \multirow{2}{*}{ Elemento } & \multicolumn{2}{c}{$s / c$} & caso $8 \mathrm{GL}$ \\
\cline { 2 - 3 } Aquecedor & início & final & $\dot{q}_{\text {antigelo }}^{\prime \prime}\left[\mathrm{kW} \cdot \mathrm{m}^{-2}\right]$ \\
\hline$J$ & $-0,1904$ & $-0,0615$ & 2,46 \\
$H$ & $-0,0615$ & $-0,0348$ & 2,93 \\
$F$ & $-0,0348$ & $-0,0249$ & 4,00 \\
$D$ & $-0,0249$ & $-0,0076$ & 6,25 \\
$B$ & $-0,0076$ & $-0,0026$ & 8,82 \\
$A$ & $-0,0026$ & 0,0047 & 12,04 \\
$C$ & 0,0047 & 0,0108 & 10,24 \\
$E$ & 0,0108 & 0,0250 & 6,55 \\
$G$ & 0,0250 & 0,0358 & 4,01 \\
$I$ & 0,0358 & 0,0644 & 2,83 \\
$K$ & 0,0644 & 0,3038 & 2,4 \\
$L$ & 0,3038 & 0,3757 & 7,65 \\
$M$ & 0,3757 & 0,4756 & 9,47 \\
$N$ & 0,4756 & 0,5761 & 8,45 \\
\hline
\end{tabular}

o caso experimental 8, aqui chamado de 8GL, da NACA sob condições de formação de gelo e de ar seco. O conteúdo de água líquida (LWC), diâmetro volumétrico médio (MVD), em conjunto com algumas configurações do túnel de gelo e aerofólio, são apresentados em Tabela 6.1. A Tabela 6.3 apresenta a geometria dos aquecedores e também as densidades de potência fornecidas pelo sistema antigelo.

\subsection{Resultados Numéricos - Análise Integral da Camada-Limite}

Nesta seção são apresentados os resultados do modelo do escoamento bifásico em torno de aerofólios com antigelo térmico considerando vários submodelos de análise integral de camada-limite e de transição laminar-turbulenta.

\subsubsection{Submodelo de Transição Laminar-turbulenta Abrupta e Submodelo de Filme Contínuo}

Foram comparados os resultados do modelo de Silva, Silvares e Zerbini (2007a), que é o de referência para as comparações nesta seção, com outro mais simplificado, que adota a análise integral de camada-limite sobre superfície isotérmica e transição abrupta.Em ambos os modelos de antigelo, é adotado o submodelo de filme contínuo ( $F$ constante) para escoamento da água residual. No modelo simplificado, a trans- 
ferência de calor laminar é avaliada pela Eqs. (4.15) e a turbulenta pela analogia de Colburn, dada pela Eq. (4.30). A existência da região de transição é ignorada e o escoamento passa do regime laminar ao turbulento num trecho muito curto. Apesar de restrito por hipóteses arbitrárias, esse tipo de modelo é largamente utilizado na indústria. O resultado desse estudo foi publicado por Silva, Silvares e Zerbini (2008c).

A Fig. 6.3(a) apresenta as distribuições de temperatura da superfície sólida estimadas usando os modelos integrais de camada-limite isotérmico e não-isotérmico. Somente a hipótese de superfície não-isotérmica foi simplificada. As previsões são comparadas aos dados experimentais e aos resultados numéricos do ANTICE. Por outro lado, Fig. 6.3(b) compara as previsões das temperaturas quando se adota o modelo de intermitência de transição abrupta. A posição de transição abrupta foi fixada como sendo a posição média da região de transição, $s_{m}$, do modelo de referência, a qual se localiza em $s / c=0,08$ e $-0,083$ para o caso $22 \mathrm{~A}$. O valor de 0,04 em $s / c$ foi utilizado como desvio padrão médio da transição, $\sigma$.

Os efeitos na temperatura estimados pelas hipóteses na camada-limite para 0 caso 67A são mostrados nas Figuras 6.5(a) e 6.5(b). Em ambos os casos, $22 \mathrm{~A}$ e $67 \mathrm{~A}$, o modelo de referência, o qual adota modelos não-isotérmico e de intermitência, estimou temperaturas mais próximas dos resultados experimentais e numéricos ANTICE, quando comparadas àquelas obtidas com modelos isotérmicos e de transição abrupta, que é o modelo simplificado.

A Fig. 6.4(a) mostra que o modelo isotérmico apresenta variações desprezíveis em $U$ devido a variações nas propriedades termodinâmicas e que existe simetria. Por outro lado, o resultado do modelo não-isotérmico apresenta variações significativas no bordo de ataque e não apresenta simetria. Como esperado, o modelo não-isotérmico resultou em maiores valores para o coeficiente de transferência de calor na região turbulenta, devido ao aumento na diferença de temperaturas (entre a parede sólida e o ambiente) ao final do filme de água. Outra clara diferença se apresenta ao final da área protegida, onde o escoamento é turbulento, na qual o modelo não-isotérmico estima uma redução no coeficiente de transferência de calor e o modelo isotérmico, um aumento. Estes efeitos de $T_{s}$ sobre $h_{a r}$ foram extensivamente estudados por Reynolds, Kays e Kline (1958a) em escoamentos sobre placas planas aquecidas operando em túnel com ar seco.

A transição abrupta foi fixada nas posições médias das regiões de transição, que são $s / c=0,07$ e $-0,067$ para o caso 67A. Para o modelo de referência, o desvio padrão da transição, $\sigma$, foi fixado em 0,07 para o caso $67 \mathrm{~A}$ nas superfícies superior e inferior. Os parâmetros de transição $\left(s_{m}\right.$ e $\left.\sigma\right)$ foram encontrados pelo ajuste 


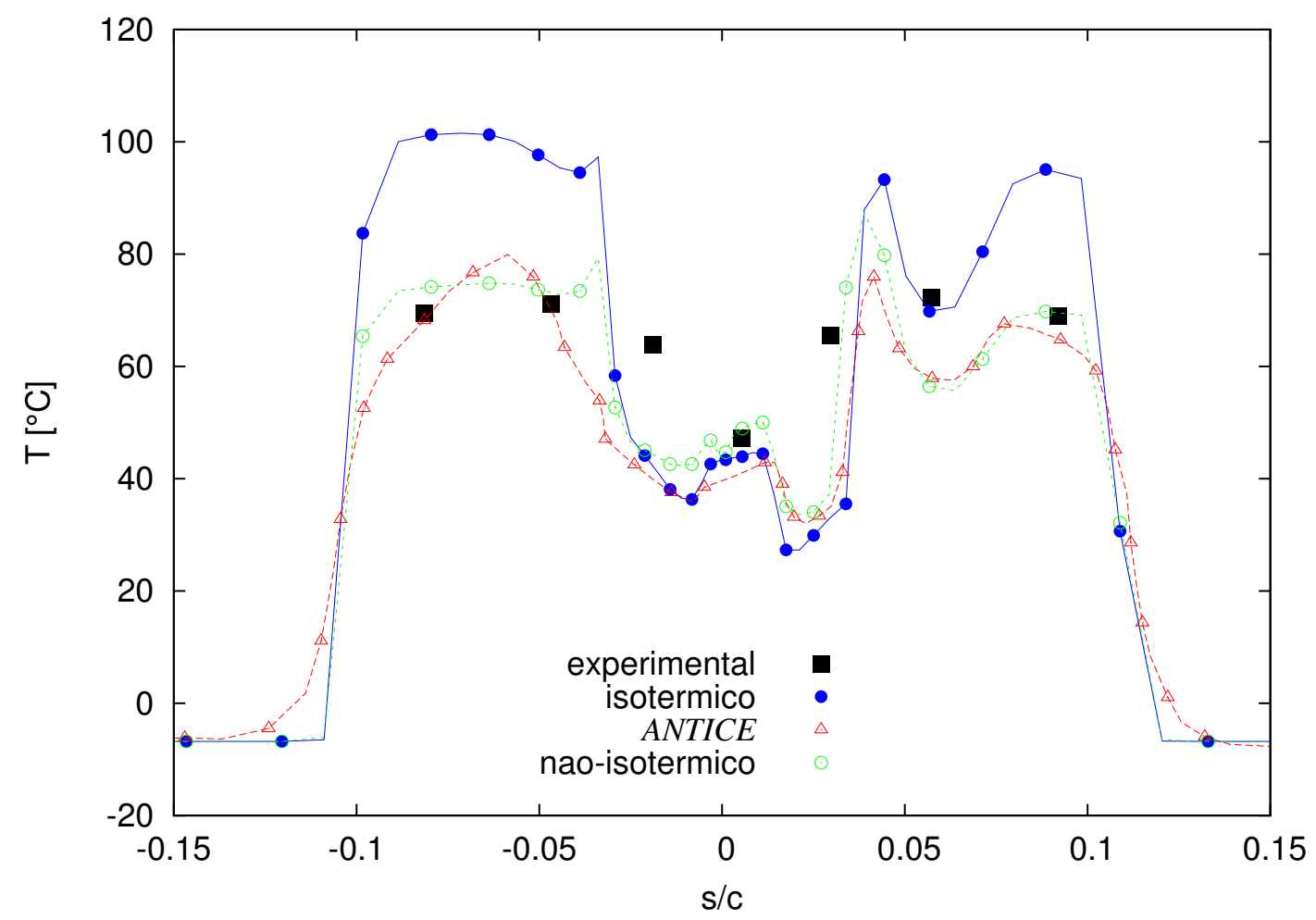

(a) Não-isotérmico e isotérmico

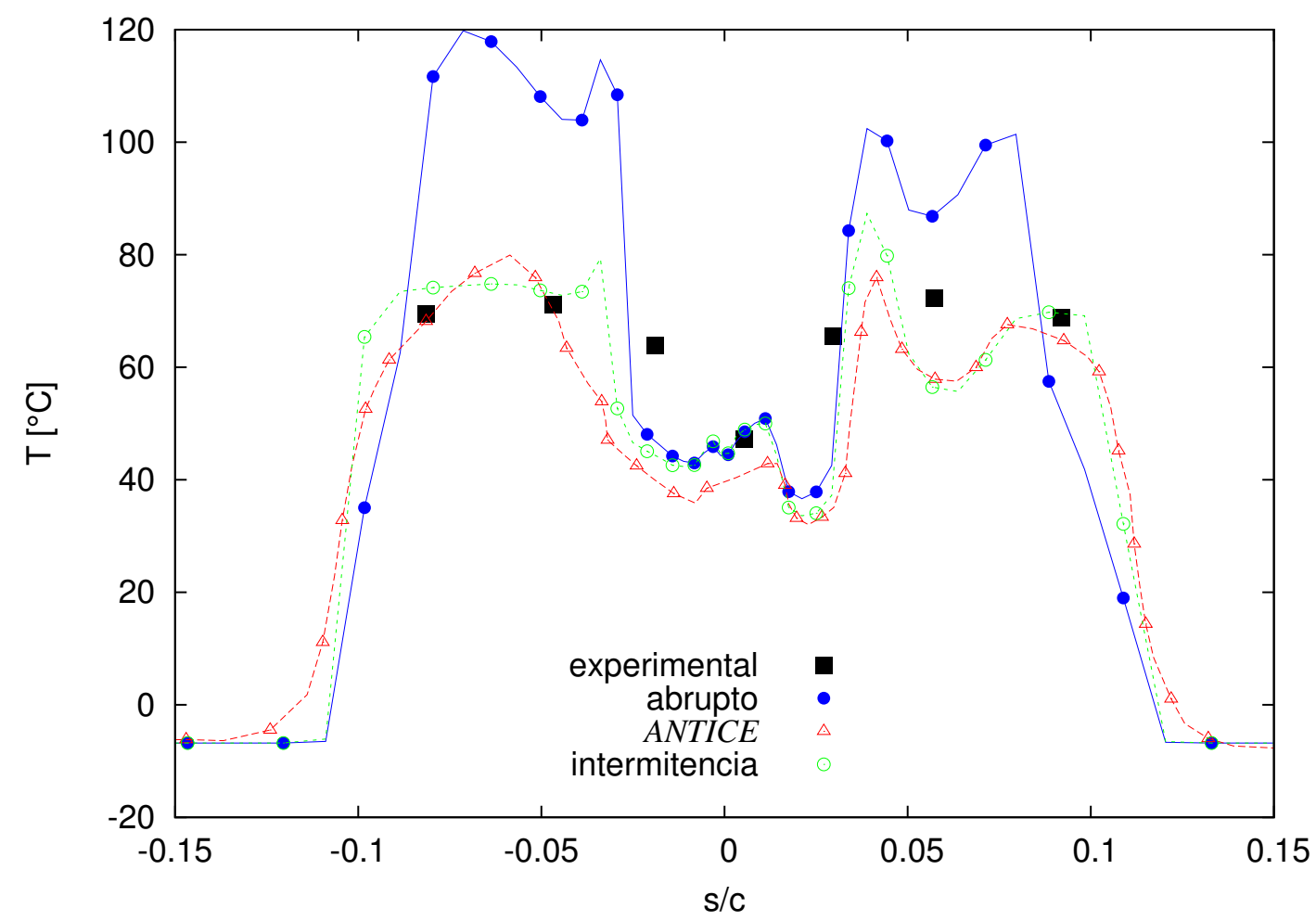

(b) Transição suave e abrupta

Figura 6.3: Temperatura de superfície - $T_{s}$ - Caso 22A - Comparação entre modelos 


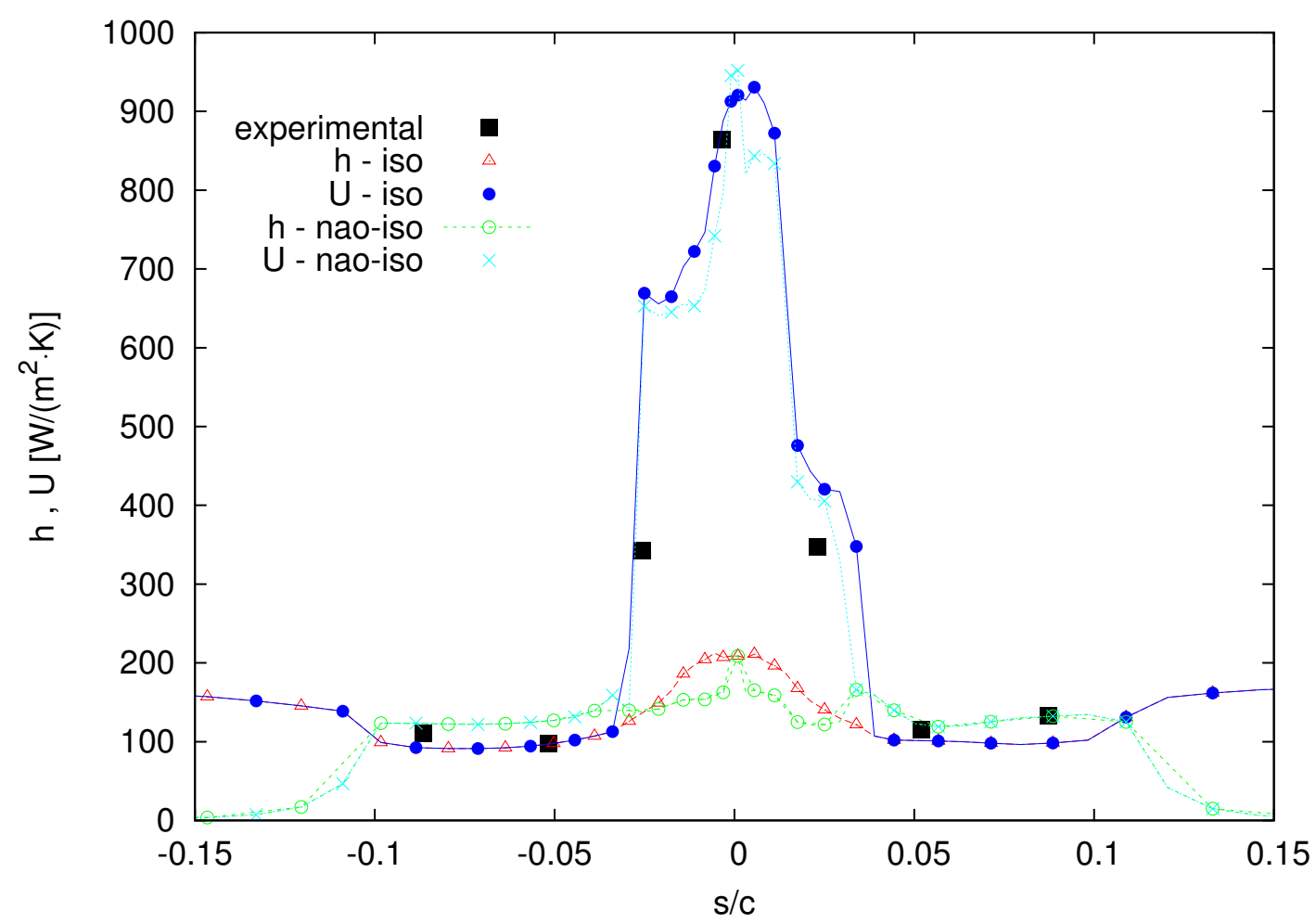

(a) Não-isotérmico e isotérmico

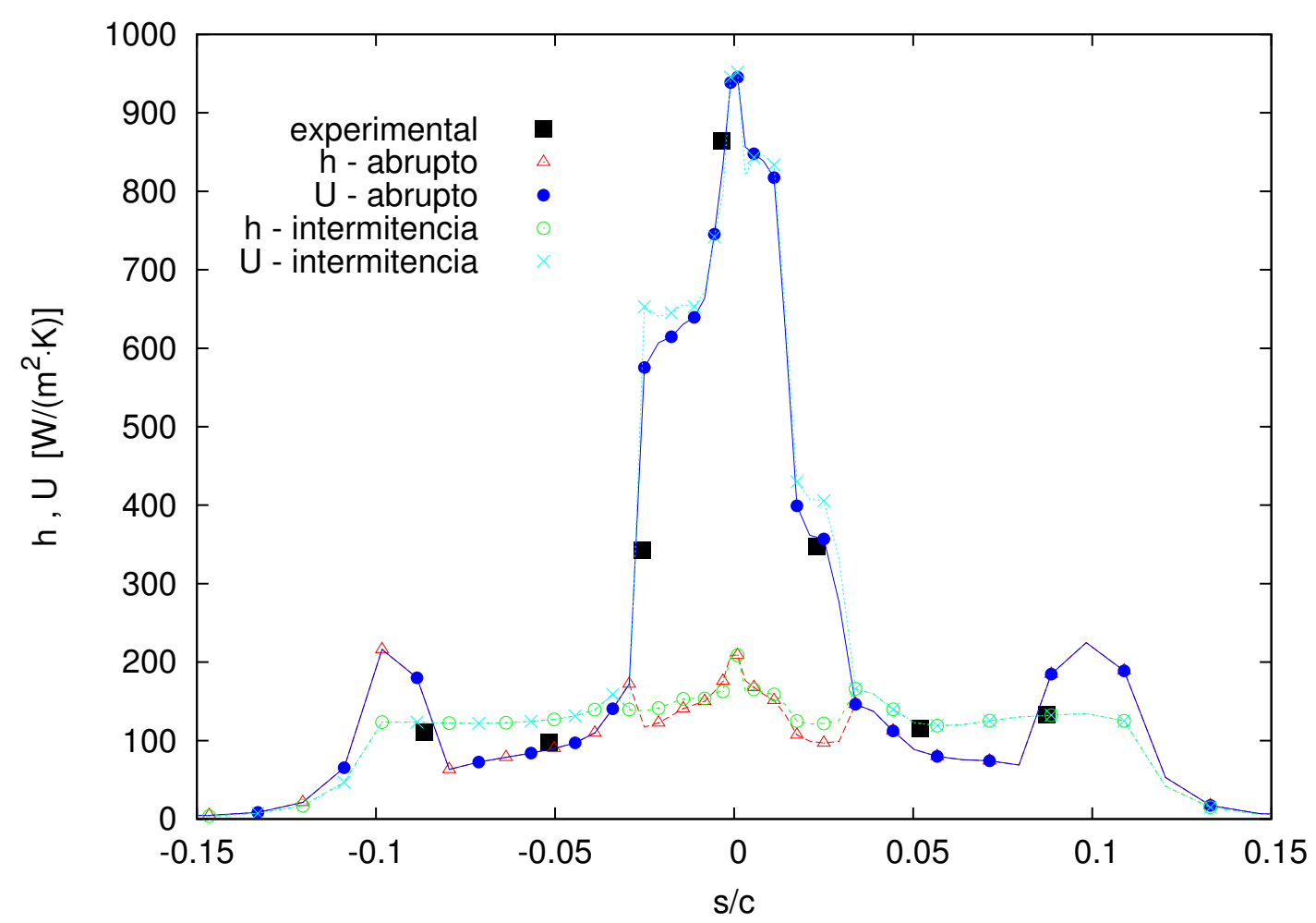

(b) Transição abrupta e suave

Figura 6.4: Coeficientes de transferência de calor global $U$ e convectivo $h_{a r}$ - Caso 22A - Comparação entre modelos 


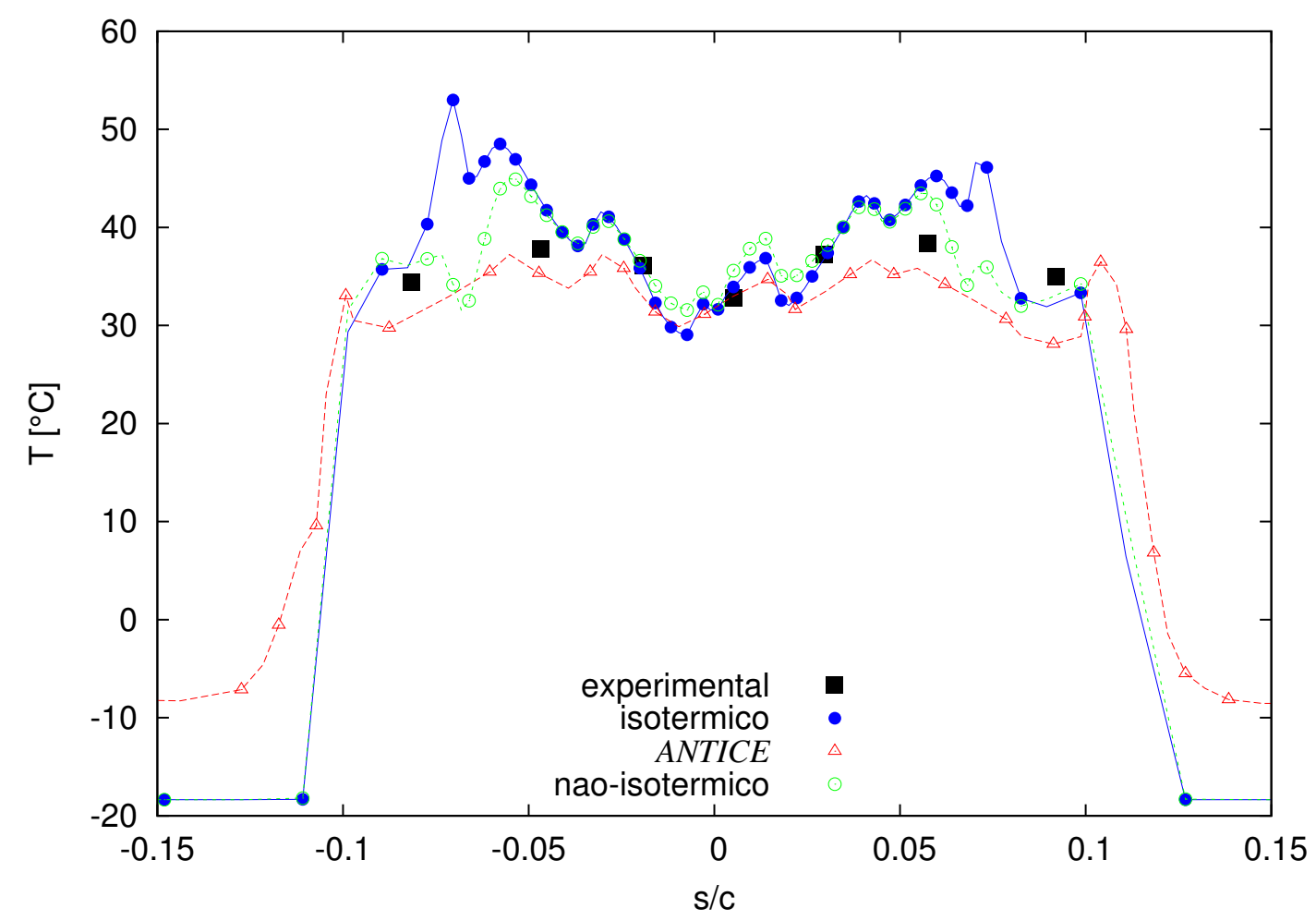

(a) Não-isotérmico e isotérmico

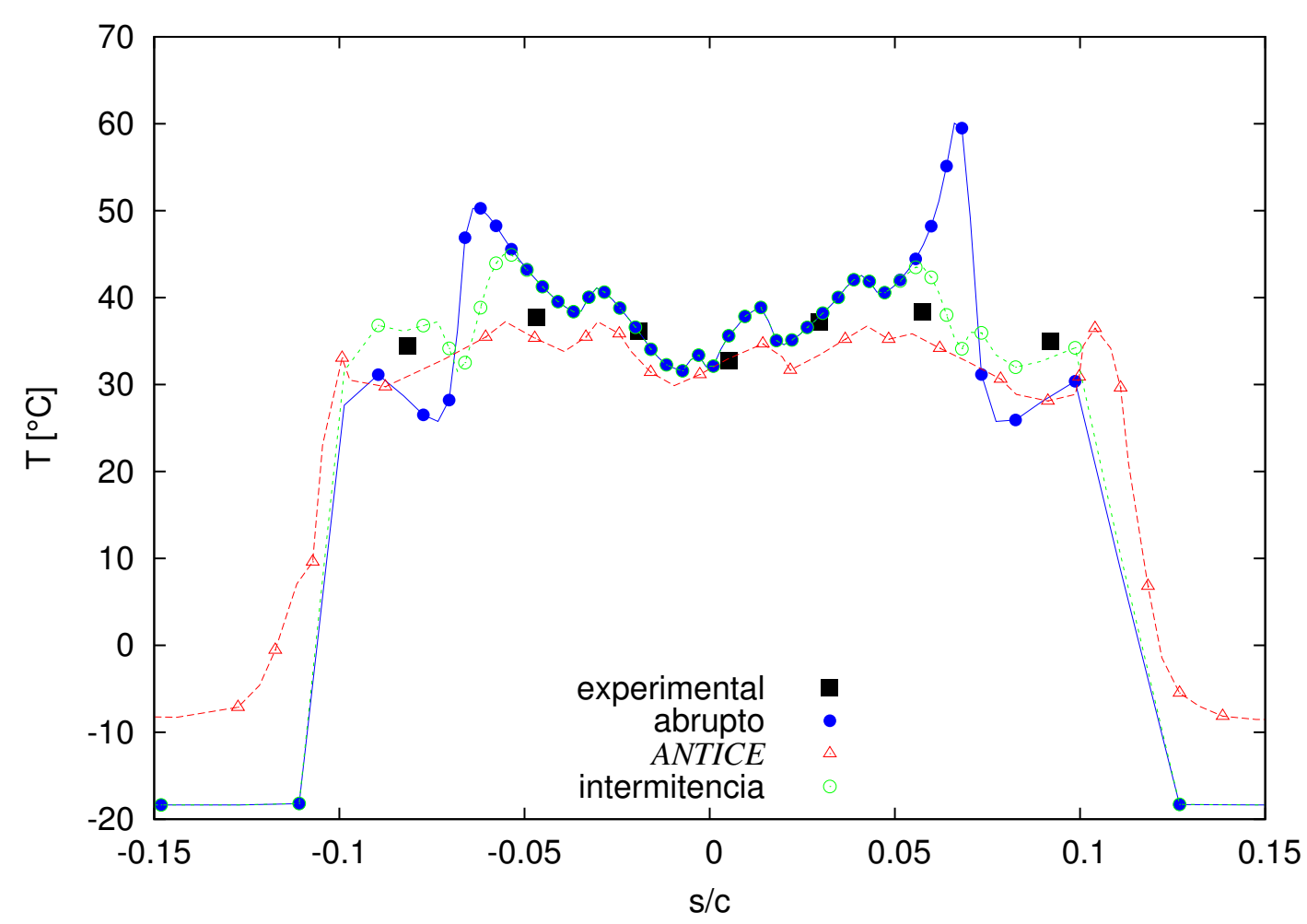

(b) Transição suave e abrupta

Figura 6.5: Temperatura de superfície - $T_{s}$ - Caso 67A - Comparação entre modelos 


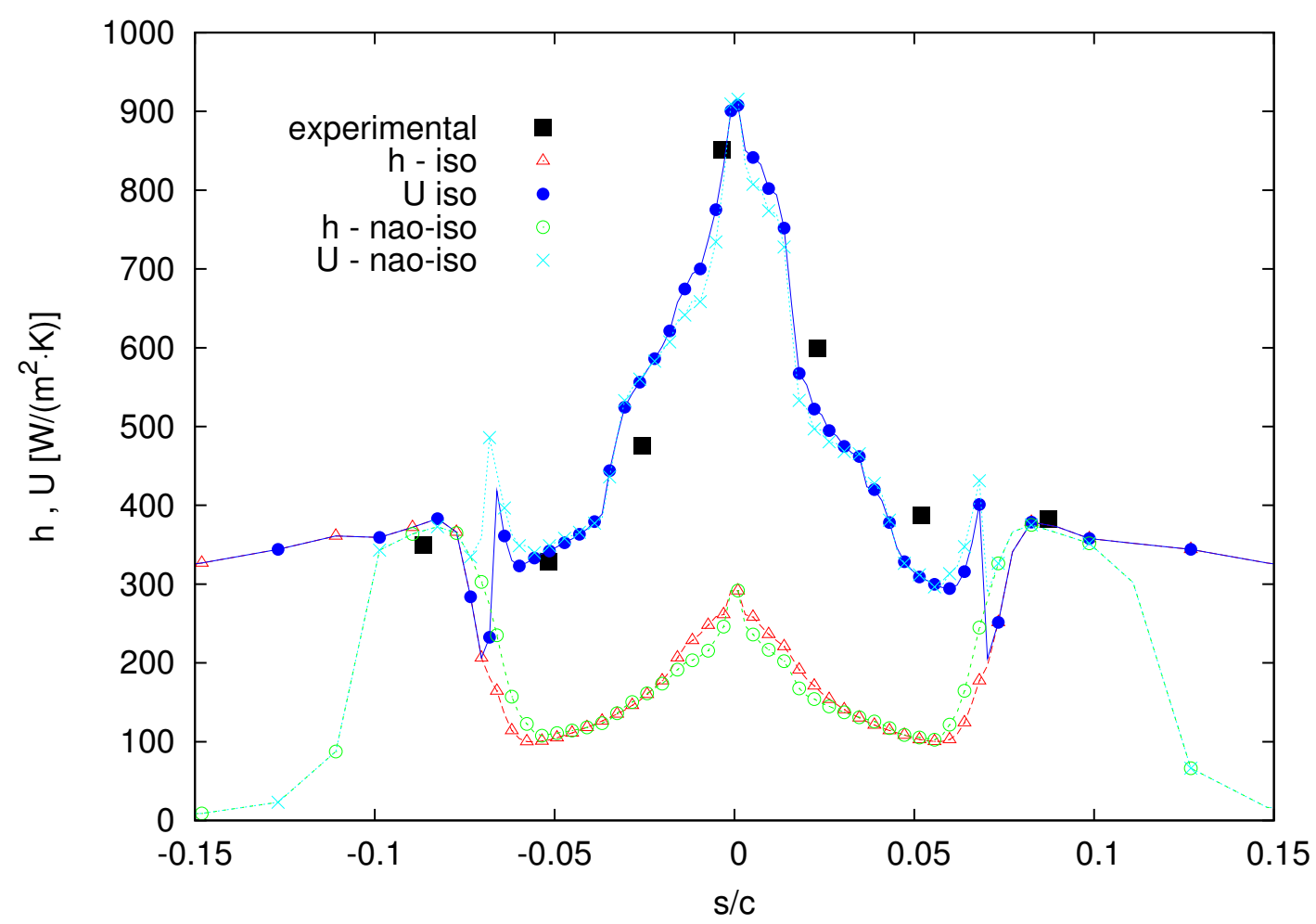

(a) Não-isotérmico e isotérmico

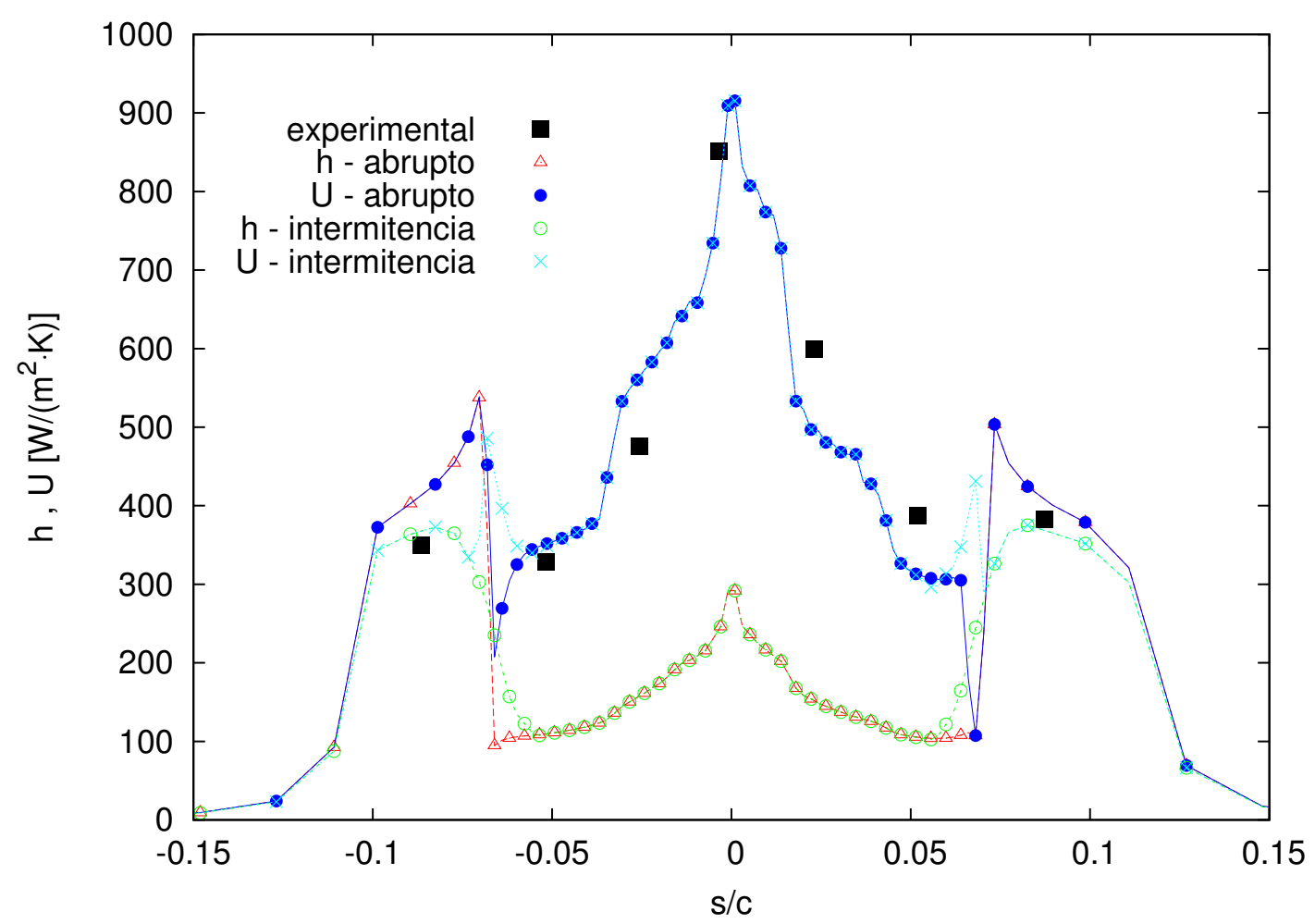

(b) Transição suave e abrupta

Figura 6.6: Coeficientes de transferência de calor global $U$ e convectivo $h_{a r}$ - Caso $67 \mathrm{~A}$ - Comparação entre modelos 
da estimativa do modelo de referência com resultados experimentais para o coeficiente global de transferência de calor. Estes valores não foram modificados quando rodaram-se os modelos isotérmico e de transição abrupta. A Fig. 6.6(a) apresenta um aumento repentino na transferência de calor convectiva no modelo de transição abrupta enquanto o modelo de intermitência resultou em uma curva mais suave e mais próxima aos dados experimentais. Devido a uma distribuição de temperaturas mais constante no caso $67 \mathrm{~A}$ do que no $22 \mathrm{~A}$, existem pequenos desvios no coeficiente de transferência de calor por convecção dos modelos não-isotérmico e isotérmico. Exceto nas regiões de final de escoamento de água e região de aquecimento, ambos os modelos apresentam comportamento semelhante. Um aumento repentino em ambos os coeficientes de transferência de calor, $h$ e $U$, são observados nos resultados do modelo de transição abrupta apresentados em Fig. 6.6(b). Este fato é causado pela evaporação instantânea de toda água e, portanto, resulta em aumento da $T_{s}$ local.

Para o caso 22A, todos os modelos (não-isotérmico e isotérmico, transição abrupta e suave) previram evaporação da água residual na posição de escoamento $s / c=0,024$ tanto na superfície superior quanto inferior. Mas, no caso 67A, o modelo de referência (não-isotérmico e transição suave) resultou em $s / c=0,077 \mathrm{e}$ $s / c=-0,073$ para as posições de desaparecimento da água residual. 0 modelo isotérmico resultou nas posições $s / c=0,07$ e $s / c=-0,068$. Ao se considerar transição abrupta, as posições mudam para $s / c=0,066$ e $s / c=-0,068$. As mudanças são significativas quando comparadas à área total protegida, que se localiza entre $s / c=-0,102$ e 0,113 .

\subsubsection{Submodelo Clássico de Camada-Limite e Submodelo de Filme e Filetes}

Os modelos matemáticos listados na Tabela 6.4 estão implementados e incorporados ao modelo do antigelo do presente trabalho. O modelo de referência é chamado de presente e adota os submodelos de camada-limite integral, de transição por intermitência e de molhabilidade variável (formação de filetes). Já o modelo clássico adota submodelos de camada-limite integral sobre superfície isotérmica, de transição abrupta e de filetes. Os resultados de cada modelo, da Tabela 6.4, são comparados a resultados experimentais clássicos e recentes de Gelder e Lewis (1951) e NASA. Esse estudo foi publicado por Silva, Silvares e Zerbini (2008b).

No modelo clássico, a analogia de Colburn, (4.30), que admite escoamento sobre superfícies lisas, foi escolhido em detrimento do uso de um coeficiente de transferên- 
cia de calor convectivo plenamente rugoso, que é utilizado em códigos clássicos de formação de gelo. Este pode gerar resultados sobreestimados quando usados em sistemas antigelo, como observaram Gent, Dart e Cansdale (2000).

Em todas as figuras, os resultados do presente modelo com previsão de transição, início e extensão dados pelas Eqs. (5.10) e (5.12a), são identificados como: presente $+A S$. Foi adotado um nível de turbulência ao longe de $T u=0,7 \%$, que está de acordo com medições recentes realizadas no NASA IRT(HENZE; BRAGG; KIM, 1998) para $M V D=20 \mu \mathrm{m}$.

Tabela 6.4: Modelos de Camada-Limite Térmica e Transição Laminar-Turbulenta

\begin{tabular}{llllll}
\hline \multirow{2}{*}{ Regime } & \multicolumn{2}{c}{ Presente } & & \multicolumn{2}{c}{ Clássico } \\
\cline { 2 - 3 } \cline { 5 - 6 } Laminar & modelo & equação & & modelo & equação \\
Turbulento & Ambrok (1957) & 4.10 & & $\begin{array}{l}\text { Smith e Spalding } \\
(1958)\end{array}$ & 4.15 \\
Transicional & $4.13,4.14$ & & $\begin{array}{l}\text { analogia de } \\
\text { Colburn } \\
\text { modelo abrupto }\end{array}$ & 4.6, 4.30 \\
& $\begin{array}{l}\text { Reynolds, Kays } \\
\text { e Kline (1958b) }\end{array}$ & 5.25 & & & - \\
\hline
\end{tabular}

Tabela 6.5: Parâmetros para a região de transição do presente modelo

\begin{tabular}{|c|c|c|c|c|c|c|c|c|}
\hline & \multicolumn{4}{|c|}{ Impostos/Fixados } & \multicolumn{4}{|c|}{ Previsto - modelo AS } \\
\hline & \multicolumn{2}{|c|}{$s / c$ superior } & \multicolumn{2}{|c|}{$s / c$ inferior } & \multicolumn{2}{|c|}{$s / c$ superior } & \multicolumn{2}{|c|}{$s / c$ inferior } \\
\hline & $s_{m}$ & $\sigma$ & $s_{m}$ & $\sigma$ & $s_{m}$ & $\sigma$ & $s_{m}$ & $\sigma$ \\
\hline $22 \mathrm{~A}$ & 0,070 & 0,035 & $-0,080$ & 0,040 & 0,082 & 0,012 & $-0,084$ & 0,012 \\
\hline $67 \mathrm{~A}$ & 0,070 & 0,007 & $-0,067$ & 0,007 & 0,066 & 0,010 & $-0,066$ & 0,010 \\
\hline $8 \mathrm{GL}$ & 0,070 & 0,035 & $-0,036$ & 0,018 & 0,039 & 0,006 & $-0,039$ & 0,006 \\
\hline $8 \mathrm{GL}$ seco & 0,110 & 0,055 & $-0,070$ & 0,037 & 0,039 & 0,006 & $-0,039$ & 0,006 \\
\hline
\end{tabular}

A Fig. 6.7(a) apresenta a distribuição de temperaturas na superfície do aerofólio $T_{s}$, que se aproximam mais dos resultados experimentais do que o modelo clássico (isotérmico com transição abrupta). A principal razão para as previsões satisfatórias é que tanto as distribuições de $U$ quanto a de $h_{a r}$ são também mais próximas dos dados experimentais, Figs. 6.8(a) e 6.7(b). Os parâmetros na região de transição foram fixados arbitrariamente ou previstos. Seus valores são apresentados na Tabela 6.5 , que mostra que o modelo presente+AS previu $s_{m}$ mais à jusante e $\sigma$ menor que aqueles valores impostos no presente modelo.

As distribuições de vazões de água residual do caso 22A apresentaram aproximadamente as mesmas tendências em todos os modelos implementados no presente trabalho, como mostrado em Fig. 6.8(b). Isto pode ser resultado de pequenas diferenças entre o $h_{a r}$ previsto pelos modelos dentro da região de incidência, onde 
o filme de água líquida ainda existe. Por outro lado, as diferenças são significativas quando se comparam valores de $h_{a r}$ ao longo de todo o aerofólio dos modelos presente, presente+AS e clássico, apresentados em Fig. 6.8(a). As maiores discrepâncias são uma variação brusca de $h_{a r}$ na transição do regime laminar para turbulento e a falta de sensibilidade de $h_{a r}$ com a variação de $T_{s}$ ao longo do escoamento, nas previsões com o modelo clássico.

A Fig. 6.9 apresenta a temperatura de superfície e distribuições de coeficientes de transferência de calor ao redor do bordo de ataque para o caso 67A. Como no caso 22A, o modelo presente apresentou um menor desvio entre previsões numéricas e dados experimentais quando comparado aos modelos clássico, presente+AS e código ANTICE, o qual usa distribuição experimental de $h_{a r}$. Como as temperaturas de superfície foram aproximadamente constantes, a principal diferença entre os modelos é observada na região de transição laminar-turbulenta. O valor quase constante do $h_{a r}$ laminar, em uma região que se estende desde a estagnação ao final do escoamento residual, resultou em distribuições muito similares de $\dot{m}_{r}$. A diferença entre temperaturas de superfície começa a ser significativa na posição de início da transição laminar-turbulenta, que é próxima do final do escoamento de filetes. A Fig. 6.10(b) apresenta o escoamento residual. As principais diferenças entre os modelos localizam-se entre o início da transição e final do escoamento de filete. Neste caso, uma transição mais suave (mais longa e com início mais cedo) do presente modelo resultou no final do escoamento da água residual mais à jusante do que os outros modelos..

O fator de molhabilidade da superfície para os casos 22A e 67A é apresentado nas Figs. 6.11(a) e 6.11(b),6.11(a) and 6.11(b), respectivamente. O primeiro caso somente apresenta escoamento residual como um filme contínuo, uma vez que este termina antes dos limites de incidência. Já o segundo caso apresenta ambos padrões de escoamento de filme, com $F=1$, e e filete, o qual se distingue por valores de $F<1$.

Na presente tese, o autor simulou numericamente os experimentos clássicos antigelo de Gelder e Lewis(GELDER; LEWIS, 1951). Os dados apresentam variações significativas de $T_{s}$ devido a assimetria e não-uniformidade de aquecimento elétrico. As temperaturas de superfície previstas para os testes de ar seco e úmido, mostrados respectivamente nas Figs. 6.12(a) e 6.14(a), apresentam desvios em relação aos dados experimentais. Provavelmente, os desvios são resultantes de três fatores principais: 1) falta de medidores de fluxo de calor instalados ao redor do aerofólio, pois os autores mediram apenas o fluxo de calor fornecido aos aquecedores e, portanto, não determinaram as perdas térmicas experimentalmente; 2) aumento abrupto de 


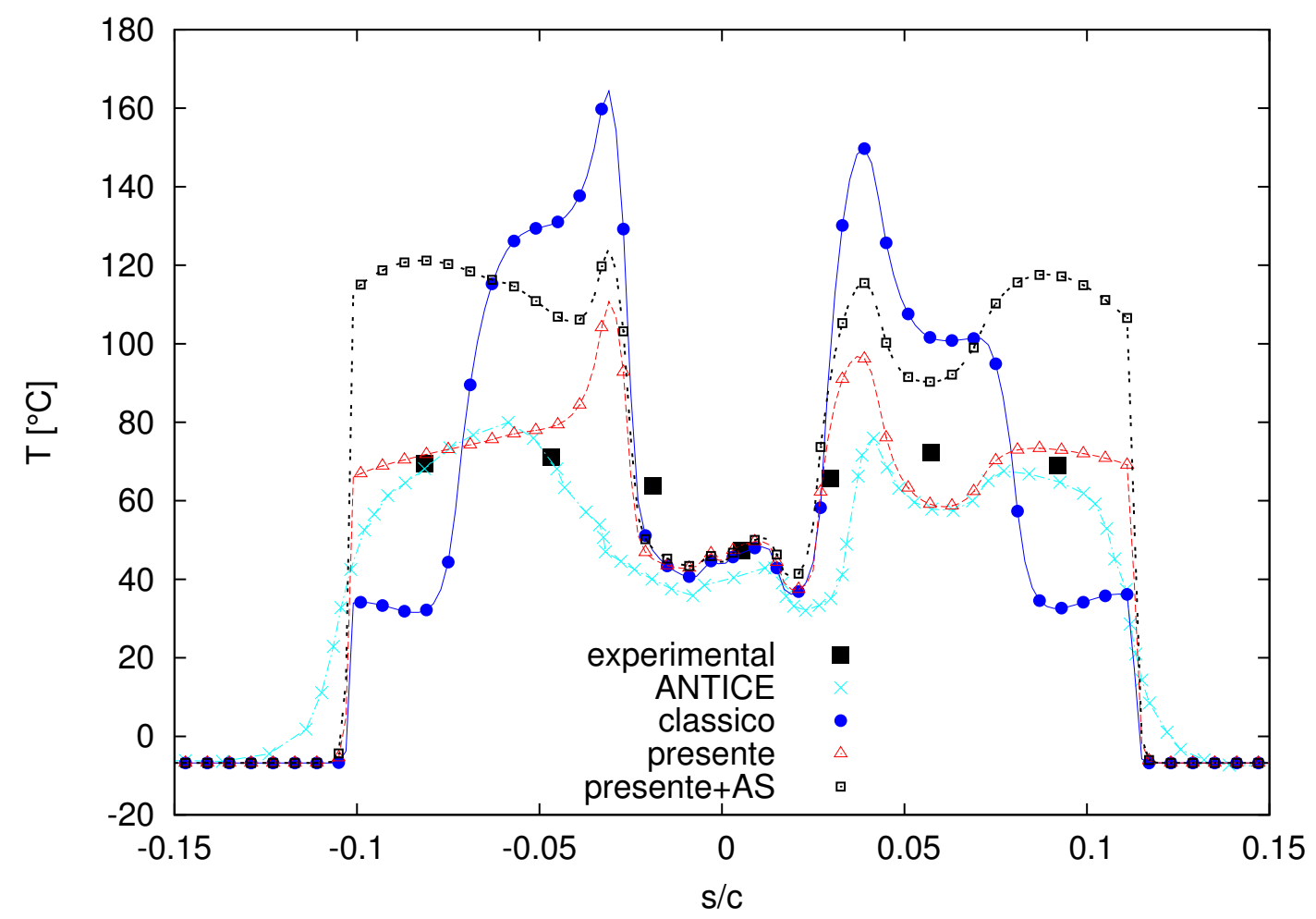

(a) Temperatura de superfície $T_{s}$

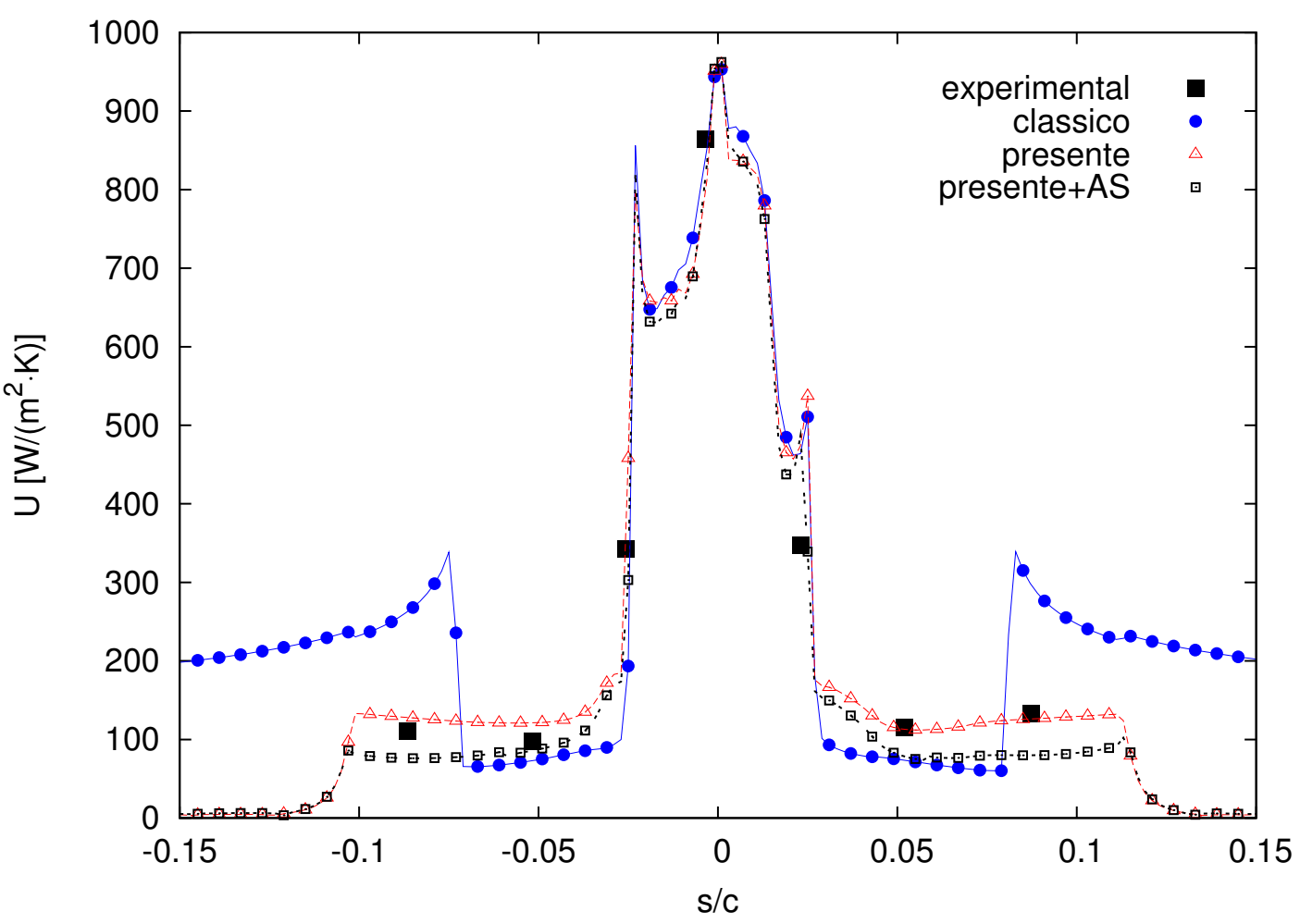

(b) Coeficiente de transferência de calor $U$

Figura 6.7: Case 22A - Comparações entre Modelos - $T_{s}$ e $U$ 


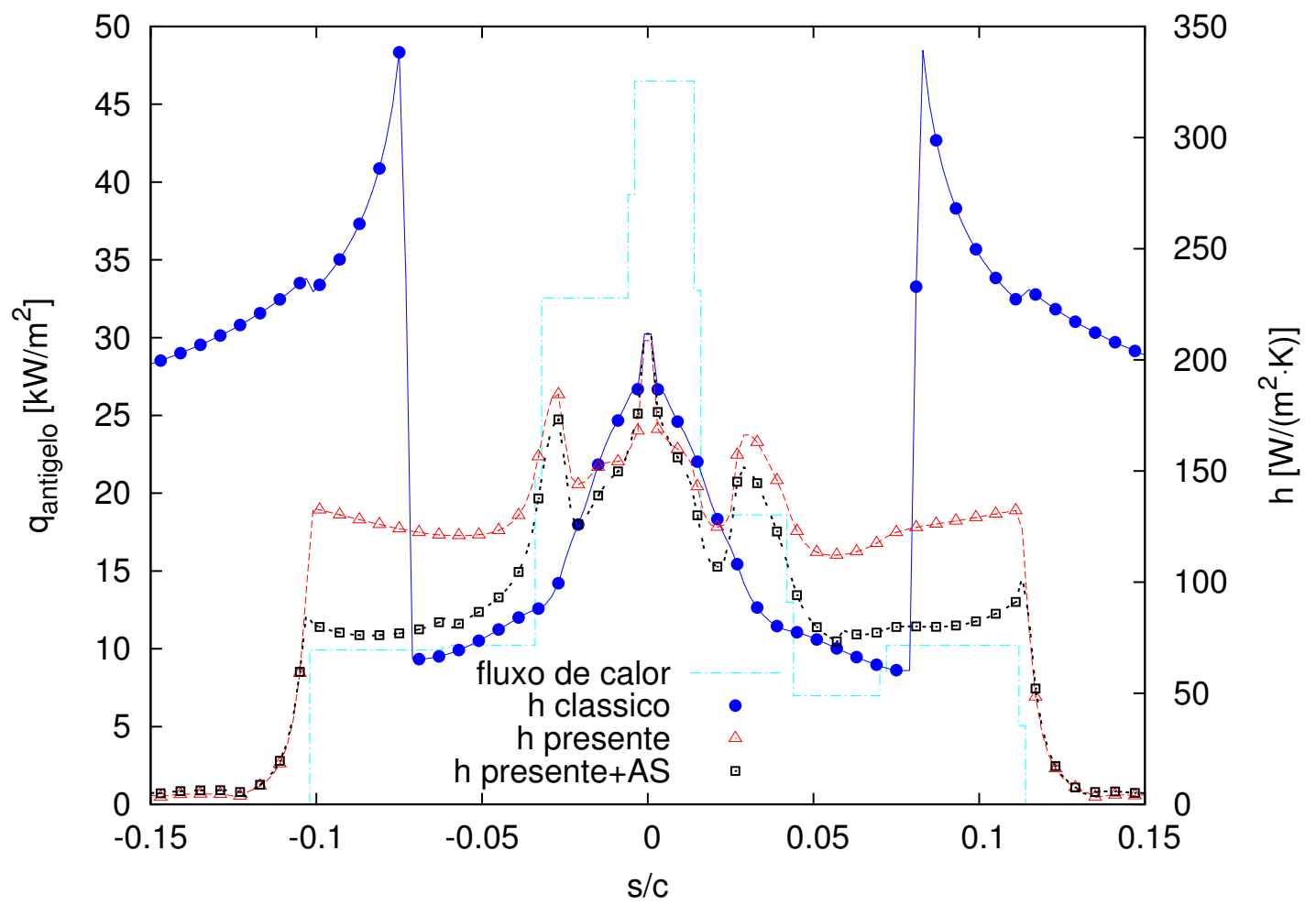

(a) Coeficiente de transferência de calor convectivo $h_{a r}$ e potência elétrica

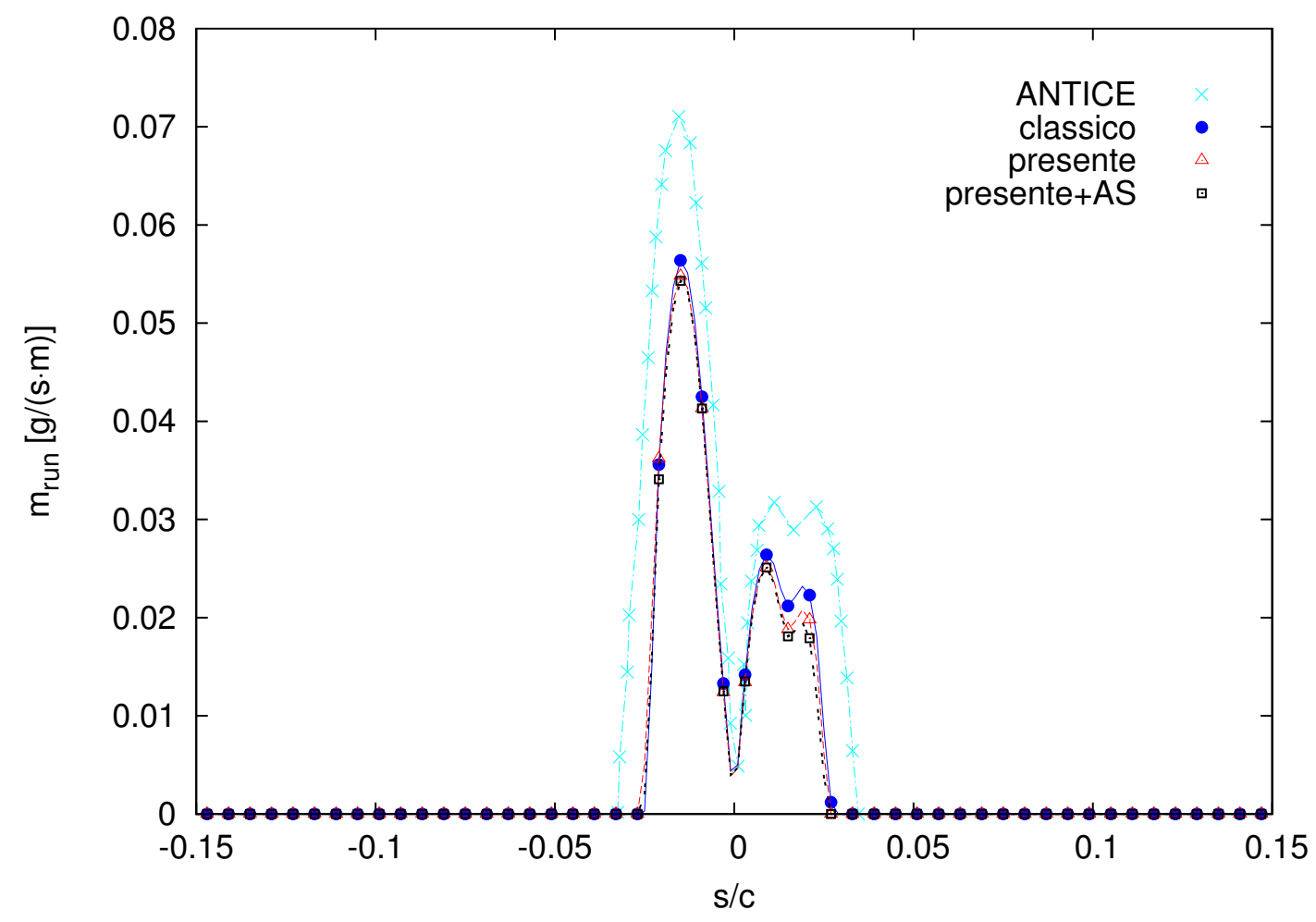

(b) Vazão de água residual $\dot{m}_{r}$

Figura 6.8: Case 22A - Comparações entre Modelos - $h_{a r}$, potência elétrica e $\dot{m}_{r}$ 
aquecimento em $s / c \approx 0.3$ resultou em um efeito significativo no valor de $h_{a r}$ experimental, que não pode ser reproduzido pelos modelos isotérmico e não-isotérmico devido a limitações intrínsecas da análise integral; 3) erros na medição de $T_{s}$ na região do bordo de ataque, como observado pelos autores Gelder e Lewis (1951), durante escoamento de ar seco em testes com superfície adiabática do aerofólio.

Todavia, as previsões, principalmente à montante de $s / c=0.3$, são consideradas aceitáveis para os propósitos de sistemas de engenharia de proteção antigelo. O valor de $h_{a r}$ previsto pelo modelo presente concordou satisfatoriamente com dados experimentais. Os resultados para $h_{a r}$ são melhores sob condições de gelo, Fig. 6.12(b), do que em ar seco, Fig. 6.14(b). Os únicos pontos que apresentaram desvios significativos localizam-se na região de aumento do aquecimento, $(s / c \approx 0.3)$, onde a densidade de potência cresce quase quatro vezes. Apesar de distúrbios de tal magnitude, os modelos presente e presente+AS previram uma distribuição de $h_{a r}$ com a mesma tendência dos dados experimentais. Isso inclui uma súbita, mas não muito intensa, variação de $h_{a r}$ no início do degrau no aquecimento.

Os resultados numéricos do presente modelo (com transição fixada), mostrados em Tabela 6.5 e Figs. 6.12 e 6.14, concordam com as observações experimentais de Gelder e Lewis(GELDER; LEWIS, 1951): 1) a transição laminar-turbulenta iniciou-se logo à jusante da estagnação; 2) a posição de início em condição de gelo localizou-se mais à montante do que na condição de ar seco; 3) a extensão da região de transição laminar-turbulenta apresenta efeitos significativos em ambos os casos.

Tabela 6.6: Término do escoamento de água residual, incidência e limites de área protegida contra gelo

\begin{tabular}{|c|c|c|c|c|c|c|c|}
\hline & & \multicolumn{3}{|c|}{$s / c$ extradorso } & \multicolumn{3}{|c|}{$s / c$ intradorso } \\
\hline & & água & captação & proteção & água & captação & proteção \\
\hline \multirow[t]{3}{*}{$22 \mathrm{~A}$} & presente, & 0,024 & 0,031 & 0,113 & $-0,026$ & $-0,031$ & $-0,102$ \\
\hline & clássico & 0,024 & & & $-0,024$ & & \\
\hline & presente+AS & 0,025 & & & $-0,025$ & & \\
\hline \multirow[t]{3}{*}{$67 \mathrm{~A}$} & presente, & 0,069 & 0,037 & 0,113 & $-0,069$ & $-0,037$ & $-0,102$ \\
\hline & clássico & 0,071 & & & $-0,069$ & & \\
\hline & presente+AS & 0,079 & & & $-0,075$ & & \\
\hline \multirow[t]{3}{*}{$8 \mathrm{GL}$} & presente, & 0,101 & 0,071 & 0,576 & $-0,131$ & $-0,131$ & $-0,190$ \\
\hline & clássico & 0,101 & & & $-0,131$ & & \\
\hline & presente+AS & 0,101 & & & $-0,131$ & & \\
\hline
\end{tabular}

O modelo presente+AS previu uma região de transição laminar-turbulenta de menor extensão, além de uma posição média mais à montante do que os modelos presente e clássico, resultando em desvios significativos entre resultados numéricos e experimentais. 


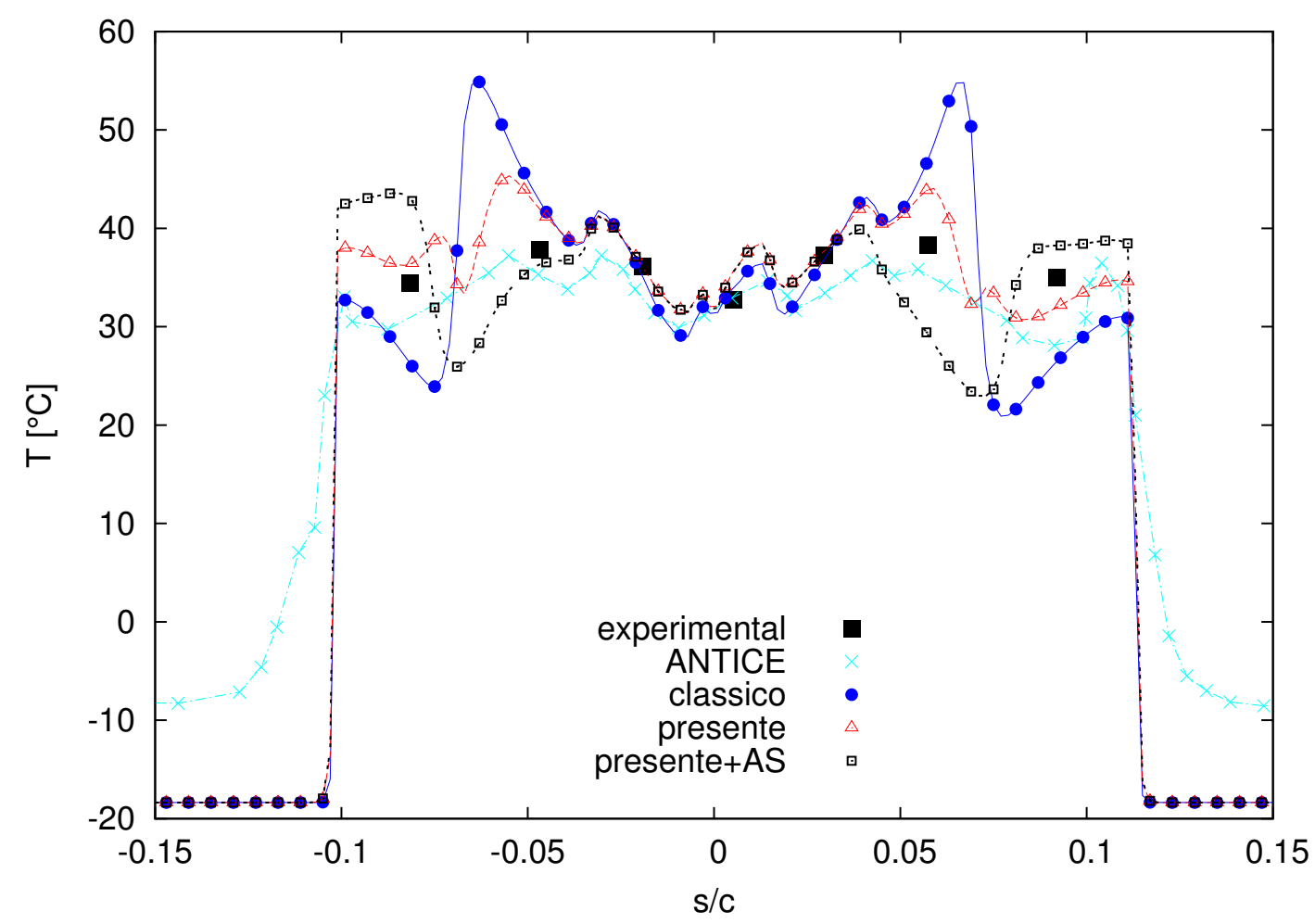

(a) Temperatura de superfície $T_{s}$

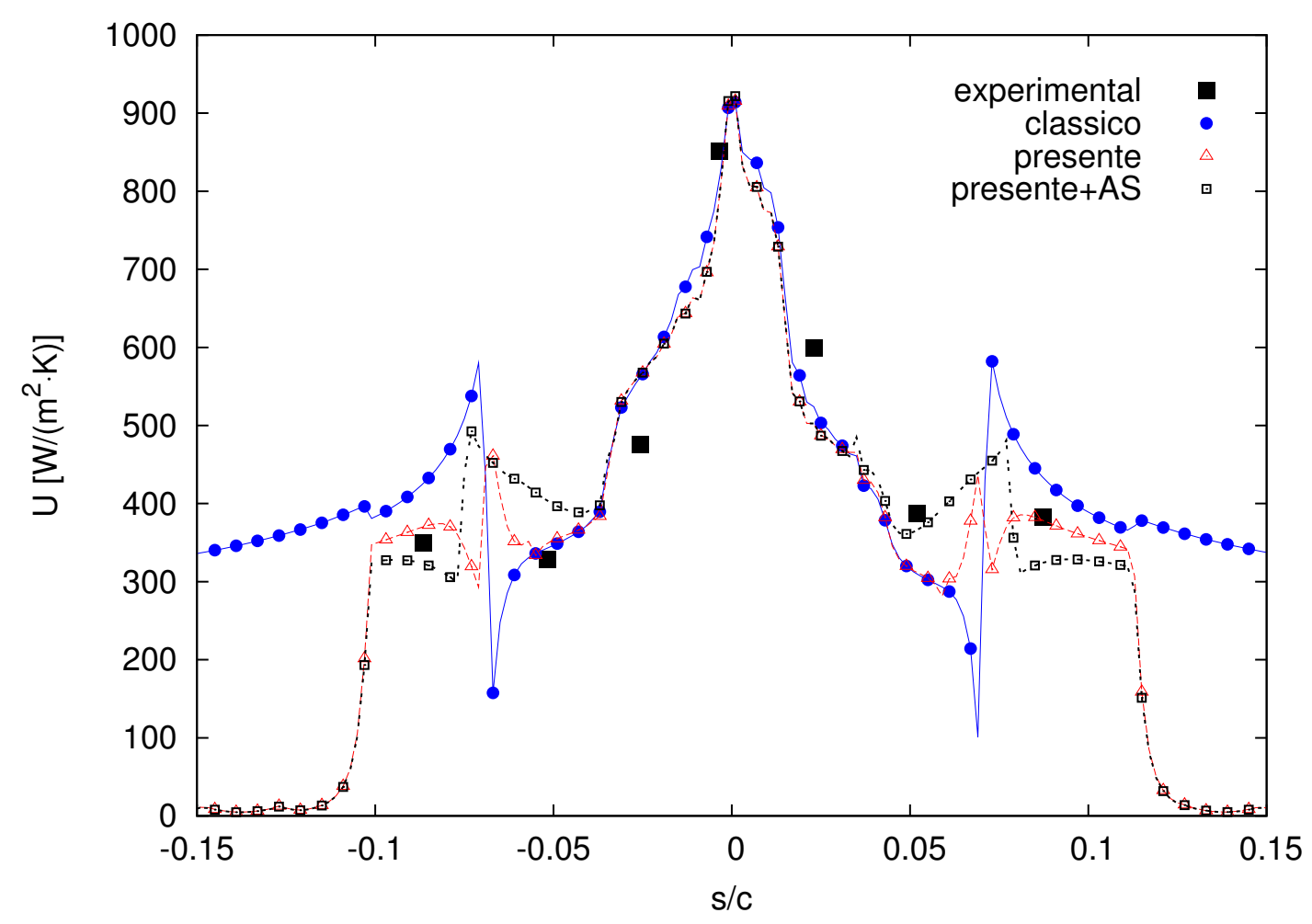

(b) Coeficiente de transferência de calor $U$

Figura 6.9: Caso 67A - Comparações entre Modelos - $T_{s}$ e $U$ 


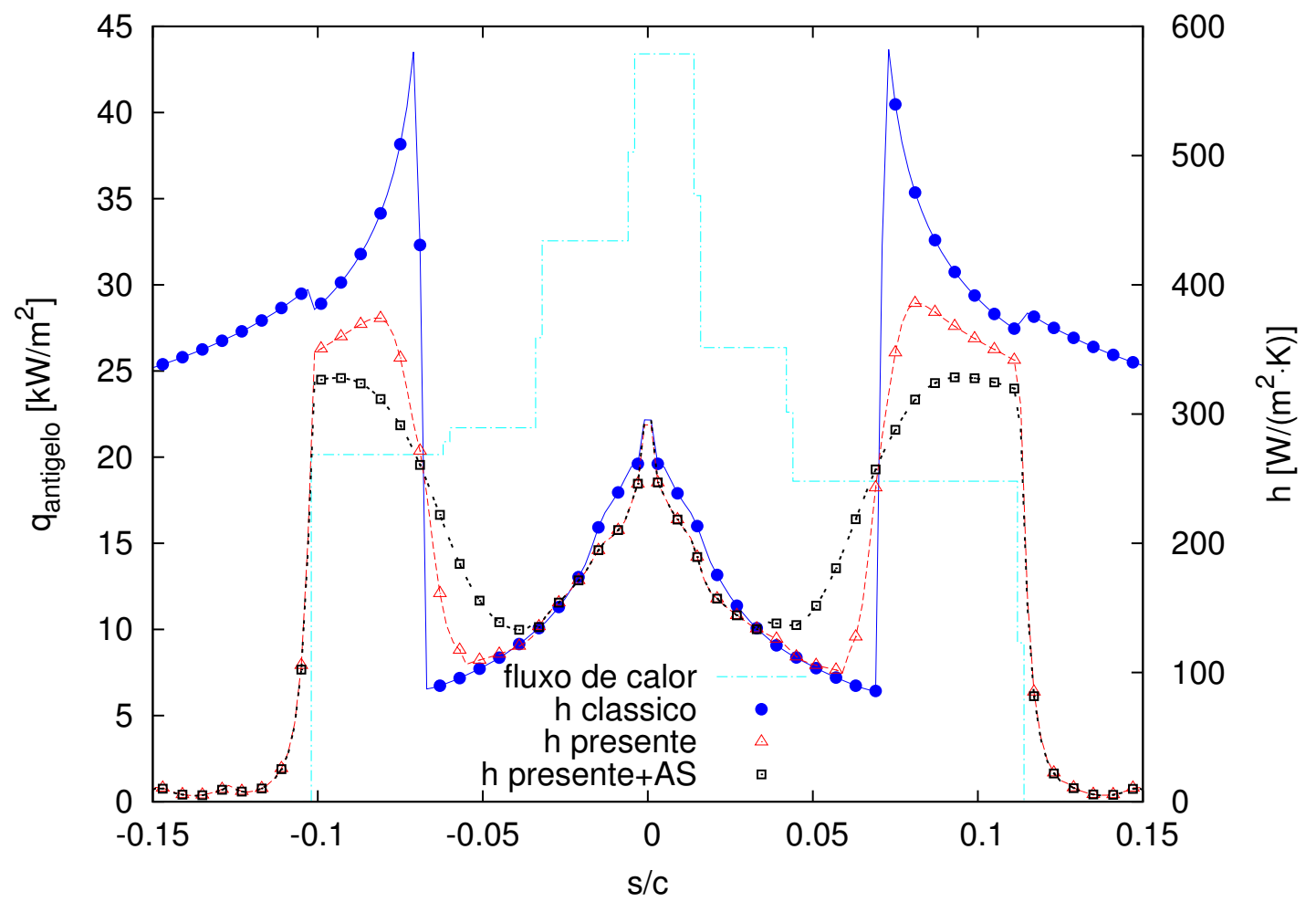

(a) Coeficiente de transferência de calor $h_{a r}$ e potência elétrica

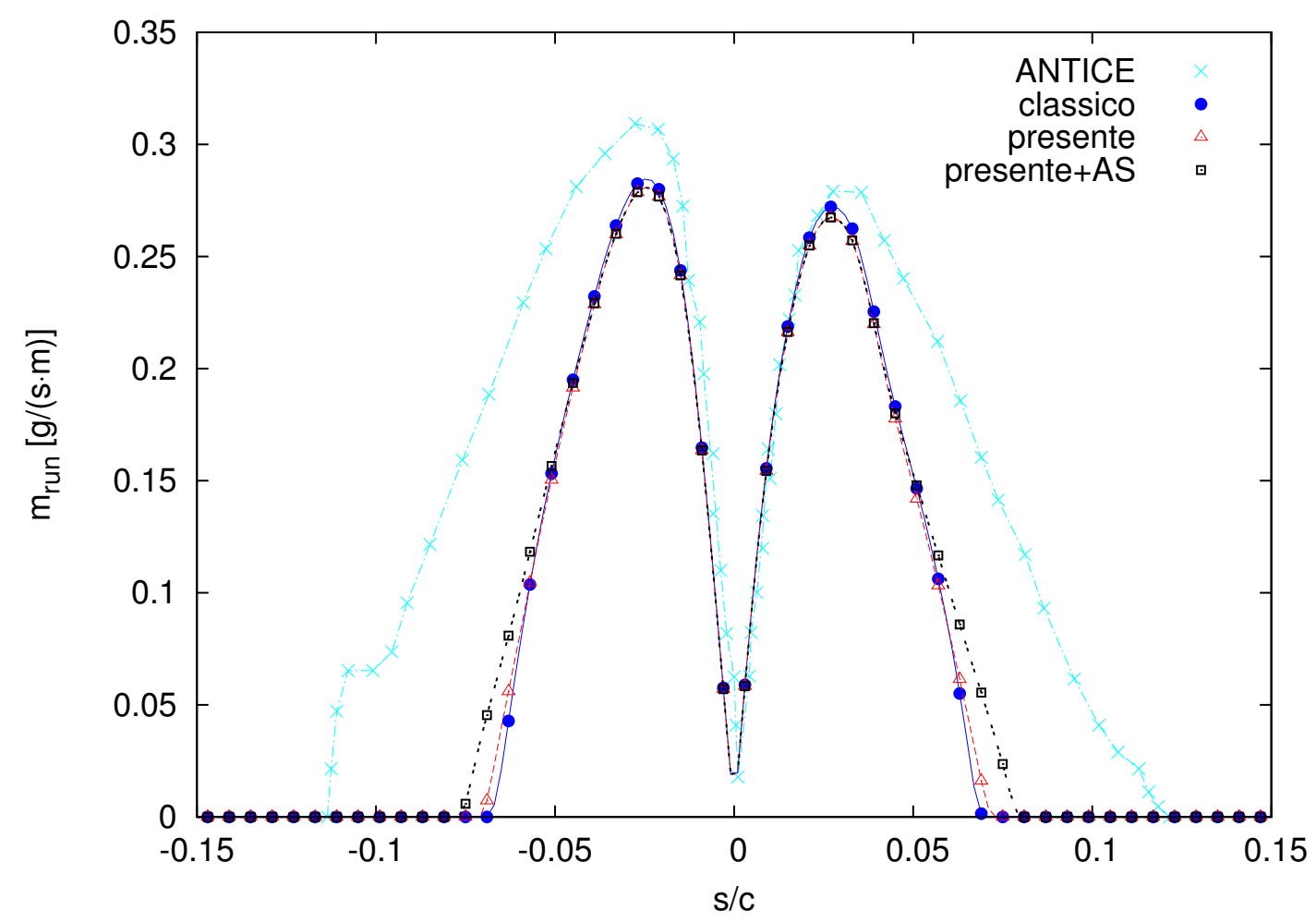

(b) Vazão de água residual $\dot{m}_{r}$

Figura 6.10: Caso 67A - Comparações entre Modelos - $h_{a r}$, potência elétrica e $\dot{m}_{r}$ 


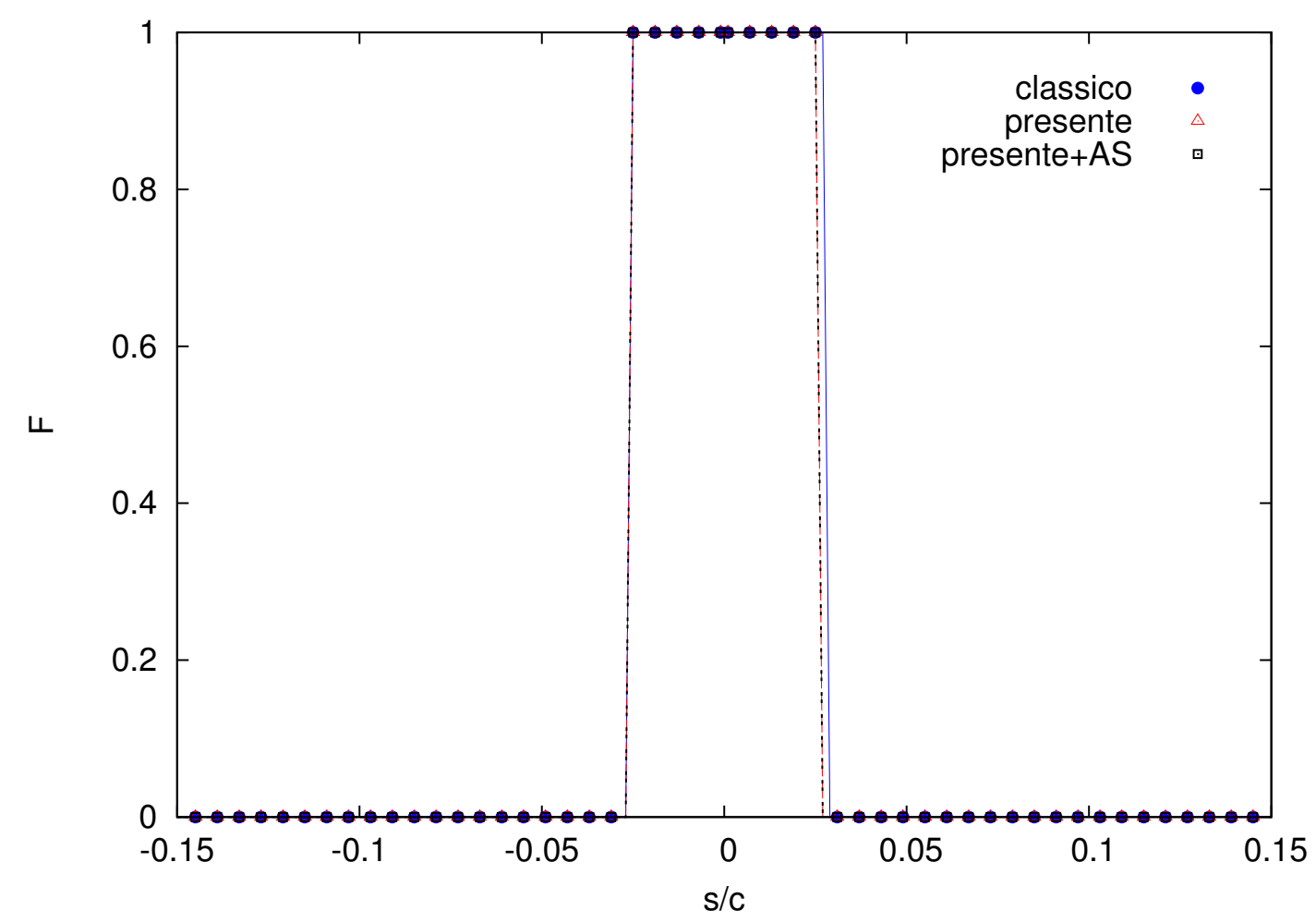

(a) Caso 22A

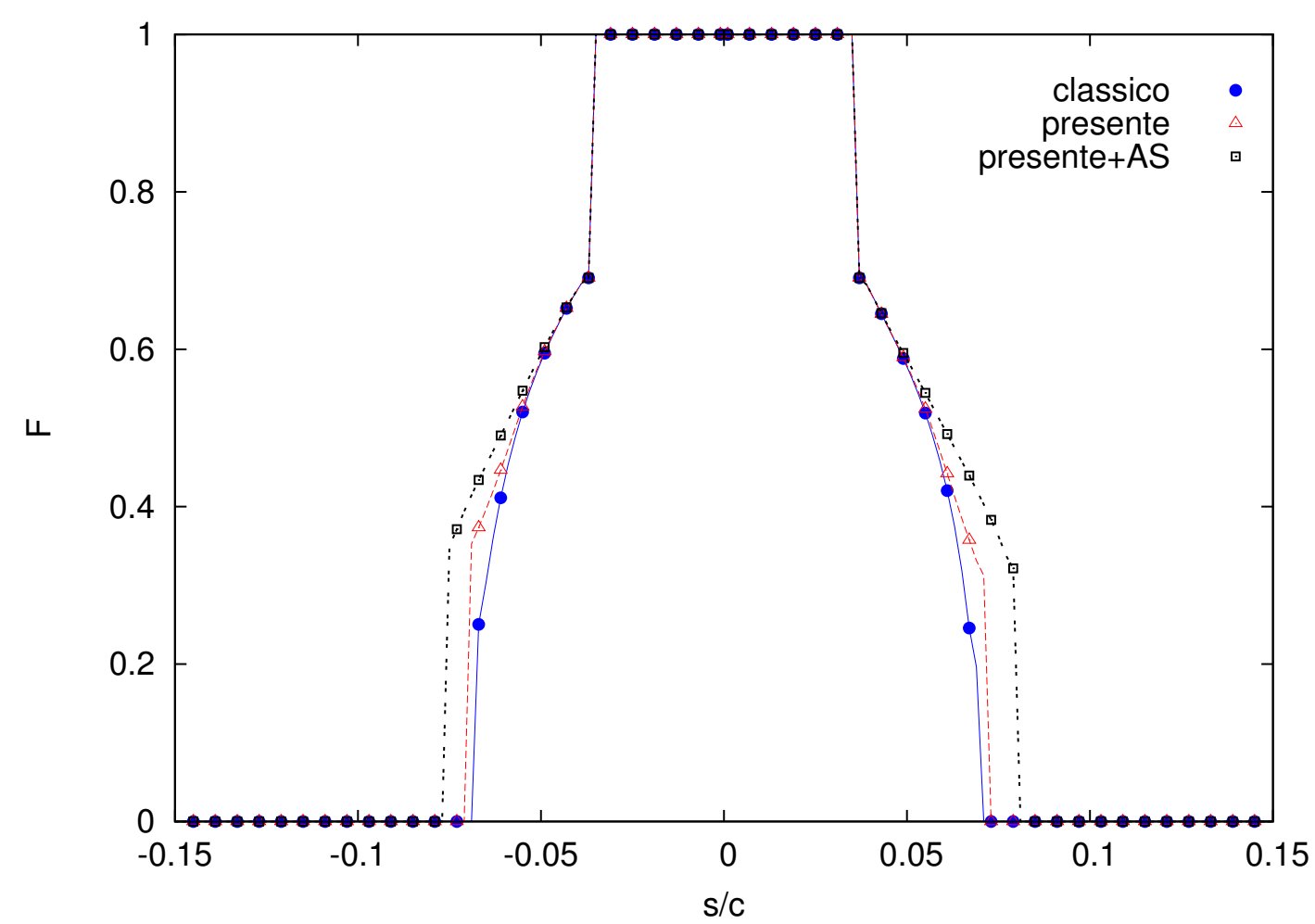

(b) Caso 67A

Figura 6.11: Previsões do presente código para fator global de molhabilidade - F 


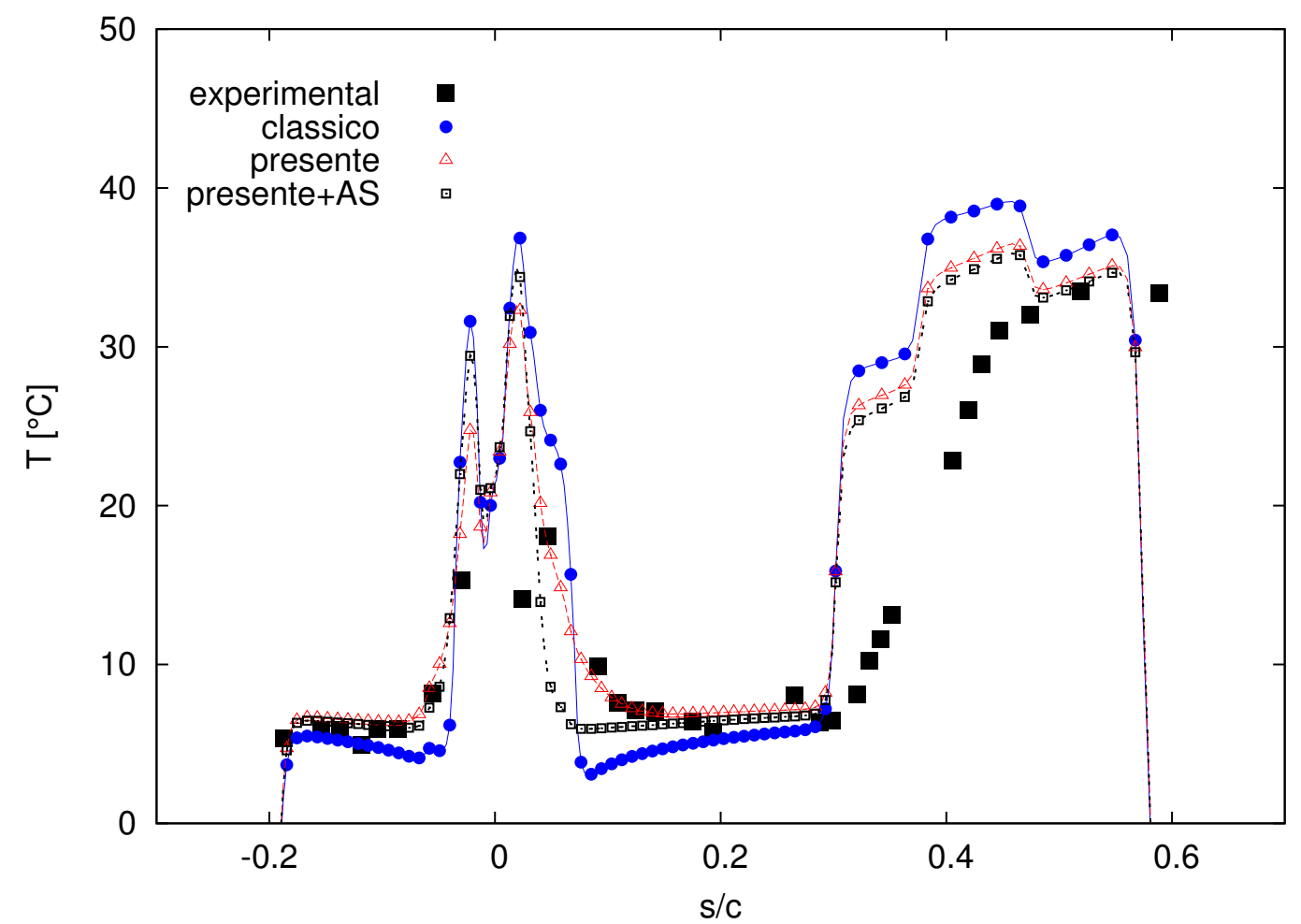

(a) Temperatura de superfície

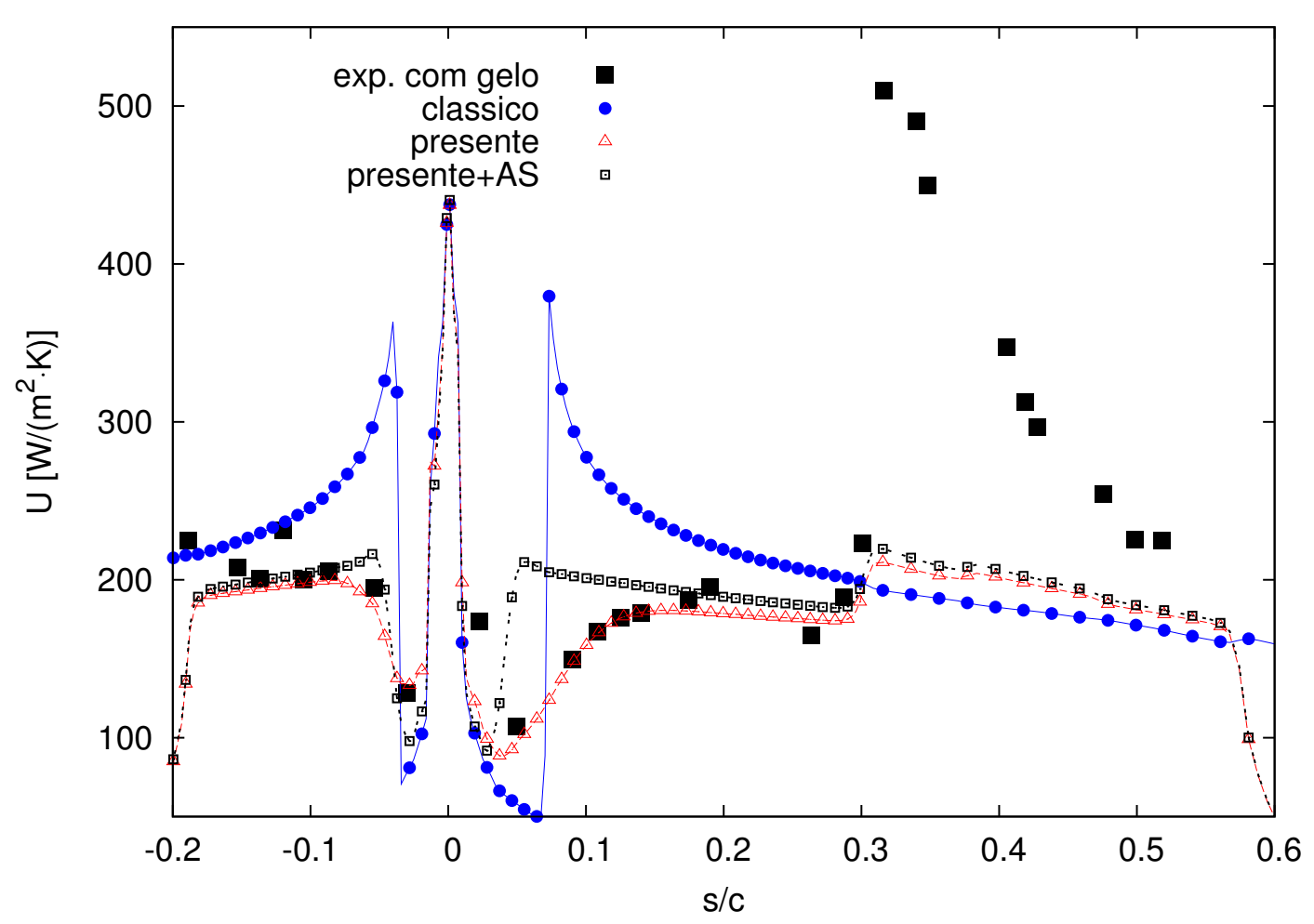

(b) Coeficiente global de transferência de calor

Figura 6.12: Condição de gelo 8 - Previsões do código atual comparadas com dados experimentais clássicos 


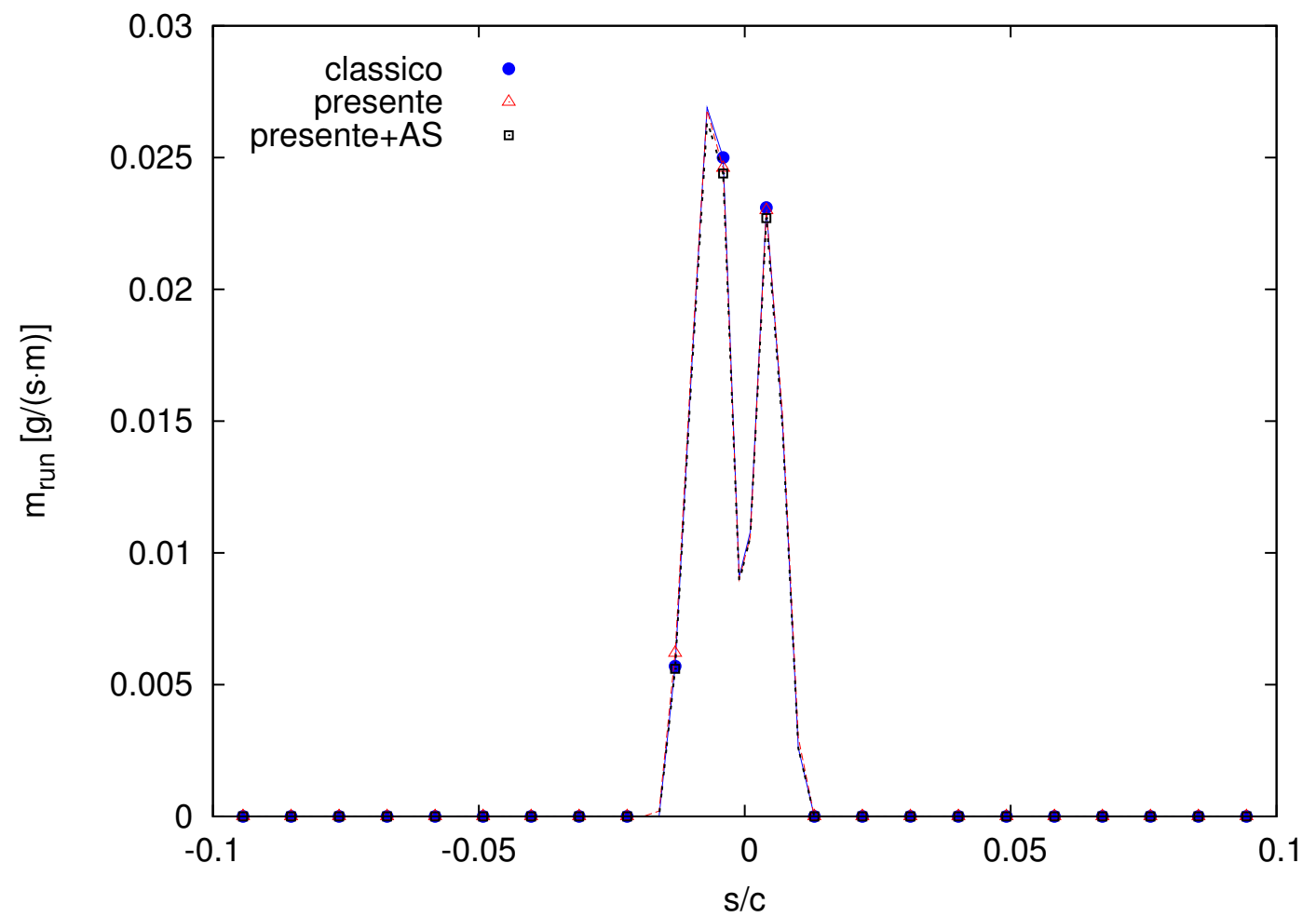

(a) Vazão de água residual

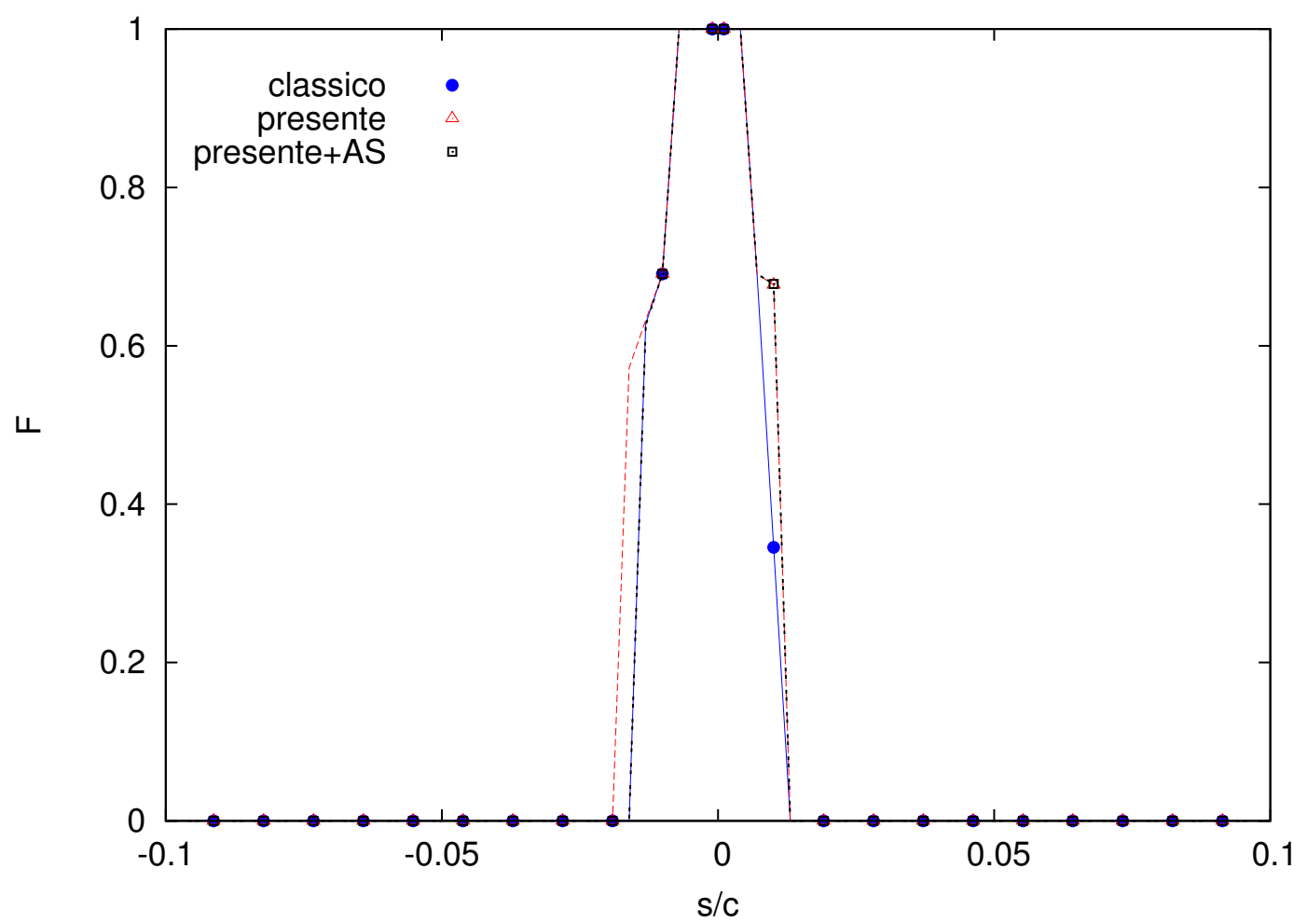

(b) Fator global de molhabilidade $F$

Figura 6.13: Caso 8GL - Comparação entre modelos 


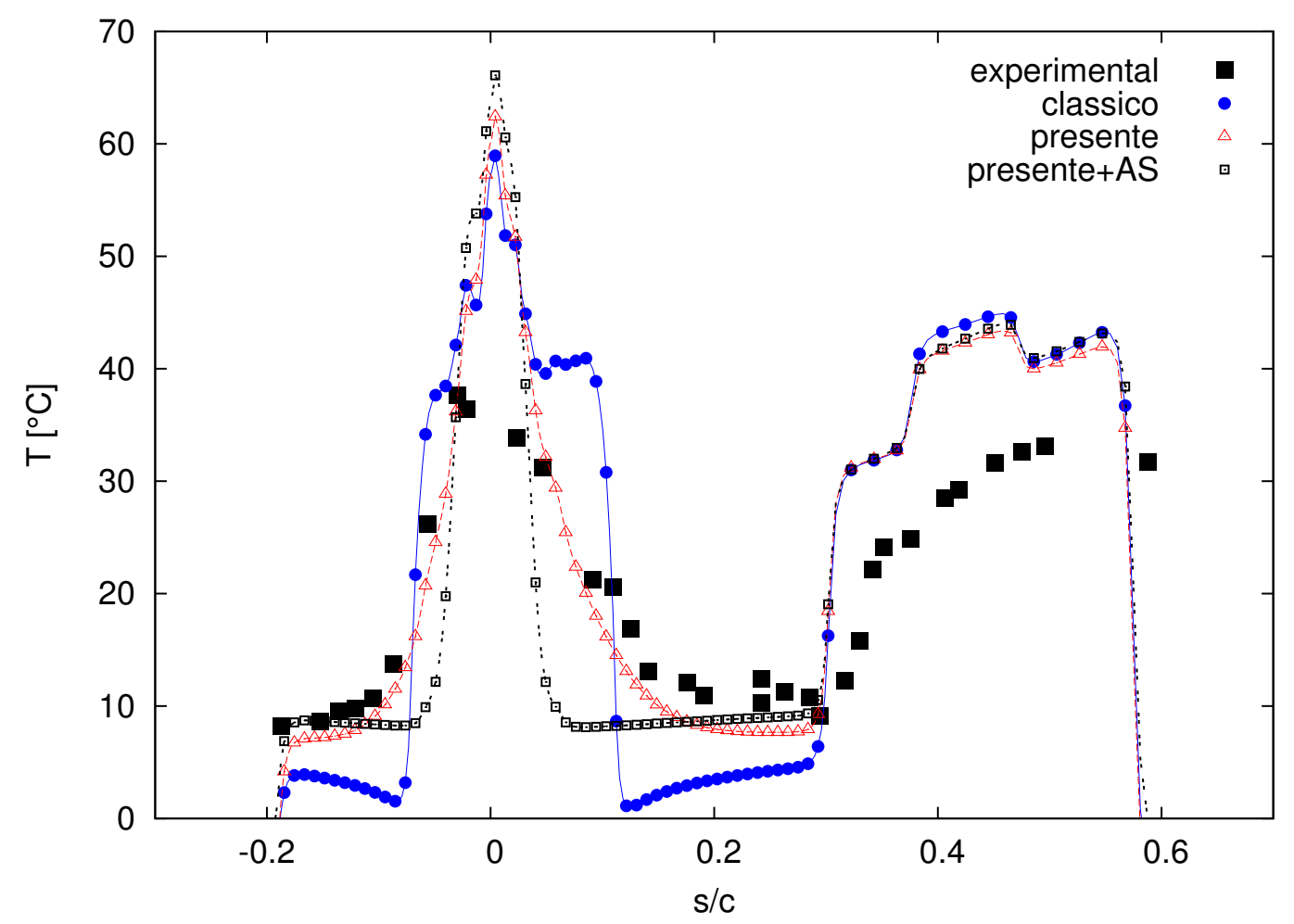

(a) Temperatura de superfície

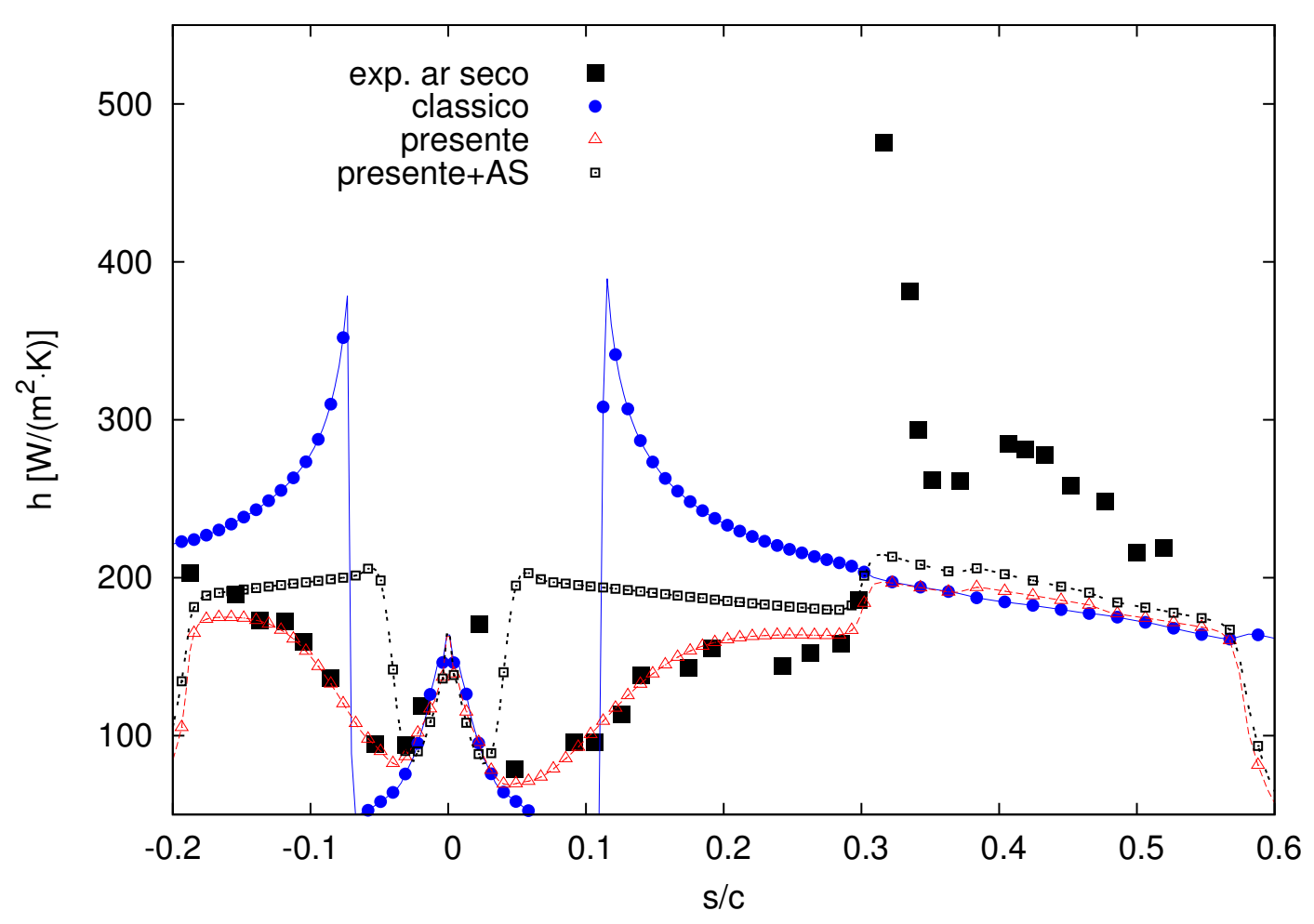

(b) Coeficiente global de transferência de calor

Figura 6.14: Caso 8GL ar seco - Comparação entre modelos 


\subsubsection{Método de Sobreposição aplicado à Camada-Limite Tér- mica}

Tabela 6.7: Modelos de Camada Limite

\begin{tabular}{llllll}
\hline \multirow{2}{*}{ Regime } & \multicolumn{2}{c}{ Não-isotérmico } & & \multicolumn{2}{c}{ Isotérmico e Sobreposição } \\
\cline { 2 - 3 } \cline { 5 - 6 } Laminar & autor & equação & & autor & equação \\
Turbulento & Ambrok (1957) & $4.10,4.11$ & & $\begin{array}{l}\text { Smith e Spalding } \\
\text { (1958) }\end{array}$ & $4.15,4.22$ \\
Transicional & $\begin{array}{l}\text { Reynolds, Kays } \\
\text { e Kline (1958b) }\end{array}$ & $5.13,4.14$ & & $\begin{array}{l}\text { Ambrok (1957) } \\
\text { modificado }\end{array}$ & $4.37,4.39$ \\
& 5.25 & & $\begin{array}{l}\text { Reynolds, Kays } \\
\text { e Kline (1958b) }\end{array}$ & 5.25 \\
\hline
\end{tabular}

Na presente seção, são apresentados os resultados numéricos da simulação de desempenho do antigelo com a adoção do modelo de camada-limite integral e modelo de filetes. O princípio da sobreposição foi aplicado à camada-limite térmica para obtenção do coeficiente de transferência de calor sobre superfície não-isotérmica, de forma original na literatura, por Silva, Silvares e Zerbini (2008a). Os resultados obtidos foram comparados a outros modelos, dados experimentais e outros códigos. Os modelos matemáticos são listados na Tabela 6.7.

Tabela 6.8: Parâmetros da Região de Transição para Modelos Não-isotérmico, Isotérmico e de Sobreposição

\begin{tabular}{llllll}
\hline & \multicolumn{2}{c}{$s / c$ extradorso } & & \multicolumn{2}{c}{$s / c$ intradorso } \\
\cline { 2 - 3 } \cline { 6 - 7 } Caso & $s_{m}$ & $\sigma$ & & $s_{m}$ & $\sigma$ \\
\hline 22A & 0,070 & 0,035 & & $-0,080$ & 0,040 \\
67A & 0,070 & 0,007 & & $-0,067$ & 0,007 \\
\hline 8GL & 0,070 & 0,035 & & $-0,036$ & 0,018 \\
8GL seco & 0,110 & 0,055 & & $-0,070$ & 0,037 \\
\hline
\end{tabular}

As distribuições de temperatura de superfície são apresentadas na Fig. 6.15(a) para as condições de teste do caso 22A de Al-Khalil et al. (2001). A posição média da transição, $s_{m}$, e o desvio padrão, $\sigma$, foram fixadas nos modelos não-isotérmico, sobreposição, e isotérmico, como apresentado na Tabela 6.8. Os resultados dos modelos de sobreposição, não-isotérmico e isotérmico têm a mesma tendência, mas o primeiro é mais próximo dos dados experimentais do que os outros. É importante enfatizar que o código numérico ANTICE não avalia $h_{a r}$ e usou a distribuição experimental do coeficiente de transferência de calor.

A Fig. 6.15(b) apresenta previsões de $U$ para todos os modelos. As maiores diferenças entre os resultados dos modelos se encontram onde o fluxo de água de- 
saparece, onde a água residual líquida para de escoar. A Fig. 6.16(a) mostra que o coeficiente de transferência de calor convectivo, $h_{a r}$, estimado pelo modelo de sobreposição é mais sensível à mudanças na temperatura de superfície do que o modelo não-isotérmico de Ambrok e, como esperado, do que o isotérmico. Na posição de término de escoamento da água, a temperatura local aumenta de forma significativa, já que o processo de resfriamento por evaporação cessa e somente a troca de calor por convecção ocorre. Como os picos de temperatura foram atenuados nas previsões de sobreposição, ocorreu diminuição dos desvios entre resultados numéricos e dados experimentais. A Figura 6.16(b) apresenta a vazão de água residual e a Fig. 6.18(a) o fator de molhabilidade superficial global $F$. Esses resultados indicam que a água evapora perto dos limites de incidência e escoa como um filme contínuo. O fim dos limites da vazão de água residual, água incidente e aquecimento nas superfícies superior e inferior são apresentados na Tabela 6.9.

A Figura 6.19 mostra os resultados de temperatura e coeficiente de transferência de calor global para o caso 67A. Como esperado em regime molhado como o caso 67A, valores previstos das distribuições de $h_{a r}$, vazão residual de água e $F$ têm variações menores do que no caso inteiramente evaporativo, o caso $22 \mathrm{~A}$. As mudanças mais significativas são devido à ocorrência de transição, já que a distribuição de temperaturas superficial apresenta pequenas variações ao longo da região moIhada em ambas superfícies superior e inferior do aerofólio. Contudo, a Fig. 6.17(a) mostra que a história do coeficiente de transferência de calor ao redor do aerofólio foi estimado com alguma discrepância por modelos isotérmico, não-isotérmico, e de sobreposição. A história diferente do escoamento, estimada em cada modelo, afetou o processo de transição laminar-turbulenta, como mostrado nas Figs. 6.17(a) e 6.19(b). Ambos os efeitos, distribuição do coeficiente de transferência local e processo de transição, fizeram com que a vazão de água residual desaparecesse mais à jusante no modelo de sobreposição do que nos outros. Os limites de área molhada previstos podem ser verificados nas Figs. 6.17(b) e 6.18(b).

As temperaturas de superfície previstas para os testes de gelo e ar da condição 8GL seco são mostradas, respectivamente, nas Figs. 6.20(a) e 6.22(a).

Os $h_{a r}$ previstos pelo presente modelo são apresentados nas Figs. 6.20(b) e 6.22(b). Em ambas as condições, de ar seco e gelo, o único ponto que apresenta maiores desvios está na região do degrau de aquecimento em $s / c \approx 0.3$, onde a densidade de potência é aumentada repentinamente. Tal degrau de aquecimento localizado distante da jusante do limite de incidência não é comum nos sistemas de antigelo de asa de aeronave modernos. O modelo de superposição previu distribuição de $h_{a r}$ com a mesma tendência dos dados experimentais. 


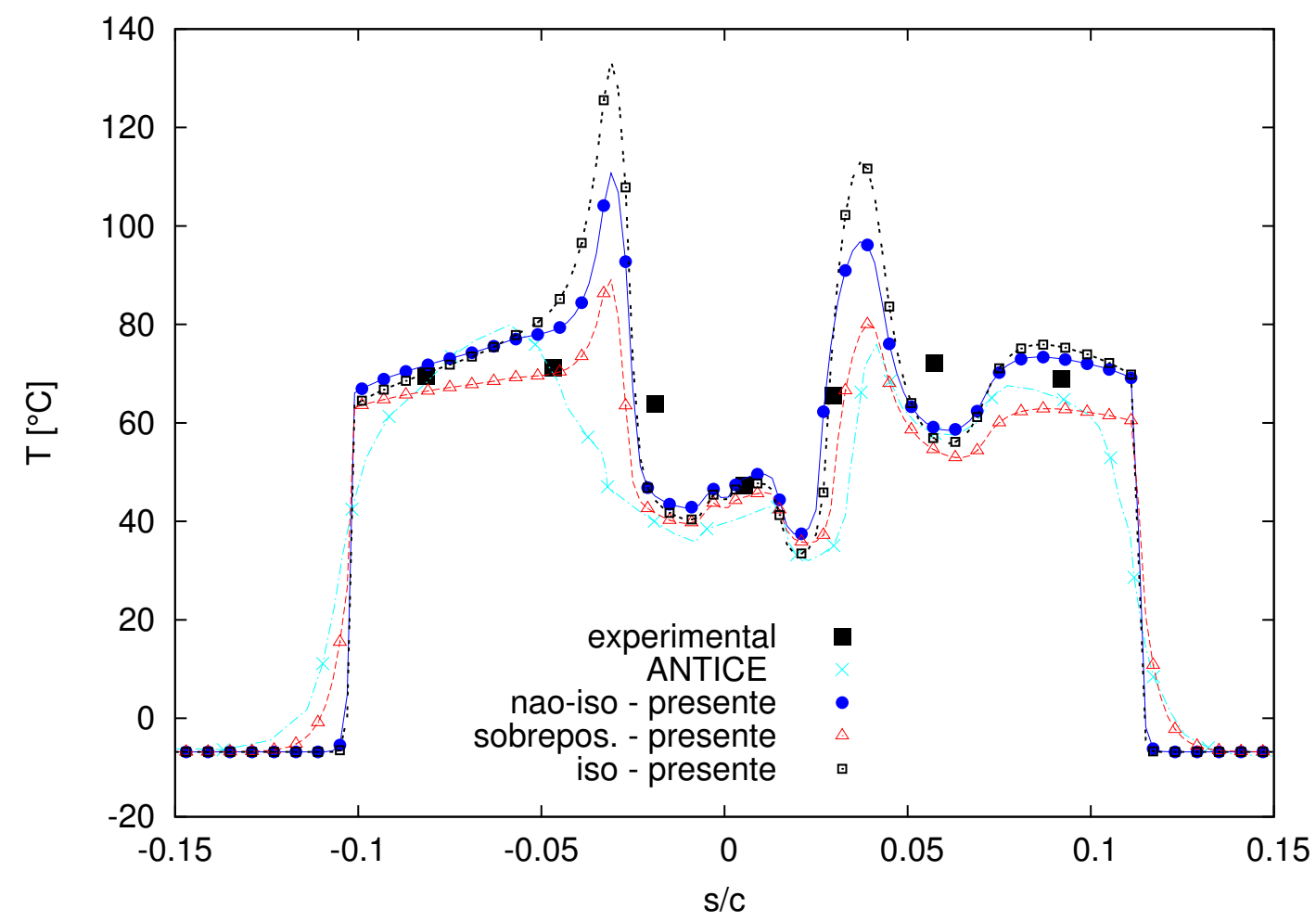

(a) Temperatura de Superfície $T_{s}$

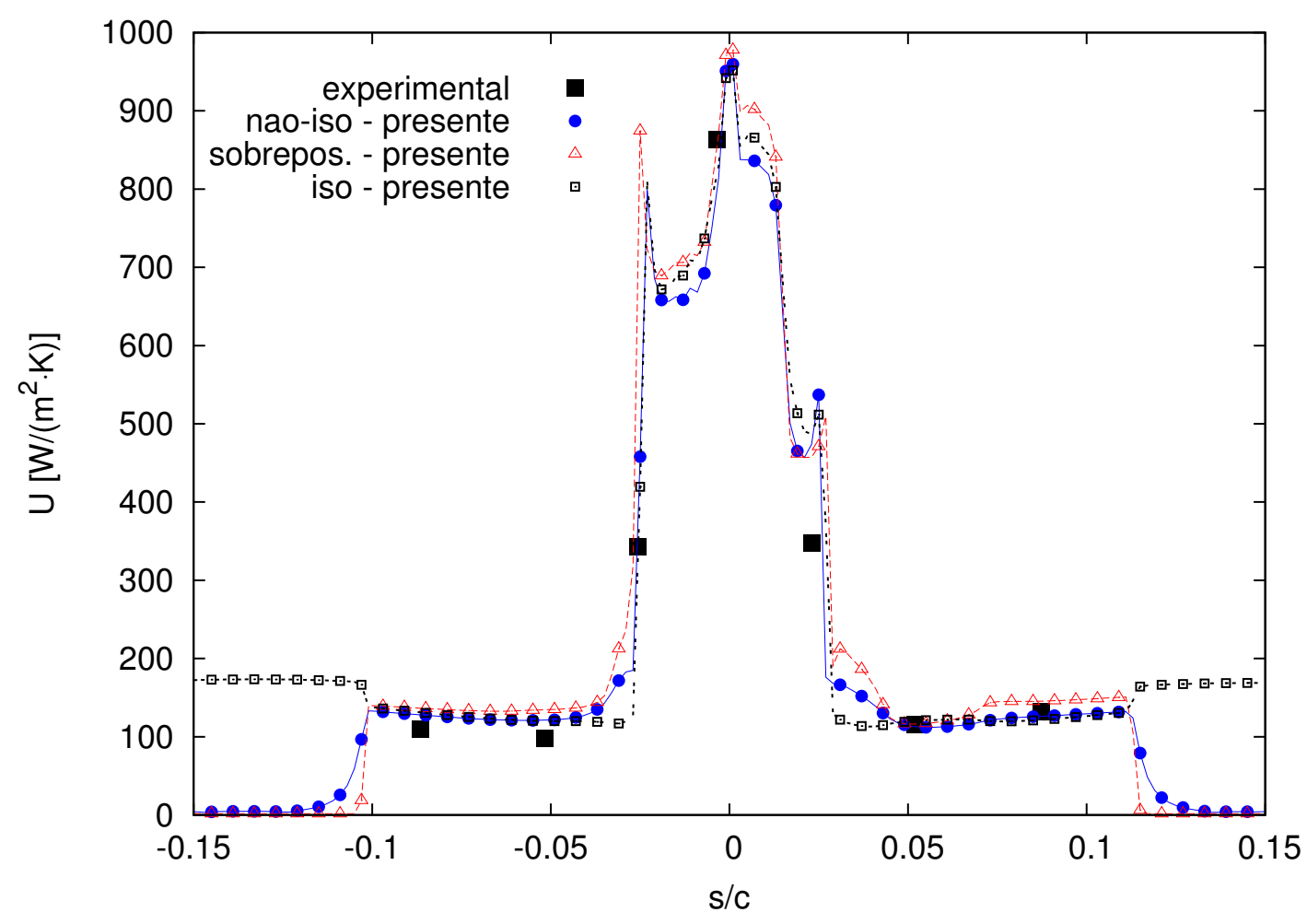

(b) Coeficientes de transferência de calor $U$ e $h_{a r}$

Figura 6.15: Caso 22A - Comparação entre modelo de sobreposição, não-isotérmico e isotérmico 


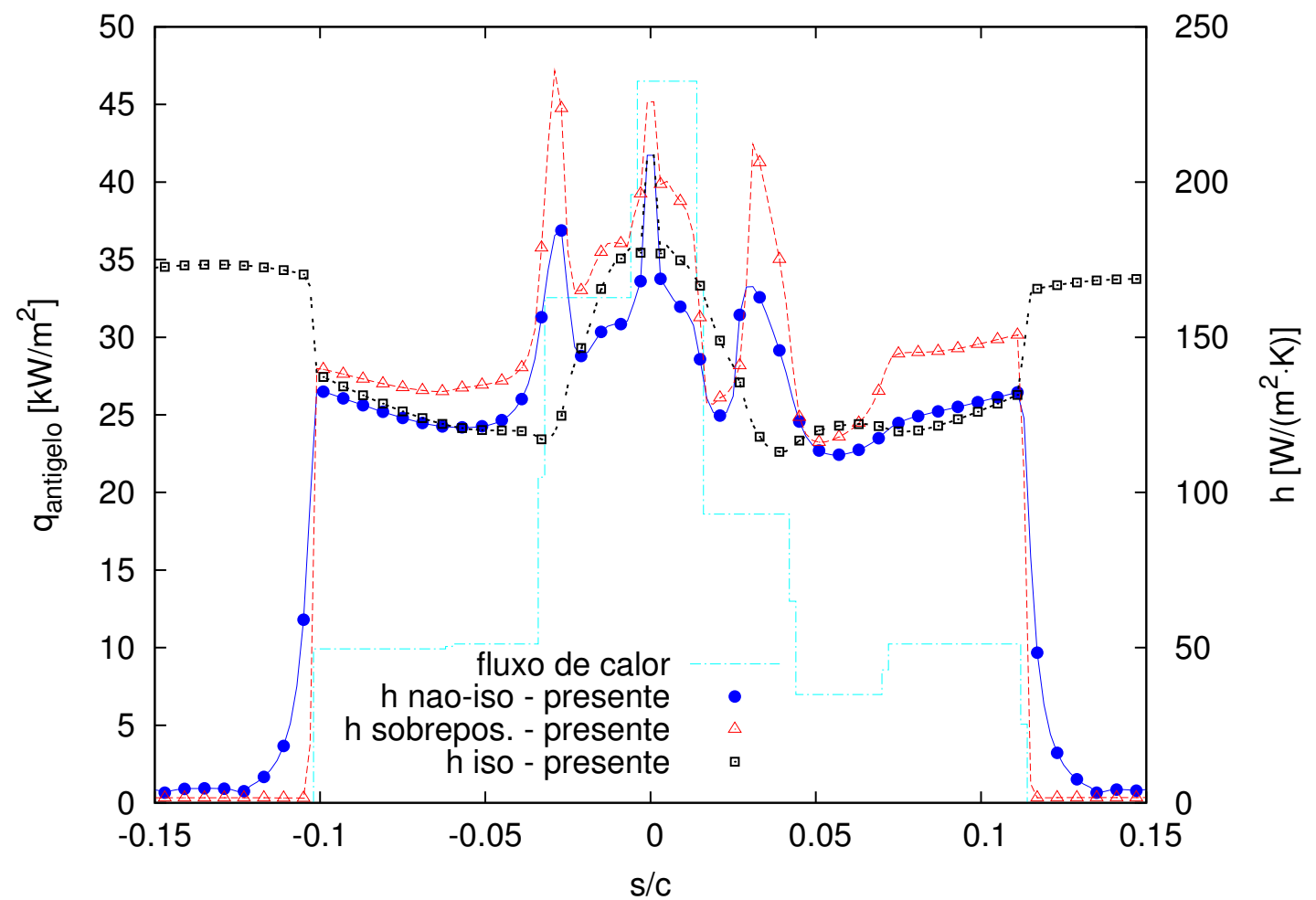

(a) Coeficiente de transferência de calor $h_{a r}$ e densidade de potência elétrica

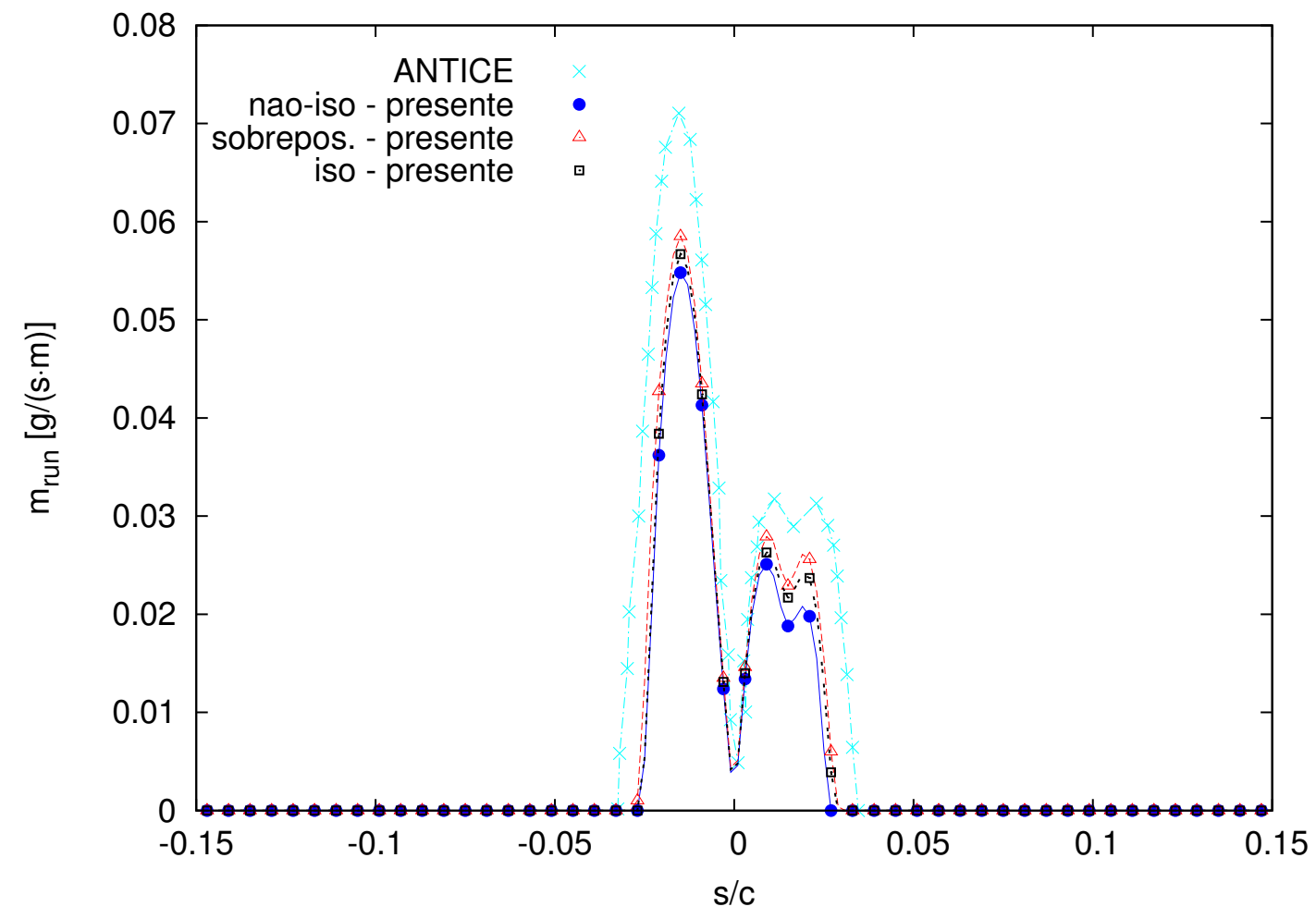

(b) Água residual $\dot{m}_{r}^{\prime}$

Figura 6.16: Caso 22A - Comparação entre modelo de sobreposição, não-isotérmico e isotérmico 


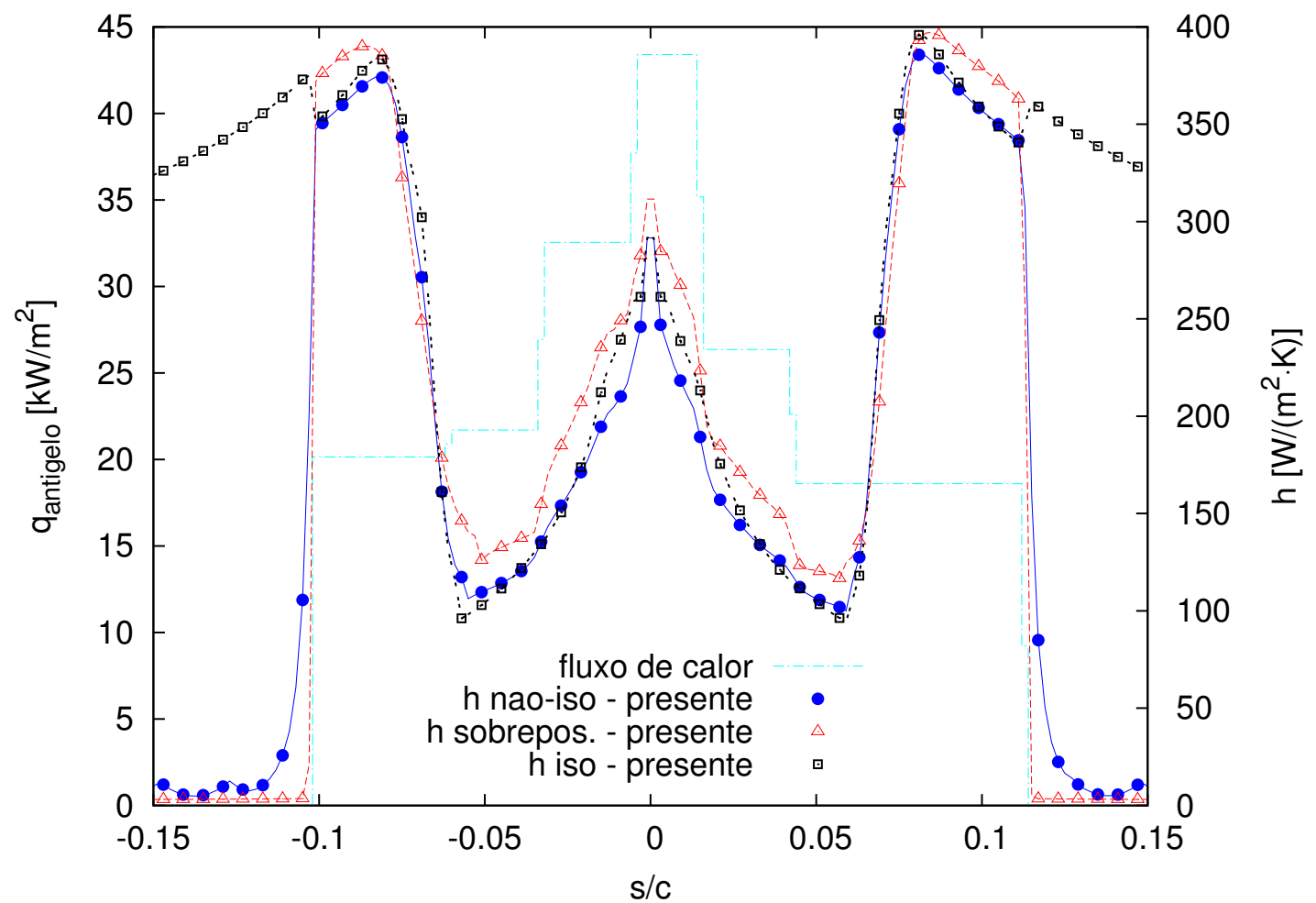

(a) Coeficiente de transferência de calor $h_{a r}$ e densidade de potência elétrica

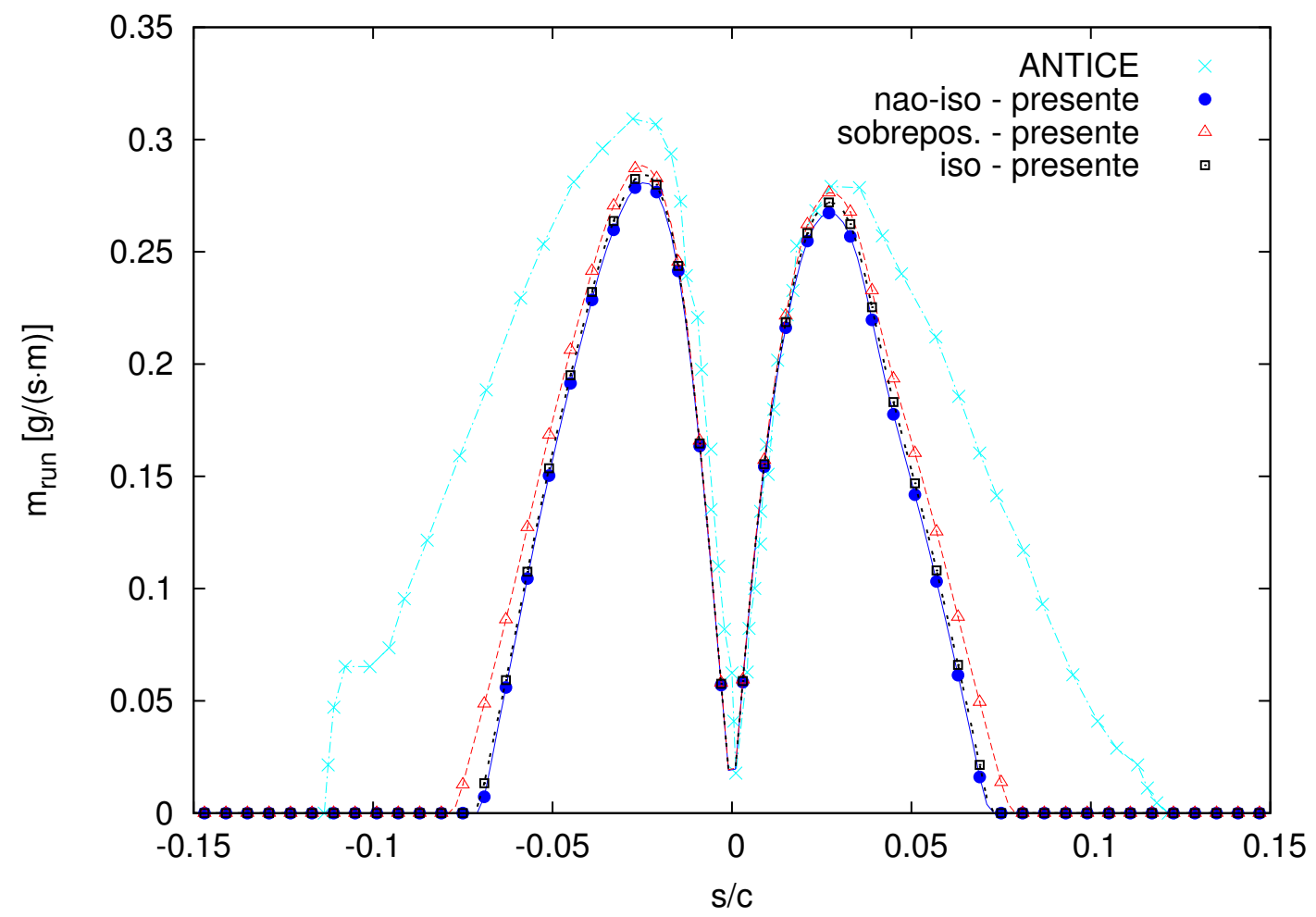

(b) Água residual $\dot{m}_{r}^{\prime}$

Figura 6.17: Caso 67A - Comparação entre modelo de sobreposição, não-isotérmico $\mathrm{e}$ isotérmico 


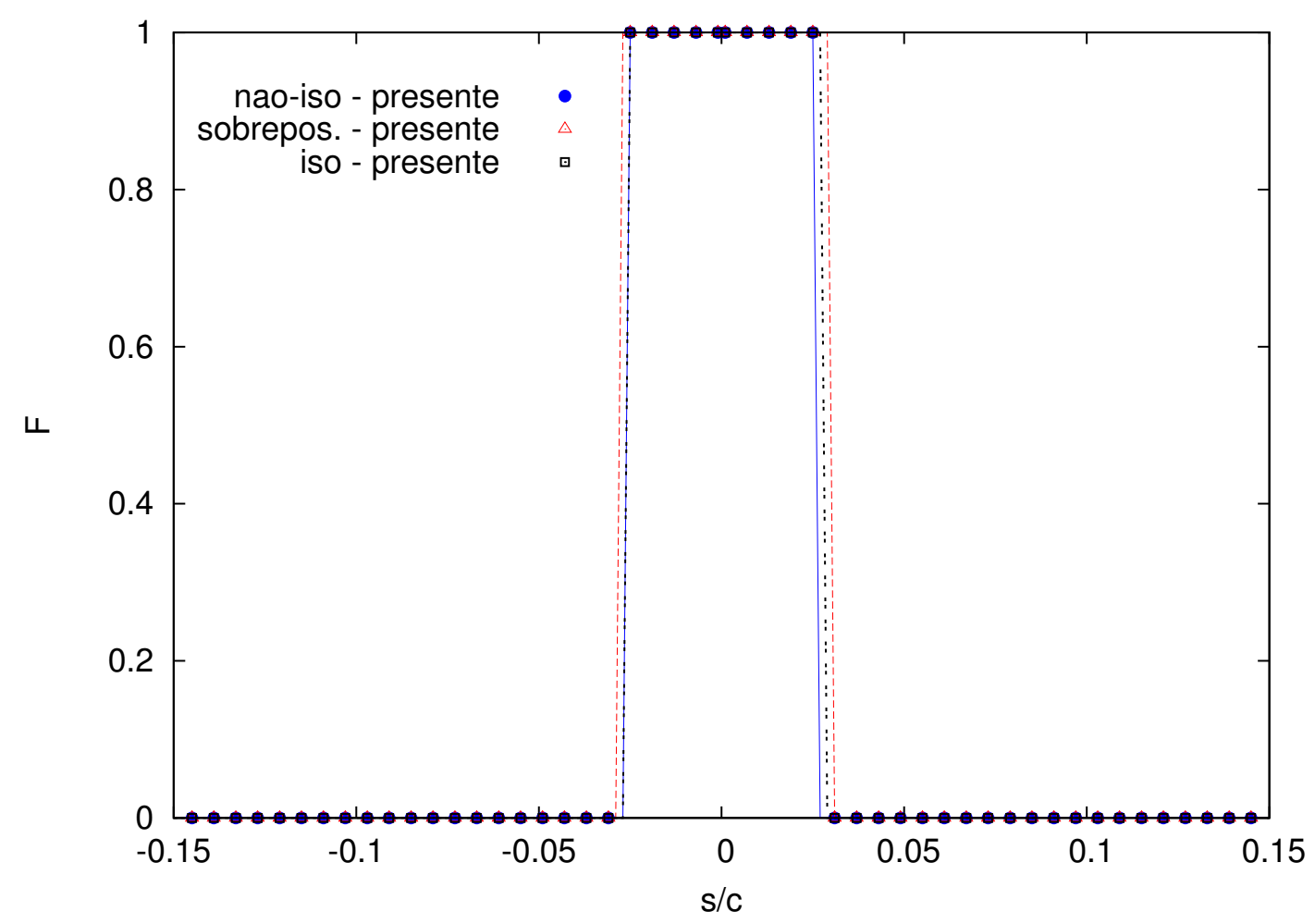

(a) Caso 22A

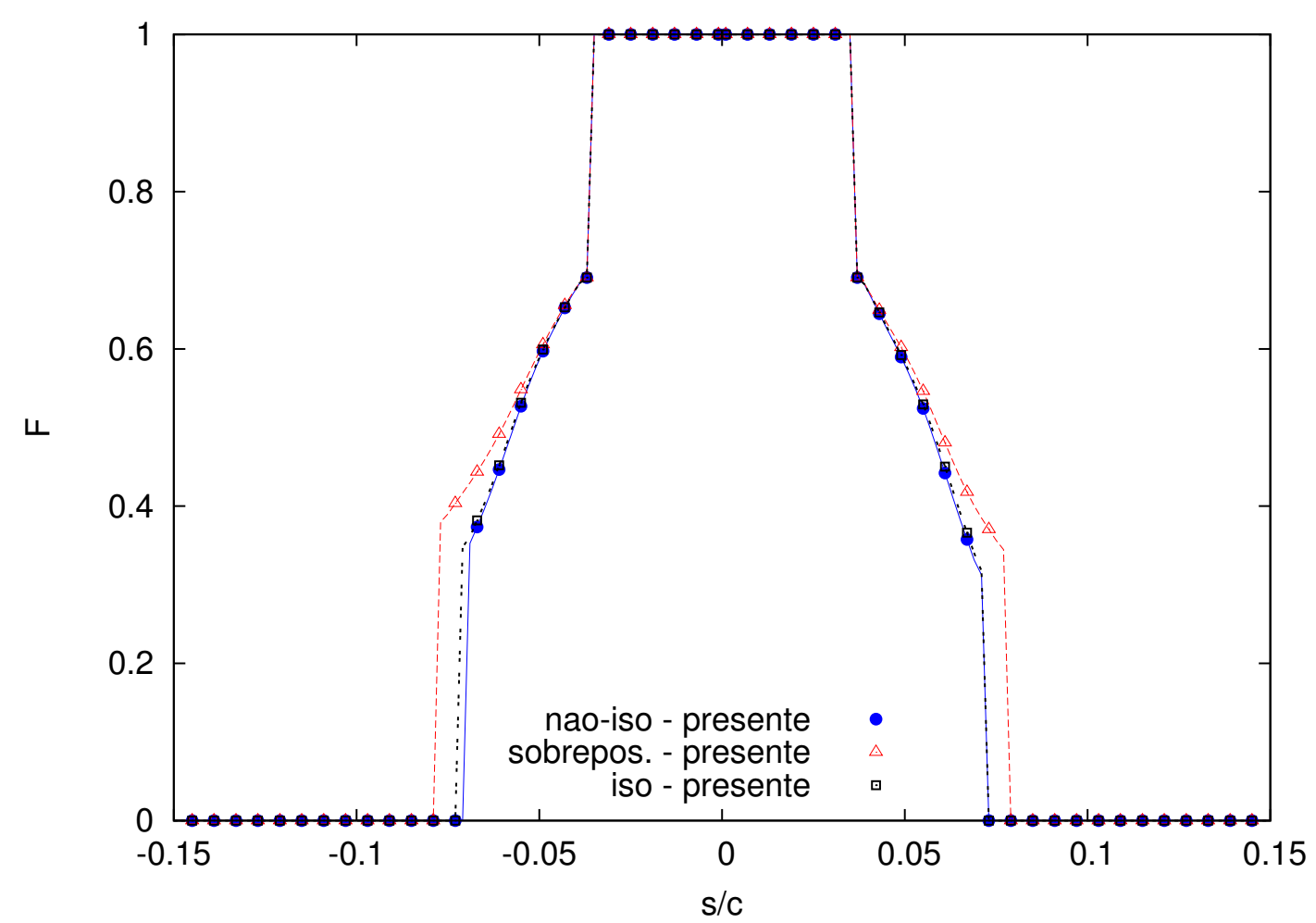

(b) Caso 67A

Figura 6.18: Fator de molhabilidade - $F$ 


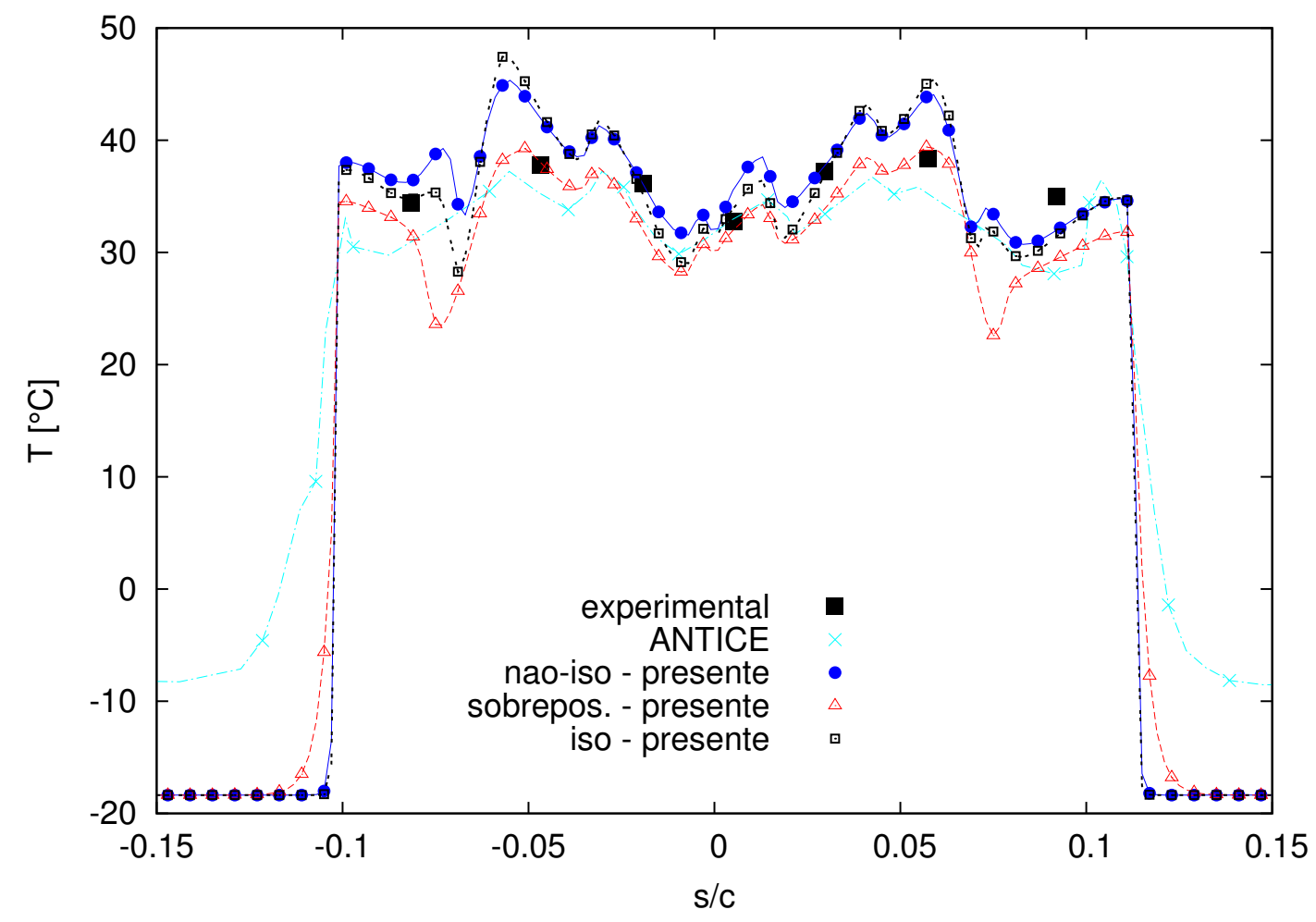

(a) Temperatura de Superfície $T_{s}$

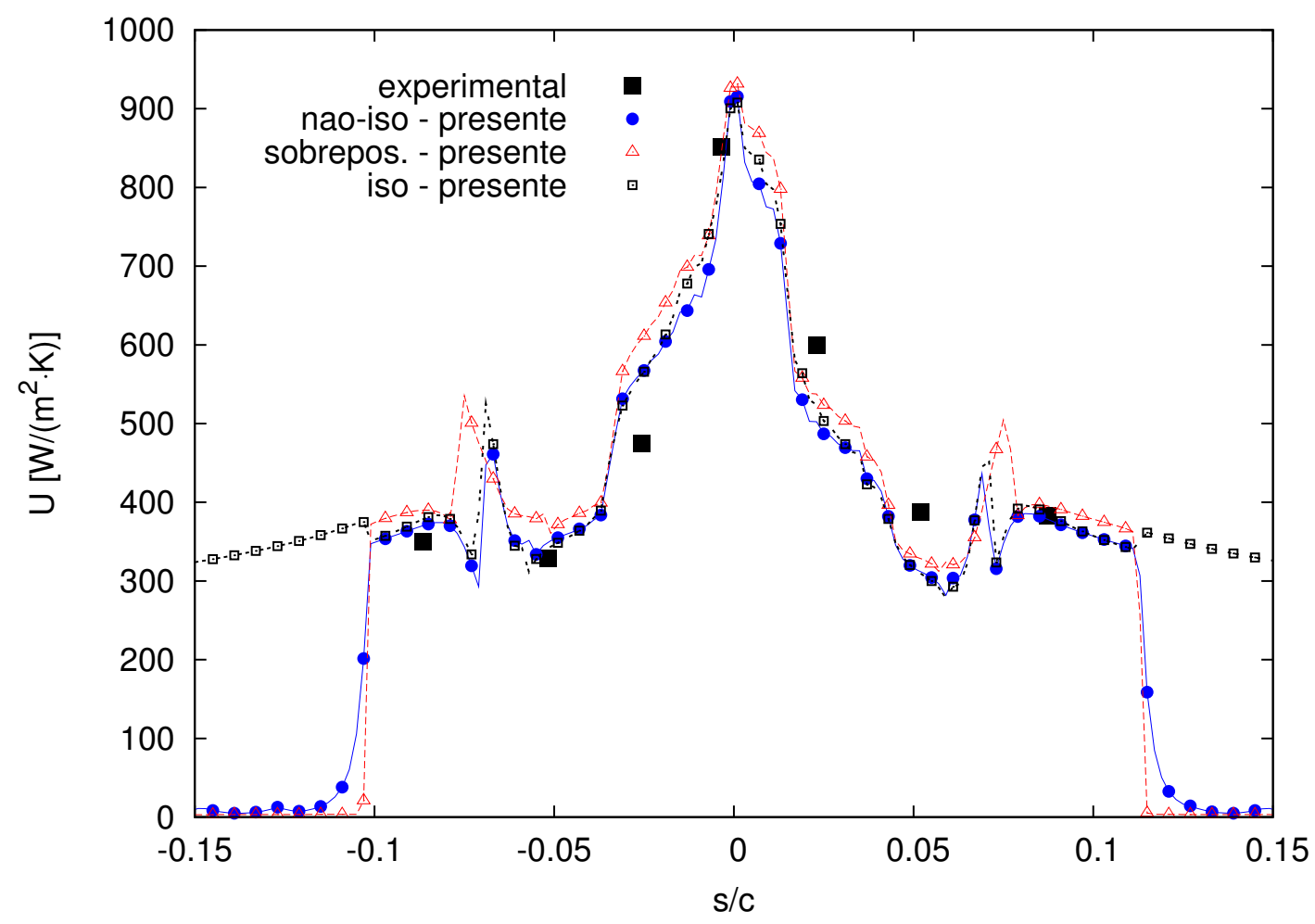

(b) Coeficientes de transferência de calor $U$ e $h_{a r}$

Figura 6.19: Caso 67A - Comparação entre modelo de sobreposição, não-isotérmico e isotérmico 


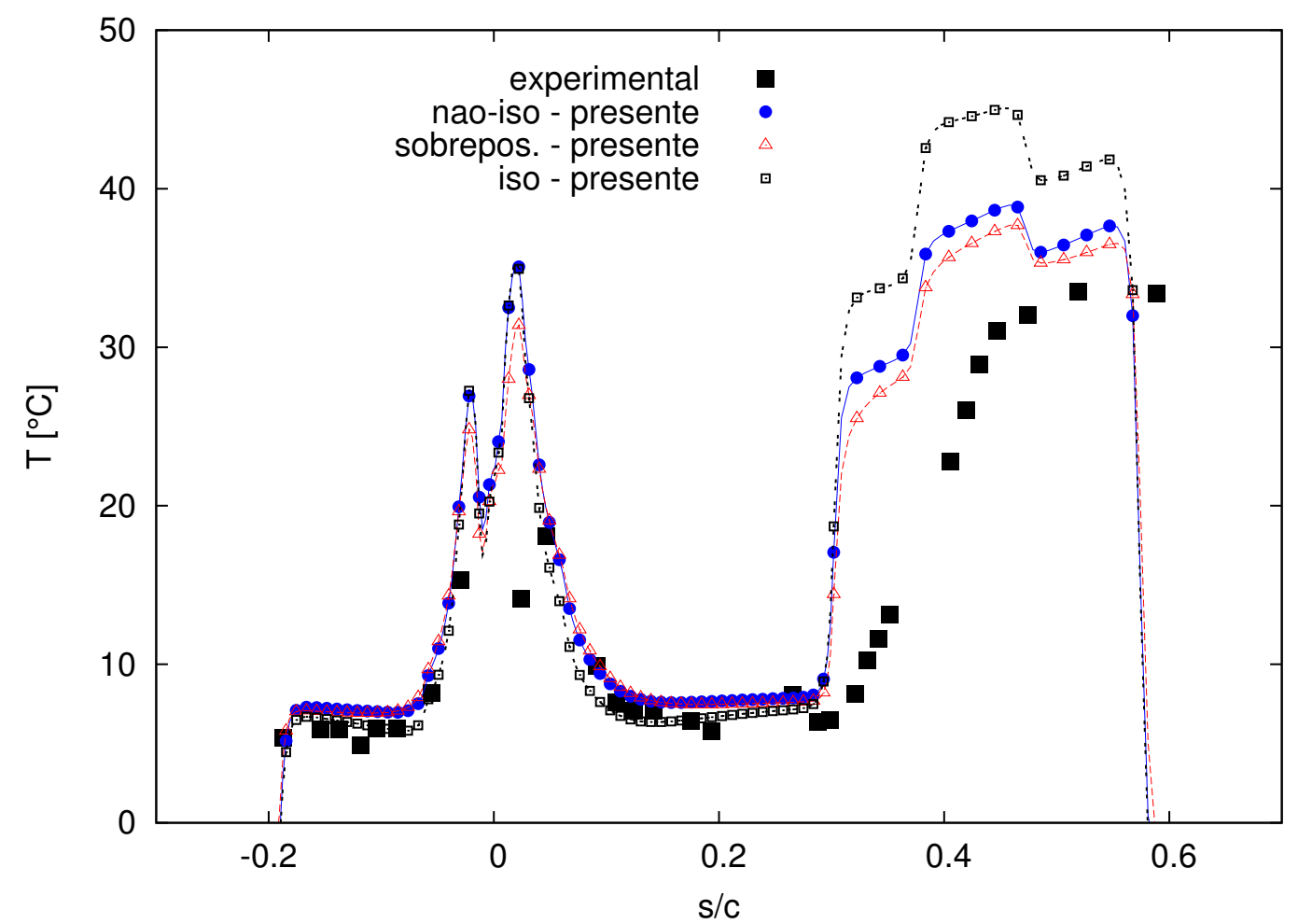

(a) Temperatura de Superfície $T_{s}$

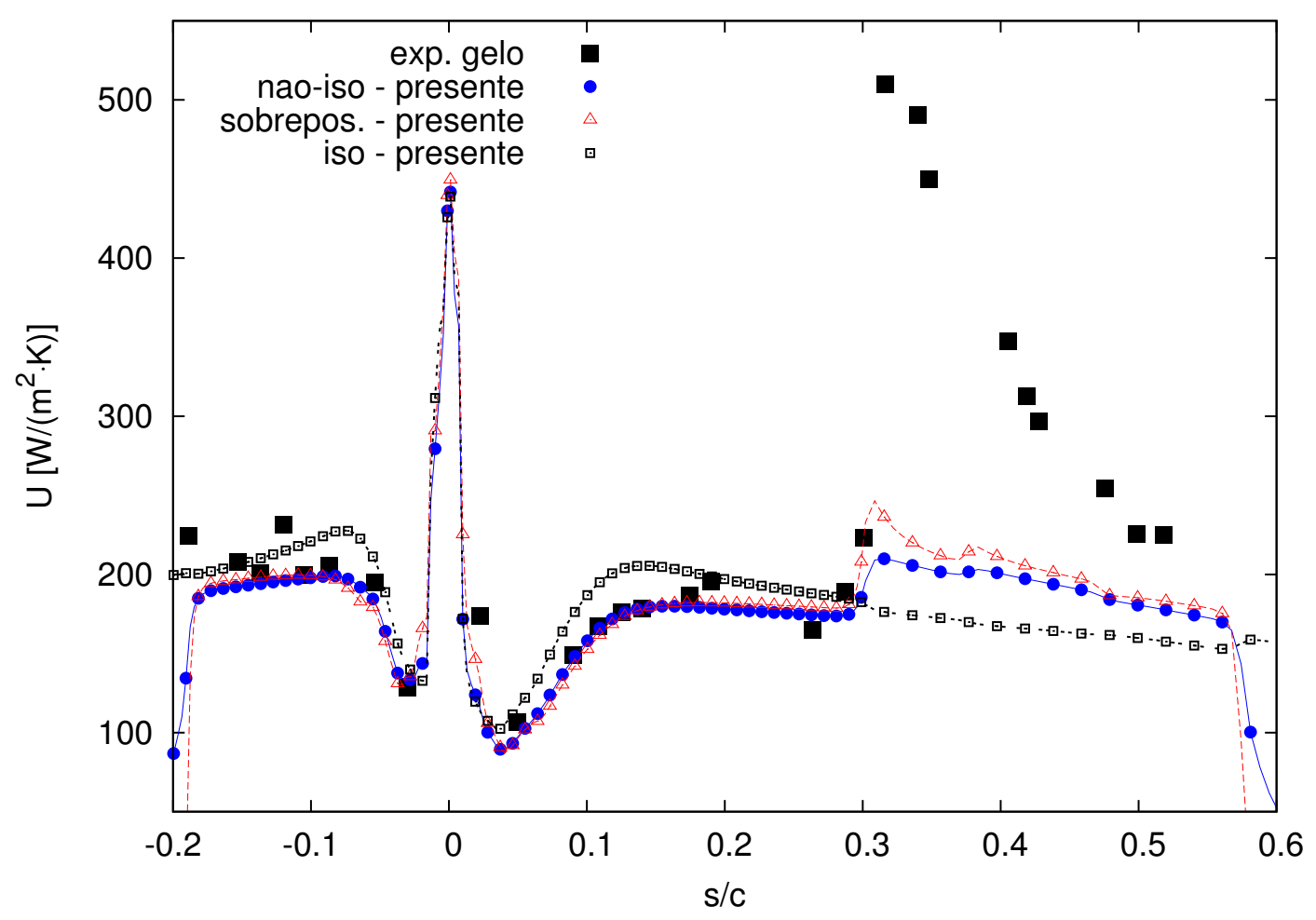

(b) Coeficientes de transferência de calor $U$ e $h_{a r}$

Figura 6.20: Caso 8GL - Condição de gelo - Comparação entre modelo de sobreposição, não-isotérmico e isotérmico 


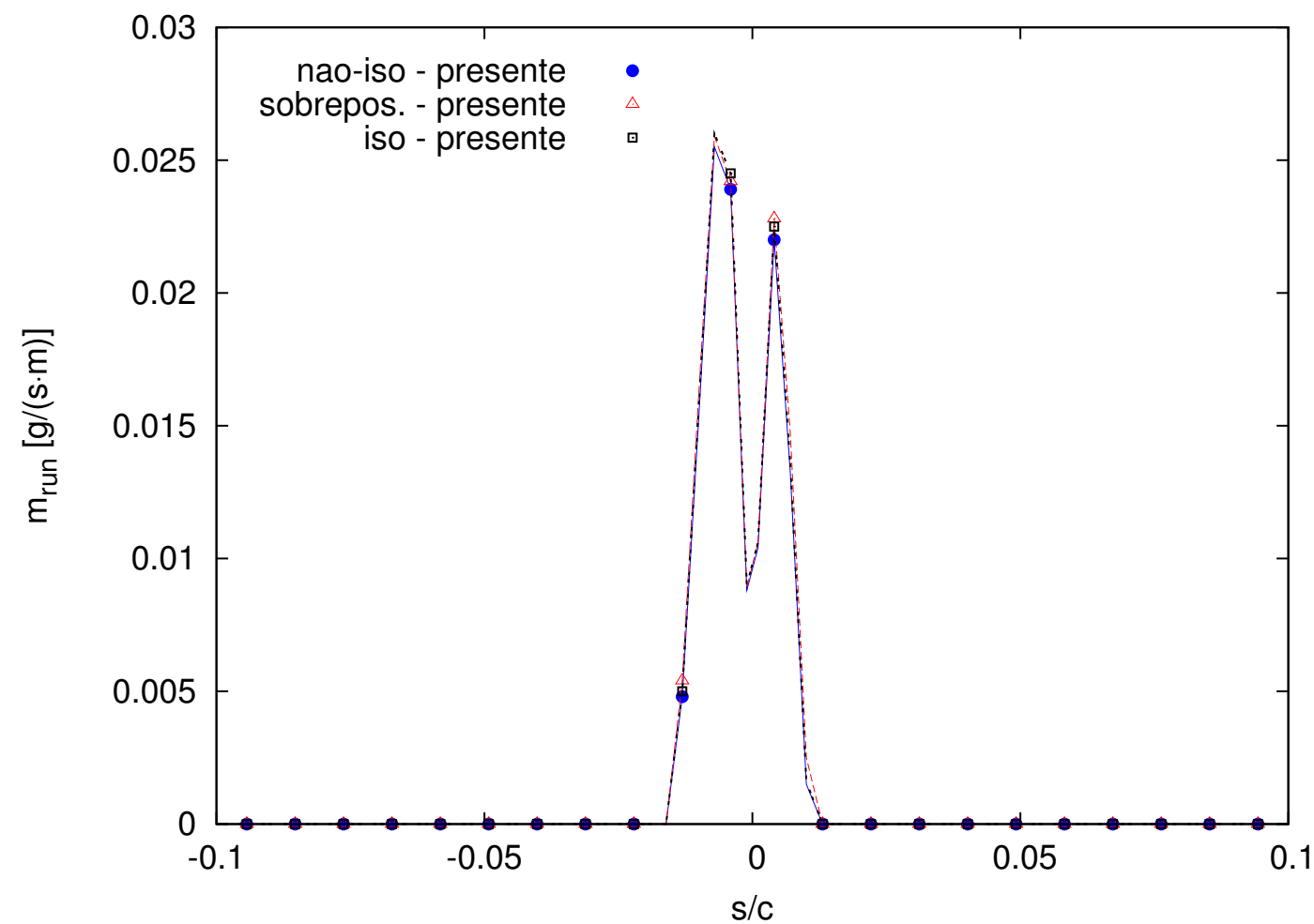

(a) Vazão de água residual $\dot{m}_{r}^{\prime}$

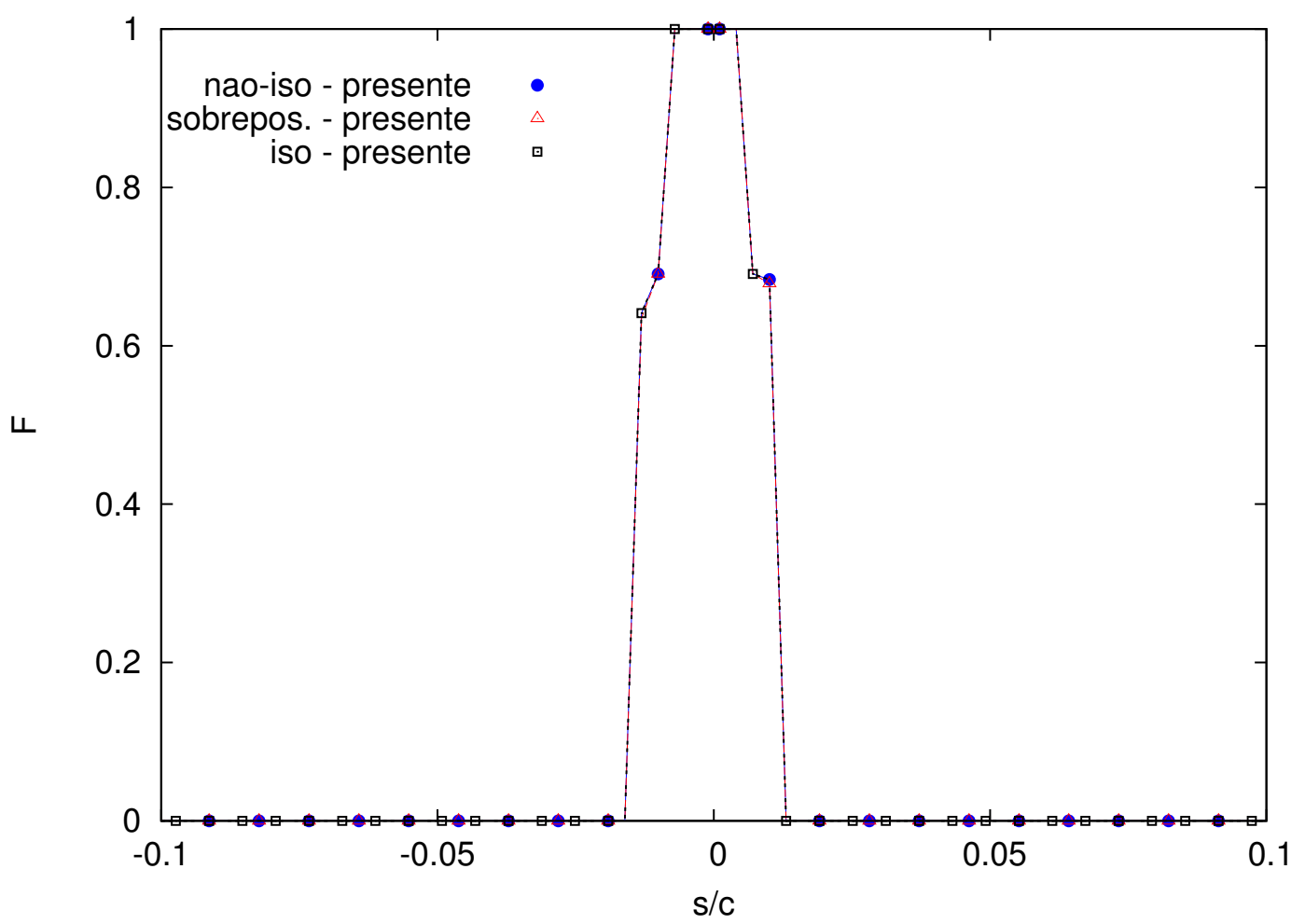

(b) Fator de molhabilidade global $F$

Figura 6.21: Caso 8GL - Condição de gelo - Comparação entre modelo de sobreposição, não-isotérmico e isotérmico 


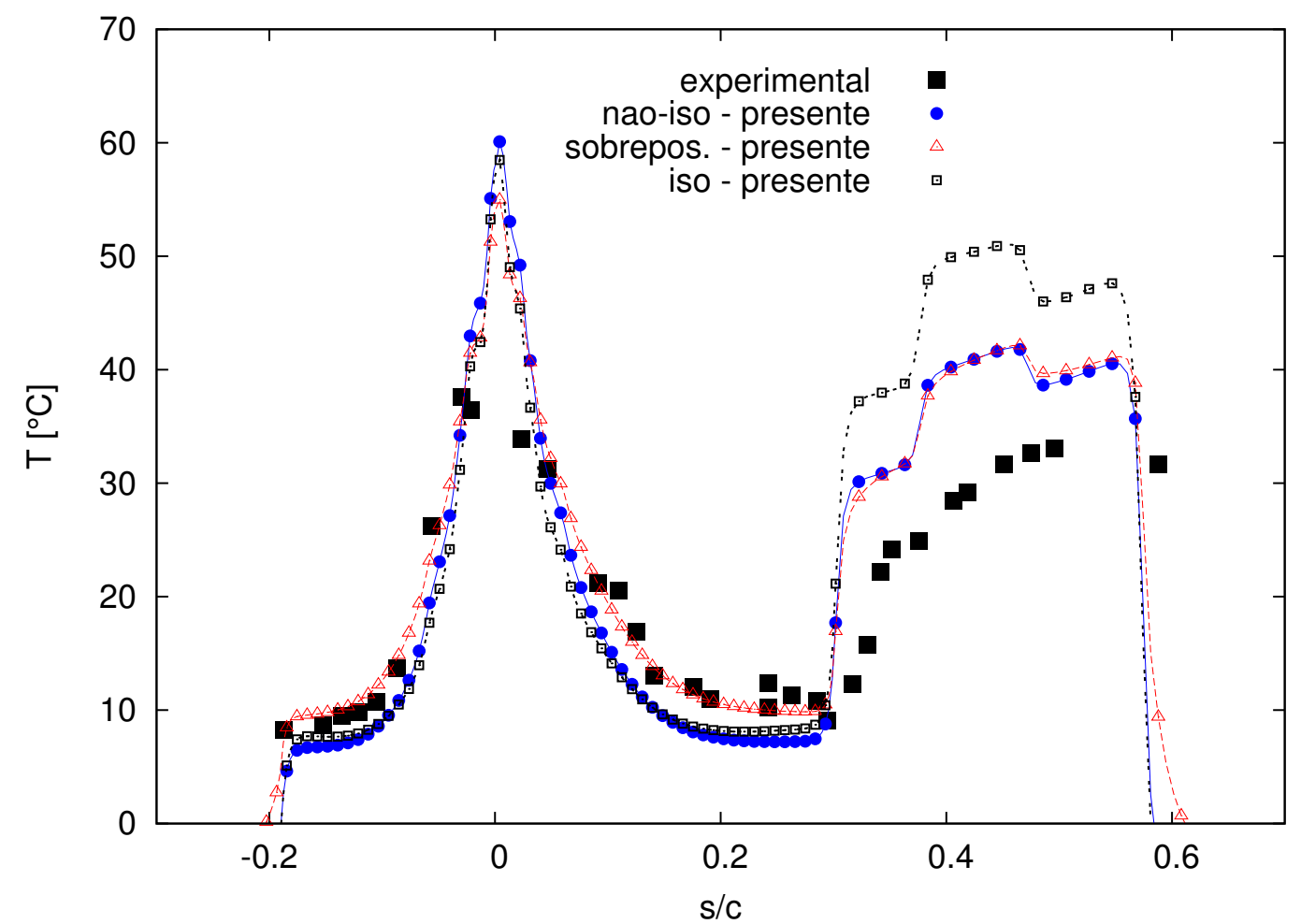

(a) Temperatura de Superfície $T_{s}$

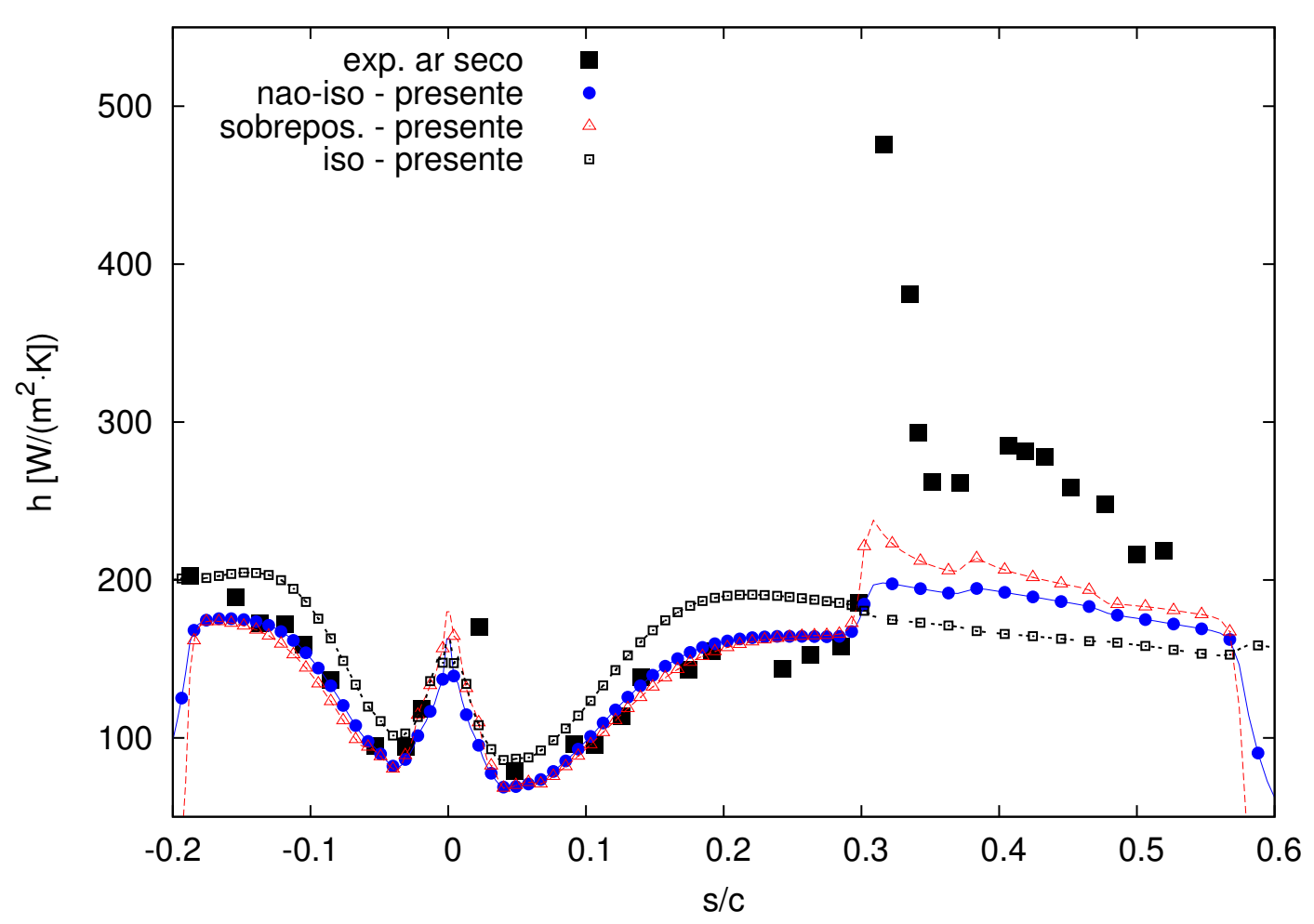

(b) Coeficientes de transferência de calor $U$ e $h_{a r}$

Figura 6.22: Caso 8GL - Condição de ar seco - Comparação entre modelo de sobreposição, não-isotérmico e isotérmico 


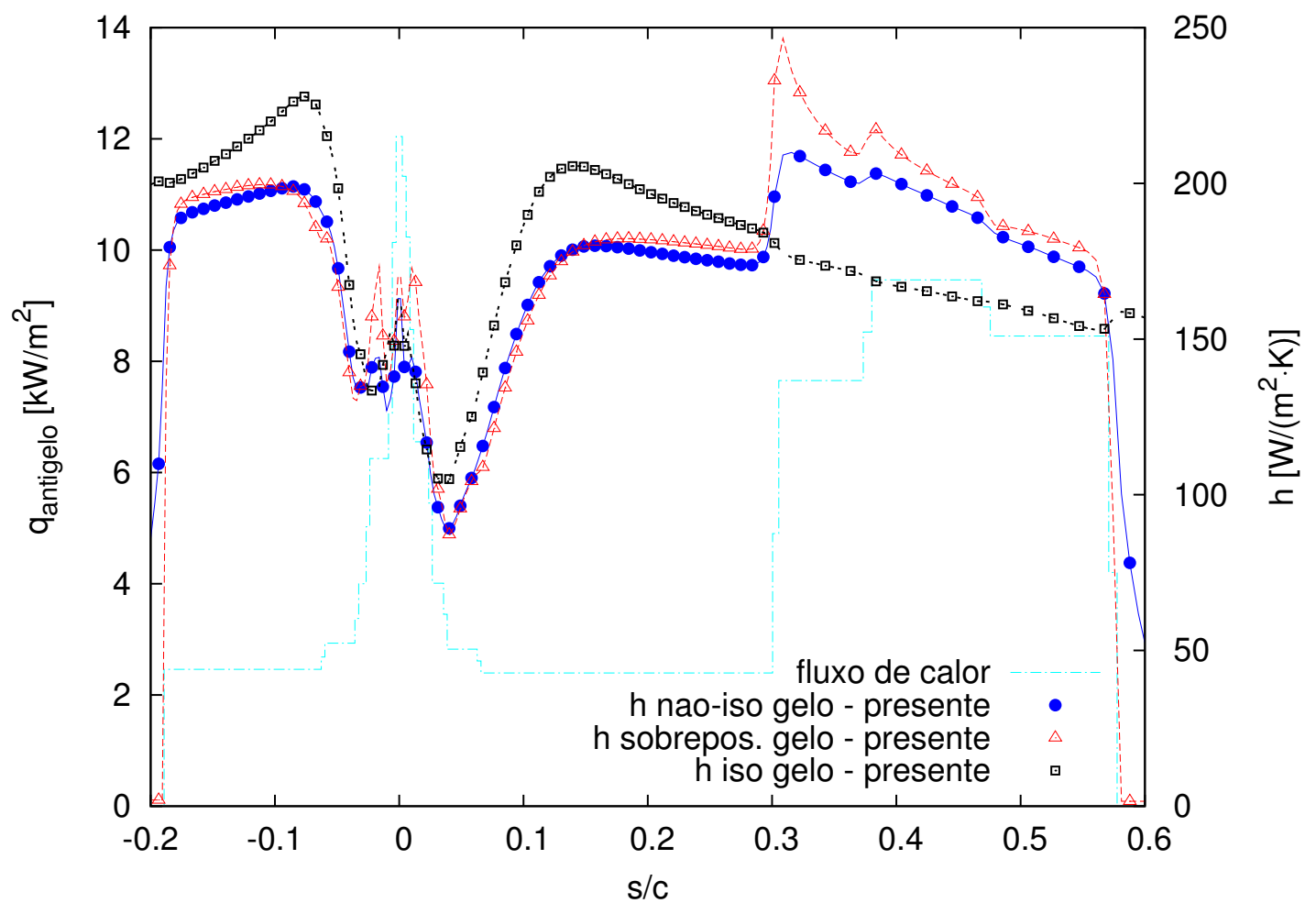

(a) Condição de Gelo

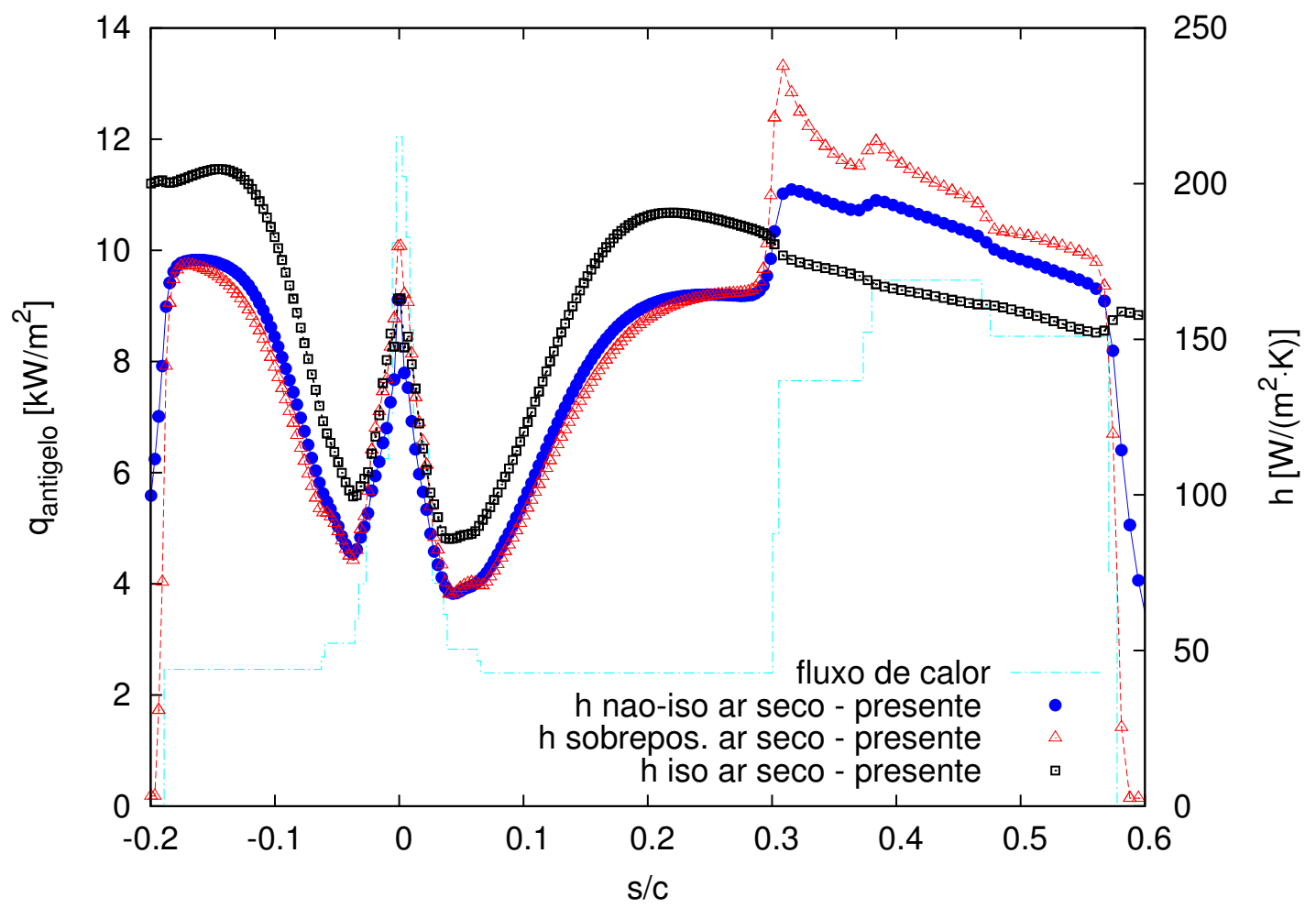

(b) $\operatorname{Ar~seco}$

Figura 6.23: Caso 8GL - Comparação entre modelo de sobreposição, não-isotérmico e isotérmico 
Tabela 6.9: Término do escoamento de água residual, incidência e limites de área protegida contra gelo

\begin{tabular}{|c|c|c|c|c|c|c|c|}
\hline \multirow[b]{2}{*}{ Caso } & & \multicolumn{3}{|c|}{$s / c$ extradorso } & \multicolumn{3}{|c|}{$s / c$ intradorso } \\
\hline & & água & captação & proteção & água & captação & proteção \\
\hline \multirow[t]{3}{*}{$22 \mathrm{~A}$} & não-isotérmico & 0,025 & \multirow[t]{3}{*}{0,031} & \multirow[t]{3}{*}{0,113} & $-0,025$ & \multirow[t]{3}{*}{$-0,031$} & \multirow[t]{3}{*}{$-0,102$} \\
\hline & sobreposição & 0,029 & & & $-0,027$ & & \\
\hline & isotérmico & 0,027 & & & $-0,025$ & & \\
\hline \multirow[t]{3}{*}{$67 \mathrm{~A}$} & não-isotérmico & 0,071 & \multirow[t]{3}{*}{0,037} & \multirow[t]{3}{*}{0,113} & $-0,069$ & \multirow[t]{3}{*}{$-0,037$} & \multirow[t]{3}{*}{$-0,102$} \\
\hline & sobreposição & 0,077 & & & $-0,077$ & & \\
\hline & isotérmico & 0,071 & & & $-0,071$ & & \\
\hline \multirow[t]{3}{*}{$8 G L$} & não-isotérmico & 0,101 & \multirow[t]{3}{*}{0,071} & \multirow[t]{3}{*}{0,576} & $-0,131$ & \multirow[t]{3}{*}{$-0,131$} & \multirow[t]{3}{*}{$-0,190$} \\
\hline & sobreposição & 0,101 & & & $-0,131$ & & \\
\hline & isotérmico & 0,101 & & & $-0,131$ & & \\
\hline
\end{tabular}

A Tabela 6.6 mostra os limites de vazão de água residual, água incidente e área protegida do gelo para a condição 8GL sob condições de ar seco e gelo. Como apresentado na Fig. 6.21(a), tanto a área de incidência quanto a quantidade total de água residual, na condição $8 \mathrm{GL}$ de gelo, apresentam níveis menores do que nos casos 22A e 67A. Como a distribuição de temperatura na região úmida, onde existe água residual, não tem uma variação significativa e o coeficiente de transferência de calor dos modelos isotérmico, não-isotérmico e de sobreposição são aproximadamente os mesmos, os resultados da vazão residual também não diferem. A Figura 6.21 mostra que os limites de incidência estão perto do ponto de estagnação. Portanto, uma região muito curta é coberta por filme contínuo de água líquida residual, onde o fator de molhabilidade é igual à unidade $F=1$. A Fig. 6.21 também mostra que a extensão do escoamento do filetes, onde $0<F<1$, é desprezível em ambos os lados ,superior e inferior, do aerofólio.

\subsection{Resultados Numéricos - Análise Diferencial da Camada-Limite}

O código de análise diferencial de camada-limite $B L P 2 C$ foi modificado e integrado ao programa de simulação do escoamento bifásico em torno de aerofólios com antigelo térmico.

Para simplificação, esse modelo de camada-limite é chamado apenas de diferencial. Foram rodados casos do modelo de antigelo com submodelos de análise integral de camada-limite e de formação de filetes no escoamento de água residual. Esse segundo modelo é chamado de integral na presente seção. Os resultados dos modelos diferencial e integral são comparados com dados experimentais e com os 
resultados numéricos do código ANTICE de Al-Khalil et al. (2001), que não avalia a camada-limite e utiliza a distribuição experimental de fluxo de calor em torno do bordo de ataque do aerofólio medida no próprio teste.

Em ambos os modelos integral e diferencial, foram adotados o submodelo de ruptura de filme e formação de filetes e a previsão de transição laminar-turbulenta pelas correlações de Abu-Ghannam e Shaw (1980).

Os casos 22A, 67A e 67B dos casos-teste de Al-Khalil et al. (2001) foram selecionados para a validação dos resultados numéricos dos modelos diferencial e integral. O caso $22 \mathrm{~A}$ é totalmente evaporativo, que tem toda a água evaporada a montante dos limites de captação ; o 67A é parcialmente evaporativo, no qual a água líquida é evaporada à montante do final da região aquecida; e o 67B é molhado, ou seja, apresenta vazão de água residual à jusante da região protegida térmicamente.

\subsubsection{Modelos Utilizados e Parâmetros da Simulação}

Os modelos utilizados e os principais parâmetros de entrada (adotados ou calculados) dos modelos diferencial e integral são apresentados nas Tabelas 6.10, 6.11 e 6.12. Particularmente, os parâmetros da região de transição previstos pelas correlações algébricas são: $s_{m}$, posição média; $\sigma$, desvio padrão; $s_{t r}$, início da região de transição e $s_{e}$, término da região de transição. $O$ nível de turbulência foi o único parâmetro variado, pois valor nominal do túnel de gelo, $T u=0,7 \%$, não apresentou resultados satisfatórios para nenhum modelo. Segundo Henze, Bragg e Kim (1998), o nível de turbulência no IRT pode aumentar até $6 \%$ quando medido perto do corpo de prova, na seção de testes. A transição laminar-turbulenta também pode ser influenciada por outras perturbações presentes durante os testes de antigelo, como efeitos de: 1) rugosidades gerada pelo filme e filetes de água; 2) ondulações na superfície, muito comuns em instalações de aquecedores elétricos não-embutidos, como no caso de Al-Khalil et al. (2001); 3) temperaturas elevadas e variações de temperatura ao longo do escoamento; 4) gotículas carregadas pelo escoamento do ar em torno do aerofólio; 5) evaporação da água. Outro fator importante é que as escalas da turbulência gerada, que são ligadas as frequências das flutuações turbulentas e a dimensão dos turbilhões, são diferentes num túnel de gelo e num túnel de vento com grelhas. Dessa forma, o nível de turbulência, requerido pelas correlações algébricas de previsão transição, pode-se ser entendido como um valor "equivalente", que compreende outras perturbações além daquelas geradas pelo Tu considerado por Abu-Ghannam e Shaw (1980). O presente trabalho adotou níveis de turbulência Tu para cada caso simulado e cada modelo, como mostrados nas Tabelas 6.10, 6.11 
e 6.12. O critério para definição de $T u$ foi aquele que gerou menores desvios entre resultados e dados experimentais de $T_{s}$ e $U$. Esses níveis encontrados, apesar de altos, representam os efeitos combinados das imprecisões inerentes às correlações algébricas e das outras perturbações sofridas pelo escoamento laminar.

Tabela 6.10: Modelos e Parâmetros das Simulações - Caso 22A

\begin{tabular}{|c|c|c|c|c|c|}
\hline \multicolumn{3}{|c|}{ Diferencial } & \multicolumn{3}{|c|}{ Integral } \\
\hline parâmetros & valor & detalhes & parâmetros & valor & detalhes \\
\hline$s_{m} / c ; \sigma / c$ & 0, 091;0, 012 & extradorso & $s_{m} / c ; \sigma / c$ & 0,$083 ; 0,011$ & extradorso \\
\hline$s_{m} / c ; \sigma / c$ & 0,$091 ; 0,013$ & intradorso & $s_{m} / c ; \sigma / c$ & 0,$082 ; 0,010$ & intradorso \\
\hline$s_{t r} / c ; s_{e} / c$ & 0,$054 ; 0,129$ & extradorso & $s_{t r} / c ; s_{e} / c$ & 0,$051 ; 0,115$ & extradorso \\
\hline$s_{t r} / c ; s_{e} / c$ & 0,$054 ; 0,129$ & extradorso & $s_{t r} / c ; s_{e} / c$ & 0,$054 ; 0,112$ & extradorso \\
\hline$F_{i m p}$ & 1,00 & na captação & $F_{i m p}$ & 1,00 & na captação \\
\hline $\mathbf{S t}_{\text {lam }}$ & BLP2C & diferencial & $\mathbf{S t}_{/ a m}$ & Ambrok & integral \\
\hline $\mathbf{S t}_{\text {turb }}$ & BLP2C & diferencial & $\mathbf{S t}_{\text {turb }}$ & Ambrok & integral \\
\hline $\begin{array}{l}\gamma \\
\text { sobreposição }\end{array}$ & $\begin{array}{c}\text { Abu-Ghannam } \\
\text { não }\end{array}$ & $\begin{array}{l}\text { intermitência } \\
\text { lam/turb/trans }\end{array}$ & $\begin{array}{l}\gamma \\
\text { sobreposição }\end{array}$ & $\begin{array}{l}\text { Abu-Ghannam } \\
\text { não }\end{array}$ & $\begin{array}{l}\text { intermitência } \\
\text { lam/turb/trans }\end{array}$ \\
\hline $\mathbf{R e}_{\text {crit }}$ & Abu-Ghannam & critério & $\mathbf{R e}_{\text {crit }}$ & Abu-Ghannam & critério \\
\hline$\alpha$ & $68,0^{\circ}$ & contato & $\alpha$ & $68,0^{\circ}$ & contato \\
\hline$T u$ & $3,1 \%$ & turbulência & $T u$ & $4,5 \%$ & turbulência \\
\hline
\end{tabular}

Tabela 6.11: Modelos e Parâmatros das Simulações - Caso 67A

\begin{tabular}{|c|c|c|c|c|c|}
\hline \multicolumn{3}{|c|}{ Diferencial } & \multicolumn{3}{|c|}{ Integral } \\
\hline parâmetros & valor & detalhes & parâmetros & valor & detalhes \\
\hline$s_{m} / c ; \sigma / c$ & 0,$512 ; 0,152$ & extradorso & $s_{m} / c ; \sigma / c$ & 0,$070 ; 0,009$ & extradorso \\
\hline$s_{m} / c ; \sigma / c$ & 0,$512 ; 0,152$ & intradorso & $s_{m} / c ; \sigma / c$ & 0,$070 ; 0,009$ & intradorso \\
\hline$s_{t r} / c ; s_{e} / c$ & 0,$055 ; 0,969$ & extradorso & $s_{t r} / c ; s_{e} / c$ & 0,$044 ; 0,097$ & extradorso \\
\hline$s_{t r} / c ; s_{e} / c$ & 0,$054 ; 0,969$ & extradorso & $s_{t r} / c ; s_{e} / c$ & 0,$044 ; 0,097$ & extradorso \\
\hline$F_{i m p}$ & 1,00 & na captação & $F_{i m p}$ & 1,00 & na captação \\
\hline $\mathbf{S t}_{/ a m}$ & BLP2C & diferencial & $\mathbf{S t}_{/ a m}$ & Ambrok & integral \\
\hline $\mathbf{S t}_{\text {turb }}$ & BLP2C & diferencial & $\mathbf{S t}_{\text {turb }}$ & Ambrok & integral \\
\hline $\begin{array}{l}\gamma \\
\text { sobreposição }\end{array}$ & $\begin{array}{c}\text { Abu-Ghannam } \\
\text { não }\end{array}$ & $\begin{array}{l}\text { intermitência } \\
\text { lam/turb/trans }\end{array}$ & $\begin{array}{l}\gamma \\
\text { sobreposição }\end{array}$ & $\begin{array}{l}\text { Abu-Ghannam } \\
\text { não }\end{array}$ & $\begin{array}{l}\text { intermitência } \\
\text { lam/turb/trans }\end{array}$ \\
\hline $\mathbf{R e}_{\text {crit }}$ & Abu-Ghannam & critério & $\mathbf{R e}_{\text {crit }}$ & Abu-Ghannam & critério \\
\hline$\alpha$ & $68,0^{\circ}$ & contato & $\alpha$ & $68,0^{\circ}$ & contato \\
\hline$T u$ & $1,9 \%$ & turbulência & Tu & $2,7 \%$ & turbulência \\
\hline
\end{tabular}

\subsubsection{Resultados Numéricos e Comparação}

A Fig. 6.24(a) apresenta a distribuições de temperaturas da superfície do aerofólio previstas pelos modelos diferencial e integral. Elas são comparadas aos dados experimentais e resultados numéricos de Al-Khalil et al. (2001). Para um valor de $T u=3,1 \%$, o modelo diferencial previu $T_{s}$ e $U$ com desvios satisfatórios sem relação aos dados experimentais, como pode ser observado nas Figs. 6.24(a) e 6.24(b). Por outro lado, não foram encontrados valores de Tu (nem menores ou maiores do 
Tabela 6.12: Modelos e Parâmetros das Simulações - Caso 67B

\begin{tabular}{|c|c|c|c|c|c|}
\hline \multicolumn{3}{|c|}{ Diferencial } & \multicolumn{3}{|c|}{ Integral } \\
\hline parâmetros & valor & detalhes & parâmetros & valor & detalhes \\
\hline$s_{m} / c ; \sigma / c$ & 0,$502 ; 0,156$ & extradorso & $s_{m} / c ; \sigma / c$ & 0,$052 ; 0,007$ & extradorso \\
\hline$s_{m} / c ; \sigma / c$ & 0,$502 ; 0,156$ & intradorso & $s_{m} / c ; \sigma / c$ & 0,$051 ; 0,007$ & intradorso \\
\hline$s_{t r} / c ; s_{e} / c$ & 0,$034 ; 0,970$ & extradorso & $s_{t r} / c ; s_{e} / c$ & 0,$031 ; 0,073$ & extradorso \\
\hline$s_{t r} / c ; s_{e} / c$ & 0, 033;0, 971 & extradorso & $s_{t r} / c ; s_{e} / c$ & 0,033;0, 072 & extradorso \\
\hline$F_{i m p}$ & 1,00 & na captação & $F_{i m p}$ & 1,00 & na captação \\
\hline $\mathbf{S t}_{\text {lam }}$ & BLP2C & diferencial & $\mathbf{S t}_{/ a m}$ & Ambrok & integral \\
\hline $\mathbf{S t}_{\text {turb }}$ & BLP2C & diferencial & $\mathbf{S t}_{t u r b}$ & Ambrok & integral \\
\hline $\begin{array}{l}\gamma \\
\text { sobreposição }\end{array}$ & $\begin{array}{c}\text { Abu-Ghannam } \\
\text { não }\end{array}$ & $\begin{array}{l}\text { intermitência } \\
\text { lam/turb/trans }\end{array}$ & $\begin{array}{l}\gamma \\
\text { sobreposição }\end{array}$ & $\begin{array}{l}\text { Abu-Ghannam } \\
\text { não }\end{array}$ & $\begin{array}{l}\text { intermitência } \\
\text { lam/turb/trans }\end{array}$ \\
\hline $\mathbf{R e}_{\text {crit }}$ & Abu-Ghannam & critério & $\mathbf{R e}_{c r i t}$ & Abu-Ghannam & critério \\
\hline$\alpha$ & $68,0^{\circ}$ & contato & $\alpha$ & $68,0^{\circ}$ & contato \\
\hline$T u$ & $3,0 \%$ & turbulência & $T u$ & $4,1 \%$ & turbulência \\
\hline
\end{tabular}

que os 3\% da solução diferencial) que satisfizessem a previsão de temperaturas em torno do aerofólio. O valor de $T u=4,5 \%$ gerou os resultados numéricos com menores desvios do que outros valores de $T u$, porém ainda considerados insatisfatórios. O modelo diferencial apresentou uma distribuição de vazão de água líquida e molhabilidade muito próxima daquela do modelo integral, Fig. 6.25, pois as temperaturas, previstas por ambos os modelos, nessa região ficaram muito próximas. As principais diferenças entre as previsões são localizadas na área seca, a jusante da posição de evaporação da água residual e a montante do final do aquecimento.

Os resultados de $T_{s}$ e $U$ para o caso 67A são apresentados na Fig. 6.26. Para $T u=1,9 \%$ foram encontrados desvios aceitáveis entre os resultados do modelo diferencial e os dados experimentais. O início e o término da região de transição foi prevista automaticamente por meio de correlações algébricas. O modelo integral requereu $T u=2.7 \%$, como mostrado na Tabela 6.11, para atingir resultados aceitáveis de $T_{s}$. Todavia, enquanto o modelo diferencial previu menores desvios nas previsões $h_{a r}$ e $U$, o modelo integral $T_{s}$ mais próxima dos dados experimentais. Em termos de vazão de água residual, Fig. 6.27, o modelo diferencial previu uma posição de evaporação da água mais a jusante do que os resultados do modelo integral e do ANTICE.

Para a simulação do caso 67B, definida na Tabela 6.12, foram adotados níveis de turbulência de $3 \%$ e $4,1 \%$ para os modelos diferencial e integral, respectivamente. Como apresentado na Fig. 6.28, os resultados do modelo diferencial ficaram mais próximos dos dados experimentais e dos resultados do ANTICE do que os resultados do modelo integral. Não foi possível encontrar um nível de turbulência que aproximassem mais os resultados do modelo integral dos dados experimentais. Os resultados de vazão de água líquida fornecida por ambos os modelos ficaram próxi- 
mos entre si e abaixo daqueles do ANTICE, Fig. 6.29. Todavia, a taxa de congelamento inicial prevista pelo modelo diferencial foi de 0,29 e 0,33 g/s no extradorso e intradorso; e aquela prevista pelo integral foi de 0,26 e 0,31 g/s, como apresentado na Tabela 6.15.

Tabela 6.13: Conservação da Massa - Escoamento de Água Residual - Caso 22A

\begin{tabular}{crr}
\multicolumn{3}{c}{ Diferencial } \\
\hline & extradorso & intradorso \\
\hline$\dot{m}_{\text {evap }}, \mathrm{kg} / \mathrm{s}$ & $0,266 E-03$ & $0,267 E-03$ \\
$\dot{m}_{\text {imp }}, \mathrm{kg} / \mathrm{s}$ & $0,266 E-03$ & $0,267 E-03$ \\
$\left(\dot{m}_{\text {evap }}-\dot{m}_{\text {imp }}\right), \mathrm{kg} / \mathrm{s}$ & $-0,542 E-19$ & $0,108 E-18$ \\
$\dot{m}_{r}, \mathrm{~kg} / \mathrm{s}$ & $0,000 E+00$ & $0,000 E+00$ \\
$\dot{m}_{g e l o}, \mathrm{~kg} / \mathrm{s}$ & $0,000 E+00$ & $0,000 E+00$ \\
$s_{i m p} / c$ & $0,267 E-01$ & $-0,285 E-01$ \\
$s_{s e c o} / c$ & $0,243 E-01$ & $-0,231 E-01$ \\
\hline
\end{tabular}

\begin{tabular}{crr}
\multicolumn{3}{c}{ Integral } \\
\hline & extradorso & intradorso \\
\hline$\dot{m}_{\text {evap }}, \mathrm{kg} / \mathrm{s}$ & $0,254 E-03$ & $0,255 E-03$ \\
$\dot{m}_{\text {imp }}, \mathrm{kg} / \mathrm{s}$ & $0,254 E-03$ & $0,255 E-03$ \\
$\left(\dot{m}_{\text {evap }}-\dot{m}_{\text {imp }}\right), \mathrm{kg} / \mathrm{s}$ & $0,000 E+00$ & $-0,542 E-19$ \\
$\dot{m}_{r}, \mathrm{~kg} / \mathrm{s}$ & $0,000 E+00$ & $0,000 E+00$ \\
$\dot{m}_{g e l o}, \mathrm{~kg} / \mathrm{s}$ & $0,000 E+00$ & $0,000 E+00$ \\
$s_{\text {imp }} / c$ & $0,270 E-01$ & $-0,290 E-01$ \\
$s_{s e c o} / c$ & $0,250 E-01$ & $-0,250 E-01$ \\
\hline
\end{tabular}

Tabela 6.14: Conservação da Massa - Escoamento de Água Residual - Caso 67A

\begin{tabular}{crr}
\multicolumn{3}{c}{ Diferencial } \\
\hline & extradorso & intradorso \\
\hline$\dot{m}_{\text {evap }}, \mathrm{kg} / \mathrm{s}$ & $0,533 E-03$ & $0,533 E-03$ \\
$\dot{m}_{\text {imp }}, \mathrm{kg} / \mathrm{s}$ & $0,533 E-03$ & $0,533 E-03$ \\
$\left(\dot{m}_{\text {evap }}-\dot{m}_{\text {imp }}\right), \mathrm{kg} / \mathrm{s}$ & $-0,108 E-18$ & $0,108 E-18$ \\
$\dot{m}_{r}, \mathrm{~kg} / \mathrm{s}$ & $0,000 E+00$ & $0,000 E+00$ \\
$\dot{m}_{\text {gelo }}, \mathrm{kg} / \mathrm{s}$ & $0,000 E+00$ & $0,000 E+00$ \\
$s_{\text {imp }} / c$ & $0,368 E-01$ & $-0,368 E-01$ \\
$s_{\text {seco }} / c$ & $0,685 E-01$ & $-0,661 E-01$ \\
\hline
\end{tabular}

\begin{tabular}{crr}
\multicolumn{3}{c}{ Integral } \\
\hline & extradorso & intradorso \\
\hline$\dot{m}_{\text {evap }}, \mathrm{kg} / \mathrm{s}$ & $0,522 E-03$ & $0,522 E-03$ \\
$\dot{m}_{\text {imp }}, \mathrm{kg} / \mathrm{s}$ & $0,522 E-03$ & $0,522 E-03$ \\
$\left(\dot{m}_{\text {evap }}-\dot{m}_{\text {imp }}\right), \mathrm{kg} / \mathrm{s}$ & $-0,108 E-18$ & $0,000 E+00$ \\
$\dot{m}_{r}, \mathrm{~kg} / \mathrm{s}$ & $0,000 E+00$ & $0,000 E+00$ \\
$\dot{m}_{g e l o}, \mathrm{~kg} / \mathrm{s}$ & $0,000 E+00$ & $0,000 E+00$ \\
$s_{i m p} / c$ & $0,369 E-01$ & $-0,369 E-01$ \\
$s_{s e c o} / c$ & $0,767 E-01$ & $-0,741 E-01$ \\
\hline
\end{tabular}

Tabela 6.15: Conservação da Massa - Escoamento de Água Residual - Caso 67B

\begin{tabular}{crr} 
& \multicolumn{3}{c}{ Diferencial } \\
\hline & extradorso & intradorso \\
\hline$\dot{m}_{\text {evap }}, \mathrm{kg} / \mathrm{s}$ & $0,508 E-03$ & $0,508 E-03$ \\
$\dot{m}_{i m p}, \mathrm{~kg} / \mathrm{s}$ & $0,218 E-03$ & $0,175 E-03$ \\
$\left(\dot{m}_{\text {evap }}-\dot{m}_{i m p}\right), \mathrm{kg} / \mathrm{s}$ & $0,290 E-03$ & $0,334 E-03$ \\
$\dot{m}_{r}, \mathrm{~kg} / \mathrm{s}$ & $0,000 E+00$ & $0,000 E+00$ \\
$\dot{m}_{g e l o}, \mathrm{~kg} / \mathrm{s}$ & $0,290 E-03$ & $0,334 E-03$ \\
$s_{g e l o} / \mathrm{c}$ & $0,115 E+00$ & $-0,104 E+00$ \\
$s_{i m p} / c$ & $0,384 E-01$ & $-0,384 E-01$ \\
$s_{s e c o} / \mathrm{c}$ & $0,115 E+00$ & $-0,104 E+00$ \\
\hline
\end{tabular}

\begin{tabular}{crr}
\multicolumn{3}{c}{ Integral } \\
\hline & extradorso & intradorso \\
\hline$\dot{m}_{\text {evap }}, \mathrm{kg} / \mathrm{s}$ & $0,508 E-03$ & $0,508 E-03$ \\
$\dot{m}_{i m p}, \mathrm{~kg} / \mathrm{s}$ & $0,243 E-03$ & $0,199 E-03$ \\
$\left(\dot{m}_{\text {evap }}-\dot{m}_{i m p}\right), \mathrm{kg} / \mathrm{s}$ & $0,265 E-03$ & $0,309 E-03$ \\
$\dot{m}_{r}, \mathrm{~kg} / \mathrm{s}$ & $0,000 E+00$ & $0,000 E+00$ \\
$\dot{m}_{g e l o}, \mathrm{~kg} / \mathrm{s}$ & $0,265 E-03$ & $0,309 E-03$ \\
$s_{g e l o} / c$ & $0,113 E+00$ & $-0,101 E+00$ \\
$s_{i m p} / c$ & $0,384 E-01$ & $-0,384 E-01$ \\
$s_{s e c o} / c$ & $0,113 E+00$ & $-0,101 E+00$ \\
\hline
\end{tabular}

Os resultados da conservação da massa aplicada ao escoamento de água líquida residual são apresentados nas Tabelas 6.13, 6.14 e 6.15, respetivamente para os casos 22A, 67A e 67B. A diferença entre a vazão de água captada e a evaporada resulta em: 1) zero, se o regime é evaporativo; 2) na vazão de água residual, se a água escoa a jusante da área protegida, mas não congela; 3) na taxa de congelamento inicial, se a água escoa a jusante da área protegida e congela. A posição do final da captação, de evaporação da água ou de seu congelamento também são apresentados nas mesmas tabelas. 


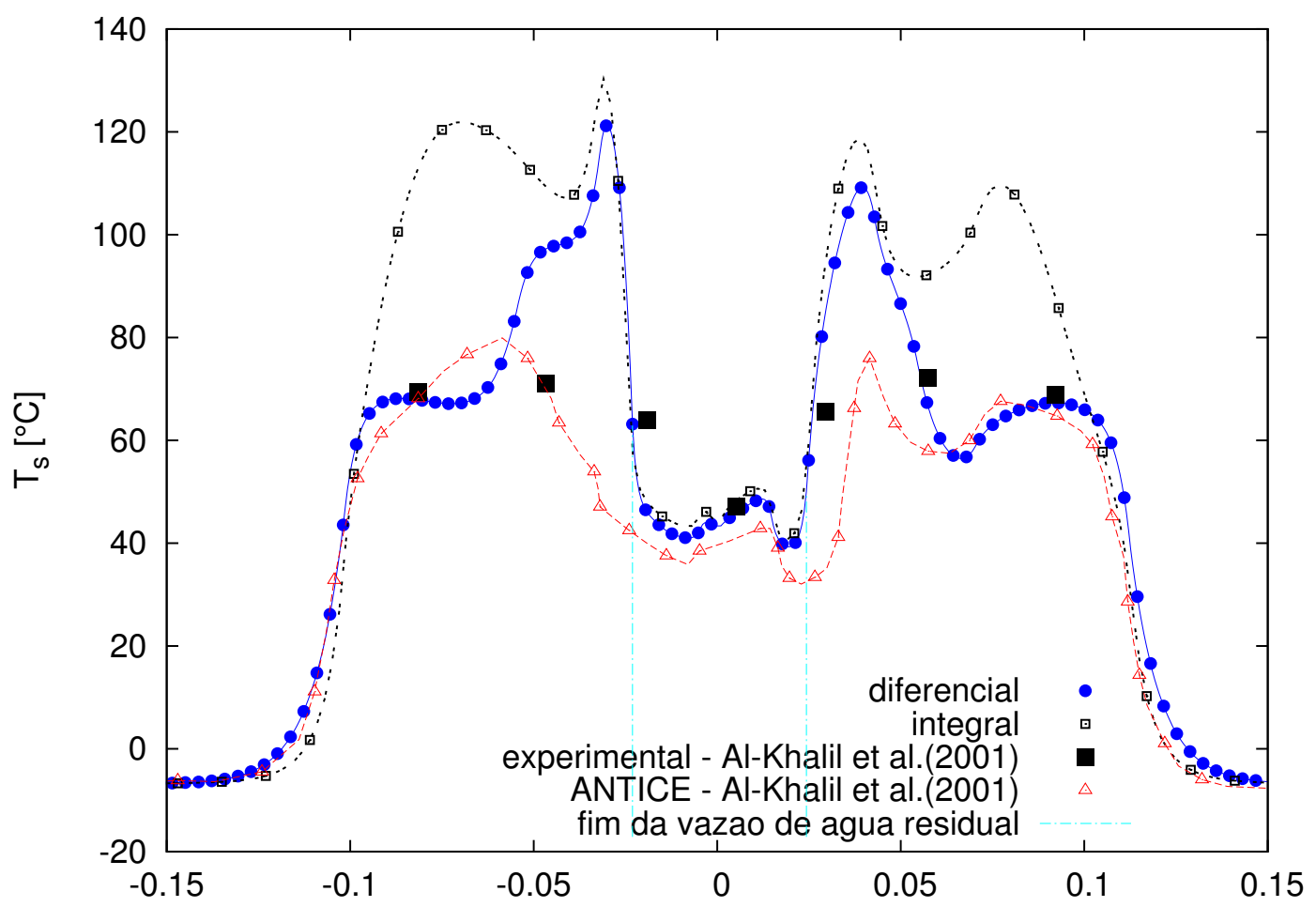

(a) Temperatura de Superfície - $T_{s}$ - Caso 22A

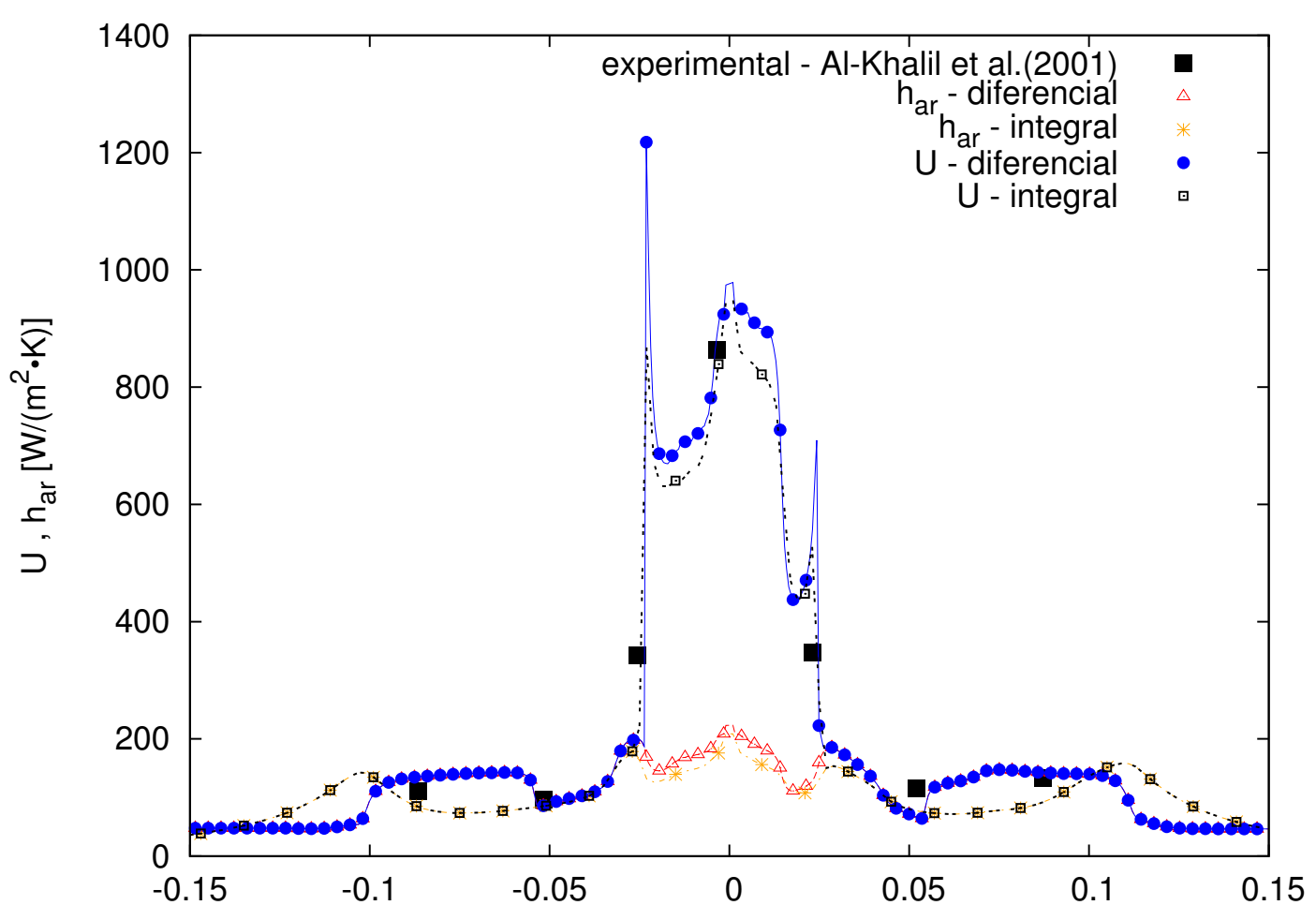

(b) Coeficientes de Transferência de Calor - U e $h_{a r}$ - Caso 22A

Figura 6.24: Resultados de Temperatura e Transferência de Calor - Caso 22A 


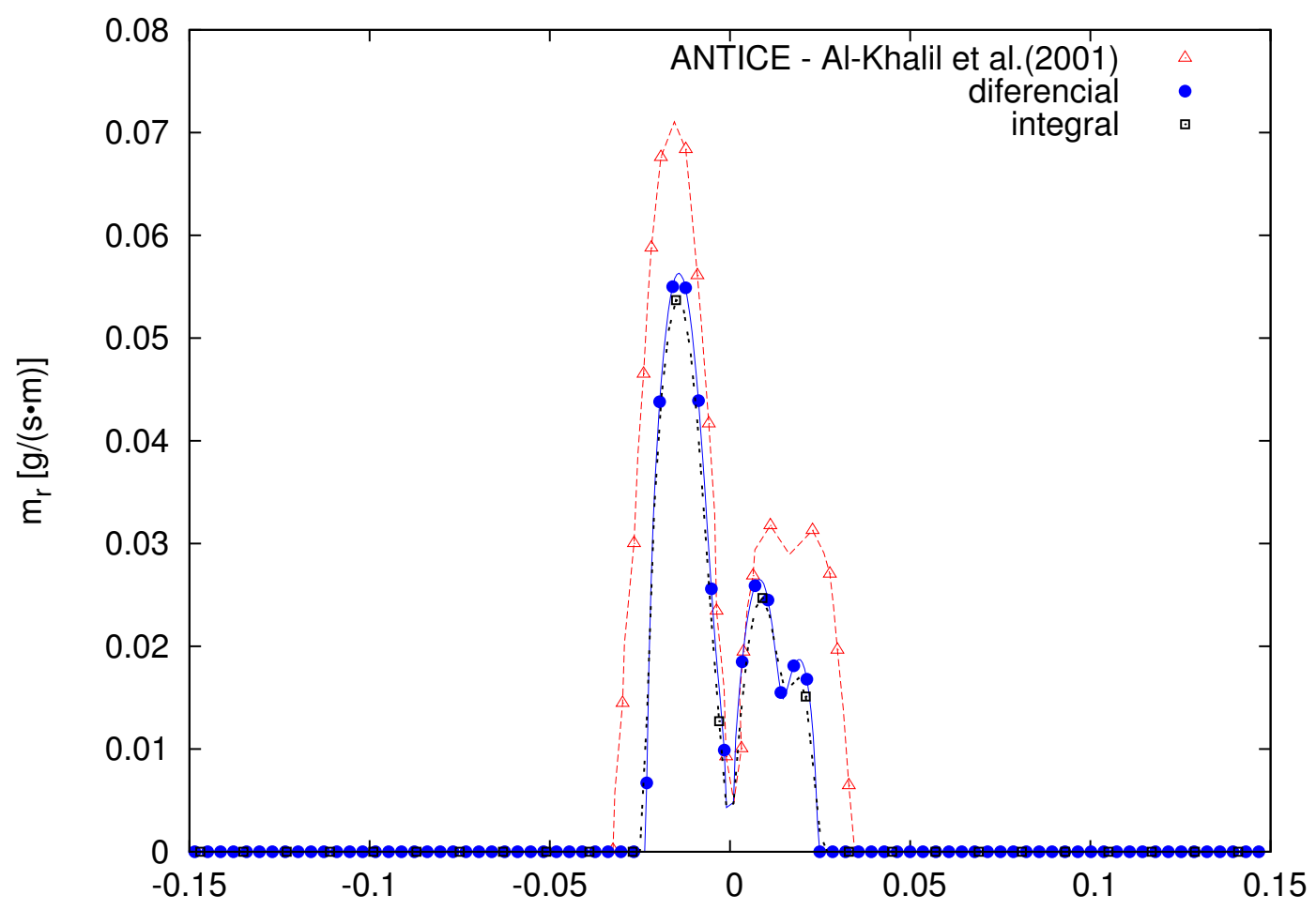

(a) Vazão de Água - $\dot{m}_{r}^{\prime}$ - Caso 22A

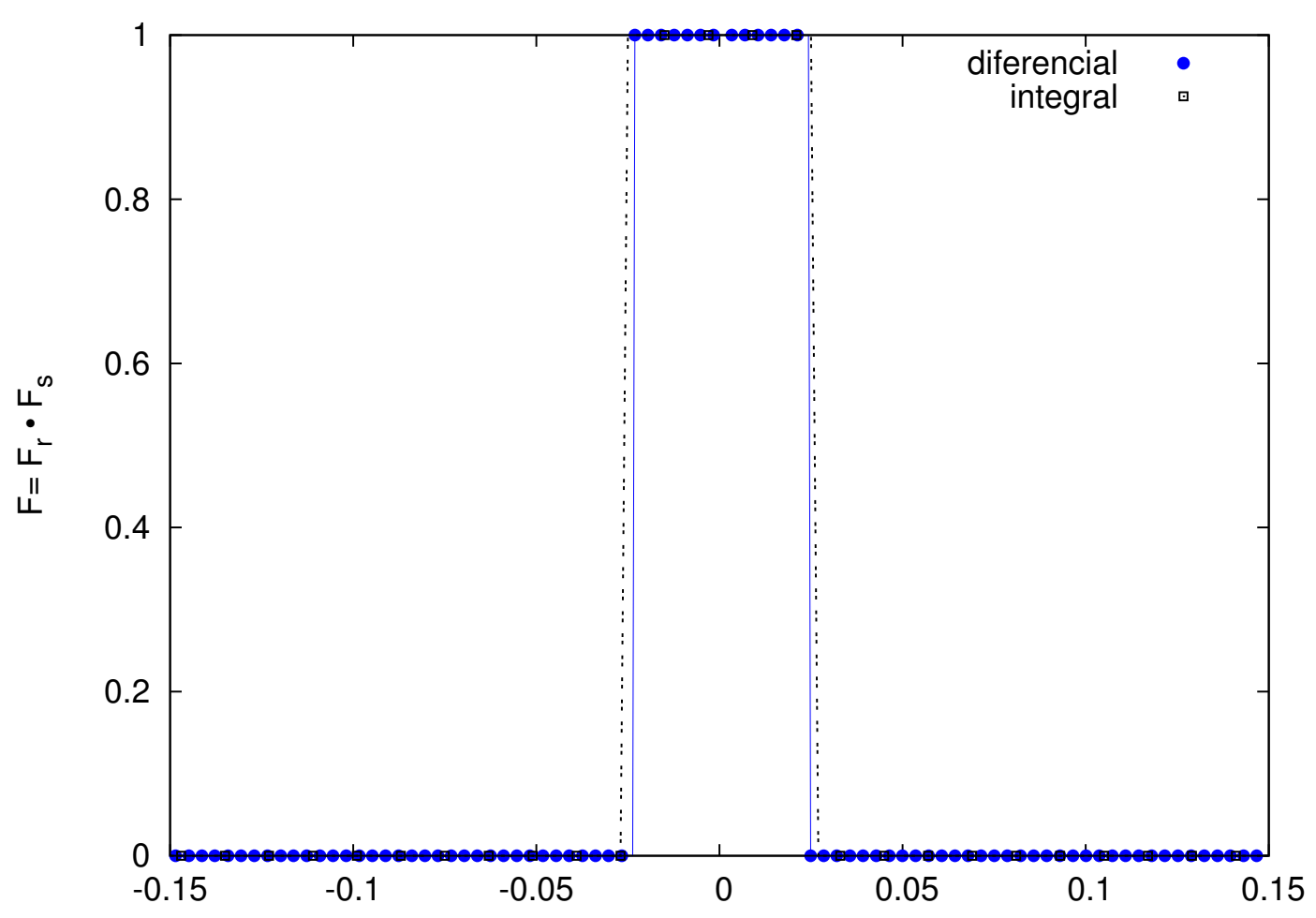

(b) Molhablidade da Superfície - F - Caso 22A

Figura 6.25: Resultados do Escoamento da Água Residual - Caso 22A 


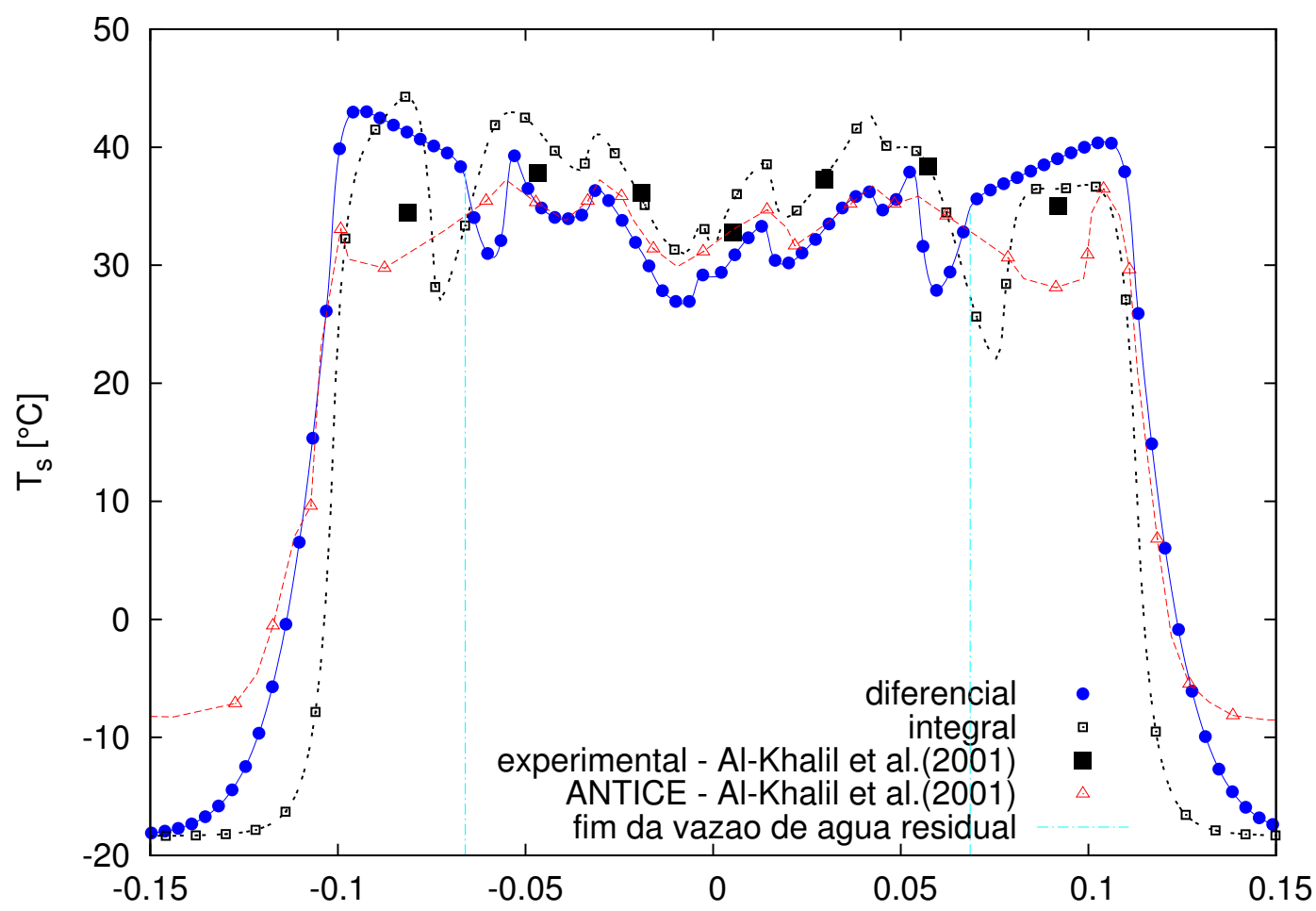

(a) Temperatura de Superfície - $T_{s}$ - Caso 67A

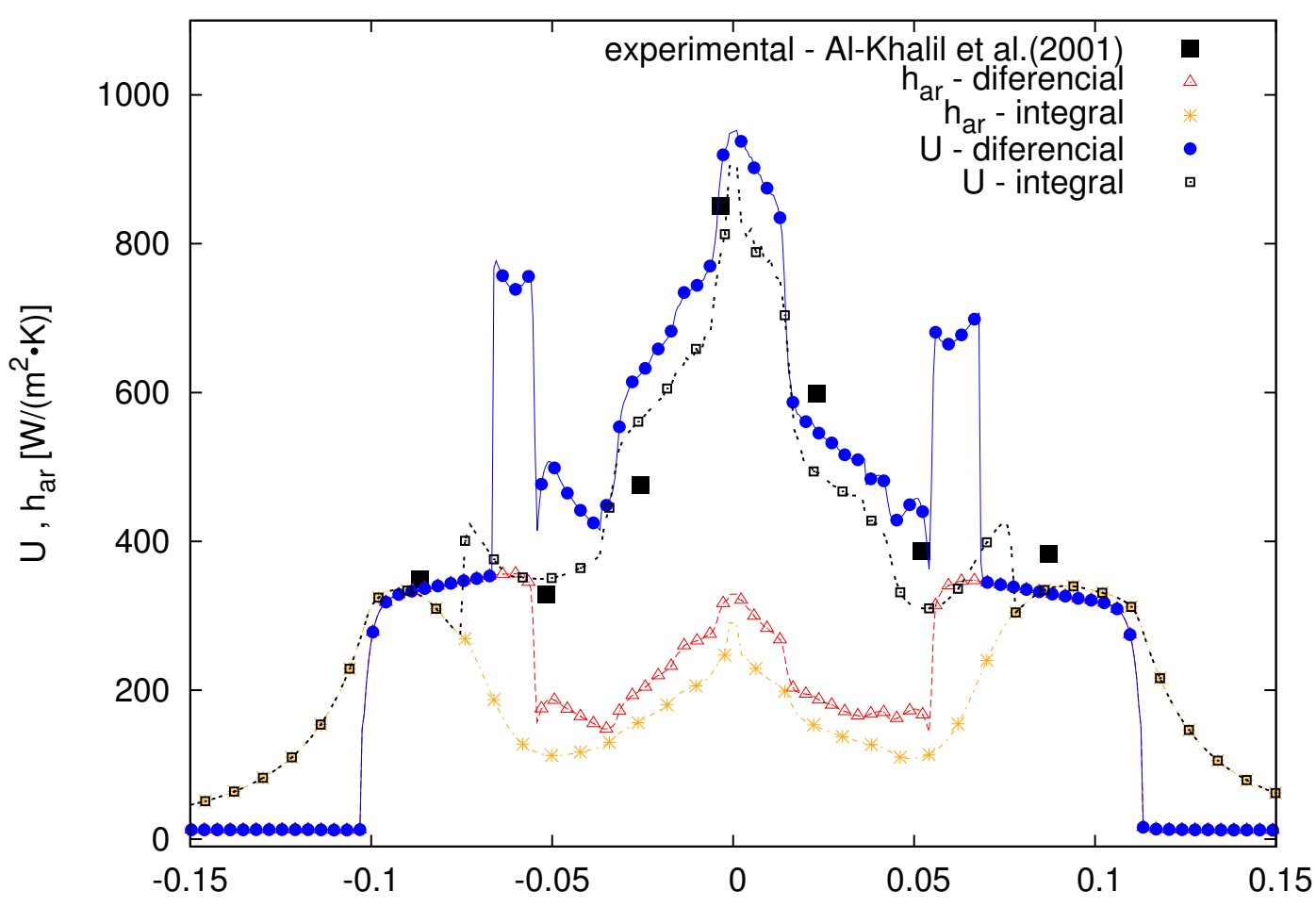

(b) Coeficientes de Transferência de Calor - U e $h_{a r}$ - Caso 67A

Figura 6.26: Resultados de Temperatura e Transferência de Calor - Caso 67A 


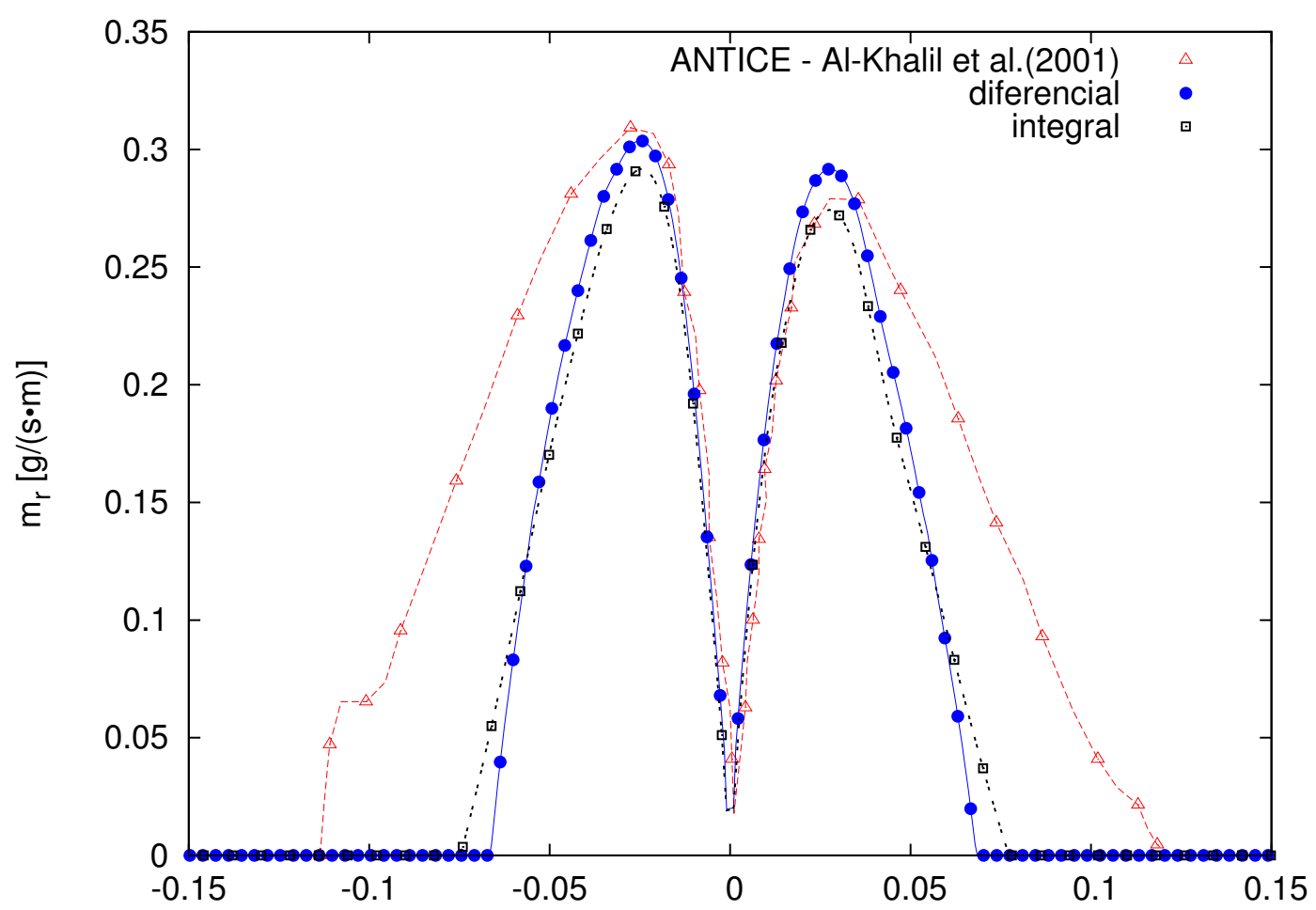

(a) Vazão de Água - $\dot{m}_{r}^{\prime}$ - Caso 67A

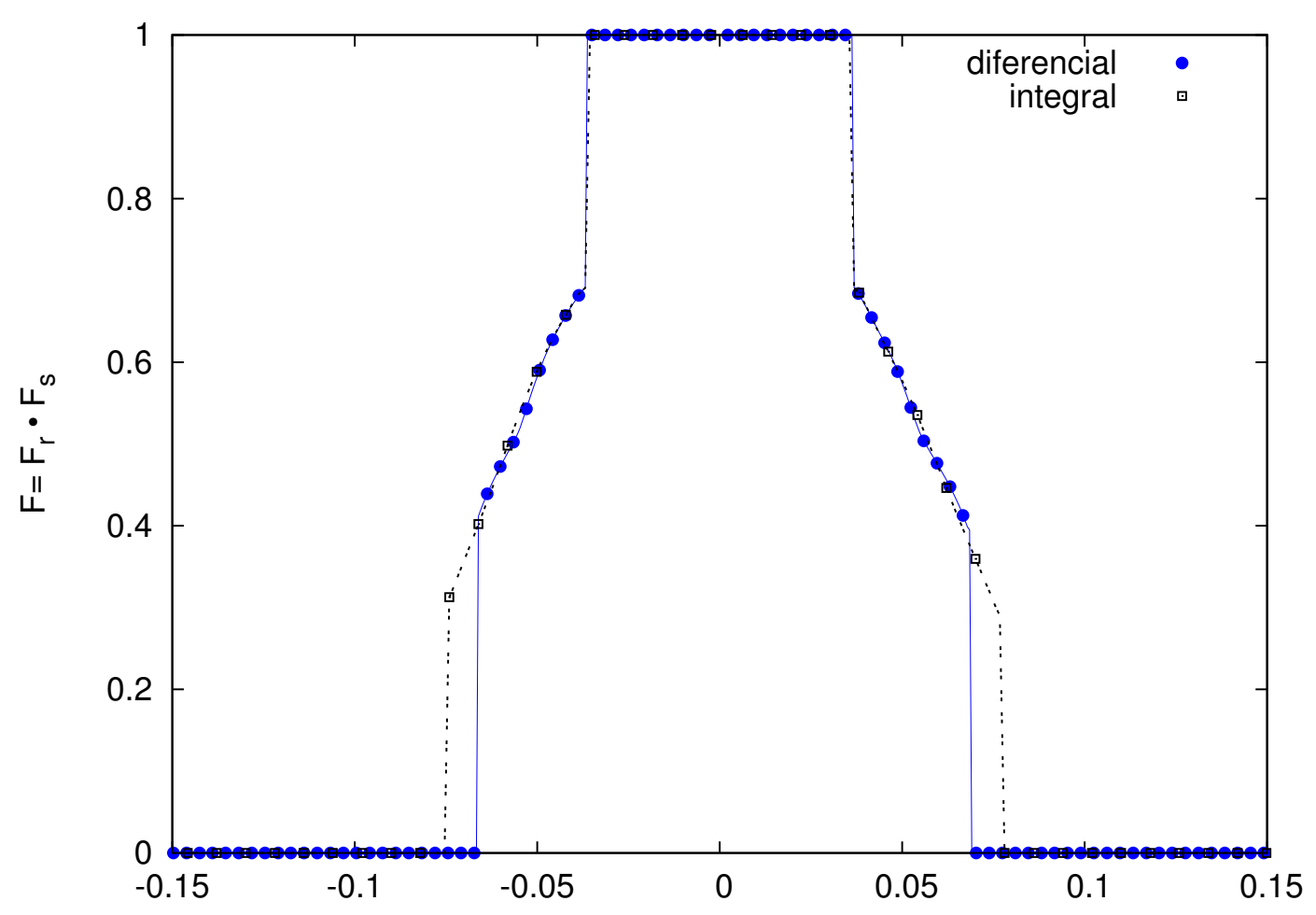

(b) Molhablidade da Superfície - F - Caso 67A

Figura 6.27: Resultados do Escoamento da Água Residual - Caso 67A 


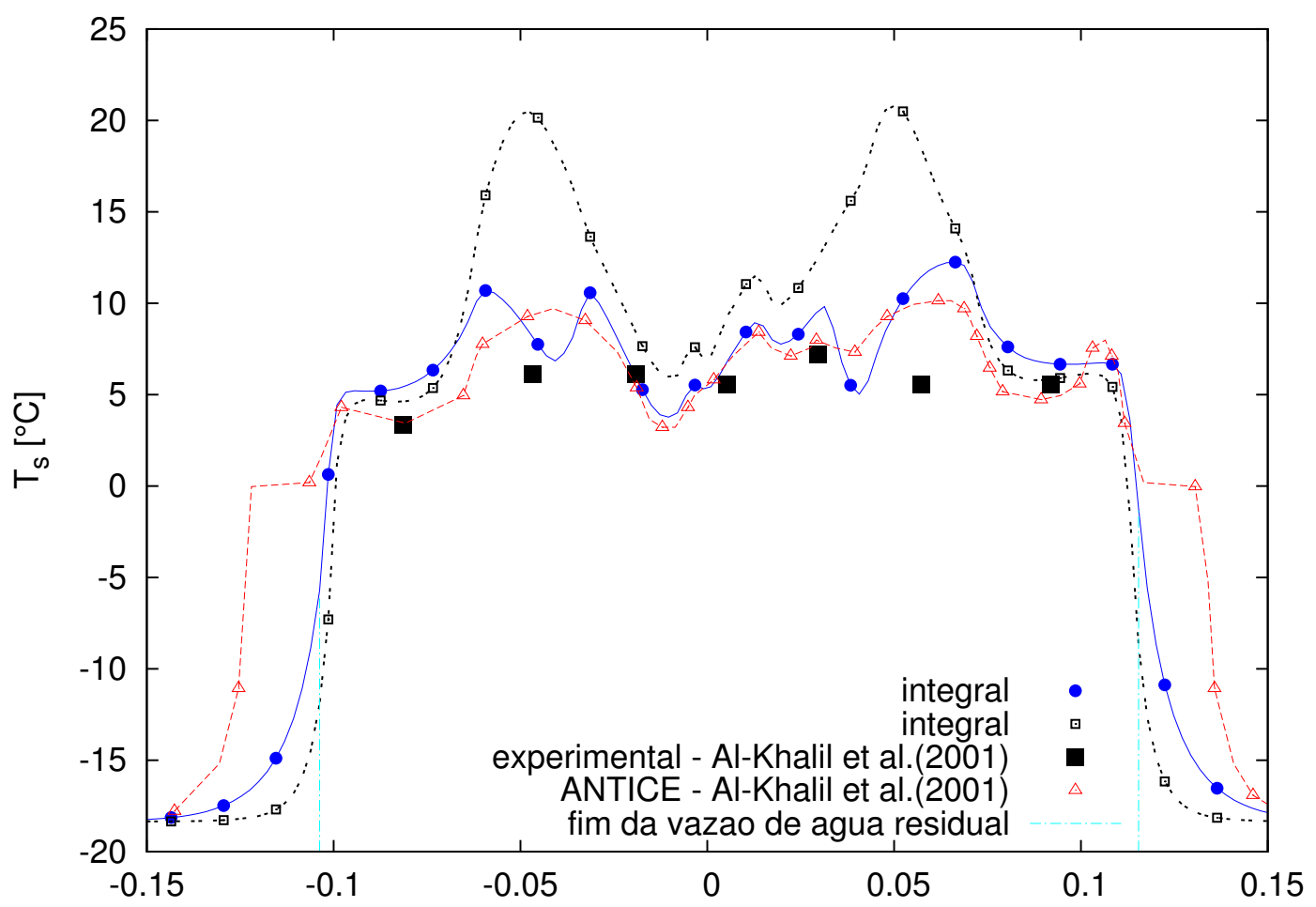

(a) Temperatura de Superfície - $T_{s}$ - Caso 67B

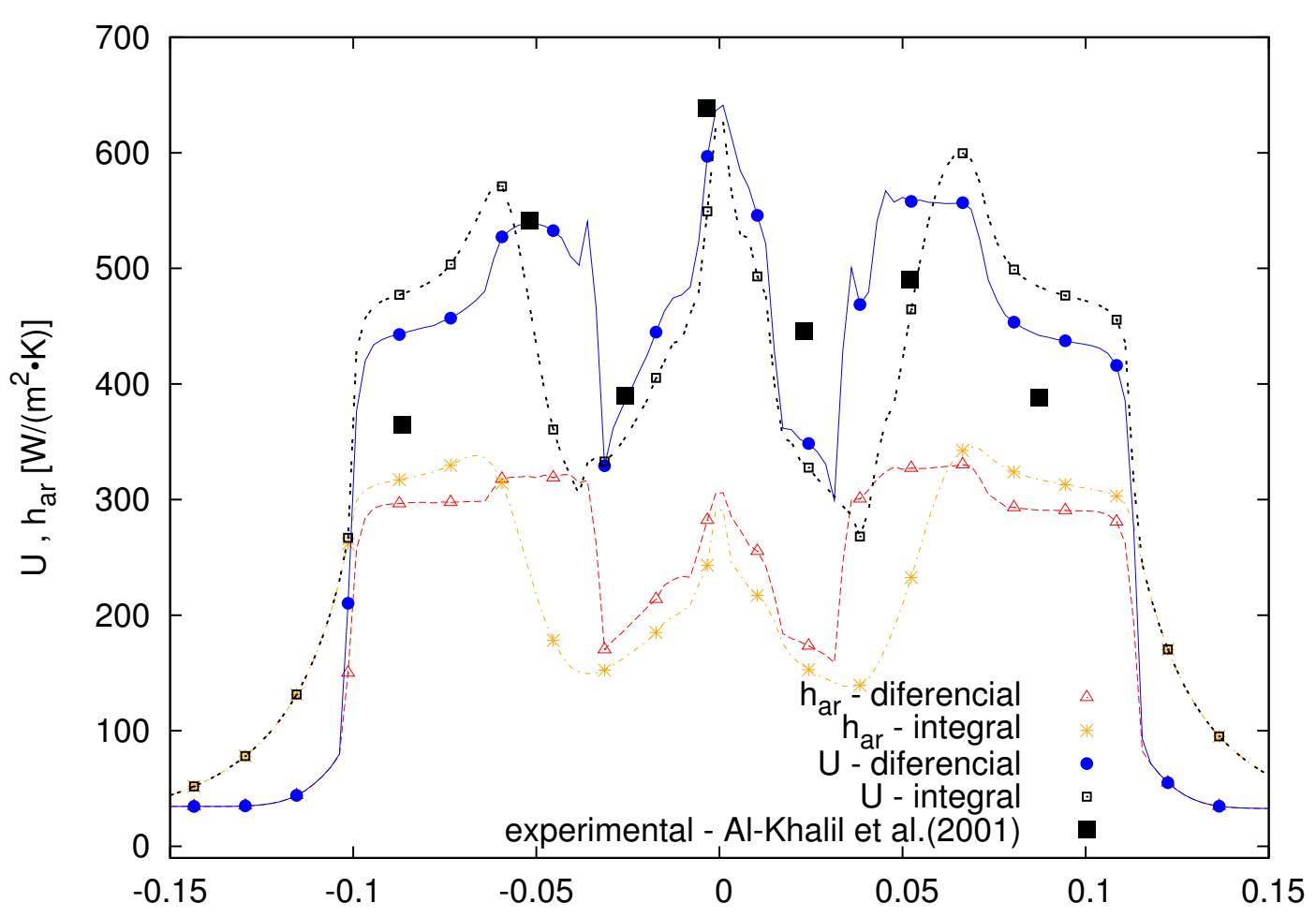

(b) Coeficientes de Transferência de Calor - $U$ e $h_{a r}$ - Caso 67B

Figura 6.28: Resultados de Temperatura e Transferência de Calor - Caso 67B 


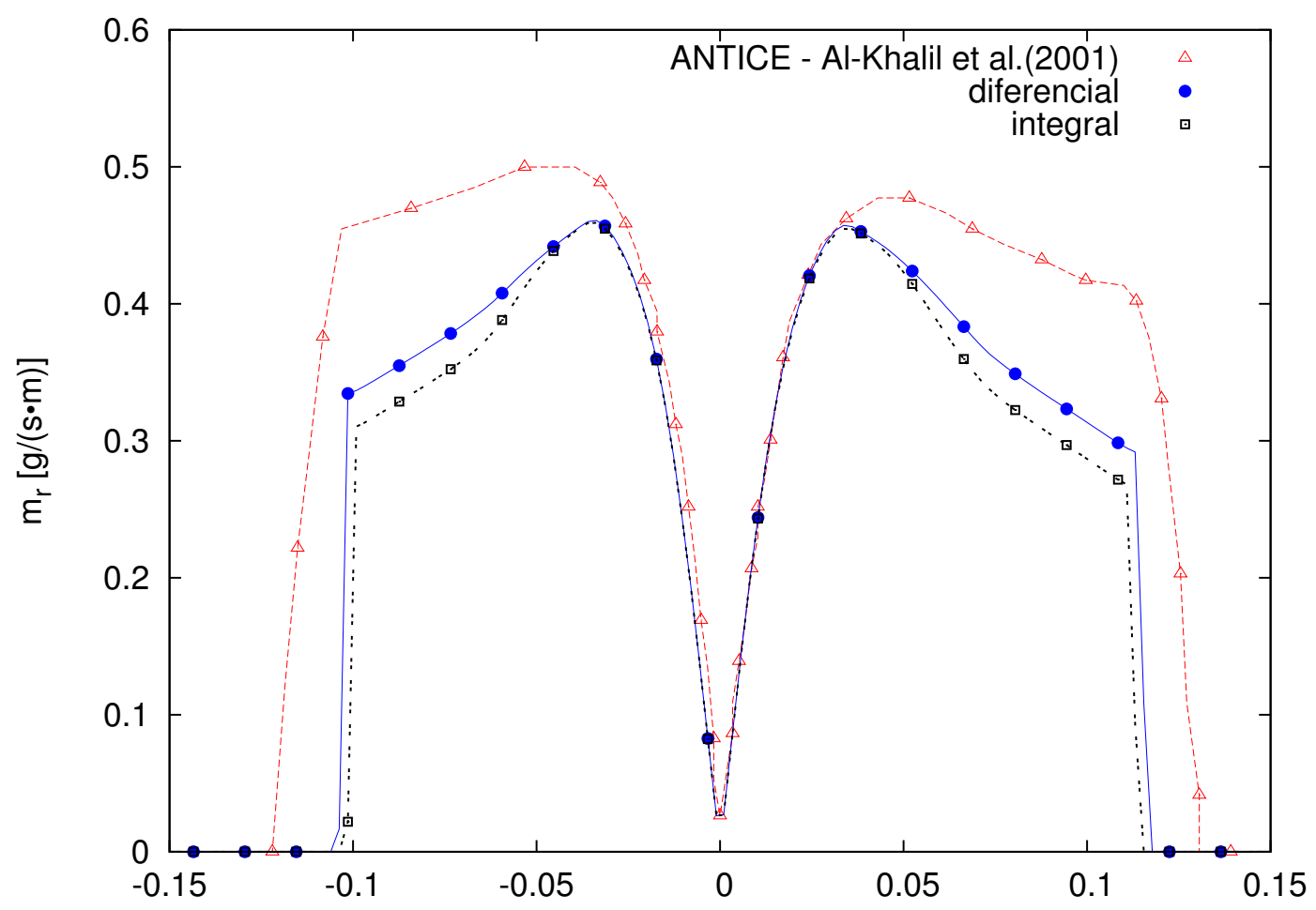

(a) Vazão de Água - $\dot{m}_{r}^{\prime}$ - Caso 67B

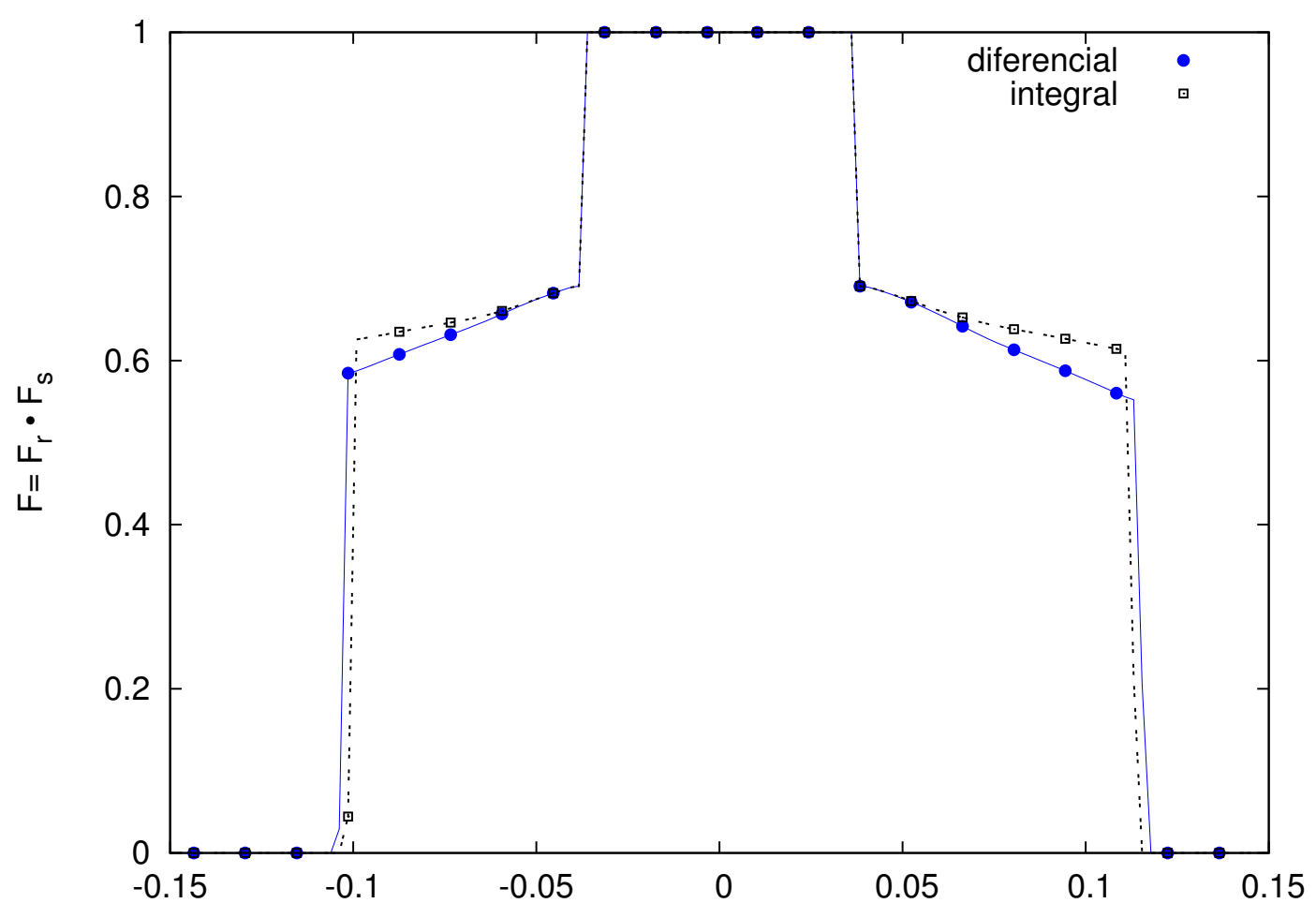

(b) Molhablidade da Superfície - F - Caso 67B

Figura 6.29: Resultados do Escoamento da Água Residual - Caso 67B 


\subsubsection{Análise de Demanda Térmica e da Área Protegida}

A previsão das temperaturas máximas da região seca e aquecida é importante para o projeto de sistemas antigelo, pois possibilita a seleção de materiais e análise de tensões dos aquecedores e da estrutura da asa. Já a previsão das temperaturas na região molhada pelo escoamento de água residual é requerida para a estimativa da demanda térmica para dimensionamento da capacidade do sistema antigelo. Devido a necessidade de economizar potência elétrica, as áreas secas são minimizadas no projeto para aeronaves comerciais. A situação ideal é aquela atingida pela condição operacional do caso 67A, que tem a maior parte da área protegida coberta pelo escoamento de água. No entanto, o projeto de sistemas deve evitar, o quanto possível, a ocorrência de um condição operacional com aquela do caso 67B, que apresenta formação de gelo decorrente da vazão de água para regiões a jusante da área protegida.

Dois parâmetros de projeto são a definição da área protegia e da densidade de potência elétrica a ser dissipada nos aquecedores. Simplificadamente, a área protegida está relacionada com a extensão molhada pelo escoamento de água, ou seja, pela capacidade de evaporação a montante do final do aquecimento. Já a demanda térmica está ligada a transferência de calor entre a superfície do aerofólio e o escoamento externo, principalmente os efeitos de convecção e evaporação de água.

No presente trabalho, o sistema de antigelo e suas condições operacionais, dos casos experimentais de Al-Khalil et al. (2001), já foram definidos previamente por AlKhalil et al. (2001). Logo, resta apenas estimar as margens de projeto do sistema já construído. No caso de um novo sistema, o presente trabalho poderia servir para apoiar a definição da área protegia e a potência elétrica fornecida, a partir de uma matriz de casos críticos operacionais.

Tabela 6.16: Análise do Fluxo de Calor Requerido e Fornecido

\begin{tabular}{lrrrrrrrr}
\hline caso & $\begin{array}{c}\dot{q}_{\text {tot }} \\
\mathrm{kW}\end{array}$ & $\begin{array}{c}\overline{\dot{q}}^{\prime \prime}{ }_{\text {tot }} \\
\mathrm{kW} / \mathrm{m}^{2}\end{array}$ & $\begin{array}{c}\dot{\bar{q}}^{\prime \prime}{ }_{\text {agua }} \\
\mathrm{kW} / \mathrm{m}^{2}\end{array}$ & $\begin{array}{c}\dot{q}_{\text {req }} \\
\mathrm{kW}\end{array}$ & $\begin{array}{c}\dot{\dot{q}}^{\prime \prime}{ }_{\text {req }} \\
\mathrm{kW} / \mathrm{m}^{2}\end{array}$ & $\begin{array}{c}\dot{q}_{\text {req }} / \dot{q}_{\text {tot }} \\
\%\end{array}$ & $\begin{array}{c}\Delta \dot{q}_{\text {req }} \\
\%\end{array}$ & $\begin{array}{c}\Delta \dot{q}_{\text {evap }} \\
\%\end{array}$ \\
\hline 22A diferencial & 3,2 & 16,4 & 33,5 & 1,6 & 36,8 & 49,3 & 102,8 & 142,7 \\
22A integral & 3,3 & 16,7 & 33,5 & 1,6 & 35,3 & 49,2 & 103,3 & 157,5 \\
67A diferencial & 4,7 & 23,8 & 26,7 & 3,8 & 30,9 & 81,2 & 23,1 & 75,6 \\
67A integral & 4,7 & 24,0 & 26,1 & 3,6 & 25,8 & 75,5 & 32,4 & 80,5 \\
67B diferencial & 2,1 & 10,4 & 10,3 & 2,4 & 11,9 & 116,4 & $-14,1$ & $-19,1$ \\
67B integral & 2,1 & 10,4 & 10,5 & 2,5 & 12,8 & 121,7 & $-17,9$ & $-19,1$ \\
\hline
\end{tabular}

A Tabela 6.16 apresenta, para cada caso simulado: o fluxo de calor fornecido pelo antigelo( $\left.\dot{q}_{t o t}\right)$; a densidade de potência média para a região molhada e a área 
Tabela 6.17: Análise do Escoamento da Água Residual

\begin{tabular}{|c|c|c|c|c|c|c|c|c|}
\hline \multirow[b]{2}{*}{ Caso } & \multicolumn{4}{|c|}{ extradorso } & \multicolumn{4}{|c|}{ intradorso } \\
\hline & $\begin{array}{c}s_{r} \\
\mathrm{~mm}\end{array}$ & $\begin{array}{l}s_{i m p} \\
\mathrm{~mm}\end{array}$ & $\begin{array}{l}s_{\text {prot }} \\
\mathrm{mm}\end{array}$ & $\begin{array}{c}s_{r} / s_{\text {prot }} \\
\%\end{array}$ & $\begin{array}{c}s_{r} \\
\mathrm{~mm}\end{array}$ & $\begin{array}{l}s_{i m p} \\
\mathrm{~mm}\end{array}$ & $\begin{array}{l}s_{\text {prot }} \\
\mathrm{mm}\end{array}$ & $\begin{array}{c}s_{r} / s_{\text {prot }} \\
\%\end{array}$ \\
\hline 22A diferencial & 22,2 & 24,4 & 103,3 & 21,5 & $-21,1$ & $-26,0$ & $-93,6$ & 22,6 \\
\hline $22 \mathrm{~A}$ integral & 22,9 & 24,7 & 103,3 & 22,1 & $-22,9$ & $-26,5$ & $-93,6$ & 24,4 \\
\hline 67A diferencial & 62,6 & 33,7 & 103,3 & 60,6 & $-60,4$ & $-33,7$ & $-93,6$ & 64,6 \\
\hline 67A integral & 70,2 & 33,7 & 103,3 & 68,0 & $-67,7$ & $-33,7$ & $-93,6$ & 72,4 \\
\hline 67B diferencial & 105,6 & 35,1 & 103,3 & 102,2 & $-94,9$ & $-35,1$ & $-93,6$ & 101,4 \\
\hline 67B integral & 103,4 & 35,1 & 103,3 & 100,2 & $-92,7$ & $-35,1$ & $-93,6$ & 99,1 \\
\hline
\end{tabular}

protegida ( ${\overline{\dot{q}^{\prime \prime}}}_{\text {tot }},{\overline{\dot{q}^{\prime \prime}}}_{\text {agua }}$ ); o fluxo de calor estimado para evaporar toda a água $\left(\dot{q}_{\text {req }}\right)$; e a densidade média de fluxo de calor dentro da área molhada $\left({\overline{\dot{q}^{\prime \prime}}}_{\text {req }}\right)$.

Além desses resultados integrais, a Tabela 6.16 apresenta três indicadores de eficiência e de margem de projeto:

- $\frac{\dot{q}_{\text {req }}}{\dot{q}_{\text {tot }}}$, que indica a proporção entre o fluxo de calor requerido (demanda) e o fornecido pelo sistema antigelo;

- $\Delta \dot{q}_{\text {req }}=\frac{\dot{q}_{\text {tot }}-\dot{q}_{\text {req }}}{\dot{q}_{\text {req }}}$, que indica a margem de projeto do sistema antigelo em relação a demanda das condições analisadas;

- $\Delta \dot{q}_{\text {evap }}=\frac{\dot{q}_{\text {tot }}-\sum \dot{m}_{\text {imp }} \cdot \dot{i}_{V}}{\sum \dot{m}_{\text {imp }} \cdot \dot{i}_{V}}$, que indica a margem de projeto do sistema antigelo em relação ao requerido para evaporar toda a água captada pelo aerofólio.

A Tabela 6.17 apresenta os limites de captação de proteção térmica e evaporação (casos 22A e 67A) ou congelamento (caso 67B) da água residual. A relação entre o comprimento coberto pelo escoamento da água residual e o comprimento aquecido está relacionado com a margem de dimensionamento da área protegida. Essa relação, dada por $s_{r} / s_{\text {prot }}$, é mostrada na Tabela 6.17 para o extradorso e intradorso do aerofólio. A condição operacional do caso $22 \mathrm{~A}$ apresenta uma margem bem significativa e, talvez, sobreestimada. Por outro lado, a condição do caso 67B não possui nenhuma margem e apresenta congelamento. $\mathrm{O}$ caso $67 \mathrm{~A}$ apresenta uma margem mais otimizada que as outras duas, já que permite economizar potência elétrica sem prejudicar a prevenção contra formação de gelo.

\subsection{Comentários}

Os resultados do presente modelo ficaram mais próximos dos dados experimentais, para os casos-teste selecionados, tão próximos quanto o ANTICE, que Al-Khalil 
et al. (2001) desenvolveu para a NASA, EUA, e que usou a distribuição de coeficiente de transferência de calor experimental, medida durante os próprios testes.

As previsões numéricas apresentaram desvios menores em relação aos dados experimentais para todos os casos simulados, quando os seguintes submodelos foram adotados:

- escoamento de água líquida residual: ruptura de filme e formação de filetes de água líquida residual por meio do critério da Energia Total Mínima (ETM);

- escoamento na camada-limite: análise diferencial e compressível por meio da solução por média de Reynolds das equações acopladas de quantidade de movimento, energia e turbulência;

- transição laminar-turbulenta: previsão de início e término da região de transição por meio de correlação algébrica que considera os efeitos de gradiente de pressão e nível de turbulência do escoamento ao longe; 


\section{Conclusões e Próximos TRABALHOS}

\subsection{Conclusões}

O objetivo do presente trabalho foi atingido pois o modelo matemático de desempenho térmico de aerofólios com sistemas de antigelo, desenvolvido na presente tese, foi capaz de prever a transferência de calor e de massa no escoamento bidimensional bifásico em torno de aerofólios de uso aeronáutico equipados com sistema de antigelo térmico, que operam em regime permanente e sob condições de formação de gelo. O simulador, aqui desenvolvido, foi capaz de:

1) estimar a molhabilidade da superfície em torno do aerofólio considerando o padrão de escoamento de filme contínuo e filetes para a água líquida residual;

2) avaliar as camadas-limite dinâmica e térmica, nos regimes laminar, transicional e turbulento, em torno do aerofólio com superfície lisa, não-isotérmica e com transpiração por meio de modelos integrais e diferenciais;

3) estimar a posição de início ("onset") e término da região de transição laminarturbulenta das camadas-limite dinâmica e térmica por meio de correlações que consideram efeitos do gradiente de pressão e do nível de turbulência ao longe;

4) fornecer resultados numéricos, de temperatura de superfície e coeficiente de transferência de calor, com desvios menores ou iguais em relação ao dados experimentais do que os resultados dos trabalhos anteriores ou aqueles dos códigos clássicos, como o ANTICE da NASA, que utilizou os dados experimentais de transferência de calor e não calculou a camada-limite em torno do aerofólio.

Outros resultados importantes para o projeto de sistemas antigelo eletrotérmicos, obtidos pelo modelo do escoamento bifásico em torno de aerofólios com antigelo, foram as estimativas de potência elétrica requerida, de área coberta pelo escoamento de água residual líquida e das eventuais posições de congelamento. 
Resumidamente, a presente tese preencheu as lacunas de modelagem deixadas por trabalhos anteriores e de outros autores, pois implementou conjuntamente submodelos de molhabilidade, analise diferencial de camada-limite e previsão de transição laminar-turbulenta no modelo-base do aerofólio com sistema térmico de antigelo. O novo modelo proposto, formado pelo modelo-base iniciado no mestrado e pelas contribuições incluídas na tese de doutorado, foi capaz de representar a transição laminar-turbulenta realisticamente, ou seja, as correlações empíricas conseguiram prever a região de transição sobre o aerofólio. Ao contrário dos modelos anteriores, o presente modelo não precisou de ajuste na posição de início e término da região de transição, já que a transferência de calor inclui efeitos da molhabilidade parcial da superfície e da história de gradiente de pressão e temperaturas de superfície.

Demonstrou-se também que a modelagem da região de transição é importante para obtenção de resultados numéricos mais próximos dos dados experimentais em túneis de formação de gelo, como o Icing Research Tunnel (IRT) do Centro de Pesquisas Glenn, da National Aeronautics and Space Administration (NASA), EUA. Dois trabalhos de mestrado foram originados a partir desta constatação, um que investigou a importância da modelagem da transição na formação de gelo em aerofólios de uso aeronáutico e outro que implementou um modelo de transição diferencial de transporte de intermitência para aplicação de Computational Fluid Dynamics (CFD) em simulações de aerofólios ou entradas de motor com sistemas antigelo.

Como esperado, a escolha de um conjunto de hipóteses adequado para os submodelos mais fundamentais (níveis II, III e IV) resultou em menores desvios entre as previsões numéricas (do modelo do nível I) e os dados experimentais. A melhora na precisão das estimativas de temperatura de superfície e coeficiente de transferência de calor foi devida a implementação ou incorporação de novos submodelos de escoamento de água líquida residual, camada-limite e transição laminar-turbulenta ao modelo do antigelo.

Um aerofólio aquecido operando sob condições de formação de gelo possui algumas características que o diferenciam de um aerofólio adiabático sujeito à formação de gelo. Na presença de proteção térmica para prevenção contra formação de gelo, a adoção de um submodelo de camada-limite sobre superfícies isotérmicas e de uma transição laminar-turbulenta abrupta, hipóteses muito usuais no meio aeronáutico, não representam adequadamente a transferência de calor em torno do aerofólio. $O$ gradiente da temperatura superficial na direção do escoamento e a ocorrência de uma região de transição, dentro da área protegida, são efeitos que devem ser representados adequadamente pelos modelos matemáticos. 
A modelagem matemática do escoamento dos filetes de água residual na região a jusante da captação mostrou-se necessária para prever os parâmetros operacionais nos casos molhados e parcialmente evaporativos, que possuem uma área moIhada significativa em relação a área protegida. Sem a representação dos efeitos dos filetes, a transferência de calor não pode ser calculada de forma satisfatória e os desvios entre as previsões e os dados experimentais foram significativos.

Para prever o início e término da região de transição foram adotadas correlações algébricas desenvolvidas a partir de um conjunto abrangente de dados experimentais e que consideram efeitos do gradiente de pressão e do nível de turbulência ao longe. Essas correlações são largamente utilizadas por códigos numéricos que avaliam transferência de calor em aerofólios de turbinas. Em termos de rotas de transição para a turbulência, as correlações selecionadas cobrem até aproximadamente $10 \%$ de nível de turbulência, ou seja, abrangem desde a transição natural até a de contorno (bypass). O primeiro tipo pode ser encontrado em voos de gelo natural (sob condições atmosféricas de formação de gelo) e o segundo pode ocorrer em túneis de gelo. A necessidade de prever a transição numa faixa abrangente de rotas de transição, fez a escolha do método de previsão recair sobre as correlações algébricas em detrimento da análise linear de estabilidade combinada com o critério do $e^{n}$, que são limitados a um máximo de nível de turbulência de 3, 0\%.

A classificação da modelagem matemática do sistema antigelo ajudou o presente autor a: 1) visualizar o papel de cada submodelo fundamental no modelo da aplicação de engenharia; 2) manter o foco no objetivo final de modelagem, já que a quantidade de submodelos e possibilidade de estudos aumenta em grande número quanto mais fundamental for o nível de modelagem; 3) estabelecer um processo de verificação e validação para o desenvolvimento do código numérico de simulação de antigelo térmico; 4) definir o nível II (modelos de camada-limite) como aquele mais baixo para as implementações realizadas no presente trabalho, já que o nível I foram implementados correlações algébricas ou adotados códigos externos; 5) entender que o nível I (modelos de escoamento) está distante da aplicação final e, muitas vezes, requer desenvolvimentos, experimentos e validações específicas, o que fica inteiramente fora de escopo do presente trabalho. A estratégia de classificação de níveis de modelagem, ora proposta, não foi encontrada na literatura de simulação de sistemas antigelo.

Devido à quantidade de opções de submodelos , foi necessário estabelecer um processo, mesmo que simplificado, de verificação dos resultados dos submodelos e validação dos resultados do modelo do antigelo. O processo mostrou-se útil para verificar se os códigos numéricos estavam fornecendo resultados conforme esperado, 
depurar erros de implementação, identificar limitações nos submodelos e, por fim, entender a relevância de cada hipótese nos resultados dos submodelos e do modelo do antigelo. Sem o processo, seria impossível concluir as causas da melhora da precisão ou, mesmo, as razões dos desvios obtidos.

No presente trabalho, foram estimados o fluxo de calor requerido para a proteção térmica do aerofólio para prevenção de formação de gelo e a área coberta pelo escoamento de água líquida residual. Esses dois parâmetros são fundamentais para o dimensionamento e projeto de sistemas de antigelo aeronáuticos. Como a configuração dos sistemas de antigelo simulados já tinham sido definidos, o presente trabalho propôs índices para analisar as margens de projeto: a proporção entre o fluxo de calor requerido e o fornecido bem como a proporção entre a área coberta pelo escoamento da água e a área protegida termicamente. A proposta deste tipo de análise não foi encontrada na literatura pesquisada.

A escolha de um submodelo de camada-limite diferencial e compressível mostrou-se adequada, pois considerou os efeitos de: 1) acoplamento entre a pressão e a temperatura do escoamento por meio da densidade; 2) variação das temperaturas de superfície; 3) variação do gradiente de pressão. Além disso, com base no processo de verificação realizado, conclui-se que a análise diferencial adotada pode ser utilizada também escoamentos que tenham transição laminar-turbulenta causada por pequenas bolhas de separação laminar ou que sejam compressíveis em alguma posição no intradorso ou extradorso, i.e., Ma local > 0,3. Todavia, o código diferencial de camada-limite apresenta uma limitação, que é comum aos códigos pesquisados no presente trabalho, para simular o escoamento em torno de aerofólios aquecidos operando sob formação de gelo. A camada-limite, no regime laminar e turbulento, não é influenciada pelas condições ambientais de amplitude e frequência das flutuações turbulentas, i.e., pelo nível e escala da turbulência do escoamento em torno do aerofólio.

Três tipos de análise integral de camada-limite foram implementadas: sobre superfície isotérmica, sobre superfície não-isotérmica bem como sobre superfície nãoisotérmica por meio da aplicação do princípio da sobreposição. O primeiro tipo apresentou resultados não satisfatórios para todos os casos simulados em relação as distribuições de $T_{s}$ e $h_{a r}$. É o tipo de análise adotada pelos códigos clássicos de formação de gelo, pois a superfície do gelo é aproximadamente isotérmica. No entanto, o uso desse tipo de análise é aceito pela indústria e consta em alguns manuais de projeto da área de sistemas aeronáuticos de antigelo, apesar de possuírem superfíces com temperatura variável. Já o segundo e o terceiros tipos demonstraram ser aplicáveis à várias condições operacionais, se utilizadas com critério. Os prin- 
cipais desvios entre seus resultados numéricos e as medições experimentais foram observados nas regiões de aceleração do escoamento, logo a jusante da posição de estagnação, e naquelas regiões do escoamento que apresentam gradiente de pressão adverso. A análise sobre superfície não-isotérmica, ora adotada, considerou adequadamente os efeitos das variações de temperatura de superfície sobre o coeficiente de transferência de calor, exceto quando muitas variações de temperatura ocorriam em sequência. Por outro lado, a aplicação do princípio da sobreposição fez as previsões ficaram mais perto dos dados experimentais do que a análise integral sobre superfície não-isotérmica. Todas as análise integrais apresentaram restrições quando utilizadas com correlações algébricas para previsão de transição. Os procedimentos integrais produziram previsões satisfatórias quando o início e o final da região de transição foram definidos pelo usuário com base em dados experimentais ou experiência.

Devido às limitações de correlações algébricas ou de análises diferenciais que considerassem os efeitos combinados das perturbações presentes em testes de aerofólios aquecidos sob condição de gelo, não foi possível definir os parâmetros da região de transição com a precisão requerida. Entre as fontes causadoras de perturbações, que são importantes, mas não são consideradas pelas correlações utilizadas, estão: 1) a presença das gotículas no escoamento; 2) o conjunto de nebulização (spray bars) gerador do escoamento bifásico, no caso da operação em túneis de gelo; 3) o impacto das gotículas da superfície do aerofólio; 4) a rugosidade gerada pela presença de escoamento de água residual na superfície do aerofólio; 5) a temperatura de superfície e seu gradiente ao longo do escoamento; 6) a não-uniformidade espacial da distribuição das flutuações turbulentas no túnel de gelo. Além disso, as medições experimentais para caracterizar o escoamento no túnel de gelo da NASA detectaram uma diferença significativa entre o máximo nível de turbulência ao longe, $1,5 \%$, e aquele medido perto do corpo de prova, $6,0 \%$, na seção de teste. Um tipo de perturbação, também não contalizada, é aquela gerada pela escala da turbulência, que é associada com as frequências das flutuações turbulentas e as dimensões dos turbilhões. Mas, a escala da turbulência também depende das fontes geradoras de turbulência, como grades ou condicionadores de fluxo, ou de outras perturbações, como dos alguns itens listados no presente parágrafo.

No entanto, a escolha de uma correlação algébrica mostrou-se apropriada, já que o nível de turbulência pode ser entendido como "equivalente", ou seja, conter outros efeitos além daqueles considerados pelos experimentos utilizados no desenvolvimento das correlações. Na literatura, os códigos numéricos permitem a variação dos parâmetros de nível de turbulência ou fator de amplificação crítico para que 
a simulação contabilize os efeitos particulares de cada instalação experimental ou condição de teste em voo. Essa abordagem também é adotada pelos fornecedores de ferramentas numéricas CFD. Em suma, o usuário precisa ter um banco de dados dos resultados dos ensaios em túnel e em voo que o auxilie a definir as condições iniciais e de contorno para a previsão adequada da transição laminar-turbulenta. 


\subsection{Sugestões para Próximos Trabalhos}

Recomenda-se que no desenvolvimento de novos trabalhos na área de simulação térmica de sistemas de antigelo de aerofólios sejam considerados os seguintes pontos:

- simulação de sistemas antigelo em aerofólios multi-corpos (slats e corpo principal), nos quais a presença das regiões descoladas no escoamento é significativa;

- acoplamento com modelos de escoamento e/ou de transferência de calor dos jatos de ar quente incindentes na superfície interna do bordo de ataque e dentro do compartimento " $\mathrm{D}$ ";

- validação do modelo para escoamentos dentro de um envelope operacional amplo, considerando outros ângulos de ataque, outras geometrias de aerofólios bem como para condições naturais obtidas em testes em voo e simuladas em outros túneis de gelo;

- resolução tridimensional da condução na superfície do aerofólio;

- desenvolvimento e implementação de modelo de antigelo tridimensional para análise térmica de asas enflechadas aquecidas operando sob condições de gelo;

- obtenção de dados experimentais de número de St ou fluxo de calor de escoamentos de ar seco e/ou com gotículas sub-resfriadas em torno de aerofólios com superfície não-isotérmica e transição laminar-turbulenta para várias intensidades e escalas de turbulência;

- desenvolvimento e/ou implementação de modelos para a consideração dos efeitos de intensidade e escala da turbulência do escoamento ao longe na análise diferencial de camada-limite nos regimes laminar e/ou turbulento;

- estudo sobre transição laminar-turbulenta em escoamentos em torno de aerofólios ou sobre placas planas com gradiente de pressão variável e que possuam transferência de calor ou temperatura variável na superfície.

- implementação e comparação dos modelos de intermitência e das correlações para previsão de início e término da região de transição, encontradas na presente pesquisa bibligráfica, para inclusão no modelo de antigelo; 
- incorporação do efeito do raio de curvatura e de fluxo de evaporação na avaliação diferencial da camada-limite nos regimes laminar e turbulento;

- consideração do efeito das bolhas de separação laminar e da ocorrência da transição laminar-turbulenta na avaliação diferencial da camada-limite e na solução do escoamento externo de forma acoplada;

- estudo sobre a previsão dos parâmetros de transição considerando escoamentos com gotículas, com presença de filme de água líquida, evaporação e de fluxo de calor de aquecimento; incorporação de outros modelos para a região de transição laminar-turbulenta da camada-limite.

- estudo dos efeitos da rugosidade do escoamento de água líquida residual sobre a transição laminar-turbulenta em asas enflechadas;

- estudo e desenvolvimento de métodos de regras de escala para garantir a similaridade operacional entre as condições de voo naturais em gelo e os testes de aerofólios com sistemas antigelo em túneis de gelo. 


\section{ANEXO A - CONCEITOS GERAIS}

O estudo das condicões que ocorrem nos processos de formacão de gelo sobre e o de prevenção contra a formação de gelo em aerofólios envolve um conjunto de conceitos que são apresentados nesta seção.

\section{A.1 Conteúdo de água Líquida (LWC - Liquid Water Content)}

O conteúdo de água líquida numa nuvem, LWC, é definido como a concentracão em massa de água líquida por volume de nuvem. O LWC determina a vazão máxima de água que pode ser captada por uma determinada área na superfície do bordo de ataque do aerofólio:

$$
\begin{gathered}
d \dot{m}_{\infty}=L W C \cdot \vec{V}_{\infty} \cdot 1 \cdot d \vec{y} \\
\dot{m}_{\infty}=\int_{\phi_{2}}^{\phi_{1}} d \dot{m}_{\infty}=\int_{y_{2}}^{y_{1}} L W C \cdot \vec{V}_{\infty} \cdot 1 \cdot d \vec{y}
\end{gathered}
$$

$\mathrm{Na}$ Eq. (A.1a), $d \dot{m}_{\infty}$ é a vazão de massa de água que atravessa uma área $1 \cdot d y$ entre duas linhas de corrente $(\phi)$ consecutivas, normais a velocidade média $V_{\infty}$, ver Fig. A.1. A massa total que escoa através de uma área ao longe, de altura $\Delta y=\left(y_{1}-y_{2}\right)$ e largura unitária, é dada pela Eq. (A.1b).

\section{A.2 Diâmetro Mediano Volumétrico (MVD - Median Vo- lumetric Diameter)}

Para um mesmo escoamento e mesmo aerofólio, a trajetória de uma gotícula depende do seu diâmetro. As gotinhas maiores têm maior probabilidade de atingir a superfície do aerofólio, aumentando o que se denomina eficiência de coleta. Já as gotículas menores tendem a seguir as linhas de corrente, pois as forcas de arrasto são maiores do que as de inércia. Assim a definicão de um diâmetro de gotícula de 
uma nuvem é um parâmetro importante para a análise das condições de formacão de gelo, pois afeta diretamente a quantidade de água que impinge o bordo de ataque.

Em termos estatísticos, o MVD é a mediana da distribuicão de diâmetros de gotículas de uma nuvem. Por definicão a mediana é menos sensível a valores extremos de uma amostragem do que a média ponderada pela frequência dos diâmetros da amostra. Isto faz com que os diâmetros extremos (os menores e os maiores) sejam considerados pelo seu volume (ou massa) e não pela sua frequência, por isso o diâmetro mediano volumétrico (MVD) é adequado para o cálculo das trajetórias de gotículas e eficiência de coleta. Mais informações podem ser encontradas na dissertação de mestrado (SILVA, 2002).

\section{A.3 Eficiência de Coleta Local $(\boldsymbol{\beta})$}

Para calcular a massa total de água que incide no aerofólio é necessário saber a eficiência de coleta local na superfície, definido como $\beta(s)$.

A eficiência de coleta local numa determinada distância $s$ na superfície do aerofólio é $\beta(s)$, sendo que $\beta \cdot\left(S_{U}\right) \rightarrow 0$ no limite superior e $\beta\left(S_{L}\right) \rightarrow 0$ limite inferior de impingimento, onde a trajetória das gotículas tangenciam a superfície do aerofólio, como mostrado na Fig. A.1. Da definicão de LWC temos que:

$$
\begin{gathered}
d \dot{m}_{\infty}=L W C \cdot V_{\infty} \cdot 1 \cdot d y \\
d \dot{m}_{i m p}=\dot{m}_{i m p}^{\prime \prime} \cdot 1 \cdot d y
\end{gathered}
$$

Onde $d \dot{m}_{i m p}$ é a vazão de massa de água entre duas trajetórias que impinge no aerofólio, $\dot{m}_{i m p}^{\prime \prime}$ é o fluxo de massa água impingido no aerofólio, $1 \cdot d s$ é a área da superfície do aerofólio, e 1 · dy é a área ao longe entre duas trajetórias.

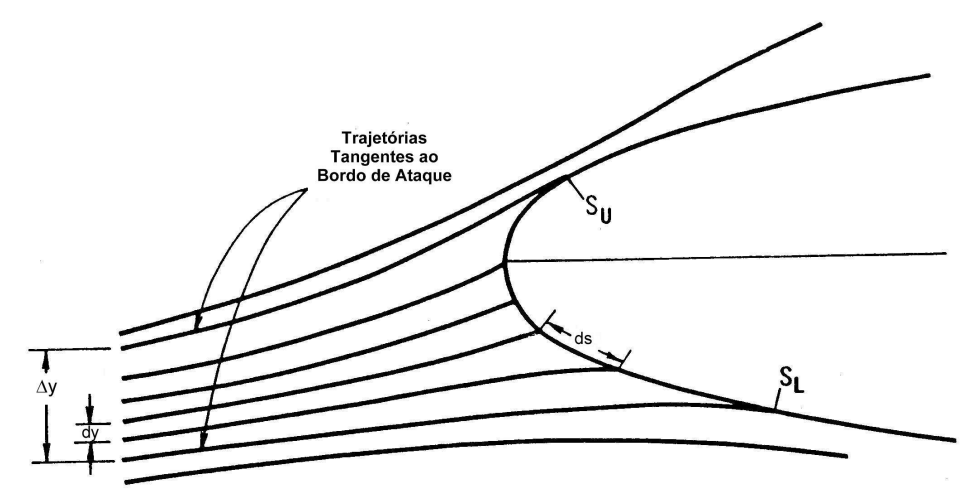

Figura A.1: Trajetórias das gotículas, definição da eficiência de coleta local, $\beta$,e dos limites de impingimento superior $S_{U}$ e inferior $S_{L}$ 
Aplicando a Equação da Continuidade entre duas trajetórias de gotículas:

$$
\begin{gathered}
d \dot{m}_{\infty}^{\prime \prime}=d \dot{m}_{i m p}^{\prime \prime} \\
\dot{m}_{i m p}^{\prime \prime}=V_{\infty} \cdot L W C \cdot \beta \\
\beta=\left(\frac{d y}{d s}\right)
\end{gathered}
$$

Ou seja, a eficiência de coleta local é a razão das áreas definidas no escoamento ao longe e na superfície do bordo de ataque entre duas trajetórias de gotículas. A Fig. A2 apresenta esta definição graficamente, no qual $s / c$ é a distância na superfície do aerofólio normalizada pela corda do aerofólio.
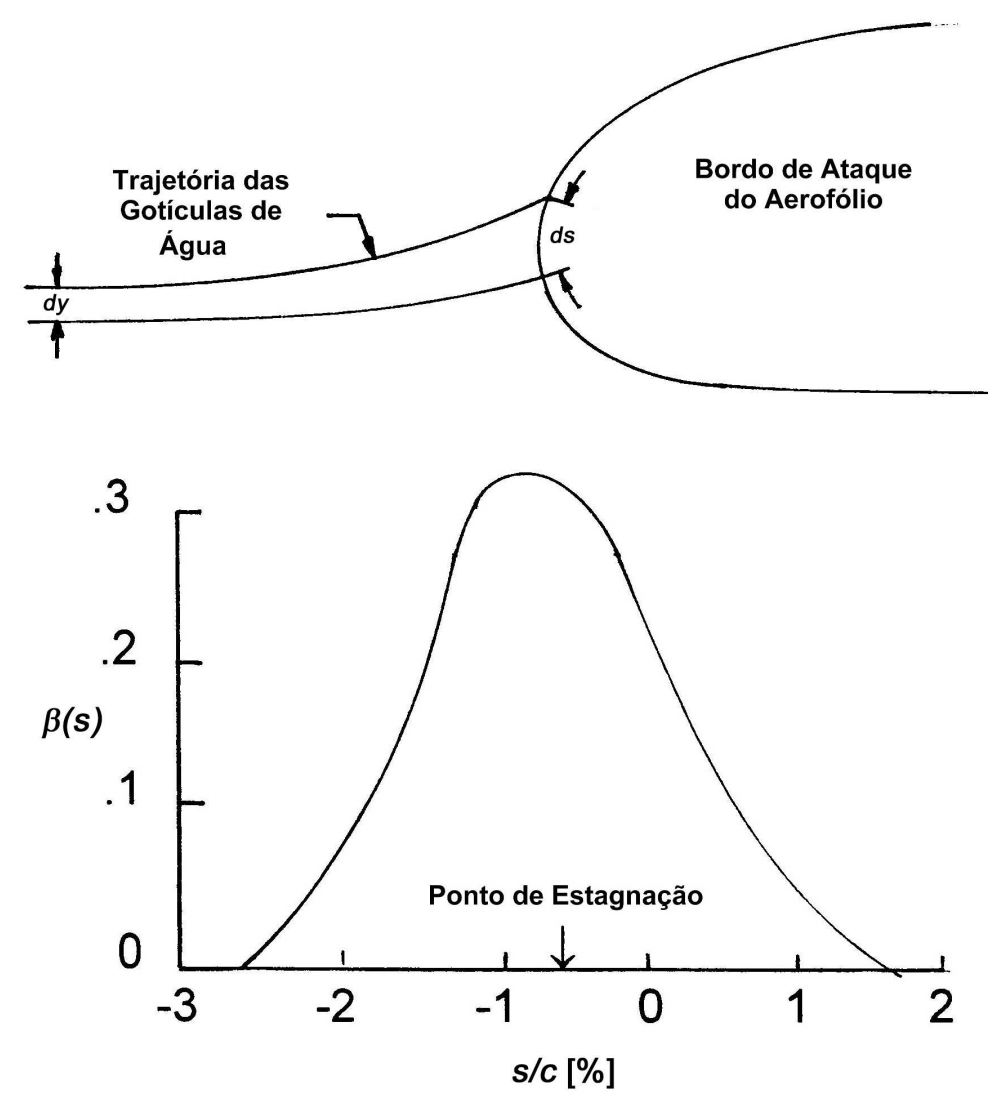

Figura A.2: Eficiência de coleta local, $\beta$

\section{A.4 Fração de Congelamento $\left(n_{f}\right)$}

A formação de gelo em voo ocorre quando uma aeronave passa por uma nuvem de gotículas de água sub-resfriada. Após o impacto a massa de água pode congelar parcialmente ou totalmente. Uma fração da entalpia de solidificação é liberada pela fração de água que congela, tendendo a aquecer a massa de água líquida restante e o gelo formado. O ganho de energia interna devido a liberação da entalpia de 
solidificação é contrabalançado pela transferência de calor e massa por convecção (perda) para o ambiente.

A relação entre a massa de água que congela sobre a superfície em um determinado ponto e a massa total de água líquida presente no mesmo ponto é dada pela fração de congelamento $n_{f}$.

Sob temperaturas baixas e baixo LWC, a temperatura do gelo acumulado permanece abaixo de $0{ }^{\circ} \mathrm{C}$. Isso faz com que as gotas congelem completamente no momento do impacto. Por outro lado, com um alto LWC ou temperaturas das gotículas próximas à $0^{\circ} \mathrm{C}$, a temperatura de equilíbrio no bordo será próxima de $0^{\circ} \mathrm{C} \mathrm{e}$ somente uma parte da água líquida irá congelar após o impacto, e a fração de congelamento nf é menor do que um $\left(n_{f}<1\right)$. A água líquida restante tenderá a escorrer a jusante ("runback") devido à ação do arrasto causado pelo escoamento externo do ar à superfície do líquido. Logo a água pode vir a congelar em pontos posteriores da superfície, onde a eficiência de coleta é menor e a perda de calor por convecção pode ser maior se o escoamento for turbulento.

O LWC de uma nuvem tem um papel importante na determinação da fração de congelamento e consequentemente da forma final do gelo, massa específica e rugosidade. Com alto LWC (mais água líquida impingindo na superfície), a transferência de calor e massa por convecção pode ser insuficiente para remover a entalpia de solidificação da massa de água de um determinado volume de controle. Nesse caso, admitindo-se condições de saturação (sem sub-resfriamento), somente uma fração da água líquida congela e a temperatura média do volume de controle fica em torno da temperatura de solidificação e $n_{f}<1$. Já com um baixo LWC, a entalpia de solidificação da massa de água líquida do volume de controle pode ser transferida por convecção para o escoamento gasoso, o que resulta em $n_{f}=1$ e temperaturas de gelo abaixo do ponto de solidificação da água. Nesse caso, a convecção é suficiente para transferir calor do volume de controle, causar a mudança de fase e ainda diminuir sua temperatura.

\section{A.5 Formação de Gelo}

A formação de gelo ocorre quando uma aeronave passa através de uma nuvem formada por gotículas de água sub-resfriada em equilíbrio metaestável numa temperatura abaixo do seu ponto de solidificação. Um exemplo de formação de gelo é apresentado na Fig. A.3. 


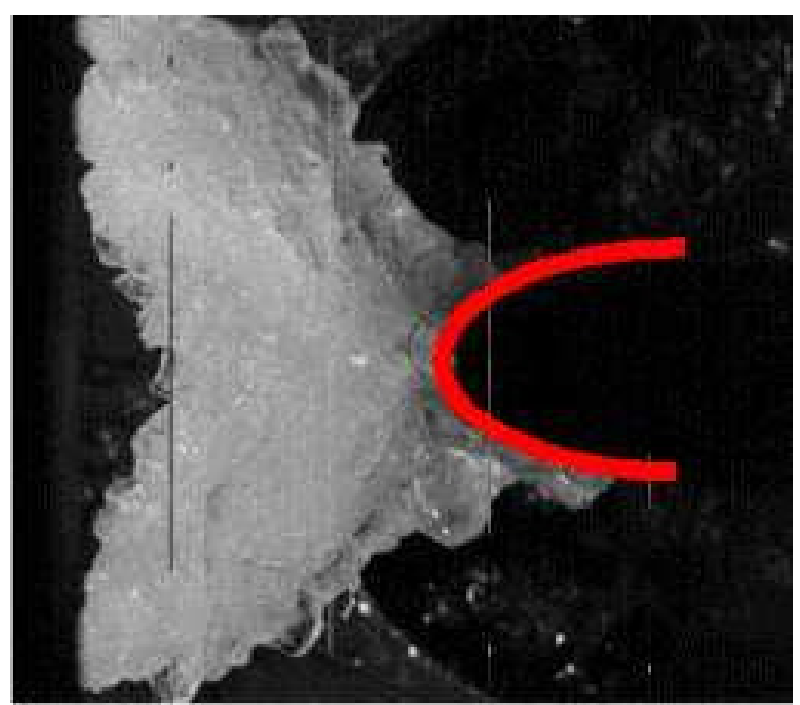

Figura A.3: Formação de gelo num aerofólio (sítio da rede internet, ONERA 2002) ${ }^{1}$

A Fig. A.4 apresenta formacões de gelo do tipo glaze sobre um aerofólio enflechado utilizado como estabilizador horizontal traseiro de um jato executivo. Devido ao enflechamento, as formas de gelo são tridimensionais e as protuberâncias são descontínuas no sentido da envergadura. São as denominadas "penas", como mostrado em detalhes na foto no canto inferior esquerdo da Fig. A.4.

\section{A.6 Formação de Nuvens de Gotículas Sub- Resfriadas}

O sub-resfriamento é atingido durante a formação e ascensão da nuvem na atmosfera podendo ser influenciado por fatores dinâmicos do movimento da nuvem, como turbulência e vórtices, fatores atmosféricos e fatores topográficos. Como a gotícula está num equilíbrio metaestável, qualquer perturbação de natureza térmica, mecânica ou química pode causar o início do processo de congelamento. Devido a essa sensibilidade às perturbações, não é possível definir com precisão em que temperatura se formarão os núcleos de gelo no interior da gotícula de água. Todavia, pode-se definir uma probabilidade para o crescimento de cristais de gelo conhecendo-se o diâmetro das gotículas, a taxa de resfriamento e a concentração de contaminantes. Este fato foi constatado por Mason (1971) pela demonstração que a concentração de cristais de gelo em nuvens aumenta com a altitude à medida que a temperatura diminui, resultando numa concentração significativamente alta em temperaturas

\footnotetext{
${ }^{1}$ ONERA (Office National D'etudes et de Recherches Aérospatiales) Chattillon Cedex, França. Apresenta atividades desenvolvidas na área de formação de gelo em aeronaves e helicópteros. Disponível em: http://www.onera.fr/dmph-en/givrage/index.html. Acesso em: 29 jan. 2002.

${ }^{2} \mathrm{NASA}, 2008$, Galeria de Imagens, Sítio da rede mundial de computadores Internet. As imagens são de propriedade da NASA, EUA, mas estão disponível no domínio publico para uso acadêmico e não-comercial. Disponível em: http://grcimagenet.grc.nasa.gov/. Acesso em: 16 Agosto 2008.
} 

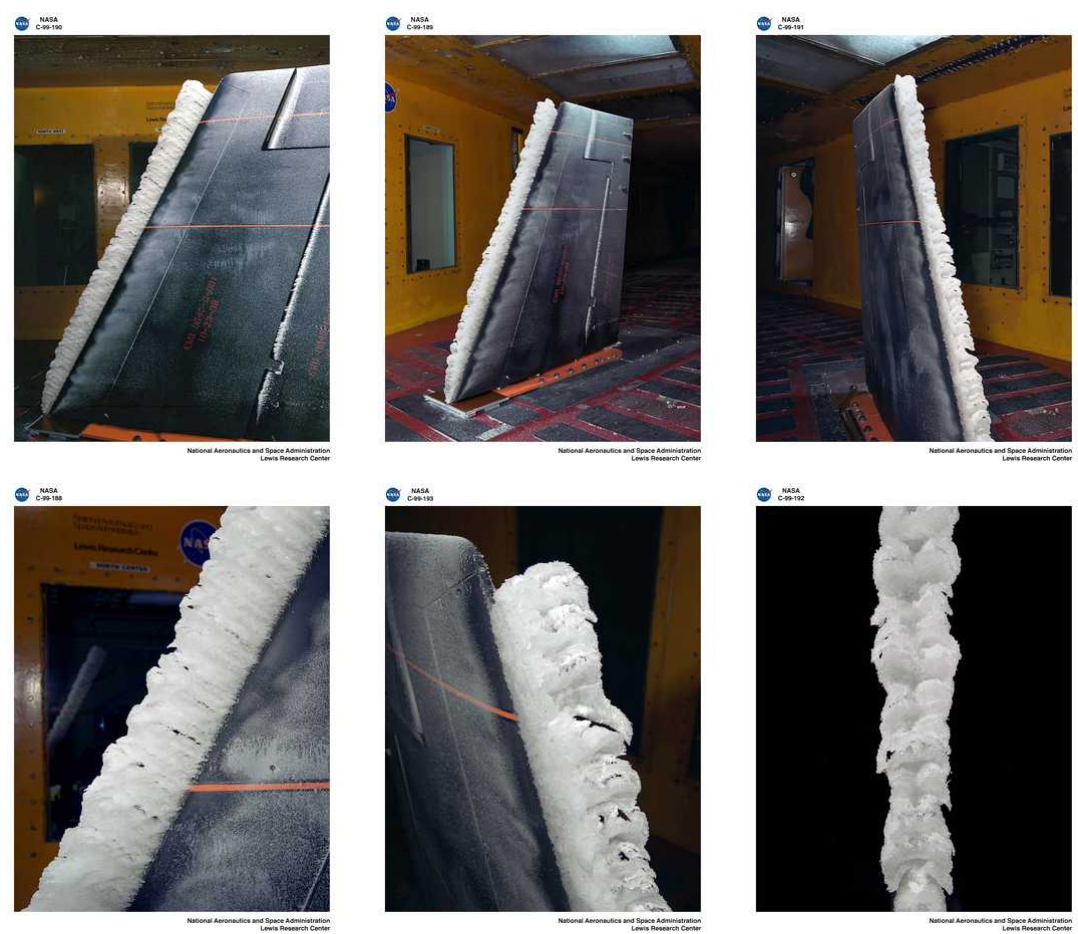

Figura A.4: Formação de gelo sobre um aerofólio enflechado²

abaixo de $-30^{\circ} \mathrm{C}$. Abaixo de $-40^{\circ} \mathrm{C}$ a presença de água líquida é inexistente e toda a água presente está na forma de cristais de gelo.

Para um mesmo diâmetro de gotícula e taxa de resfriamento, a probabilidade de existência de água líquida decai exponencialmente a partir de $0^{\circ} \mathrm{C}$ para as temperaturas menores, sendo muito pequena (praticamente nula) em $-40^{\circ} \mathrm{C}$. Modelos teóricos, validados por observações experimentais (KUHNS; MASON, 1968), mostram que quanto menor o diâmetro da gotícula ou maior a taxa de resfriamento das gotas, maior a probabilidade de congelamento de gotículas de água líquida subresfriada em temperaturas menores do que $0^{\circ} \mathrm{C}$. Ou seja, numa determinada temperatura abaixo de $0^{\circ} \mathrm{C}$, a probabilidade de existência de água líquida pode variar dependendo do tamanho das gotículas e do fluxo de calor retirado das gotículas ${ }^{3}$ Contaminantes podem iniciar e intensificar o processo de nucleação de cristais de gelo, aumentando a probabilidade de congelamento em temperaturas mais elevadas, porém alguns contaminantes químicos podem atuar de forma contrária e diminuir a temperatura de congelamento das gotículas.

\footnotetext{
${ }^{3}$ Segundo Kuhns e Mason (1968), a probabilidade de não congelamento, $(1-P)$, à temperatura $T_{S}$ menor do que temperatura de saturação $T_{S A T}$ para a pressão local, de uma gotícula de água de volume $V$, submetida à uma taxa de resfriamento $d T / d t$, é:

$$
\ln (1-P)=-\frac{V}{\frac{d T}{d t}} \int_{T_{S}}^{T_{S A T}} J\left(T_{S}\right) d T_{S} \quad \text { e } J\left(T_{S}\right) \cong \frac{n k T_{S}}{h} \cdot \exp \left[\frac{-(U+\Delta G)}{k T_{S}}\right]
$$

Onde $\mathrm{J}\left(T_{S}\right)$ é a taxa de nucleação de gelo por volume e por tempo em função da temperatura $T_{S}, k$ é a constante de Boltzmann, $h$ é a constante de Planck, $U$ é a energia de ativação para a difusão de uma molécula no líquido, e $\Delta G$ é o trabalho para a formação de um núcleo de gelo.
} 
Resumidamente uma nuvem pode se formar pela ação da convecção natural, da topografia, da convergência de correntes de ar causada por gradiente de pressão, e pelo encontro de frentes de ar frio com uma de ar quente. Na Fig. A.7 são exemplificados os processos primários de formação de nuvens na natureza e a escala de distância associadas a cada um dos fenômenos. As nuvens com condições de formação de gelo, ou seja, que têm gotículas de água sub-resfriada, são formadas basicamente pela convecção e pela ação da topografia.

Durante a ascensão da nuvem, a água contida no ar no estado líquido ou vapor pode passar por processos tais como: formação de núcleos de condensado; aglutinação, crescimento e precipitação das gotículas; resfriamento devido às condições climáticas locais (dentro da nuvem) de temperatura e pressão; e formação de núcleos gelo e crescimento de cristais de gelo. Dependendo das condições atmosféricas, concentração de contaminantes, grau de sub-resfriamento ou da dinâmica interna da nuvem (correntes de ar, vórtices, turbulência) podem ser geradas condições necessárias para a existência de gotículas de água sub-resfriada. Perturbações atmosféricas podem ocorrer a qualquer instante, deslocando a água do estado metaestável possibilitando a formação dos primeiros núcleos de gelo. As nuvens formadas somente por gotículas de água líquida não sub-resfriadas ou de cristais de gelo não são críticas para a segurança de voo, pois não causam formação de gelo nas superfícies aerodinâmicas, não degradando o desempenho da aeronave significativamente.

Sabe-se que, além das condições internas e externas à nuvem, o terreno tem um papel fundamental na formação das nuvens de gotículas sub-resfriadas. É muito mais provável encontrar nuvens com condições para a formação de gelo em regiões de terrenos acidentados devido a ocorrência de correntes ascendentes intensas, como pode ser visto na condição (b) mostrada na Fig. A.7.

\section{A.7 Tipos de Formação de Gelo}

O gelo do tipo "rime" se forma quando $n_{f}=1$ (baixas temperaturas ou baixo LWC). Esse tipo de formação é resultado do congelamento instantâneo das gotículas no ponto de impacto. A temperatura de equilíbrio do gelo permanece abaixo do ponto de solidificação e a forma do gelo depende exclusivamente do ponto de impacto e da trajetória das gotículas. De forma geral, o gelo acumulado é rugoso ou granular, tem um formato bastante simples, aparência opaca e leitosa devido a inclusões de pequenas bolhas de ar, como mostrado na Fig. A.5.

Quando $n_{f}<1$ começam a prevalecer as condições de formação de gelo do 


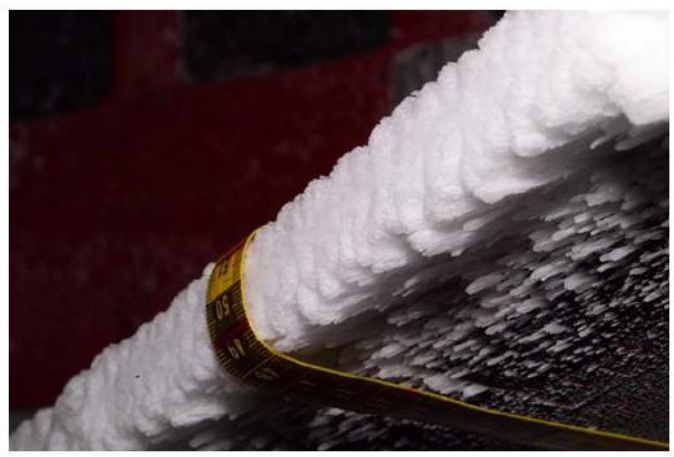

Figura A.5: Forma de gelo real do tipo rime em aerofólio NACA 0012 com enflechamento de $45^{\circ}$ (VARGAS; TSAO, 2007)

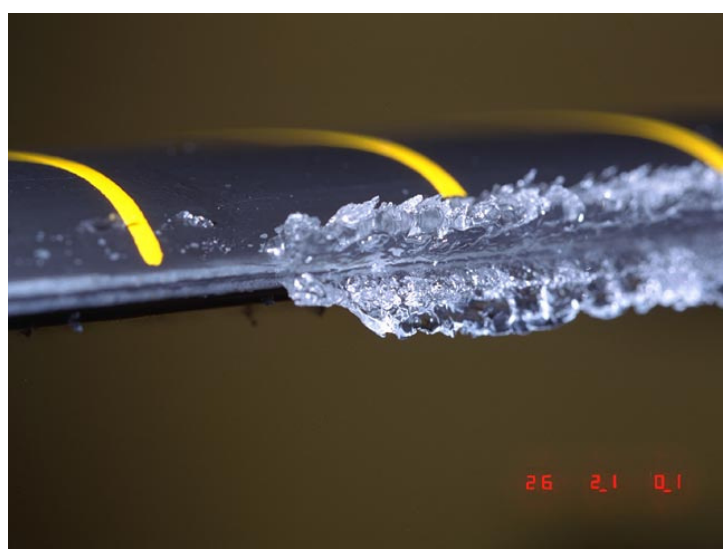

Figura A.6: Forma de gelo do tipo glaze sobre aerofólio de uso em asas rotativas ${ }^{2}$

tipo "glaze", que tem formas mais complexas do que o "rime", pois a formação do gelo sofre o efeito da presença de água líquida na região de impacto de gotas. $A$ água escoa para partes posteriores da superfície e tende a congelar em algum lugar a jusante do seu ponto de impingimento. Como resultado ocorre a formação de geometrias complexas conhecidas como chifres de gelo ("ice horns") e rabos de lagosta ("lobster tails"). O gelo "glaze" é geralmente transparente e liso, tendo poucas bolhas de ar em seu interior, como mostrado na Fig. A.6. As formações que podem ter características de gelo "rime" e "glaze" são chamadas de mistas ("mixed").

\section{A.8 Crescimento de Gelo}

O crescimento do gelo pode ser classificado como molhado ("wet growth") ou seco ("dry growth"), dependendo da existência de água líquida durante o congelamento. O primeiro é bem mais complexo e pode resultar em formações do tipo "glaze" ou mistas, e o segundo resulta em formações de gelo "rime". 


\section{A.9 Água Residual (Runback)}

Durante o processo de crescimento molhado, admite-se que gelo é formado na região de incidência das gotas e que a água líquida residual escoa devido às tensões de cisalhamento aplicadas pelo escoamento do ar na superfície da lâmina de água. Este filme escoa movido pelo cisalhamento e pressão e se quebra quando as forças de inércia se sobrepõem às forças de tensão superficiais. Esta razão é representada adimensionalmente pelo número de Weber, We $=\frac{\rho_{a r} \cdot u_{\infty} \cdot L}{\sigma}$. Quando o filme se quebra, podem ser formados pequenos filetes de água (rivulets), que continuam seu curso até seu congelamento ou evaporação total.

Quando acontece a formação dos filetes há dois efeitos imediatos: 1) a razão entre a área na interface líquido/ar e o volume de água no filete aumenta em relação a um filme contínuo de água, resultando num maior fluxo de convecção de calor e massa para o escoamento de ar externo; 2) a rugosidade da superfície aumenta, pois os filetes atuam como protuberâncias, intensificando a transferência de calor e massa para o escoamento de ar externo;

\section{A.10 Aspectos Operacionais da Aeronaves}

Os pilotos de aeronaves civis mudam suas rotas e evitam o voo em determinadas regiões problemáticas, já conhecidas pelas tripulações e controladores de voo, para prevenir a operação sob condições de gelo. Por outro lado, os pilotos de testes, meteorologistas e engenheiros de voo envolvidos com processo de certificação de aeronaves, procuram voar sobre regiões frias, durante o inverno e com terreno montanhoso para justamente aumentar as chances de encontrar condições favoráveis à formação de gelo.

A formação de gelo pode ocorrer também no solo, o que requer procedimentos adicionais para a operação de aeronaves na fase do pré-voo e decolagem. Sob condições climáticas adversas, especificadas na regulamentação, os voos devem ser cancelados. A precipitação de neve, granizo, chuva e chuvisco congelante podem causar acúmulo de gelo em áreas não protegidas da aeronave, como o dorso superior da asa e a fuselagem. Além de causar degradação aerodinâmica, estes blocos de gelo podem se desprender e ir para a entrada de ar dos motores, o que acarreta perda de empuxo e até danos catastróficos aos propulsores. Dependendo dos danos

\footnotetext{
${ }^{3}$ KOHLMAN, D. L.; SAND, W. (The Univeristy of Kansas, Overland Park, Kansas, EUA) Aircraft icing: meteorology, protective systems, instrumentation and certification. Material do curso de especilização.
} 


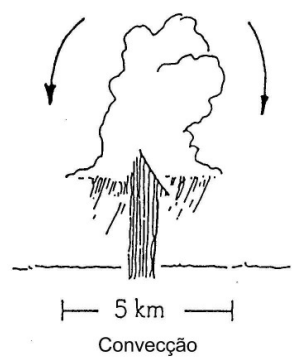

(a)

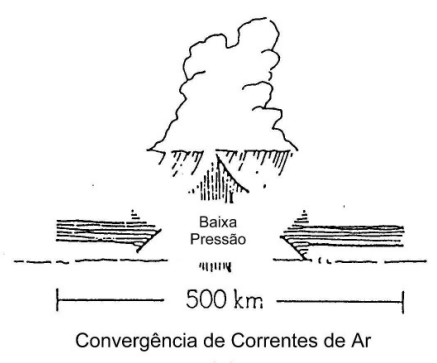

(c)

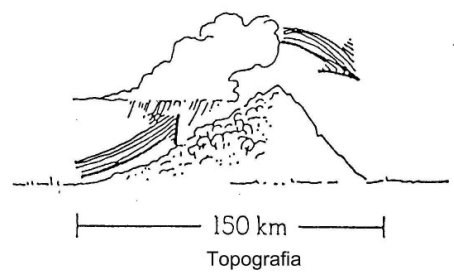

(b)

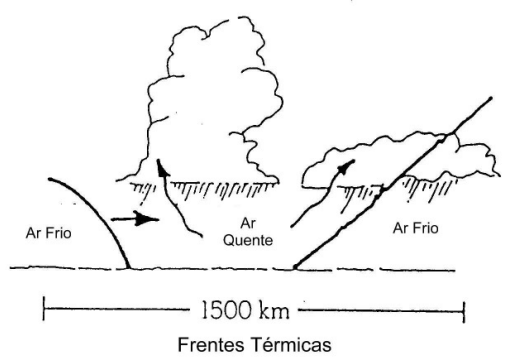

(d)

Figura A.7: Processos naturais primários de formação de nuvens ${ }^{3}$

ocorridos e da consequente diminuição do empuxo, o desempenho de decolagem é prejudicado colocando em risco a tripulação e seus passageiros.

A regulamentação define o envelope operacional especificando condições meteorológicas seguras para decolagem e os procedimentos obrigatórios e recomendados para determinada aeronave. Uma descrição completa sobre operação no solo em condições de gelo pode ser encontrada em Heinrich et al. (1991).

O conhecimento das condições atmosféricas em uma rota pode servir para que os pilotos e controladores de tráfego aéreo diminuam ao máximo a exposição da aeronave à condições de gelo. Para isso, é preciso fornecer às tripulações informações precisas sobre o tipo de nuvem, gotícula e potencial de acúmulo de gelo na sua rota. Paralelamente, é preciso intensificar a comunicação entre tripulações e controladores de voo, que centralizam as informações sobre condições de gelo, para que as regiões críticas sejam identificadas. Muitos destes procedimentos e sistemas já estão implementados e fazem parte da rotina do planejamento de voo e operação das aeronaves em países que apresentam inverno rigoroso.

\section{A.11 Prevenção contra a Formação de Gelo}

A definição das áreas a serem protegidas (Fig. 1.1) é uma das etapas mais importantes do projeto de um sistema de proteção contra formação de gelo, pois além de ter implicações com segurança, tem impacto direto no desempenho dos moto- 
res e consumo de combustível. De um modo geral, o tipo de sistema de proteção contra formação de gelo depende diretamente do impingimento das gotículas e da severidade do acúmulo de gelo em relação ao desempenho da aeronave e operacionalidade dos sistemas. Há dois tipos básicos de proteção contra gelo:

1) Sistemas de Antigelo: previnem a formação de gelo. Operam continuamente e garantem a não formação de gelo nas superfícies protegidas;

2) Sistemas de Degelo: removem o gelo acumulado na superfície. Atuam depois da formação de uma certa quantidade de gelo, operando ciclicamente para remover a camada de gelo da superfície protegida ciclicamente;

Considerando a variedade de sistemas e o objetivo deste trabalho, serão citados apenas os tipos de sistemas mais utilizados para a proteção de asas e empenagens.
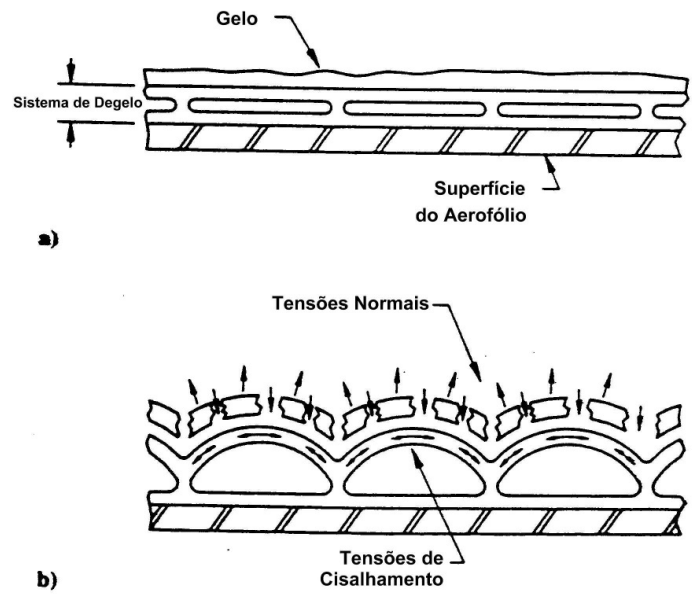

Figura A.8: Mecanismo de um Sistema de Degelo Pneumático - "Boot System" (HEINRICH et al., 1991)

1) Entre os tipos de sistemas de antigelo pode-se citar:

1a) Térmicos de Ar Quente: estes sistemas transferem calor à superfície protegida utilizando ar quente sangrado dos compressores dos motores. O tipo mais comum utiliza jatos ar quente incidentes e é o tipo mais utilizado em asas, empenagens e entrada de ar de motores dos aviões civis de médio e grande porte, a Fig. A.9 apresenta sua instalação no interior de um aerofólio;

1b) Eletrotérmicos: estes sistemas utilizam aquecimento por resistências elétricas; geralmente são instalados em sondas, radomes (capô de radares), estruturas, hélices, e também em entradas de motores e bordos de ataque de alguns aviões de médio ou pequeno porte. 
2) Entre os tipos de sistemas de degelo pode-se citar:

2a) Expulsão Pneumática: estes sistemas removem o gelo mecanicamente através da deformação de uma camada de material elástico ("pneumatic boots") que cobre o bordo de ataque; o sistema permite a formação de uma camada fina de gelo e atua ciclicamente quebrando o gelo acumulado por deformação da superfície de material elástico devido ao insuflamento de ar comprimido (ver Fig. A.8); o sistema é utilizado em aviões comerciais do tipo turboélice.

2b) Eletrotérmicos: estes sistemas transferem calor à superfície protegida utilizando resistências elétricas distribuídas ao longo da área protegida. O sistema opera ciclicamente, admitindo a formação de uma camada fina de gelo. Quando acionado derrete ou faz com que o gelo desprenda da superfície. O sistema é instalado em sondas, estruturas e em bordos de ataque de alguns aviões de pequeno porte.

2c) Expulsão Eletromagnética: estes sistemas removem o gelo mecanicamente através da deformação da superfície do bordo de ataque do aerofólio sob ação de forças eletromagnéticas geradas por elementos solenoides; o sistema permite a formação de uma camada bem mais espessa de gelo do que outros sistemas de degelo; tem a vantagem de ser mais eficiente na remoção de gelo e causar menos degradação aerodinâmica do que o sistema pneumático; além disso, demanda menos potência elétrica do que o sistema eletrotérmico;

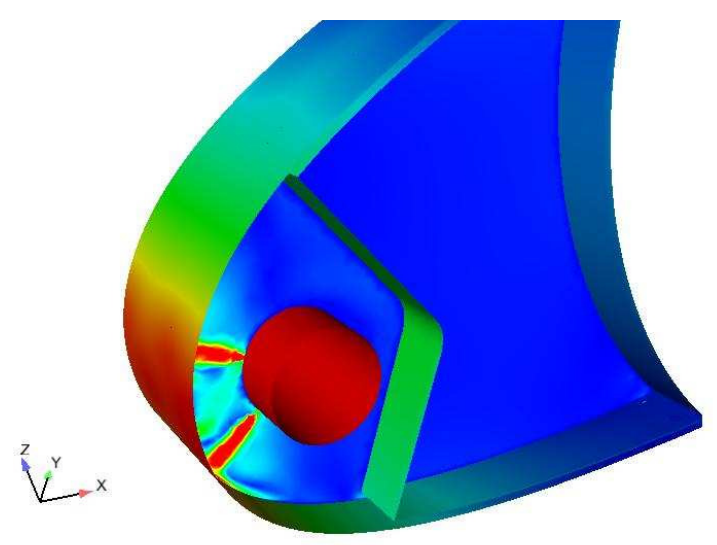

Figura A.9: Aerofólio com sistema de antigelo de ar quente (DOMINGOS et al., 2007) 


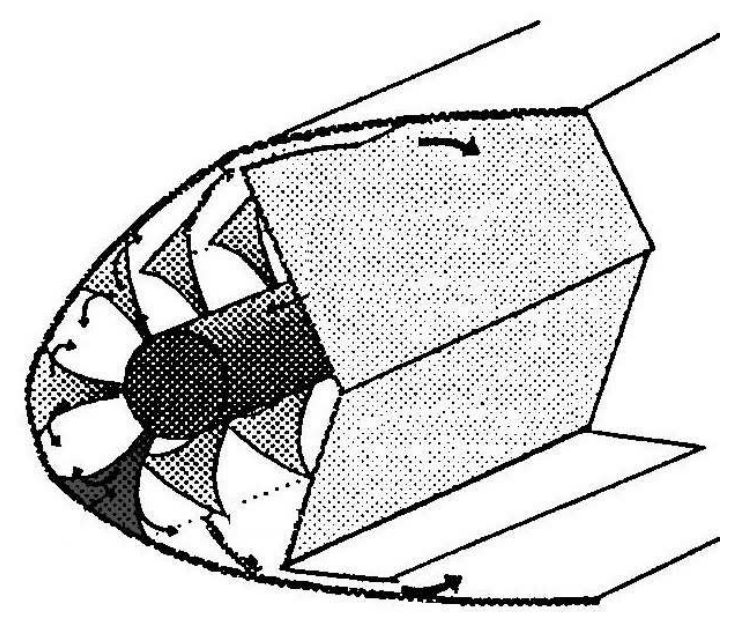

Figura A.10: Jatos incidentes de ar quente descarregados pelo tubo piccolo do Sistema de Antigelo de um aerofólio (BUCHLIN et al., 1994)

\section{A.11.1 Sistemas Antigelo de Ar Quente}

Os sistemas de antigelo de ar quente são os mais utilizados para a proteção de asas e estabilizadores horizontais em aeronaves de médio e grande porte. Quando há detecção de condições potenciais de formação de gelo o sistema de antigelo de ar quente é acionado automaticamente. Para prevenir a degradação aerodinâmica do perfil, um detector de gelo aciona o sistema antes que o gelo se acumule nas superfícies protegidas.

O ar quente sangrado dos últimos estágios do compressor motor é distribuído por vários tubos instalados no interior do bordo de ataque da asa, das empenagens ou do bordo de ataque do alojamento dos motores ("nacelle lips"). Nesses tubos com orifícios, chamados de tubos "piccolo", há uma ou mais fileiras de orifícios para garantir uma distribuição apropriada e uma eficiente proteção contra a formação de gelo.

Um tubo distribuidor tipo flauta, chamado de piccolo, é montado no interior de um compartimento existente entre a estrutura da asa e a superfície côncava interior do bordo de ataque, como apresentado na Fig. A.10, Devido ao seu formato a cavidade é denominada compartimento " $D$ ". A transferência de calor por convecção dos jatos de ar quente que incidem na superfície interna do bordo de ataque, como mostrado na Fig. A.10, é mais intensa no seu foco (região central de impacto do jato) e perde intensidade com o aumento da distância do foco. 


\section{ANEXO B - AVAliaçÃo da Camada-LImite POR DIFERENÇAS FINITAS}

\section{B.1 RANS Compressível}

A aplicação da segunda lei de Newton a um volume de controle infinitesimal permite obter as equações de conservação de momento para o escoamento do fluido. Essas equações são gerais, porém sua solução torna-se difícil caso as propriedades do escoamento variem de forma aleatória, como é o caso de um escoamento turbulento. Para contornar esse problema, as equações de Navier-Stokes são reescritas com o uso da média temporal destas propriedades. Para cada uma delas, toma-se seu valor instantâneo como a somatória de um valor médio mais uma flutuação. Procedendo dessa maneira, obtém-se as chamadas Reynolds Averaged Navier-Stokes - RANS.

$$
\rho u \frac{\partial u}{\partial x}+\overline{\rho v} \frac{\partial u}{\partial y}=-\frac{d p}{d x}+\frac{\partial}{\partial y}\left(\mu \frac{\partial u}{\partial y}-\rho \overline{u^{\prime} v^{\prime}}\right)
$$

\section{B.1.1 RANS Compressível da camada-limite}

A tensão de Reynolds, $u^{\top} v^{\prime}$ é modelada utilizando-se a viscosidade turbulenta aparente, "eddy viscosity", definida como:

$$
-\overline{u^{\prime} v^{\prime}}=\epsilon_{m} \frac{\partial u}{\partial y}
$$

Na região de escoamento externo, pode-se considerar regime permante, incompressível, adiabático, invíscido e irrotacional. Com a aplicação dessas hipóteses na equação de Navier-Stokes, ou seja, a aplicação da conservação da quantidade de movimento a uma linha de corrente adjacente à borda superior da camada-limite de velocidade, onde $u(y=\delta)=0.99 \cdot u_{e}$, obtém-se:

$$
-\frac{d p}{d x}=\rho_{e} u_{e} \frac{d u_{e}}{d x}
$$


Substituindo as equações B.2 e B.3 em B.1, obtém-se a equação de momento com média temporal que rege o escoamento de uma camada-limite turbulenta compressível:

$$
\rho u \frac{\partial u}{\partial x}+\overline{\rho v} \frac{\partial u}{\partial y}=\rho_{e} u_{e} \frac{d u_{e}}{d x}+\frac{\partial}{\partial y}\left[\left(\mu+\rho \epsilon_{m}\right) \frac{\partial u}{\partial y}\right]
$$

\section{B.1.2 Modelo de Turbulência de Cebeci e Smith (1974)}

Cebeci e Smith (1974) desenvolveram um modelo algébrico para a viscosidade turbulenta aparente que considera a camada-limite composta por duas regiões, a interna (sub-índice i) e a externa,(sub-índice o).

$$
\begin{gathered}
\left(\epsilon_{m}\right)_{i}=l^{2}\left|\frac{\partial u}{\partial y}\right|^{2} \gamma_{t r} \gamma, \quad 0 \leq y \leq y_{c} \\
\left(\epsilon_{m}\right)_{0}=0,0168\left|\int_{0}^{\infty}\left(u_{e}-u\right) d y\right| \gamma_{t r} \gamma, \quad y_{c} \leq y \leq \delta \\
\left(\epsilon_{m}\right)_{o}=\left(\epsilon_{m}\right)_{i}, \quad y=y c \\
I=\kappa y\left[1-\exp \left(-\frac{y}{A}\right)\right], \quad N=\left[1-11,8 \frac{\mu_{w}}{\mu_{e}}\left(\frac{\rho_{e}}{\rho_{w}}\right)^{2} p^{+}\right]^{1 / 2} \\
A=26 \frac{\nu}{N} u_{T}^{-1}\left(\frac{\rho}{\rho_{w}}\right)^{1 / 2},
\end{gathered}
$$

\section{B.2 Descrição Breve do Código BLP2C}

Os principais modelos, hipóteses, métodos numéricos, algoritmo e subrotinas de cálculo do código BLP2C de Cebeci e Cousteix (2005) são descritos brevemente na presente seção para referência eventual do leitor.

\section{B.2.1 Transformação de Falkner-Skan}

Uma transformação de coordenadas possibilita a redução de um sistema de equações diferenciais parciais não lineares em um sistema de equações diferenciais ordinárias.Obtém-se um sistema de equações cuja solução é mais simples sob o ponto de vista numérico, sem a perda do significado físico das equações.

Uma transformação utilizada para escoamentos externos compressíveis em regime laminar é a Transformação de Falkner-Skan. Cebeci e Cousteix (2005) adotam 
a Eq. (B.10) mesmo para escoamentos no regime turbulento ou para aqueles que não apresentam similaridade, pois a adimensionalização torna as equações menos sensíveis à variação das propriedades do escoamento no sentido longitudinal (direção $x$ ). A transformação adotada no $B L P 2 C$ é dada por:

$$
d \eta=\sqrt{\frac{u_{e}}{\nu_{e} X}} \frac{\rho}{\rho_{e}} d y \quad \psi(x, y)=\sqrt{\rho_{e} \mu_{e} u_{e} X} \cdot f(x, \eta)
$$

A definição de função de corrente é dada por:

$$
\rho u=\frac{\partial \psi}{\partial y} \quad \rho v=-\frac{\partial \psi}{\partial x}
$$

Aplicando estas transformações nas equações de momento e de energia, obtêmse suas equações transformadas, equações B.12 e B.13:

$$
\begin{gathered}
\left(b f^{\prime \prime}\right) f^{\prime}+m_{1} f f^{\prime \prime}+m_{2}\left[c-\left(f^{\prime}\right)^{2}\right]=x\left(f^{\prime} \frac{\partial f^{\prime}}{\partial x}-f^{\prime \prime} \frac{\partial f}{\partial x}\right) \\
\left(e S^{\prime}+d f^{\prime} f^{\prime \prime}\right)+m_{1} f S^{\prime}=x\left(f^{\prime} \frac{\partial S}{\partial x}-S^{\prime} \frac{\partial f}{\partial x}\right)
\end{gathered}
$$

Assumindo a não existência de transferência de massa, as condições de contorno para as equações não transformadas são:

$$
\begin{array}{lll}
y=0, & v=0, & u=0, \\
y=\delta, & u=u_{e}(x), & H=H_{w}(x) \text { or }\left(\frac{\partial H}{\partial y}\right)_{w}=-\frac{c_{p_{w}}}{k_{w}} \dot{q}_{w},
\end{array}
$$

Caso efeitos de transferência de massa sejam considerados, as condições de contorno para a parede devem incluir uma velocidade de transpiração, $v_{w}$ :

$$
v=v_{w}(x)
$$

Aplicando as transformações para as condições de contorno, obtêm-se:

$$
\begin{aligned}
& \eta=0, \quad f=0, \quad f^{\prime}=0, \quad S=S_{w}(x) \quad \text { ou } \quad S_{w}^{\prime}=-\frac{c_{p_{w}} C_{w} x \dot{q}_{w}}{k_{w} H_{e} \sqrt{R_{x}}} \\
& \eta=\eta_{e}, \quad f^{\prime}=1, \quad S \equiv H / H_{e}=1 .
\end{aligned}
$$

Caso haja transferência de massa, para a parede:

$$
f_{w}=\frac{-1}{\left(u_{e} \mu_{e} \rho_{e} x\right)^{1 / 2}} \int_{0}^{x} \rho_{w} v_{w} d x
$$


Nas equações acima apresentadas, os coeficientes b, C, c, d, e, $m_{1}, m_{2}$ e $R_{x}$ são definidos para os escoamentos laminar e turbulento, como apresentado a seguir:

- No regime laminar, os coeficientes são dados por:

$$
\begin{aligned}
& b=C \\
& C \equiv \frac{\rho \mu}{\rho_{e} \mu_{e}}, \quad c=\frac{\rho_{e}}{\rho} \\
& d=\frac{C u_{e}^{2}}{H_{e}}\left(1-\frac{1}{P r}\right), \\
& e=\frac{b}{P r} \\
& m_{1}=\frac{1}{2}\left[1+m_{2}+\frac{x}{\rho_{e} \mu_{e}} \frac{d}{d x}\left(\rho_{e} \mu_{e}\right)\right], \quad m_{2}=\frac{x}{\mu_{e}} \frac{d u_{e}}{d x}, \quad R_{x}=\frac{u_{e} x}{\nu_{e}}
\end{aligned}
$$

- No regime turbulento, somente seguintes coeficientes são modificados:

$$
\begin{aligned}
b=C\left(1+\epsilon_{m}^{+}\right), & e=\frac{C}{P r}\left(1+\epsilon_{m}^{+} \frac{P r}{P r_{t}}\right), \\
d=\frac{C u_{e}^{2}}{H_{e}}\left[1-\frac{1}{P r}+\epsilon_{m}^{+}\left(1-\frac{1}{P r_{t}}\right)\right], & \epsilon_{m}^{+}=\frac{\epsilon_{m}}{\nu} .
\end{aligned}
$$

Ainda restam serem transformadas as equações que descrevem o modelo algébrico de turbulência de Cebeci e Smith (1974). Estas equações, em termos das variáveis transformadas, tornam-se (lembrando que $v=f^{\prime \prime}$ ):

$$
\begin{aligned}
& \left(\epsilon_{m}^{+}\right)_{i}=\frac{0.16}{c^{2}} \frac{\mu_{e}}{\mu} \sqrt{R_{x}} I^{2} v^{2}\left[1-\exp \left(-\frac{y}{A}\right)\right]^{2} \gamma_{t r} \gamma, \\
& \left(\epsilon_{m}^{+}\right)_{o}=\frac{0.0168}{c} \frac{\mu_{e}}{\mu} \sqrt{R_{x}}\left[\int_{0}^{\eta_{e}} c(1-u) d \eta\right] \gamma_{t r} \gamma,
\end{aligned}
$$

Onde com $\epsilon_{m}^{+}=\epsilon_{m} / \nu$,

$$
\begin{aligned}
I & =\int_{0}^{\eta} c d \eta, & \frac{y}{A} & =\frac{N}{26} c^{-3 / 2} \frac{C_{w}}{C} R_{x}^{1 / 4} I v_{w}^{1 / 2}, \\
N^{2} & =1-1.18 \frac{\mu_{w}}{\mu} C_{w}^{2} p^{+}, & p^{+} & =\frac{m_{2}}{R_{x}^{1 / 4}}\left(\frac{\mu_{e}}{\mu_{w}}\right)^{3 / 2} \frac{1}{v_{w}^{3 / 2}} .
\end{aligned}
$$

\section{B.2.2 Método numérico}

A seção B.2.1 apresentou a transformação das equações RANS por meio da transformação compressível de Falkner-Skan. A presente seção tem por objetivo apresentar a implementação numérica para a resolução das equações transformadas. O modelo de turbulência desenvolvido por Cebeci e Smith (1974) será utilizado na resolução das equações.

As equações obtidas são resolvidas por meio da caixa de Keller (1970), chamado também de "Box Method" ou "Keller Box", que consiste nos seguintes passos: 
1) reduzir as equações para um sistema de primeira ordem, 2) escrever equações de diferenças utilizando diferenças centradas, 3) linearizar as equações algébricas resultantes (se já não forem lineares), e reescrevê-las sob a forma matricial, 4) resolver o sistema linear pelo método da eliminação tridiagonal de blocos.

\section{B.2.3 Mudança de variáveis}

Para se obter um sistema de equações de primeira ordem, as equações transformadas são escritas através de novas variáveis independentes, $u(x, \eta), v(x, \eta)$ e $p(x, \eta)$. As equações de momento e energia são escritas por:

$$
\begin{aligned}
& f^{\prime}=u \\
& u^{\prime}=v \\
& g^{\prime}=p \\
&(b v)^{\prime}+m_{1} f v+m_{2}\left(c-u^{2}\right)=x\left(u \frac{\partial u}{\partial x}-v \frac{\partial f}{\partial y}\right), \\
&(e p+d u v)^{\prime}+m_{1} f p=x\left(u \frac{\partial g}{\partial x}-p \frac{\partial f}{\partial x}\right)
\end{aligned}
$$

Nestas, $g$ é definido como a razão entre as entalpias totais, $g=H / H_{e}$, dado por $S$ na equação B.13. Com a mudança de variáveis, as condições de contorno são dadas da seguinte maneira:

$$
\begin{aligned}
f(x, 0) & =f(x), & u(x, 0)=0, \\
g(x, 0) & =g_{w}(x) \text { or } p(x, 0)=p_{w}^{\prime}(x), & \\
u\left(x, \eta_{e}\right)=1, & & g\left(x, \eta_{e}\right)=1 .
\end{aligned}
$$

\section{B.2.4 Método da Caixa de Keller (1970)}

A resolução das equações diferencias de primeira ordem obtidas são resolvidas utilizando a caixa de Keller, que é representada na Fig. B.1.

O método consiste em escrever as três primeiras equações diferenciais, B.22aB.22c, em termos do ponto mediano $\left(x_{m}, \eta_{j-1 / 2}\right)$ do segmento $P_{1} P_{2}$ apresentado na Fig. B.1. Já as equações B.22d e B.22e são escritas em termos do ponto central 


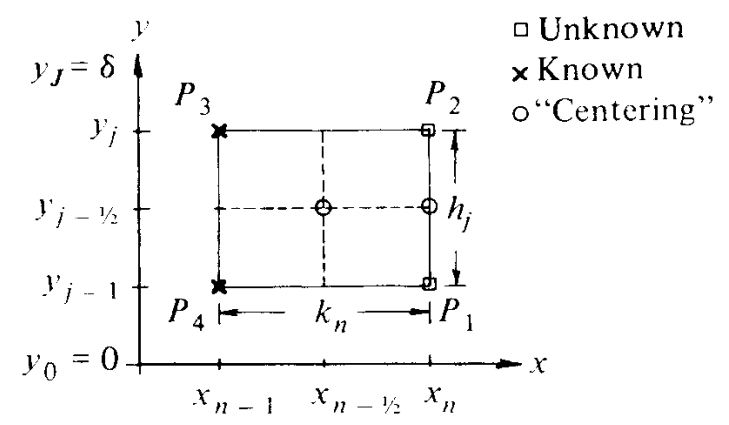

Figura B.1: Malha de diferenças finitas para o método da caixa de Keller (1970)

$\left(x_{n-1 / 2}, \eta_{j-1 / 2}\right)$ do retângulo $P_{1} P_{2} P_{3} P_{4}$. A aplicação deste procedimento resulta em:

$$
\begin{gathered}
h_{j}^{-1}\left(f_{j}^{n}-f_{j-1}^{n}\right)=u_{j-1 / 2}^{n}, \\
h_{j}^{-1}\left(u_{j}^{n}-u_{j-1}^{n}\right)=v_{j-1 / 2}^{n}, \\
h_{j}^{-1}\left(g_{j}^{n}-g_{j-1}^{n}\right)=p_{j-1 / 2}^{n}, \\
h_{j}^{-1}\left(b_{j}^{n} v_{j}^{n}-b_{j}^{n}-b_{j-1}^{n} v_{j-1}^{n}\right)+\left(m_{1}^{n}+\alpha_{n}\right)(f v)_{j-1 / 2}^{n}-\left(m_{2}^{n}+\alpha_{n}\right)\left(u^{2}\right)_{j-1 / 2}^{n} \\
+\alpha_{n}\left(v_{j-1 / 2}^{n-1} f_{j-1 / 2}^{n}-f_{j-1 / 2}^{n-1} g_{j-1 / 2}^{n}\right)=R_{j-1 / 2}^{n-1} \\
h_{j}^{-1}\left(e_{j}^{n} p_{j}^{n}-e_{j-1}^{n} p_{j-1}^{n}\right)+h_{j}^{-1}\left(d_{j}^{n} u_{j}^{n} v_{j}^{n}-\right. \\
\left.d_{j-1}^{n} u_{j-2}^{n} v_{j-1}^{n}\right)+\left(m_{1}^{n}+\alpha_{n}\right)(f p)_{j-1 / 2}^{n} \\
-\alpha_{n}\left[(u g)^{n}+j-1 / 2+u_{j-1 / 2}^{n-1} g_{j-1 / 2}^{n}-g_{j-1 / 2}^{n-1} u_{j-1 / 2}^{n}+\right. \\
\left.f_{j-1 / 2}^{n-1} p_{j-1 / 2}^{n}-p_{j-1 / 2}^{n-1} f_{j-1 / 2}^{n}\right]=T_{j-1 / 2}^{n-1}
\end{gathered}
$$

onde

$$
\begin{aligned}
& \begin{array}{l}
\alpha_{n}=\frac{x^{n-1 / 2}}{k_{n}} R_{j-1 / 2}^{n-1}=-L_{j-1 / 2}^{n-1} \\
+\alpha_{n}\left[(f v)_{j-1 / 2}^{n-1}-\left(u^{2}\right)_{j-1 / 2}^{n-1}\right]-m_{2}^{n} c_{j-1 / 2}^{n}
\end{array} \\
& \begin{aligned}
& L_{j-1 / 2}^{n-1}=\left(h_{j}^{-1}\left(b_{j} v_{j}-b_{j-1} v_{j-1}\right)+m_{1}(f v)_{j-1 / 2}+\right. \\
&\left.m_{2}\left[c_{j-1 / 2}-\left(u^{2}\right)_{j-1 / 2}\right]\right) T_{j-1 / 2}^{n-1}=-M_{j-1 / 2}^{n-1} \\
&+\alpha_{n}\left\{(f p)_{j-1 / 2}^{n-1}-(u g)_{j-1 / 2}^{n-1}\right\}
\end{aligned}
\end{aligned}
$$

Para levar em conta condições de contorno mistas na parede (nesta pode-se especificar a temperatura ou o fluxo de calor), a condição de contorno na parede, 
$\mathrm{j}=0$, é dada por:

$$
\alpha_{0} \cdot g_{0}+\alpha_{1} \cdot p_{0}=\gamma_{0}
$$

As condições de contorno para a parede nas equações de momento e energia são as seguintes:

$$
f_{0}^{n}=0, \quad u_{0}^{n}=0, \quad \alpha_{0} g_{0}^{n}+\alpha_{1} p_{0}^{n}=\gamma_{0}^{n} .
$$

As condições de contorno para a borda (edge) são:

$$
u_{j}^{n}=1, \quad g_{j}^{n}=1
$$

Na equação B.27, caso se especifique a temperatura, escolhe-se $\alpha_{0}=1, \alpha_{1}=0$ e, uma vez que a razão de entalpias na superfície, $g_{0}(x)$, é dada $\gamma_{0}=g_{0}(x)$.Para fluxo de calor, utilizam-se $\alpha_{0}=0, \alpha_{1}=1$, e $\gamma_{0}$ iguala-se ao gradiente de entalpia total adimensional na parede.

\section{B.2.5 Método de Newton}

Para a resolução do sistema de equações diferenciais não lineares obtidos no desenvolvimento apresentado no item B.2.3, utiliza-se o método de Newton. Para aplicá-lo, assumem-se conhecidos os valores das variáveis na posição anterior, de tal forma a se determinar seus valores na posição seguinte.

De acordo com a Fig. B.1, conhece-se o valor da variável na posição $n-1$ para $0 \leq j \leq J$, ou seja, são conhecidos $f_{j}^{n-1}, u_{j}^{n-1}, v_{j}^{n-1}, g_{j}^{n-1}$ e $p_{j}^{n-1}$. Assim, forma-se um sistema de $5 \mathrm{~J}+5$ equações não lineares com $5 \mathrm{~J}+5$ incógnitas $\left(f_{j}^{n}, u_{j}^{n}, v_{j}^{n}, g_{j}^{n}\right.$ e $\left.p_{j}^{n}\right)$. A aplicação do método de Newton consiste em resolver esse sistema não linear com um chute inicial para o valor da incógnita igual ao valor da posição anterior. Logo, pode-se definir que:

$$
\begin{array}{ll}
f_{j}^{(i+1)}=f_{j}^{(i)}+\delta f_{j}^{(i)} & u_{j}^{(i+1)}=u_{j}^{(i)}+\delta u_{j}^{(i)} \\
v_{j}^{(i+1)}=v_{j}^{(i)}+\delta v_{j}^{(i)} & g_{j}^{(i+1)}=g_{j}^{(i)}+\delta g_{j}^{(i)} \\
p_{j}^{(i+1)}=p_{j}^{(i)}+\delta p_{j}^{(i)} &
\end{array}
$$

O lado direito das equações B.29 são substituidos nas equações B.24, B.27 e B.28, desprezando os termos que são quadráticos em $\delta$. Por questão de simplicidade, as equações desenvolvidas por Cebeci e Cousteix (2005) não serão reprodu- 
zidas aqui. O sistema de equações é escrito sob a forma:

$$
A \delta=r
$$

\section{B.2.6 Eliminação de blocos}

A matriz A do sistema linear apresentado pela equação B.30 é tridiagonal, ou seja, possui somente os elementos $a_{i, j-1}, a_{i, j}$ e $a_{i, j+1}$. A eliminação de blocos consiste em subdividir a matriz $\mathbf{A}$ em submatrizes, as quais são resolvidas para obtenção da solução.

\section{B.2.7 Entradas/Saídas}

O diagrama de blocos abaixo resume o funcionamento do programa BLP2C, com a definição de seus dados de entrada e saída.

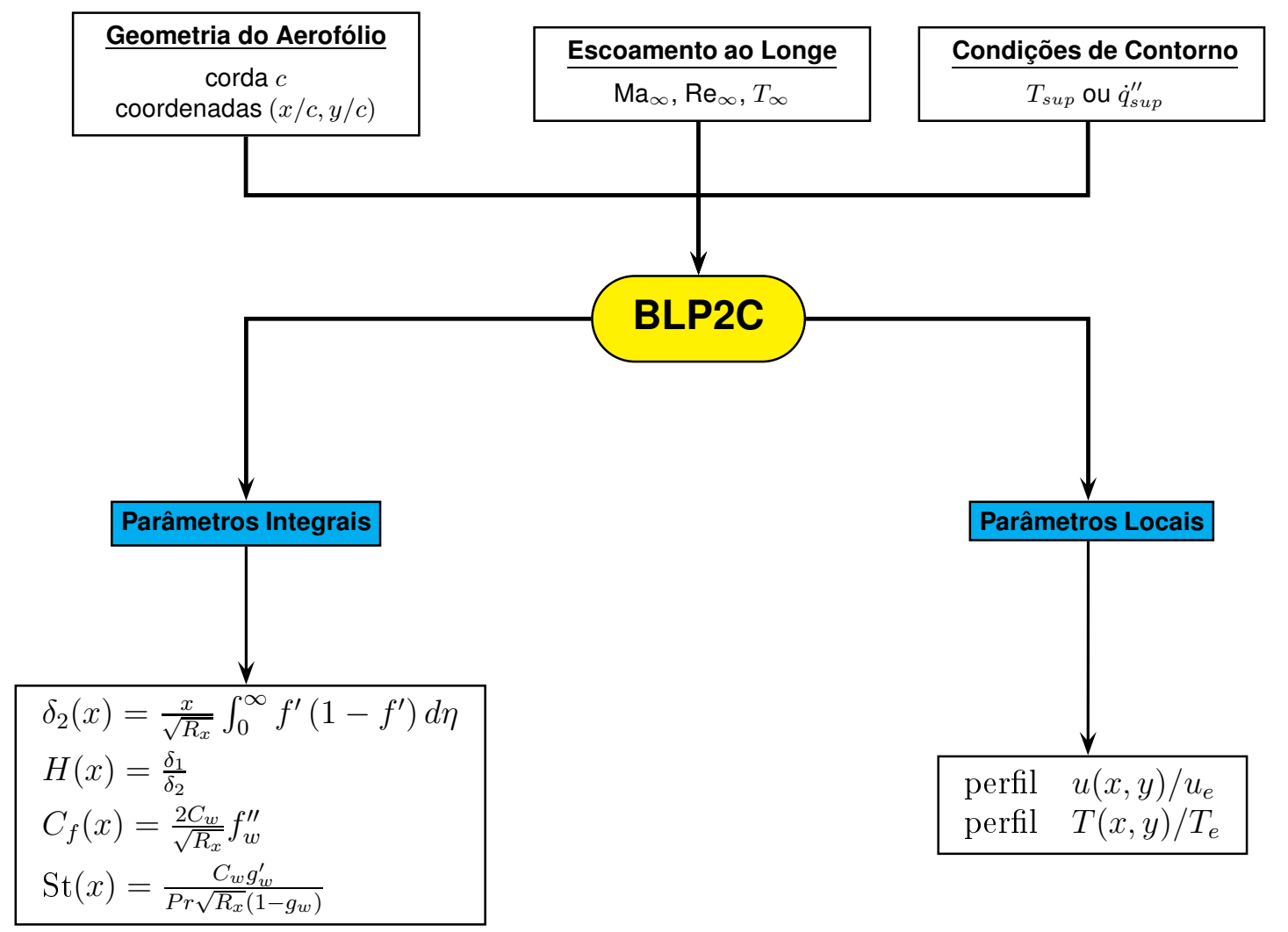

Figura B.2: Entradas e Saídas do BLP2C

\section{B.2.8 Fluxograma do Código Numérico}

O código $B L P 2 C$ é composto por uma rotina principal, MAIN, que contém a lógica principal do programa, e as subrotinas INPUT, IVPL, EDDY, COEF, OUTPUT e SOLV5. Um fluxograma de solução é apresentado na figura B.3 


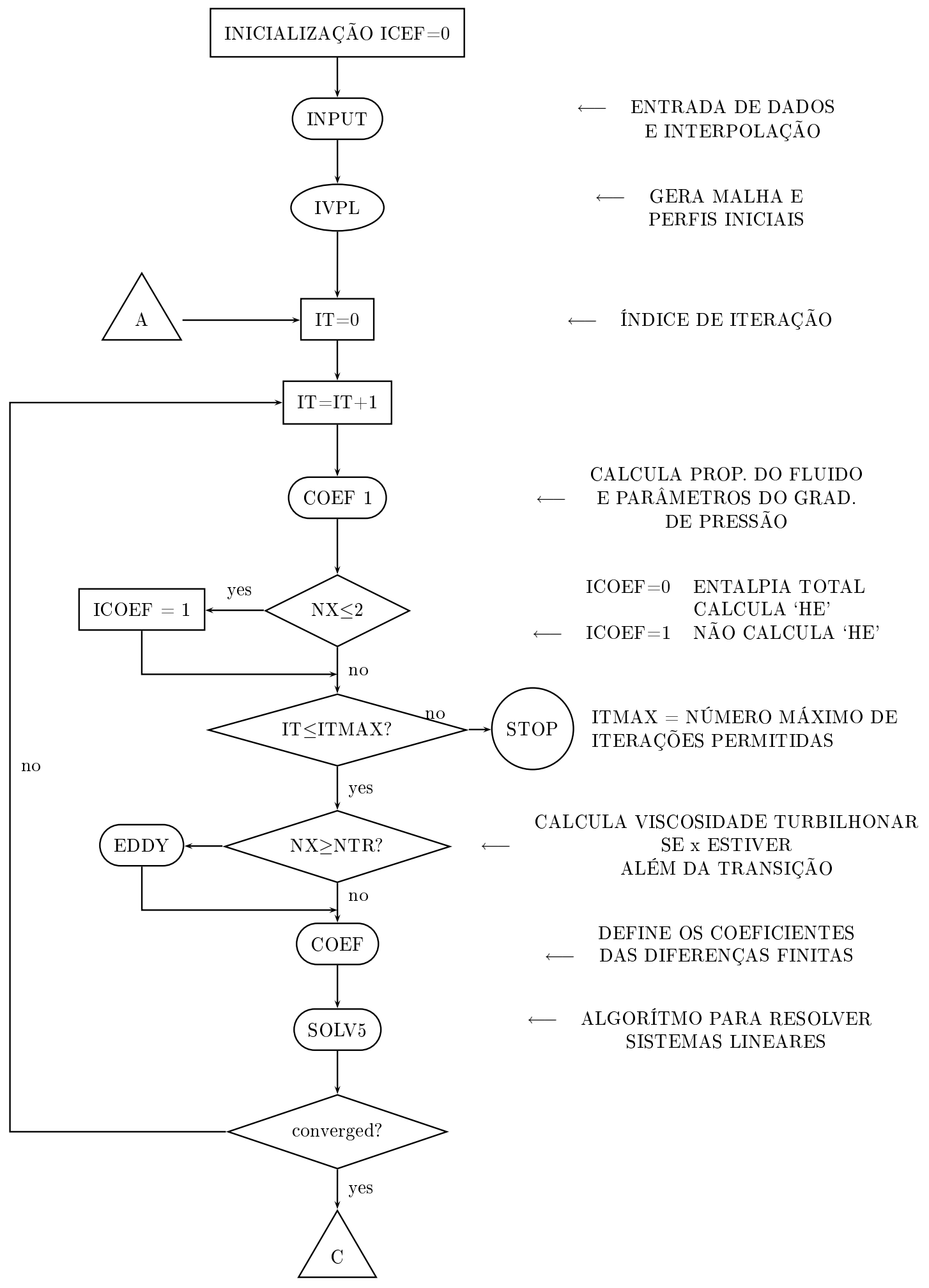

Figura B.3: Fluxograma para o programa BLP2C - Parte 1 


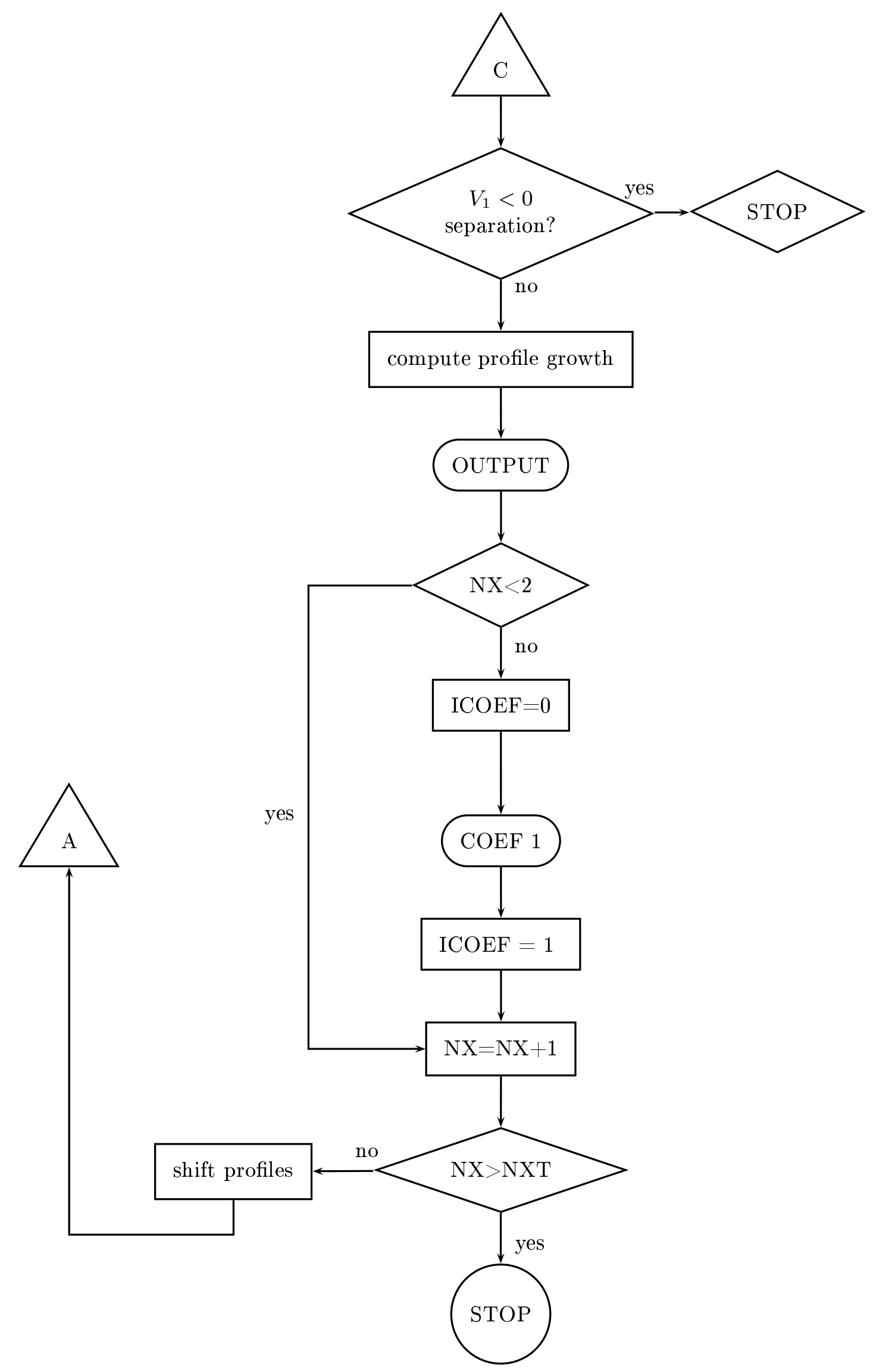

Figura B.4: Fluxograma para o programa BLP2C - Parte 2 


\section{B.2.9 Algoritmo - Programa Principal - MAIN}

O programa principal é composto pela rotina MAIN, que se utilizada das subrotinas mencionadas para outros cálculos. A rotina MAIN contém a lógica principal do programa, gera uma malha normal ao escoamento, calcula as propriedades do fluido e leva em conta o crescimento da camada-limite. Além disso, contém critérios de convergência das iterações. O parâmetro de convergência é a tensão na parede, $v_{0}$. Para uma escoamentos laminares, o cálculo é interrompido quando:

$$
\left|\delta v_{0}^{(i)}\right|<10^{-5}
$$

Este critério possibilita uma precisão de quatro dígitos na solução. Caso $v_{0}$ se torne negativo em alguma iteração, o processo é interrompido. Para escoamentos turbulentos, o critério de convergência é dado em termos de porcentagem:

$$
\left|\frac{\delta_{0}^{(i)}}{v_{0}+\delta_{0}^{(i)} / 2}\right|<0.02
$$

A malha gerada é não uniforme para levar em conta a variação do perfil de velocidades em um escoamento turbulento, que é mais rápida que em um escoamento laminar. Os parâmetros $\mu, \mathrm{c}, \mathrm{C}, \mathrm{b}$, e e d que aparecem nas equações de momento e energia transformadas são calculados como apresentados em seção anterior. A viscosidade dinâmica é calculada utilizando-se a fórmula de Sutherland:

$$
\mu=1,45 \cdot 10^{-6} \frac{T^{3 / 2}}{T+110} \quad\left[\mathrm{~kg} \mathrm{~m} m^{-1} s^{-1}\right]
$$

Para a maior parte das camadas-limite em regime laminar, espessura $\eta_{e}(x)$ é constante. Um valor de $\eta_{e}=8$ é suficiente para que a velocidade no bordo da camada-limite atinja 0.9999 da velocidade do escoamento livre. Para a camada-limite turbulenta, o valor de $\eta_{e}(x)$ cresce com valores crescentes de $x$. Para determinar estimar um valor para $\eta_{e}(x)$, requere-se que $\eta_{e}\left(x_{n}\right) \geq \eta_{e}\left(x_{n-1}\right)$. A rotina MAIN, após completar os cálculos para $x=x_{n},(n \geq 1)$, testa se $\left|v_{J}^{n}\right| \leq \epsilon_{v}$, onde $\eta_{J}=\eta_{e}(x)$ com $\epsilon_{v}=10^{-3}$, por exemplo. Caso o teste seja verdadeiro, faz-se $\eta_{e}\left(x_{n+1}\right)=\eta_{e}\left(x_{n}\right)$, ou seja, a camada-limite turbulenta não cresce mais. Caso o teste seja falso, a rotina MAIN adiciona novos pontos na direção perpendicular ao escoamento, $J_{\text {novo }}=$ $J_{v e l h o}+t$, onde t é o número de pontos adicionados. Os parâmetros $f_{j}^{n}, u_{j}^{n}, v_{j}^{n}, g_{j}^{n}, p_{j}^{n}$, $b_{j}^{n}$ e $e_{j}^{n}$ são calculados para os novos pontos $\eta_{j}$. Também são utilizados os valores $u_{J}=1, g_{J}=1, v_{j}^{n}=v_{J}^{n}, p_{j}^{n}=p_{J}^{n}, c_{j}^{n}=c_{J}^{n}, d_{j}^{n}=d_{J}^{n}, e_{j}^{n}=e_{J}^{n}, \mu_{j}^{n}=\mu_{J}^{n}, C_{j}^{n}=C_{J}^{n}$, $f_{j}^{n}=\left(\eta_{j}-\eta_{e}\right) u_{J}^{n}+f_{j}^{n}$. O mesmo procedimento é feito para a estação anterior, $(n-1)$. 


\section{B.2.10 Subrotinas}

Abaixo são apresentadas descrições breves das subrotinas do BLP2C.

INPUT Subrotina que especifica as condições de contorno na parede para a equação da energia, o número total de estações x (NXT), a localização da transição (NTR), o gradiente de pressão adimensional $m_{2}$ na primeira estação $x$, além dos parâmetros variáveis para a geração da malha.

Além disto, os parâmetros do escoamento livre, $M a_{\infty}, T_{\infty}$ e $p_{\infty}$, e o número de Prandtl molecular são calculados. Também se especifica $u_{e} / u_{\infty}$ como uma função da posição na superfície. Os gradientes de pressão adimensionais $m_{1}$ e $m_{2}$ são calculados numericamente, à exceção do primeiro ponto. A derivada $d u_{e} / d x$ é calculada utilizando uma interpolação lagrangiana por três pontos, à exceção dos primeiro e último pontos da malha.

Os valores de $\mu_{\infty}, u_{\infty}, \rho_{\infty}$, e $H_{e}$ são calculados para o ar utilizando as seguintes relações:

$$
\begin{aligned}
\mu_{\infty} & =1.45 \times 10^{-6} \frac{T_{\infty}^{3 / 2}}{T_{\infty}+110} \quad \mathrm{~kg} \mathrm{~m}^{-1} \mathrm{~s}^{-1}, \\
u_{\infty} & =20 \cdot 40 M_{\infty} \sqrt{T_{\infty}} \mathrm{m} \mathrm{s}^{-1}, \\
\rho_{\infty} & =\frac{p_{\infty}}{287 T_{\infty}} \mathrm{kg} \mathrm{m} \mathrm{m}^{-3} \\
H_{e} & =1004 T_{\infty}+\frac{1}{2} u_{\infty}^{2} \quad \mathrm{~m}^{2} \mathrm{~s}^{-2} .
\end{aligned}
$$

A temperatura deve ser especificada em Kelvin. Os valores de bordo de camadalimite, $T_{e}$ e $p_{e}$, são calculados por:

$$
\begin{aligned}
\frac{T_{e}}{T_{\infty}} & =1-\frac{\gamma-1}{2} M_{\infty}^{2}\left[\left(\frac{u_{e}}{u_{\infty}}\right)^{2}-1\right] \\
\frac{p_{e}}{p} & =\left(\frac{T_{e}}{T_{\infty}}\right)^{\gamma / \gamma-1}
\end{aligned}
$$

Para calcular $\mu_{e}$ e $\rho_{e}$ são utilizadas equações semelhantes à equação B.34, com a ressalva de que os valores de temperatura e pressão utilizados são aqueles calculados pelas equações anteriores. A condição de contorno é especificada utilizando a equação B.27, escolhendo-se adequadamente os valores de $\alpha$ de acordo com a condição de contorno escolhida. Ressalta-se que os valores de $u_{e}$ são dados na forma dimensional $m s^{-1}$ 
IVPL Subrotina que é utilizada para criar o perfil de velocidades inicial para um escoamento laminar compressível similar. Entretanto, inicialmente um perfil de escoamento laminar incompressível é gerado como chute inicial. Com as iterações para solução, é gerado o perfil de velocidades para o escoamento compressível laminar, transicional ou turbulento.

EDDY Subrotina que contém as equações utilizadas no modelo de turbulência de Cebeci e Smith (1974), como apresentado em B.2.1. As equações transformadas são implementadas, sem levar em os efeitos de transferência de massa e baixo número de Reynolds.

COEF Subrotina que gera os coeficientes das equações de momento e energia linearizadas, apresentadas no item B.2.5.

SOLV5 Subrotina que resolve o sistema linear obtido pelo método da eliminação de blocos, apresentado em B.2.6.

OUTPUT Subrotina que é responsável por gerar os resultados dos perfis de $f_{j}$, $u_{j}, v_{j}, g_{j}, p_{j}$ e $b_{j}$ como função ed $\eta_{j}$. São também fornecidos os parâmetros de camada-limite $\theta, \delta^{*}, H, c_{f}, N u_{x}, S t_{x}, R_{\theta}, R_{\delta^{*}}$, e $R_{x}$. Esses parâmetros integrais da camada-limite laminar, transicional e turbulenta são definidos por:

$$
\begin{aligned}
\delta_{2} & =\int_{0}^{\infty} \frac{\rho u}{\rho_{e} u_{e}}\left(1-\frac{u}{u_{e}}\right) d y=\frac{x}{\sqrt{R_{x}}} \int_{0}^{\infty} f^{\prime}\left(1-f^{\prime}\right) d \eta \\
\delta_{1} & =\int_{0}^{\infty}\left(1-\frac{\rho u}{\rho_{e} u_{e}}\right) d y=\frac{x}{\sqrt{R_{x}}} \int_{0}^{\infty}\left(c-f^{\prime}\right) d \eta, \\
H & =\frac{\delta_{1}}{\delta_{2}} \\
C_{f} & =\frac{\tau_{w}}{\frac{1}{2} \rho_{e} u_{e}^{2}}=\frac{2 C_{w}}{\sqrt{R_{x}}} f_{w}^{\prime \prime}, \\
N u_{x} & =\frac{\dot{q}_{w} X}{\left(T_{w}-T_{e}\right) k}=\frac{C_{w} g_{w}^{\prime} \sqrt{R_{x}}}{1-g_{w}}, \\
S t_{x} & =\frac{\dot{q}_{w}}{\rho_{e} u_{e}\left(H_{w}-H_{e}\right)}=\frac{C_{w} g_{w}^{\prime}}{\operatorname{Pr} \sqrt{R_{x}}\left(1-g_{w}\right)}, \\
R_{\theta} & =\frac{u_{e} \theta}{\nu_{e}}, \quad \operatorname{Re}_{\delta^{*}}=\frac{u_{e} \delta^{*}}{\nu_{e}}, \quad R_{x}=\frac{u_{e} X}{\nu_{e}} .
\end{aligned}
$$




\section{B.3 Descrição Breve do Código TEXSTAN}

O programa TEXSTAN avalia diferencialmente a camada-limite em escoamentos incompressíveis. Portanto, a formulação para a equação de Navier-Stokes apresentada na seção B.1 deve simplificada para:

$$
\bar{u} \frac{\partial u}{\partial x}+\bar{v} \frac{\partial u}{\partial y}=-\frac{1}{\rho} \frac{d p}{d x}+\frac{\partial}{\partial y}\left(\nu \frac{\partial \bar{u}}{\partial y}-\overline{u^{\prime} v^{\prime}}\right)
$$

As equações da conservação da massa e da energia também são escritas para um escoamento incompressível:

$$
\begin{gathered}
\frac{\partial}{\partial x} \bar{u}+\frac{\partial}{\partial y} \bar{v}=0 \\
\bar{u} \frac{\partial \bar{T}}{\partial x}+\bar{v} \frac{\partial \bar{T}}{\partial y}=\frac{\partial}{\partial y}\left(\frac{k}{\rho c_{p}} \frac{\partial \bar{T}}{\partial y}-\overline{T^{\prime} v^{\prime}}\right)
\end{gathered}
$$

\section{B.3.1 Equações para a camada-limite}

Assim como a modelagem apresentada na seção B.1, a turbulência nas equações para escoamento incompressível são modeladas utilizando o conceito de "viscosidade turbulenta aparente", com o uso do gradiente de pressão na borda da camada-limite dada pelo escoamento ao longe incompressível, adiabático, invíscido e irrotacional:

$$
\begin{aligned}
-\overline{u^{\prime} v^{\prime}} & =\epsilon_{m} \frac{\partial u}{\partial y} & -\overline{T^{\prime} v^{\prime}}=\frac{\epsilon_{m}}{\operatorname{Pr}_{t}} \frac{\partial u}{\partial y} \\
-\frac{d p}{d x} & =\rho_{e} u_{e}\left(\frac{d u_{e}}{d x}\right) &
\end{aligned}
$$

Substituindo essas expressões na equação B.37, obtém-se a equação RANS para a camada-limite turbulenta:

$$
\bar{u} \frac{\partial u}{\partial x}+\bar{v} \frac{\partial u}{\partial y}=-\frac{\rho_{e} u_{e}}{\rho} \frac{d u_{e}}{d x}+\frac{\partial}{\partial y}\left[\left(\nu-\epsilon_{m}\right) \frac{\partial u}{\partial y}\right]
$$

\section{B.3.2 Modelo de turbulência de Kays e Crawford (1993)}

O código TEXSTAN utiliza o modelo de comprimento de mistura desenvolvido por Kays e Crawford (1993) a partir dos conceitos criados por Prandt:

$$
\left(\epsilon_{m}\right)_{i}=I^{2}\left|\frac{\partial u}{\partial y}\right|^{2}
$$




$$
\begin{gathered}
I=\min \left\{\kappa y\left[1-\exp \left(-\frac{y^{+}}{A^{+}}\right)\right], \lambda \cdot \delta\right\} \\
A^{+}=\frac{25}{a\left\{v_{w}^{+} b\left[p^{+} /\left(1+c v_{w}^{+}\right)\right]\right\}+1} \\
\lambda=\min \left[0,085, \frac{0,24944}{\left(\operatorname{Re}_{\delta_{2}}\right)^{0,0125}}\left(1-67,5 \frac{v_{s}}{U_{\infty}}\right)\right]
\end{gathered}
$$

\section{B.3.3 Equações de Transporte}

O código TEXSTAN escreve as equações de transporte de momento, energia e massa em escoamentos que obedeçam a aproximação de camada-limite. As equações presentes são escritas sob a forma turbulenta para um escoamento axissimétrico. Por resolver o escoamento em regime permanente, as equações de transporte assumem a forma geral:

$$
\text { convection }(\phi)=\text { diffusion }(\phi) \pm\{\text { sources }(\phi)\}
$$

Portanto, a obtenção das equações de transporte de momento, energia e massa são obtidas através da escolha adequada de $\varphi$. A equação B.47 apresenta a forma geral para uma equação de transporte, em coordenadas cilíndricas. O coeficiente $C$ representa o coeficiente adimensional apropriado para o transporte efetivo das variáveis escalares, $\phi$. O termo $S_{\phi}$ representa o termo fonte das variáveis. Assim, tem-se que:

$$
\rho u \frac{\partial \phi}{\partial x}+\rho v \frac{\partial u}{\partial y}=\frac{1}{r} \frac{\partial}{\partial y}\left(r \frac{\mu_{\text {eff }}}{C} \frac{\partial \phi}{\partial y}\right)+\left\{S_{\phi}\right\}
$$

Nesta equação, $\mu_{\text {eff }}$ é a viscosidade efetiva definida por:

$$
\mu_{\text {eff }}=\mu+\mu_{t}=\rho\left(\nu+\epsilon_{m}\right)
$$

A tabela B.1 apresenta cada uma das constantes a serem aplicadas, sendo que cada equação é representada por:

- u: equação de momento na camada-limite;

- $i^{*}$ : equação de entalpia de estagnação na camada-limite;

- T: equação da temperatura

A equação da temperatura, apresentada abaixo, é obtida através da redefinição do coeficiente de difusão $\mathrm{C}$ por $\left(\mu_{\text {eff }} / P r_{\text {eff }}\right)=\left(k_{\text {eff }} / c\right)$ na equação da entalpia de 
estagnação. Pode-se escrever:

$$
\begin{gathered}
k_{\text {eff }}=k+k_{t}=k+\rho c \epsilon_{H} \\
P r_{\text {eff }}=\frac{\mu_{\text {eff }}}{k_{\text {eff }} / c}=\frac{1-\epsilon_{M} / \nu}{1 / \operatorname{Pr}+\left(\epsilon_{M} / \nu\right) / P r_{t}}
\end{gathered}
$$

Tabela B.1: Coeficientes para a equação de transporte

\begin{tabular}{ccc}
\hline$\phi$ & $\mathrm{C}$ & $S_{\phi}$ \\
\hline $\mathrm{u}$ & 1 & $-\frac{d P}{d x}+X$ \\
$i^{*}$ & $P r_{\text {eff }}$ & $\frac{1}{r} \frac{\partial}{\partial y}\left[r \mu_{\text {eff }}\left(1-\frac{1}{P r_{\text {eff }}}\right) \frac{\partial\left(1 / 2 u^{2}\right)}{\partial y}+u X+S\right]$ \\
$\mathrm{T}$ & $P r_{\text {eff }}$ & $\frac{\mu_{\text {eff }}}{c}\left(\frac{\partial u}{\partial y}\right)^{2}$ \\
\hline
\end{tabular}

A equação para o transporte de massa de uma substância $\phi=m_{j}$ para um escoamento laminar é:

$$
\rho u \frac{\partial m_{j}}{\partial x}+\rho v \frac{\partial m_{j}}{\partial y}=\frac{1}{\rho} \frac{\partial}{\partial y}\left(r \frac{\mu}{S c_{j}} \frac{\partial m_{j}}{\partial y}\right)
$$

O termo de difusão pode ser redefinido por $\mu / S c_{j}=\gamma_{j}$. A versão turbulenta desta equação não foi amplamente validada como as de quantidade de movimento, energia e massa.

As equações são apresentadas em coordenadas axissimétricas, para possibilitar a solução de escoamentos axissimétricos. Fazendo $r=1$ tem-se as equações em sistema de coordenadas cartesiano.

\section{B.3.4 Condições de Contorno}

O código TEXSTAN apresenta duas condições de contorno para o escoamento externo, uma junto à parede e outra na borda superior da camada-limite, apresentadas na figura B.5. Para a parede, a condição de contorno padrão é a adesão completa do fluido, ou seja, $u_{\text {wall }}=0$. O vetor de velocidades normal à parede pode ser nulo ou não nulo para o caso de transpiração na parede. Resumindo, para a equação de quantidade de movimento é dada por:

$$
\begin{aligned}
u(x, y=0) & =0 \\
v(x, y=0) & =v_{s}(x)=\dot{m}_{s}(x) / \rho_{s} \\
u(x, y \rightarrow \infty) & =u_{\infty}(x)
\end{aligned}
$$




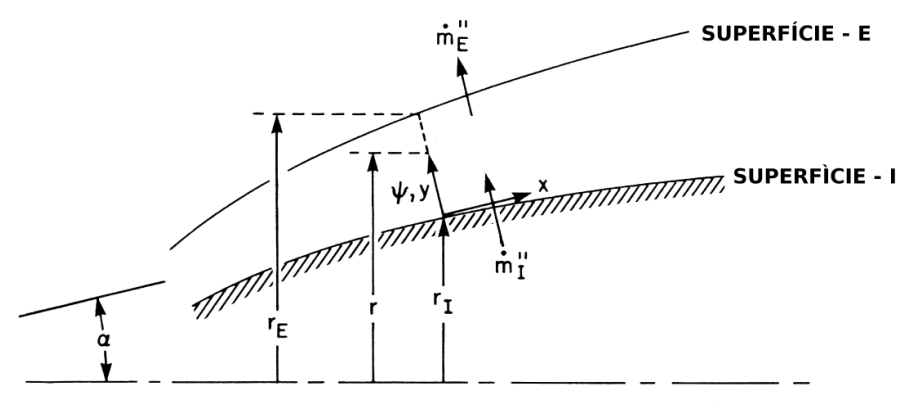

Figura B.5: Condições de contorno para o código TEXSTAN

Para solucionar a equação da energia, a superfície pode ser não-isotérmica ou ter fluxo de calor variável. Para a borda da camada-limite, caso o escoamento apresente velocidades maiores ( $\mathrm{Ma}>0.3$ ), a equação da entalpia é solucionada e a condição de contorno a ser especificada é a temperatura de estagnação, a ser convertida em entalpia de estagnação. Caso o escoamento seja de baixas velocidades, a temperatura estática do escoamento ao longe é a condição de contorno. Estas condições de contorno estão resumidas abaixo:

$$
\begin{gathered}
T(x, y=0)=T_{s}(x) \quad \text { or } \quad \dot{q}^{\prime \prime}(x, y=0)=\dot{q}_{s}(x) \\
i^{*}=(x, y \rightarrow \infty)=i_{\infty}^{*}=\left(c T_{\infty}+u_{\infty}^{2} / 2\right) \quad \text { or } \quad T(x, y \rightarrow \infty)=T_{\infty}
\end{gathered}
$$

\section{B.3.5 Condições Iniciais}

O domínio da resolução do escoamento é compreendido entre as bordas superior e inferior (superfície) da camada-limite. As propriedades do escoamento no início do domínio ( $x$ inicial) são conhecidas. Existem duas possibilidades para a escolha dos perfis iniciais: o usuário pode entrar com perfis "experimentais" ou permitir ao TEXSTAN gerar os perfis de velocidade no regime laminar por meio admitindo o escoamento sobre cantos, ou de Falkner-Skan.

\section{B.3.6 Propriedades Termodinâmicas}

O código TEXSTAN pode trabalhar com propriedades constantes ou variáveis. Para o uso de propriedades constantes, deve-se fornecer quantidades tais como densidade, viscosidade dinâmica e número de Prandtl. Fluidos com propriedades variáveis as tem fornecidas através de subrotinas. O TEXSTAN apresenta três modelos para ar com propriedades variáveis: 1) interpolação de tabelas com propriedades para o ar; 2) cálculo por meio de gás perfeito e equação de Sutherland no cálculo da 
viscosidade dinâmica; 3) avaliação com modelos incorporam efeitos de escoamento com alta velocidade.

\section{B.3.7 Modelos de Turbulência}

Há três tipos de modelos de turbulência no TEXSTAN: 1) algébrico: comprimento de mistura de Prandtl com amortecimento de Van Driest; 2) uma equação: energia cinética turbulenta $k 3$ ) duas equações: diversos modelos de $k-\epsilon$ para baixo número de Reynolds. No entanto, no presente trabalho, somente os comprimentos de mistura são utilizados. O fluxo de calor turbulento é solucionado através do conceito de número de Prandtl (ou Schmidt) turbulento. Apresenta-se o modelo de comprimento de mistura de Prandtl, uma vez que este foi utilizado. Sendo assim:

$$
\mu_{t}=\rho l^{2}\left|\frac{\partial u}{\partial y}\right|, \quad \epsilon_{M}=l^{2}\left|\frac{\partial u}{\partial y}\right|
$$

A formulação completa para o comprimento de mistura é:

$$
\begin{gathered}
I(y)=\left\{\begin{array}{l}
\kappa y D \\
\lambda \delta_{99}
\end{array}\right. \\
D=\left(1-e^{-y^{+} / A^{+}}\right) \\
I(y)=\min \left(\kappa y D, \lambda \delta_{99}\right)
\end{gathered}
$$

Nestas, $D$ é a função de amortecimento de Van Driest; $A^{+}$é a constante de amortecimento da subcamada; $y^{+}$é a distância adimensional da parede em coordenadas da parede; $\mu_{t}$ é a velocidade de atrito ou de cisalhamento; as constantes do modelo são $\kappa$, a constante de von Kármán, e $\lambda$, a constante da região externa à camada. Para escoamentos externos, a espessura de camada-limite $\delta_{99}$ é dada quando $u / u_{\infty}=0.99$.

O TEXSTAN permite a escolha do modelo utilizado para o cálculo da viscosidade turbulenta por meio do valor da variável de controle ktmu.. Os valores das constantes para cada ktmu, para escoamentos externo, são apresentados na tabela B.2. Observa-se que $k t m u=2$ permite a escolha dos valores pelo usuário através de $a x x$, bxx e cxx.

A função $A^{+}$representa a subcamada e seu valor é afetado pela condição de contorno na parede devido à rugosidade ou transpiração, além das fontes de quantidade de movimento existentes na camada-limite, tais como gradientes de pressão. Como pode ser visto na tabela, o valor de $A^{+}$está relacionado ao parâmetro de gradiente 
Tabela B.2: constantes do modelo de turbulência

\begin{tabular}{cl}
\hline ktmu & Escolhas para o modelo de turbulência em esc. externo \\
\hline 1 & $\kappa=0.41, \lambda_{\infty}=0.085, A_{\infty}^{+}=25$ \\
2 & $\kappa=a x x, \lambda_{\infty}=b x x, A_{\infty}^{+}=c x x$ \\
3 & $\kappa=0.41, \lambda_{\infty}=f n\left(\lambda_{\infty}, R e_{\delta_{2}}, v_{s} / u_{\infty}\right), A_{\infty}^{+}=25$ \\
4 & $\kappa=0.41, \lambda_{\infty}=0.085, A_{\infty}^{+}=f n\left(A_{\infty}^{+}, p^{+}, v_{s}^{+}\right)$ \\
5 & $\kappa=0.41, \lambda_{\infty}=f n\left(\lambda_{\infty}, R e_{\delta_{2}}, v_{s} / u_{\infty}\right), A_{\infty}^{+}=f n\left(A_{\infty}^{+}, p^{+}, v_{s}^{+}\right)$ \\
\hline
\end{tabular}

de pressão adimensional $p^{+}$e ao parâmetro de transpiração na parede $v_{s}^{+}$.

\section{B.3.8 Modelos de Transição}

O TEXSTAN é capaz de analisar escoamentos com a presença de transição laminar-turbulenta. Para baixas intensidades de turbulência, $T u<1 \%$, o modelo de transição deve ser acoplado com algum método de avaliação da estabilidade linear para representar satisfatoriamente o escoamento. O TEXSTAN não trabalha com tais valores baixos de Tu e se propõe apenas a avaliar escoamentos sujeitos a transição de contorno (do tipo bypass).

Há três modelos de transição com base no comprimento de mistura. Dois modelos são baseados no conceito de intermitência, um deles desenvolvido por AbuGhannam e Shaw (1980) e o outro por Mayle (1991). Um terceiro modelo (CRAWFORD; KAYS, 1976) utiliza uma função $A^{+}$de Van Driest que varie de forma suave para simular a transição.

\section{B.3.9 Método numérico}

A equação geral de transporte generalizada, apresentada na seção B.3.3, é reapresentada a seguir:

$$
r \rho u \frac{\partial \phi}{\partial x}+r \rho v \frac{\partial \phi}{\partial y}=\frac{\partial}{\partial y}\left(r \frac{\mu_{\text {eff }}}{C} \frac{\partial \phi}{\partial y}\right)+\left\{S_{\phi}\right\}
$$

Para a solução numérica, é aplicada uma transformação de coordenadas. As variáveis independentes $(x, y)$ são transformadas em $(x, \psi)$ através da introdução da função de corrente, $\psi$, utilizando de transformação de von Mises. Posteriormente as variáveis independentes são transformadas de $(x, \psi)$ para as coordenadas de Patankar-Spalding $(x, \omega)$, nas quais $\omega$ é a função de corrente adimensional. Após as 
transformações, a equação de transporte generalizada é dada por:

$$
\frac{\partial \phi}{\partial x}+\left(\frac{a+b \omega}{\Delta \Psi}\right) \frac{\partial \phi}{\partial \omega}=\left(\frac{1}{\Delta \Psi}\right) \frac{\partial}{\partial \omega}\left(r j_{\phi}\right)+\left\{\frac{1}{r \rho U} S_{\phi}\right\}
$$

Nesta equação, são definidos:

$$
\begin{gathered}
j_{\phi}=\frac{\mu_{e f f}}{C} \frac{\partial \phi}{\partial y} \\
a=r_{l} \dot{m}_{l}^{\prime \prime} \\
b=\left(r_{E} \dot{m}_{E}^{\prime \prime}-r_{l} \dot{m}_{l}^{\prime \prime}\right) \\
\Delta \Psi=\left(\Psi_{E}-\Psi_{l}\right)
\end{gathered}
$$

Os sub-índices I e E referem-se à parede e ao bordo da camada-limite no TEXSTAN. A solução da equação B.56 é feita utilizando o método os volumes finitos em um domínio compreendido entre I e E na direção perpendicular ao escoamento e a posição x na qual as condições iniciais são especificadas.

A solução compreende quatro passos básicos:

1) Subdividir a o domínio em diversos subdomínios, chamados de volumes finitos;

2) Identificar a localização que represente a variável dependente $(\phi)$ dentro do volume;

3) Desenvolver um método que relacione o valor da variável dependente no volume finito àqueles da mesma variável nos volumes finitos vizinhos;

4) Resolver o sistema de equações obtidos para encontrar $\phi(x, \omega)$ e, então, transformá-lo de volta à $\phi(x, y)$

As equações a serem resolvidas são parabólicas, ou seja, sua solução independe da posição da condição inicial. Entretanto, em escoamentos externos, a condição inicial não pode ser dada em um ponto de singularidade, como por exemplo o ponto de estagnação, devido à natureza da transformação e von Mises.

Para se relacionar o valor da variável dependente em uma célula com seus vizinhos, diversos métodos podem ser estabelecidos. De uma forma geral, todos estes métodos se valem da substituição das equações diferenciais por equações de diferenças finitas, as quais se tornam as equações algébricas da solução.

As equações de diferença formam, então, um sistema de equações. Assim a matriz tridiagonal é iterada até a convergência da solução. 


\section{ANEXO C - ANÁLISE LINEAR DE ESTABILIDADE DO ESCOAMENTO LAMINAR}

\section{C.1 Introdução}

Se as perturbações ambientais forem suficientemente pequenas, a aplicação da análise de estabilidade linear à simulação de sistemas antigelo de aerofólios pode melhorar as previsões da posição inicial da transição laminar turbulenta em relação ao uso das correlações empíricas clássicas. Pois análise de estabilidade representa satisfariamente os fenômenos físicos, que ocorrem na transição natural. As correlações empíricas possuem aplicabilidade limitada às condições experimentais utilizadas na sua dedução ou interpolação. Esta aplicação serve, também, como referência para a análise dos dados experimentais ou dos resultados numéricos, pois fornece a distância entre o início da transição real (causada por perturbações de maior amplitude) e a posição onde poderia ser a transição natural (causadas por perturbações infinitesimais). Além disso, a aplicação da análise linear pode estimar o ponto de indiferença (onde o escoamento laminar é estável), algumas propriedades do escoamento laminar perturbado e na região da transição laminar-turbulenta (HASSAN, 2006).

A utilização da análise linear de estabilidade em simulação de sistemas antigelo não foi encontrada na literatura pesquisada. Entretanto, diversos autores implementaram, a análise de estabilidade acoplada a códigos de camada-limite (integrais e diferenciais) em torno de aerofólios (DRELA; GILES, 1987; CEBECI, 1989b; CEBECI, 1999; HASSAN, 2006).

Devido a linearização das equações do movimento, espera-se que a previsão de início da transição laminar-turbulenta apresente maior desvio em relação aos dados experimentais nos casos de perturbações de maior amplitude. Isso pode ser encontrado em escoamentos com alto nível turbulência (por exemplo, em túneis de gelo) ou sujeitos à perturbações significativas na superfície (por exemplo, características da rugosidade e distribuição não uniforme da temperatura de superfície). 


\section{C.2 Modelo Matemático para Estabilidade Linear}

Aplicando as equações de Navier-Stokes por média de Reynolds, RANS, para o escoamento incompressível na camada-limite laminar, Schlichting e Gersten (2000) definem:

$$
\begin{gathered}
\frac{\partial u^{\prime}}{\partial t}+U \frac{\partial u^{\prime}}{\partial x}+v^{\prime} \frac{\partial U}{\partial y}+\frac{1}{\rho} \frac{\partial p^{\prime}}{\partial x}=\nu \Delta u^{\prime} \\
\frac{\partial u^{\prime}}{\partial t}+U \frac{\partial v^{\prime}}{\partial x}+\frac{1}{\rho} \frac{\partial p^{\prime}}{\partial y}=\nu \Delta v^{\prime} \\
\frac{\partial u^{\prime}}{\partial x}+\frac{\partial v^{\prime}}{\partial y}=0
\end{gathered}
$$

onde,

$$
\begin{gathered}
U=U(y) \quad \text { e } \quad V=W=0 \\
u=U+u^{\prime} \\
v=V+v^{\prime} \\
w=0 \quad \text { e } \quad p=P+p^{\prime} \\
\Delta \equiv \partial^{2} / \partial x^{2}+\partial^{2} / \partial y^{2}
\end{gathered}
$$

Para analisar a estabilidade da camada-limite, uma tentativa de solução é utilizada para que função de corrente inclua um modo de perturbação:

$$
\psi(x, y, t)=\varphi(y) e^{i(\alpha x-\beta t)}
$$

onde $\alpha$ é o número de onda, $\lambda=2 \pi / \alpha$ é comprimento de onda, e $\beta=\beta_{r}+i \beta_{i}$ é o modo de freqüência, sendo $\beta_{i}$ o fator de amplificação temporal. Se $\beta_{i}<0$, a onda é amortecida e o escoamento laminar é estável. Se $\beta_{i}>0$, há instabilidades.

É conveniente definir uma velocidade de fase como:

$$
c=\frac{\beta}{\alpha}=c_{r}+i c_{i}
$$

onde $c_{i}$ também é um fator de amplificação da escala de velocidade. Se $c_{i}<0$, a onda é amortecida e o escoamento laminar é estável. Se $c_{i}>0$, há instabilidades.

A função de amplitude da perturbação $\varphi(y)$ é dependente somente de $y$, desde que o escoamento médio também só dependente de $y$. Logo, as componentes de 
perturbação das velocidades são escritas como:

$$
\begin{gathered}
u^{\prime}=\frac{\partial \psi}{\partial y}=\varphi^{\prime}(y) e^{i(\alpha x-\beta t)} \\
v^{\prime}=\frac{-\partial \psi}{\partial x}=-i \varphi^{\prime}(y) e^{i(\alpha x-\beta t)}
\end{gathered}
$$

Inserindo as Eqs. (C.7) e (C.8) nas Eqs. (C.1), (C.2), e (C.3) eliminando a pressão, o resultado é a seguinte equação ordinária diferencial de quarta ordem, chamada de Orr-Sommerfeld:

$$
(U-c)\left(\varphi^{\prime \prime}-\alpha^{2} \varphi\right)-U^{\prime \prime} \varphi=\frac{i}{\alpha R e}\left(\varphi^{\prime \prime \prime}-2 \alpha \varphi^{\prime \prime}+\alpha^{4} \varphi\right)
$$

onde cada apostrofo (') equivale a uma derivação $\partial / \partial(y / b)$ ou $\partial / \partial(y / \delta)$, e, dependendo da coordenada adimensional, o número de Reynolds pode ser $R e=$ $U_{e} b / \nu$ ou $R e=U_{e} \delta / \nu$.

As condições de contorno para a Eq. (C.9) são:

$$
\begin{aligned}
& y=0 \Rightarrow u^{\prime}=v^{\prime}=0: \varphi=0: \varphi^{\prime}=0 \\
& y=\infty \Rightarrow u^{\prime}=v^{\prime}=0: \varphi=0: \varphi^{\prime}=0
\end{aligned}
$$

Se o efeito da viscosidade for desprezado ou se $R \rightarrow \infty$, a Eq. (C.9) é reduzida para:

$$
(U-c)\left(\varphi^{\prime \prime}-\alpha^{2} \varphi\right)-U^{\prime \prime} \varphi=0
$$

A Eq. (C.12) é a equação de Rayleigh, que é de segunda ordem, logo, somente duas das quatro condições de contorno podem ser satisfeitas:

$$
\begin{aligned}
& y=0 \Rightarrow \varphi=0 \\
& y=\infty \Rightarrow \varphi=0
\end{aligned}
$$

Para analisar o limite de estabilidade de um escoamento, faz-se $c_{i}=0$, resolve-se as Eq. (C.9) para escoamento viscoso, ou Eq. (C.12), para o invíscido. Desse modo, as curvas de estabilidade neutra pode ser traçadas. A Fig. C.1 apresenta as curvas de estabilidade neutra para escoamentos viscosos e invíscidos para a camada-limite de Blasius. O escoamento pode ser instável se tiver na parte interna da curva, e certamente estável se estiver na parte externa. O ponto de inflexão no perfil de velocidades é uma condição suficiente como mostram as curvas da Fig. C.1. A determinação do ponto de indiferença pode ser feita por meio da curva de estabilidade neutra como mostrado na Fig. C.1. 


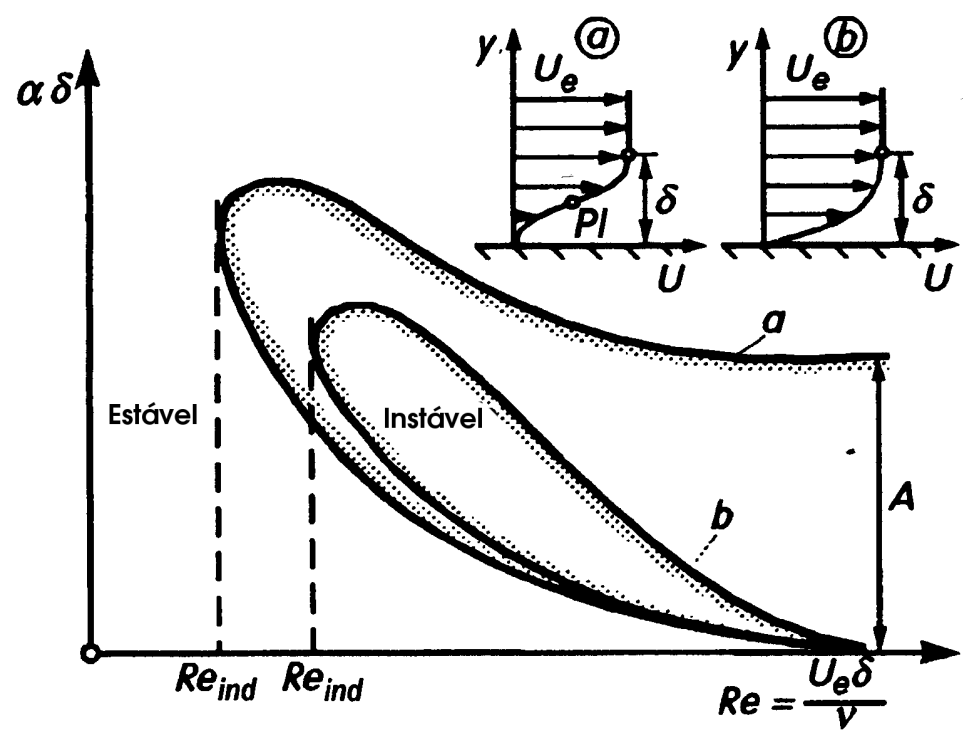

Figura C.1: Curva de estabilidade neutra para (a) Rayleigh e (b) Orr-Sommerfeld. 0 perfil de velocidade (a) tem ponto de inflexão $\mathrm{PI}$ e $\mathrm{o}(\mathrm{b})$ não tem ponto de inflexão (SCHLICHTING; GERSTEN, 2000)

A teoria da estabilidade linear apresenta resultados satisfatórios quando comparada com dados experimentais como apresentado na Fig. C.2. O $\operatorname{Re}_{i}$ nd calculado por Tollmien como 420, ao invés, do valor reconhecido 520 devido à presença de perturbações acústicas nos túneis de vento mais antigos (REED; SARIC, 2006).

As Figs. (C.3) e (C.4) apresentam o efeito do gradiente de pressão sobre a posição da estabilidade neutra e do ponto de indiferença. Quando há aceleração do escoamento ( $d p / d x<0$ ou $\left.d U_{e} / d x>0\right)$, o escoamento é mais estável do que quando o escoamento está desacelerando $\left(d p / d x>0\right.$ ou $\left.d U_{e} / d x<0\right)$. Para números negativos de $\Lambda=\left(\delta_{1}^{2} / \nu\right)\left(d U_{e} / d x\right)$, o $\operatorname{Re}_{\delta 1}$ no ponto de indiferença é menor do que 520 .

O efeito da temperatura de superfície, ou da transferência de calor, pode ser estimado considerando a dependência da viscosidade. Pode-se escrever, na superfície, que:

$$
\left(\frac{d^{2} U}{d y^{2}}\right)_{w}=\frac{-1}{\mu_{w}}\left(\frac{d \mu}{d y}\right)_{w}\left(\frac{d U}{d y}\right)_{w}
$$

Se a superfície estiver numa temperatura mais alta que o escoamento de ar, $T_{w}>T_{\infty[20 ?]}$, o gradiente de temperatura na parede é negativo e o termo $\left(\frac{d \mu}{d y}\right)_{w}<0$ - O gradiente de velocidade na parede é positivo, logo, teremos $\left(\frac{d^{2} U}{d y^{2}}\right)_{w}>0$ na parede. Para $y \rightarrow \infty$, o termo $\left(\frac{d^{2} U}{d y^{2}}\right)_{w}<0$. Logo há um ponto de inflexão, que é condição suficiente para instabilidade do escoamento. Assim, se o fluido estiver sendo aquecido, o escoamento sofre uma instabilização. Por outro lado, o resfriamento do ar causa uma estabilização. 


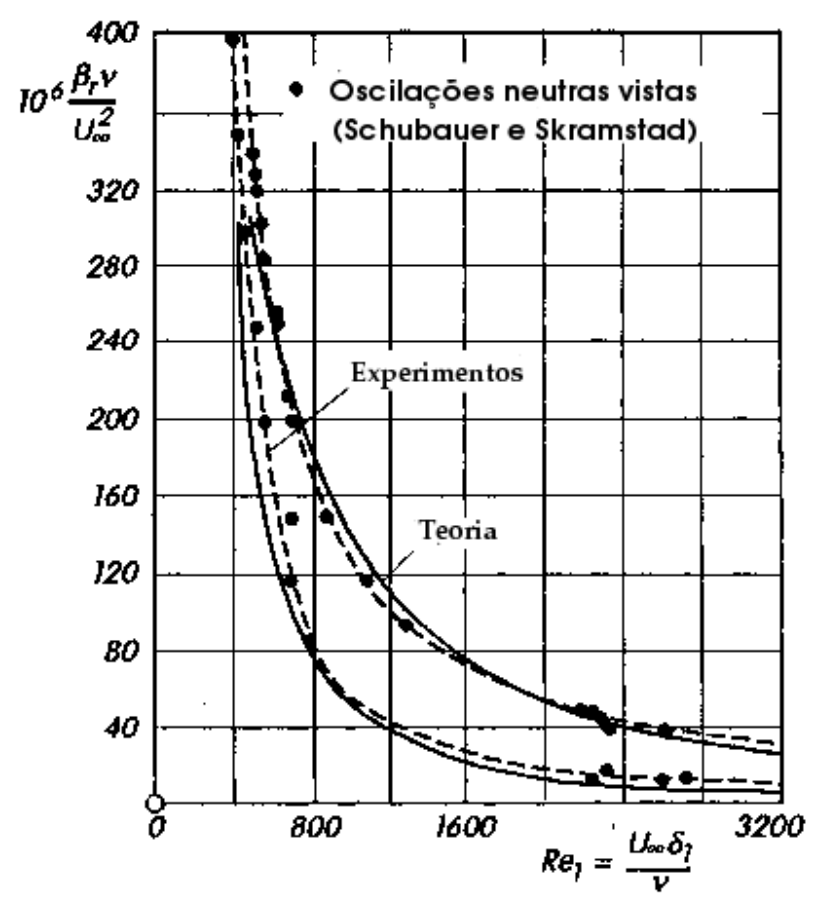

Figura C.2: Comparações das medições de Schubauer e Skramstad (1948) com as previsões de Tollmien em 1927 (SCHLICHTING; GERSTEN, 2000)

O efeito da temperatura pode ser descrito por:

$$
R e_{\text {ind }}=\left(R e_{\text {ind }}\right)_{\infty}\left[1+\frac{T_{w}-T_{\infty}}{T_{\infty}}\left(\frac{d \mu}{d T} \frac{T}{\mu}\right) A_{\mu}\left(\operatorname{Pr}_{\infty}\right)\right]
$$

Para placas planas com Tw constante, $A_{\mu}\left(\operatorname{Pr}_{\infty}\right)=-1.2$. Outras condições, como fluxo de calor constante na parede ou densidade variável com a temperatura foram tabelas por HERWIG e SCHAEFER (SCHLICHTING; GERSTEN, 2000, apud).

A Fig. C.5 apresenta o efeito da temperatura de superfície nas curvas de estabilidade neutra.

\section{C.3 Estabilidade Linear por meio do Método $e^{9}$}

O cálculo de engenharia mais utilizado para prever a transição, do regime laminar para o turbulento, em escoamentos de camadas-limite em torno de aerofólios é o chamado método e9.

O método e9 fornece respostas satisfatórias para objetivos de engenharia, pois as pequenas perturbações, observadas na condição de transição natural, permitem a aplicação da teoria de estabilidade linear com sucesso.

Porém quando o processo de transição natural é contornado (bypass), devido a perturbações finitas de maior intensidade sofridas pela camada-limite, o mecanismo 


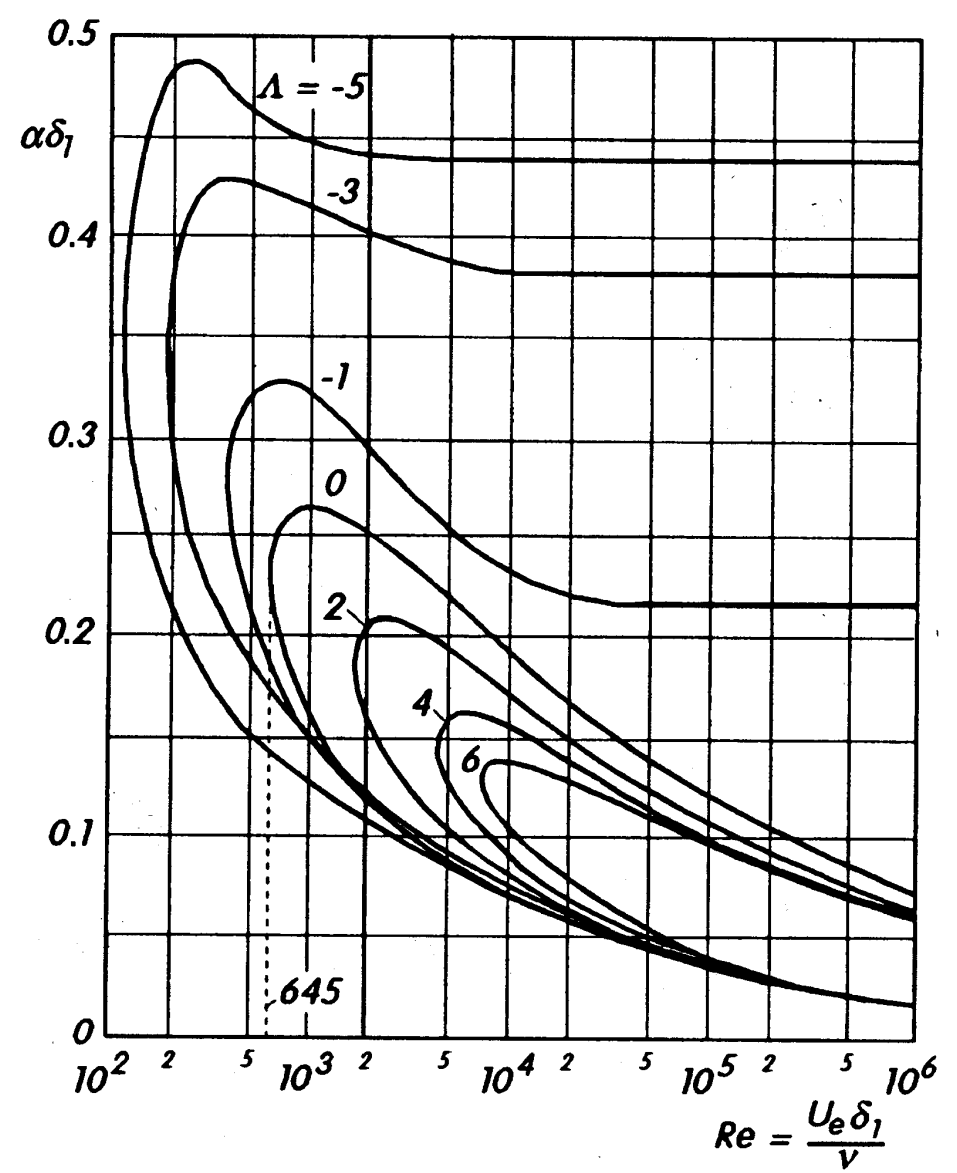

Figura C.3: Curvas de estabilidade neutra para vários gradientes de pressão, representado pelo fator de gradiente de pressão $\Lambda=\left(\delta_{1}^{2} / \nu\right)\left(d U_{e} / d x\right)$

(SCHLICHTING; GERSTEN, 2000)

de amplificação não-linear é dominante e o desenvolvimento da transição não pode mais ser descrito mais pelas equações de estabilidade linear.

\section{C.4 Previsão do início da transição laminar- turbulenta}

A equação de Orr-Sommerfeld pode ser escrita como:

$$
v\left(\frac{\partial^{4} \phi}{d y^{4}}-2 \alpha \frac{\partial^{2} \phi}{d y^{2}}+\alpha^{4} \phi\right)=i\left[(\alpha u-\omega)\left(\frac{\partial^{2} \phi}{d y^{2}}-\alpha^{2} \phi\right)-\alpha \frac{\partial^{2} u}{d y^{2}} \phi\right]
$$

onde u é o perfil de velocidades na direção do escoamento e $\phi(y) \equiv \phi_{r}+i \phi_{i}$ é a amplitude complexa da perturbação da função de linha de corrente $\psi$ ', definida por:

$$
u^{\prime}=\frac{\partial \psi^{\prime}}{\partial y} \quad \text { e } \quad v^{\prime}=-\frac{\partial \psi^{\prime}}{\partial x}
$$

O comprimento de onda das perturbações é definido como $\lambda=2 \pi / \alpha$, onde 


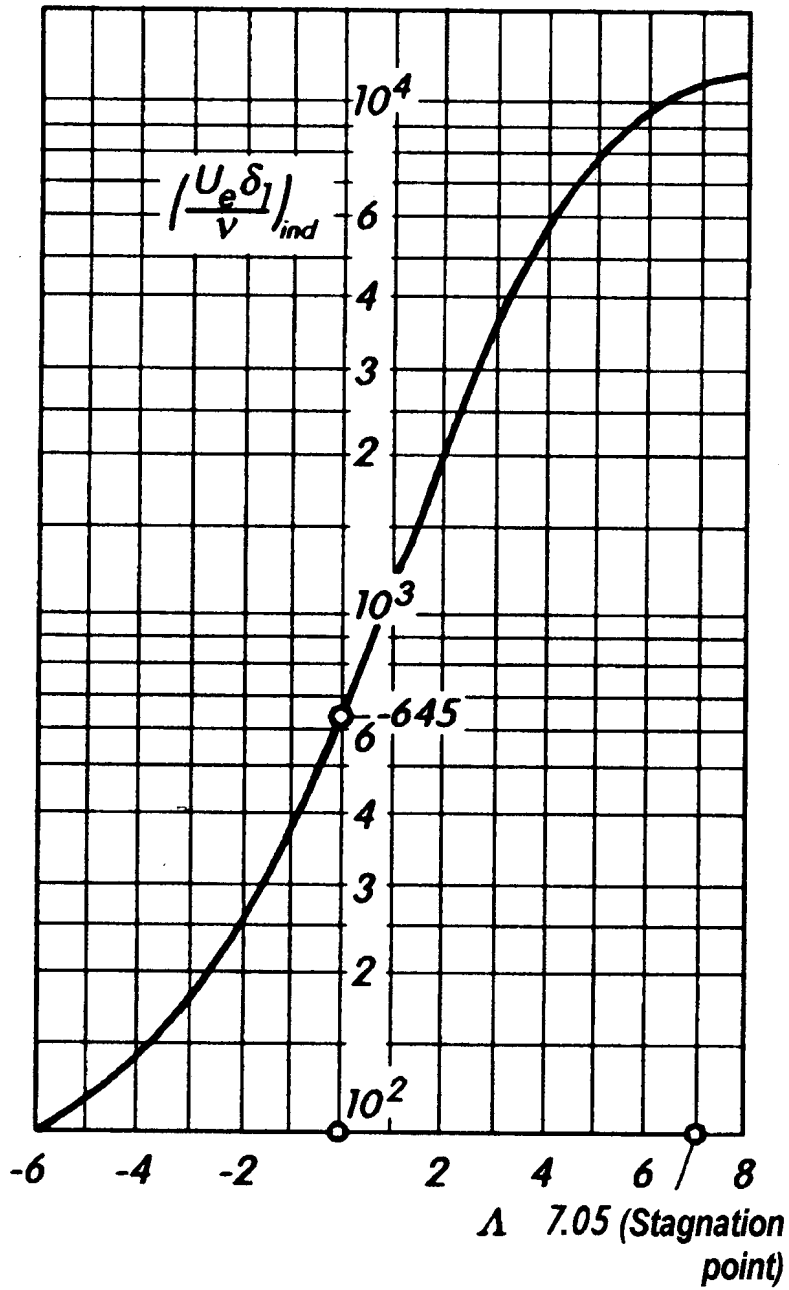

Figura C.4: $\mathbf{R e}_{\delta 1}$ no ponto de indiferença em função do fator de gradiente de pressão $\Lambda=\left(\delta_{1}^{2} / \nu\right)\left(d U_{e} / d x\right)($ SCHLICHTING; GERSTEN, 2000)

$\alpha=\alpha_{r}+i \alpha_{i}$ é o número de onda, e a freqüência angular é definida como $\omega=\omega_{r}+$ $i \omega_{i}$. A amplificação espacial das perturbações é relacionada com $\alpha$ e a amplificação temporal $\operatorname{com} \omega$.

A equação de Orr-Sommerfeld adimensionalizada é escrita como:

$$
\frac{\partial^{4} \phi}{d y^{4}}-2 \alpha_{l} \frac{\partial^{2} \phi}{d y^{2}}+\alpha_{l}^{4} \phi=i R e \cdot\left[\left(\alpha_{l} \bar{u}-\bar{\omega}\right)\left(\frac{\partial^{2} \phi}{d y^{2}}-\alpha_{l}^{2} \phi\right)-\alpha_{l} \frac{\partial^{2} \bar{u}}{d y^{2}} \phi\right]
$$

onde, $\alpha_{l}=\alpha \cdot l \quad, \quad \bar{u}=\frac{u}{u_{0}}, \quad \bar{\omega}=\frac{u_{0} \omega}{l}$ e $R e=\frac{u_{0} l}{v}$

Na parede as condições de contorno são:

$$
\bar{y}=0 \Rightarrow \phi=0 \quad \text { e } \quad \frac{\partial \phi}{\partial y}=0
$$

No escoamento ao longe $(y \rightarrow \infty)$, as condições de contorno são:

$$
\bar{y}=\delta \Rightarrow\left(D^{2}-\xi_{1}^{2}\right) \phi+\left(\xi_{1}+\xi_{2}\right)\left(D+\xi_{1}\right) \phi=0 \text { e }\left(D+\xi_{2}\right)\left(D^{2}+\xi_{1}^{2}\right) \phi=0
$$




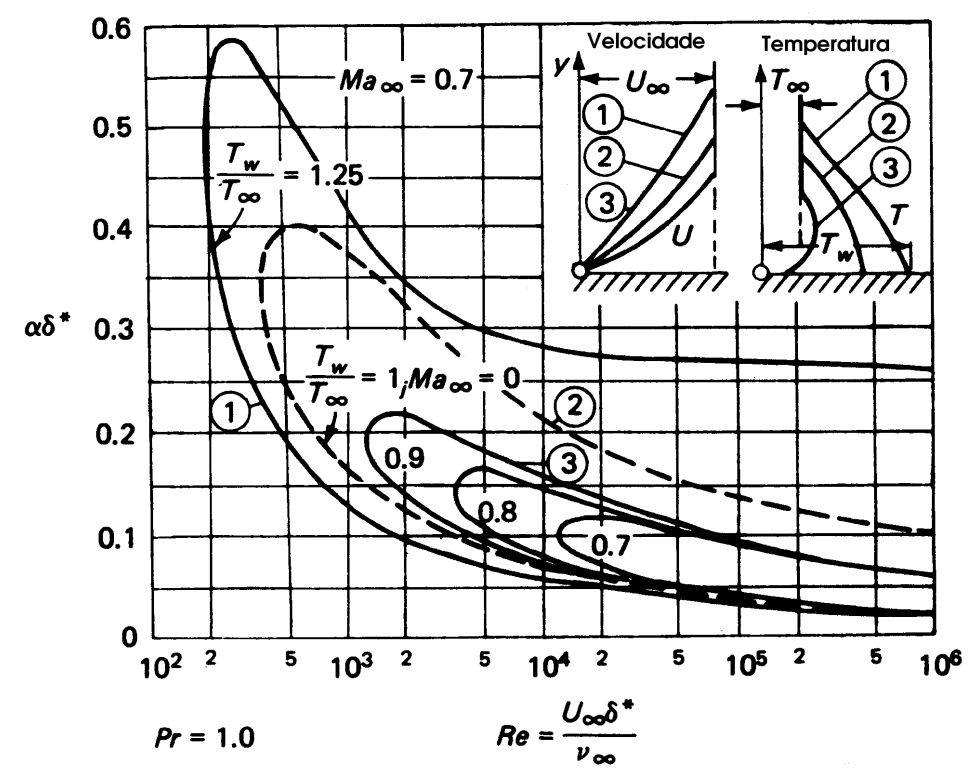

Figura C.5: Curvas de estabilidade neutra para várias temperaturas de parede $T_{w}$ $/ T_{\infty}$ (WHITE, 2000)

onde

$$
D \equiv d / d \bar{y} \quad \text { e } \quad \xi_{1}^{2}=\alpha_{l}^{2}, \quad \xi_{2}^{2}=\xi_{1}^{2}+i \cdot \operatorname{Re}\left(\alpha_{l} \cdot \bar{u}-\bar{\omega}\right)
$$

\section{C.5 Descrição do Procedimento de cálculo}

Para calcular a transição utilizando o procedimento $e^{n}$ é necessário o cálculo das taxas de amplificação $\left(-\alpha_{i}\right)$ em função de $\operatorname{Re}($ ou $x$ ) numa faixa de freqüência dimensional $\omega^{*}=\bar{\omega} \cdot u_{0} / l$.

Os cálculos de estabilidade linear são precedidos pela solução da camada-limite laminar, para dada distribuição de velocidade ao longe $u_{e}(x)$ e Re do escoamento livre, que fornece o perfil de velocidades médio $u(y)$ e sua segunda derivada $u^{\prime \prime}(y)$. A resolução da equação da estabilidade linear começa quando o escoamento atinge um valor de $R \boldsymbol{e}_{\delta *}=\frac{u_{e} \delta *}{v}$ um pouco maior do que o número crítico $R \boldsymbol{e}_{\delta *, c r i t}=\frac{u_{e} \delta *}{v}$, no ramo inferior da curva de estabilidade neutra $\left(\alpha_{i}=0\right)$ num local $x_{1}$.

O procedimento pode ser resumido em:

1) em $x_{1}$, sabe-se $u, u^{\prime \prime}$ e Re, acha-se o ponto 1 (fig 1), $\alpha_{r}$ e $\omega$ na curva de estabilidade neutra $\left(\alpha_{i}=0\right)$;

2) a partir do ponto 1 , traça-se a linha 1 com $\omega^{*}$ constante;

3) em $x_{2}$, sabe-se $u, u^{\prime \prime}$ e Re, acha-se o ponto 2 (fig 1), $\alpha_{r}$ e $\omega$ na curva de estabilidade neutra $\left(\alpha_{i}=0\right)$; 
4) a partir do ponto 2 , traça-se a linha 2 com $\omega^{*}$ constante;

5) com Re do ponto 2 e $\omega^{*}$ do ponto 1 acha-se o ponto 1 a e $\alpha=\alpha_{r}+i \alpha_{i}$;

6) encontram-se os pontos $2 \mathrm{~b}$ e $1 \mathrm{~b}$ de forma similar ao passo (5);

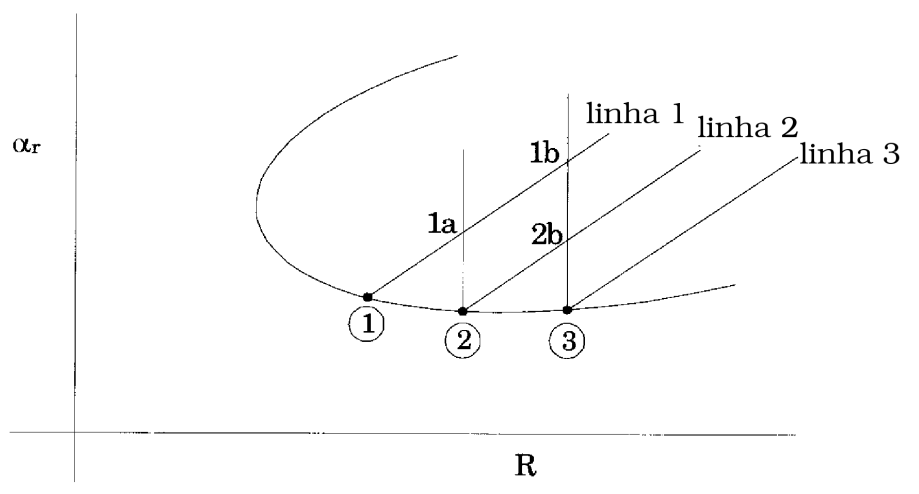

Figura C.6: Estratégia para cálculo da transição por meio do método e ${ }^{n}$ (CEBECl, 2000)

Para cada freqüência dimensional $\omega^{*}$ (linhas na Fig. 11), a taxa integrada de amplificação (expoente $n$ ) é definida por:

$$
n=-\int_{x 0}^{x} \alpha_{i} \cdot d x
$$

Onde $x_{0}$ é o valor de $x$ na curva de estabilidade neutra para uma certa freqüência (início das linhas 1, 2 e 3 na Fig. C.6), os valores de $\alpha_{i}$ são avaliados nos pontos na linha de freqüência constante (por ex. 1a, 1b) que cruzam os Re associados com os locais $x$ (no caso, $x_{2}$ e $x_{3}$ ).

Este procedimento resulta em várias curvas de freqüência constante, Fig. C.7, que tem como envelope o fator de amplificação máximo. A transição é computada quando o fator de amplificação atinge um valor entre 8 e 9 (CEBECI, 1989b; CEBECI, 1999).

De acordo com a teoria de amplificação espacial (ARNAL, 1994), a amplitude de onda $A$ no ponto $x$ pode ser relacionada com sua amplitude inicial de onda $A_{0}$ no seu ponto neutro $x_{0}$ por:

$$
\frac{A}{A_{0}}=\exp \int_{x_{0}}^{x}-\alpha_{i} d x
$$

Smith e Gamberoni (1956) e, em paralelo, van Ingen (1956) correlacionaram dados experimentais e verificaram que o fator de amplificação $n$ era praticamente constante $(7<n<9)$ no ponto de transição medido. O que significa que a rota para a transição é iniciada quando a onda T-S mais amplificada se torna $e^{7}(=1097)$ a $e^{9}$ (= 8103) maior do que sua amplitude inicial. 


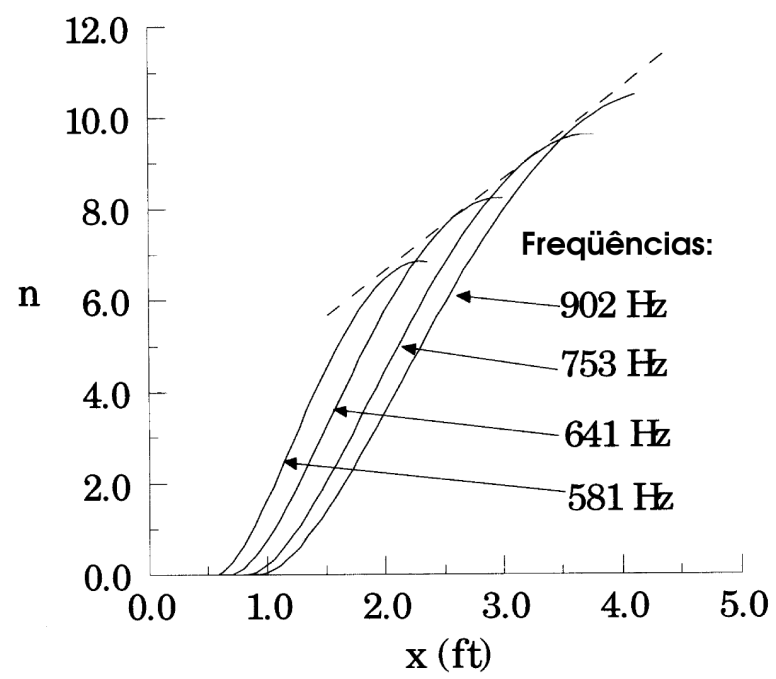

Figura C.7: Variação do fator de amplificação integrada com a distância e frequência para escoamento com gradiente de pressão nulo (CEBECl, 2000)

O princípio do método $e^{n}$ é apresentado na Fig. C.8. Para cada frequência fixa $f_{1}$, associada com a frequência angular dimensional $\omega_{1}{ }^{*}$, a onda passa primeiro por uma região estável, é amortecida até $x_{0}$, amplificada até $x_{1}$, e amortecida novamente depois a jusante de $x_{1}$.

A solução da equação de Orr-Sommerfeld para cálculo do fator de amplificação integrada pode ser feita por meio de métodos assintóticos aproximados, no entanto, a solução numérica por meio de diferenças finitas resulta em melhor aproximação. Cebeci (1989b), Cebeci (1999) recomenda o uso do esquema da caixa de Keller (1970) seguindo o procedimento acima descrito.

O efeito da turbulência do escoamento livre pode ser parcialmente levada em consideração pela seguinte expressão empírica desenvolvida por Mack (CEBECI, 1989b; CEBECI, 1999):

$$
n=-8,43-2,4 \cdot \ln T u
$$

onde $T u=\frac{\sqrt{\overline{u^{2}}}}{u_{\infty}}$ é o nível de turbulência do escoamento livre. Pode-se notar que se $\mathrm{Tu}=2.98 \%$, o fator $n=0$, logo, a transição é do tipo "bypass", ou seja, os mecanismos lineares de instabilização são contornados. Com base em dados experimentais de aerofólios, a Eq. (C.23) extrapola o uso da análise linear de estabilidade para escoamentos com níveis turbulência mais altos. Então o método não é mais chamado de $e^{9}$, mais sim de $e^{n}$. É importante notar que o limite crítico de amplificação $n_{\text {crit }}=e^{9}$ pode não ser observado em voos, que pode apresentar $11 \leq n_{\text {crit }} \leq 13$ (CEBECI, 1999).

A transferência de calor na parede pode desestabilizar (aquecimento) ou estabi- 


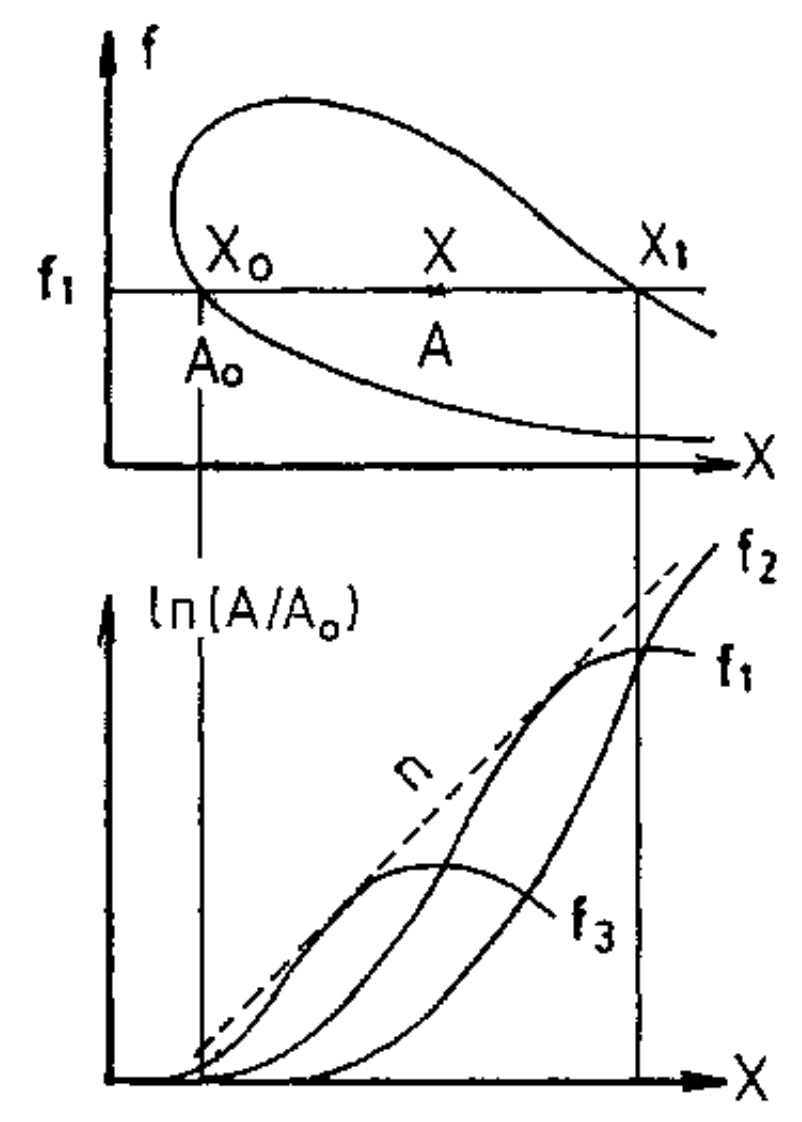

Figura C.8: $O$ princípio do método $e^{n}$ (ARNAL, 1994)

lizar (resfriamento) o escoamento laminar de gases. Arnal (1994) apresenta resultados satisfatórios nas comparações das previsões do método $e^{n}$ com dados de testes experimentais, no quais há transferência de calor na parede.

\section{C.6 Descrição Breve do Código STPD2}

O programa STP2D de Cebeci (2004) consiste de uma rotina principal, MAIN, e quatro subrotinas, VELPRO, CSAVE, NEWTON e NEWTONI. A descrição de cada uma é a que se segue:

\section{C.6.1 Sub-Rotinas do STPD2}

MAIN Na rotina principal são identificados o número total de posições $x(N X T)$ e posição na qual se inicia o cálculo de estabilidade $(N X)$. Além disto também é identificado o requerimento para estabilidade neutra $(I X T=0)$ ou transição. Para este último caso também é necessário especificar o número de frequências a serem calculadas; isto é feito escolhendo-se um valor entre 1 e 20 para a variável $I X T$, na qual o valor 1 implica no cálculo para uma só frequência, 2, para duas frequências e assim por diante. 
O cálculo das curvas de estabilidade neutra requerem a especificação da velocidade externa adimensional UE $(I)\left(\equiv u_{e} / u_{\infty}\right)$ com função da distância até a superfície $S(I)(\equiv S / L)$, em conjunto com o número de Reynolds $R_{l}\left(\equiv u_{\infty} L / \nu\right)$, um comprimento de referência $L$ e velocidade $\operatorname{UINF}\left(u_{\infty}\right)$. O número de Reynolds de estabilidade é calculado utilizando-se $R_{x}$ dado por:

$$
R_{x}=\bar{u}_{e}\left(\frac{S}{L}\right) R_{L}
$$

O cálculo dos autovalores $\alpha$ e $\omega$ em $N X=N X 0\left(s=s_{0}\right)$ também precisam de uma estimativa inicial do número de Reynolds correspondente ao seu valor em $s_{0}$. Existem diagramas com linhas de estabilidade já construidas, sendo necessária atenção as escalas de comprimento e velocidade utilizadas na estimativa dos autovalores. Elas devem ser as mesmas utilziadas no STP.

A rotina MAIN se utiliza da subrotina VELPRO para o cálculo dos perfis de velocidade $u$ e $u^{\prime \prime}$ utilizados na equação de estabiliade. A subrotina NEWTON calcula a estabilidade neutra, enquanto NEWTONI calcula os fatores de amplificação $\alpha_{i}$ e os fatores $n$.

VELPRO Os perfis de velocidade para o STP podem ser obtidos por meio de qualquer método de camada-limite ou serem analiticamente gerados. Em escoamentos externos, assume-se o uso do programa BLP2. Os valores de entrada $K X$ e $N P$, desta subrotina, referem-se à estação $N X$ e aos pontos $j,(J)$ nos quais os perfis são calculados. Especificando-se $U(J)\left(\equiv f^{\prime}\right)$ e $V(J)\left(\equiv f^{\prime \prime}\right)$ como função de $\operatorname{ETA}(J)\left(\equiv n_{j}\right), \operatorname{UUDP}(J)\left(\equiv u^{\prime \prime}\right)$ é calculado pela diferenciação de $V(J)$ em relação a $\eta$

CSAVE Esta subrotina calcula as soluções da equação de Orr-Sommerfeld para um certo conjunto de $\alpha$ e $\omega$ quando se necessita da curva de estabilidade neutra ou quando se quer determinar a posição do início da transição, utilizando $\alpha_{r}$ ou $\alpha_{i}$. A subrotina CSAVE possui também possui o algorítimo de eliminação de blocos para a solução de sistemas.

NEWTON Para estimativas iniciais de $A L F A(\equiv$ alphar $)$ e OMEGA $(\equiv \omega)$, a subrotina se utiliza do método apresentado em Cebeci (2004). Os valores das quantidades de perturbação $D A L F A\left(\equiv \delta \alpha_{r}\right)$ e DOMEGA $(\equiv \delta \omega)$ são calculados.

Após convergência das iterações, as frequências dimensionais $W S O(I X)\left(\equiv \omega^{*}\right)$ são calculadas e mostradas para cada estação $N X$, e cada frequência correspon- 
dente, $I X$, junto a valores de $\alpha \mathrm{e} \omega$, é guardada e servem de estimativa inicial para a próxima posição $N X$.

Também são guardados valores de $U M\left(\equiv f_{0}\right), \quad U M A\left(\equiv \partial f_{0} / \partial \alpha\right)$, UMO $\left(\equiv \partial f_{0} / \partial \omega\right), U M R\left(\equiv \partial f_{0} / \partial R\right), U E$ e $R E Y$.

NEWTONI Para cada valor de frequência dimensional $\omega^{*}$, um valor do fator de amplificação $n$ é calculado. Este resultado é utilizado na solução da equação de OrrSommerfeld com CLOGA correspondendo ao expoente $n$ no método $e^{n}$. O valor de $n$ pode ser obtido por:

$$
n=-\int_{\xi_{0}}^{\xi}\left(\frac{\alpha_{i} R}{\xi}\right) d \xi
$$




\section{APÊNDICE A - EFEITO DA TRANSFÊRENCIA de Massa na Camada-Limite Térmica}

\section{A.1 Modelo de Evaporação da Água}

Análise de sensibilidade do efeito da evaporação na convecção de calor

Frações em Massa

$$
\begin{aligned}
M_{H 2 O G} & =\frac{P_{\text {vapG }}}{29 / 18 \cdot P_{a r}-11 / 18 \cdot P_{\text {vapG }}} \\
M_{H 2 O S} & =\frac{P_{\text {vapS }}}{29 / 18 \cdot P_{\text {ar }}-11 / 18 \cdot P_{\text {vapS }}}
\end{aligned}
$$

Força motriz (driving force) de transferência de massa

$$
B_{m}=\frac{M_{H 2 O G}-M_{H 2 O S}}{M_{H 2 O S}-1}
$$

Propriedades termodinâmicas

$$
\begin{gathered}
T_{\text {filme }}=\frac{T_{a r}+T_{\text {agua }}}{2} \\
P D_{A B}=2,634 \cdot\left(\frac{T_{\text {filme }}+273,15}{298}\right)^{1,5}
\end{gathered}
$$

Avaliação da Transferência de Massa

Coeficiente de transferência de massa com efeito da transpiração

$$
g_{m}^{*}=\left(h_{0} / c p_{a r}\right) \cdot L e_{a r}^{2 / 3}
$$

Fluxo de evaporação

$$
M_{\text {evap }}=g_{m}^{*} \cdot \ln \left(1+B_{m}\right)
$$




\section{Avaliação da influência da evaporação na camada-limite térmica}

Modelo: velocidade ao longe variável (iterativo)

Coeficiente de transferência de calor para o modelo

$$
h=h_{0} \cdot k
$$

Parâmetro de insuflamento para transferência de calor do modelo

$$
b h=M_{\text {evap }} \cdot c p_{a r} / h
$$

Fator para redução do coeficiente de transferência de calor com insuflamento pelo modelo

$$
k=\frac{\ln (1+b h)}{b h}
$$

Parâmetro de insuflamento para transferência de momento

$$
F=\frac{M_{\text {evap }}}{\rho_{\text {ar }} \cdot V_{\infty}}
$$

\section{A.1.1 Regime Turbulento}

Cálculo de $\boldsymbol{h}_{\boldsymbol{x}}$ para velocidade constante

$$
\begin{gathered}
S t_{L}=\frac{0,0287}{0,8} \cdot R e_{L}^{-0,2} \cdot \operatorname{Pr}_{a r}^{-0,4} \\
R e_{L}=\frac{V_{\infty} \cdot L}{\mu_{a r} / \rho_{a r}} \\
S t_{L}=\frac{h_{0}}{\rho_{a r} \cdot c p_{a r} \cdot V_{\infty}}
\end{gathered}
$$

\section{A.1.2 Resultados}

Na Tabela A.1 é mostrado o efeito da variação da temperatura da água sobre o fator de redução de $\boldsymbol{h}$ por $\boldsymbol{h}_{\mathbf{0}}$.

As Figuras A.1(a) e A.1(b) mostram respectivamente o efeito da variação da temperatura da água no parâmetro de insuflamento $\boldsymbol{B}_{\boldsymbol{h}}$ e no fator de redução de $\boldsymbol{h}$ por $h_{0}$. 
Tabela A.1: Efeito da variação da Temperatura da Água

\begin{tabular}{lccccc}
\hline Caso & $\boldsymbol{T}_{\text {agua }}$ & $\boldsymbol{M}_{\text {evap }}$ & $\boldsymbol{F}$ & $\boldsymbol{b h}$ & $\boldsymbol{k}$ \\
\hline 1 & 10 & 0,002323 & 0,00004669 & 0,005861 & 0,9971 \\
2 & 20 & 0,005605 & 0,0001147 & 0,0142 & 0,9929 \\
3 & 30 & 0,01133 & 0,000236 & 0,02892 & 0,9858 \\
4 & 40 & 0,02105 & 0,0004461 & 0,05441 & 0,9736 \\
5 & 50 & 0,03733 & 0,0008046 & 0,0985 & 0,9533 \\
6 & 60 & 0,06469 & 0,001418 & 0,1768 & 0,9208 \\
7 & 70 & 0,1122 & 0,0025 & 0,3263 & 0,8654 \\
8 & 80 & 0,2019 & 0,004573 & 0,662 & 0,7673 \\
9 & 90 & 0,2809 & 0,006412 & 1,028 & 0,6878 \\
\hline
\end{tabular}

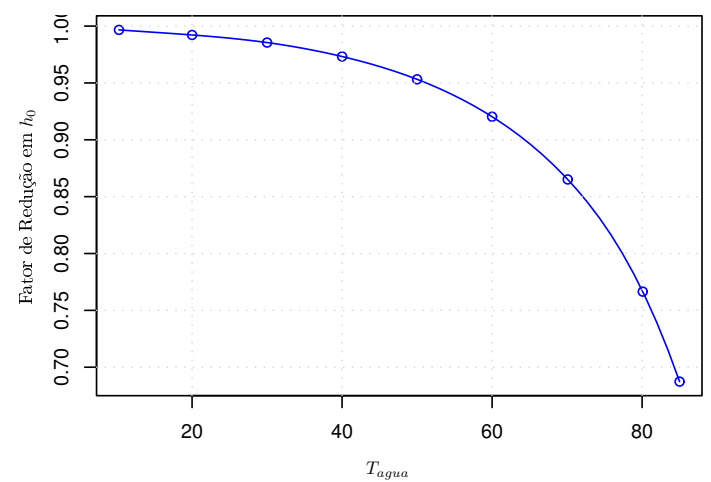

(a) Fator de Redução em $\boldsymbol{h}_{0}$

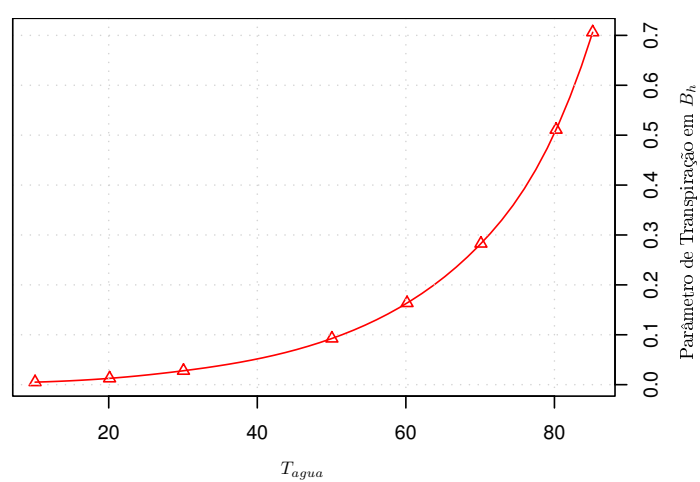

(b) Parâmetro de Transpiração em $\boldsymbol{B}_{\boldsymbol{h}}$

Figura A.1: Parâmetros de Insuflamento

Na Tabela A.2 é mostrado o efeito causado na temperatura da água modificando a taxa de insuflamento $\boldsymbol{F}$, o número de Mach $\boldsymbol{M}$, a altitude alt $_{\text {tunel }}$ e a temperatura do $\operatorname{ar} \boldsymbol{T}_{a r}$.

\section{A.1.3 Conclusão}

De acordo com os resultados obtidos, quando a temperatura da água está abaixo de $50^{\circ} \mathrm{C}$ a correção do número de Stanton é menor do que $5 \%$. Isto significa que para os casos estudados no presente trabalho o efeito da transpiração é desprezível. Mesmo assim a correção foi implementada no modelo de antigelo desenvolvido no presente trabalho.

\section{A.2 Validade da Correção para Regime Laminar}

A falta de dados experimentais no caso laminar pode ser suprida pela disponibilidade de soluções análiticas da camada-limite.O modelo proposto por Spalding 
Tabela A.2: Combinações de $M, T_{\text {ar }}$, alt $t_{\text {tunel }}$ e $\boldsymbol{F}$

\begin{tabular}{lcccccccc}
\hline Caso & $\begin{array}{c}\boldsymbol{T}_{\text {agua }} \\
{[\mathbf{C}]}\end{array}$ & $\begin{array}{c}\boldsymbol{M}_{\text {evap }} \\
{\left[\mathbf{k g} /\left(\mathbf{s m}^{2}\right)\right]}\end{array}$ & $\begin{array}{c}\boldsymbol{h}_{\mathbf{0}} \\
\left.\left[\mathbf{W} / \mathbf{m}^{2} \mathbf{K}\right)\right]\end{array}$ & $\begin{array}{c}\boldsymbol{V}_{\infty} \\
{[\mathbf{m} / \mathbf{s}]}\end{array}$ & $\boldsymbol{M}$ & $\begin{array}{c}\boldsymbol{T}_{\text {ar }} \\
{[\mathbf{C}]}\end{array}$ & $\begin{array}{c}\text { alt } \\
{[\mathbf{f t}]}\end{array}$ & $\boldsymbol{F}$ \\
\hline 1 & 28,87 & 0,006072 & 211,3 & 93,77 & 0,3 & -30 & 0 & 0,00005 \\
2 & 31,15 & 0,006076 & 213,9 & 99,39 & 0,3 & 0 & 0 & 0,00005 \\
3 & 14 & 0,002869 & 115,3 & 93,77 & 0,3 & -30 & 20000 & 0,00005 \\
4 & 18,66 & 0,002854 & 116,3 & 99,39 & 0,3 & 0 & 20000 & 0,00005 \\
5 & 91,32 & 0,2179 & 198,1 & 93,77 & 0,3 & -30 & 0 & 0,002 \\
6 & 91,4 & 0,2201 & 201,6 & 99,39 & 0,3 & 0 & 0 & 0,002 \\
7 & 70,36 & 0,1037 & 108,6 & 93,77 & 0,3 & -30 & 20000 & 0,002 \\
8 & 70,5 & 0,1046 & 110,4 & 99,39 & 0,3 & 0 & 20000 & 0,002 \\
9 & 25,27 & 0,002037 & 88,09 & 31,26 & 0,1 & -30 & 0 & 0,00005 \\
10 & 27,99 & 0,002036 & 89,1 & 33,13 & 0,1 & 0 & 0 & 0,00005 \\
11 & 10,83 & 0,0009619 & 48,06 & 31,26 & 0,1 & -30 & 20000 & 0,00005 \\
12 & 16,29 & 0,0009553 & 48,43 & 33,13 & 0,1 & 0 & 20000 & 0,00005 \\
13 & 88,66 & 0,07296 & 82,46 & 31,26 & 0,1 & -30 & 0 & 0,002 \\
14 & 88,77 & 0,07366 & 83,93 & 33,13 & 0,1 & 0 & 0 & 0,002 \\
15 & 67,81 & 0,03472 & 45,2 & 31,26 & 0,1 & -30 & 20000 & 0,002 \\
16 & 67,99 & 0,035 & 45,96 & 33,13 & 0,1 & 0 & 20000 & 0,002 \\
\hline
\end{tabular}

(1963):

$$
\frac{g}{G_{\infty}}=\frac{C_{1} \mu^{1 / 2} G_{\infty}^{C_{2}}}{\left(\int_{0}^{x} G_{\infty}^{C_{3}} d x\right)^{1 / 2}}
$$

A comparação é observada na Fig. A.2, onde as constantes $\boldsymbol{C}_{1}, \boldsymbol{C}_{2}$ e $\boldsymbol{C}_{3}$ foram definidas a partir de cálculos analíticos, considerando gradiente de pressão nulo. $\mathrm{Na}$ Tabela A.3 observa-se os valores das constantes calculadas em função de $\boldsymbol{B}$. Foi adotado um $\boldsymbol{g} / \boldsymbol{g}^{*}$ médio, integrando-se a equação acima numa corda de comprimento $L$.

Tabela A.3: Valores de $C_{1}, C_{2}$ e $C_{3}$ para $P r=0.7$

\begin{tabular}{lccc}
\hline $\boldsymbol{B}$ & $\boldsymbol{C}_{\mathbf{1}}$ & $\boldsymbol{C}_{\mathbf{2}}$ & $\boldsymbol{C}_{\mathbf{3}}$ \\
\hline$-0,9$ & 1,85 & 0,05 & 1,1 \\
$-0,6$ & 0,812 & 0,15 & 1,3 \\
0,0 & 0,418 & 0,435 & 1,87 \\
1,0 & 0,244 & 0,65 & 2,3 \\
3,0 & 0,316 & 1,15 & 3,3 \\
9,0 & 0,060 & 1,90 & 4,8 \\
\hline
\end{tabular}

\section{A.2.1 Conclusão}

Para o caso laminar, o modelo de correção de coeficiente de transferência de calor devido aos efeitos da transpiração foi considerado satisfatório. 


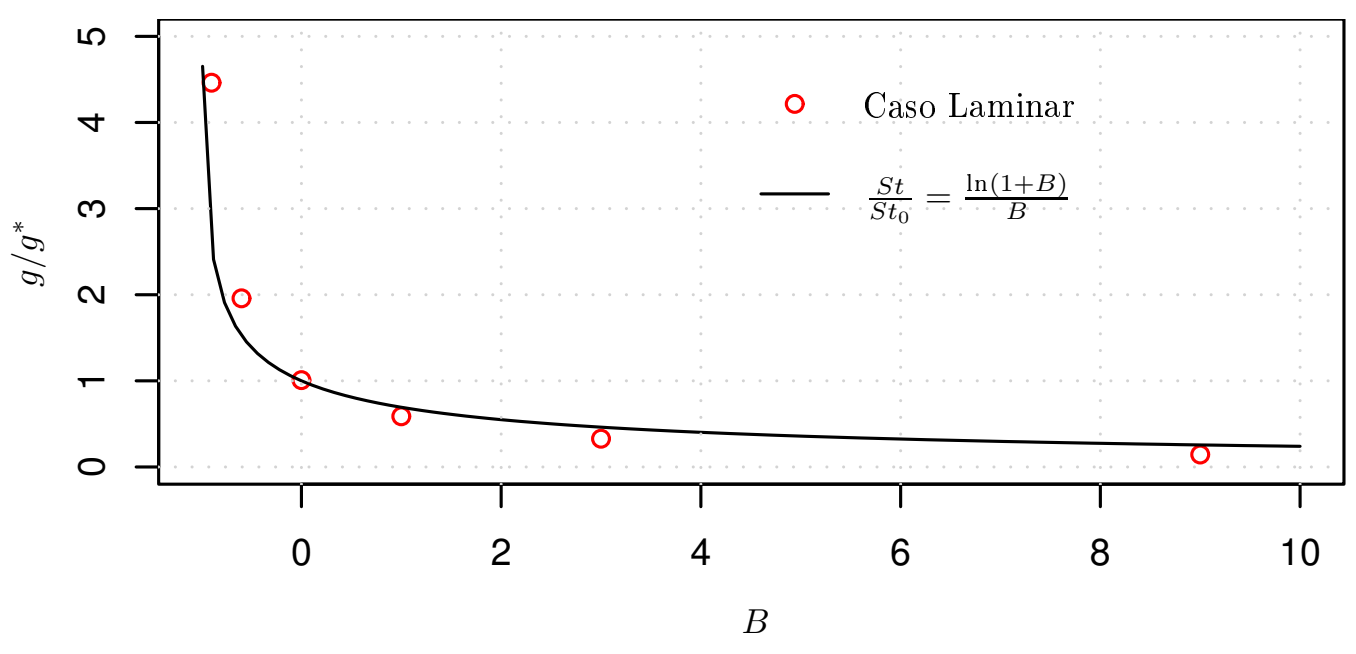

Figura A.2: Comparação do caso laminar com o modelo proposto

\section{A.3 Validade da Correção para Regime Turbulento}

\section{A.3.1 Condições do Teste}

Para os casos simulados foram adotadas as seguintes condições: Temperatura do ar entre $60^{\circ} \boldsymbol{F}$ e $70^{\circ} \boldsymbol{F}$; Velocidade do ar entre 20 pés/s e 40 pés/s; Pressão do ar igual a $\mathbf{3 0} \mathrm{inHg}$.

Segundo Whitten (1967), a seguinte equação relaciona St com $\boldsymbol{R e}_{\boldsymbol{\Delta}_{2}}$ :

$$
S t P r^{0.5}=0.0125 \operatorname{Re}_{\Delta_{2}}^{-0.25}\left(\frac{\ln (1+B)}{B}\right)^{1.25}(1+B)^{0.25}
$$

\section{A.3.2 Resultados}

Como pode ser observado nos gráficos a seguir, o modelo proposto é coerente com os dados experimentais da literatura (WHITTEN, 1967). A Fig. A.3(a) mostra o comportamento do St em função do $\operatorname{Re}_{\boldsymbol{\Delta}_{2}}$ para diferentes valores de $\boldsymbol{F}$. Já a Fig. A.3(b) apresenta a correção de St em função do parâmetro de insuflamento $\boldsymbol{B}$. A proximidade das linhas contínuas aos dados experimentais, em ambos os gráficos, deixam claro que o modelo é representa satisfatoriamente os efeitos.

Kays e Moffat (1975) testaram o modelo de correção com 14 condições de teste diferentes, abordando os casos de insuflamento $(\boldsymbol{F}>\mathbf{0})$ e sucção $(\boldsymbol{F}<\mathbf{0})$. O autor conclui que o modelo fica satisfatoriamente próximo ao conjunto de pontos obtidos experimentalmente, como observado na Fig. A.5.

A Fig. A.4 apresenta os resultados experimentais e os cálculos realizados por Whitten (1967) para os casos de degrau de transpiração, degrau de temperatura e 


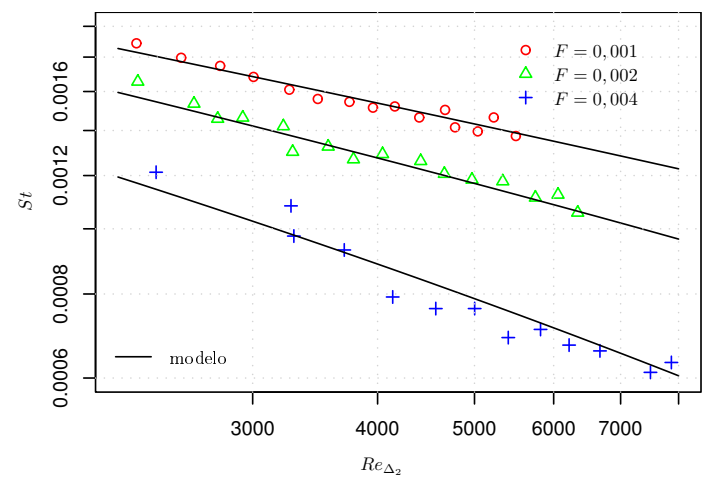

(a) Relação entre Stanton e Reynolds

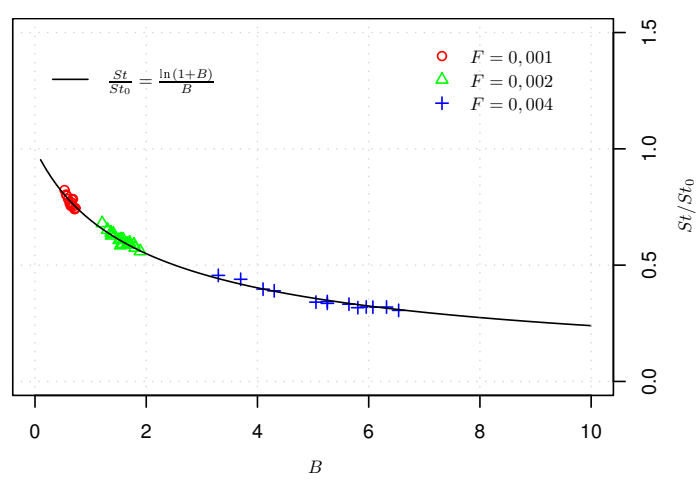

(b) Correção do Número de Stanton

Figura A.3: Relação entre Stanton e Reynolds e Correção do Stanton

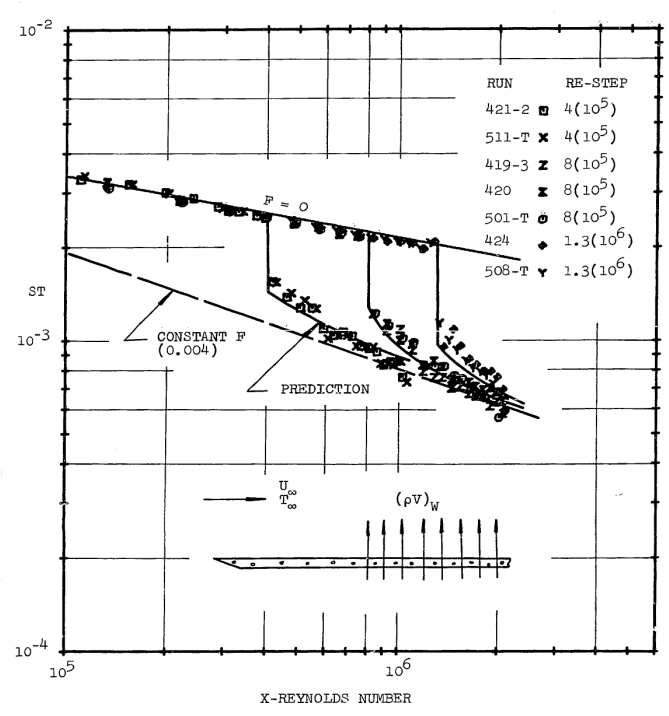

(a) Degrau de Insuflamento

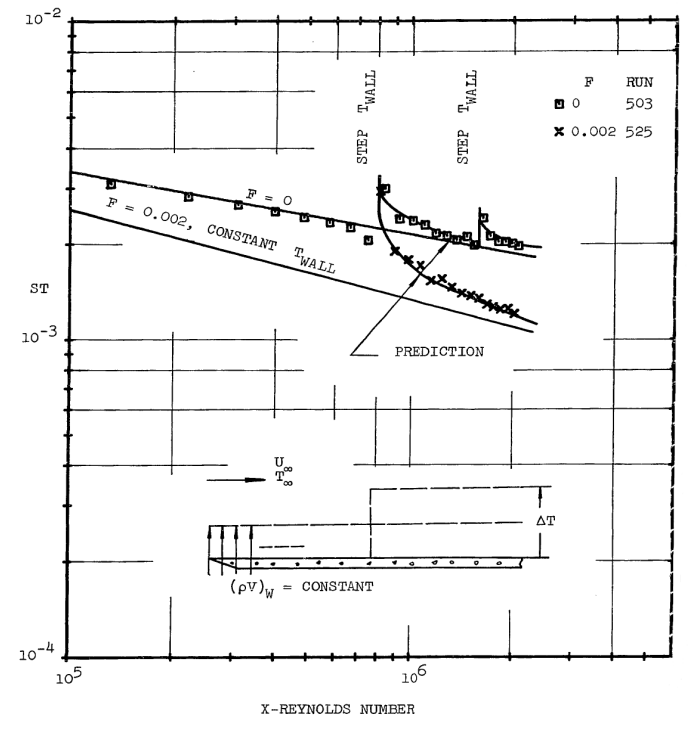

(b) Degrau de Temperatura

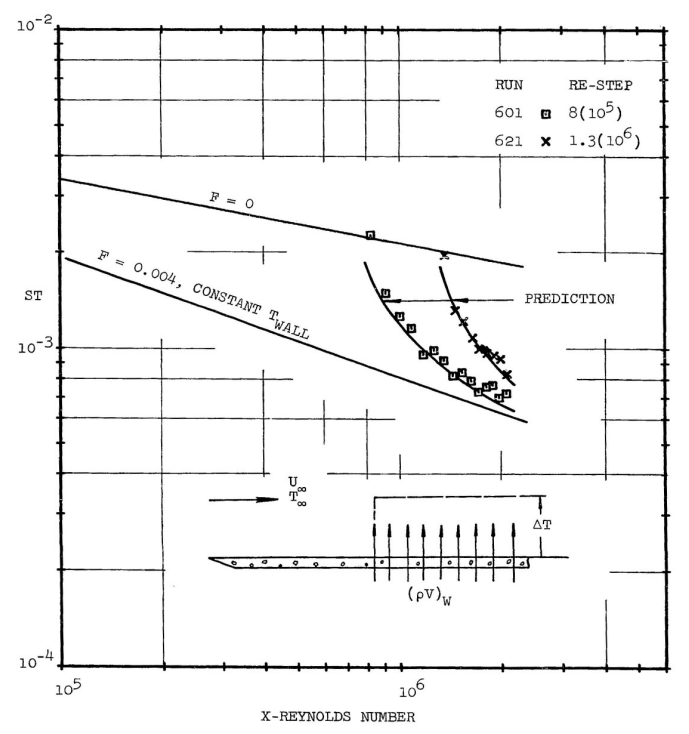

(c) Degrau de Insuflamento e Temperatura

Figura A.4: Diversos casos experimentais 


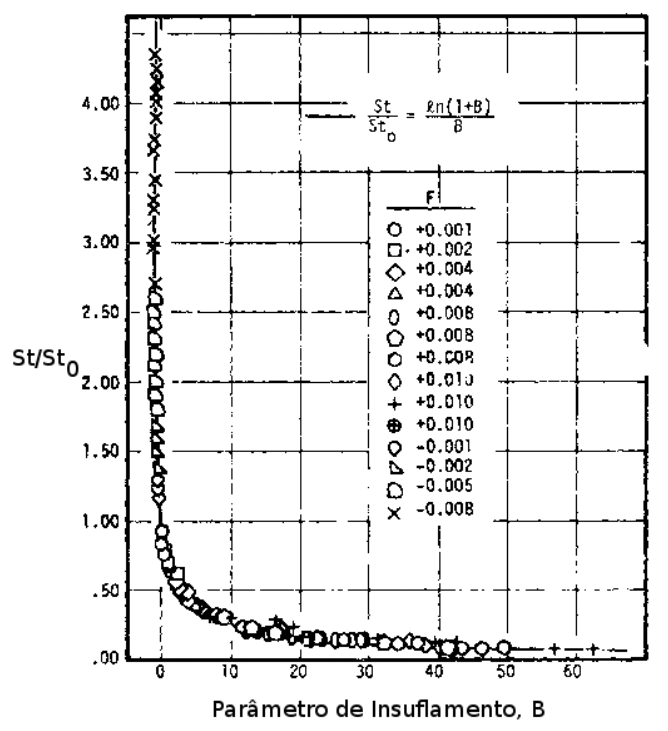

Figura A.5: Correção do Número de Stanton para vários valores de $F$

degrau de ambos. Essas condições de teste demonstram que há um efeito de história (inércia dinâmica) do escoamento quando ocorrem mudanças súbitas de condições de contorno. Esses efeitos foram desconsiderados no presente modelo, pois as temperaturas de superfície ficam abaixo de $50^{\circ} \mathrm{C}$ e a taxa de insuflamento é muito baixa para esses efeitos fiquem importantes.

\section{A.3.3 Conclusões}

O fator de correção $\boldsymbol{k}$, adotado no presente modelo, adere a um grande número de resultados experimentais obtidos por Kays e Moffat (1975) e Whitten (1967).

Para as taxas baixas de insuflamento encontradas no presente trabalho, o efeito instantâneo da transpiração na transferência de calor é considerado, mas os efeitos são desprezados.

A correção de $\boldsymbol{S} \boldsymbol{t}$ foi implementada no programa de simulação de antigelo para as regiões laminares e turbulentas, mesmo que, no casos-teste adotados no presente trabalho, a temperatura de superfície seja menor que $50^{\circ} \mathrm{C}$ e a correção seja menor do que $5 \%$. 


\section{APÊNDICE B - VERIFICAÇÃO DOS Resultados Numéricos para os Casos ERCOFTAC}

\section{B.1 Definição dos Casos}

Tabela B.1: Casos Selecionados ERCOFTAC

\begin{tabular}{lcccc}
\hline casos & T3A & T3AM & T3C2 & T3C5 \\
\hline $\operatorname{Re}_{L}\left(\mathbf{1 0}^{6}\right)$ & 0,53 & 2,02 & 0,6 & 1,13 \\
$\operatorname{Tu}[\%]$ & 3,0 & 0,87 & 2,4 & 2,45 \\
$\boldsymbol{V}_{\infty}[\mathrm{m} / \mathrm{s}]$ & 5,2 & 19,53 & 5,67 & 9,65 \\
$\boldsymbol{\rho}_{\infty}\left[\mathrm{kg} / \mathrm{m}^{3}\right]$ & 1,21 & 1,19 & 1,18 & 1,21 \\
\hline
\end{tabular}

\section{B.2 Fatores Críticos de Amplificação}

O fator de amplificação máxima das instabilidades lineares, $\boldsymbol{n}_{\text {crit }}$, desenvolvido por Mack (1977) para escoamentos de baixo Tu com base em resultados da análise linear, é dado por:

$$
n_{c r i t}=-8,43-2,4 \cdot \ln \left(T u^{\prime}\right)
$$

Para obter resultados para níveis de turbulência mais altos, $\mathbf{T u}>\mathbf{2 . 9 8 \%}$, Drela (1998) modificou a 5.14 com a definição de:

$$
T u^{\prime}=2,7 \tanh \left(\frac{T u}{2,7}\right)
$$

Com base em dados experimentais, van Ingen (2008) propôs que a região de transição laminar-turbulenta poderia ser estimada por meio da análise de estabilidade linear levando em consideração os efeitos da turbulência ao longe. A correlação para o início da transição proposta pelo autor é: 


$$
N_{1}=2,13-6,1810 \cdot \log (T u)
$$

E o término da região de transição é dado por:

$$
N_{2}=5-6,1810 \cdot \log (T u)
$$

\section{B.3 Caso T3A}

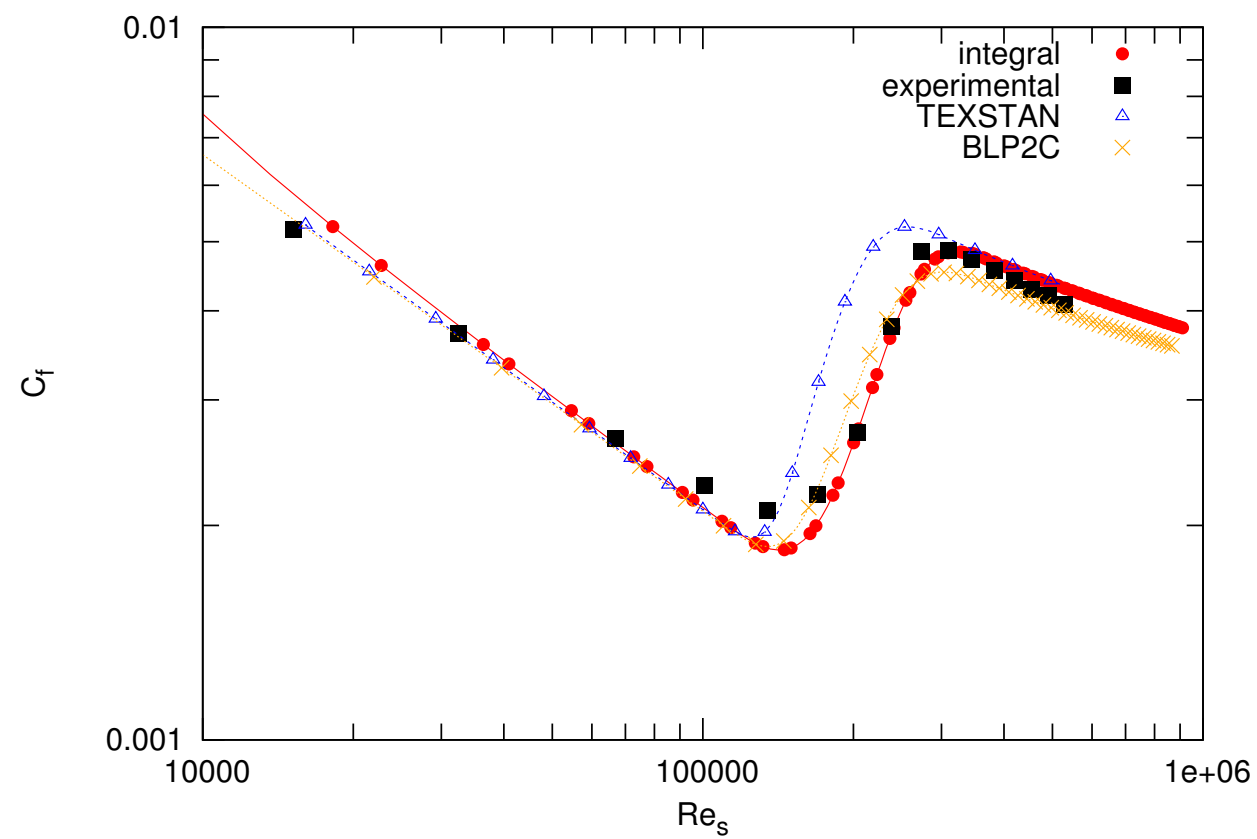

Figura B.1: Caso T3A - coeficiente de Atrito - $C_{f}-T u=3,0 \%$ - gradiente de pressão nulo ao longo da placa - correlação algébrica

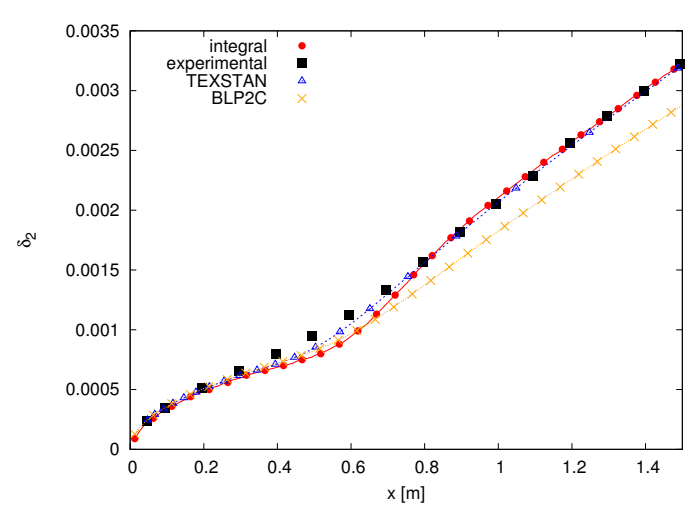

(a) Espessura de Quantidad de Movimento - $\delta_{2}$

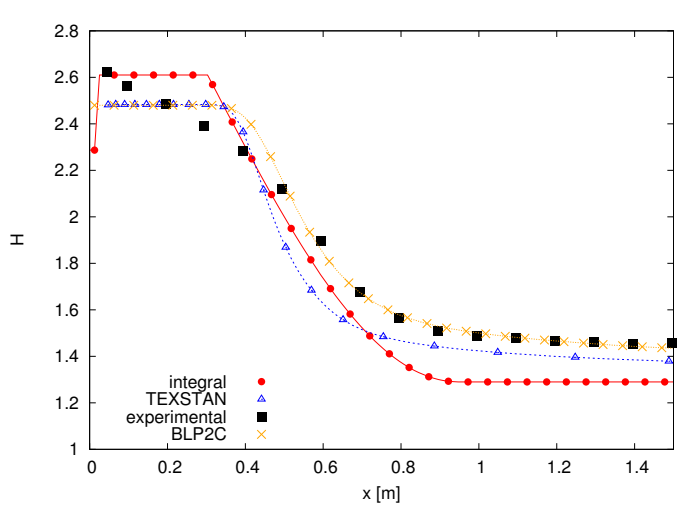

(b) Fator de Forma $-\boldsymbol{H}=\delta_{1} / \delta_{2}$

Figura B.2: Caso T3A - Tu = 3,0\% - gradiente de pressão nulo - correlação algébrica 


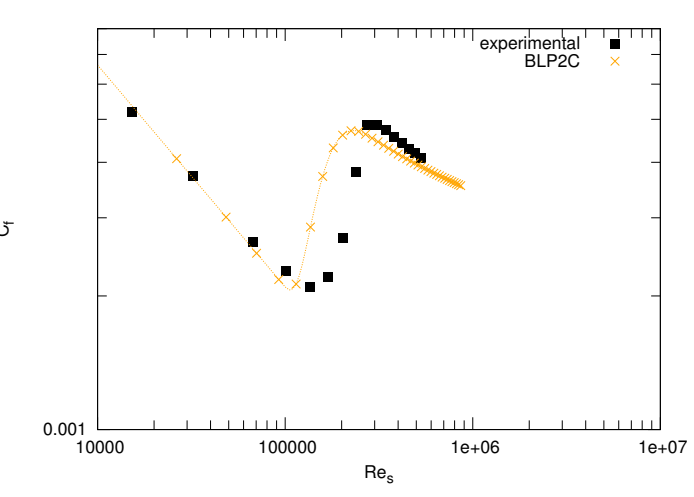

(a) Coeficiente de Atrito - $\boldsymbol{C}_{\boldsymbol{f}}$

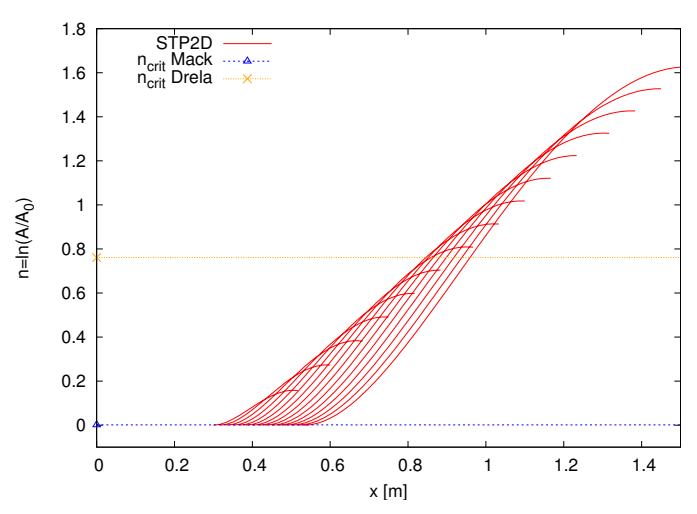

(b) Amplificação, $\boldsymbol{n}$, e Critérios, $\boldsymbol{n}_{\text {crit }}$

Figura B.3: Caso T3A - Tu = 3,0\% - gradiente de pressão nulo - estabilidade linear diferencial

Tabela B.2: Caso T3A - $T u=3,0 \%$

\begin{tabular}{lcccc}
\hline casos & $\boldsymbol{n}_{\text {mack }}$ & $\boldsymbol{n}_{\text {drela }}$ & $\boldsymbol{N}_{\mathbf{1}}$ & $\boldsymbol{N}_{\mathbf{2}}$ \\
\hline $\mathrm{s}[\mathrm{m}]$ & 0,300 & 0,846 & 0,300 & 1,533 \\
$\mathrm{f}[\mathrm{Hz}]$ & 52,02 & 34,46 & 52,02 & 26,76 \\
\hline
\end{tabular}

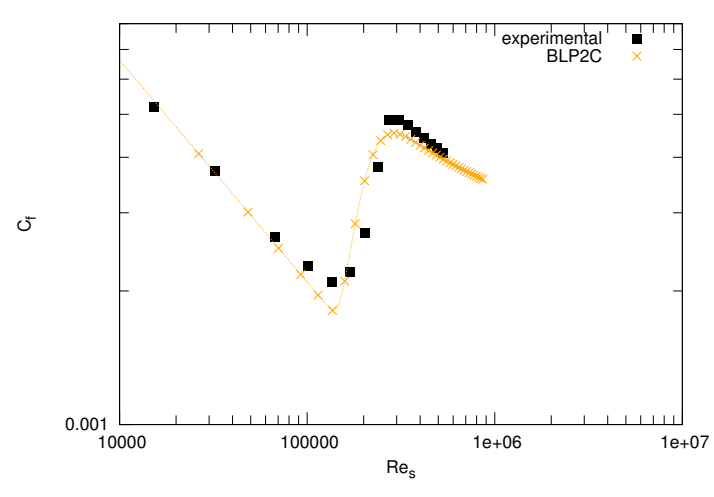

(a) Coeficiente de Atrito - $\boldsymbol{C}_{\boldsymbol{f}}$

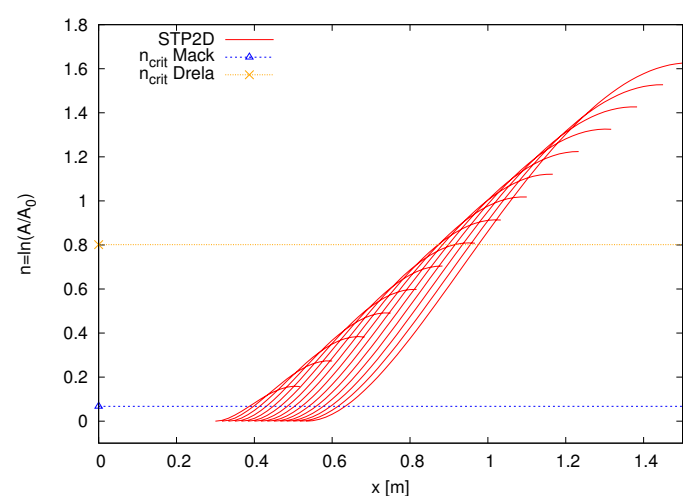

(b) Amplificação, $\boldsymbol{n}$, e Critérios, $\boldsymbol{n}_{\text {crit }}$

Figura B.4: Caso T3A - Tu = 2, 9\% - gradiente de pressão nulo - estabilidade linear diferencial

Tabela B.3: Caso T3A - Tu $=2,9 \%$

\begin{tabular}{lcccc}
\hline casos & $\boldsymbol{n}_{\text {mack }}$ & $\boldsymbol{n}_{\text {drela }}$ & $\boldsymbol{N}_{\mathbf{1}}$ & $\boldsymbol{N}_{\mathbf{2}}$ \\
\hline $\mathrm{s}[\mathrm{m}]$ & 0,387 & 0,873 & 0,300 & 1,533 \\
$\mathrm{f}[\mathrm{Hz}]$ & 52,02 & 34,46 & 52,02 & 26,76 \\
\hline
\end{tabular}




\section{B.4 Caso T3AM}

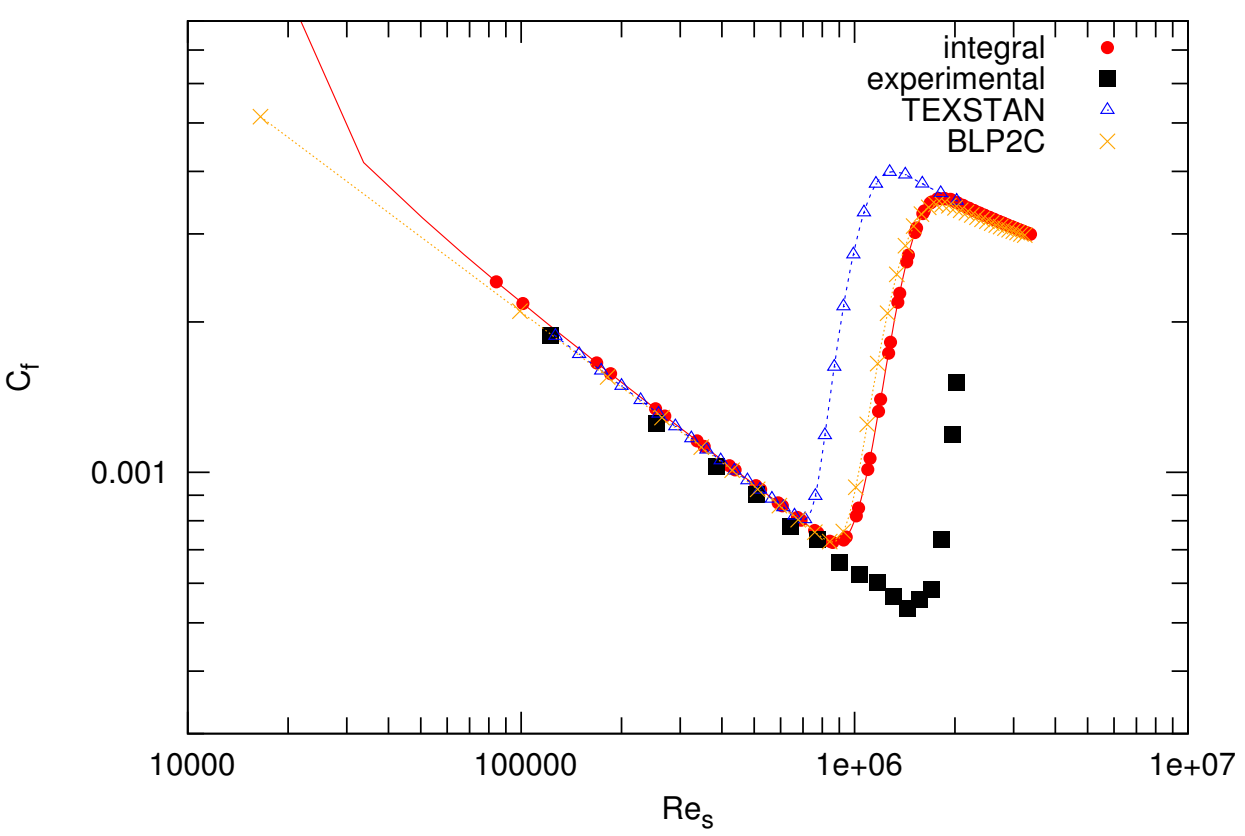

Figura B.5: Caso T3AM - Coeficiente de Atrito $-C_{f}-T u=0,87 \%$ - gradiente de pressão nulo ao longo da placa - correlação algébrica

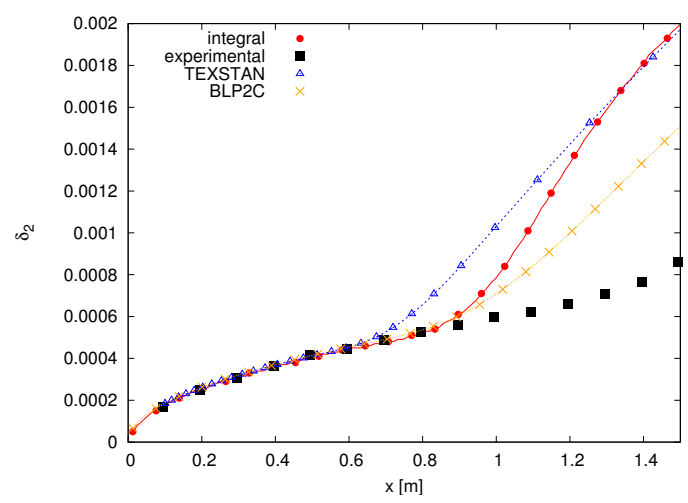

(a) Espessura de Quantidade de Movimento - $\boldsymbol{\delta}_{\mathbf{2}}$

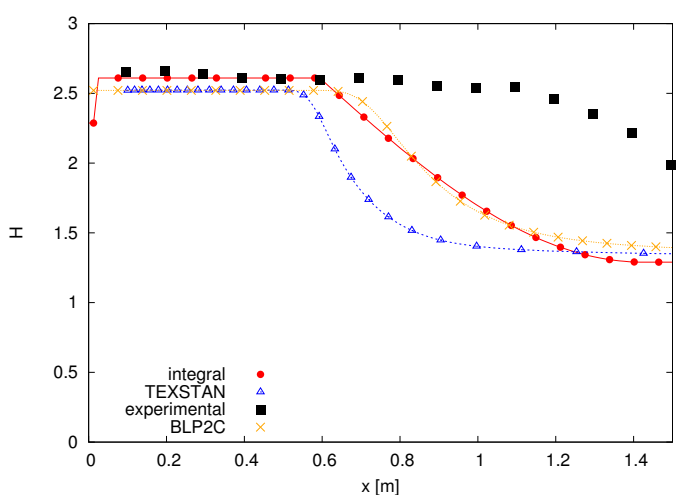

(b) Fator de Forma - $\boldsymbol{H}=\delta_{1} / \delta_{2}$

Figura B.6: Caso T3AM - Tu = 0,87\% - gradiente de pressão nulo - correlação algébrica 


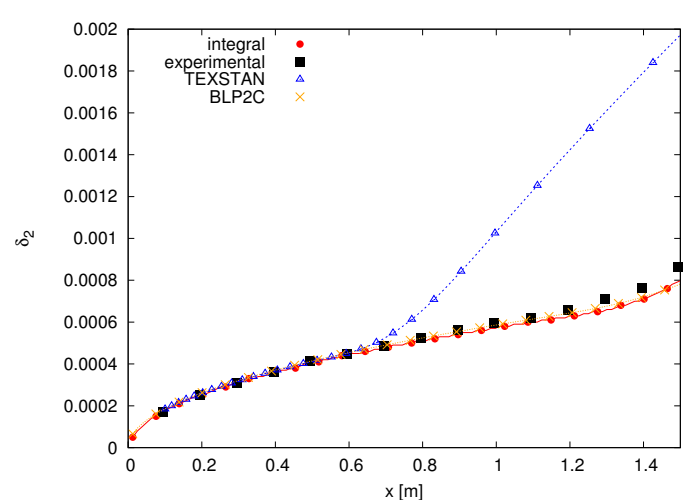

(a) Espessura de Quantidade de Movimento - $\boldsymbol{\delta}_{\mathbf{2}}$

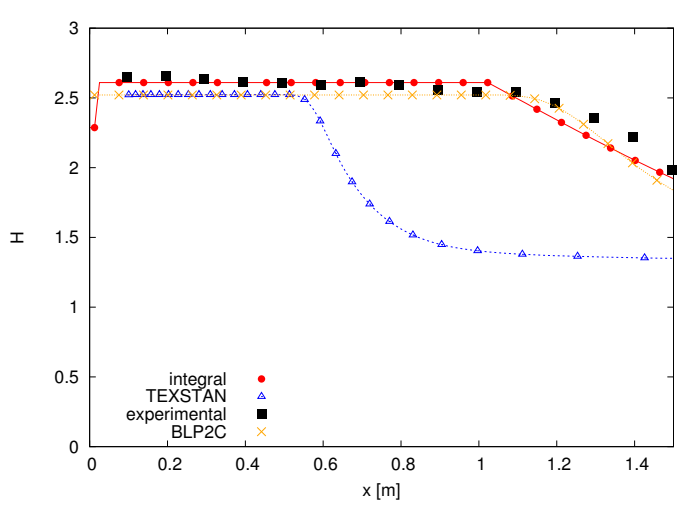

(b) Fator de Forma - $\boldsymbol{H}=\delta_{1} / \delta_{2}$

Figura B.7: Caso T3AM - Tu = 0,5\% - gradiente de pressão nulo - correlação algébrica

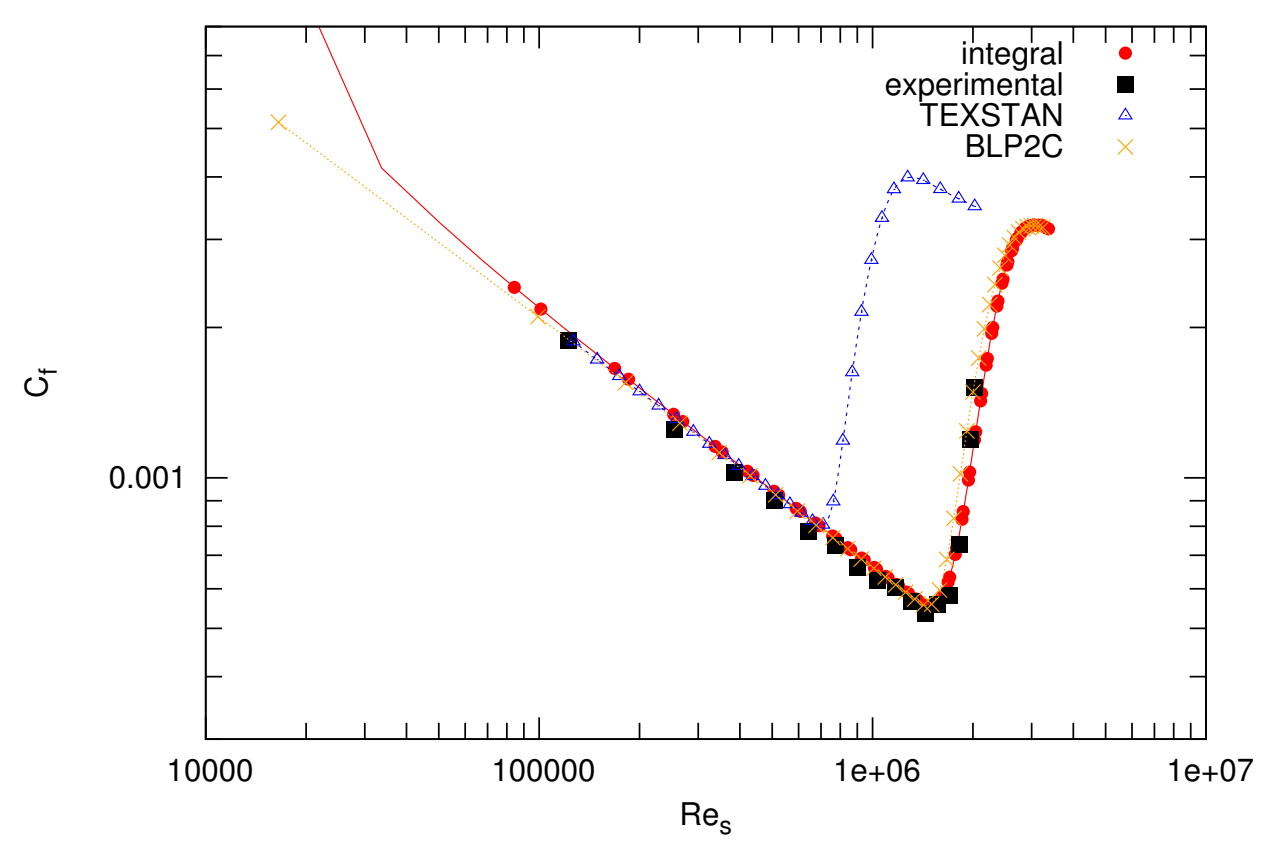

Figura B.8: Caso T3AM - Coeficiente de Atrito - $C_{f}-T u=0,5 \%$ - gradiente de pressão nulo ao longo da placa - correlação algébrica

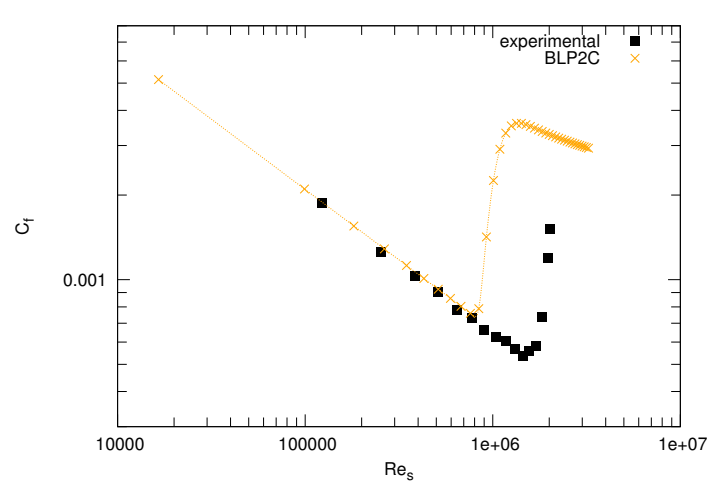

(a) Coeficiente de Atrito - $\boldsymbol{C}_{\boldsymbol{f}}$

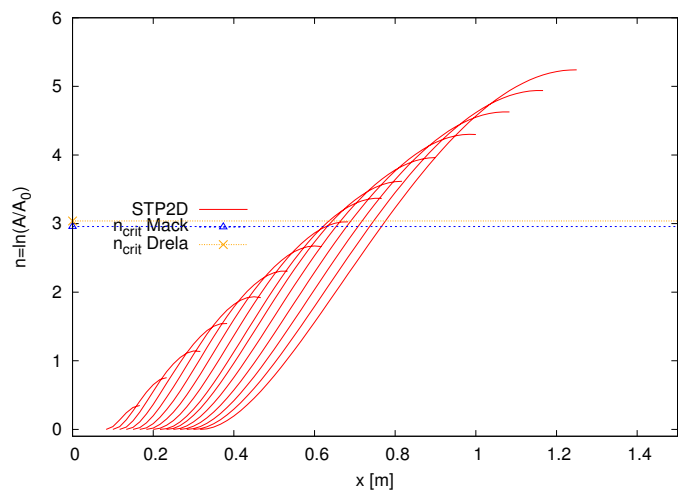

(b) Amplificação, $\boldsymbol{n}$, e Critérios, $\boldsymbol{n}_{\text {crit }}$

Figura B.9: Caso T3AM - Tu = 0,87\% - gradiente de pressão nulo - estabilidade linear diferencial 
Tabela B.4: Fatores Críticos de Amplificação - Caso T3AM - Tu = 0, 87\%

\begin{tabular}{lcccc}
\hline casos & $\boldsymbol{n}_{\text {mack }}$ & $\boldsymbol{n}_{\text {drela }}$ & $\boldsymbol{N}_{\mathbf{1}}$ & $\boldsymbol{N}_{\mathbf{2}}$ \\
\hline $\mathrm{s}[\mathrm{m}]$ & 0,621 & 0,636 & 0,527 & 1,250 \\
$\mathrm{f}[\mathrm{Hz}]$ & 265,99 & 265,99 & 310,73 & 189,36 \\
\hline
\end{tabular}

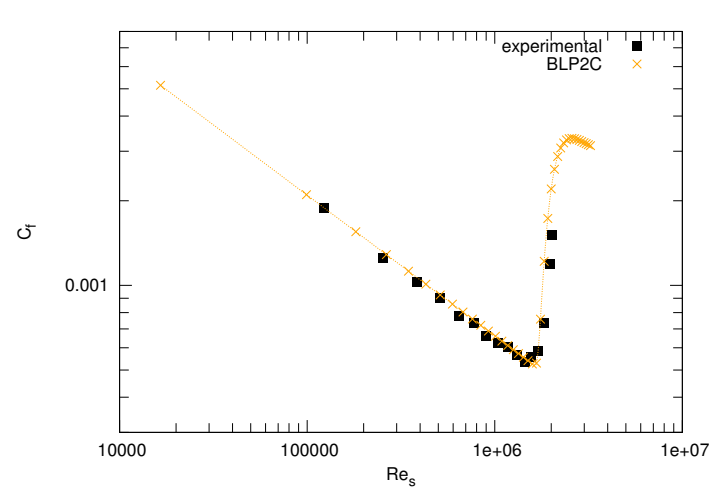

(a) Coeficiente de Atrito - $\boldsymbol{C}_{\boldsymbol{f}}$

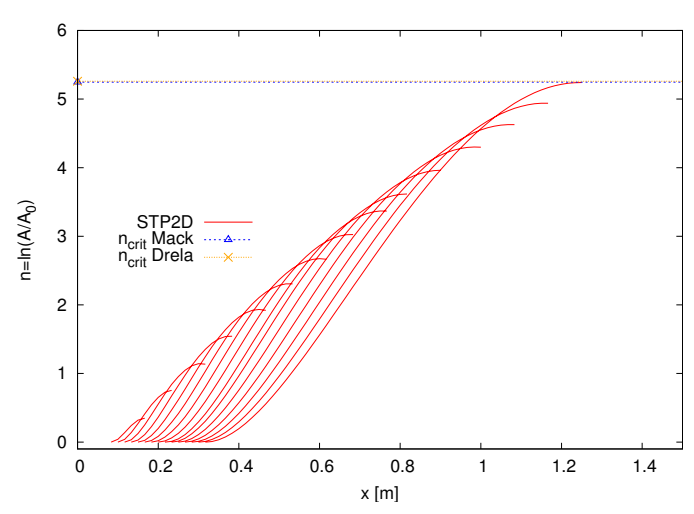

(b) Amplificação, $\boldsymbol{n}$, e Critérios, $\boldsymbol{n}_{\text {crit }}$

Figura B.10: Caso T3AM - Tu = 0,34\% - gradiente de pressão nulo - estabilidade linear diferencial

Tabela B.5: Fatores Críticos de Amplificação - Caso T3AM - Tu = 0, 34\%

\begin{tabular}{lcccc}
\hline casos & $\boldsymbol{n}_{\text {mack }}$ & $\boldsymbol{n}_{\text {drela }}$ & $\boldsymbol{N}_{\mathbf{1}}$ & $\boldsymbol{N}_{\mathbf{2}}$ \\
\hline $\mathrm{s}[\mathrm{m}]$ & 1,250 & 1,250 & 1,123 & 1,250 \\
$\mathrm{f}[\mathrm{Hz}]$ & 189,36 & 189,36 & 189,36 & 189,36 \\
\hline
\end{tabular}




\section{B.5 Caso T3C2}

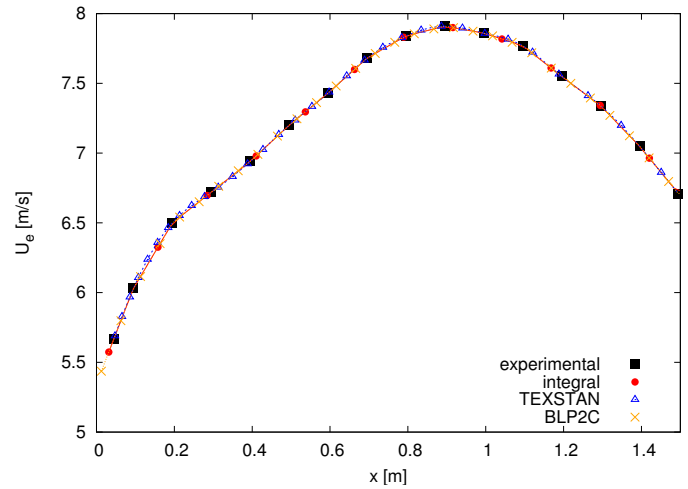

(a) Caso $\mathrm{T3C2}$

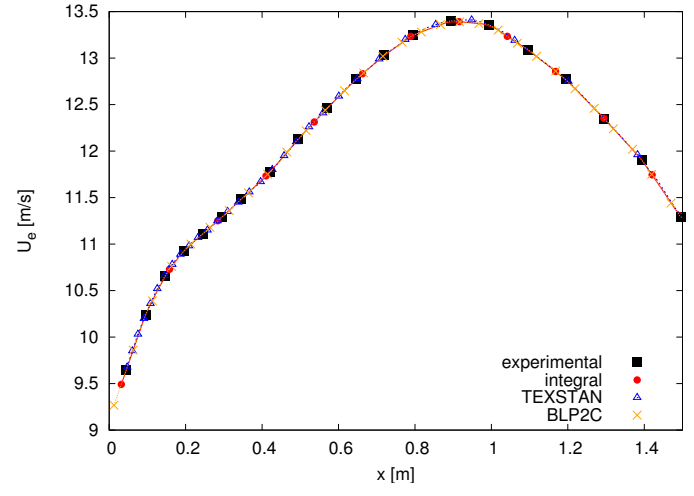

(b) Caso T3C5

Figura B.11: Dados experimentais da velocidade na borda da camada-limite e resultados das interpolações - gradiente de pressão variável

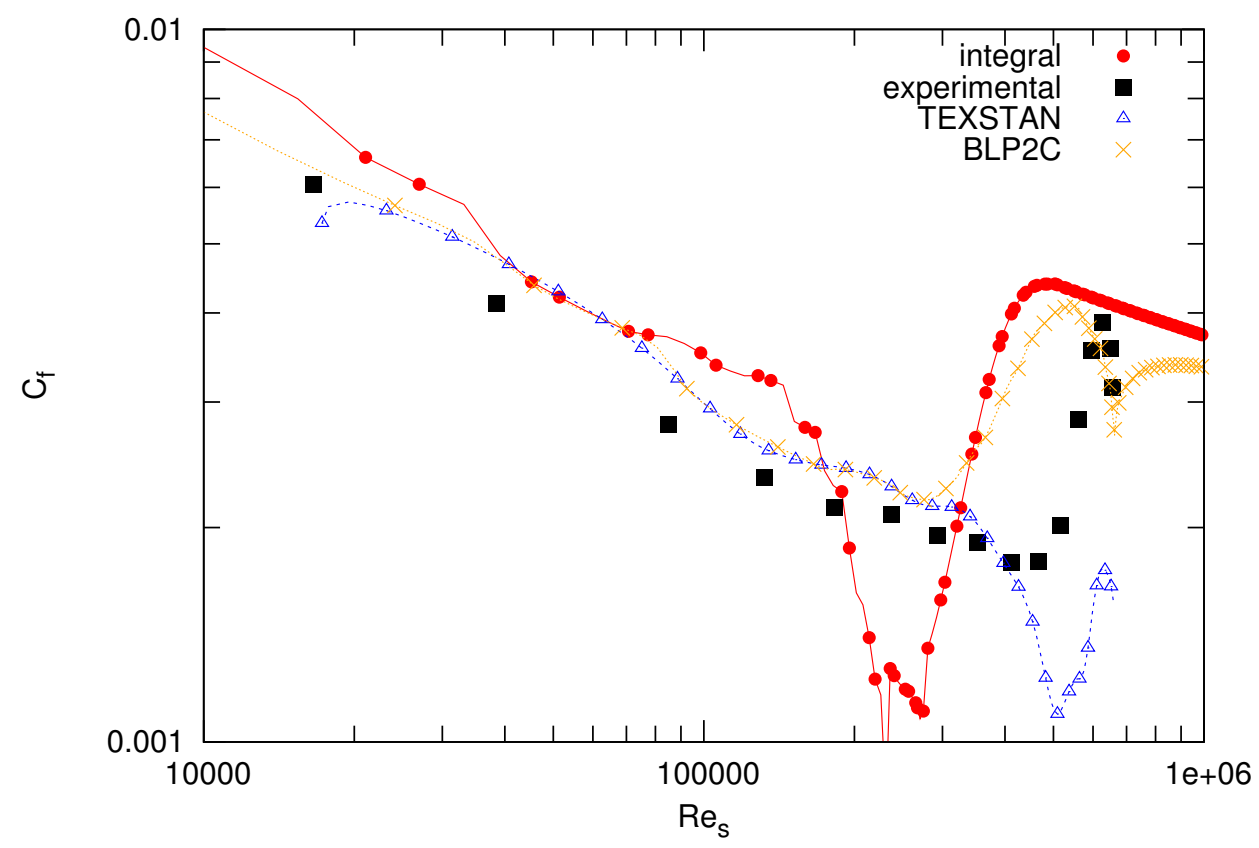

Figura B.12: Caso T3C2 - Coeficiente de Atrito - $C_{f}-T u=2,4 \%$ - gradiente de pressão variável - correlação algébrica 


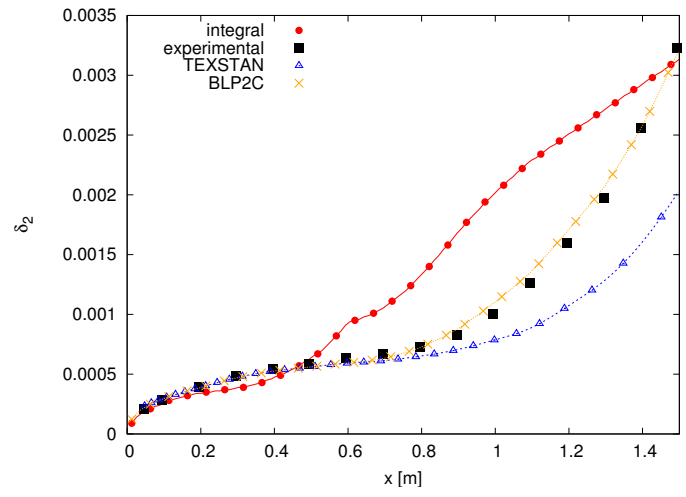

(a) Espessura de quantidade de movimento

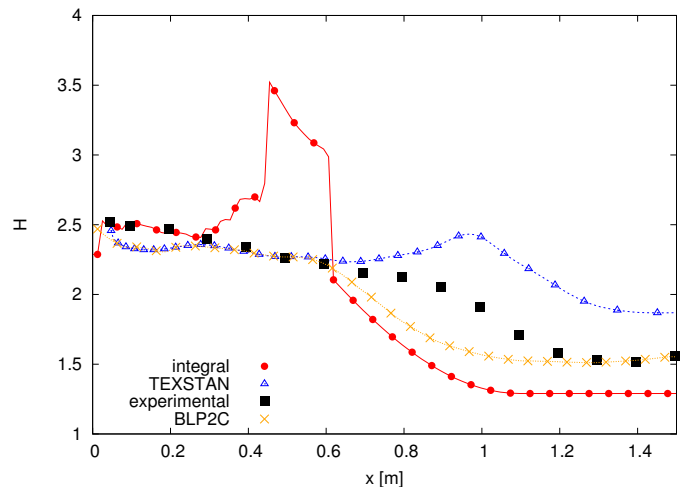

(b) Fator de forma

Figura B.13: Caso T3C2 - Tu = 2, 4\% - gradiente de pressão variável - correlação algébrica

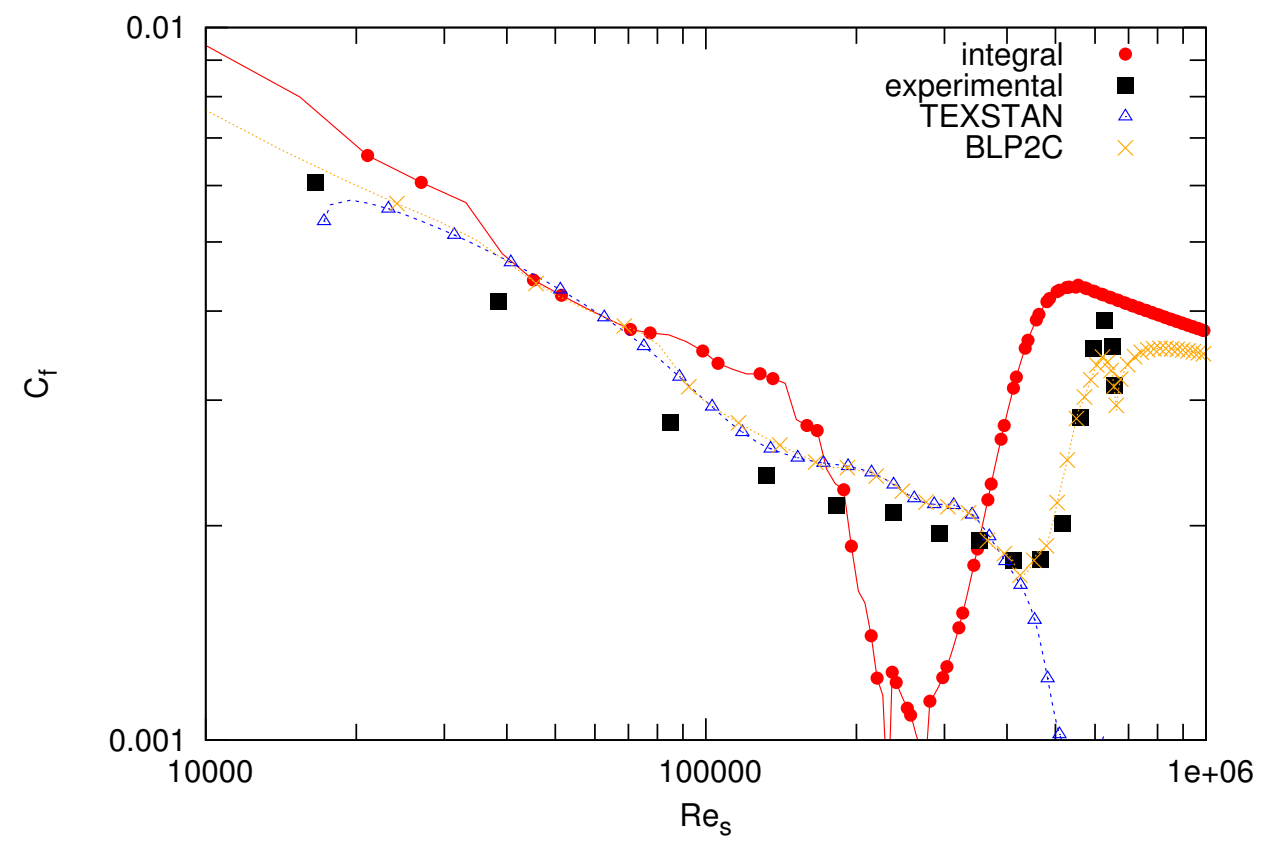

Figura B.14: Caso T3C2 - coeficiente de atrito - $C_{f}-T u=2,0 \%$ - gradiente de pressão variável - correlação algébrica

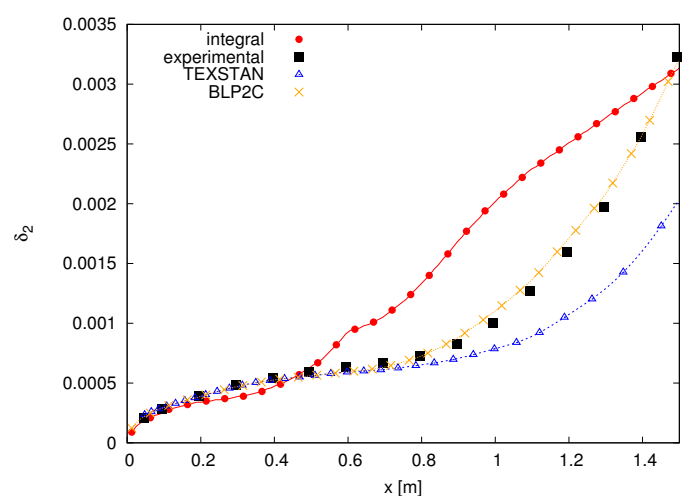

(a) Espessura de Quantidade de Movimento

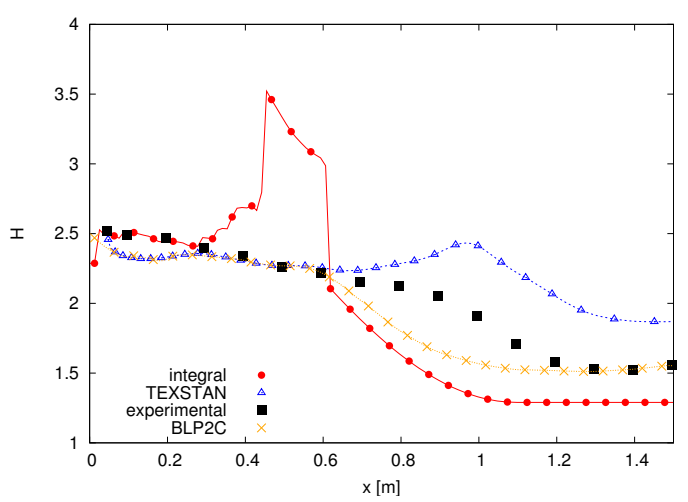

(b) Fator de Forma

Figura B.15: Caso T3C2 - Tu = 2, 0\% - gradiente de pressão variável 


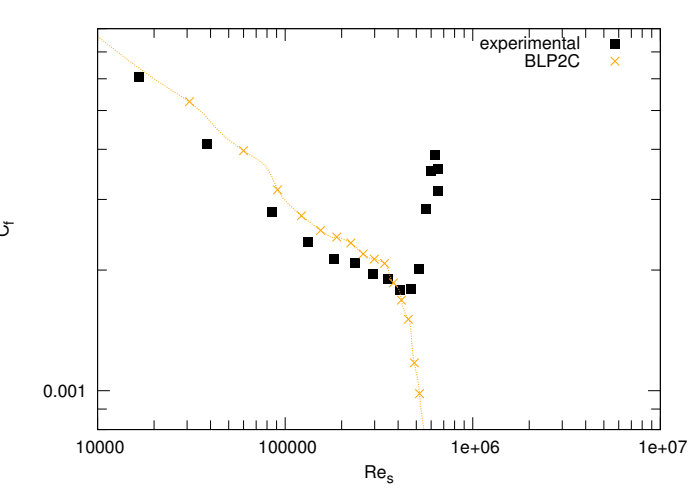

(a) Coeficiente de Atrito - $\boldsymbol{C}_{\boldsymbol{f}}$

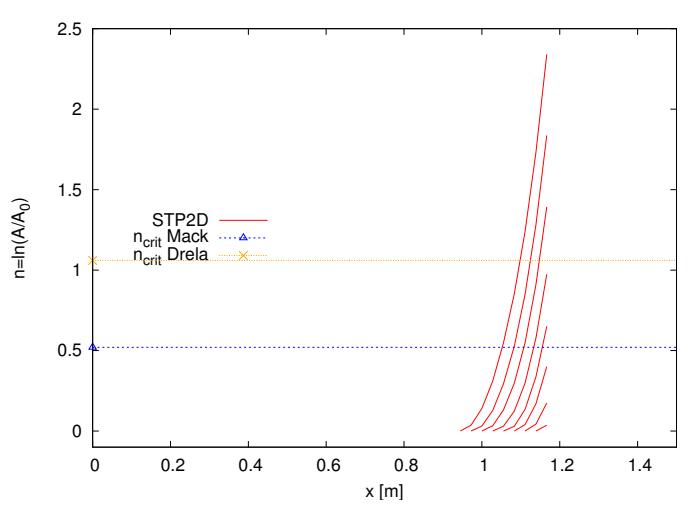

(b) Amplificação, $\boldsymbol{n}$, e Critérios, $\boldsymbol{n}_{\text {crit }}$

Figura B.16: Caso T3C2 - Tu = 2, 4\% - gradiente de pressão variável - estabilidade linear diferencial

Tabela B.6: Fatores Críticos de Amplificação - Caso T3C2 - Tu = 2, 4\%

\begin{tabular}{lcccc}
\hline casos & $\boldsymbol{n}_{\text {mack }}$ & $\boldsymbol{n}_{\text {drela }}$ & $\boldsymbol{N}_{\mathbf{1}}$ & $\boldsymbol{N}_{\mathbf{2}}$ \\
\hline $\mathrm{s}[\mathrm{m}]$ & 1,167 & 1,167 & 0,944 & 1,167 \\
$\mathrm{f}[\mathrm{Hz}]$ & 8,15 & 8,15 & 49,49 & 8,15 \\
\hline
\end{tabular}

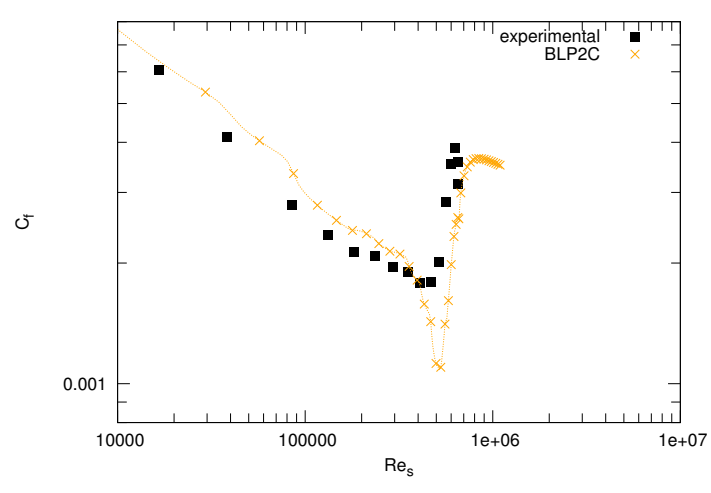

(a) Coeficiente de Atrito - $\boldsymbol{C}_{\boldsymbol{f}}$

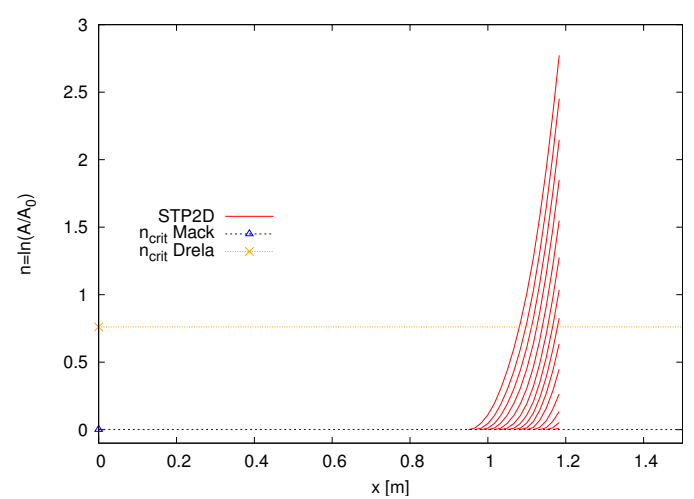

(b) Amplificação, $\boldsymbol{n}$, e Critérios, $\boldsymbol{n}_{\text {crit }}$

Figura B.17: Caso T3C2 - Tu $=3.0 \%$ - gradiente de pressão variável - estabilidade linear diferencial

Tabela B.7: Fatores Críticos de Amplificação - Caso T3C2 - Tu = 3, 0\%

\begin{tabular}{lcccc}
\hline casos & $\boldsymbol{n}_{\text {mack }}$ & $\boldsymbol{n}_{\text {drela }}$ & $\boldsymbol{N}_{\mathbf{1}}$ & $\boldsymbol{N}_{\mathbf{2}}$ \\
\hline $\mathrm{s}[\mathrm{m}]$ & 0,950 & 1,183 & 0,950 & 1,183 \\
$\mathrm{f}[\mathrm{Hz}]$ & 47,71 & 4,72 & 47,71 & 4,72 \\
\hline
\end{tabular}




\section{B.6 Caso T3C5}

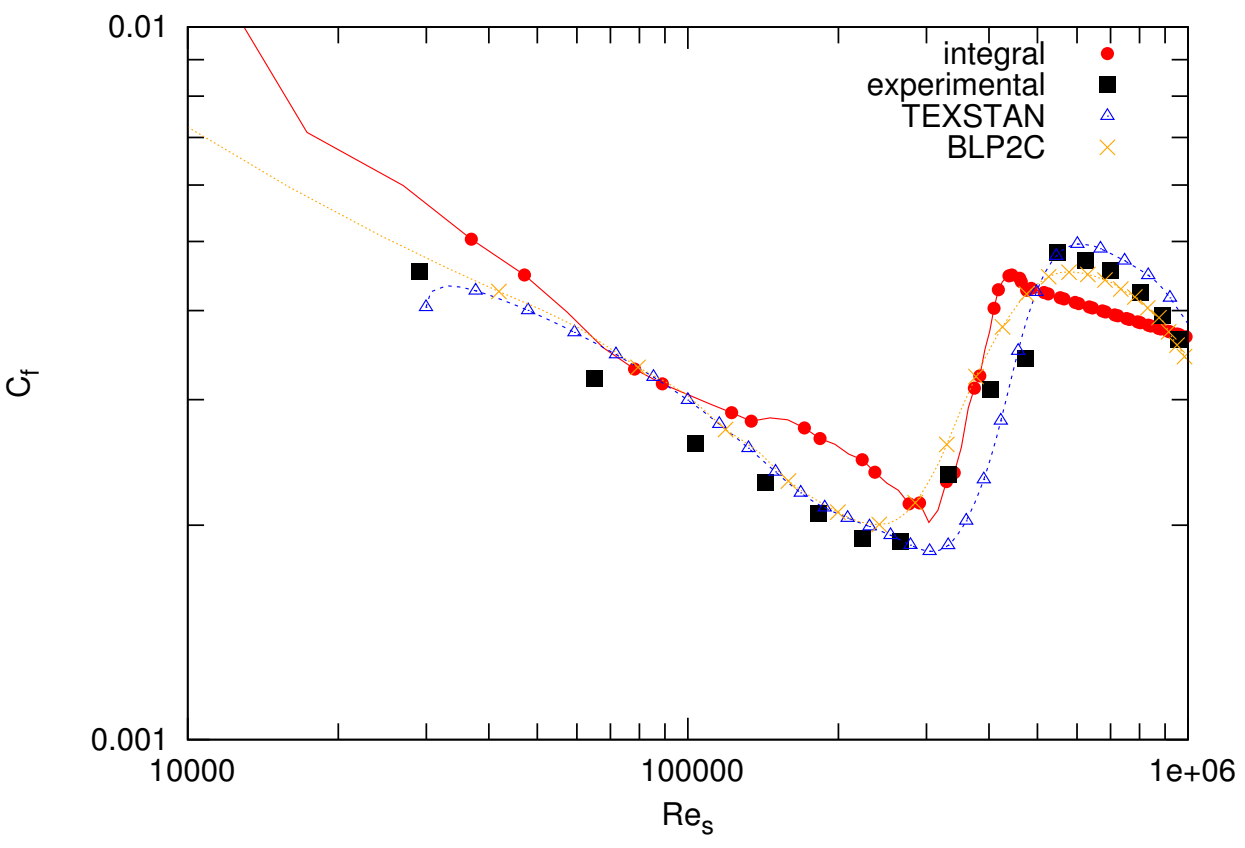

Figura B.18: Coeficiente de atrito - $C_{f}$ - Caso T3C5 - Tu $=2,45 \%$ - gradiente de pressão variável - correlação algébrica

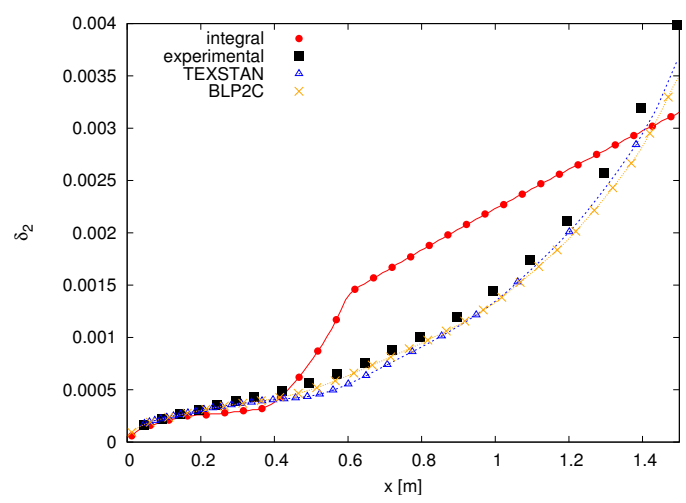

(a) Espessura de quantidade de movimento

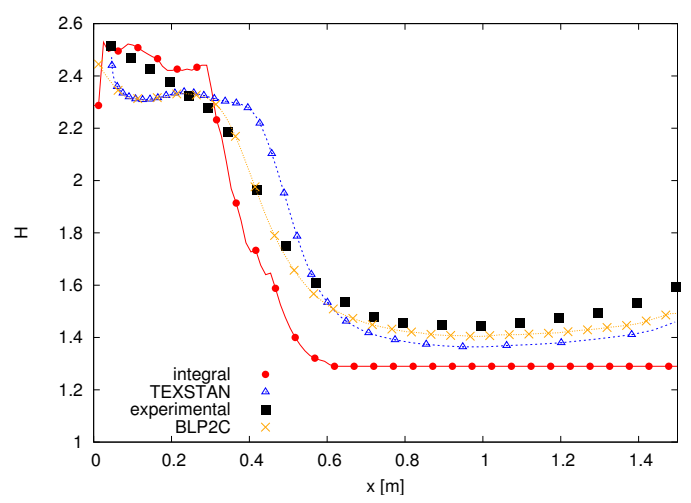

(b) Fator de forma

Figura B.19: Caso T3C5 - Tu = 2, 45\% - gradiente de pressão variável - correlação algébrica 


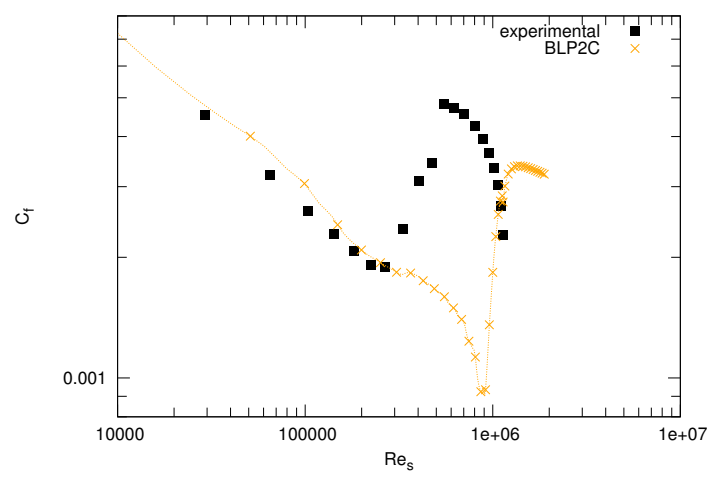

(a) Coeficiente de atrito - $\boldsymbol{C}_{\boldsymbol{f}}$

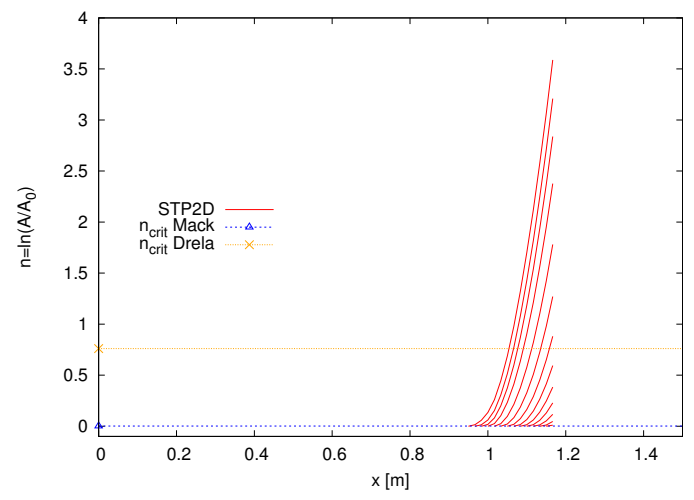

(b) Amplificação, $\boldsymbol{n}$, e critérios, $\boldsymbol{n}_{\text {crit }}$

Figura B.20: Caso T3C5 - Tu $=3,0 \%$ - gradiente de pressão variável - estabilidade linear diferencial

Tabela B.8: Fatores Críticos de Amplificação - Caso T3C5 - Tu = 3, 0\%

\begin{tabular}{lcccc}
\hline casos & $\boldsymbol{n}_{\text {mack }}$ & $\boldsymbol{n}_{\text {drela }}$ & $\boldsymbol{N}_{\mathbf{1}}$ & $\boldsymbol{N}_{\mathbf{2}}$ \\
\hline $\mathrm{s}[\mathrm{m}]$ & 0,950 & 1,167 & 0,950 & 1,167 \\
$\mathrm{f}[\mathrm{Hz}]$ & 95,15 & 10,36 & 95,15 & 10,36 \\
\hline
\end{tabular}




\section{REFERÊNCIAS BIBLIOGRÁFICAS}

ABID, R. Evaluation of two-equation turbulence models for predicting transitional flows. International Journal of Engineering Sciences, v. 31, n. 6, p. 831-840, 1993.

ABU-GHANNAM, B.; SHAW, R. Natural transition of boundary layers - the effects of turbulence, pressure gradient and flow history. Journal of Mechanical Engineering Science, v. 22, n. 5, p. 213-228, 1980.

ADAMSON, A. W. Physical Chemical of Surfaces. 5. ed. New York: John Wiley \& Sons, Inc., 1990.

AlHARA, T. Augmentation of convective heat transfer by gas-liquid mist. In: INTERNATIONAL HEAT TRANSFER CONFERENCE, 9. 1990, Jerusalem. Heat Transfer 1990. New York: Hemisphere Publishing Co., 1990. v. 1, p. 445-461.

AL-KHALIL, K. M. Numerical simulation of a an aircraft anti-icing system incorporating a rivulet model for the runback water. Tese (Doutorado) - University of Toledo, Toledo, Ohio, USA, 1991.

AL-KHALIL, K. M.; HORVATH, C.; MILLER, D. R.; WRIGHT, W. Validation of NASA thermal ice protection computer codes. Part 3 - Validation of ANTICE. Cleveland, $\mathrm{OH}$ : National Aeronautics and Space Agency, 2001. 18 p. (Contractor Report, 2001-210907).

AL-KHALIL, K. M.; KEITH, T. G.; DE, W. K. J. Development of an improved model for runback water on aircraft surfaces. J. Aircraft, v. 31, n. 2, p. 271-278, 1994.

ALLAIS, I.; ALVAREZ, C.; FLICK, D. Analyse du transfert thermique entre un cylindre et un écoulement d'air faiblement chargé en gouttelettes d'eau. Revue Générale Thermique, v. 36, n. 4, p. 276-287, Abril 1997.

ALLEN, R. F.; BIGGIN, C. M. Longitudinal flow of a lenticular liquid filmanent down a inclined plane. Physics of Fluids, v. 17, n. 2, p. 287-291, February 1974.

AMBROK, G. S. Approximate solution of equations for the thermal boundary layer with variations in boundary layer structure. Soviet Physics - Technical Physics, n. 2, p. 1979-86, 1957.

AMICK, J. L. Comparison of the Experimental Pressure Distribution on an NACA 0012 Profile at High Speeds With That Calculated by the Relaxation Method. [S.I.]: National Advisory Committee for Aeronautics, 1950. (Technical Note, TN-2174).

ARNAL, D. Description and prediction of transition in two-dimensional incompressible flow. In: Special Course on Progress on Stability and Transition of Laminar Flow. Neuilly sur Seine: Advisory group for aerospace research and development, 1984. cap. 2, p. 1-26. 232 p. (AGARD Report, 709). 
ARNAL, D. Transition description and prediction. In: PIRONNEAU, O.; W.RODI; I.L.RYHMING; A.M.SAVILL; T.V.TRUONG (Ed.). Numerical simulation of unsteady flows and transition to turbulence. Cambridge: Cambridge University Press, 1992.

ARNAL, D. Boundary layer transtion: Predictions based on linear theory. In: SARIC, W. S. (Ed.). Special Course on Progress in Transition Modelling. Neuilly sur Seine: Advisory group for aerospace research and development, 1994. cap. 2, p. 1-63. 284 p. (AGARD Report, 793).

BANKOFF, S. G. Minimum thickness of a draining liquid film. Int. J. Heat and Mass Transfer, v. 14, p. 2143-2146, 1971.

BANKOFF, S. G. Stability of liquid flow down a heated inclined plate. Int. J. Heat and Mass Transfer, v. 14, p. 377, 1971.

BAXTER, D. C.; REYNOLDS, W. C. Fundamental solutions for heat transfer from nonisothermal plates. Journal of the Aeronautical Sciences, v. 25, p. 403-404, 1958.

BENTWICH, M.; GLASSER, D.; KERN, J.; WILLIAMS, D. Analysis of rectilinear rivulet flow. AIChE Journal, v. 22, n. 4, p. 772-779, 1976.

BERNARDIN, J. D.; MUDAWAR, I.; CHRISTOPHER, F.; WALSH, B.; FRANSESI, E. I. Contact angle temperature dependence for water droplets on practical aluminum surfaces. Int. J. Heat and Mass Transfer, v. 40, n. 5, p. 1017-1033, 1997.

BRAGG, M. B.; CUMMINGS, S. L.; HENZE, C. M. Boundary-layer and heat transfer measurements on an airfoil with simulated ice roughness. In: AEROSPACE SCIENCES AND MEETING, 34., 1996, Reno. AIAA Paper 96-0866. Reston: America Institute of Aeronautics and Astronautics, 1996. p. 1-16.

BREDIF, M. A fast finite element method for transonic potential flow calculations. In: AEROSPACE SCIENCES MEETING AND EXHIBIT, 21., 1983, Reno. AIAA Paper 83-16755. Reston: America Institute of Aeronautics and Astronautics, 1983.

BREDIF, M. Finite element method calculation of potential flow around wings. Lecture Notes on Physics, v. 218, 1985.

BUCHLIN, J.-M.; PRETREL, H.; PLANQUART, P.; LANGER, H.; THIRY, F. Infrared thermography study of a thermal anti-icing system. In: Von Karman Institute Preprint n. 1994-54. Rhode Saint Genese: Von Karman Institute, 1994. (Apresentado ao 42. Eurotherm, Quantitative Infrared Thermography, Sorento, 1994).

CANSDALE, J. T.; GENT, R. Ice Accretion on Aerofoils in Two-dimensional Compressible Flow - A Theoretical Model. Farnborough: Royal Aircraft Establishment, 1983. (Technical Report, 82128).

CAREY, V. P. Liquid-vapor phase change phenomena. Hebron: Taylor and Francis, 1992. (Series in Chemical and Mechanical Engineering).

CEBECI, T. Calculation of compressible turbulent boundary layers with heat and mass transfer. AIAA Journal, v. 9, n. 6, p. 1091-7, 1971.

CEBECI, T. Calculation of flow over iced airfoils. Journal of Aircraft, v. 27, n. 7, p. 853-61, Junho 1989. 
CEBECI, T. Essential ingredients of a method for low reynolds-number airfoils. AIAA Journal, v. 27, n. 12, p. 1680-1688, 1989.

CEBECI, T. An engineering approach to the calculation of aerodynamic flows. Long Beach: Horizons Publishing, 1999.

CEBECI, T. Stability and Transition: Theory and application. Long Beach, CA: Horizons Publishing and Springer, 2004.

CEBECI, T.; BRADSHAW, P. Physical and Computational Aspects of Convective Heat Transfer. New York: Springer-Verlag, 1984.

CEBECI, T.; CHEN, H. H.; ALEMDAROGLU, N. Fortified lewice with viscous effects. Journal of Aircraft, v. 28, n. 9, p. 564-71, Setembro 1991.

CEBECI, T.; COUSTEIX, J. Modeling and computation of boundary-layer flows : laminar, turbulent and transitional boundary layers in incompressible and compressible flows. Long Beach: Horizons Publishing, 2005.

CEBECI, T.; HEFAZI, H.; ROKNALDIN, F.; CARR, L. W. Predicting stall and post-stall behavior of airfoils at low mach numbers. AIAA Journal, v. 33, n. 4, p. 595-602, April 1995.

CEBECI, T.; SMITH, A. Analysis of turbulent boundary layers. 1. ed. New York: Academic Press, 1974.

CHEN, K. K.; THYSON, N. A. Extension of emmon's spot theory to flows on blunt bodies. AIAA Journal, v. 9, n. 5, 1971.

CRAWFORD, M. E. TEXSTAN Manual. Austin, TX: University of Texas, 2004. 21 p. (Revisão 092004.1).

CRAWFORD, M. E.; KAYS, M. E. STAN5 - A Program for Numerical Computation of Two-Dimensional Internal and External Boundary Layer Flows. Washington: National Aeronautics and Space Administration, 1976. 140 p. (Contractor Report, 2742).

CROCE, G.; BEAUGENDRE, H.; HABASHI, W. Cht3d: Fensap-ice conjugate heat transfer computations with droplet impingement and runback effects. In: AEROSPACE SCIENCES MEETING \& EXHIBIT 40., 2002, Reno. AIAA Paper 2002-0386. Reno, Nevada: America Institute of Aeronautics and Astronautics, 2002. p. $1-10$.

DEY, J. On the momentu balance in linear-combination for the transition zone. Journal of Turbomachinery, v. 122, p. 587-8, Julho 2000.

DHAWAN, S.; NARASIMHA, R. Some properties of boundary layer flow during the transition from laminar to turbulent motion. Journal of Fluid Mechanics, v. 3, p. 418-436, 1958.

DOMINGOS, R. H.; PUSTELNIK, M.; TRAPP, L. G.; SILVA, G. A. L.; CAMPO, W.; SANTOS, L. C. C. Development of an engine anti-ice protection system using experimental and numerical approaches. In: SAE AIRCRAFT AND ENGINE ICING INTERNATIONAL CONFERENCE, 2007. SAE paper 2007-01-3355. Warrendale: Society of Automotive Engineers, 2007. 
DOWNS, S. J.; JAMES, E. H. Heat transfer characteristics of an aero-engine intake fitted with a hot air jet impingement anti-icing system. In: NATIONAL HEAT TRANSFER CONFERENCE 25., 1988, Houston. Proceedings... New York: American Society of Mechanical Engineers, 1988. v. 1, p. 163-170.

DRAZIN, P. G.; REID, W. H. Hydrodynamic Stability. 2. ed. Cambridge: Cambridge University Press, 2004.

DRELA, M. MISES Implementation of Modified Abu-Ghannam and Shaw Transition Criterion. Boston: Aero-Astro Department, MIT, 1998. (Technical Report, 13 p.).

DRELA, M.; GILES, M. Viscous-inviscid analysis of transonic and low reynolds number airfoils. AIAA J., v. 25, n. 10, p. 1347-1355, October 1987.

ECKERT, E. R. G. Die berechnung des wärmeübergangs in der lamineren grenzschicht umströmer körper. V. D. I. Forschungsheft, n. 416, 1942.

ECKERT, E. R. G. Engineering relations for friction and heat transfer to surfaces in high velocity flow. Journal of the Aeronautical Sciences, v. 22, p. 585-587, 1955.

EL-GENK, M. S.; SABER, H. H. Minimum thickness of a flowing down liquid film on a vertical surface. Int. J. Heat and Mass Transfer, v. 44, p. 2809-2825, 2001.

EL-GENK, M. S.; SABER, H. H. An investigation of the break-up of an evaporating liquid film, falling down a vertical, uniformly heated wall. Trans. ASME - Journal of Heat Transfer, v. 124, p. 39-50, 2002.

EMMONS, $\mathrm{H}$. The laminar-turbulent transition in a boundary layer - Part I. Journal of the Aeronautical Sciences, v. 234, n. 2348, p. 490-498, 1951.

FRICK, C. W.; MCCULLOUGH, G. B. A method for determining the rate of heat transfer from a wing or streamline body. Moffet Field: National Advisory Committee for Aeronautics, 1942. (Ames Aeronautical Laboratory, NACA Report, 830, 23 p.).

GELDER, T. F.; LEWIS, J. P. Comparison of heat transfer from airfoil in natural and simulated icing conditions. Washington: National Advisory Committee for Aeronautics, 1951. 52 p. (Technical Note, 2480).

GENT, R. TRAJICE2 - A Combined Water Droplet Trajectory and Ice Accretion Prediction Program For Aerofoils. Farnborough: Royal Aerospace Establishment, 1990. (Technical Report, 90054).

GENT, R.; MOSER, R.; CANSDALE, J.; DART, N. The role of analysis in the development of rotor ice protection system. In: FAA IN-FLIGHT ICING, GROUND DE-ICING INTERNATIONAL CONFERENCE \& EXHIBITION, 1., Chicago, 2003, IL. SAE Paper 2003-01-2090. Warrendale: Society of Automotive Engineers, 2003.

GENT, R. W.; DART, N. P.; CANSDALE, J. Aircraft icing. Phil. Trans. Royal Society London A, n. 358, p. 2873-2911, 2000.

GUFFOND, D.; BRUNET, L. Validation du programme bidimensionnel de capitation. Chátillon Cedex, France: Office National D'Études et de Recherches Aérospatiales, 1988. (Rapport Technique , RP 20/5146 SY). 
HARTLEY, D. E.; MURGATROYD, W. Criteria for the break-up of thin liquid layers flowing isothermally over solid surfaces. Int. J. Heat and Mass Transfer, n. 7, p. 1003, 1964.

HASSAN, H. A. Transition modeling and applications. In: SARIC, W. S.; REED, H. L.; HASSAN, H. A. (Ed.). Stability and Transition: theory, modelling, experiments and applications. Reston: American Institute of Aeronautics and Astronautics, 2006. cap. 3. (AIAA Professional Development Course, San Francisco, Junho, 2006).

HAVUGIMANA, P.; LUTZ, C.; SAEED, F.; PARASCHIVOIU, I.; KEREVANIAN, G.; SIDORENKO, A.; BENARD, E.; COOPER, R. K.; RAGHUNATHAN, R. S. A comparison of skin friction and heat transfer prediction by various roughness models. Reston: American Institute of Aeronautics and Astronautics, 2002.

HEINRICH, A.; ROSS, R.; ZUMWALT, G.; PROVORSE, J.; PADMANABHAN, V. Analytical methods: Test methods and facilities. In: HEINRICH, A.; ROSS, R.; ZUMWALT, G.; PROVORSE, J.; PADMANABHAN, V. (Ed.). Aircraft lcing Handbook. Atlantic City: Federal Aviation Administration, U.S. Department of Transportation, 1991. v. 2, cap. 2. (FAA Technical Center Report, DOT/FAA/CT-88/8-2).

HENRY, R. Etude du fonctionnement d'un degivreur electrique : modelisation et mesure en soufflerie givrante de temperature parietale par thermographie infrarouge. Tese (Doutorado) - Blaise Pascal Université, Clemont-Ferrand, 1989.

HENRY, R. Development of an electrothermal de-icing/anti-icing model. Chatillon Cedex: Office National d'Etudes et de Recherches Aérospatiales, 1992. (Rapport ONERA TAP, 92005).

HENZE, C. M.; BRAGG, M. B.; KIM, H. S. Freestream turbulence measurements in icing condition. In: AEROSPACE SCIENCES MEETING AND EXHIBIT, 36., 1998, Reno. AIAA Paper 1998-96. Reston: America Institute of Aeronautics and Astronautics, 1998.

HOBLER, T. Minimal surface wetting. Chemia Stosow, v. 2B, n. 201, 1965.

IHNATOWICZ, E.; GUMKOWSKI, S.; MIKIELEWICZ, J. Experimental study of evaporation and breakdown of thin liquid films driven by shear stresses. J. Heat Transfer, v. 101, p. 712-717, 1979.

JOHNSON, M. W.; FASHIFAR, A. Statistical properties of turbulent bursts in transitional boundary layers. Int. J. Heat and Fluid Flow, v. 15, n. 4, August 1994.

KAYS, W. M.; CRAWFORD, M. E. Convective heat and mass transfer. New York: McGraw-Hill, 1993.

KAYS, W. M.; CRAWFORD, M. E.; WEIGAND, B. Convective Heat and Mass Transfer. 4. ed. New York: McGraw-Hill, 2004. (Apendices com descricao do programa TEXSTAN).

KAYS, W. M.; MOFFAT, R. J. The behaviour of transpired turbulent boundary layers. In: LAUNDER, B. (Ed.). Studies in Convection. Theory, Measurements and Applications. New York: Academic Press, 1975. v. 1, p. 223-319.

KELLER, H. B. A new difference scheme for parabolic problems. In: BRAMBLE, J. (Ed.). Numerical Solution of Partial-Differential Equations. New York: Academic Press, 1970. II. 
KERHO, M. F.; BRAGG, M. B. Airfoil boundary-layer development and transition with large leading-edge roughness. AIAA Journal, v. 35, n. 1, p. 75-84, January 1997.

KUHNS, I. E.; MASON, B. J. The supercooling and freezing of small droplets falling in air and other gases. Proceedings of Royal Society, A302, p. 437-52, 1968.

LIGHTHILL, M. J. Contributions to the theory of heat transfer through a laminar boundary layer. Royal Society of London Proceedings Series A, v. 202, p. 359-377, aug 1950.

MACARTHUR, C.; KELLER, J.; LUERS, J. Mathematical modeling of airfoil ice accretion on airfoils. In: AEROSPACE SCIENCES MEETING AND EXHIBIT, 20., 1987, Reno. AIAA Paper 82-36042. Reston: America Institute of Aeronautics and Astronautics, 1982.

MACK, L. M. Transition prediction and linear stability theory. In: AGARD Symposium on Laminar-Turbulent Transition. Lyngby: AGARD, 1977. p. 1.1-1.22. (Technical Report, AGARD-CP-224).

MAKKONEN, L. Heat transfer and icing of a rough cylinder. Cold Regions and Technology, v. 10, p. 105-116, 1985.

MASON, B. J. The Physics of the Clouds. Oxford: Oxford University Press, 1971.

MATEER, G. G.; MONSON, D. J.; MENTER, F. R. Skin-friction measurements and calculations on a lifting airfoil. AIAA Journal, v. 34, n. 2, p. 231-236, 1996.

MAYLE, R. The role of laminar-turbulent transition in gas turbine engines. ASME Journal of Turbomachinery, v. 113, n. 5, p. 509-537, 1991.

MENTER, F. R.; LANGTRY, R. B.; LIKKI, S. R.; SUZEN, Y. B.; HUANG, P. G.; VOELKER, S. A correlation based transition model using local variables part I model formulation. In: ASME TURBO EXPO 2004 - POWER FOR LAND, SEA, AND AIR 2004, Viena. Proceedings of ASME Turbo Expo 2004. New York: American Society of Mechanical Engineers, 2004.

MESSINGER, B. L. Equilibrium temperature of an unheated icing surface as a function of air speed. Journal of Aeronautical Sciences, v. 20, n. 1, 1953.

MICHEL, R. Etude de la transition sur les profiles d'aile. Establissement d'un critére de Determination de Point de Transition et Calcul de la Trainee de Profile Incompressible. Chatillon Cedex: Office National D'Études et de Recherches Aérospatiales, 1951. (ONERA Rapport, 1/1578A).

MIKIELEWICZ, J.; MOSZYNSKI, J. R. Breakdown of a shear driven liquid film. Polzka Akademia Nauk. - Prace Instytutu Maszyn Przeplywowych, n. 66, p. 3-11, 1975.

MIKIELEWICZ, J.; MOSZYNSKI, J. R. An improved analysis of breakdown of thin liquid films. Arch. Mech., n. 30, p. 489-500, 1978.

MIKIELEWICZ, J.; MOSZYNSKI, J. R. Breakdown and evaporation of thin shear driven liquid films. In: Proceedings International Centre of Heat and Mass Transfer. Gdanski: ICHMT, 1982. p. 467-481. 
MORENCY, F.; TEZOK, F.; PARASCHIVOIU, I. Anti-icing system simulation using canice. Journal of Aircraft, v. 36, n. 6, 1999.

MORENCY, F.; TEZOK, F.; PARASCHIVOIU, I. Heat and mass transfer in the case of an anti-icing system modelisation. In: AEROSPACE SCIENCES MEETING AND EXHIBIT, 37., 1999, Reno. AIAA Paper 99-0623. Reston: American Institute of Aeronautics and Astronautics, 1999.

MORETTI, P. M. Heat transfer through an incompressible turbulent boundary layer with varying free steam velocity and varying surface temperature. Tese (Doutorado) - Stanford University, Stanford, November 1964. (Technical Report PG-1. Dept. of Mechanical Engineering. Thermosciences Division).

MORETTI, P. M.; KAYS, W. M. Heat transfer to a turbulent boundary layer with varying free-stream velocity and varying surface temperature- an experimental study. International Journal of Heat and Mass Transfer, v. 8, p. 1187-1202, 1965.

MORKOVIN, M. V. On receptivity to environmental disturbances. In: HUSSAINI, M.; VOIGT, R. (Ed.). Instability and Transition. New York: Springer-Verlag, 1989. (ICASE/NASA LaRC Series, II).

NARASIMHA, R. On the distibution of intermittency in the transition region of a boundary layer. Journal of Aerospace Sciences, v. 24, p. 711-712, 1957.

NARASIMHA, R. The laminar-turbulent transition zone in the boundary layer. Progress in Aerospace Science, v. 22, p. 29-80, 1985.

NARASIMHA, R. Modelling the transitional boundary layer. Washington: National Aernautics and Space Administration, 1990. 30 p. (Contractor Report, 187487).

NEEL, J. C. B.; BERGRUN, N. R. The calculation of the heat required for wing thermal ice prevention in specified icing conditions. Washington: National Advisory Committee for Aeronautics, 1947. (Technical Note, 1472).

PIMENTA, M. M. The turbulent boundary layer: an experimental study of the transport of momentum and heat with the effects of roughness. Tese (Doutorado) Stanford University, Stanford, May 1975.

POTAPCZUK, M. G. Rever!!!! a review of nasa lewis' development plans for computational simulation of aircraft icing. AIAA-99-0243, 1999.

RAW, M.; SCHNEIDER, G. A new implicit solution procedure for multidimensional finite-difference modeling of the stefan problem. Numerical Heat Transfer, v. 8, p. 559-571, 1985.

REED, H. L.; SARIC, W. S. Tools for boundary layer stability analysis. In: SARIC, W. S.; REED, H. L.; HASSAN, H. A. (Ed.). Stability and Transition: theory, modelling, experiments and applications. Reston: American Institute of Aeronautics and Astronautics, 2006. cap. 1. (AIAA Professional Development Course, San Francisco, Junho, 2006).

RESHOTKO, E. Transient growth: A factor in bypass transition. Physics of Fluids, v. 13, n. 5, p. 1067-75, May 2001. 
REYNOLDS, W. C.; KAYS, W. M.; KLINE, S. J. Heat transfer in the turbulent incompressible boundary layer. III - Arbitrary wall temperature and heat flux. Washington, D.C.: National Aeronautics and Space Administration, 1958. (Memorandum, 12-3-58W).

REYNOLDS, W. C.; KAYS, W. M.; KLINE, S. J. Heat transfer in the turbulent incompressible boundary layer. IV - Effect of location of transtion and prediction of heat transfer in a known transition region. Washington, D.C.: National Aernautics and Space Administration, 1958. (Memorandum, 12-4-58W).

ROACH, P.; BRIERLEY, D. The influence of a turbulent free stream on zero pressure gradient transitional boundary layer development. part 1: testcases $\mathrm{t} 3 \mathrm{a}$ and $\mathrm{t} 3 \mathrm{~b}$. In: PIRONNEAU, O.; W.RODI; I.L.RYHMING; A.M.SAVILL; T.V.TRUONG (Ed.). Numerical Simulation od Unsteady Flows and Transition to Turbulence - Proceedings of the ERCOFTAC Workshop held at EPFL. Cambridge: Cambridge University Press, 1992, (ICASE/NASA LaRC Series, II).

ROTHMAYER, A. P.; TSAO, J. C. Water film runback on an airfoil surface. In: AEROSPACE SCIENCES MEETING AND EXHIBIT, 38., 2000, Reno. AIAA Paper 2000-0237. Reston: America Institute of Aeronautics and Astronautics, 2000. p. $1-11$.

ROTHMAYER, A. P.; TSAO, J. C. On the incipient motion of air driven water beads. In: AEROSPACE SCIENCES MEETING \& EXHIBIT 39., 2001, Reno. AIAA 2001-0676.

Reston: America Institute of Aeronautics and Astronautics, 2001. p. 1-11.

RUFF, G. A.; BERKOWITZ, B. M. Users Manual for the NASA Lewis Ice Accretion Prediction Code (LEWICE). Cleveland: National Aernautics and Space Administration, 1990. 240 p. (Contractor Report, 185129).

SABER, H. H.; EL-GENK, M. S. On the break-up of a thin liquid film subject to interfacial shear. J. Fluid Mech., v. 500, n. 113-133, 2004.

SARIC, W. S.; REED, H. L. The role of stability in transition to turbulence. In: SARIC, W. S.; REED, H. L.; HASSAN, H. A. (Ed.). Stability and Transition: theory, modelling, experiments and applications. Reston: American Institute of Aeronautics and Astronautics, 2006. cap. 1. (AIAA Professional Development Course, San Francisco, Junho, 2006).

SAVILL, A. A synthesis of $\mathrm{t} 3$ test case predictions. In: PIRONNEAU, O.; W.RODI; I.L.RYHMING; A.M.SAVILL; T.V.TRUONG (Ed.). Numerical Simulation od Unsteady Flows and Transition to Turbulence - Proceedings of the ERCOFTAC Workshop held at EPFL. Cambridge: Cambridge University Press, 1992, (ICASE/NASA LaRC Series, II).

SAVILL, A. M. New strategies in modelling by-pass transition. In: LAUNDER, B.; SANDHAM, N. (Ed.). Closure Strategies for Turbulent and Transitional flows. Cambridge: Cambridge University Press, 2002. cap. 18, p. 464-521.

SCHLICHTING, H.; GERSTEN, K. Boundary-Layer Theory. 8. ed. Berlin: Springer-Verlag, 2000.

SCHMID, P. J.; HENNINGSON, D. S. Stability and Transition in Shear Flows. New York: Springer-Verlag, 2001. 
SCHMUKI, P.; LASO, M. On the stability of rivulet flow. J. Fluid Mechanics, v. 215, p. 125-143, 1990.

SCHUBAUER, G.; KLEBANOFF, P. Contributions on the Mechanics of BoundaryLayer Transition. Washington: National Advisory Committee for Aeronautics, 1955. 31 p. (Contractor Report, 1289).

SCHUBAUER, G.; SKRAMSTAD, H. Laminar boundary layer oscillations and transition on a flat plate. Washington: National Advisory Committee for Aeronautics, 1948. X p. (Technical Report, 909).

SHARMA, O. P. Momentum and thermal boundary layer development on turbine airfoil suction surfaces. In: AIAA/SAE/ASME JOINT PROPULSION CONFERENCE, 23., 1987, Reno. AIAA Paper 87-1918. New York: America Institute of Aeronautics and Astronautics, 1987. p. 1-11.

SILVA, G. A. L. Modelagem e simulação da operação de sistema antigelo eletrotérmico de um aerofólio. Dissertação (Mestrado) - Escola Politécnica da Universidade de São Paulo, São Paulo, SP, Brazil, Abril 2002.

SILVA, G. A. L.; SILVARES, O. M. Technical Bulletin. Airfoil anti-ice system thermal simulation. São Paulo, SP: Escola Politécnica da Universidade de São Paulo, 2002. 12 p. (Boletim Técnico, BT / PME / 0207).

SILVA, G. A. L.; SILVARES, O. M.; ZERBINI, E. J. G. J. Airfoil anti-ice system modeling and simulation. In: AEROSPACE SCIENCES MEETING AND EXHIBIT, 43., 2005, Reno. AIAA Paper 2003-734. Reston: America Institute of Aeronautics and Astronautics, 2003.

SILVA, G. A. L.; SILVARES, O. M.; ZERBINI, E. J. G. J. Simulation of an airfoil electro-thermal anti-ice system operating in running wet regime. In: AEROSPACE SCIENCES MEETING AND EXHIBIT, 41., 2003, Reno. AIAA Paper 2005-1374. Reston: American Institute of Aeronautics and Astronautics, 2005.

SILVA, G. A. L.; SILVARES, O. M.; ZERBINI, E. J. G. J. Water film breakdown and rivulets formation effects on thermal anti-ice operation simulation. In: AIAA/ASME JOINT THERMOPHYSICS AND HEAT TRANSFER CONFERENCE, 9., 2006, San Francisco. AIAA Paper 2006-3785. Reston: America Institute of Aeronautics and Astronautics, 2006.

SILVA, G. A. L.; SILVARES, O. M.; ZERBINI, E. J. G. J. Numerical simulation of airfoil thermal anti-ice operation. Part 1: Mathematical modeling. Journal of Aircraft, v. 44, n. 2, p. 627-33, March-April 2007.

SILVA, G. A. L.; SILVARES, O. M.; ZERBINI, E. J. G. J. Numerical simulation of airfoil thermal anti-ice operation. part 2: Implementation and results. Journal of Aircraft, v. 44, n. 2, p. 634-41, March-April 2007.

SILVA, G. A. L.; SILVARES, O. M.; ZERBINI, E. J. G. J. Aircraft wing electrothermal anti-icing: Heat and mass transfer effects. In: 5TH EUROPEAN THERMALSCIENCES CONFERENCE, EINDHOVEN. Proceedings of Eurotherm. New York: Begell House, Inc., 2008. 
SILVA, G. A. L.; SILVARES, O. M.; ZERBINI, E. J. G. J. Boundary-layers integral analysis - heated airfoils in ice conditions. In: AIAA AEROSPACE SCIENCES MEETING AND EXHIBIT, 46th, 2008, Reno. AIAA Paper 2008-0475. Reston: American Institute of Aeronautics and Astronautics, 2008.

SILVA, G. A. L.; SILVARES, O. M.; ZERBINI, E. J. G. J. Differential and integral analyses of the convective heat transfer around ice protected airfoils. In: ICHMT INTERNATIONAL SYMPOSIUM ON ADVANCES IN COMPUTATIONAL HEAT TRANSFER, MARRAKESH. Proceedings of CHT-08. Ankara: International Centre of Heat and Mass Transfer, 2008.

SILVEIRA, R. A. Simulação Numérica da Formação de Gelo na Borda de Ataque de Perfis Aerodinâmicos. Dissertação (Mestrado) — Universidade Federal de Santa Catarina, Florianópolis, 2001.

SINGER, B. Modeling the transition region. In: SARIC, W. S. (Ed.). Special Course on Progress in Transition Modelling. NEUILLY SUR SEINE: Advisory group for aerospace research and development, 1993. 284 p. (AGARD Report, 793).

SMITH, A.; GAMBERONI, N. Transition, Pressure Gradient and Stability Theory. El Segundo: Douglas Aircraft, 1956. (Technical Report, ES-26388).

SMITH, A. G.; SPALDING, D. B. Heat transfer in a laminar boundary layer with constant fluid properties and constant wall temperature. Journal of the Royal Aeronautical Society, v. 62, p. 60-64, 1958.

SOGIN, H. H. A design manual for thermal anti-icing systems. Illinois: Wright Air Development Center Technical, 1954. (Technical Report, 54-13).

SPALART, P. R. Topics in industrial viscous flow calculations. In: HENKES, R. A. W. M.; VAN INGEN, J. L. (Ed.). Transitional Boundary Layer in Aeronautics. Amsterdam: North-Holland, 1996. cap. 5, p. 269-82.

SPALDING, D. B. Heat transfer from surfaces of non-uniform temperature. Journal of Fluid Mechanics, n. 4, p. 22-32, 1958.

SPALDING, D. B. Convective mass transfer, an introduction. New York: McGraw-Hill, 1963.

STEELANT, J.; DICK, E. Modelling of bypass transition with conditioned average navier stokes equations coupled to an intermittency transport equation. International Journal of Numerical Methods in Fluids, v. 23, p. 193-220, 1996.

STEFANINI, L. M.; SILVARES, O. M.; SILVA, G. A. L.; ZERBINI, E. J. G. J. Convective heat transfer effects in airfoil icing. In: 19TH INTERNATIONAL CONGRESS OF MECHANICAL ENGINEERING. Procedings of COBEM 2007. Rio de January: Brazilian Society of Mechanical Sciences and Engineering, 2007.

STEFANINI, L. M.; SILVARES, O. M.; SILVA, G. A. L.; ZERBINI, E. J. G. J. Boundary-layers integral analysis - airfoil icing. In: AIAA AEROSPACE SCIENCES MEETING AND EXHIBIT, 46th, 2008, Reno. AIAA Paper 2008-474. Reston: America Institute of Aeronautics and Astronautics, 2008.

SUZEN, Y.; HUANG, P. Modeling of Flow Transition Using an Intermittency Transport Equation. Washington: National Aernautics and Space Administration, 1999. 34 p. (Contractor Report, 1999-209313). 
THWAITES, B. Approximate calculation of the laminar boundary layer. Aero. Quart., v. 10 , p. $245-79,1949$.

THWAITES, B. (Ed.). Incompressible Aerodynamics: An account of the theory and observation of the steady flow of incompressible fluid past aerofoils, wings, and other bodies. 1. ed. New York: Dover Publications Inc., 1960.

TOBALDINI NETO, L. Estudo Numérico da Transição Laminar-Turbulenta. Dissertação (Mestrado) - Escola Politécnica da Universidade de São Paulo, São Paulo, SP, 2006.

TOBALDINI NETO, L.; PIMENTA, M. M.; SILVA, G. A. L. Laminar-turbulent transition modeling strategies for thermally protected airfoils. In: 2008 ASME FLUIDS ENGINEERING CONFERENCE. Proceedings of FEDSM2008. Reston: American Society of Mechanical Engineers, 2008. p. 1-9.

TOWELL, G. D.; ROTHFELD, L. B. Hydrodynamics of rivulet flow. AICHE Journal, v. 12 , n. 5 , p. $972-980,1966$.

TRELA, M.; MIKIELEWICZ, J. An analysis of rivulet formation during flow of an air/water mist accross a heated cylinder. Int. J. Heat and Mass Transfer, v. 35, n. 10, p. 2429-2434, 1992.

VAN INGEN, J. L. A Suggested Semi-Empirical Method for the Calculation of The Boundary Layer Transition Region. 2a. ed. Delft: TU Delft, 1956. (Report VTH-74).

VAN INGEN, J. L. The en method for transition prediction. historical review of work at tu delft. In: 38., Fluid Dynamics Conference and Exhibit. AlAA Paper 2008-3830. Reston: American Insitute of Aeronautics and Astronautics, 2008.

VARGAS, M.; TSAO, J.-C. Parametric study of ice accretion formation on a swept wing at sld conditions. In: SAE AIRCRAFT AND ENGINE ICING INTERNATIONAL CONFERENCE, 2007. SAE Paper 2007-01-3345. Warrendale: Society of Automotive Engineers, 2007.

VINOD, N.; GOVINDARAJAN, R. The signature of laminar instabilities in the zone of transition to turbulence. Journal of Turbulence, v. 8, n. 2, January 2007.

VOLINO, R. J.; SIMON, T. W. NASA CR. Measurements in Transitional Boundary Layers Under High Free-Stream Turbulence and Strong Acceleration Conditions. Washington: National Aeronautics and Space Administration, 1995. (Contractor Report, 198413, 662 p.).

VON DOENHOFF, A. E.; HORTON, E. A. A Low-Speed Experimental Investigation Of The Effect Of A Sandpaper Type Of Roughness On Boundary-Layer Transition. Washington: National Advisory Committee for Aeronautics, 1956. (Technical Note, 3858).

WADE, S. J. Modeling of the performance of a thermal anti-icing system for use on aero-engine intakes. Dissertação (Mestrado) — Loughborough University of Technology, Loughborough, 1986.

WAZZAN, A. R.; GAZLEY, J. C.; SMITH, A. M. O. Tollmien-schlichting waves and transition. heated and adiabatic wedge flows with application to bodies of revolution. Progress in Aerospace Science, v. 18, p. 351-92., 1979. 
WAZZAN, A. R.; GAZLEY, J. C.; SMITH, A. M. O. H-rx method for predicting transition. AIAA Journal, v. 19, n. 6, p. 310-12, June 1981.

WHITE, F. M. Viscous Fluid Flow. 2a. ed. New York: McGraw-Hill, 2000.

WHITTEN, D. G. Turbulent boundary layer on a porous plate: experimental heat transfer with variable suction, blowing and surface temperature. Tese (Doutorado) Stanford University, Stanford, December 1967. (Technical Report, HMT-3).

WRIGHT, W.; GENT, R.; GUFFOND, D. DRA/NASA/ONERA Collaboration on Icing Research Part II - Prediction of Airfoil Ice Accretion. Cleveland: National Aeronautics and Space Administration, 1997. 50 p. (Contractor Report,202349).

WRIGHT, W. B. NASA CR. User Manual for the Improved NASA Lewis Ice Accretion Code LEWICE 1.6. Cleveland: National Aeronautics and Space Administration, 1995. 95 p. (Contractor Report, 198355).

WRIGHT, W. B. User Manual for the NASA Glenn Ice Accretion Code LEWICE Version 2.0. Cleveland: National Aeronautics and Space Administration, 1999. 181 p. (Contractor Report, 209409). 